\title{
Low band gap polymers for organic photovoltaics
}

\section{Bundgaard, Eva}

Publication date:

2007

\section{Document Version}

Publisher's PDF, also known as Version of record

Link back to DTU Orbit

\section{Citation (APA):}

Bundgaard, E. (2007). Low band gap polymers for organic photovoltaics. Risø National Laboratory. Risø-PhD No. 31(EN)

\section{General rights}

Copyright and moral rights for the publications made accessible in the public portal are retained by the authors and/or other copyright owners and it is a condition of accessing publications that users recognise and abide by the legal requirements associated with these rights.

- Users may download and print one copy of any publication from the public portal for the purpose of private study or research.

- You may not further distribute the material or use it for any profit-making activity or commercial gain

- You may freely distribute the URL identifying the publication in the public portal

If you believe that this document breaches copyright please contact us providing details, and we will remove access to the work immediately and investigate your claim 


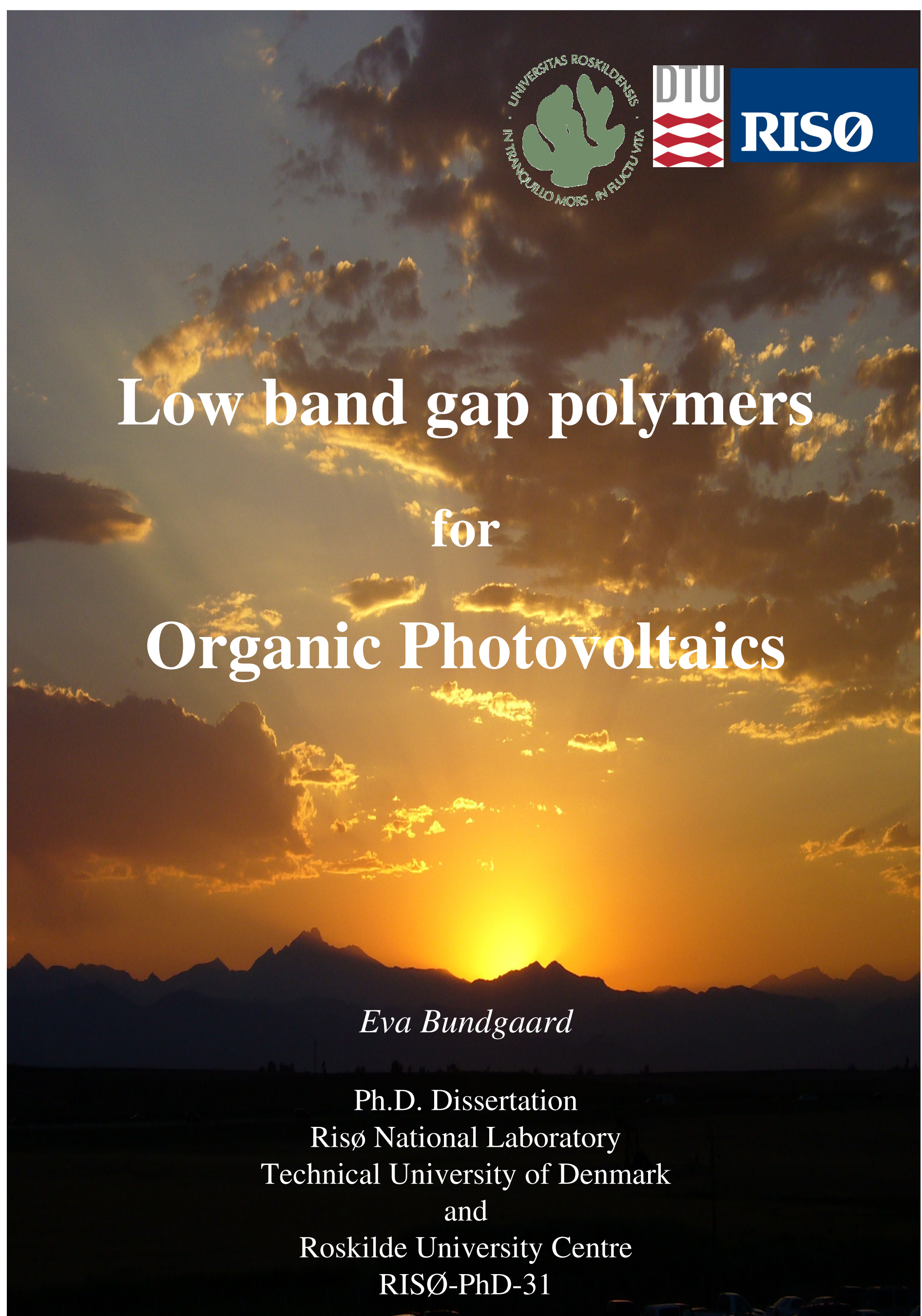




\title{
Low band gap polymers
}

\author{
for \\ organic photovoltaics
}

PhD Dissertation

Eva Bundgaard

June 2007

Risø National Laboratory
And
Roskilde University Centre

Thesis supervisors

Dr. Frederik Christian Krebs, Risø National Laboratory

Dr. Søren Hvidt, Roskilde University Centre 
Author: Eva Bundgaard

Title: Low band gap polymers for Organic photovoltaics Department: The polymer department

This thesis is submitted in partial fulfillment of the requirements for the Ph.D. degree at Roskilde University Centre
Report number: Risø-PhD-31

(EN)

Publication date June 2007

ISBN: 978-87-550-3613-0

Information Service Department

Risø National Laboratory

Technical University of Denmark

P.O.Box 49

DK-4000 Roskilde

Denmark

Telephone +4546774004

bibl@risoe.dk

Fax +45 46774013

www.risoe.dk 


\section{Alositict}

Several research groups within the area of organic photovoltaics are focusing on low band gap polymers, a type of polymer which absorbs light with wavelengths longer than $620 \mathrm{~nm}$. These systems are believed to increase the efficiency of organic photovoltaics due to a better overlap of the absorption spectrum of the polymer with the solar spectrum.

In this dissertation the synthesis of 16 new low band gap copolymers based on thiophene, benzothiadiazole and benzo-bis(thiadiazole) are described. The polymers have been prepared by two strategies; one using oxidative ferric chloride polymerization and one using Stille cross coupling polymerization. The polymers were purified chemically and by Size Exclusion Chromatography (SEC).

The polymers were characterized by UV-vis and Ultraviolet Photoelectron Spectroscopy (UPS), and the optical band gap and the electronic structure of the polymer were determined. The copolymers show optical band gaps from $1.65-2.0$ $\mathrm{eV}$ for the copolymers of thiophene and benzothiadiazole, where a decrease in the band gap was observed with an increase in the number of thiophene units in the repeating unit $(\mathrm{n}=1-4)$. A band gap down to $0.65 \mathrm{eV}$ was observed for the copolymers of thiophene and benzo-bis(thiadiazole).

The film forming ability of the polymers was studied by attaching different alkyl side chains on the polymer back-bone, i.e. hexyl-, 2-ethylhexyl-, dodecyl- and 3,7,11trimethyldodecyl-groups. The 3,7,11-trimethyldodecyl-group was found to give the best film forming ability and highest absorbance, when the polymer was spin coated from solvents like THF, chloroform and 1,2-dichlorobenzene.

The copolymer of thiophene and benzothiadiazole with four thiophenes in the repeating unit and 3,7,11-trimethyldodecyl-group as side chains with a band gap of $1.65 \mathrm{eV}$ was applied in organic photovoltaic devices with active areas of $0.1,3$ and 10 $\mathrm{cm}^{2}$. The morphology of the active layer was studied, and it was found that the morphology and the photovoltaic performance of the device was affected by the choice of solvent, the spin coating conditions, the concentration of polymer, the ratio between polymer and PCBM and the annealing temperature. The highest efficiency of $1 \%$ was achieved when the ratio between the polymer and PCBM was 1:2 and the device was annealed at $110{ }^{\circ} \mathrm{C}$. Lifetime and incident photon to current efficiency (IPCE) of the devices are also described.

Finally, the polymer was applied in hybrid PV devices based on $\mathrm{ZnO}$ nano-fibers and the results of these studies are given. 


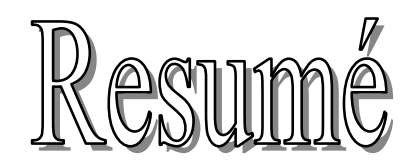

Indenfor organisk solceller fokuseres i denne tid på polymere med lavt båndgap, dvs. polymerer som absorberer lys med bølgelængder længere end $620 \mathrm{~nm}$. Disse lavbåndgabs polymere har vist sig at kunne øge effiktiviteten af organiske solceller ved et bedre overlap mellem polymerens absorptionsspektrum og solens spektrum.

I denne afhandling beskrives syntesen af 16 nye lavbåndgabs copolymere som er baseret på thiophen, benzothiadiazol og benzo-bis(thiadiazol). Der blev benyttet to syntese strategier: én med oxydativ polymerisation og én med Stille krydskoblingspolymerisation. Polymererne blev oprenset kemisk og vha. størrelseskromatografi (SEC).

Polymererne blev karakteriseret med UV-vis og ultraviolet photoelectron spetroskopi (UPS), og derved blev båndgabet og den elektroniske struktur af polymererne bestemt. De 16 nye polymerer havde et båndgab på $1.65-2.0 \mathrm{eV}$ for copolymererne baseret på thiophen og benzothiadiazol og helt ned til $0.65 \mathrm{eV}$ for copolymererne baseret på thiophen og benzo-bis(thiadiazol). For copolymererne baseret på thiophen og benzothiadiazol blev der observeret et fald i båndgabet, når antallet af thiophenringe i monomerenheden steg $(n=1-4)$.

Polymererne blev syntetiseret med forskellige alkyl sidekæder (hexyl, 2-ethylhexyl, dodecyl og 3,7,11-trimethyldodecyl grupper) for at undersøge hvilken der resulterede i den bedste film, når polymerene blev "spincoated" fra forskellige opløsningsmidler. 3,7,11-Trimethyldodecyl-sidekæder viste de bedste resultater, når polymeren blev "spincoated" fra THF, chloroform,1,2-dichlorbenzen eller lignende.

Copolymeren baseret på fire thiophen-grupper og en benzothiadiazol-gruppe i repetitionsenheden og med 3,7,11-trimethyldodecyl-gruppen som sidekæde havde et båndgab på $1.65 \mathrm{eV}$ og blev anvendt $\mathrm{i}$ solceller med et aktivt areal på $0.1,3$ og 10 $\mathrm{cm}^{2}$. Morfologien af det aktive lag blev studeret, og det kan konkluderes, at morfologien og effektiviteten af solcellen afhænger af, hvilket opløsningsmiddel der benyttes til "spin-coating", polymer koncentrationen, forholdet mellem polymeren og PCBM og "annealing" temperaturen. Den højeste effiktivitet på 1\% blev opnået for en solcelle, hvor forholdet mellem polymeren og PCBM var 1:2 og annealing temperaturen var $110^{\circ} \mathrm{C}$. Detaljer for levetid og IPCE er også beskrevet.

Derudover blev polymeren anvendt i hybridsolceller med $\mathrm{ZnO}$ nano-fibre og resultaterne for disse forsøg er kort beskrevet. 


\section{Table of content}

Abstract

Resumé (in Danish)

Table of content

Preface

iii

List of abbreviations vil

List of nomenclature $\quad$ ix

1. Motivation

1.1. Introduction

1.2. Photovoltaic - inorganic vs. organic 2

1.3. The aim

References

2. Low band gap polymers

2.1. Introduction 5

2.2. Achieving a low band gap $\quad 8$

2.3. State-of-the-art of low band gap polymers 10

2.4. Choice of system 12

2.5. Summary 12

References

3. Synthesis and purification

3.1. Synthetic strategies towards low band gap polymers based on thiophene, benzothiadiazole and benzo-bis(thiadiazole) 17

3.2. Polymerization methods 18

3.2.1. Oxidative ferric chloride polymerization 18

3.2.1.1. Mechanism 19

3.2.1.1. Reaction condition $\quad 20$

3.2.2. Stille cross coupling polymerization 21

3.2.2.1. Mechanism 21

3.2.2.1. Reaction condition 23

3.3. Synthesis of copolymers based on thiophene, benzothiadiazole $\begin{array}{ll}\text { and benzo-bis(thiadiazole) } & 24\end{array}$

3.3.1. Oxidative ferric chloride polymerizations 24

3.3.2. Stille cross coupling polymerizations 26

3.3.3. Attempted syntheses $\quad 32$

3.4. Side Chains and film-forming ability 33

3.5. Purification $\quad 34$

3.5.1. Chemical purification $\quad 34$

3.5.2. Soxhlet extraction $\quad 35$

3.5.3. Size exclusion Chromatography (SEC) 36

3.5.3.1. Introduction $\quad 36$

3.5.3.2. Results 38

3.6. Summary 39

References 
4. Physical characterization

4.1. Ultraviolet Visible Spectroscopy (UV-vis) 41

4.1.1. Introduction 41

4.1.2. Results 43

4.2. Ultraviolet Photoelectron Spectroscopy (UPS) 46

4.2.1. Introduction 46

4.2.2. Results 47

4.3. Summary $\quad 49$

References

5. Organic photovoltaics

5.1. Introduction 51

5.1.1. Principles of OPVs 51

5.1.2. Important parameters $\quad 55$

5.2. Low band gap polymers in OPV devices $\quad 56$

$\begin{array}{ll}\text { 5.3. Device preparation } & 58\end{array}$

5.4. What affects the efficiency of OPV devices?

5.4.1. Solvent, concentration and active layer thickness $\quad 59$

$\begin{array}{ll}\text { 5.4.2. Ratio between polymer and acceptor } & 60\end{array}$

5.4.3. Annealing temperature $\quad 60$

5.4.4. Molecular weight 61

5.4.5. Other factors 63

5.5. Lifetime studies $\quad 64$

5.6. The $1 \%$ device 64

5.7. Hybrid PV based on $\mathrm{ZnO} \quad 64$

5.7.1. Introduction 64

$\begin{array}{ll}\text { 5.7.2. Results } & 65\end{array}$

$\begin{array}{ll}\text { 5.8. Summary } & 67\end{array}$

$\begin{array}{ll}\text { Conclusion } & 71 \\ \text { Appendix 1: Experimental } & 73\end{array}$

$\begin{array}{ll}\text { Appendix 1: Experimental } & 73\end{array}$

Appendix 2: Papers, proceedings and posters $\quad 81$ 


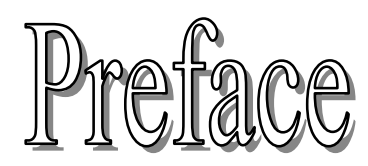

This dissertation is based on the work carried out at Risø National Laboratory, Denmark, from April 2004 to April 2007, as a part of the Danish research program to obtain a PhD degree under the supervision of Dr. Frederik C. Krebs and Dr. Søren Hvidt. Part of the work was carried out at the National Renewable Energy Laboratory (NREL), Colorado, USA, under the supervision of Dr. Sean E. Shaheen and Prof. David S. Ginley. The project was part of the project Polymers Solar Cells based on Macromolecular Cascades and was financially supported by the Danish Technical Research Council (STVF 2058-03-0016). I have chosen to use the title Low band gap polymers for organic photovoltaics as the title of this dissertation because this refers directly to the work I have done the past three years.

\section{Structure of dissertation}

This dissertation is divided into 5 chapters. After a short introduction to the renewable energy and organic photovoltaics in Chapter 1, the low band gap polymers are described in Chapter 2 with focus on, why we need these polymers and how we can obtain them. In Chapter 3 the synthesis of low band gap polymers are described by a introduction of the two strategies, which was applied to synthesize new low band gap copolymers based on thiophene, benzothiadiazole and benzo-bis(thiadiazole) followed by details on the methods and the synthetic steps. In the last part of Chapter 3 is purification of the polymers described. In Chapter 4 are physical characterization methods (UV-vis and UPS) and results there of described. Chapter 5 describes the details on the OPV and hybrid PV, which have been prepared with some of the polymers described in Chapter 3. After conclusion the experimental details and published papers are given in the Appendix 1 and 2.

\section{Acknowledgement}

A special thanks to my supervisor at Risø National Laboratory, Dr. Frederik $C$. $K r e b s$, for your commitment, knowledge and encouragement, working in your group have been a inspiration to me and I am grateful for your motivation and for your believe in me and my project.

I would like to thank Dr. Søren Hvidt, my supervisor at Roskilde University Centre, for always showing interest in my research and for pushing my limits by letting me teach a chemistry class at the university.

The last three years at Risø National Laboratory would not have been the same without the people in the Solar Cell Group (Frederik, Mikkel, Ole, Jan, Kim, Kion, Matteo, Virginie, Holger and Mette), I am truly grateful for having the pleasure to work with all of you and I would like to express my sincere gratitude for your help in the lab, fruitful discussions and off course your friendship inside and outside of Risø National Laboratory. 
During my stay at NREL I met some fantastic people and I am thankful for the opportunities I got when I was there, therefore a special thank goes to: Prof. David S. Ginley and Dr. Sean E. Shaheen (for giving me the opportunity to work in their lab and sharing their expertise), Matt White, Will Rance, Teresa Barnes, Matthew Dabney, Mikael van Heest, Jennifer Nekuda, Matthew Taylor, Andrew Leenheer, Alexander Miedaner (for fruitful discussions, help in the lab and friendship), Mikkel Svoldgaard Gadsbøll and John Benner (for help with the legally agreements), the rest of the staff at the SERF (for making my stay a pleasure) and finally Wendy, Matthew and Teresa (for bringing me into your home).

I thank the people who helped me in the lab with various experiments: Lene Hubert (for doing the ESCA measurements at Risø National Laboratory), Zheshen Li (for assistance at the synchrotron in Aarhus where the UPS measurements were carried out), Ole Hagemann (for help with the SEC measurements and for purifying samples for me, when I was at NREL), Sønnik Clausen, Jimmy Bak and Tanja Begovic (for lending me their equipment for the NIR measurements and for kind assistance during the experiments), Jao van de Langemaat (for recording the AFM images at NREL), Noemi Rozlosnik (for assistance with AFM measurements at Risø National Laboratory), Bobby To (for recording the SEM images at NREL) Matteo Biancardo (for help with measurements of OPV devices at Risø National Laboratory) and Jan Alstrup (for help with the preparation of OPV devices at Risø National Laboratory and for help with DSC measurements).

A thank goes to the staff at the Polymer Department at Risø National Laboratory and especially Ole Kristoffersen and Birgit Jensen for making the daily round much easier and pleasant. For comments on my dissertation I would like to thank: Frederik, Mikkel, Mette, David, Søren and Brian.

Finally, I would like to thank my family and friends for their support and understanding during the last three years. A special thanks to Brian for everything. 


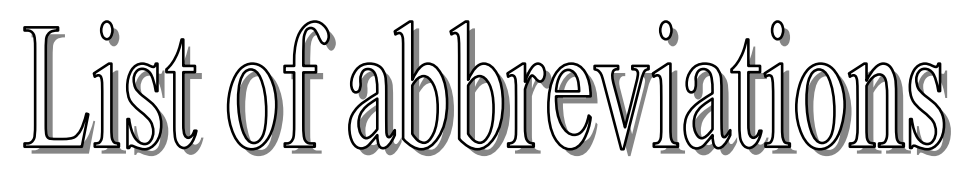

A

AFM

AM1.5

ASTRID

BTPF70

$\mathrm{C}_{60}$

$\mathrm{C}_{70}$

COD

$\mathrm{CV}$

D

DOE

EDG

EQE

ESCA

EWG

GFC

GPC

$\mathrm{HH}$

HOMO

HPSEC

HT

ITO

LED

LUMO

NBS

$\mathrm{Ni}(\mathrm{dppp}) \mathrm{Cl}_{2}$

NIR

MALDI-TOF

MDMO-PPV

MEH-PPV

MIM

OPV

P3AT

PCBM

PCPDTB

PEDOT:PSS

PET

PFTBT acceptor

atomic force microscopy

air mass 1.5

Aarhus storage ring in Denmark

3'-(3,5-bis-trifluoromethylphenyl)-1'-(4-

nitrophenyl)pyrazolino[70]fullerene

Buckminsterfullerene-60

Buckminsterfullerene-70

cyclooctadiene

cyclic voltammetry

donor

Department of Energy

electron donating group

external quantum efficiency

Electron Spectroscopy for Chemical Analysis

electron withdrawing group

gel filtration chromatography

gel permeation chromatography

head-to-head (coupling)

highest occupied molecular orbital

high pressure size exclusion chromatography

head-to-tail (coupling)

Indium Tin Oxide

light emitting diode

lowest unoccupied molecular orbital

$\mathrm{N}$-bromo-succinimide

[1,3-bis(diphenylphosphino)-propane]dichloronickel(II)

near infra red

matrix-assisted laser desorption/ionization-time of fligth

poly(2-methoxy-5-(3',7'-dimethyloctyloxy)-1,4-

phenylene-vinylene)

poly(2-methoxy-5-(2'-hexyloxy)-1,4-phenylene-

vinylene)

metal-insulator-metal model

organic photovoltaic

poly(3-alkylthiophene)

$[6,6]$-phenyl- $\mathrm{C}_{61}$-butyric acid methylester

poly(cyclopentadithiophene-benzothiadiazole)

poly(3,4-ethylenedioxythiophene) doped with

poly(styrenesulfonate)

polyethylene

poly(fluorene-thiophene-benzothiadiazole-thiophene) 
PFTQT

PFTTPT

P3HT

PITN

PPV

P(T-ITN-T)

PTPB

P(T-TP-T)

PV

SEC

SEM

TLC

TMEDA

TMS-Cl

TT

W

UV-vis

UPS poly(fluorene-thiophene-thiadiazolequinoxalinethiophene)

poly(fluorene-thiophene-thienopyrazine-thiophene)

poly(3-hexylthiophene)

poly(isothianaphthene)

poly(phenylene-vinylene)

poly(thiophene-isothianaphthene-thiophene)

poly(thiophene-pyrrole-benzothiadiazole)

poly(thiophene-thienopyrazine-thiophene)

photovoltaic

size exclusion chromatography

scanning electron microscopy

thin layer chromatography

$N, N, N$, $N$ '-tetra-methyl-ethylen-diamine

trimethylsilylchloride

tail-to-tail (coupling)

depletion area

ultraviolet visible

ultraviolet photoelectron spectroscopy 


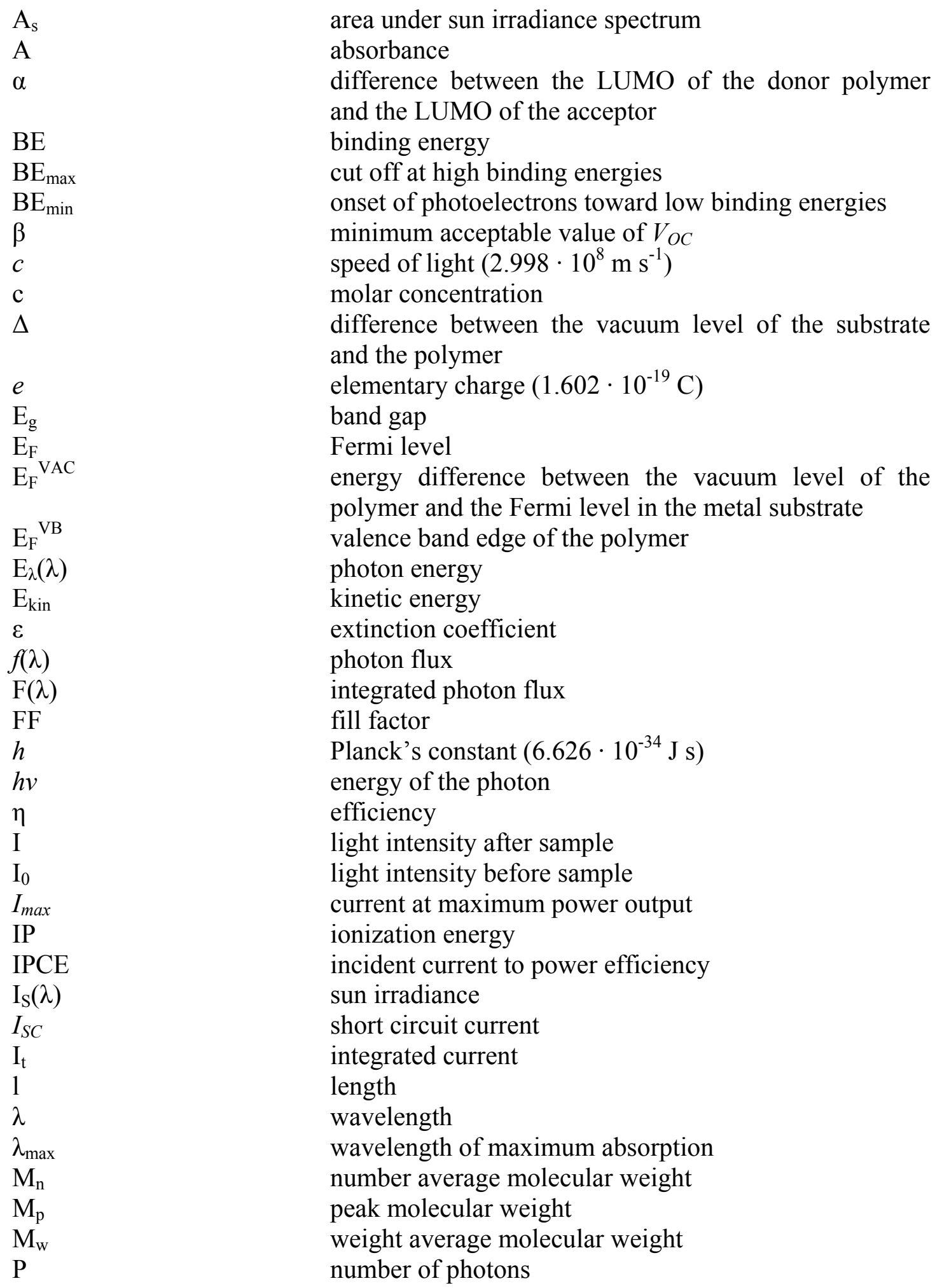


$P_{\text {in }}$

$\mathrm{P}_{\max }$

$\mathrm{P}_{\text {out }}$

$V_{O C}$

$V_{\max }$

$\Phi_{\mathrm{S}}$

$\Phi_{\mathrm{Au}}$ input power

maximum power output

output power

open circuit voltage

voltage at maximum power output

spectrometer work function

work function of gold 


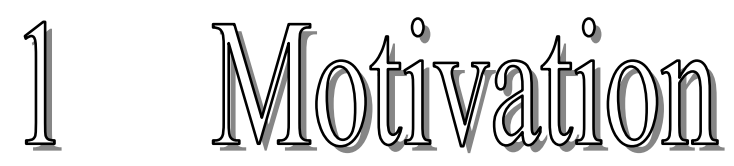

\subsection{Introduction}

According to Prof. Smalley, ${ }^{1}$ a Nobel Prize laureate, the main problem to solve in the world today is the energy problem. In 2004 the consumption of energy to run the world for a day was equal to 220 million barrels of oil or 14.5 terawatt. The International Energy Outlook 2006 report $^{2}$ from the Department of Energy (DOE) in USA predicts that energy consumption will increase over the next 25 years by a factor of 1.7. The predictions are bound up with the price of oil. The increase in the population on Earth will of course cause an increase in the energy consumption and according to Prof. Smalley we will, during our lifetime, see an increase in the population to 10 billion people. Thus, we would have to produce 60 terawatt corresponding to 900 million barrels of oil per day assuming $2 \mathrm{kWh}$ per person per day. There are different kinds of energy sources which can relieve this problem; however, fossil fuels are not the solution. Although coal and oil are of great importance in today's energy production, these energy sources will come to an end. Furthermore, according to the Kyoto Protocol, ${ }^{2} \mathrm{CO}_{2}$ emission has to be reduced and this should be done by using less fossil fuel. Hence, the $\mathrm{CO}_{2}$ problem is another reason why new and renewable energy forms, such as wind, bio-energy, geothermal and solar-energy, need to be taken into account. In February 2007 the Intergovernmental Panel of Climate Change, a panel under the United Nations, released the $4^{\text {th }}$ assessment report on Climate Change $2007^{3}$ in which it is stated that the climate is changing due to a tremendous increase in the atmosphere concentration of $\mathrm{CO}_{2}$ as a result of human activity. Global warming is a direct result of the $\mathrm{CO}_{2}$ emission, and this will cause a change in the weather (more storms etc.) and increase the mean sea level. These changes are already seen throughout the world and discussed daily in the media. As a consequence the 27 members of the European Union agreed in March 2007 to reduce the $\mathrm{CO}_{2}$ emission with $20 \%$ and that $20 \%$ of the energy should come from solar, wind and water sources by $2020 .{ }^{4}$ Hence the focus on renewable energy is needed in the upcoming years.

The sun delivers 165 thousand terawatt of power each day to the Earth, which corresponds to $1000 \mathrm{~W} \mathrm{~m}^{-2}$ at the surface of the Earth. ${ }^{1}$ Solar cells or photovoltaic (PV) convert the solar energy into electricity by absorption of light. ${ }^{5-7}$ An example given by Prof. Lewis of the California Institute of Technology illustrates how the energy problem of the future, i.e. $2 \mathrm{kWh}$ per person for 10 billion people everyday, is solved. On a global map six squares $\left(100 \times 100 \mathrm{~km}^{2}\right)$ is placed in areas with the highest solar radiation, e.g. south US, Brazil, north Africa, middle-East, north China and mid Australia. The total energy which can be achieved will be 60 terawatt per day using different conversion factors. This corresponds to the energy needed for 10 billion people per day. ${ }^{1}$ Thus, research in solar energy and PVs are of great importance.

There are two main classes of PV, organic and inorganic, and in the following are the organic and the inorganic silicon based photovoltaics compared. First, a few examples 
of inorganic PVs I have seen in places, where energy supply is limited or impossible. The first two pictures (Figure 1.1 top) show solar panels in the Amazon, Brazil used as energy supply for the local school (the high-voltage transmission line seen in the background of the pictures is a cross-country power line, but the locals are not allowed to use this power supply). The third picture (Figure 1.1 bottom) shows a solar panel used as energy supply for a hotel at the North Rim of the Grand Canyon, USA. Both places are remote, and on-grid energy supply to these areas is difficult.
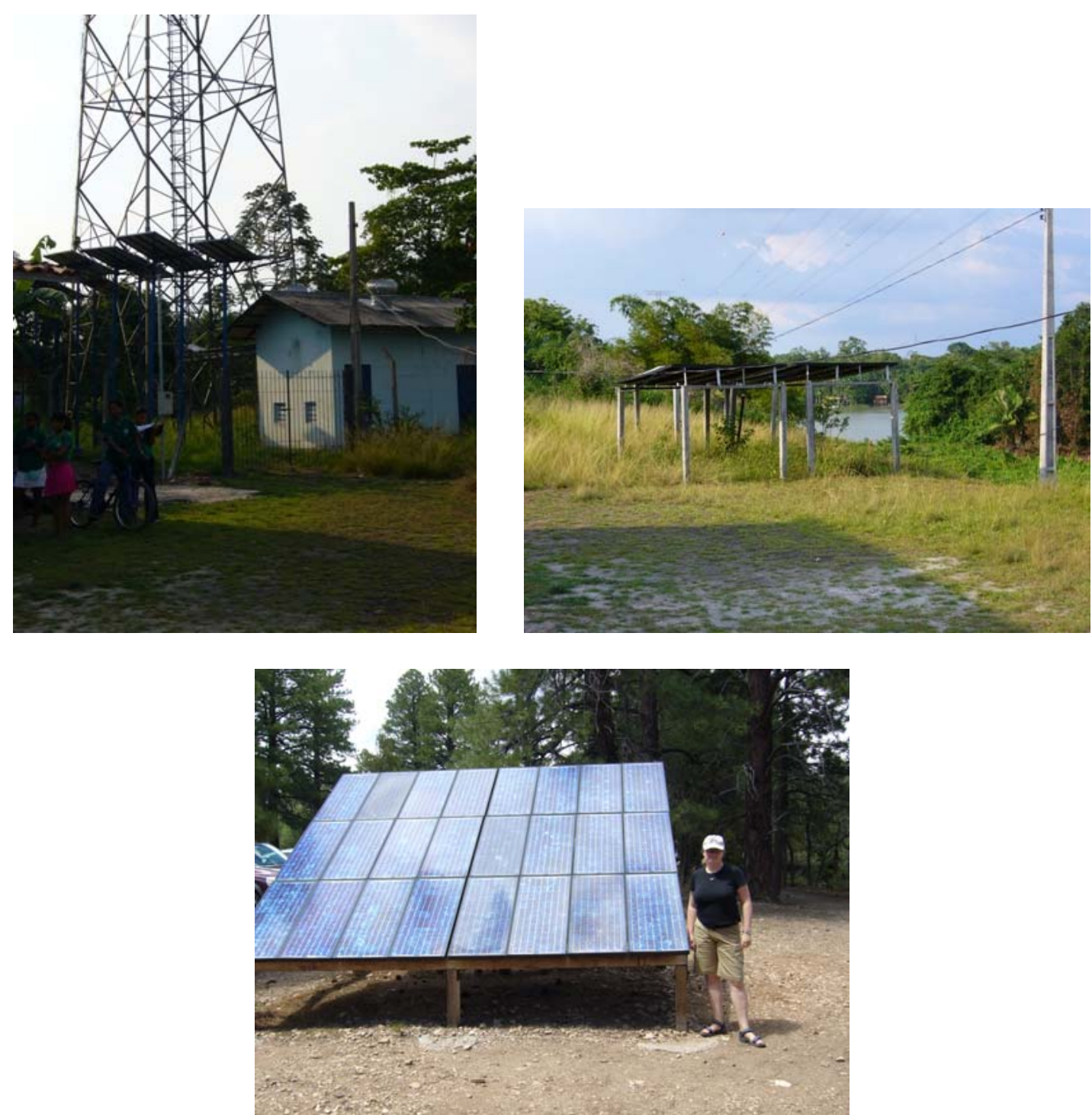

Figure 1.1. Pictures of PVs in the world: top) Amazon, Brazil and bottom) Grand Canyon, USA.

\subsection{Photovoltaic - inorganic vs. organic}

The focus on organic photovoltaic (OPV) has increased tremendously the past two decades. In this section, some of the advantages and disadvantages of OPVs are described.

There are three factors, which are always compared for renewable energy systems that show the compatibility of the OPV compared with inorganic PV based on silicon. These are: efficiency, lifetime and cost. $^{8}$

Photovoltaic efficiency is determined by the ratio of power output to power input (see Chapter 5). The efficiency of various silicon-based PVs is in the range of $10-25 \%$, 
which compares with OPVs in which maximum efficiency reported so far is about 5 $\%$. ${ }^{10,11}$ However, the efficiency has been estimated to reach $10 \%$ if the right conditions are chosen. ${ }^{12,13}$

The lifetime of a device is defined as the time it takes for the device to reach half its initial efficiency or half its short circuit current value. ${ }^{14}$ The lifetime of the siliconbased PVs is about 35 years or more, ${ }^{15,16}$ whereas for the OPV only a few reports in the literature have described lifetime results and these are very short (typically only a few hours in air, see Appendix A2.1 and A2.3). However, recently an operational lifetime of 20,000 hours was estimated from an accelerated test on a thermocleavable polythiophene based device. $^{17}$

The cost of inorganic PV production is very high due to the slow production and the necessarily high purity and high production temperatures. The production cost of OPVs is much smaller, because the production is much simpler, i.e. the active layer can be either printed or spin coated. Therefore, with a printing machine the production time is reduced from one year to only a few hours for the same area. ${ }^{8}$ For a typical silicon wafer production plant with a $30 \mathrm{~cm}$ wafer process the area, which is produced is about $88000 \mathrm{~m}^{2} /$ year, however, for the OPV using a printing machine the same area can be produced in only 1-10 hours. ${ }^{8}$

Therefore, the main advantage of OPVs when compared to inorganic PVs is the possibility to produce flexible very large area devices in a fast and cheap printing production. $^{8}$

The first two factors explain why the PVs shown in Figure 1.1 are inorganic, i.e. the long lifetime and the high efficiency. However, the reason why the inorganic PV are only seen as a niche market and not as a resource of energy all over the world is explained by the last factor, i.e. the high production cost. Summarizing the three factors in a diagram, as illustrated in Figure 1.2, we find that the OPVs have the possibility to compete with the inorganic PV market, since the lifetime and efficiency of the OPV are still increasing.

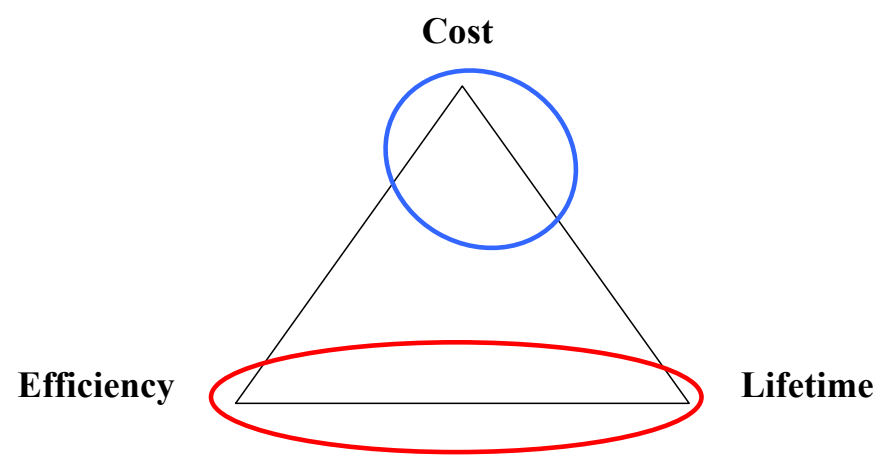

Figure 1.2. Brabec triangle ${ }^{7}$ with OPV and inorganic PV marked as blue and red, respectively.

However, there are several crucial factors a polymer material chosen for the OPV has to fulfill for the OPV market to be possible, i.e. pure large quantities, high efficiency and long lifetime.

\subsection{The aim}

The aim of this project was to synthesize new low band gap polymers and to apply these in OPV devices. The synthesis and characterization of 16 new low band gap polymers based on thiophene, benzothiadiazole or benzo-bis(thiadiazole) are described. In addition the photovoltaic responses of OPV devices with some of these 
low band gap copolymers are described along with a discussion of some of the factors which affects the efficiency of OPV devices, such as morphology.

\section{References}

$1 \quad$ R. E. Smalley, MRS Bull. 30 (2005) 412-417.

2 Energy Information Administration (EIA), International Energy Outlook 2006, report \# DOE/EIA-0484 (2006).

3 www.ipcc.ch

4 Politiken.dk, http://politiken.dk/eu/article261249.ece (article in danish).

5 H. Spanggaard, F. C. Krebs, Sol. Ener. Mater. Sol. Cells 83 (2004) 125-146.

6 H. Hoppe, N. S. Sariciftci, J. Mater. Res. 19 (2004) 1924-1945.

7 C. J. Brabec, N. S. Sariciftci, J. C. Hummelen, Adv. Funct. Mater. 11 (2001) 15-26.

8 C. J. Brabec, Sol. Ener. Mater. Sol. Cells 83 (2004) 273-292.

9 S. E. Shaheen, D. S. Ginley, G. E. Jabbaour, MRS Bull. 30 (2005) 10-15.

10 M. Reyes-Reyes, K. Kim, J. Dewald, R. López-Sandoval, A. Avadhanula, S. Curran, D. L. Carroll, Org. Lett. 7 (2005) 5749-5752.

11 W. Ma, C. Yang, X. Gong, K. Lee, A. J. Heeger, Adv. Funct. Mater. 15 (2005) 1617-1622.

12 M. C. Scharber, D. Mühlbacher, M. Koppe, P. Denk, C. Waldauf, A. J. Heeger, C. J. Brabec, Adv. Mater. 18 (2006) 789-794.

13 L. J. A. Koster, V. D. Mihailetchi, P. W. M. Blom, Appl. Phys. Lett. 88 (2006) 093511 1-3.

14 J. Alstrup, K. Norrman, M. Jørgensen, F. C. Krebs, Sol. Ener. Mater. Sol. Cells 90 (2006) 2777-2792.

15 webpage of DOE - Energy Efficiency and Renewable Energy, http://www1.eere.energy.gov/solar/pv_basics.html

16 webpage of Energy Research Centre of the Netherlands (ECN), http://www.ecn.nl/en/news/itm/article/155/1/

17 F. C. Krebs, H. Spanggaard, Chem. Mater. 17 (2005) 5235-5237. 


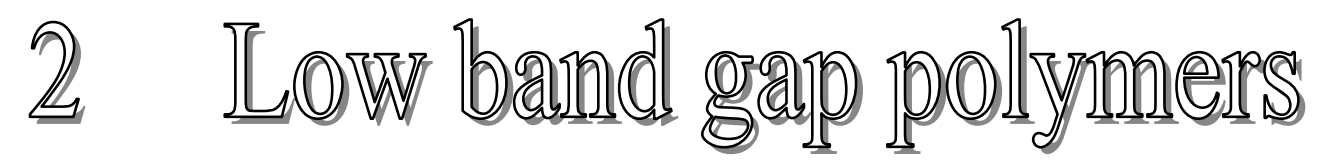

In the first part of this chapter some of the answers to why we need to focus research on low band gap polymers are explained by looking at the solar spectrum and the absorption spectrum of low band gap polymers in addition I describe how we obtain the low band gap by looking at some of the factors which affects the band gap of polymers. In the last part of the chapter a short introduction to the low band gap polymers from the literature and my choice of system is described.

\subsection{Introduction}

The band gap $\left(\mathrm{E}_{\mathrm{g}}\right)$ of a polymer is defined as the energy difference between the Highest Occupied Molecular Orbital (HOMO) and the Lowest Unoccupied Molecular Orbital (LUMO), and is typically reported in electronvolt (eV) (see Figure 2.1). The band gap can be measured in different ways, where the two most important ones are the optical band gap estimated from UV-vis spectroscopy and the electronic band gap determined from Cyclic Voltammetry (CV). The low band gap polymers are in general defined as polymers with a band gap below $2 \mathrm{eV}$, i.e. the polymer absorbs light with wavelengths $(\lambda)$ longer than $620 \mathrm{~nm}$.

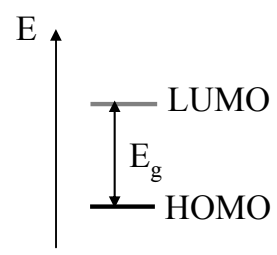

Figure 2.1. Definition of band gap, $\mathrm{E}_{\mathrm{g}}$.

Low band gap polymers have received more attention the past few years, since it is believed that they can improve the efficiency of the photovoltaic devices, due to a better overlap between the absorption spectra of the polymer and the solar spectrum. ${ }^{1-}$ ${ }^{3}$ In the following this is shown by a study of the solar spectrum. First a comparison of the solar spectrum, shown as sun irradiance, with the absorption spectra of a low band gap polymer and commonly applied polymers in OPV, i.e. MEH-PPV and P3HT is shown in Figure 2.2.

The sun spectrum in Figure 2.2 corresponds to the AM1.5 spectrum (i.e. the spectrum at the latitude of northern Europe and northern America). It is achieved by measuring the amount of energy $\left(\mathrm{W} \mathrm{m}^{-2}\right)$ for every nanometre in the spectrum, i.e. $\lambda_{\mathrm{k}}$ to $\lambda_{\mathrm{k}+1}$, and hence the unit of the sun irradiance, $\mathrm{W} \mathrm{m}^{-2} \mathrm{~nm}^{-1}$. It is clear from Figure 2.2 that the low band gap polymer absorbs light where P3HT and MEH-PPV do not. 


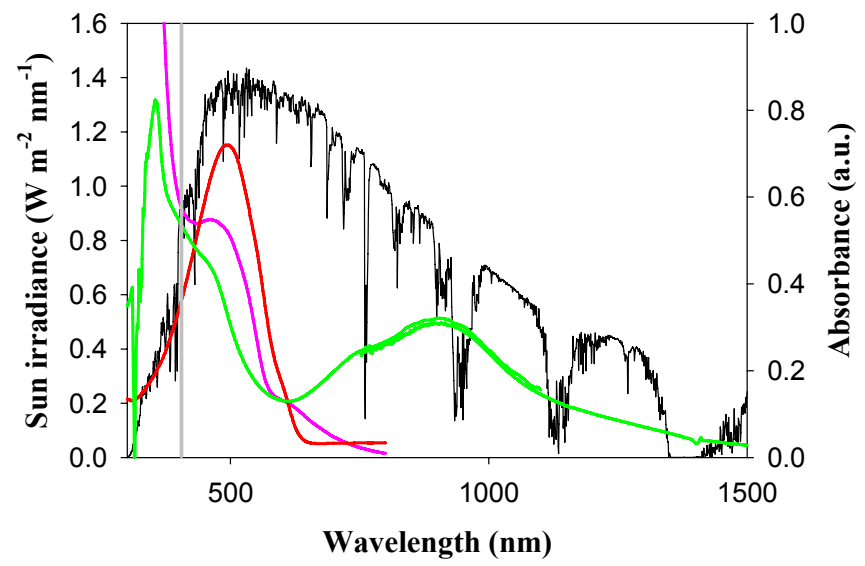

Figure 2.2. Solar spectrum (black) and the film absorption spectra of MEH-PPV (pink), P3HT (red) and a low band gap polymer (green) from 300 to $1500 \mathrm{~nm}^{4}{ }^{4}$ The absorption below $400 \mathrm{~nm}$ is ascribed to the substrate (marked with the grey line).

When the photon flux is plotted as a function of the wavelength the maximum is shifted towards longer wavelengths, and hence, to absorb more photons a polymer that absorbs light at longer wavelengths should be used (see Figure 2.3a). The photon flux $(f(\lambda))$ is achieved from the sun irradiance using Eq. (2.1), where $\mathrm{I}_{S}(\lambda)$ is the sun irradiance in $\mathrm{W} \mathrm{m}^{-2} \mathrm{~nm}^{-1}$ and $\mathrm{E}_{\lambda}(\lambda)$ is the photon energy in $\mathrm{J}$ determined from Eq. (2.2).

$$
\begin{aligned}
& f(\lambda)=\frac{\mathrm{I}_{\mathrm{S}}(\lambda)}{\mathrm{E}_{\lambda}(\lambda)} \\
& \mathrm{E}_{\lambda}(\lambda)=h v=h \frac{c}{\lambda}
\end{aligned}
$$

In Eq. (2.2) $h$ is Planck constant $\left(6.626 \cdot 10^{-34} \mathrm{~J} \mathrm{~s}\right), c$ is the speed of light $\left(2.998 \cdot 10^{8}\right.$ $\left.\mathrm{m} \mathrm{s}^{-1}\right)$ and $\lambda$ is the wavelength in $\mathrm{nm}$. The integrated photon flux $(\mathrm{F}(\lambda))$ is calculated from the photon flux $f(\lambda)$ by Eq. (2.3), where $\mathrm{A}_{\mathrm{s}}$ is the area under the sun irradiance curve determined from Eq. (2.4). The marginal values from 280 to $4000 \mathrm{~nm}$ are chosen, because the sun irradiance is close to zero beyond these limits.

$$
\begin{aligned}
& \mathrm{F}(\lambda)=\frac{\int_{\lambda=280}^{\lambda} f(\lambda) d \lambda}{\mathrm{A}}=\frac{\Delta \lambda \cdot \sum_{\lambda=280}^{\lambda} f(\lambda)}{\mathrm{A}} \\
& \mathrm{A}_{\mathrm{s}}=\int_{\lambda=280}^{\lambda=4000} f(\lambda) d \lambda=\Delta \lambda \cdot \sum_{\lambda=280}^{\lambda=4000} f(\lambda)
\end{aligned}
$$

The $F(\lambda)$ is then transformed into the maximum theoretical current (integrated current, $\mathrm{I}_{\mathrm{t}}$ ) by Eq. (2.5) assuming that one photon is converted to one electron in the OPV.

$$
\mathrm{I}_{\mathrm{t}}=\mathrm{F}(\lambda) \cdot e
$$

In Eq. $(2.5) e$ is the elementary charge $\left(1.602 \cdot 10^{-19} \mathrm{C}\right)$. The photon flux, the integrated photon flux and the integrated current are plotted as a function of the 
wavelength and we see that absorption at longer wavelengths results in a higher maximal theoretical current (see Figure 2.3b).
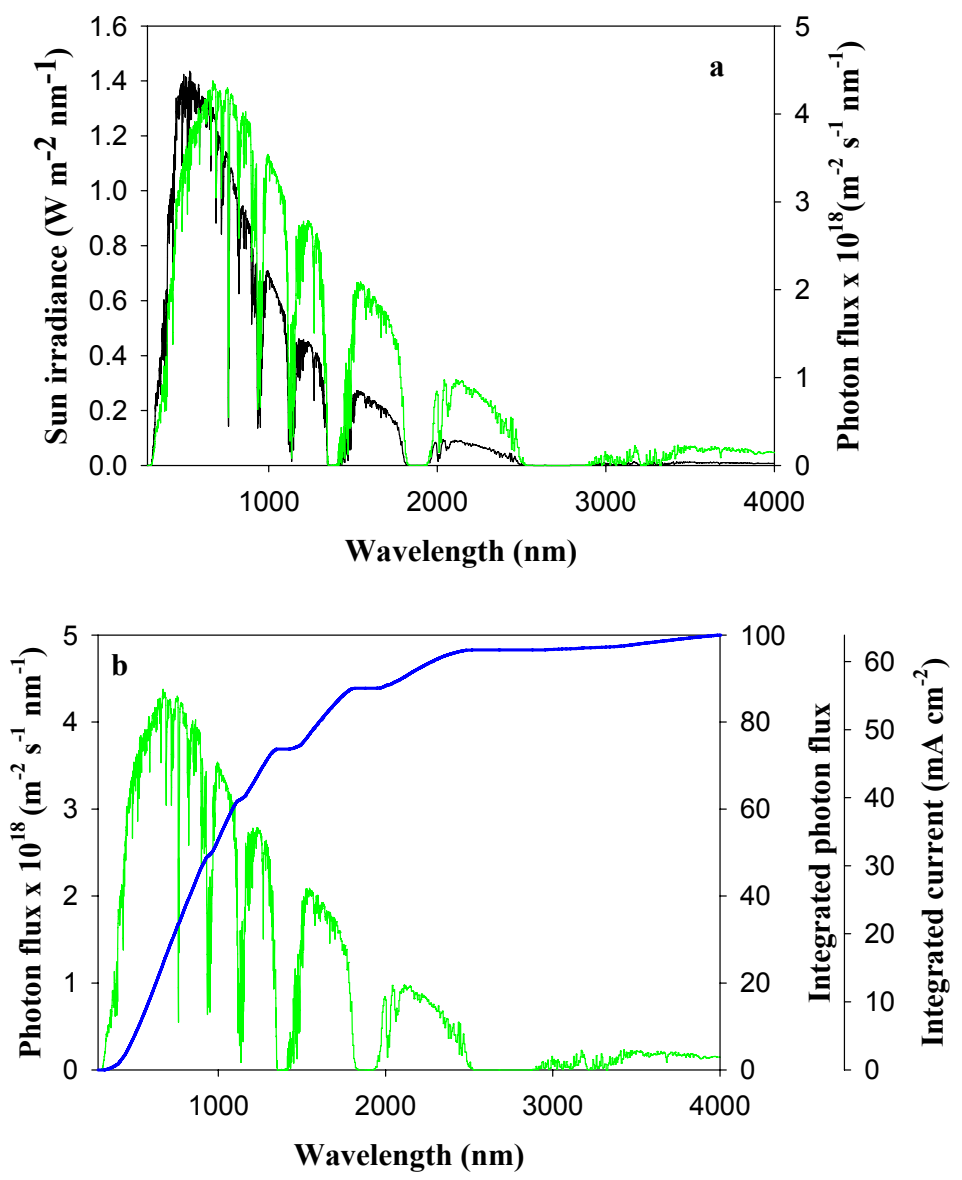

Figure 2.3. a) Sun irradiance (black) and photon flux (green) as a function of wavelength. b) Photon flux as a function of wavelength (green). The integral (blue) is shown with two axes, one showing the integrated photons and one the theoretical current.

This phenomenon is illustrated with the example of two polymers, A and B. Polymer A absorbs light with wavelengths up to $600 \mathrm{~nm}$ and polymer B absorbs light with wavelengths up to $1000 \mathrm{~nm}$. Figure $2.3 \mathrm{~b}$ shows that polymer A absorbs $17 \%$ of the photons and that polymer B absorbs $53 \%$ of the photons in the solar spectrum. The maximum theoretical current, which can be achieved, is thus $11.1 \mathrm{~mA} \mathrm{~cm}^{-2}$ for polymer A and $43.9 \mathrm{~mA} \mathrm{~cm}{ }^{-2}$ for polymer $\mathrm{B}$. These values are all based on the assumption that the polymers absorb all the light from 280 to 600 and $1000 \mathrm{~nm}$, respectively. This clearly shows that the low band gap polymers are of great importance, when the maximum theoretical current of the OPV, and hence the efficiency, has to be increased.

There is of course seldom absorption in the entire spectral range from 280 to $1000 \mathrm{~nm}$ as for example shown in the absorption spectrum of a real low band gap polymer. In Figure 2.4 this absorption spectrum is shown together with the photon flux and the integrated current. This example shows that the polymer can absorb light up to just above $700 \mathrm{~nm}$, but the absorption decreases at longer wavelengths. Therefore, the maximum theoretical current, which can be achieved, is $12 \mathrm{~mA} \mathrm{~cm}^{-2}$ and not $20 \mathrm{~mA}$ $\mathrm{cm}^{-2}$ as determined from Figure 2.3. 

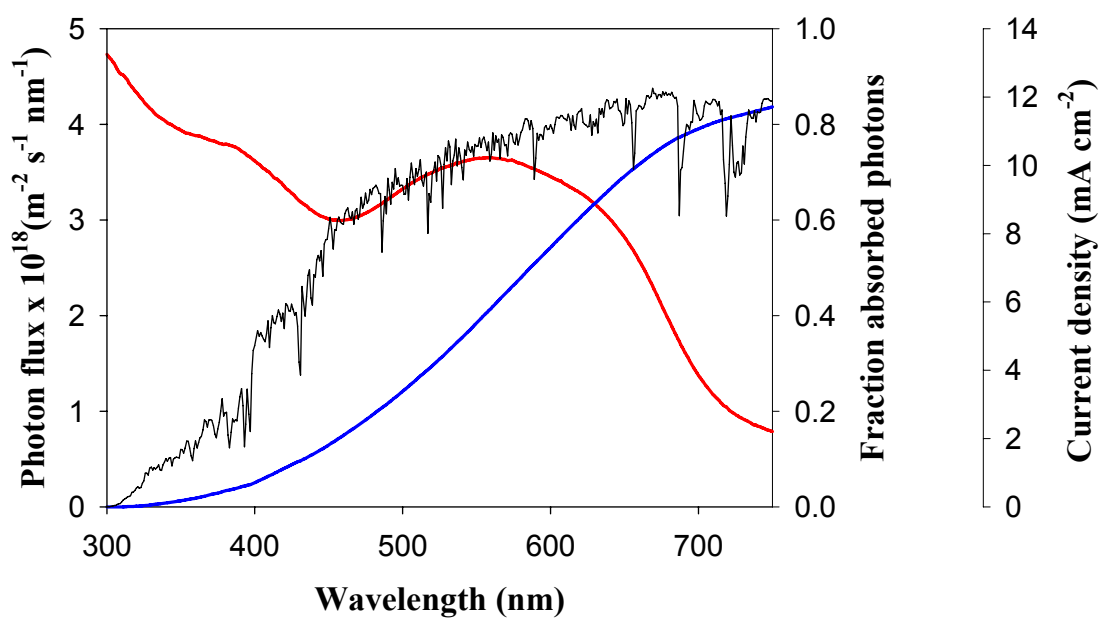

Figure 2.4. Photon flux (black) and an example of a low band gap polymer absorption spectra (red) and maximum current (blue), which can be achieved.

By examining the solar irradiance and the absorption spectra of low band gap polymers it can be concluded that a higher short circuit current of OPV devices can be achieved. However, there are several other factors which affect the efficiency of an OPV device (see Chapter 5). As a result, the calculations carried out in Figure 2.4 should use the incident photon to current efficiency (IPCE) curve instead of the absorption spectra. The IPCE curve is a device measurement, which describes how much of the absorbed photons are converted to current. Therefore doing the calculation in Figure 2.4 with the IPCE would give a more accurate estimate of the theoretical maximum current, since factors like morphology and charge carrier mobility have been taken into account. However, the efficiency of an OPV device also depends on the open circuit voltage $\left(V_{O C}\right)$ and the fill factor $(\mathrm{FF})$, and since the energy of the charge carriers at longer wavelengths is lower, this limits the voltage difference that the device can produce. Hence, decreasing the band gap of the polymer to $0.5 \mathrm{eV}$, which results in an increase in the maximum theoretical current, may result in a decrease in voltage and thus a decrease in the efficiency of the device. Therefore there is an optimum of the band gap.

\subsection{Achieving a low band gap}

Few examples of low band gap polymers have been described in the literature (see Section 2.3). There are different factors, which affect the band gap that should be taken into account when designing new polymers with low band gaps, i.e. intra-chain charge transfer, substituents effect, $\pi$-conjugation length etc. ${ }^{5}$

A fused ring system will lower the band gap, due to the stable quinoid structure formed in the resonance forms of the polymer (see Figure 2.5 ). ${ }^{5}$

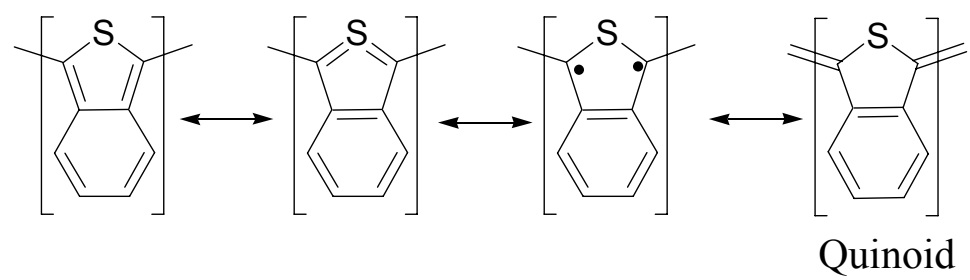

Figure 2.5. Resonance structures of a fused ring system, here poly(isothianaphthene), PITN. ${ }^{6}$ 
The fused ring system is often applied in a copolymer as an electron acceptor unit coupled with an electron donor unit. Copolymers based on the electron donor and electron acceptor moieties are low band gap polymers, for three main reasons. First, due to the enhanced double bond character between the donor and acceptor unit the quinoid structure of the fused ring system is stabilized. This is also seen in the two main resonance forms of the polymer: $\mathrm{D}-\mathrm{A} \leftrightarrow \mathrm{D}^{+}=\mathrm{A}^{-7}$. Second, the band gap of the donor/acceptor copolymer is determined by the HOMO of the donor and LUMO of the acceptor (see Figure 2.6), and therefore a high energy level of the HOMO of the donor and a low energy level of the LUMO of the acceptor results in a low band gap. $^{8,9}$

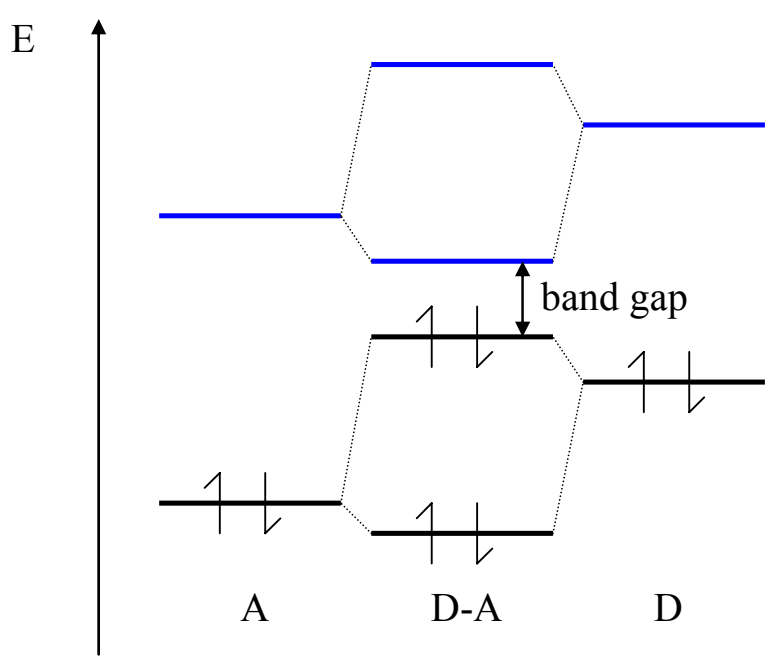

Figure 2.6. Band gap of copolymer based on donor and acceptor moieties, where the HOMO levels are marked with black and the LUMO levels are marked with blue.

The substituents on the donor and acceptor units can affect the band gap. The energy level of the HOMO of the donor can be increased by attaching electron donating groups (EDG), such as thiophene and pyrrole. Similarly, the energy level of the LUMO of the acceptor is lowered, when electron withdrawing groups (EWG), such as nitrile, thiadiazole and pyrazine, are attached. This will result in improved donor and acceptor units, and hence, the band gap of the polymer is decreased. ${ }^{10}$ The side groups also have another effect. It has been shown that the electronic band structure can be tuned without tuning the band gap by addition of EWG and EDG and this can be of great importance when the energy level alignment in an OPV device is taken into account (see Section 5.2) ${ }^{11-14}$ Finally, in the donor/acceptor copolymer the intra-chain charge transfer is shown by the electron affinity. It has been shown by mathematical simulation that the electron affinity is higher at the acceptor unit compared with the donor unit, i.e. a charge separation within the polymer. ${ }^{15-18}$

Besides this, the intermolecular interactions affect the band gap. It has been shown that the way the polymer P3HT orders in the solid phase causes a red shift in the whole absorption spectrum and hence, a lower band gap is achieved. ${ }^{5,19-34}$ Further, the $\pi$-conjugation length is of great importance since a torsion in the polymer back bone causes a decrease in the conjugation length and the band gap increases. Therefore, a high $\pi$-conjugation length results in a low band gap polymer. 5,35 


\subsection{State-of-the-art of low band gap polymers}

The low band gap polymers described in the literature are based often on fused ring systems in copolymers of a donor and an acceptor moiety. Examples of low band gap polymers with corresponding band gap size are summarized in Table 2.1.

Table 2.1. Structure of part of the low band gap polymers described in the literature along with the size of their band gap.

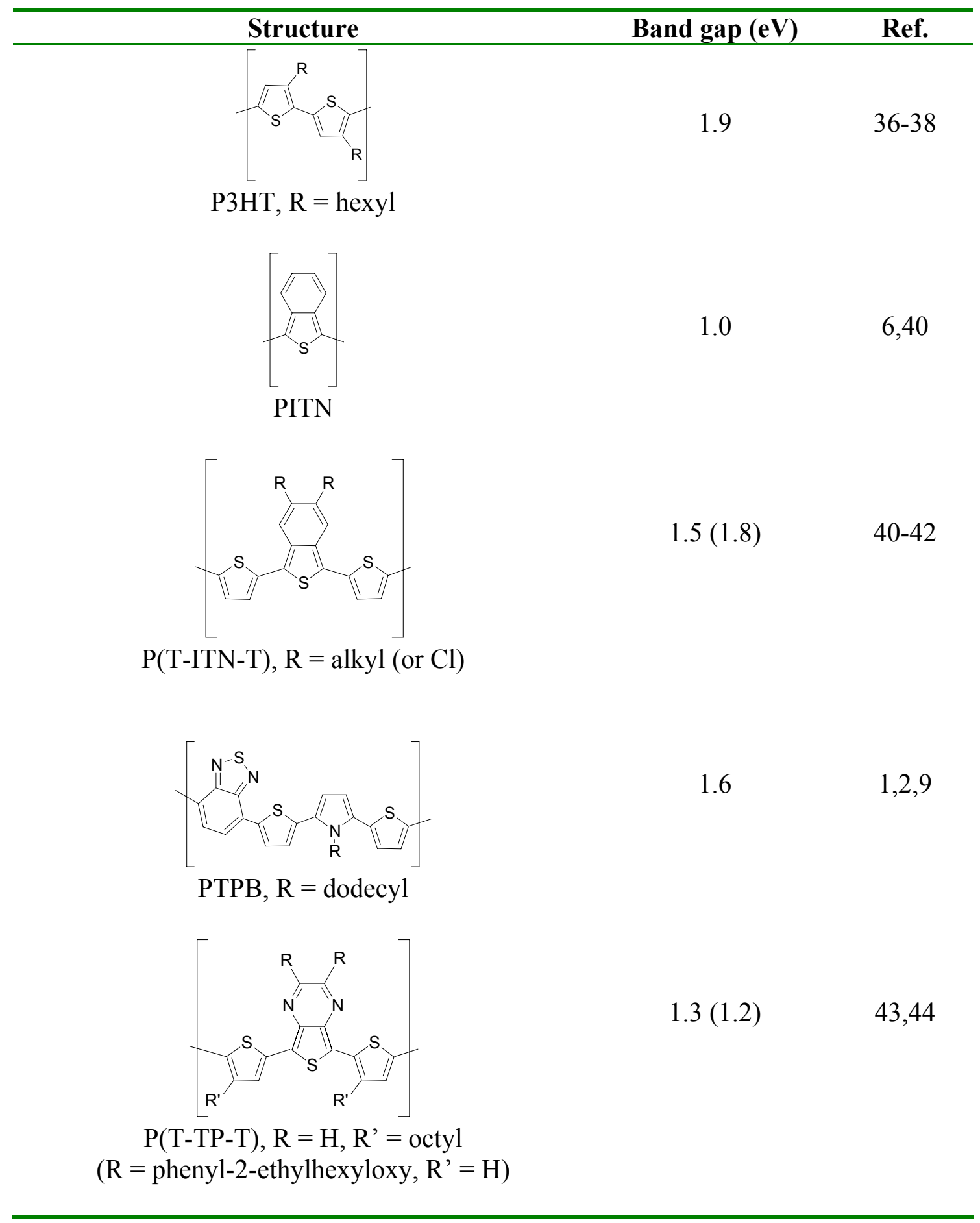


Table 2.1. Structure of part of the low band gap polymers described in the literature along with the size of their band gap (continued).

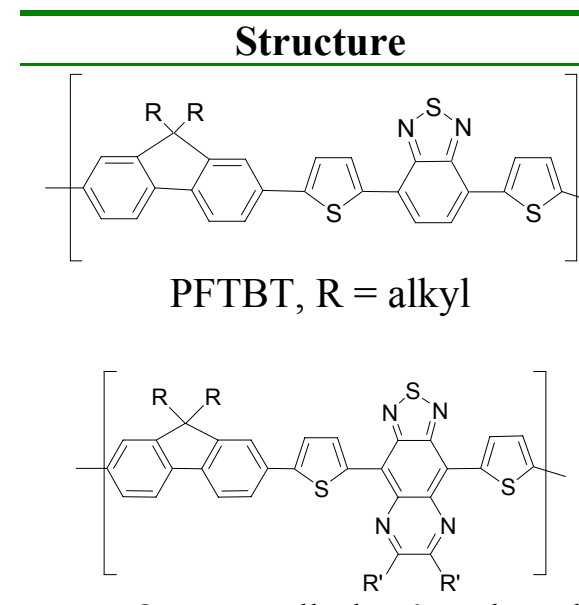

Band gap (eV)

Ref.

2.0

PFTQT, $\mathrm{R}=$ alkyl, $\mathrm{R}^{\prime}=$ phenyl

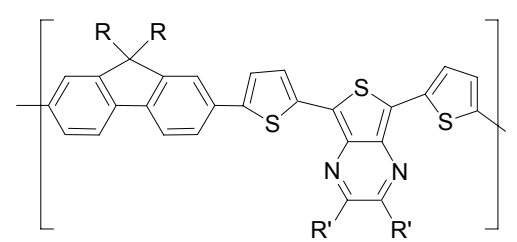

PFTTPT, R = alkyl, R' = phenyl

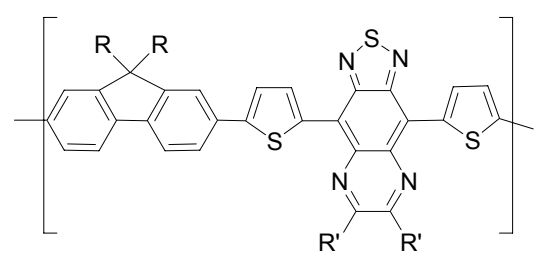

PFTQT, R = alkyl, R' = alkyl

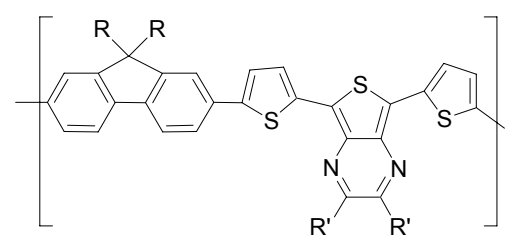

PFTTPT, $\mathrm{R}=$ alkyl, R'= phenyl-

O-alkyl

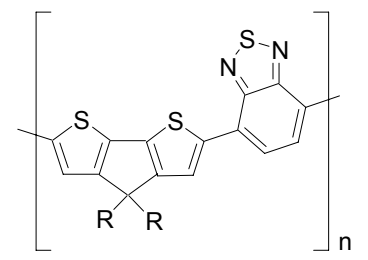

PCPDTB, R = 2-ethylhexyl 
For an up-to-date review on these low band gap polymers and examples of other low band gap polymers see Appendix A2.3.

\subsection{Choice of system}

As can be seen above, the low band gap polymers described in the literature are often copolymers based on donor and acceptor moieties. Therefore, in the design of new low band gap polymers I chose to focus on copolymers with the choice of thiophene as the donor and benzothiadiazole or benzo-bis(thiadiazole) as acceptor. ${ }^{8,54}$ Thiophene is an electron rich aromatic five membered heterocyclic ring and therefore an electron donating unit. ${ }^{55,56}$

The benzothiadiazole and benzo-bis(thiadiazole) are electron accepting units and the quinoid form, i.e. the 1,2,5-thiazole ring, which is one of the resonance forms as shown in Figure 2.7 will result in a lower band gap. ${ }^{8,54}$ Benzo-bis(thiadiazole) has been shown to exceed the highest electron-accepting ability among other accepting units, such as thienopyrazine, pyrazine-quinoxaline and benzothiadiazole, ${ }^{8,54}$ and hence the band gap of the copolymers based on this moiety is predicted to be very low.

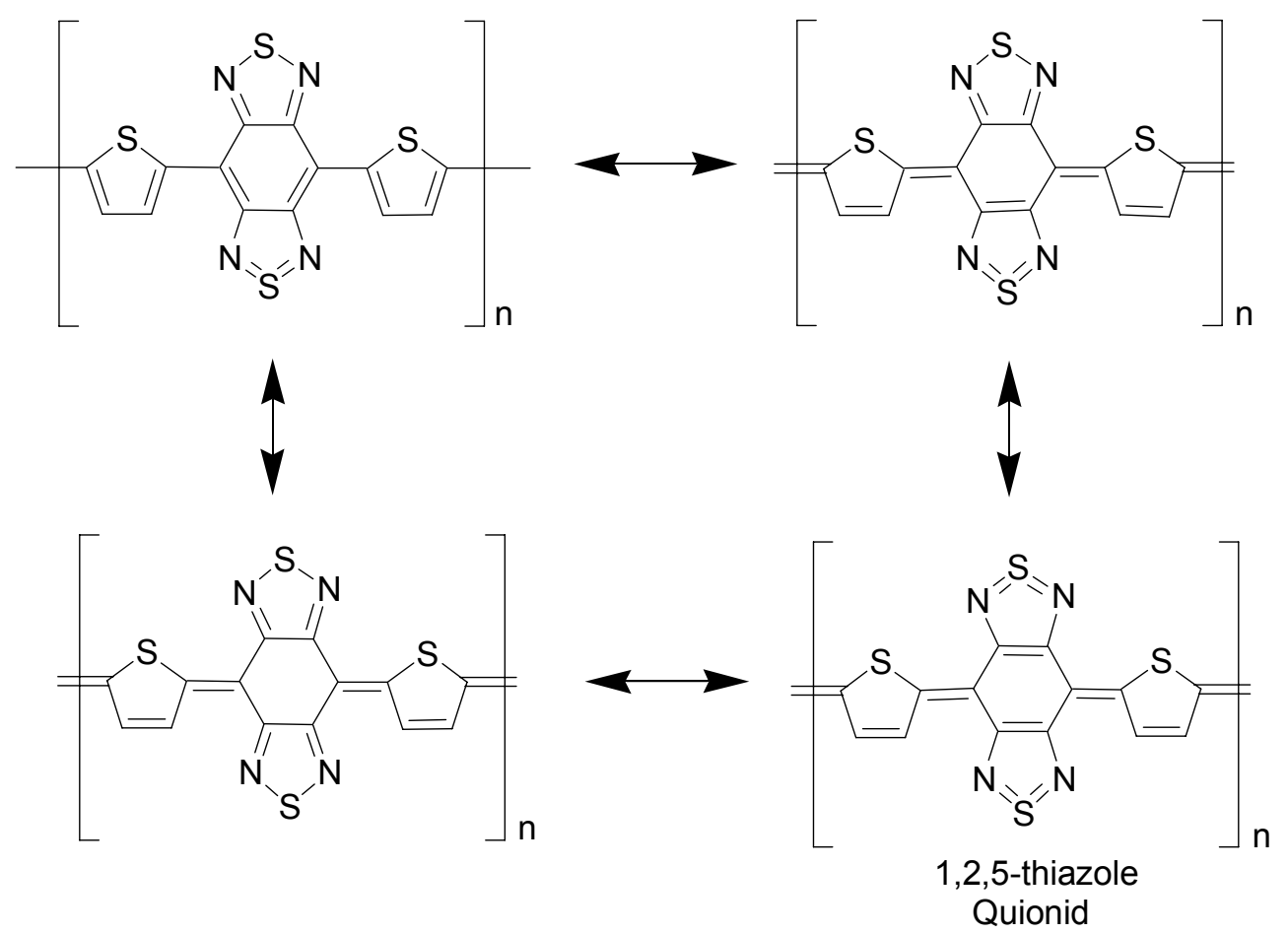

Figure 2.7. Resonance structures of benzo-bis(thiadiazole).

The synthetic strategies and syntheses of these copolymers is described in Chapter 3.

\subsection{Summary}

The low band gap polymers have the possibility to increase the efficiency of OPVs, due to a better overlap of the absorption spectrum and the solar spectrum. The design of the polymer structure is of great importance to achieve a low band gap and there are several factors which should be taken into account, such as intra-chain charge transfer and substituents effects. The design of new low band gap polymers focused on copolymers based on thiophene, benzothiadiazole and benzo-bis(thiadiazole). A 
short introduction was given to the low band gap polymers described in the literature which are most often copolymers based on donor and acceptor moieties.

\section{References}

1 A. Dhanabalan, J. K. J. van Duren, P. A. van Hal, J. L. J. van Dogen, R. A. J. Janssen, Adv. Funct. Mater. 11 (2001) 255-262.

2 J. K. J. van Duren, A. Dhanabalan, P. A. van Hal, R. A. J. Janssen, Synth. Met. 121 (2001) 1587-1588.

3 H. Neugebauer, C. J. Brabec, N. S. Sariciftci, R. Kiebooms, F. Wudl, S. Luzzati, J. Chem. Phys. 110 (1999) 12108-12115.

$4 \quad$ National Renewable Energy Laboratory (NREL), MS Excel ${ }^{\mathrm{TM}}$ spreadsheet file $^{\mathrm{N}}$ downloaded from http://rredc.nrel.gov/solar/spectra/am1.5/

5 C. Winder, N. S. Sariciftci, J. Mater. Chem. 14 (2004) 1077-1086.

6 F. Wudl, M. Kobayashi, A. J. Heeger, J. Org. Chem. 49 (1984) 3382-3384.

7 M. Chen, E. Perzon, M. R. Andersson, S. Marcinkevicius, S. K. M. Jönsson, M. Fahlman, M. Berggren, Appl. Phys. Lett. 84 (2004) 3570-3572.

8 C. Kitamura, S. Tanaka, Y. Yamashita, Chem. Mater. 8 (1996) 570-578.

9 M. Jayakannan, P. A. van Hal, R. A. J. Janssen, J. Pol. Scien. A, Pol. Chem. 40 (2002) 251-261.

10 A. Ajayaghosh, Chem. Soc. Rev. 32 (2003) 181-191.

11 M. Jørgensen, F. C. Krebs, Pol. Bul. 51 (2003) 23-30.

12 F. C. Krebs, Pol. Bull. 52 (2004) 49-56.

13 F. C. Krebs, M. Jørgensen, Macromolecules 35 (2002) 7200-7206.

14 J. L. Brédas, A. J. Heeger, Chem. Phys. Lett. 217 (1994) 507-512.

15 K. G. Jespersen, W. J. D. Beenken, Y. Zaushitsyn, A. Yartsev, M. Andersson, T. Pullerits, V. Sundström, J. Chem. Phys. 121 (2004) 12613-12617.

16 K. G. Jespersen, A. Yartsev, T. Pascher, V. Sundström, Synth. Met. 155 (2005) 262-265.

17 N.-K. Persson, M. Sun, P. Kjellberg, T. Pullerits, O. Inganäs, J. Chem. Phys. 123 (2005) 204718 1-9.

18 L. Yang, J.-K. Feng, A.-M. Ren, Polymer 46 (2005) 10970-10981.

19 S. C. Rasmussen, B. D. Straw, J. E. Hutchison, Semiconducting Polymers applications properties and synthesis, ACS Symposium series 735 (Eds. B. R. Hsieh, Y. Wei) Am. Chem. Soc. Washington DC, ISBN: 0-8412-3612-7 (1999) 347-366.

20 P. Schilinsky, U. Asawapirom, U. Scherf, M. Biele, C. J. Brabec, Chem. Mater. 17 (2005) 2175-2180.

21 D. W. Breiby, E. J. Samuelsen, O. Konovalov, Synth. Met. 139 (2003) 361369.

22 D. W. Breiby, E. J. Samuelsen, J. Pol. Sci. B: Pol. Phys. 41 (2003) 2375-2393.

23 K. E. Aasmundtveit, E. J. Samuelsen, M. Guldstein, C. Steinsland, O. Flornes, C. Fagermo, T. M. Seeberg, L. A. A. Pettersson, O. Inganäs, R. Feidenhans'1, S. Ferrer, Macromolecules 33 (2000) 3120-3127.

24 K. E. Aasmundtveit, E. J. Samuelsen, W. Mammo, M. Svensson, M. R. Andersson, L. A. A. Pettersson, O. Inganäs, Macromolecules 33 (2000) 54815489.

25 D. Fichou, J. Mater. Chem. 10 (2000) 571-588.

26 H. J. Fell, E. J. Samuelsen, M. R. Andersson, J. Als-Nielsen, G. Grübel, J. Mårdalen, Synth. Met. 73 (1995) 279-283. 
27 H. J. Fell, E. J. Samuelsen, J. Mårdalen, M. R. Andersson, Synth. Met. 69 (1995) 283-284.

28 J. Mårdalen, E. J. Samuelsen, Synth. Met. 48 (1992) 363-380.

29 T. J. Prosa, M. J. Winokur, J. Moulton, P. Smith, A. J. Heeger, Macromolecules 25 (1992) 4364-4372.

30 L. Sicot, C. Fiorini, A. Lorin, P. Raimond, C. Sentein, J.-M. Nunzi, Sol. Energy Mater. Sol. Cells 63 (2000) 49-60.

31 J. Nakamura, K. Murata, K. Takahashi, Appl. Phys. Lett. 87 (2005) 132105 13.

32 J. Huang, G. Li, Y. Yang. Appl. Phys. Lett. 87 (2005) 112105 1-3.

33 A. J. Mozer, N. S. Sariciftci, A. Pivrikas, R. Österbacka, G. Juška, L. Brassat, H. Bässler, Phys. Rev. B 71 (2005) 035214 1-9.

34 R. J. Kline, M. D. McGehee, E. N. Kadnikova, J. Liu, J. M. J. Fréchet, M. F. Toney, Macromolecules 38 (2005) 3312-3319.

35 K. Sivula, C. K. Luscombe, B. C. Tompson, J. M. Fréchet, J. Am. Chem. Soc. 128 (2006) 13988-13989.

36 L. J. A. Koster, V. D. Mihailetchi, P. W. M. Blom, Appl. Phys. Lett. 88 (2006) 093511 1-3.

37 M. R. Andersson, O. Thomas, W. Mammo, M. Svensson, M. Theander, O. Inganäs, J. Mater. Chem. 9 (1999) 1933-1940.

38 R. D. McCullough, Adv. Mater. 10 (1998) 93-116.

39 M. Kobayashi, N. Colaneri, M. Boysel, F. Wudl, A. J. Heeger, J. Chem. Phys. 82 (1985) 5717-5723.

40 A. Henckens, M. Knipper, I. Polec, J. Manca, L. Lutsen, D. Vanderzande, Thin Solid Films 451-452 (2004) 572-579.

41 S. E. Shaheen, D. L. Vangeneugden, R. Kiebooms, D. Vanderzande, T. Fromherz, F. Padinger, C. J. Brabec, N. S. Sariciftci, Synth. Met. 121 (2001) 1583-1584.

42 D. L. Vangeneugden, R. H. L. Kiebooms, D. J. M. Vanderzande, J. M. J. V. Gelan, Synth. Met. 101 (1999) 120-121.

43 L. M. Campos, A. Tontcheva, S. Günes, G. Sonmez, H. Neugebauer, N. S. Sariciftci, F. Wudl, Chem. Mater. 17 (2005) 4031-4033.

44 M. M. Wienk, M. G. R. Turbiez, M. P. Struijk, M. Fonrodona, R. A. J. Janssen, Appl. Phys. Lett. 88 (2006) 153511 1-3.

45 Q. Hou, Y. Xu, W. Yang, M. Yuan, J. Peng, Y. Cao, J. Mater. Chem. 12 (2002) 2887-2892.

46 M. Svensson, F. Zhang, S. C. Veenstra, W. J. H. Verhees, J. C. Hummelen, J. M. Kroon, O. Inganäs, M. R. Andersson, Adv. Mater. 15 (2003) 988-991.

47 E. Perzon, X. Wang, F. Zhang, W. Mammo, J. L. Delgado, P. de la Cruz, O. Inganäs, F. Langa, M. R. Andersson, Synth. Met. 154 (2005) 53-56.

48 M. Chen, E. Perzon, N. Robisson, S. K. M. Jönsson, M. R. Andersson, M. Fahlman, M. Berggren, Synth. Met. 146 (2004) 233-236.

49 E. Perzon, X. Wang, S. Admassie, O. Inganäs, M. R. Andersson, Polymer 47 (2006) 4261-4268.

50 F. Zhang, E. Perzon, X. Wang, W. Mammo, M. R. Andersson, O. Inganäs, Adv. Funct. Mater. 15 (2005) 745-750.

51 X. Wang, E. Perzon, W. Mammo, F. Oswald, S. Admassie, N.-K. Persson, F. Langa, M. R. Andersson, O. Inganäs, Thin Solid Films 511-512 (2006) 576580 . 
52 D. Mühlbacher, M. Scharber, M. Morana, Z. Zhu, D. Waller, R. Gaudiana, C. J. Brabec, Adv. Mater. 18 (2006) 2884-2889.

53 D. Mühlbacher, M. Scharber, M. Morana, Z. Zhu, D. Waller, R. Gaudiana, C. J. Brabec, Adv. Mater. 18 (2006) 2884-2889, correction.

54 M. Karikomi, C. Kitamura, S. Tanaka, Y. Yamashita, J. Am. Chem. Soc. 117 (1995) 6791-6792.

55 J. Clayden, N. Greeves, S. Warren, P. Wothers, Organic Chemistry, Oxford University Press, 1991, ISBN: 0-19-850346-6.

56 M. Jones, Jr., Organic Chemistry, W. W. Norton \& Company, 1997, ISBN: 0393-97079-5. 
In this chapter the synthesis of the low band gap copolymers based on thiophene, benzothiadiazole and benzo-bis(thiadiazole) designed in Section 2.4 are described. The low band gap copolymers were prepared by either the oxidative ferric chloride polymerization or the palladium-catalyzed Stille cross coupling polymerization. These methods are therefore described in detail followed by the synthetic procedures carried out to achieve the low band gap copolymers. In the last part of the chapter the purification methods and results from Size Exclusion Chromatography (SEC) are described.

\subsection{Synthetic strategies towards low band gap polymers based on thiophene, benzothiadiazole and benzo-bis(thiadiazole)}

Based on the design of low band gap polymers I chose to synthesize copolymers based on thiophene, benzothiadiazole and benzo-bis(thiadiazole). In Figure 3.1 the strategies to prepare the copolymers are shown. The first is based on the oxidative ferric chloride polymerization of co-monomers of thiophene, benzothiadiazole and benzo-bis(thiadiazole). The second is based on the palladium-catalyzed Stille cross coupling polymerization between di-stannyl derivates of thiophene and di-bromo derivates of benzothiadiazole or benzo-bis(thiadiazole).

When the two strategies are compared we find advantages in both. The oxidative ferric chloride polymerization has been reported to result in higher molecular weight polymers and there is also no need for reactive groups such as the halide or stannyl groups. This is because the polymerization is carried out on a co-monomer with hydrogen at the position of the new bond. The advantages of the Stille cross coupling polymerization strategy are the number of possible polymers which can be prepared. In Figure $3.1 \mathrm{~m}$ can be any given number, which results in an even number of thiophenes in the repeating unit in strategy I. However, the number of thiophenes in the repeating unit in strategy II can be varied depending on the choice of $l$.

There are several other methods, which have been described in the literature, e.g. Suzuki cross coupling and Kumada cross coupling, which could be used to synthesize the low band gap polymers. However, these are variations of the Stille cross coupling that I chose to use. 
Strategy I:
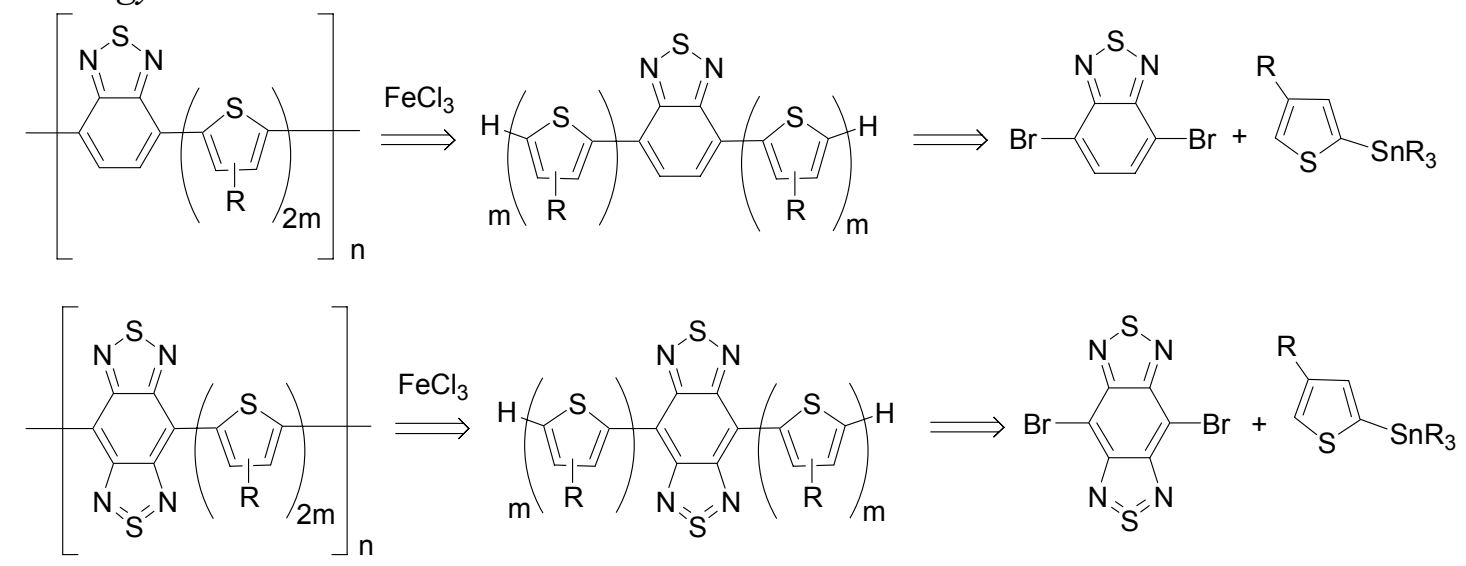

Strategy II:

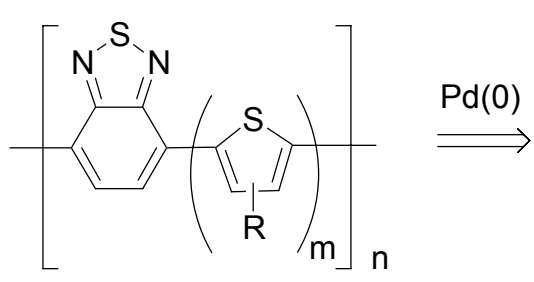<smiles>Brc1ccc(-c2ccc(-c3ccc(Br)s3)c3nsnc23)s1</smiles><smiles>Brc1ccc(Br)c2nsnc12</smiles>

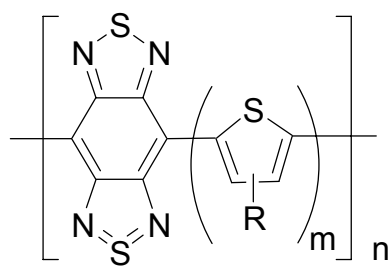<smiles>[R]CC(C)(C)c1ccc(Br)s1</smiles>

Figure 3.1. Retrosynthetic strategies to prepare copolymers of thiophene and benzothiadiazole or benzo-bis(thiadiazole) via I) oxidative ferric chloride polymerization and II) Stille cross coupling polymerization.

\subsection{Polymerization methods}

\subsubsection{Oxidative ferric chloride polymerization}

In oxidative ferric chloride polymerization a monomer is polymerized using ferric(III)chloride $\left(\mathrm{FeCl}_{3}\right)$ as a reagent (shown in Figure 3.2).

$$
\left.\mathrm{H}-\mathrm{Ar}-\mathrm{H} \stackrel{2 \mathrm{FeCl}_{3}}{\longrightarrow}-\mathrm{Ar}\right]_{\mathrm{n}}+2 \mathrm{FeCl}_{2}+2 \mathrm{HCl}
$$

Figure 3.2. Oxidative ferric chloride polymerization, where Ar represents an aromatic ring.

In this polymerization method there is no need for active groups on the reagents (e.g. stannyl or halide) since the polymerization occurs where hydrogen is attached. 


\subsubsection{Mechanism}

The mechanism of oxidative ferric chloride polymerization is not known exactly. In Figure 3.3 three proposed mechanisms are shown with thiophene as an example. ${ }^{1-3}$ The thiophene radical units are represented with double bonds specified for the atoms but a more correct way to show this is displaying the positive radical all over the thiophene unit as illustrated in Figure 3.4.

1):
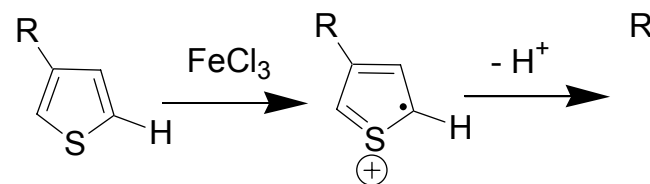<smiles>[R]c1ccsc1</smiles><smiles>[R]c1csc(C2SC=CC2[R])c1</smiles><smiles>[R]C1=CC=[Se]C1c1cc([R])cs1</smiles><smiles>CC[PH+]C</smiles><smiles>[R]c1csc(-c2sccc2[R])c1</smiles>

2):<smiles>[R]c1cc(-c2sc(CC(C)C)cc2[R])sc1C</smiles><smiles></smiles><smiles>[R]c1ccsc1C(C)C</smiles><smiles></smiles><smiles>[R]c1cc(-c2sc(-c3sccc3[R])cc2[R])sc1C[C@@H]1C[C@H](C)[PH+]1</smiles>

3):

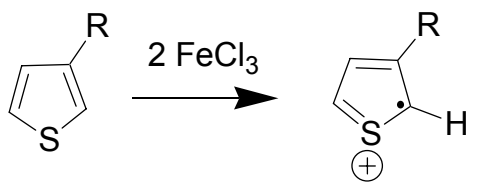<smiles>[R]c1cc[se]c1</smiles><smiles>[R]C1=CC=[S+]=C1C1[C@H]([R])C=C[C@H]1[R]</smiles><smiles>CC[PH2+]</smiles><smiles>[R]c1ccsc1-c1sccc1[R]</smiles>

Figure 3.3. Proposed mechanisms of oxidative ferric chloride polymerization: 1) radical, 2) carbocation and 3) radical carbocation.<smiles>[R]c1cscc1C#Cc1sccc1[R]</smiles>

Figure 3.4. Correct way to see the radical thiophene unit.

In the radical mechanism the first step is the formation of a radical by oxidation of thiophene and the simultaneous reduction of $\mathrm{Fe}(\mathrm{III})$ to $\mathrm{Fe}(\mathrm{II})$ followed by elimination 
of a proton, which gives the radical. The radical reacts with a neutral thiophene ring forming a new radical. Oxidation with $\mathrm{Fe}(\mathrm{III})$ followed by proton elimination results in the polymer product. ${ }^{1}$

In the carbocation mechanism thiophene is oxidized by $\mathrm{FeCl}_{3}$ to give a radical cation in the initial step. The propagation step goes through a carbocation forming the bipolaron. In Figure 3.3 the bipolaron is shown on the adjacent thiophenes but it is believed that these two positive charges may be further apart. ${ }^{2}$ The positively charged thiophene reacts with a monomer in an electrophilic aromatic substitution reaction. This step has been shown to be regioselective where the reaction takes place at the $2^{\text {nd }}$ position. The polymer is formed when hydrogens are eliminated as protons and the thiophene rings regains its aromacity. ${ }^{2}$

Finally, in the radical cation mechanism the first step is the formation of a radical by oxidation with the simultaneous reduction of Fe(III) to Fe(II). Two radicals react in the propagation step and give a dimer which is no longer aromatic. The aromaticity is gained by elimination of two protons. The dimer can then be oxidized to form a new radical which can then react with another radical to form a trimer, and so on. ${ }^{3}$

The radical mechanism was proposed by Niemi et al. ${ }^{1}$ These authors based their proposal on two conclusions: 1) the polymerization was only observed in solvents where $\mathrm{FeCl}_{3}$ was insoluble and from this it was concluded that the polymerization took place on the surface of the ferric chloride, and 2) calculation of energy and atomic charges on the carbon atoms of the possible polymerization species which suggested that the more stable radical reacts with a neutral species and forms the HT coupled polymer.

The carbocation mechanism was proposed by Andersson et al. ${ }^{12}$ and was based on the observation of polymerization leading to "highly" regioregular (94\% HT) poly(octylphenyl-thiophene) when $\mathrm{FeCl}_{3}$ in $\mathrm{CHCl}_{3}$ suspension was added in small portions.

The radical cation mechanism was proposed by Barbarrel et al., ${ }^{3}$ who found that the polymerization of thiophenes could take place in solvents where $\mathrm{FeCl}_{3}$ was partly or completely soluble. This led to the theory that the mechanism was carried out by a radical cation mechanism. ${ }^{3,4}$ In addition, it was found that the oxidation of the monomer is the rate determining step. ${ }^{4}$

The three research groups suggested that the oxidative ferric chloride polymerization led to regioregular HT-coupled polymer products. However, since the synthesis of highly regioregular (99\%) HT-coupled polymer by Kumada coupling and Negishi coupling polymerizations ${ }^{5,6}$ and the report on the polymerization of alkyl-thiophene using the oxidative ferric chloride polymerization, which led to $25 \%$ defects, ${ }^{7,8}$ the oxidative ferric polymerization is recognized for high molecular weight polymer products, but with little control of the regioregularity. This also makes sense considering the suggested radical mechanisms.

\subsubsection{Reaction conditions}

For the synthesis of polythiophenes the reaction was carried out at room temperature in different solvents, such as $\mathrm{CHCl}_{3}, \mathrm{CH}_{2} \mathrm{Cl}_{2}, \mathrm{CH}_{3} \mathrm{NO}_{2}$ and pentane. ${ }^{3}$ The reaction time is varied from a few hours to overnight; however, the polymerization is seen immediately as a change in colour..$^{2-4,9,10}$ The oxidative ferric chloride polymerization results in high molecular weights and hence to a lower band gap because of the longer conjugation length. 
The oxidative ferric chloride polymerization has been used to prepare many polymers such as poly-alkyl-thiophene with high molecular weight, ${ }^{7,8,11-16}$ poly-octylphenylthiophene ${ }^{2}$ and copolymers of thiophene and isothianaphthene ${ }^{9,10}$ or thienopyrazine. ${ }^{17}$

\subsubsection{Stille cross coupling reaction}

The Stille cross coupling ${ }^{18,19}$ is a reaction between an organo-electrophile and an organo-stannyl reagent using palladium as a catalyst, which proceeds under mild neutral conditions and with high yields. ${ }^{18,20}$ The organo-electrophile includes organohalides, -triflates or -carboxylates. ${ }^{21}$ The Stille cross coupling polymerization is shown in Figure 3.5 and as shown there is the possibility to prepare copolymers of donor and acceptor moieties if different $\mathrm{R}$ and $\mathrm{R}$ ' groups are used.

$$
\left.\mathrm{n} \mathrm{X}-\mathrm{R}-\mathrm{X}+\mathrm{n} \mathrm{R}{ }_{3} \mathrm{Sn}-\mathrm{R}^{\prime}-\mathrm{SnR}_{3} \stackrel{\mathrm{PdL}_{4}}{\longrightarrow}-\mathrm{R}-\mathrm{R}^{\prime}\right]_{\mathrm{n}}+2 \mathrm{nX}^{-\mathrm{SnR}^{\prime \prime}}{ }_{3}
$$

Figure 3.5. Stille cross coupling polymerization catalyzed by Pd reagent.

The advantage of the Stille cross coupling reaction is that it has the ability to couple many different kinds of organo-halides and organo-stannyl compounds and that both can have a variety of functional groups (e.g. $\mathrm{CO}_{2} \mathrm{R}, \mathrm{CN}, \mathrm{OH}$ or $\mathrm{CHO}$ ) attached with no need for pre-protection of these groups.

\subsubsection{Mechanism}

The cyclic catalytic reaction mechanism (shown in Figure 3.6) consists of four steps: 1) ligand dissociation, 2) oxidative addition of the metal, 3) transmetallation and 4) reductive elimination. ${ }^{24}$ Other polymerization methods based on transition metals (e.g. Suzuki cross coupling) used in the literature to prepare low band gap polymers also follow this reaction cycle.

The presence of carbon monoxide in the reaction mixture results in insertion of a carbonyl group in the product (R-CO-R') and the mechanism of this reaction includes an additional carboxylation step between the oxidative addition step and the transmetallation; however, this is not an issue for this dissertation and will not be further discussed here. ${ }^{18,24}$ 


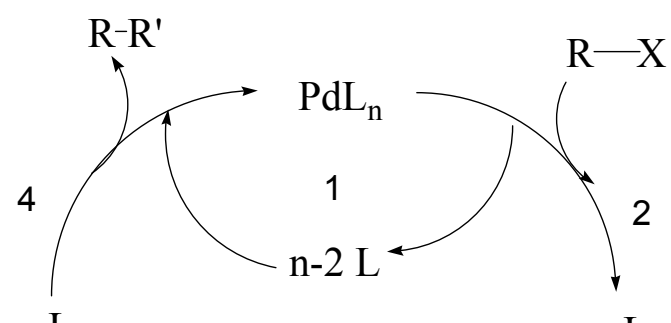

cis

$\mathrm{L}$

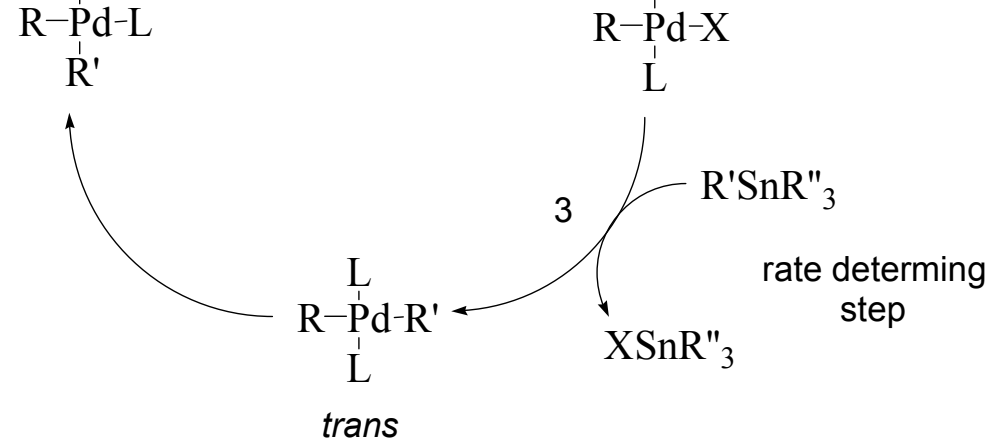

Figure 3.6. Mechanism of the Stille cross coupling reaction cycle. ${ }^{18,23}$

The first step of the catalytic reaction cycle is the ligand dissociation (step 1 in Figure 3.6). The catalyst $\mathrm{M}\left(\mathrm{PPh}_{3}\right)_{4}$, where $\mathrm{M}$ is $\mathrm{Ni}^{0}, \mathrm{Pd}^{0}$ or $\mathrm{Pt}^{0}$, is coordinatively saturated but undergoes dissociation to form the more reactive compound with two phosphine groups. In that sense the active catalyst is $\mathrm{M}\left(\mathrm{PPh}_{3}\right)_{2}{ }^{22,23}$ The phosphine groups form $\sigma$ bonds with the metal by donating the lone pair on phosphorus to the empty $d$ orbital on the metal (see Figure 3.7). ${ }^{23}$ The donation of the lone pair from the phosphorus increases the electron density on the metal. Hence, the metal is more nucleophilic and thus oxidative addition is favored..$^{22,23}$

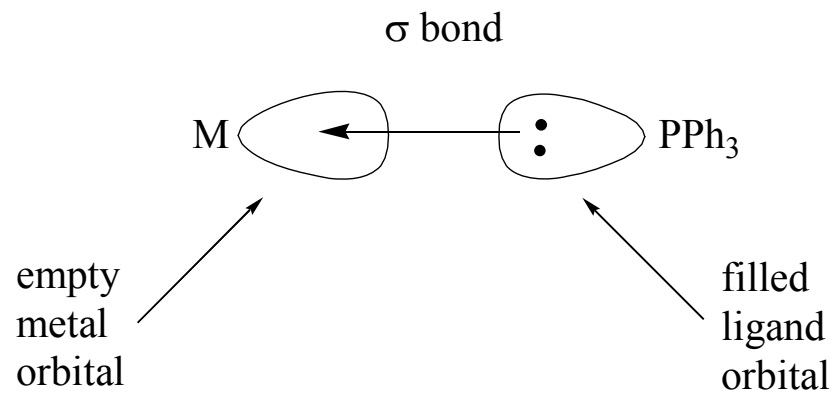

Figure 3.7. Metal-ligand $\sigma$ bond.

In the oxidative addition (step 2 in Figure 3.6) an organo-halide (RX) is added to the $\mathrm{Pd}(0)$ complex by oxidation of $\mathrm{Pd}$. This is followed by an increase in the coordination number. ${ }^{22,23}$ It is characteristic for complexes of the metals in Group VIII (Fe, Ni, Ru, $\mathrm{Pd}, \mathrm{Pt}$ etc.) with $d^{8}$ and $d^{10}$ electronic configuration, to undergo oxidative addition. ${ }^{22,23}$ There are two main factors which have to be fulfilled for the metal to undergo oxidative addition. These are: 1) the metal must be in a low valence state and 2) the catalyst must be a coordinatively unsaturated species. In the low valence state the metal behaves as a nucleophile or a reducing agent, in which case electrons are removed from the metal under reaction. For metals in Group VIII the low valence state is normally the atomic state obtained through ligand complexation. ${ }^{22,23}$ The 
coordinatively unsaturated species is obtained by generation of a vacant site which results from ligand dissociation. ${ }^{22,23}$

Compounds, which undergo oxidative addition are divided into two groups, polar and non-polar. The non-polar compounds are hydrocarbons (e.g. alkenes, aromatics and aldehydes) with a stereospecifically cis addition. The polar are the organo-halides, which are susceptible to nucleophillic attack from the metal due to the good leaving group. ${ }^{23}$ The mechanism of oxidative addition depends on the type of metal and on the type of organic halide. For the aryl halide three different mechanisms have been proposed: a nucleophilic aromatic substitution-like mechanism, an electron-transfer mechanism or a three-center mechanism, which all emphasize the nucleophilic nature of the low-valence metal. ${ }^{22}$

The mechanism of the transmetallation (step 3 in Figure 3.6) is not well understood but this has been determined as the rate-determining step. ${ }^{18,20}$ Several mechanisms have been proposed. First, a dissociative mechanism, in which ligand dissociation from the electron-rich $\mathrm{Pd}$ complex takes place before transmetallation to give a coordinatively unsaturated complex, which is supported by solvent and reacts with the stannyl compound in the transmetallation. Second, a cyclic associative mechanism which involves a cylic transition state of the transmetallation resulting in the cis-R/R' $\mathrm{Pd}$ complex rather than the trans-R/R' $\mathrm{Pd}$ complex needed for the reductive elimination. Finally, an open associative mechanism, which is the only possibility if no bridging ligands are available in the coordination sphere of $\operatorname{Pd}(\mathrm{II})$ to produce the cyclic intermediate. This mechanism results in inversion of the stereochemistry on the $\alpha$ carbon transferred from the stannyl group and results in trans and cis $\mathrm{R} / \mathrm{R}^{\prime} \mathrm{Pd}$ complexes. $^{20}$

In the reductive elimination (step 4 in Figure 3.6) the formal oxidation state and the coordination number of the metal are increased by 2 , the product is eliminated from the $\mathrm{Pd}$ catalyst and the $\mathrm{Pd}$ gain two ligands to return to the stating point. ${ }^{23}$ The reductive elimination is an intermolecular reaction, and a cis/trans isomerisation of the $\mathrm{Pd}(\mathrm{II})$ complex has to take place before the reductive elimination of the two $\mathrm{R}$ groups, which also have to be cis to each other. ${ }^{25-27}$ There are several ways in which this can take place: 1) dissociation of phosphine to give a three coordinate intermediate, 2) association of phosphine to give a five-coordinate complex, 3) conversion of these two complexes to a cis square-planar complex by recoordination of dissociation after rearrangement, etc. ${ }^{23}$ The mechanism of the reductive elimination is not well understood, but has been proven to be a non-radical mechanism, due to: 1) retention of the stereochemistry (overall), 2) absence of cyclic products and 3) no radical inhibition. ${ }^{23}$

\subsubsection{Reaction conditions}

Preparation of the organo-stannyl compounds can be done by lithiation followed by reaction with trimethylstannyl-chloride or tributylstannyl-chloride. Several other methods have been described in the literature. ${ }^{19}$

Typical catalysts include $\mathrm{Pd}\left(\mathrm{PPh}_{3}\right)_{2} \mathrm{Cl}_{2}, \mathrm{Pd}\left(\mathrm{PPh}_{3}\right)_{4}, \mathrm{Pd}\left(\mathrm{PPh}_{3}\right)_{2} \mathrm{BnCl}, \mathrm{Pd}(\mathrm{MeCN})_{2} \mathrm{Cl}_{2}$ etc. $^{20,21,28}$ As described above the active catalyst is $\mathrm{Pd}\left(\mathrm{PPh}_{3}\right)_{2}$, which is the coordinatively unsaturated species. Excess of $\mathrm{PPh}_{3}$ has been found to slow down the reaction. ${ }^{20}$

Side reactions including dehalogenation, homo-coupling and $\beta$-hydride elimination (see Figure 3.8) have been observed in the Stille cross coupling. ${ }^{20,21}$ One of the few limitations of Stille cross coupling and other palladium-catalyzed reactions is that organo-halides with a $\beta$ hydrogen cannot be used because of faster $\beta$-hydride 
elimination compared to the transmetallation. ${ }^{18,23}$ The formation of the trans $\mathrm{R} / \mathrm{R}^{\prime}$ in the $\mathrm{Pd}(\mathrm{II})$ complex generated by oxidative addition and transmetallation explains the reason for homocoupling products. ${ }^{23}$

a

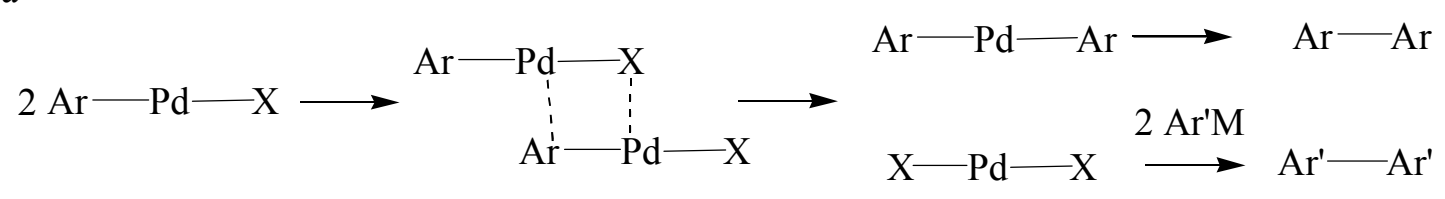

b

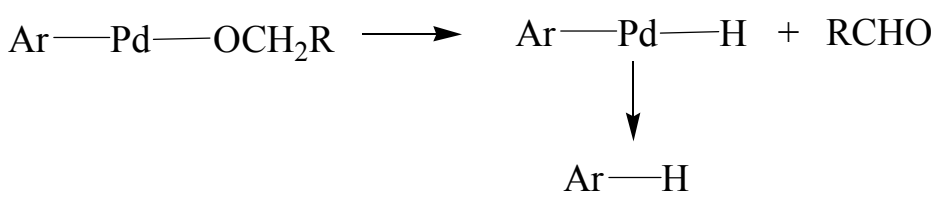

Figure 3.8. Examples of side reactions of the Stille cross coupling. a) homo-coupling and b) $\beta$-hydride elimination.

Different alkyl-stannyl groups have been used, e.g. $\mathrm{R}-\mathrm{SnBu}_{3}$ and $\mathrm{R}-\mathrm{SnMe}_{3}$, and the by-products in the reaction are $\mathrm{Bu}_{3} \mathrm{SnX}$ and $\mathrm{Me}_{3} \mathrm{SnX}$. The $\mathrm{Bu}_{3} \mathrm{SnX}$ is soluble in many organic solvents and purification by column chromatography is difficult. Consequently it is not trivial to purify the product (R-R') from the $\mathrm{Bu}_{3} \mathrm{SnX}{ }^{20} \mathrm{Me}_{3} \mathrm{SnX}$ has a low boiling point and can be removed by evaporation at reduced pressure or, since it has a low solubility in organic solvents, it can be removed during work-up by washing the reaction mixture with water. However, $\mathrm{Me}_{3} \mathrm{SnX}$ is extremely toxic. ${ }^{20}$

Despite the toxicity of stannyl compounds compared to boron- and zinc-compounds for example, they are still used due to ease of preparation, stability towards water and air once prepared and the large variety of residues on tin which can be transferred. ${ }^{20}$

Stille cross coupling polymerization has been applied in the literature for the synthesis of regioregular P3HT resulting in $96 \%$ regioregularity. ${ }^{29,30}$ Copolymers based on thiophene, pyrrole and benzothiadiazole have also been prepared by Stille cross coupling polymerization; however, because of side reactions this only led to low molecular weight oligomers. ${ }^{31,32}$

\subsection{Synthesis of copolymers based on thiophene, benzothiadiazole and benzo-bis(thiadiazole).}

\subsubsection{Oxidative ferric chloride polymerizations}

In Figure $3.9-3.18$ the successful synthetic steps toward the 16 new low band gap polymers based on thiophene, benzothiadiazole and benzo-bis(thiadiazole) are shown. The syntheses in Figure 3.9 and 3.10 are based on the oxidative ferric chloride polymerization strategy and, as shown, this strategy resulted in one polymer with two thiophenes in the repeating unit (1) and three polymers with four thiophenes in the repeating unit. The latter polymer was prepared with different alkyl side chains (i.e. hexyl- (2), dodecyl- (3) and 2-ethyl-hexyl-groups (4)). The synthesis of polymer 1 consisted of the following steps: preparation of the thiophene unit and the benzothiadiazole unit, coupling of these two by a Stille cross coupling to give the comonomer of thiophene and benzothiadiazole, followed by oxidative ferric polymerization to give the copolymer based on thiophene and benzothiadiazole (see 
Figure 3.9). The same procedure was used in the preparation of polymers $2-4$; however, an additional bromination followed by Stille cross coupling was necessary to obtain the co-monomer with four thiophene units (see Figure 3.10).

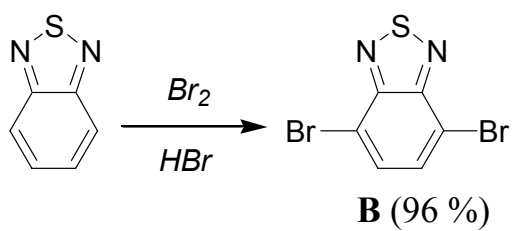

$\mathbf{B}+\mathbf{T} \frac{P d\left(P P h_{3}\right)_{2} C_{2}}{T H F}$

$(22 \%)$

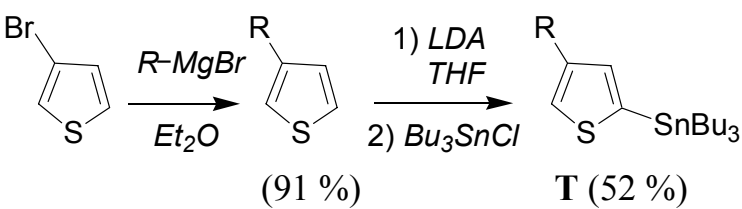

$(91 \%)$

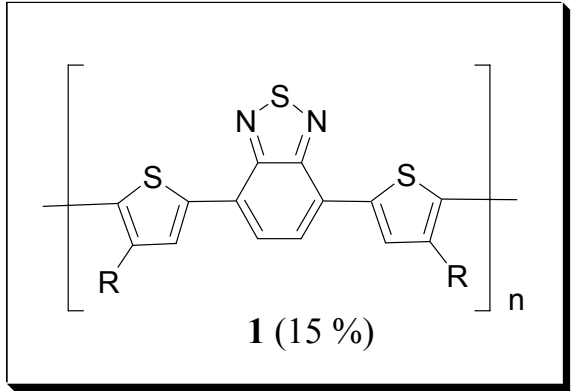

Figure 3.9. The synthesis of copolymers based on thiophene and benzothiadiazole (1) by oxidative ferric chloride polymerization. $\mathrm{R}=$ hexyl. 

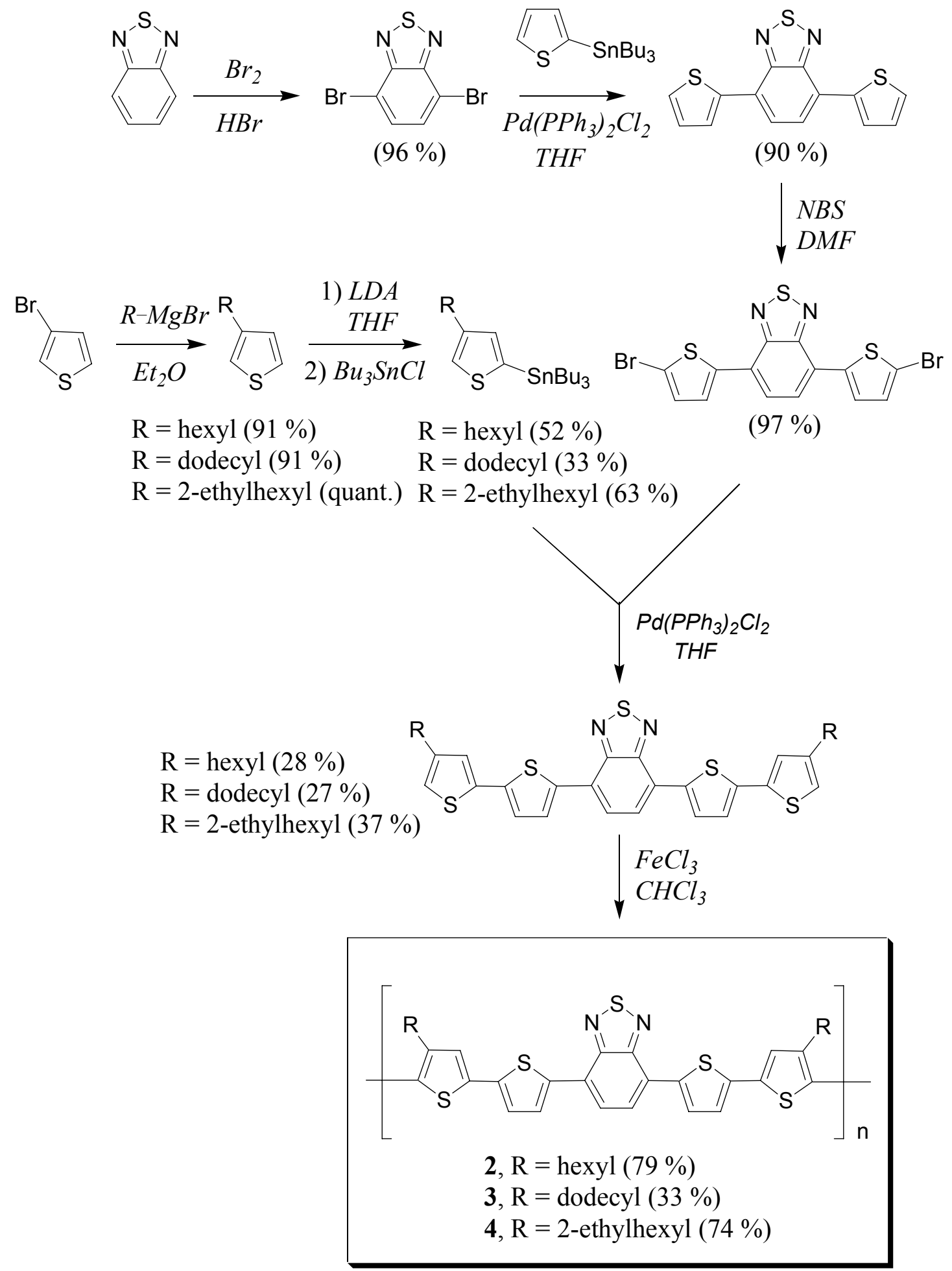

Figure 3.10. The synthesis of copolymers based on thiophene and benzothiadiazole $(\mathbf{2}-\mathbf{4})$ by oxidative ferric chloride polymerization.

\subsubsection{Stille cross coupling polymerizations}

In Figure 3.11 - 3.16 the synthesis of the di-stannyl derivates of thiophene and dithiophene and di-bromo derivates of benzothiadiazole and benzo-bis(thiadiazole) are shown. These are the building blocks used in the second strategy employing Stille cross coupling polymerization. The synthesis of the benzothiadiazole building blocks (B1 and B2) is described in the literature and consists of the following steps: 
bromination of benzothiadiazole to $\mathbf{B 1}$, which is reacted with tributylstannylthiophene in a Stille cross coupling reaction followed by a bromination resulting in $\mathbf{B 2}$ (see Figure 3.11). ${ }^{33,34}$

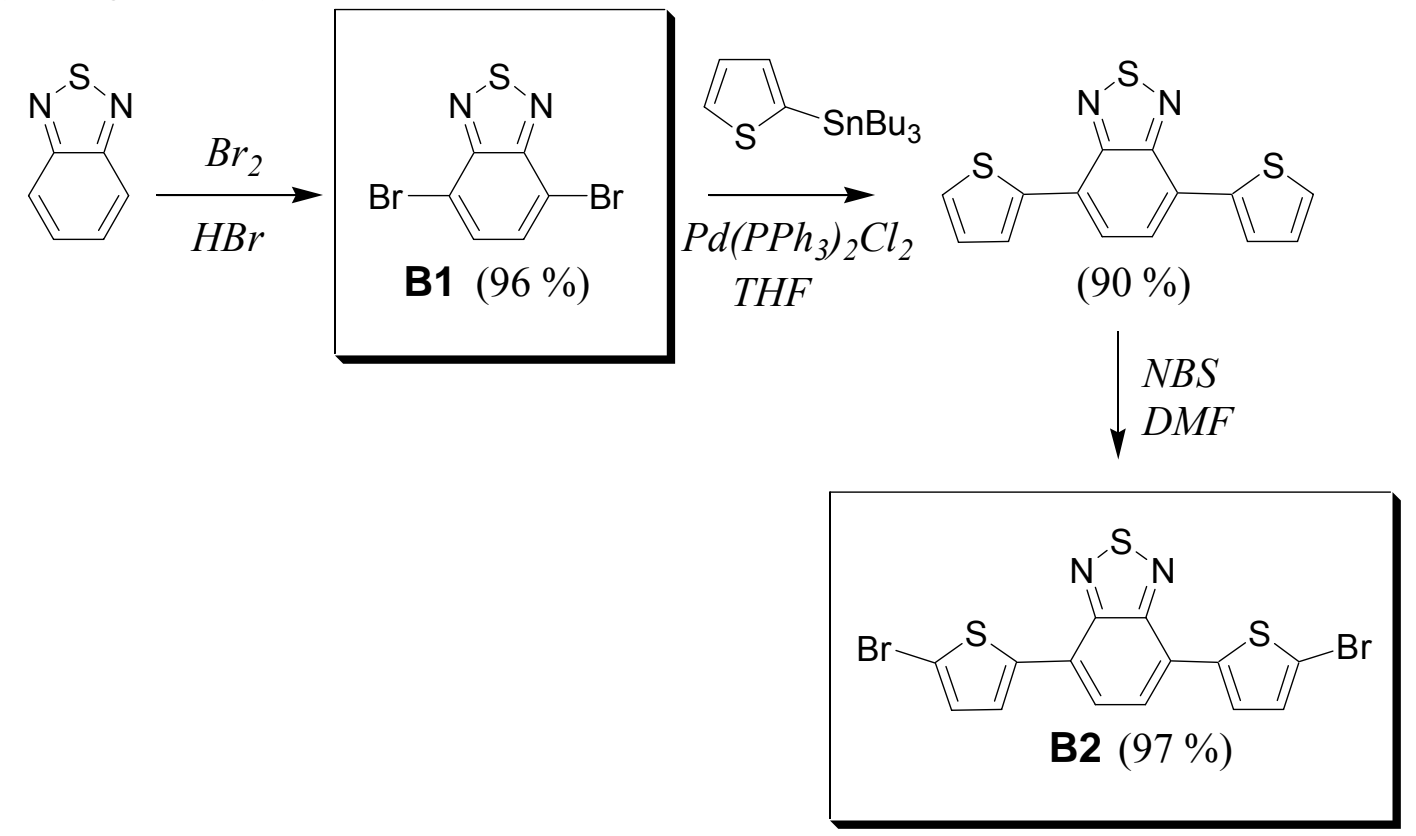

Figure 3.11. Synthesis of benzothiadiazole based building blocks (B1 and B2).

The synthesis of benzo-bis(thiadiazole) building block (B3) was carried out as described in the literature ${ }^{35,36}$ by the following steps: 1) nitration of the benzene ring, 2) introduction of the thiophene groups by Stille cross coupling, 3) reduction of the nitro groups using iron powder and acid and 4) ring closing with $N$-sulfinylaniline. ${ }^{35,36}$ This was followed by a bromation with NBS in $\mathrm{CHCl}_{3} / \mathrm{AcOH}$ to give $\mathbf{B 3}$ (see Figure 3.12).<smiles>O=[N+]([O-])c1c(Br)c(Br)c2nsnc2c1[N+](=O)[O-]</smiles>

$(20 \%)$<smiles>O=[N+]([O-])c1c(-c2cccs2)c(-c2cccs2)c2nsnc2c1[N+](=O)[O-]</smiles>

$(65 \%)$

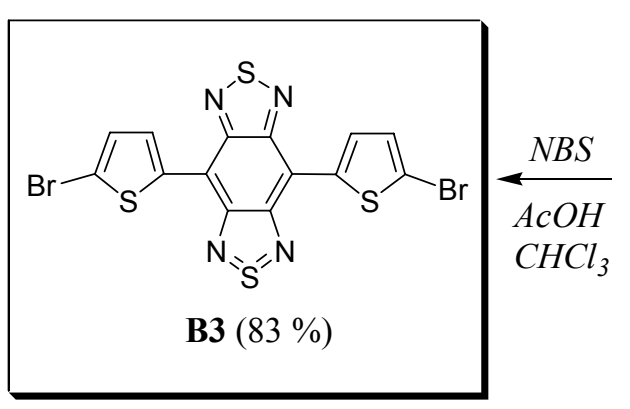<smiles>c1csc(-c2c3c(c(-c4cccs4)c4nsnc24)N=S=N3)c1</smiles>

$(82 \%)$

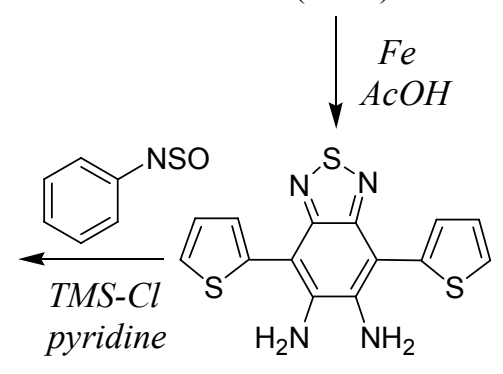

$(49 \%)$

Figure 3.12. Synthesis of a benzo-bis(thiadiazole) based building block (B3). 
The di-stannyl derivative of thiophene (B4) was obtained by reaction with $t$-BuLi (see Figure 3.13). However, several attempts to synthesize B4 were carried out with $t$ $\mathrm{BuLi} / \mathrm{TMEDA}$ and under different reaction temperatures using $n$-BuLi.t-BuOK.

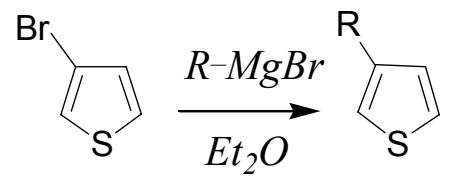

$(61 \%)$

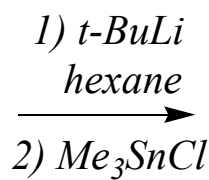

2) $\mathrm{Me}_{3} \mathrm{SnCl}$

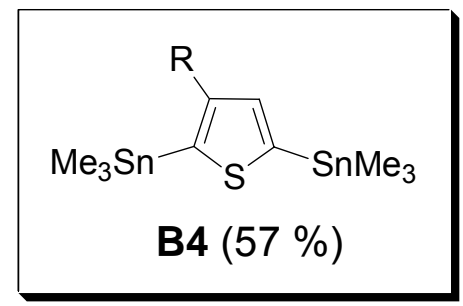

Figure 3.13. Synthesis of the di-stannyl derivates of thiophene (B4). R = 3,7,11-trimethyldodecyl.

In Figure 3.14 the synthesis of the di-stannyl derivative of di-thiophene (B5) is shown. The synthesis of the di-thiophene precursor to building block B5 was complicated. The synthesis of the precursor was attempted in several ways: 1) Ullmann coupling between two 2-bromo-3-(3,7,11-trimethyldodecyl)-thiophene using $\mathrm{Cu}$ as a catalyst, 2) Kumada coupling of the Grignard derivative of 2-bromo-3-(3,7,11trimethyldodecyl)-thiophene using $\mathrm{Ni}$ as a catalyst, 3) Stille cross coupling between a bromo and stannyl derivative of 3-(3,7,11-trimethyldodecyl)-thiophene, and 4) Stille homo-coupling of a stannyl derivative of 3-(3,7,11-trimethyldodecyl)-thiophene. This is discussed in detail in Appendix A2.2. The di-thiophene was finally successfully obtained by Stille cross coupling of a stannyl derivative of 3-(3,7,11trimethyldodecyl)-thiophene and an iodo-derivative of 3-(3,7,11-trimethyldodecyl)thiophene prepared in situ. An attempt to synthesize the di-stannyl derivate of the dithiophene (B5) was carried out with $t$-BuLi; however, B5 was achieved by reaction with $n$-BuLi as shown in Figure 3.14.

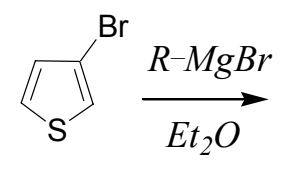<smiles>Fc1ccsc1</smiles>

$(61 \%)$
1) $n-B u L i$ THF

2) $I_{2}$

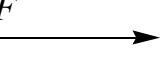

(1)

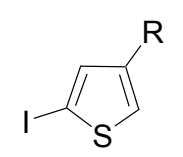

T1 (in situ)

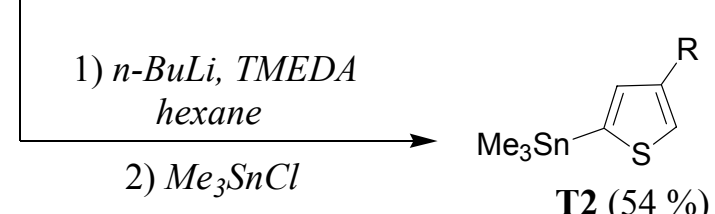

T2 $(54 \%)$

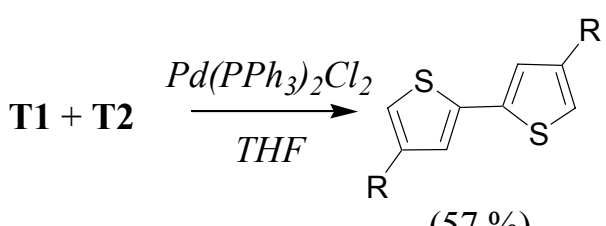

R 1) $n$-BuLi, TMEDA $\underset{\text { 2) } \mathrm{Me} \mathrm{S}_{3} \mathrm{SnCl}}{\stackrel{\text { hexane }}{\longrightarrow}}$

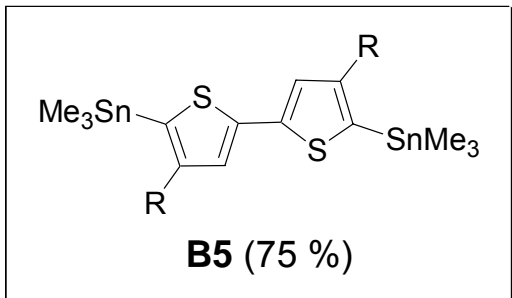

Figure 3.14. Synthesis of the di-stannyl derivates of di-thiophene (B6). $R=3,7,11$-trimethyldodecyl. 
The di-stannyl thiophene building blocks with 2-ethylhexyl- (B6) and hexyl-groups (B7) were synthesized using $n$-BuLi/TMEDA and $t$-BuLi respectively (see Figure 3.15 and 3.16).

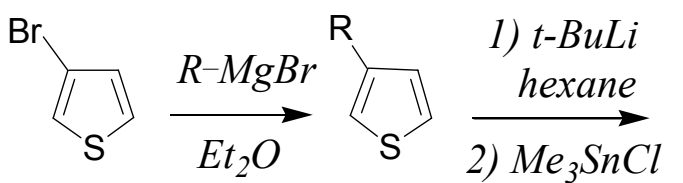

$(95 \%)$

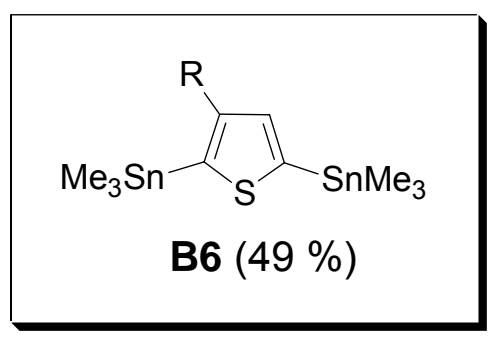

Figure 3.15. Synthesis of the di-stannyl derivates of thiophene (B6). R = 2-ethylhexyl.<smiles>[R]c1csc(-c2sccc2[R])c1</smiles>

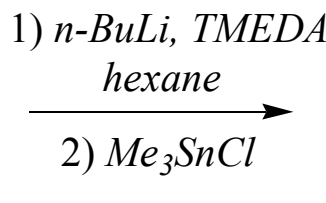<smiles></smiles>

B7 (95\%)

Figure 3.16. Synthesis of the di-stannyl derivates of di-thiophene (B7). R = hexyl.

The final synthetic step in the Stille cross coupling polymerization strategy is shown in Figure 3.17 and 3.18. The combination of the two different thiophene building blocks with 3,7,11-trimethyldodecyl as a side chain (B4 and B5) with the di-bromo derivatives of benzothiadiazole and benzo-bis(thiadiazole) resulted in six different polymers (i.e. four based on benzothiadiazole (polymer 5 - 8) and two based on benzo-bis(thiadiazole) (polymer $\mathbf{9}$ and 10) as shown in Figure 3.17).

Besides these polymers three polymers with hexyl side chains and three with 2ethylhexyl side chains was prepared, polymer 14 - 16 and 11 - 13 respectively (see Figure 3.18). 
Synthesis and purification

$$
\mathbf{B 1}+\mathbf{B} 4 \underset{\mathrm{THF}}{\stackrel{\mathrm{Pd}\left(\mathrm{PPh}_{3}\right)_{2} \mathrm{Cl}_{2}}{\longrightarrow}}
$$

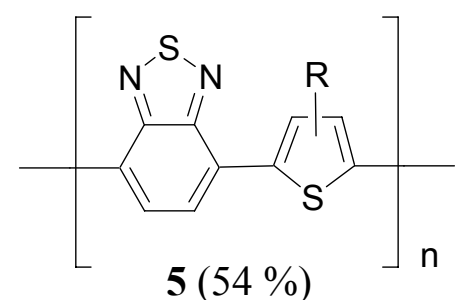

B1 + B5 $\underset{T H F}{\stackrel{P d\left(P P h_{3}\right)_{2} \mathrm{Cl}_{2}}{\longrightarrow}}$

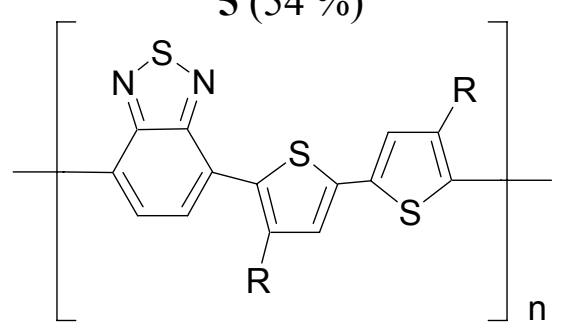

$6(60 \%)$

$\mathbf{B 2}+\mathbf{B} 4 \underset{\mathrm{THF}}{\stackrel{P d\left(P P h_{3}\right)_{2} \mathrm{Cl}_{2}}{\longrightarrow}}$
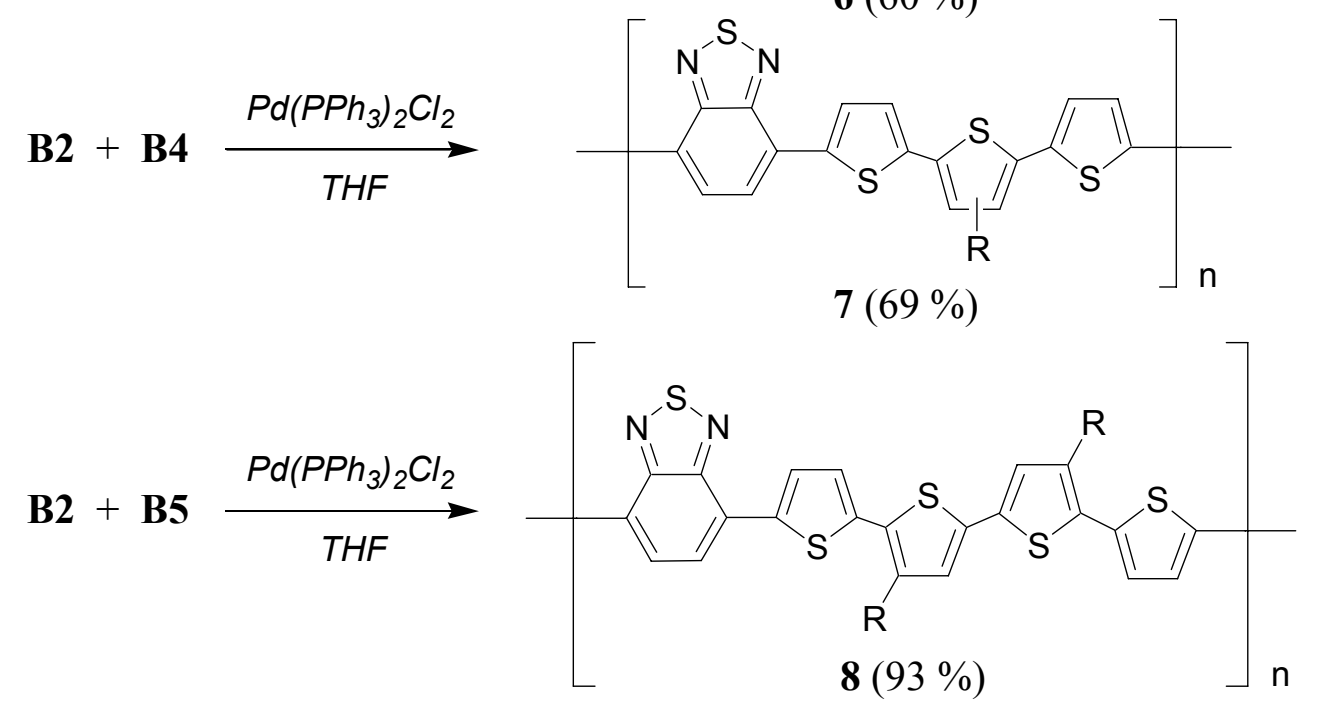

$$
\mathbf{B 3}+\mathbf{B 4} \underset{T H F}{\stackrel{P d\left(P P h_{3}\right)_{2} C_{2}}{\longrightarrow}}
$$

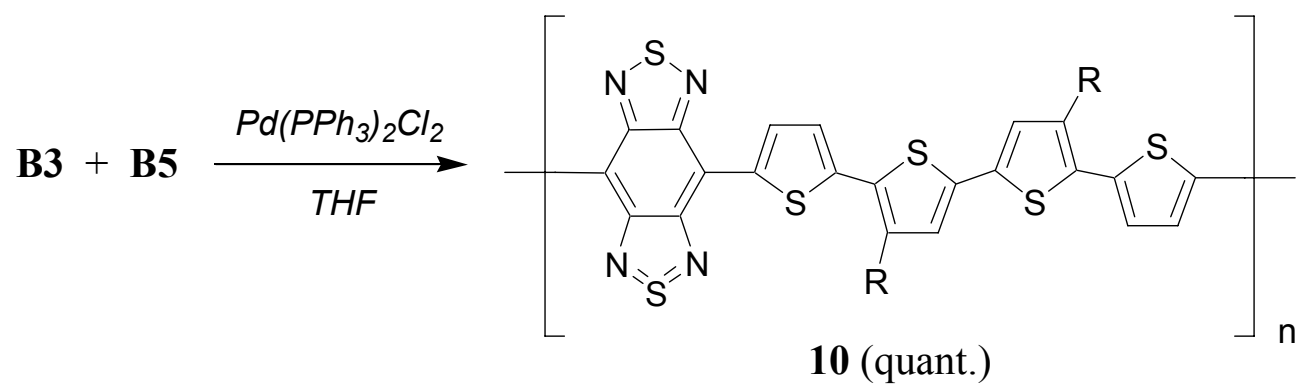

Figure 3.17. Polymer 5 - 10 prepared by Stille cross coupling polymerization. $\mathrm{R}=3,7,11$ trimethyldodecyl. 


$$
\text { B1 }+ \text { B6 } \underset{T H F}{\stackrel{P d\left(P P h_{3}\right)_{2} \mathrm{Cl}_{2}}{\longrightarrow}}
$$
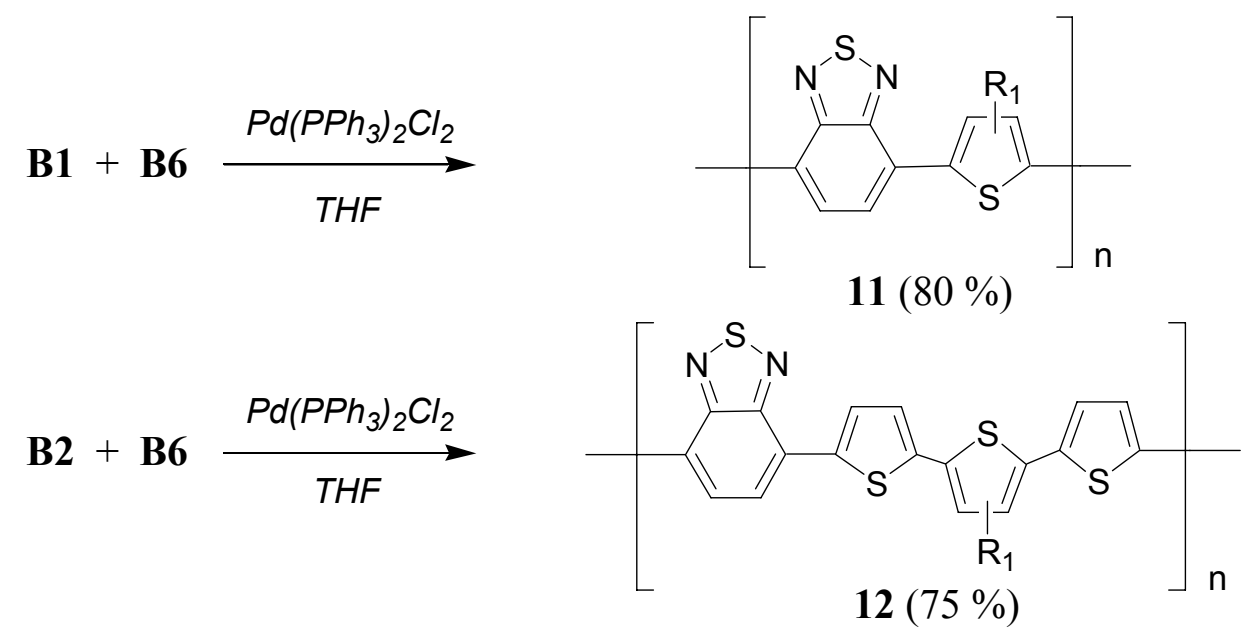

B3 + B6 $\underset{T H F}{\stackrel{P d\left(P P h_{3}\right)_{2} \mathrm{Cl}_{2}}{\longrightarrow}}$

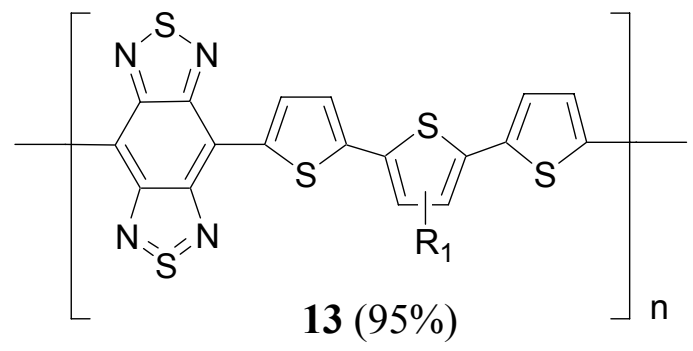

B1 + B7 $\underset{T H F}{\stackrel{P d\left(P P h_{3}\right)_{2} \mathrm{Cl}_{2}}{\longrightarrow}}$
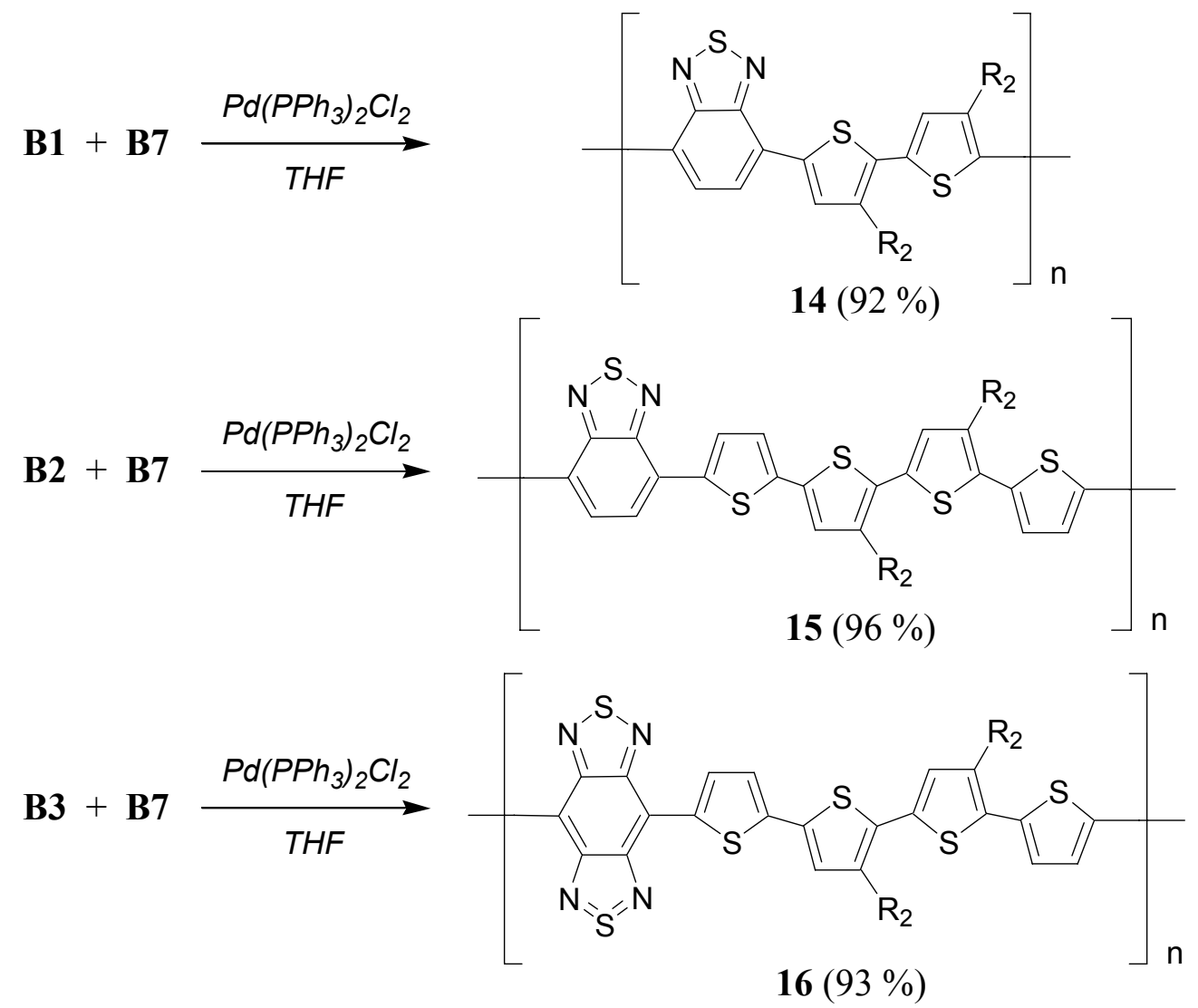

Figure 3.18. Polymer 11 - 16 prepared by Stille cross coupling polymerization. $R_{1}=2$-ethylhexyl and $\mathrm{R}_{2}=$ hexyl. 


\subsubsection{Attempted syntheses}

In Figure 3.1 the strategy based on oxidative ferric chloride polymerization also presents the copolymers based on thiophene and benzo-bis(thiadiazole). Several attempts were made to synthesize the benzo-bis(thiadiazole) derivative of polymer $\mathbf{1}$ (Figure 3.19) using the same procedures as for the di-thiophene-benzobis(thiadiazole) shown in Figure 3.12. These attempts included: 1) reduction of the nitro groups followed by either ring closing or attachment of the thiophene groups by Stille cross coupling, 2) attachment of the thiophene groups by Stille cross coupling followed by reduction of the nitro groups and ring closing, and 3) introduction of the nitro groups on the di-thiophene-benzothiadiazole. However, none of these attempts succeeded as discussed in detail in Appendix A2.6.

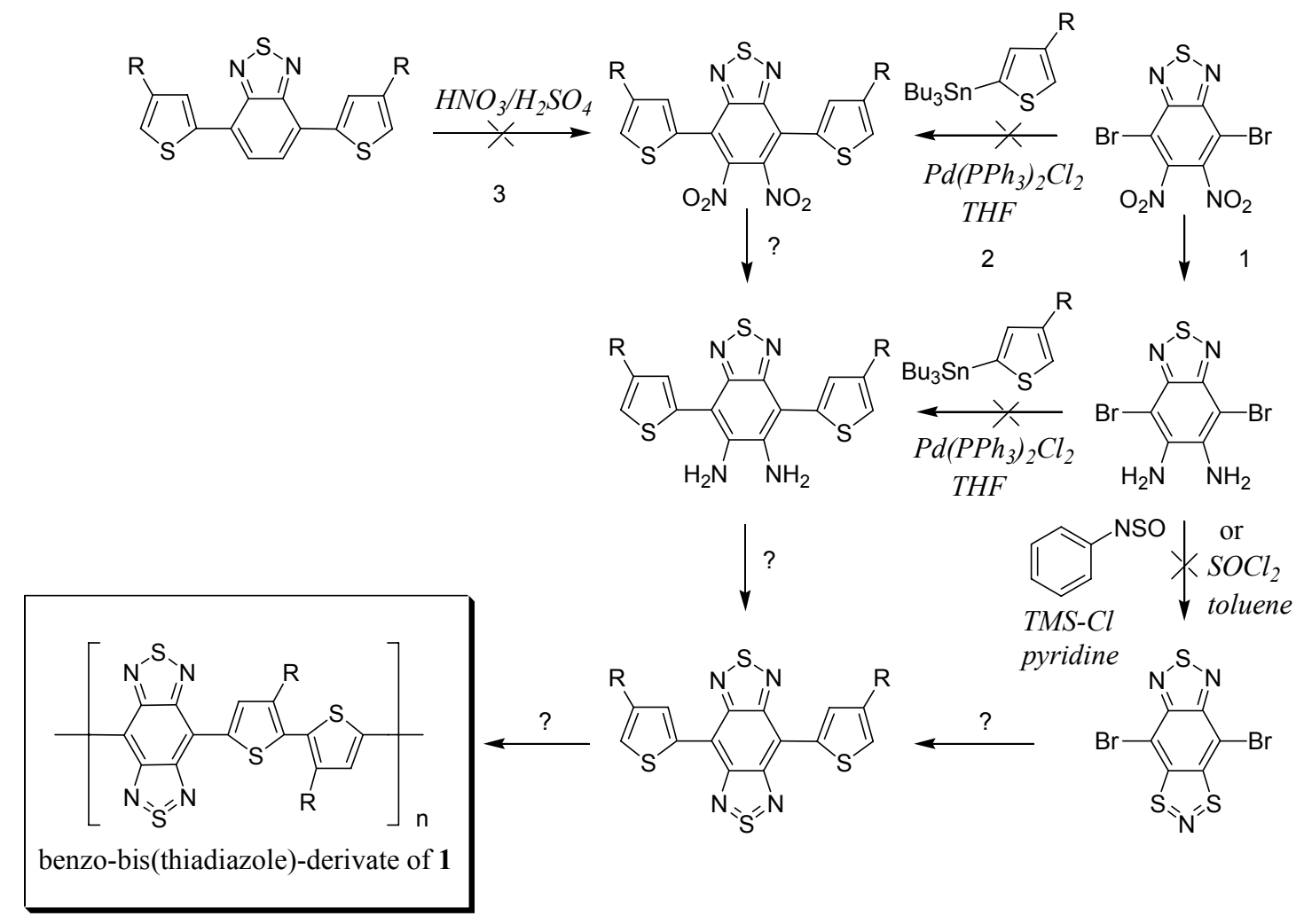

Figure 3.19. Attempts to synthesize copolymers based on benzo-bis(thiadiazole) and two thiophene by oxidative ferric chloride polymerization. $\mathrm{R}=$ hexyl. Reaction arrows marked with a cross indicates steps, which were not successful and reactions arrows marked with? indicates reactions, which were not carried out due to unsuccessful synthesis of precursors.

For the benzo-bis(thiadiazole) derivative of polymer 2 (see Figure 3.20) the comonomer was achieved in very small yield ( $7 \%)$. Furthermore, due to the short hexyl side chains, the monomer was insoluble in the solvents used for the oxidative ferric polymerization and attempts to increase the solubility by preparation of a monomer with other alkyl side chains were not completed because of the poor yield and difficulty of the reaction. 


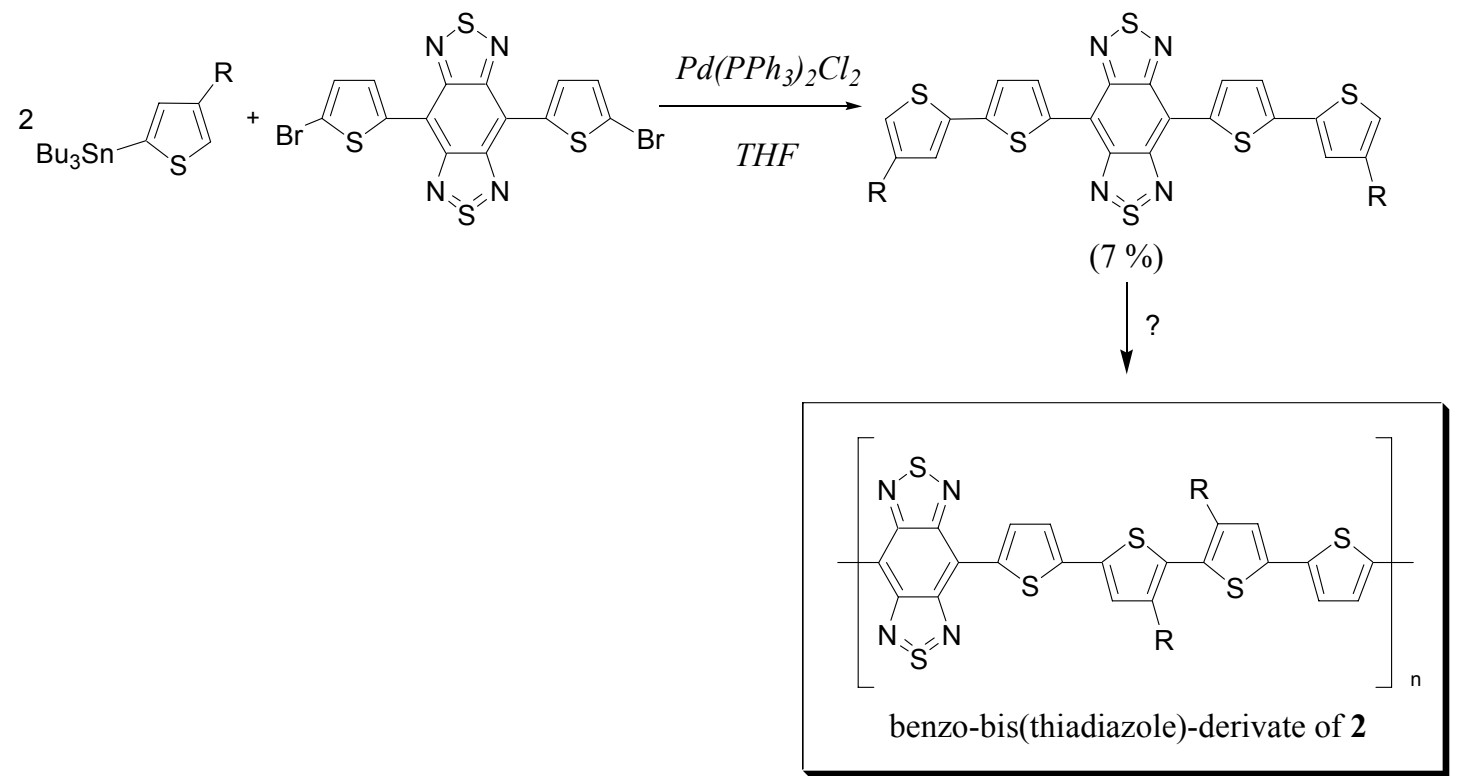

Figure 3.20. Attempts to synthesize copolymers based on benzo-bis(thiadiazole) and four thiophene by oxidative ferric polymerization. $\mathrm{R}=$ hexyl.

\subsection{Side chains and film forming ability}

In the preparation of OPV devices the ability of the polymer to form a smooth film is of great importance (see Chapter 5). The absorption of the film should be at least 0.3 or higher to achieve efficient harvesting of photons. The study of the film-forming ability and absorption of the polymers depending on the alkyl side chains (see Figure 3.21) was done by dissolving the polymer products in different solvents, spin coating and subsequently measuring the absorption of the resulting film. The results are summarized in Table 3.1.

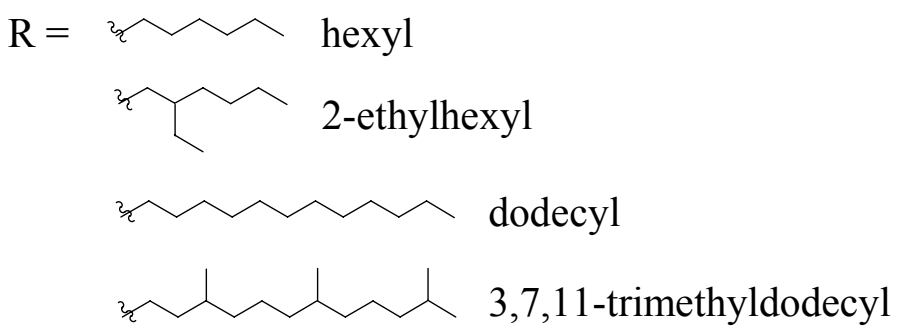

Figure 3.21. The four types of alkyl side chains applied on the copolymers to study film forming ability.

For polymers 2 - 4 the best film-forming ability and highest absorbance was seen for polymer $4(\mathrm{R}=2$-ethyl-hexyl). Polymer $\mathbf{2}$ and $\mathbf{3}$ with hexyl and dodecyl as side chains respectively resulted in poor film-forming ability and low absorption.

For polymers 11 - 16 the hexyl- and 2-ethyl-hexyl-groups resulted in poor filmforming ability due to the insolubility of the polymer. The 3,7,11-trimethyldodecylgroup (polymers 5 - 10) resulted in the best film-forming ability and the highest absorption when the polymers were spin coated from different solvents. 
Table 3.1. Absorbance at $\lambda_{\max }$ of films of polymers spin coated from different solvents (10 $\mathrm{mg}$ polymer/mL). - indicates that the experiment was not carried out. The side chains on the polymers are indicated with: $\mathrm{H}=$ hexyl, $\mathrm{EH}=$ 2-ethylhexyl, $\mathrm{D}=$ dodecyl and $\mathrm{MD}=3,7,11$-trimethyldodecyl.

\begin{tabular}{lccccc}
\hline Polymer & $\mathbf{C H C l}_{\mathbf{3}}$ & THF & 1,2-dichlorbenzene & Chlorobenzene & Toluene \\
\hline $\mathbf{1}(\mathrm{H})$ & - & - & - & - & - \\
$\mathbf{2}(\mathrm{H})$ & 0.03 & 0.02 & 0.02 & 0.02 & 0.02 \\
$\mathbf{3}(\mathrm{D})$ & $<0.001$ & $<0.001$ & $<0.001$ & $<0.001$ & $<0.001$ \\
$\mathbf{4}(\mathrm{EH})$ & 0.56 & 0.52 & 0.14 & 0.26 & 0.32 \\
$\mathbf{5}(\mathrm{MD})$ & - & - & - & - & - \\
$\mathbf{6}(\mathrm{MD})$ & 0.21 & - & - & - & - \\
$\mathbf{7}(\mathrm{MD})$ & 0.17 & 0.21 & 0.14 & - & 0.16 \\
$\mathbf{8}(\mathrm{MD})$ & 0.31 & 0.40 & 0.11 & 0.16 & 0.21 \\
$\mathbf{9}(\mathrm{MD})$ & 0.13 & 0.21 & 0.06 & - & 0.12 \\
$\mathbf{1 0}(\mathrm{MD})$ & 0.29 & 0.26 & 0.04 & 0.09 & 0.12 \\
$\mathbf{1 1}(\mathrm{EH})$ & 0.22 & 0.19 & 0.07 & 0.11 & 0.15 \\
$\mathbf{1 2}(\mathrm{EH})$ & 0.16 & 0.15 & 0.08 & 0.09 & 0.11 \\
$\mathbf{1 3}(\mathrm{EH})$ & 0.10 & 0.10 & 0.10 & 0.05 & 0.11 \\
$\mathbf{1 4}(\mathrm{H})$ & - & - & - & - & - \\
$\mathbf{1 5}(\mathrm{H})$ & 0.19 & 0.23 & 0.14 & 0.21 & 0.16 \\
$\mathbf{1 6}(\mathrm{H})$ & 0.09 & 0.05 & 0.09 & 0.09 & 0.04 \\
\hline
\end{tabular}

\subsection{Purification}

Purification of the polymers applied in OPV devices is very important because impurities such as Pd nano-particles have been shown to affect the efficiency of the OPV devices. ${ }^{37}$ Besides the transition metal particles the impurities in a polymer product include other inorganics (e.g. $\mathrm{FeCl}_{3}$ ), monomers and smaller molecules such as oligomers. Several methods are used to purify polymer materials and in the following some of these are described along with the results obtained with the prepared copolymers.

\subsubsection{Chemical purification}

A polymer with impurities such as $\mathrm{Fe}$ (III) ions which oxidizes the polymer in oxidative ferric chloride polymerization, is said to be p-doped (i.e. electrons have been removed from the polymer, see Section 5.1). De-doping of the polymer can be carried out by washing the polymer with different reducing agents. The polymers 1 4 were washed with sulfuric acid and sodium sulfite to remove any impurities from $\mathrm{FeCl}_{3}$.

The polymers $\mathbf{8}$ - $\mathbf{1 0}$ were treated with hydrazine and ammonia to remove any doping impurities from oxidation by oxygen but no change was observed in the absorption spectra and it was concluded that doping of the polymer if any could not be removed by chemical reaction (Appendix A2.2).

The transition metal particles from palladium-catalyzed reaction steps have been shown to be incorporated in polymers and purification of the polymer by chromatography does not result in a pure polymer. ${ }^{37}$ However, Nielsen et al. ${ }^{38,39}$ reported an efficient method to purify the polymer products from the transition metals using $\mathrm{N}, \mathrm{N}$-diethylphenylazothioformamide to form soluble complexes with the transition metals, i.e. Pd, Pt, Cu, Ni (see Figure 3.22). 


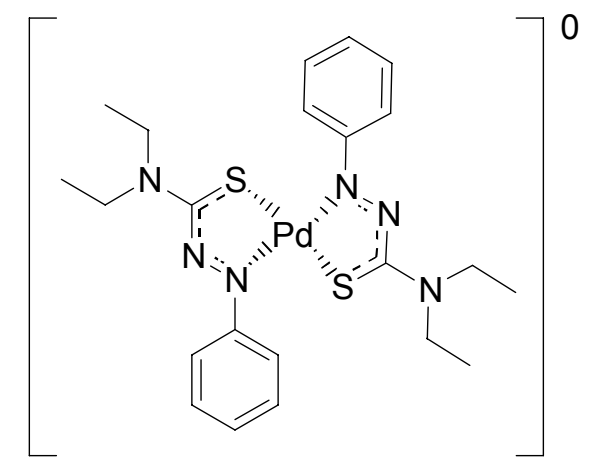

Figure 3.22. Complex, which is formed during purification with $N, N$-diethylphenylazothioformamide, here shown with Pd.

Purification of the polymer using this method is carried out by dissolving the polymer in THF adding the azothioformamide and stirring the solution for about one hour or over-night. Reprecipitation of the polymer with methanol and filtration then removes the formed complex which is soluble in methanol. The polymers $\mathbf{5 - 1 0}$ were purified by this method, and were found to contain less than $100 \mathrm{ppm}$ Pd after purification. However, there is a disadvantage of the purification method. Since the Pd-complex with the azothioformamide absorbs at $800 \mathrm{~nm}^{38,39}$ the method does not give an accurate concentration of Pd particles in a low band gap polymer with absorption in this region of the spectra. Due to insolubility in the solvent (THF) used for the purification method the polymers $\mathbf{1 1}-\mathbf{1 6}$ were not purified by this method.

\subsubsection{Soxhlet extraction}

Another way to purify and fractionate the polymer from smaller molecules is by Soxhlet extraction. In Soxhlet extraction (see Figure 3.23) the polymer material is placed in a thimble, the solvent is heated to reflux in a round-bottomed flask under stirring and evaporates through the distillation path to the condenser. The solvent then drips into the chamber with the thimble and dissolves any soluble compounds. When the solvent in the chamber reaches a certain point the dissolved compounds return to the round-bottomed flask through the backward drain and the cycle can continue. 

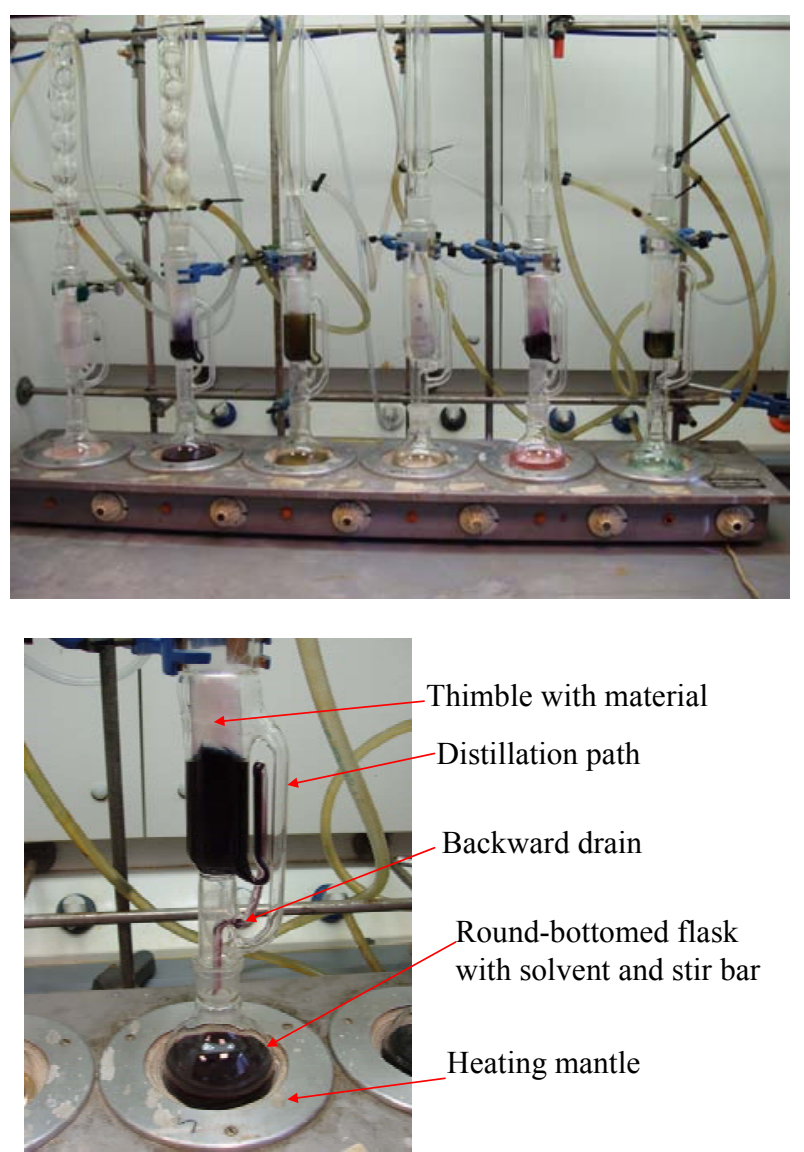

Figure 3.23. Top: Soxhlet extraction of polymer $\mathbf{5}-\mathbf{1 0}$ here the extraction with chloroform. Bottom: Principles in Soxhlet extraction.

Purification by Soxhlet extraction of the polymers $\mathbf{5}-\mathbf{1 0}$ was carried out using methanol, hexane and chloroform. Methanol and hexane removed the low molecular weight polymer fractions and other small molecules. The chloroform fraction was purified further by SEC to give fractions with a narrow molecular weight distribution. The polymers $\mathbf{1}-\mathbf{4}$ and $\mathbf{1 1}$ - $\mathbf{1 6}$ were not purified by Soxhlet extraction.

\subsubsection{Size Exclusion Chromatography (SEC)}

\subsubsection{Introduction}

One of the important characteristics of polymer materials is the molecular weight distribution. ${ }^{40,41}$ The weight-average molecular weight $\left(\mathrm{M}_{\mathrm{w}}\right)$ and the number-average molecular weight $\left(\mathrm{M}_{\mathrm{n}}\right)$ are defined in Eq. (3.1) and (3.2). ${ }^{40,41}$ The ratio between these two equations $\left(\mathrm{M}_{\mathrm{w}} / \mathrm{M}_{\mathrm{n}}\right)$ is the polydispersity. ${ }^{40,41}$

$$
\begin{aligned}
& \overline{\mathrm{M}}_{\mathrm{w}}=\frac{\sum \mathrm{N}_{\mathrm{i}} \mathrm{M}_{\mathrm{i}}^{2}}{\sum \mathrm{N}_{\mathrm{i}} \mathrm{M}_{\mathrm{i}}} \\
& \overline{\mathrm{M}}_{\mathrm{n}}=\frac{\sum \mathrm{N}_{\mathrm{i}} \mathrm{M}_{\mathrm{i}}}{\sum \mathrm{N}_{\mathrm{i}}}
\end{aligned}
$$


Size Exclusion Chromatography (SEC) is a commonly used method to determine the molecular weight distribution of polymer materials. There are two types of SEC, gel filtration chromatography (GFC) and gel permeation chromatography (GPC). In GFC the column has a hydrophilic packing and is used for characterizing biological compounds such as peptides. In GPC the packing in the column is hydrophobic and the technique is normally used for characterizing organic compounds such as polymers. $^{40-42}$

As the name indicates, in SEC the polymer molecules are separated on the basis of size or hydrodynamic volume. ${ }^{43}$ The principles of the method are shown in Figure 3.24 .

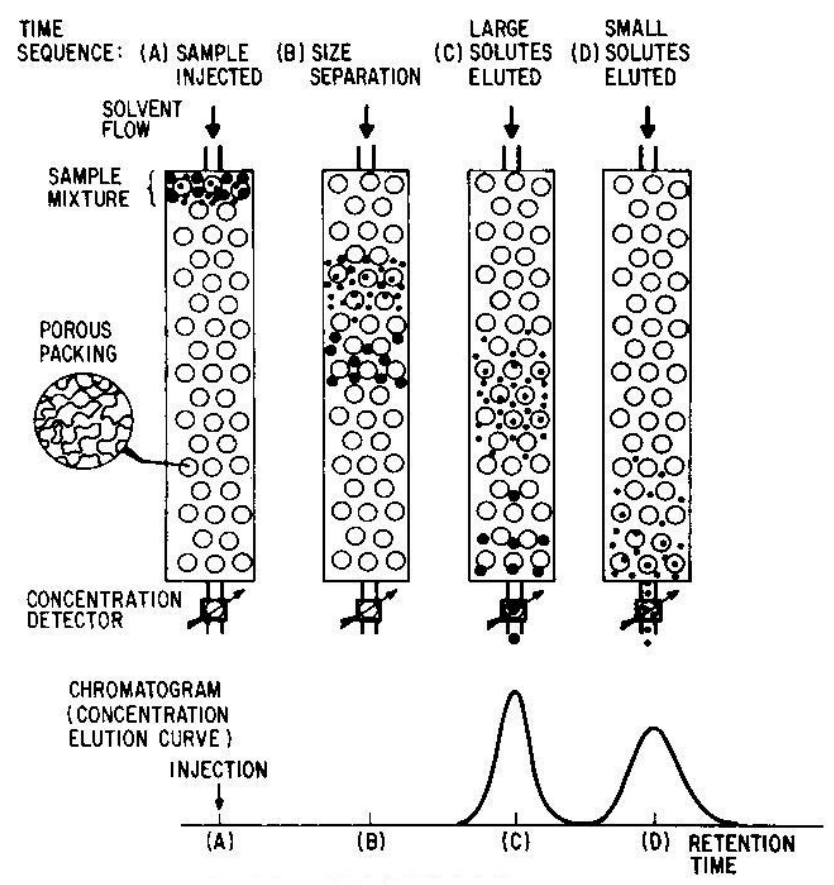

Figure 3.24. Principles in Size Exclusion Chromatography. Reprinted with permission of John Wiley \& Sons, Inc. ${ }^{41}$

The sample mixture is injected onto the column containing a porous packing (a). The different molecules are separated in the column where small molecules are trapped in the pores and larger molecules move down the column more rapidly (b). The larger molecules are then eluted due to limited accessibility in the pores and these exit the column first (c) followed by the smaller molecules (d). The polymer fractions are detected by e.g. UV-vis and the concentration in each fraction can then be determined. The raw data obtained from SEC is a molecular size distribution, which is converted to an apparent molecular weight distribution using a calibration curve (e.g. obtained from polystyrene). ${ }^{41}$ Errors in this method can occur especially during the calculations. Therefore, one has to ensure a constant and reproducible flow rate and a careful calibration. ${ }^{43}$ The method is often carried out using a closed system operating under high pressure, which is called a high performance SEC or HPSEC. ${ }^{41}$ In HPSEC the number of theoretical plates generated per second is ten times higher than normal SEC. This means that the method is faster and results in higher resolution. ${ }^{41}$

SEC can also be used as a preparative purification method, in which case the polymer is fractionized by size in order to obtain a narrow polydispersity. It is desirable to have a polymer with a low polydispersity since many of the characteristics of the 
polymer depend on the molecular weight and high and low molecular weight fractions of a polymer may not have the same properties. ${ }^{42}$

\subsubsection{Results}

SEC has been used extensively to analyze all the polymers described in Chapter 3 (further details in Appendix A2.1 and A2.2).

To study the effect of the molecular weight on the photovoltaic responses polymer $\mathbf{8}$ was fractionated by preparative SEC according to molecular weight and the fractions were applied in OPV devices. The photovoltaic responses of these devices are discussed in Section 5.4.4.

The SEC traces before and after the fractionation of polymer $\mathbf{8}$ by preparative SEC are shown in Figure 3.25. The SEC system used was a succession of columns with different pore size (100 and $1000 \AA)$. The raw polymer material was separated into fractions by preparative SEC to give five fractions with smaller polydispersity. The molecular weight and polydispersity for the fractions is given in Table 3.2 and it can be seen that the $\mathrm{M}_{\mathrm{W}}$ of the fractions decreases for each fraction (fraction $1-5$ ). $\mathrm{M}_{\mathrm{P}}$ is the molecular weight at the peak of the SEC trace which also decreases from fraction 1 to fraction 5 .

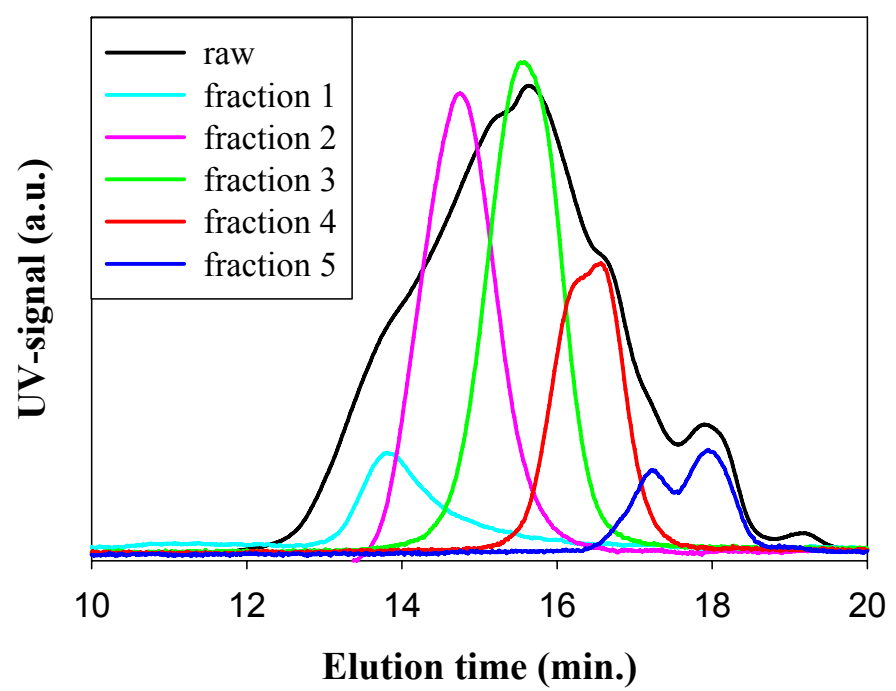

Figure 3.25. SEC traces of polymer $\mathbf{8}$ and of the narrow molecular weight fractions. The raw material refers to polymer $\mathbf{8}$ before purification. The preparative SEC system contained a gel column system comprising a succession of columns with 100 and $1000 \AA$ pore diameter, with a detector at $500 \mathrm{~nm}$.

Table 3.2. Molecular weight and polydispersity of the five fractions of polymer 8 obtained by preparative SEC. The preparative SEC system contained a gel column system comprising a succession of columns with 100 and $1000 \AA$ pore diameter, with UV-vis detection at $500 \mathrm{~nm}$.

\begin{tabular}{cccc}
\hline Fraction & $\mathbf{M}_{\mathbf{w}}$ & $\mathbf{M}_{\mathbf{p}}$ & $\mathbf{M}_{\mathbf{w}} / \mathbf{M}_{\mathbf{n}}(\mathbf{P D})$ \\
\hline $\mathbf{1}$ & 15000 & 17000 & 1.6 \\
$\mathbf{2}$ & 8500 & 7900 & 1.3 \\
$\mathbf{3}$ & 4600 & 4300 & 1.1 \\
$\mathbf{4}$ & 2500 & 2200 & 1.1 \\
$\mathbf{5}$ & 1300 & 1000 & 1.1 \\
\hline
\end{tabular}




\subsection{Summary}

The synthesis of 16 new low band gap copolymers based on thiophene, benzothiadiazole and benzo-bis(thiadiazole) has been carried out by two strategies: oxidative ferric chloride polymerization and Stille cross coupling polymerization. These two polymerization methods are described in detail along with the synthetic steps carried out to prepare the 16 new polymers.

The oxidative ferric polymerization resulted in four copolymers of thiophene and benzothiadiazole. The Stille cross coupling polymerization resulted in 8 copolymers based on thiophene and benzothiadiazole and 4 copolymers based on thiophene and benzo-bis(thiadiazole), where the number of thiophenes in the repeating unit was varied from 1 to 4 . Furthermore, the alkyl side chain influenced the film-forming ability and the absorbance. The 3,7,11-trimethyldodecyl-group was found to give the best results in this respect. The polymers were purified chemically and by SEC.

The syntheses of the copolymers described here have been published in the literature in two papers (see Appendix A2.1 and A2.2). All failed syntheses are described in Appendix 1.

\section{References}

1 V. M. Niemi, P. Knuuttila, J. E. Österholm, J. Korvola, Polymer 33 (1992) 1559-1562.

2 M. R. Andersson, D. Selse, M. Berggren, H. Järvinen, T. Hjertberg, O. Inganäs, O. Wennerström, J.-E. Österholm, Macromolecules 27 (1994) 65036506.

3 G. Barbarella, M. Zambianchi, R. Di Toro, M. Colonna Jr., D. Iarossi, F. Goldoni, A. Bongini, J. Org. Chem. 61 (1996) 8285-8292.

4 T. Olinga, B. François, Synth. Met. 69 (1995) 297-298.

5 R. D. McCullough, R. D. Lowe, M. Jayaraman, D. L. Anderson, J. Org. Chem. 58 (1993) 904-912.

6 T.-A. Chen, R. D. Reike, J. Am. Chem. Soc. 114 (1992) 10087-10088.

7 R. D. McCullough, S. P. Williams, S. Tristan-Nagle, M. Jayaraman, P. C. Ewbank, L. Miller, Synth. Met. 69 (1995) 279-282.

8 J. Roncali, Chem. Rev. 97 (1997) 173-205.

9 D. L. Vangeneugden, D. J. M. Vanderzande, J. Salbeck, P. A. van Hal, R. A. J. Janssen, J. C. Hummelen, C. J. Brabec, S. E. Shaheen, N. S. Sariciftci, J. Phys. Chem. 105 (2001) 11106-11113.

10 D. L. Vangeneugden, R. H. L. Kiebooms, D. J. M. Vanderzande, J. M. J. V. Gelan, Synth. Met. 101 (1999) 120-121.

11 R. M. S. Maior, K. Hinkelmann, H. Eckert, F. Wudl, Macromolecules 23 (1990) 1268-1279.

12 M. Sato, H. Morii, Macromolecules 24 (1991) 1196-1200.

13 G. Daoust, M. Leclerc, Macromolecules 24 (1991) 455-459.

14 Q. Pei, H. Järvinen, J. E. Österholm, O. Inganäs, J. Laakso, Macromolecules 25 (1992) 4297-4301.

15 M. R. Andersson, O. Thomas, W. Mammo, M. Svensson, M. Theander, O. Inganäs, J. Mater. Chem. 9 (1999) 1933-1940.

16 R. D. McCullough, Adv. Mater. 10 (1998) 93-116.

17 L. M. Campos, A. Tontcheva, S. Günes, G. Sonmez, H. Neugebauer, N. S. Sariciftci, F. Wudl, Chem. Mater. 17 (2005) 4031-4033.

18 J. K. Stille, Pure \& Appl. Chem. 57 (1985) 1771-1780.

19 J. K. Stille, Angew. Chem. 98 (1986) 504-519. 
20 A. de Meijere, F. Diederich, Metal-catalyzed cross-coupling reactions, $2^{\text {nd }}$ Ed., Vol. 1 and 2, Wiley-VCH, 2004, ISBN: 3-527-30518-1.

21 K. Fugami, M. Kosugi, Cross-Coupling Reactions - a practical guide, Springer, Ed. N. Miyaura, 2002, ISBN: 3-540-42175-0.

22 J. K. Stille, K. S. Y. Lau, Acc. Chem. Res. 10 (1977) 434-442.

$23 \mathrm{~J} . \mathrm{K}$. Stille, The chemistry of the metal-carbon bond- the nature and cleavage of metal-carbon bonds, Editors: F. R. Hartley, S. Patai, John Wiley \& Sons, vol. 2 (1985) 625-787, ISBN: 0-471-90282-9.

24 J. Clayden, N. Greeves, S. Warren, P. Wothers, Organic Chemistry, Oxford University Press, 1991, ISBN: 0-19-850346-6.

25 A. Gillie, J. K. Stille, J. Am. Chem. Soc. 102 (1980) 4933-4941.

26 M. K. Loar, J. K. Stille, J. Am. Chem. Soc. 103 (1981) 4174-4181.

27 A. Moravskiy, J. K. Stille, J. Am. Chem. Soc. 103 (1981) 4182-4183.

28 J. Tsuji, Palladium reagents and catalysts - innovations in organic synthesis, 1995, John Wiley \& Sons Ltd., Chichester, ISBN: 0-471-95483-7.

29 F. C. Krebs, M. Biancardo, Sol. Energy Mater. Sol. Cells 90 (2006) 142-165.

30 A. Iraqi, G. W. Baker, J. Mater. Chem. 8 (1998) 25-29.

31 A. Dhanabalan, J. K. J. van Duren, P. A. van Hal, J. L. J. van Dogen, R. A. J. Janssen, Adv. Funct. Mater. 11 (2001) 255-262.

32 A. Dhanabalan, P. A. van Hal, J. K. J. van Duren, J. L. J. van Dogen, R. A. J. Janssen, Synth. Met. 119 (2001) 169-170.

33 K. Pilgram, M. Zupan, R. Skiles, J. Heterocycl. Chem. 7 (1970) 629-633.

34 Q. Hou, Y. Xu, W. Yang, M. Yuan, J. Peng, Y. Cao, J. Mater. Chem. 12 (2002) 2887-2892.

35 C. Kitamura, S. Tanaka, Y. Yamashita, Chem. Mater. 8 (1996) 570-578.

36 M. Karikomi, C. Kitamura, S. Tanaka, Y. Yamashita, J. Am. Chem. Soc. 117 (1995) 6791-6792.

37 F. C. Krebs, R. B. Nyberg, M. Jørgensen, Chem. Mater. 16 (2004) 1313-1318.

38 K. T. Nielsen, K. Bechgaard, F. C. Krebs, Macromolecules 38 (2005) 658659.

39 K. T. Nielsen, K. Bechgaard, F. C. Krebs, Synthesis 10 (2006) 1639-1644.

40 M. P. Stevens, Polymer Chemistry - An Introduction, $3^{\text {rd }}$ Ed., Oxford University Press, 1999, ISBN: 0-19-512444-8.

41 W. W. Yau, J. J. Kirkland, D. D. Bly, Modern Size-exclusion liquid chromatography - practice of gel permeation and gel filtration chromatography, John Wiley \& Sons, 1979, ISBN: 0-471-03387-1.

42 D. A. Skoog, D. M. West, F. J. Holler, Fundamentals of analytical Chemistry, $7^{\text {th }}$ Ed., Saunders College Publishing, 1996, ISBN: 0-03-016873-2.

43 B. Trathnigg, Encyclopedia of analytical chemistry, R. A. Meyers (Ed.), John Wiley \& Sons Ltd., 2000, ISBN: 0471976709, p. 8008-8034. 


\section{Playsical characterization}

The characteristic data of a low band gap polymer, which is applied in an OPV, is the absorption spectra, the band gap and the electronic band structure, i.e. determination of the energy levels of the HOMO and LUMO. Important methods to determine these characteristics are UV-vis and Ultraviolet Photoelectron Spectroscopy (UPS). An introduction to these methods is given in this chapter in addition to some results obtained for the copolymers in Chapter 3.

\subsection{UltraViolet Visible Spectroscopy (UV-vis)}

\subsubsection{Introduction}

UV-vis is a type of electronic spectroscopy. ${ }^{1}$ In general either emission or absorption spectra (see Figure 4.1) are obtained in electronic spectroscopy. The emission is an analysis of the light, which is emitted from a compound. The absorption is an analysis of the light, which is transmitted by an absorbing medium. ${ }^{1,2}$ Here the focus is on the absorption.
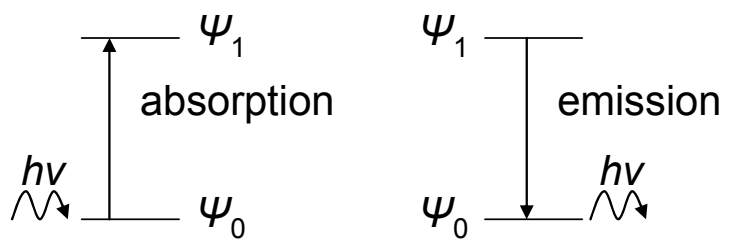

Figure 4.1. Emission and absorption principles, where $\Psi_{0}$ and $\Psi_{1}$ represents the ground state and the electronic excited state, respectively.

In UV-vis the absorbance of a material is measured using light in the near ultraviolet (UV), visible (vis) and the near infra red (NIR) regions. The wavelengths of these regions are 200-400 $\mathrm{nm}, 400-800 \mathrm{~nm}$ and 800-1200 $\mathrm{nm}$ respectively. ${ }^{1}$ The light absorbed is proportional to the number of molecules in the path and can be written as

$$
\mathrm{A}=\log \frac{\mathrm{I}_{0}}{\mathrm{I}}=\varepsilon \cdot \mathrm{c} \cdot 1
$$

where $\mathrm{A}$ is the absorbance, $\mathrm{I}_{0}$ is the light intensity before the sample, $\mathrm{I}$ is the light intensity after passing through the sample, $\varepsilon$ is the molar extinction coefficient, $\mathrm{c}$ is the molar concentration and 1 is the length (normally $1 \mathrm{~cm}$ ). Equation (4.1) is also known as Lambert-Beer's law. ${ }^{1-3}$ Lambert-Beer's law only applies for monochromatic light and dilute solutions $\left(\mathrm{c} \leq 10^{-2} \mathrm{M}\right)^{2}$ 


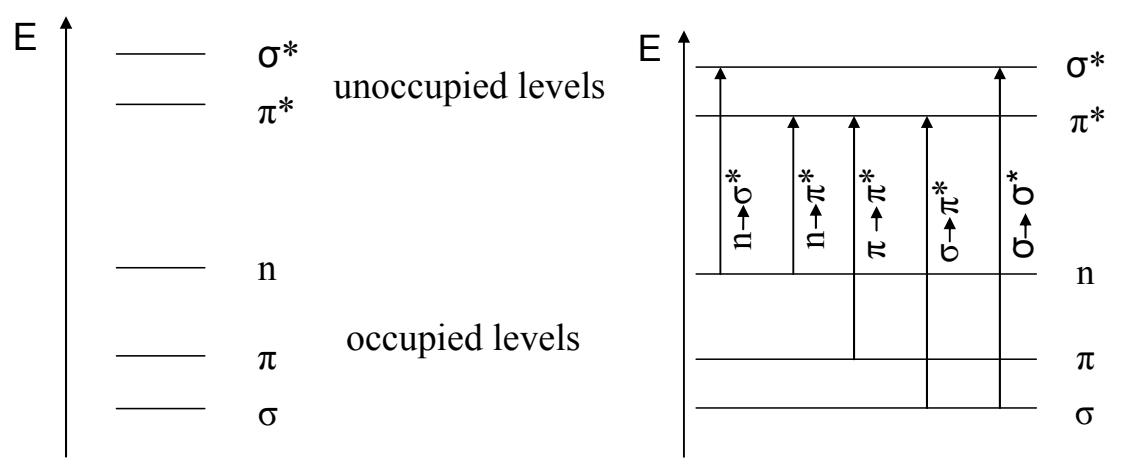

Figure 4.2. Excitation from the ground state to an excited state.

When a molecule absorbs energy an electron is excited from an occupied orbital $(\sigma, \pi$ or $n)$ to an unoccupied orbital $\left(\sigma^{*}\right.$ or $\left.\pi^{*}\right)$ of greater energy. The amount of energy corresponds to the energy of the photon $(\mathrm{E}=h v) .{ }^{1,2}$ In Figure 4.2 the different transitions are shown and Figure 4.3 shows where in the absorption spectra these transitions are seen.

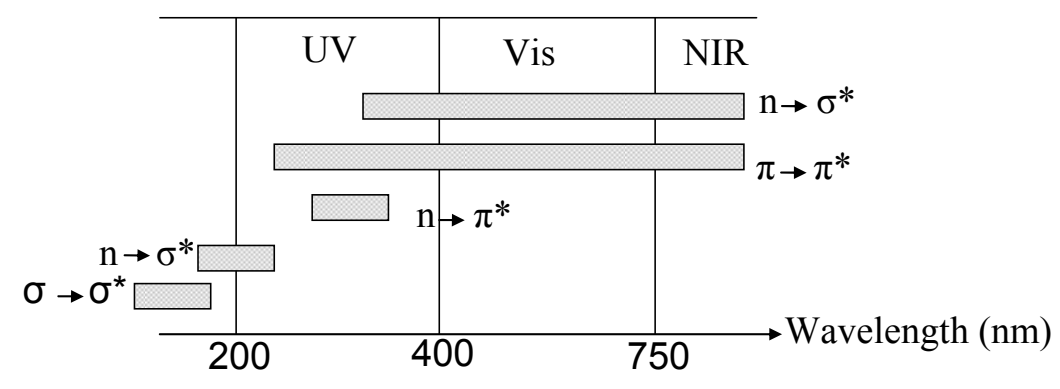

Figure 4.3. Transitions in the absorption spectra.

When the conjugation length of a molecule increases, the energy, which is required for transition, decreases and the difference between HOMO and LUMO (i.e. the band gap) becomes lower. This is seen in the absorption spectra as a red shift, or a move to longer wavelengths, i.e. a bathochromic effect. ${ }^{3}$ When a blue shift to shorter wavelengths is observed it is called a hypsochromic effect. ${ }^{3}$ The most probable transition is the one from HOMO to LUMO. ${ }^{3}$

There are two types of transitions; the allowed, where the transition does not involve a change in electron spin (no change in the spin quantum number) and the forbidden, where a spin change is required. ${ }^{3,4}$ Whether a transition is allowed can also be seen from the value of $\varepsilon$ (see Table 4.1$)^{2}$

Table 4.1. Transition determined from $\varepsilon$.

\begin{tabular}{ccccc}
\hline$\varepsilon\left(\mathrm{M}^{-1} \mathrm{~cm}^{-1}\right)$ & $\leq 10$ & $10<\mathrm{x}>1000$ & $1000<\mathrm{x}>100,000$ & $\geq 100,000$ \\
\hline Transition & $\begin{array}{c}\text { not } \\
\text { allowed }\end{array}$ & weak & allowed & strong \\
& & & \\
\hline
\end{tabular}

As mentioned in Chapter 2, the low band gap polymers described in the literature are often based on donor and acceptor moieties and this structure of the polymer is also reflected in the UV-vis spectra as a double peak (see Figure 4.4). 


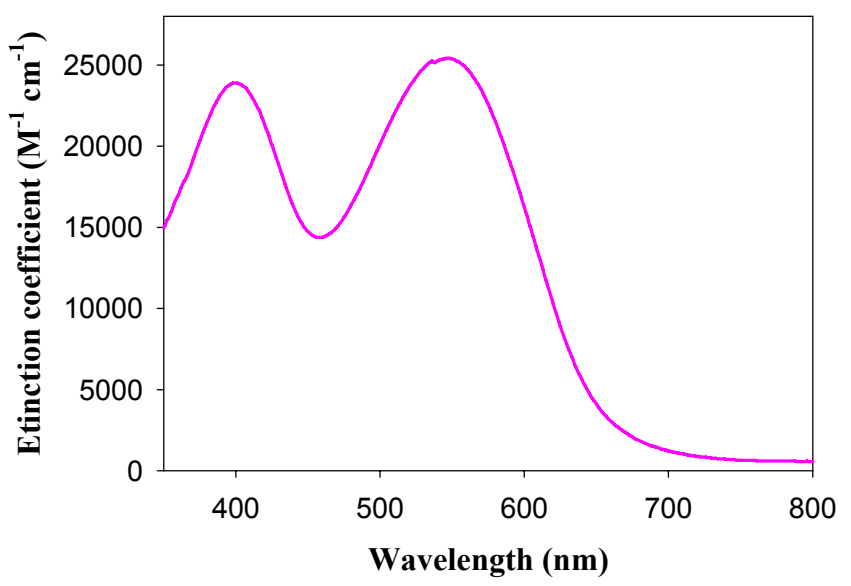

Figure 4.4. Double peak absorption spectrum of donor-acceptor copolymer (polymer 8).

The donor/acceptor moieties also show a charge transfer from the donor to the acceptor unit by increasing the length of the $\pi$ system through resonance using the non bonding electrons (e.g. on $\mathrm{S}$ in thiadiazole). This gives an extra electron in the ring and the new structure then corresponds to the excited electron in $\pi^{*}{ }^{3}$

The optical band gap of the polymer is estimated from the absorption spectra by taking the tangent to the curve and converting the cut-off to eV (see Appendix A2.2). In Section 2.1 it was shown that a low band gap (i.e. if the polymer had a cut-off in the absorption spectra at $1000 \mathrm{~nm}$ that is a band gap of $0.8 \mathrm{eV}$ ) the result is a higher theoretical current of the OPV device.

\subsubsection{Results}

The polymers 5 - 10 were analyzed by UV-vis to determine $\lambda_{\max }$ and the optical band gap of the polymers. The absorption spectra of polymer 5-10 plotted as a function of the wavelength and the energy are shown in Figure 4.5. 

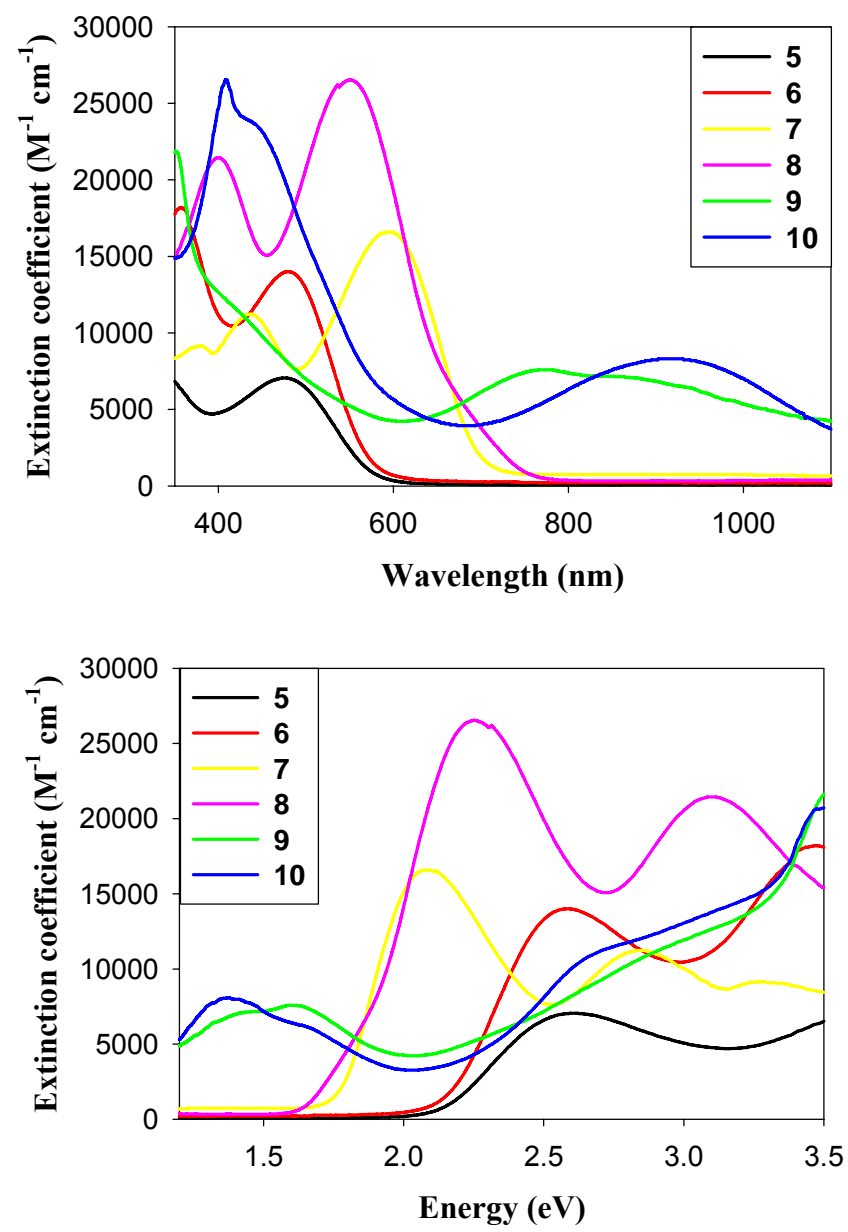

Figure 4.5. Absorption spectra of polymer $\mathbf{5}-\mathbf{1 0}$ as function of a) wavelength from $350-1100 \mathrm{~nm}$ and b) energy from $1.0-3.5 \mathrm{eV}$. The extinction coefficient was calculated from Lambert-beer's law using the molecular weight of the repeating unit in the polymer.

The absorption spectra show the characteristic double peak of a donor-acceptor copolymer; however, this is mostly for the copolymers of thiophene and benzothiadiazole (polymer 5-8). These copolymers also show a red shift in the absorption spectra, when the number of thiophenes in the repeating unit is increased $(n=1-4)$.

The copolymers based on thiophene and benzo-bis(thiadiazole) (polymer 9 and 10) also absorb light in the NIR region of the spectra (i.e. up to $1800 \mathrm{~nm}$, see Figure 4.6). 

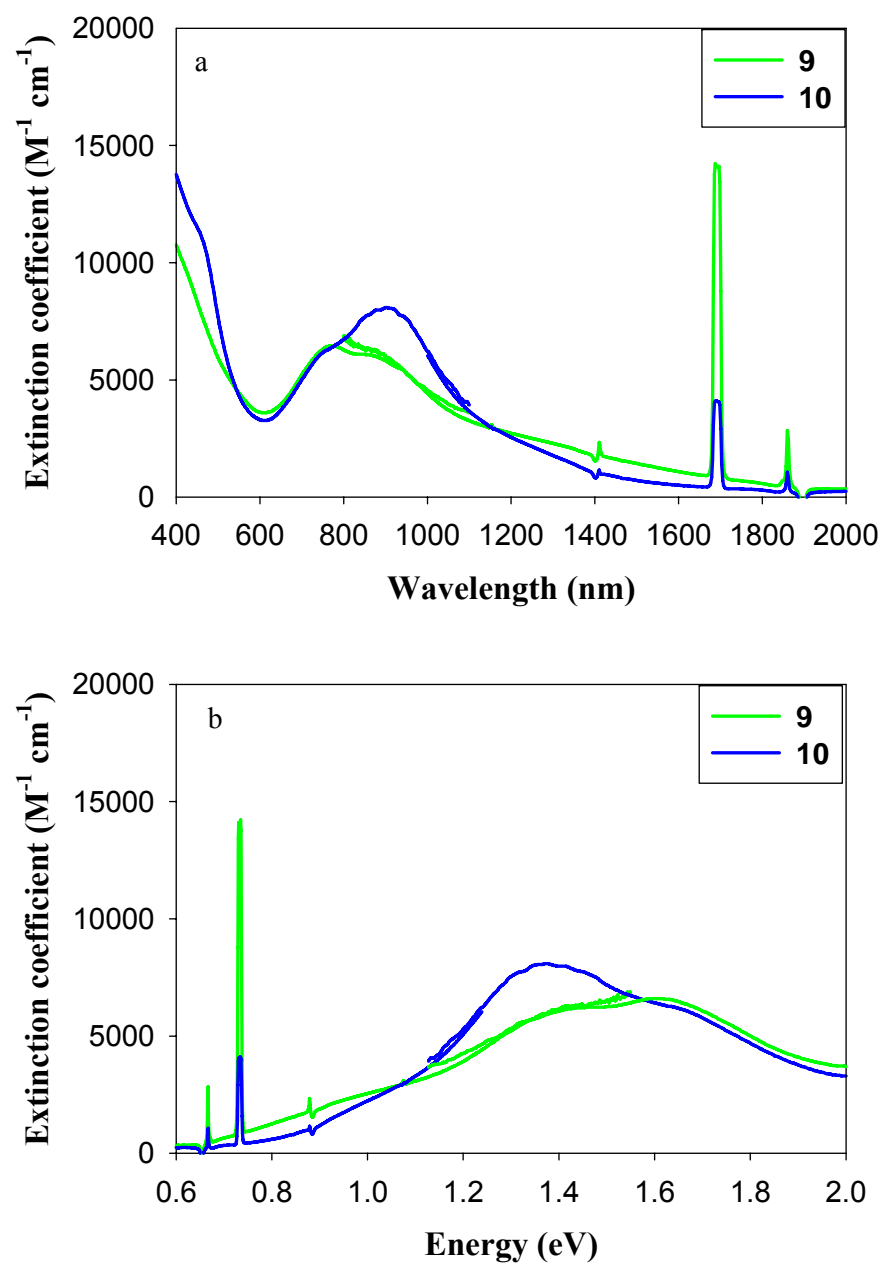

Figure 4.6. Absorption spectra of polymer $\mathbf{9}$ and $\mathbf{1 0}$ as a function of a) wavelength from $400-2000 \mathrm{~nm}$ and b) energy from $2.0-0.6 \mathrm{eV}$. The extinction coefficient was calculated from Lambert-beer's law using the molecular weight of the repeating unit in the polymer. The peaks at 1400, 1600 and $1900 \mathrm{~nm}$ are ascribed to the instrument.

The optical band gap of the polymers was estimated from the absorption spectra and these are listed in Table 4.2 along with the extinction coefficient $(\varepsilon)$ at $\lambda_{\max }$ of the polymers. According to $\varepsilon$ all transitions in the polymers $\mathbf{5}-\mathbf{1 0}$ are allowed. In addition the red shift seen in the absorption spectra of polymer $\mathbf{5}-\mathbf{8}$ is also seen for the band gap which decreases from 2.10 to $1.65 \mathrm{eV}$ when the number of thiophene units in the repeating unit increases from 1 to 4 . For further details on polymer 5-10 see Appendix A2.2.

Table 4.2. Optical band gaps and $\lambda_{\max }$ of polymer $5-\mathbf{1 0}$.

\begin{tabular}{lcccccc}
\hline & $\mathbf{5}$ & $\mathbf{6}$ & $\mathbf{7}$ & $\mathbf{8}$ & $\mathbf{9}$ & $\mathbf{1 0}$ \\
\hline$\lambda_{\max }(\mathrm{nm})$ & 477 & 479 & 435 & 450 & 770 & 902 \\
$\varepsilon\left(\mathrm{M}^{-1} \mathrm{~cm}^{-1}\right)$ & 7100 & 14000 & 11000 & 24000 & 7600 & 8100 \\
& & & 166000 & 25000 & & \\
Band gap (eV) & 2.10 & 2.10 & 1.82 & 1.65 & 0.65 & 0.67 \\
\hline
\end{tabular}


The polymers 1, $\mathbf{4}$ and $\mathbf{1 4}$ have also been analyzed using UV-vis and the band gap of these polymers were found to be $2.0,1.8$ and $2 \mathrm{eV}$, respectively. UV-vis data of the rest of the polymers $(2,3,11,12,13,15$ and 16) did not show accurate results, due to insolubility of the polymers. For further details see Appendix A2.1 and A2.2.

\subsection{Ultraviolet Photoelectron Spectroscopy (UPS)}

\subsubsection{Introduction}

It is important to know the electronic band structure of a polymer applied in OPV devices to achieve high open circuit voltage $\left(V_{O C}\right)$ and hence high efficiency $(\eta)$ of the device by optimum energy level alignment (this will be discussed in detail in Section 5.2).

Ultraviolet photoelectron spectroscopy (UPS) is a method for investigation of the electronic structure of a molecule. ${ }^{5}$ The technique establishes the electronic structure of the valence band and the bonding characteristics of a film or substance on the surface. $^{6}$ When the electron beam hits the surface an electron is ejected from an orbital and the ionization energy of the molecule is measured. ${ }^{6}$ The kinetic energy of the emitted electron is determined by Eq. (4.2). ${ }^{7}$

$$
\mathrm{E}_{\text {kin }}=h v-\mathrm{BE}-\Phi_{\mathrm{S}}
$$

In Eq. (4.2) $h v$ is the energy of the photon and BE is the binding energy of the orbital from, which the electron leaves. This can be regarded as the ionization energy of the atom for the particular shell. The $\Phi_{\mathrm{S}}$ is the spectrometer work function. ${ }^{7}$

The ionization energy of the valence electrons is several electron volts and thus, it is necessary to operate in the ultraviolet region of the spectrum. ${ }^{6}$ The measurements are carried out on a synchrotron storage ring, which consists of an electron beam traveling in a circle. ${ }^{6}$ The electrons generate radiation in a wide range from the far infrared to $\mathrm{X}$-rays, when they are constantly accelerated by the forces keeping them in their path. ${ }^{6}$

Measurements are carried out on a metal substrate and Au substrates are normally used. In a first step the Fermi level of the metal is determined. The Fermi level is defined as the energy level where the possibility to find an electron is 0.5 . For a metal the Fermi level is equal to the energy required removing one electron from the metal to the vacuum level, i.e. the work function. This is followed by measurements on a spin coated film on top of the substrate. The Fermi level of the polymer can then be determined from the Fermi level of the substrate. ${ }^{8}$ From the spectra of the substrate the work function, $\Phi_{\mathrm{Au}}$, is calculated using Eq. (4.3). ${ }^{8}$

$$
\Phi_{A u}=h v-\left|\mathrm{BE}_{\max }\right|
$$

In Eq. (4.3) $h v$ is the energy of the electron beam $(50 \mathrm{eV})$ and $\mathrm{BE}_{\max }$ is the cut-off at high binding energies. ${ }^{9}$

From the spectra obtained from the spin coated polymer film the valence band edge of the polymer, $\mathrm{E}_{\mathrm{F}}^{\mathrm{VB}}$, is determined by the onset of photoelectrons toward low binding energies, where the Fermi level of the substrate has zero binding energy (Eq. (4.4)).,

$$
\mathrm{E}_{\mathrm{F}}^{\mathrm{VB}}=\mathrm{BE}_{\text {min }}
$$


$\mathrm{E}_{\mathrm{F}}{ }^{\mathrm{VAC}}$ is the energy difference between the vacuum level of the polymer and the Fermi level in the metal substrate and is given by Eq. (4.5). ${ }^{8,9}$

$$
\mathrm{E}_{\mathrm{F}}^{\mathrm{vac}}=h v-\left|\mathrm{BE}_{\max }\right|
$$

IP is the ionization energy of the polymer and is determined by Eq. (4.6). ${ }^{8}$

$$
\mathrm{IP}=\mathrm{E}_{\mathrm{F}}^{\mathrm{VB}}+\mathrm{E}_{\mathrm{F}}^{\mathrm{VAC}}
$$

The difference between the vacuum level of the substrate and the polymer, $\Delta$, (Eq. (4.7)) is ascribed to the dipole layers at the polymer-vacuum interface and may also be influenced by the thickness of the polymer layer since dipoles are different for thicker films. $^{8,10}$

$$
\Delta=\mathrm{E}_{\mathrm{F}}^{\mathrm{VAC}}-\Phi_{A u}
$$

In Figure 4.7 it is shown how a picture of the band structure can be obtained from these values. With UPS it is not possible to determine the energy level of the LUMO of the polymer; however, as an approximation the optical band gap can be used. ${ }^{8}$

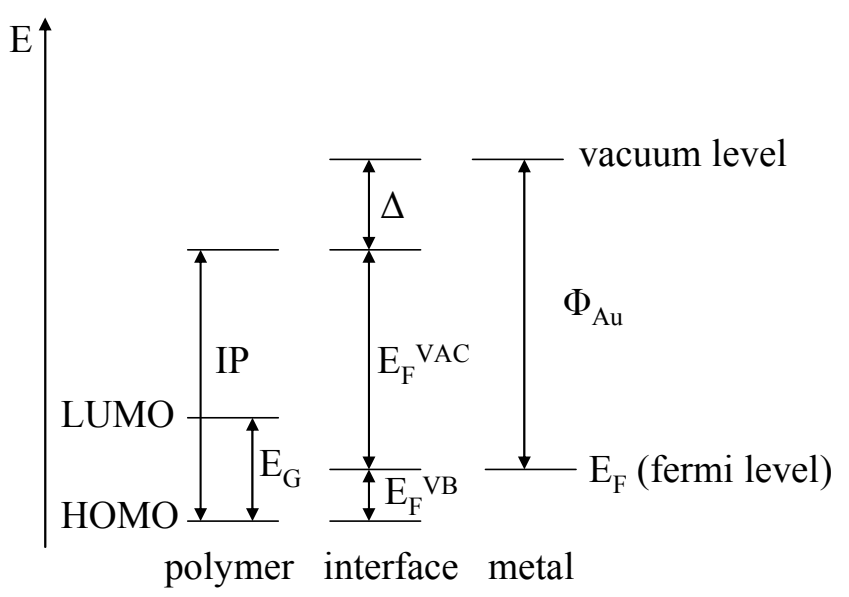

Figure 4.7. Values in band structure obtained from UPS spectra. $E_{\mathrm{g}}$ is estimated from UV-vis.

\subsubsection{Results}

UPS was used to analyze the electronic structure of polymer $\mathbf{5}-\mathbf{1 0}$. The measurements were carried out at the ASTRID synchrotron storage ring at Aarhus University, Denmark. ASTRID is a small storage ring with a circumference of $40 \mathrm{~m} .{ }^{11}$ The spectra was recorded using $50 \mathrm{eV}$ photons. Surface analysis of the samples was carried out by Electron Spectroscopy for Chemical Analysis (ESCA) ${ }^{6}$ at ASTRID in situ and at Risø National Laboratory to determine the chemical composition of the film surface, i.e. to determine if the film was thick enough to perform the UPS measurements, since Au particles on the surface indicates a thin film and would result in an incorrect picture of the band structure.

Measurements were carried out on the gold substrate first to determine the Fermi level of the substrate and the work function, $\Phi_{\mathrm{Au}}{ }^{9,10,12}$ The Fermi level was found to be 4.6 $\mathrm{eV}$. The low value of the Fermi level (normal $4.9-5.3 \mathrm{eV}$ ) may be due to contamination during transport. Measurements were then carried out on spin coated 
polymer films. The graph obtained from the measurements is shown in Figure 4.8a for polymer $\mathbf{8}$. It can be seen how $\mathrm{BE}_{\max }$ and $\mathrm{BE}_{\min }$ are determined as the cut-off and the onset respectively. These are used to calculate the ionization potential, IP etc. from Eq. (4.4) - (4.7) and the resulting band structure is drawn (see Figure 4.8b).
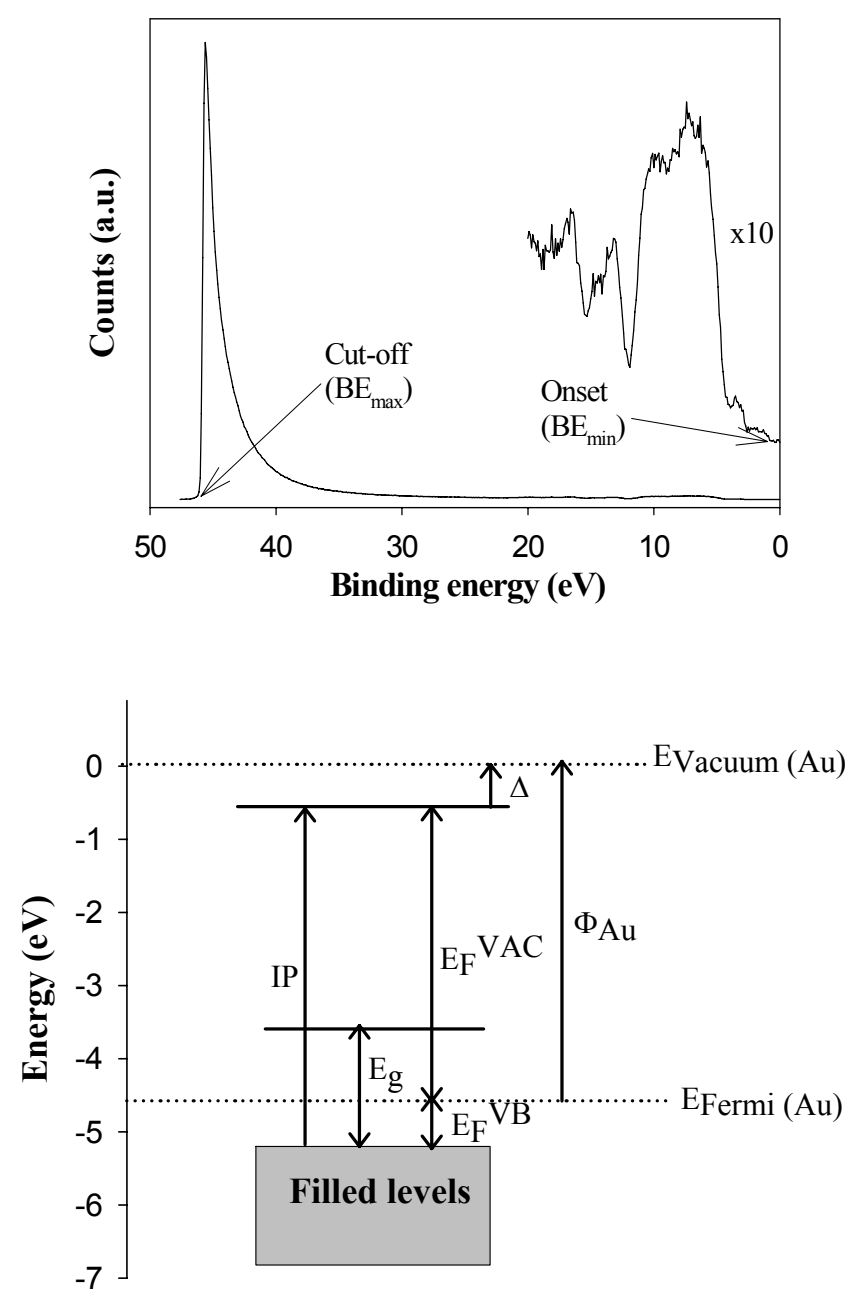

Figure 4.8. Top) UPS spectra and bottom) band structure of polymer 8 .

UPS spectra, UPS data and band structures of polymer $\mathbf{5}-\mathbf{7}$ and $\mathbf{9 - 1 0}$ are given in Appendix A2.2. It was found that the Fermi level was well aligned with the middle of the optical band gap except for the copolymers based on benzo-bis(thiadiazole) and thiophene (polymer 9 and 10). This could be due to doping of the polymer (see Section 5.1). However, as described in Section 3.5.1, purification with hydrazine and ammonia showed no difference in the absorption spectra. Thus, the band gap of the two polymers may be underestimated, and according to $\mathrm{E}_{\mathrm{F}}{ }^{\mathrm{VB}}$ the band gaps should be 0.94 and $1.04 \mathrm{eV}$ respectively. This is, however, seen as an upper limit since the UPS measurements do not show the electronic energy levels of the empty orbitals (i.e. LUMO).

For the polymers based on thiophene and benzothiadiazole (polymer 5 - 8) it was found that $\mathrm{E}_{\mathrm{F}} \mathrm{VB}$ decreased with an increase in number of thiophenes in the repeating unit $(n=1-4)$, which was also seen for the optical band gap, $E_{g}$ (see Section 4.1.2). UPS measurements were also attempted for polymer $\mathbf{1 1}-\mathbf{1 6}$ but because of the insolubility of these polymers the films obtained were not suitable for UPS measurements. 


\subsection{Summary}

Band gap and electronic structure of the polymers have been determined from UV-vis and UPS and these methods have been described in detail. It was found that the band gap of the copolymers of thiophene and benzothiadiazole was decreasing with an increase in the number of thiophenes in the repeating unit.

\section{References}

1 C. N. R. Rao, Ultra-violiet and visible spectroscopy - chemical applications, $3^{\text {rd }}$ Ed., Butterworth, 1975, ISBN: 0-408-70624-4.

2 M. Hesse, H. Meier, B. Zeeh, Spectroscopic methods in organic chemistry, Thieme, 1997, ISBN: 0-86577-667-9.

3 D. L. Pavia, G. M. Lampman, G. S. Kriz, Introduction to spectroscopy, $2^{\text {nd }}$ Ed., Saunders College Publishing, 1996, ISBN: 0-03-058427-2.

4 D. A. Senor, Electrical properties of polymers, Academic Press, 1982, ISBN: 012-633680-6.

5 A. Chandekar, J. E. Whitten, Synth. Met., 150 (2005) 259-264.

6 P. W. Atkins, Physical Chemistry, $6^{\text {th }}$ Ed., Oxford University Press, 1998, ISBN: 0-19-850102-1.

7 C. D. Wagner, W. M. Riggs, L. E. Davis, J. F. Moudler, G. E. Muilenberg, Handbook of photoelectron spectroscopy, Perkin-Elmer Corporation, 1978, ISBN: 0-9648124-1-X.

8 W. R. Salaneck, M. Lögdlund, M. Fahlman, G. Greczynski, T. Kugler, Mat. Sci. Eng. R34 (2001) 121-146.

9 F. C. Krebs, M. Jørgensen, Macromolecules 35 (2002) 7200-7206.

10 M. Jørgensen, F. C. Krebs, Pol. Bul. 51 (2003) 23-30.

11 www.isa.au.dk

12 F. C. Krebs, Pol. Bull. 52 (2004) 49-56. 


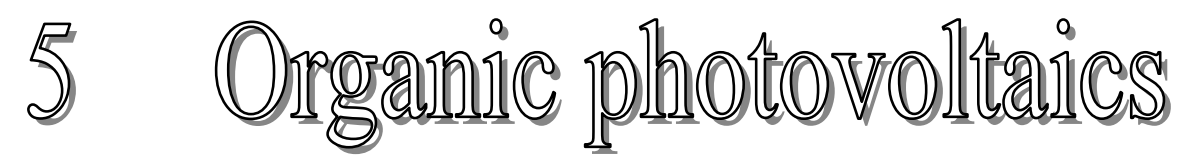

The results described in this chapter are primarily based on studies of polymer $\mathbf{8}$ in OPV devices. The studies were mainly carried out at the National Renewable Energy Laboratory in Colorado, USA. In the first part of the chapter the principles of OPVs are described along with details which should be considered when applying low band gap polymers, such as polymer $\mathbf{8}$, in OPVs. This is followed by a summary of the studies carried out with polymer $\mathbf{8}$. In the final part of the chapter results obtained on hybrid $\mathrm{PV}$ based on $\mathrm{ZnO}$ and polymer $\mathbf{8}$ is given.

\subsection{Introduction}

In organic photovoltaic (OPV) devices the active polymer layer absorbs light $(h v)$ and an electron-hole pair is formed, called an exciton. The exciton is transported to a trapping site, where a hole and an electron are formed. This charge separation is followed by charge transport to the two electrodes, i.e. holes to the electrode with the high work function and electrons to the electrode with the low work function.

\subsubsection{Principles of OPVs}

All materials are divided into three groups according to their electronic properties: insulator, semiconductor and conductor. ${ }^{1}$ Metals are conductors and the conjugated polymers applied in OPVs are semiconductors.

The energy levels in a metal are so close that they form a continuum, which is shown as a box in an energy diagram (see Figure 5.1). The work function of a metal corresponds to the energy needed to remove one electron from the metal to vacuum (i.e. the energy from the Fermi level to the vacuum). The Fermi level is defined as the energy level in which the possibility to find an electron is 0.5 .

Both insulators and semiconductors have a characteristic energy band gap between HOMO and LUMO. There are two types of doped semiconductors, known as the ntype and the p-type. For a semiconductor the Fermi level is in the middle of the band gap; however, for the n-type semiconductor the Fermi level is very close to the LUMO and for the p-type the Fermi level is close to the HOMO. ${ }^{2}$ This is summarized in Figure 5.1. 


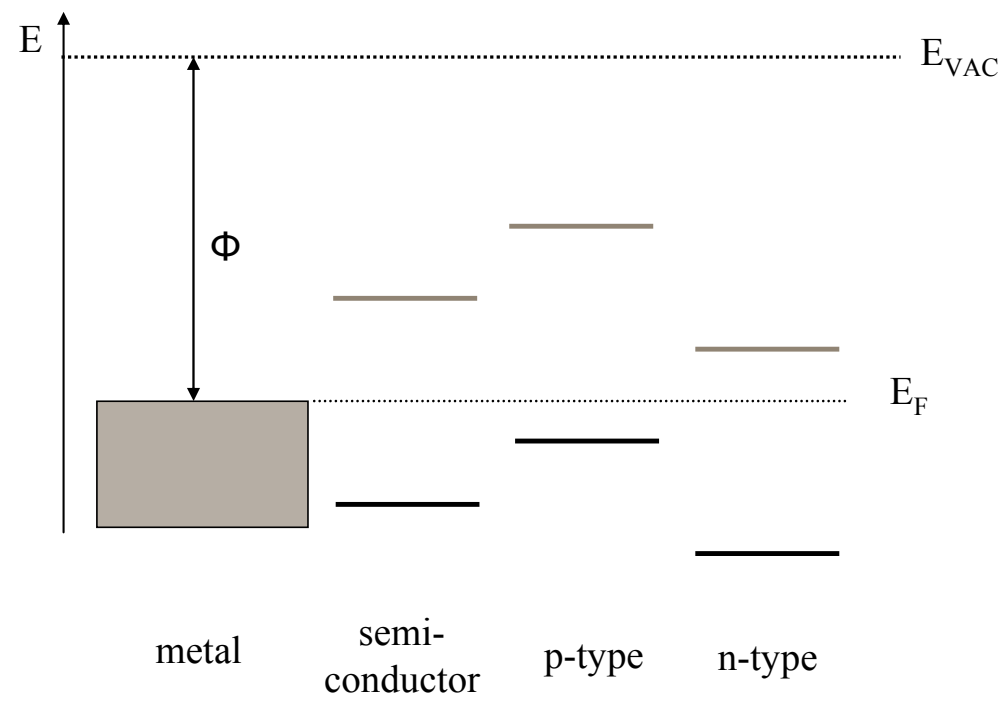

Figure 5.1. Energy diagram of a metal, an undoped semiconductor, a p-type and a n-type semiconductor. $\Phi$ is the work function, $E_{\mathrm{f}}$ is the Fermi level and $\mathrm{E}_{\mathrm{vac}}$ is the vacuum level.

Within the area of OPV there are three main types of devices: 1) single layer, 2) bilayer heterojunction and 3) bulk heterojunctions. In Figure 5.2 examples of these devices are illustrated.

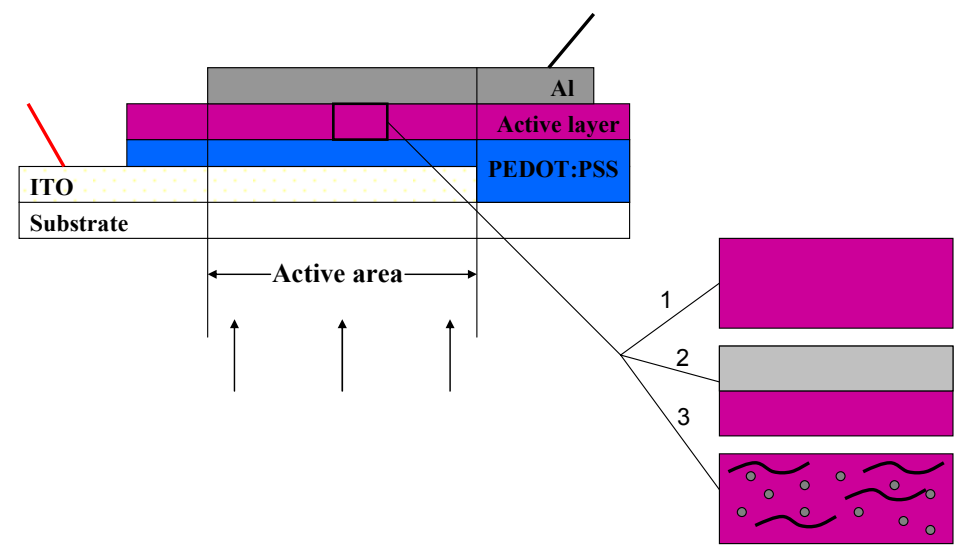

Figure 5.2. Schematic view of the different types of OPV. 1) single layer, 2) bilayer heterojunction and 3) bulk heterojunction.

The single layer device consists of a semiconducting polymer sandwiched between two electrodes with different work functions. ${ }^{3}$ The processes in the single layer device can be described by the metal-insulator-metal (MIM) model used to study inorganic photovoltaic devices. In Figure 5.3a the single layer device is shown under open circuit conditions. This means that there is no current flowing through the device and the voltage is determined by the difference in the work functions of the two electrodes. In Figure 5.3b the device is shown under short circuit conditions. Here the voltage is zero and the electrons flow from the ITO electrode to the Al electrode under illumination in which case the Fermi level of the electrodes coincide. Under illumination photons are absorbed. This process generates excitons followed by charge transfer to the electrodes and charge separation at the polymer/electrode interface. The device works as a photovoltaic. ${ }^{2-4}$ 


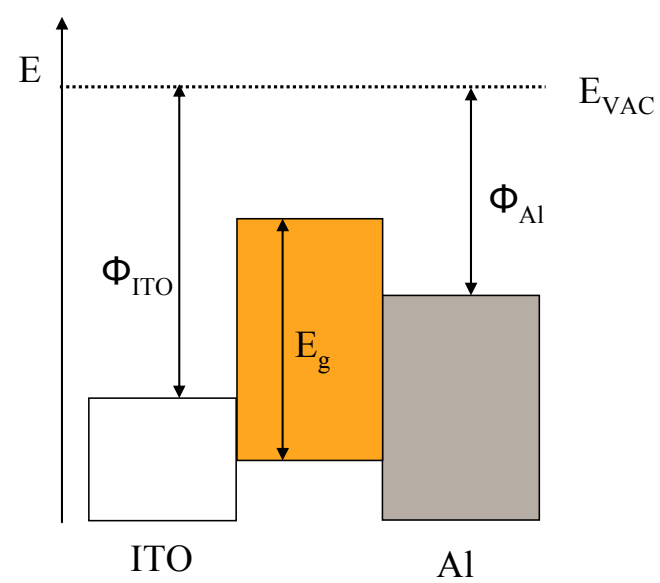

b

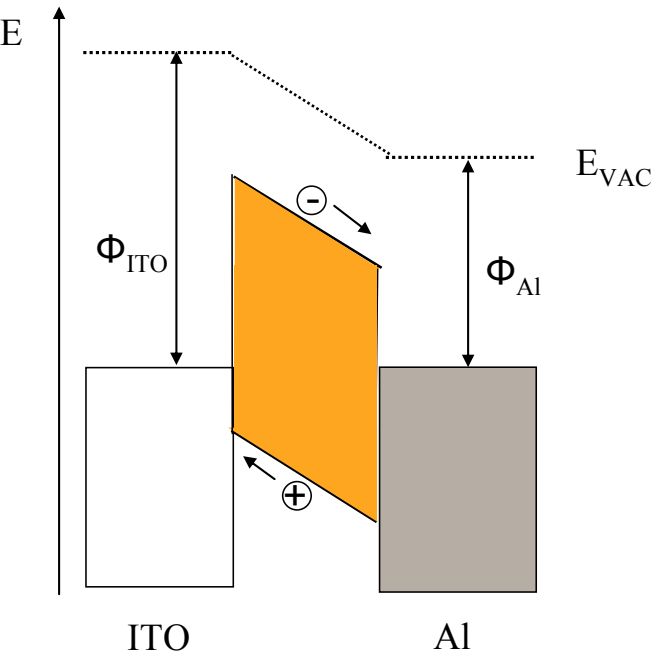

Figure 5.3. Metal-insulator-metal (MIM) model for single layer device. a) Under open circuit and b) under short circuit. $\Phi$ is the work function of the two electrodes, $E_{v a c}$ is the vacuum level and $E_{g}$ is the band gap of the polymer.

The MIM model can also be described under reverse and forward bias where the device works as a photodetector and a light emitting diode (LED). For the forward bias a voltage larger than the open circuit voltage is applied. Electrons are injected into the LUMO of the semiconductor and light is emitted when electron combines with a hole. ${ }^{2-4}$

As indicated the MIM model describes devices consisting of insulators. However, since the polymers applied in OPVs are semiconductors the model does not give an accurate picture of what happens in the device. In Figure 5.4 a Schottky device is shown under short circuit conditions. In the depletion area, W, an energy barrier of charges is built up and the bands in the semiconductor bend due to the parabolic gradient of the potential. This energy barrier is called a Schottky barrier. ${ }^{2-4}$

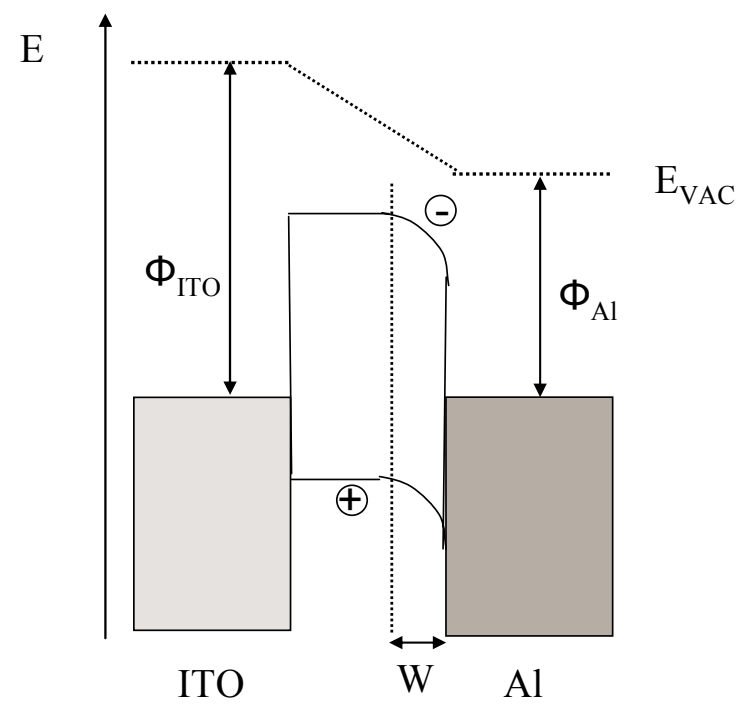

Figure 5.4. Schottky model for single layer device under short circuit conditions.

Examples of the single layer OPV in the literature have shown poor efficiency (example in Appendix A2.1). This is ascribed to the poor charge separation in the 
device. Hence, addition of an electron acceptor will increase the charge separation and thus increase the efficiency. It is believed that the photocurrent in such a device is generated as a result of charge transfer reactions between donor and acceptor molecules combined with a slow recombination rate of charges in the device. ${ }^{5}$ In 1992 the photoinduced electron transfer from a polymer to $\mathrm{C}_{60}$, resulting in an efficient charge separation, was discovered. ${ }^{6}$

The bilayer device consists of a donor and an acceptor layer, where the polymer is applied with an electron acceptor layer on top, normally $\mathrm{C}_{60}$. There are two main advantages to the bilayer compared to the single layer device. First, the recombination rate of the electron and hole is lower than the forward charge transport. Second, once the excitons have dissociated to the interface of the materials the electrons travel in the n-type acceptor material and the holes travel in the p-type donor material resulting in efficient charge separation. ${ }^{3,4}$

In Figure 5.5 the bilayer device is shown as the MIM model with no band bending for simplicity. Under open circuit conditions (a) no current runs in the device and the voltage is determined by the difference in LUMO level of the acceptor and the HOMO level of the donor. Under short circuit conditions (b) the Fermi levels of the two electrodes align and electrons are transferred from the donor to the acceptor.,
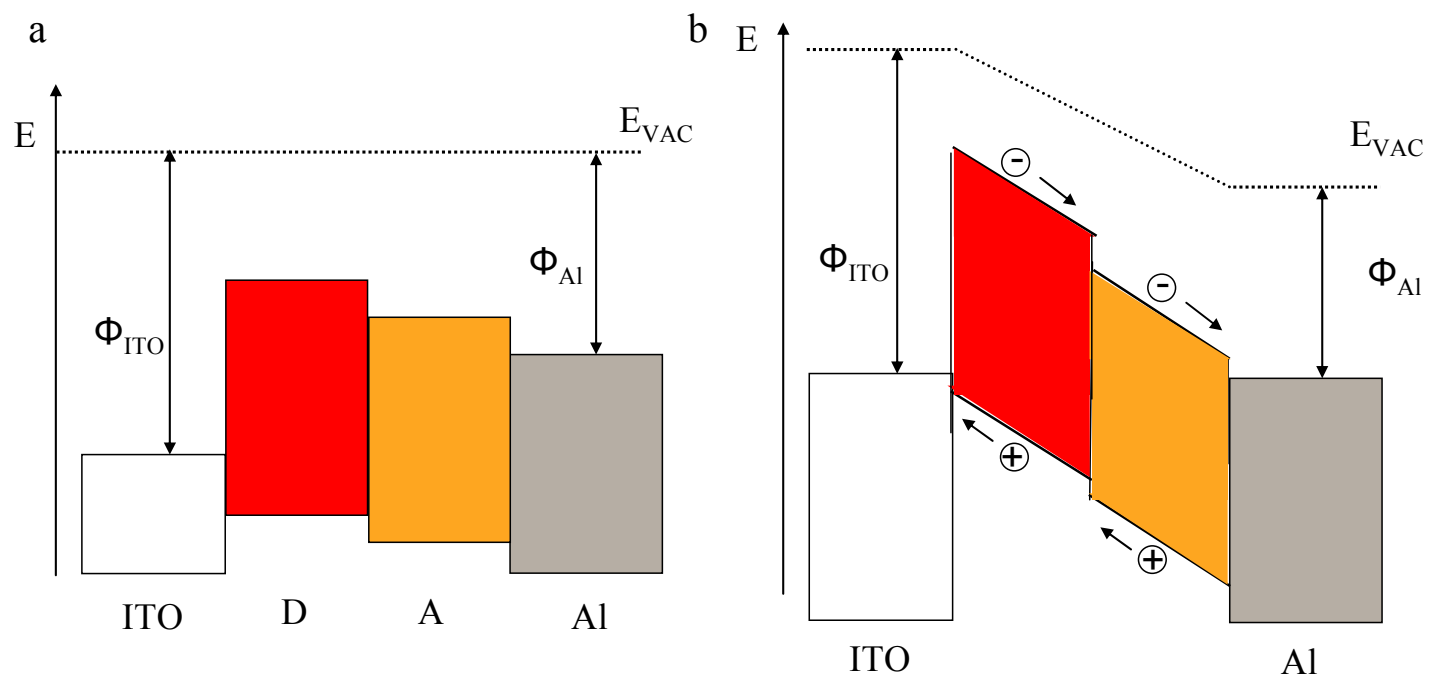

Figure 5.5. Metal-insulator-metal (MIM) model for bilayer heterojunction device. a) Under open circuit and b) under short circuit. $\Phi$ is the work function of the two electrodes, $\mathrm{E}_{\mathrm{vac}}$ is the vacuum level, $\mathrm{E}_{\mathrm{g}}$ is the band gap of the polymer and $\mathrm{D}$ and $\mathrm{A}$ is the donor and acceptor, respectively. Not to scale.

As described, the bilayer device has several advantages compared to the single layer; however, to increase the charge transport further the use of a soluble $\mathrm{C}_{60}$ derivative (e.g. PCBM) has been shown to increase the efficiency of the device. ${ }^{5}$ This is a bulk heterojunction and has several advantages compared to the bilayer heterojunction. The better contact between the donor polymer and the acceptor results in a larger surface area at which charge separation takes place and the charge recombination rate is low due to the charge separation within the different phases. ${ }^{3,4}$

In Figure 5.6 the bulk heterojunction device is shown as the MIM model without the band bending for simplicity and the donor and acceptor is shown as a mix in between the two electrodes. Under open circuit conditions (a) no current runs in the device and the voltage is determined by the difference in LUMO level of the acceptor and the HOMO level of the donor. Under short circuit conditions (b) the voltage is zero and 
the current flows from the ITO to the Al electrode as the Fermi level of the electrodes coincide. The charges are separated under illumination at the donor/acceptor interface. $^{3,4}$
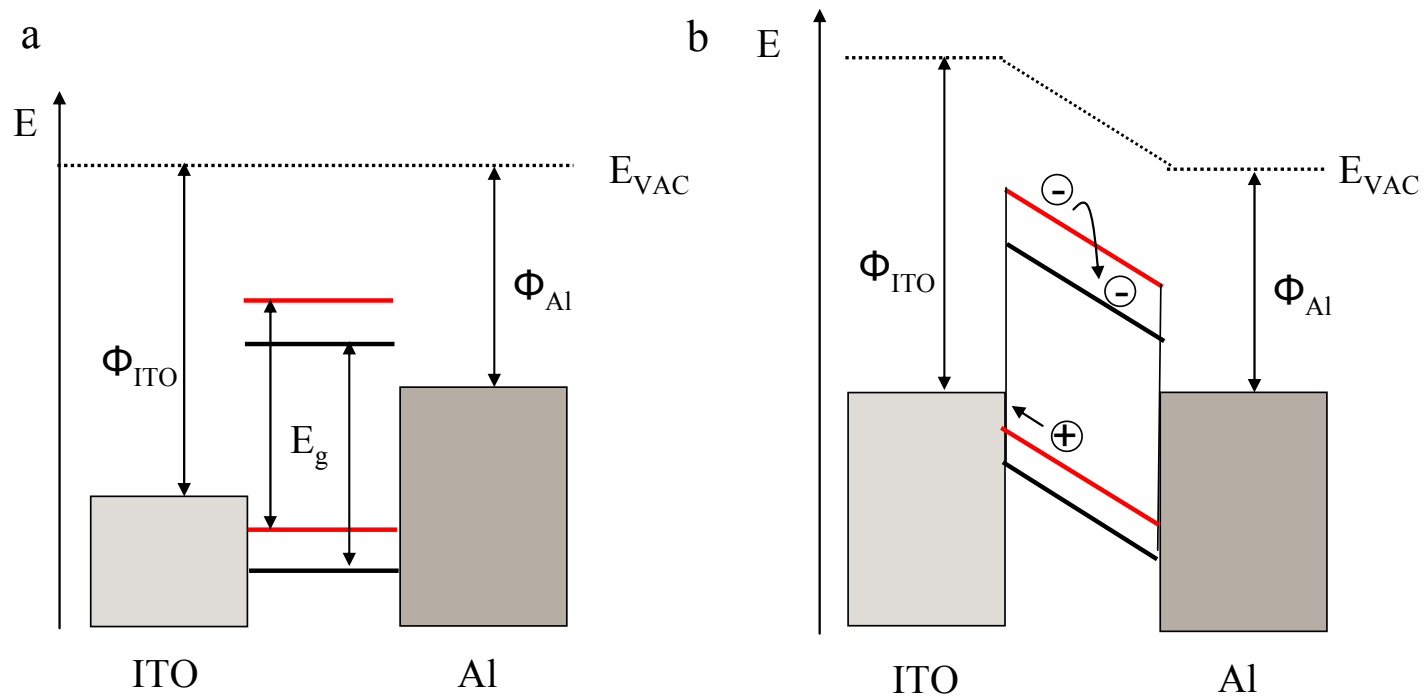

Figure 5.6. Metal-insulator-metal (MIM) model for a bulk heterojunction device. a) Under open circuit and b) under short circuit. $\Phi$ is the work function of the two electrodes, $E_{v a c}$ is the vacuum level, $E_{g}$ is the band gap of the polymer. The HOMO and LUMO of the donor and acceptor are marked with red and black lines, respectively.

Since the donor and acceptor are not attached to the electrodes separately as in the bilayer heterojunction, the donor and acceptor have to form percolation pathways within the network for the holes and electrons to be transferred to the electrodes. Therefore, the bulk heterojunction devices are very sensitive to the nano-morphology of the active layer and the blend of the polymer and acceptor. Thus, it is crucial to have an optimum domain size of the phase separation in order to get the right exciton dissociation and charge transport. ${ }^{3,4}$ The most studied device structure today is of the bulk heterojunction type (as seen in Tables 2, 3, 4, 6, 8 and 10 in Appendix A2.3) where the respective polymers are mixed with $\mathrm{PCBM}$ in a device with the structure: ITO/PEDOT:PSS/polymer:PCBM/Al.

\subsubsection{Important parameters}

There are some important parameters, which describe an OPV. These parameters are the short circuit current $\left(J_{S C}\right)$, the open circuit voltage $\left(V_{O C}\right)$, the fill factor $(\mathrm{FF})$, the efficiency $(\eta)$ and the incident photon to current efficiency (IPCE) or external quantum efficiency (EQE).

The $J_{S C}$ is the maximum current which flow in the device under illumination when no voltage is applied. The $J_{S C}$ is highly dependent on the morphology of the device and on the lifetime and mobility of the charge carriers. ${ }^{7,8}$ Further, it was shown in Section 2.1 that a decrease in the band gap results in a higher maximum theoretical current since more sun light, i.e. photons, is harvested.

The $V_{O C}$ is the maximum voltage which the device can produce under open circuit and for bulk heterojunctions it is determined by the difference between the HOMO of the donor (polymer) and the LUMO of the acceptor (e.g. PCBM). ${ }^{9,10}$ It has been found that the $V_{O C}$ is not very dependent on the work functions of the electrodes. ${ }^{11,12}$ In addition, it has been proposed that lowering the HOMO of the polymer and increasing 
the LUMO of the acceptor will cause an increase in the $V_{O C}$ resulting in higher efficiency. ${ }^{9,10}$

The fill factor is the ratio between the maximum power output of the device $\left(V_{\max }\right.$. $\left.I_{\max }\right)$ and the maximum theoretical power output, which can be achieved if the device is an ideal diode $\left(V_{O C} \cdot J_{S C}\right)$ (see Eq. (5.1)).

$$
\mathrm{FF}=\frac{\mathrm{P}_{\text {max }}}{V_{O C} \cdot J_{S C}}=\frac{V_{\text {max }} \cdot I_{\max }}{V_{O C} \cdot J_{S C}}
$$

The efficiency is determined from Eq. (5.2) and is the percentage of output power available, compared to input power.

$$
\eta(\%)=\frac{\mathrm{P}_{\mathrm{out}}}{\mathrm{P}_{\mathrm{in}}}=\frac{V_{O C} \cdot J_{S C} \cdot \mathrm{FF}}{P_{\text {in }}} \cdot 100 \%
$$

How these factors are gained from an IV curve is shown in Figure 5.7.

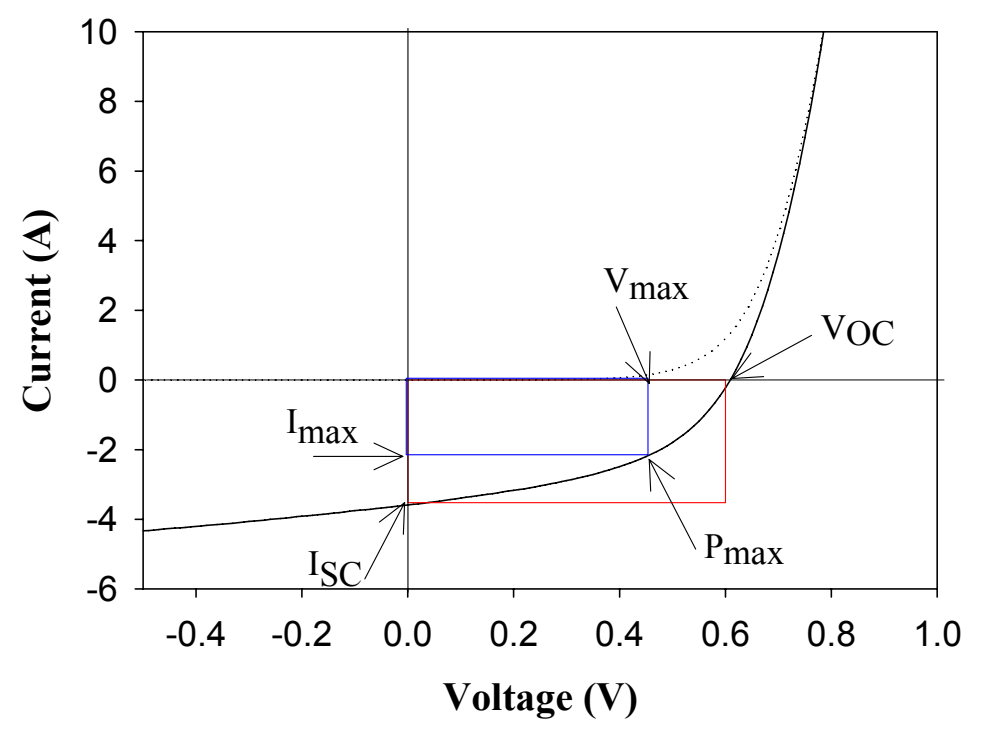

Figure 5.7. IV curve for a OPV device with polymer 8 (see Section 5.6) with indication of $J_{S C}, V_{O C}$, $V_{\max }$ and $I_{\max }$. The IV curve measured in dark is dotted and under illumination is black solid. The ratio between the area for the blue and the red box is the FF.

The IPCE shows how much of the light, which a given polymer absorbs, is converted into electrical energy in an OPV device. IPCE is determined by measurements of $J_{S C}$ as a function of the wavelength followed by calculation of the IPCE from Eq. (5.3).

$$
\operatorname{IPCE}(\%)=\frac{J_{S C}}{e \cdot \mathrm{P}} \cdot 100 \%
$$

where $\mathrm{P}$ is the number of photons and $e$ is the elementary charge $\left(1.602 \cdot 10^{-19} \mathrm{C}\right)$.

\subsection{Low band gap polymers in organic photovoltaic devices}

When a low band gap polymer is applied in an OPV the energy level alignment becomes crucial. As described in Chapter 4 the electronic structure of the polymer can 
be determined from UPS and UV-vis and this is compared with the energy levels of the acceptor. In Figure 5.8 the energy level of a low band gap polymer and an acceptor is shown. The energy $\boldsymbol{\alpha}$ in Figure 5.8 represents the difference between LUMO of the donor polymer and LUMO of the acceptor, and it should be high enough to ensure an efficient electron transfer from the polymer to the acceptor. The energy $\boldsymbol{\beta}$ represents the minimum acceptable value of $V_{O C}$. When a high band gab polymer (e.g. PPV based polymers) is applied in a device the values of $\boldsymbol{\alpha}$ and $\boldsymbol{\beta}$ are high and efficient charge transfer and high $V_{O C}$ is achieved. Application of a low band gap polymer in a device with a chosen acceptor, like PCBM, limits the values of $\boldsymbol{\alpha}$ and $\boldsymbol{\beta}$, and efficient charge transfer and high $V_{O C}$ may not be possible. Therefore, use of new acceptors with other LUMO levels are one way to solve the problem of energy level alignment in OPVs based on low band gap polymers (as shown in Table 5.1, entry 6).

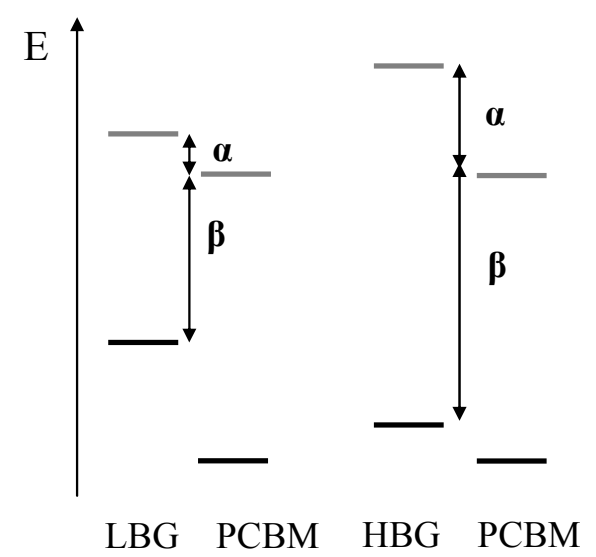

Figure 5.8. Energy level alignment in photovoltaic devices when a low band gap polymer (LBG) and a high band gap polymer (HBG) are applied. The HOMO levels are shown as black lines and the LUMO levels are shown as grey lines. $\boldsymbol{\alpha}$ represents the difference between LUMO of the polymer and LUMO of the acceptor and $\boldsymbol{\beta}$ represents the minimum $V_{O C}$.

In the literature there are several examples of low band gap polymers applied in OPV devices. The efficiencies reported are lower than the well studied P3HT the efficiency of which has reached $\eta=5 \%{ }^{13,14}$ However, the maximum $J_{S C}$ achievable for P3HT is $14.3 \mathrm{~mA} \mathrm{~cm}^{-2}$ (see Section 2.1) and has almost been obtained. Hence, reports on OPVs based on low band gap polymers have increased in the past few years. The results of part of the low band gap polymers from the literature applied in OPVs are summarized in Table 5.1.

Table 5.1. Highest $\eta$ reported for some low band gap polymers in OPV. The device structure was ITO/PEDOT:PSS/polymer:PCBM/LiF/Al. For structures of the polymers see Table 2.1.

\begin{tabular}{cccc}
\hline Polymer & $\begin{array}{c}\text { Band gap } \\
(\mathbf{e V})\end{array}$ & $\begin{array}{c}\boldsymbol{\eta} \\
(\mathbf{\%})\end{array}$ & Ref. \\
\hline PITN & 1.0 & 0.008 & 15 \\
P(T-ITN-T), R $=\mathrm{Cl}$ & 1.8 & 0.31 & 16 \\
PTPTB & 1.6 & 1.1 & 17,18 \\
P(T-TP-T) & 1.9 & 1.1 & 19 \\
PCPDTBT & 1.7 & 3.2 & 20,21 \\
PFTQT & 1.27 & $0.7^{\mathrm{a}}$ & 22 \\
\hline
\end{tabular}

${ }^{\mathrm{a}}$ The OPV device was prepared with a blend of the polymer and a $\mathrm{C}_{70}$ derivate. 
Several reviews have been written on OPVs and low band gap polymers. ${ }^{23-26}$ An upto-date review on low band gap polymers and their function in OPVs is given in Appendix A2.3.

\subsection{Device preparation}

The preparation of OPV devices is carried out in different ways by different research groups; however, a general technique is spin coating of the active layer on top of a transparent electrode followed by thermal evaporation of a metal electrode under vacuum with the resulting device structure: transparent electrode/active layer/metal electrode. Examples of three OPV devices are shown in Figure 5.9, where the active layer of polymer 8 and PCBM has a $0.1,3$ and $10 \mathrm{~cm}^{2}$ active area, respectively. In OPVs the transparent electrode consists of Indium Tin Oxide (ITO), poly(3,4ethylenedioxythiophene) doped with poly(styrenesulfonate) (PEDOT:PSS) (for flexible devices) or a combination of the two, where PEDOT:PSS is spin coated on top of ITO.

The work function of ITO has been shown to change by various surface treatments, such as UV ozone and plasma treatment. The $V_{O C}$ of the OPV has only shown a weak dependence on the changes in the work function of ITO. However, the $J_{S C}$ have shown great dependence on the surface treatments of the ITO since the treatment has a large impact on the ITO surface roughness and morphology. ${ }^{5}$

PEDOT:PSS forms uniform, transparent and conductive films. PEDOT:PSS is applied onto the ITO electrode to improve the interface between this electrode and the active layer. The thickness of the PEDOT:PSS layer is often less than $50-250 \mathrm{~nm}$ to ensure a high transmission. However, if the PEDOT:PSS is used as the transparent electrode on its own the conductivity has to be higher otherwise the result is a poorer transmission of light. The conductivity of the PEDOT:PSS can be varied by orders of magnitude using different polymerization processes, by doping and by annealing. The best results reported are for the combination of the ITO and PEDOT:PSS transparent electrode. ${ }^{5}$

The choice of metal electrode is often Al, however, several others have been reported $\mathrm{Ag}, \mathrm{Au}, \mathrm{Ca}$ and other metals. ${ }^{5}$ It has been shown that the $V_{O C}$ is independent of the work function of the metal electrode. Therefore, the most important thing to keep in mind for the choice of metal electrode is that the work function must be low for electron collection. ${ }^{5}$ 


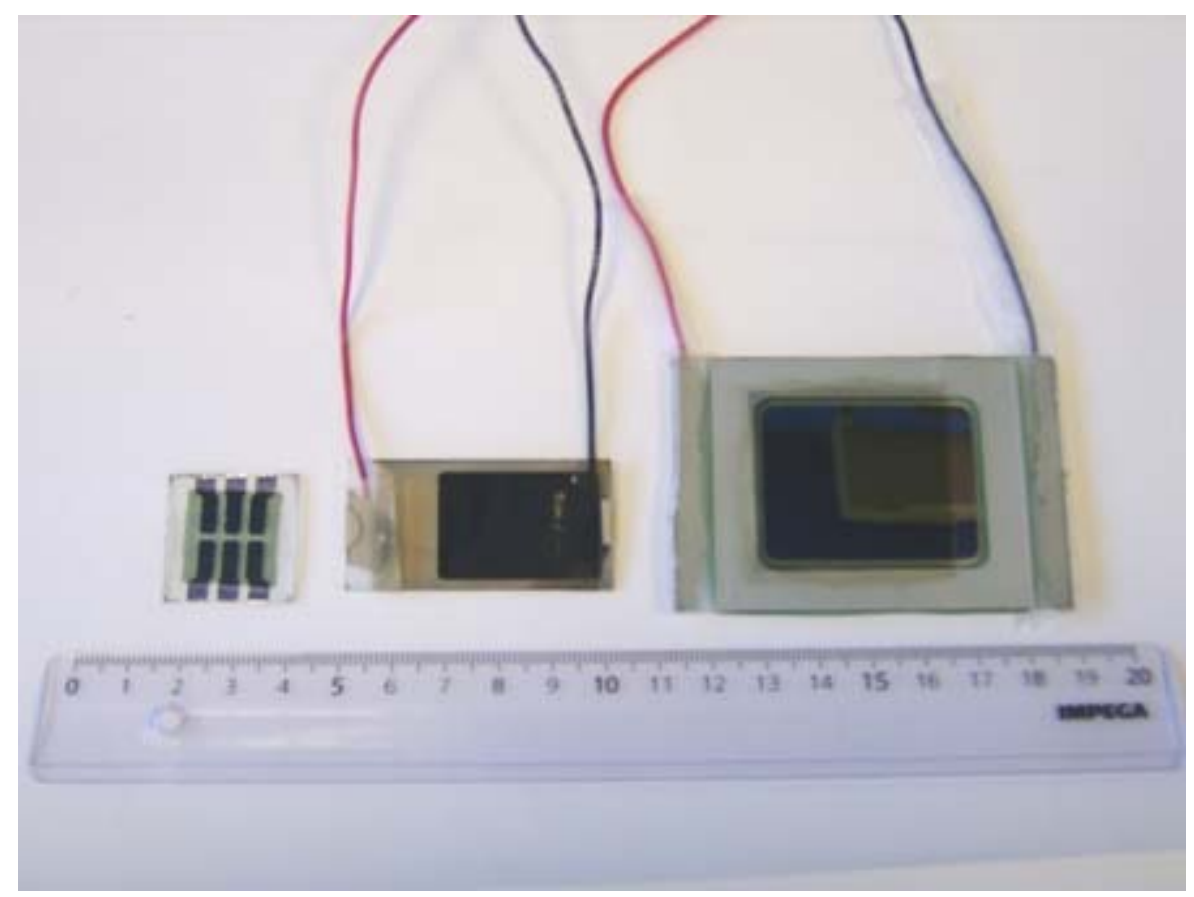

Figure 5.9. Picture of OPV devices with different active areas: a) 0.1 , b) 3 and c) $10 \mathrm{~cm}^{2}$ (encapsulated).

The reported OPVs are often devices with a small active area (e.g. $0.1 \mathrm{~cm}^{2}$ ). For small area devices the procedures used for application of the active layer are spin coating, solvent casting or doctor blading. Few reports have been published on the larger active area devices where screen printing procedures have been used. ${ }^{27-32}$ Encapsulation of the devices is important to protect the active layer from oxygen. This can be done with a PET film so the device is flexible, or as shown in Figure 5.9, where the $10 \mathrm{~cm}^{2}$ device is encapsulated in glass and $\mathrm{Al}^{33}$ Additional details on device preparation can be found in Appendix A2.1, A2.4 and A2.5.

\subsection{What affects the efficiency of OPV devices?}

Besides the band gap and energy level alignment another factor which is of great importance when it comes to the photovoltaic responses of OPVs is morphology. The morphology of the active layer in the device is affected by several factors: the solvent used for spin coating, concentration of the polymer, active layer thickness, composition of polymer and fullerene, annealing temperature and molecular weight. ${ }^{34}$ Devices prepared with P3HT have shown great dependence of the photovoltaic responses on molecular weight, ${ }^{35}$ thickness of active layer, ${ }^{36-38}$ annealing temperature, ${ }^{13,14,38-49}$ solvent $^{8}$ and solvent evaporation time. ${ }^{41}$

\subsubsection{Solvent, concentration and active layer thickness}

Since the report of an increase in efficiency from 0.9 to $2.5 \%$ for a device based on MDMO-PPV/PCBM spin coated from toluene and chlorobenzene, ${ }^{8}$ the focus on solvent and hence morphology studies has increased greatly. The choice of solvent was important for the mixing of polymer and fullerene, for the domain size and for charge transport (i.e. the solvent improved the nano-morphology). ${ }^{8}$ The effect of the solvent on photovoltaic devices based on a low band gap polymer is limited, however, a copolymer based on fluorene, thiophene and benzothiadiazole with a band gap of about $2 \mathrm{eV}$ showed that the morphology was improved when chlorobenzene was 
added to the chloroform compared to spin coating from neat $\mathrm{CHCl}_{3} .{ }^{50} \mathrm{~A}$ significant increase in $J_{S C}$ and FF was seen, when spin coating from mixtures of chloroform and other solvents such as chlorobenzene compared to spin coating from neat chloroform. At the same time $V_{O C}$ was not influenced. ${ }^{50}$ In addition, it was found that the charge mobility in the device was improved when spin coating from solvent mixtures. ${ }^{50}$

The influence of solvent and concentration on device morphology and efficiency has also been investigated for polymer $\mathbf{8}$ in bulk heterojunction devices. The efficiency was shown to depend on the solvent, the spin rate, the spin time and on the concentration. For polymer $\mathbf{8}$ and PCBM a smoother surface and a higher efficiency was achieved when the active layer was spin coated from 1,2-dichlorobenzene compared to spin coating from a mixture of chloroform and chlorobenzene. This does not correspond with the data obtained for annealing measurements on P3HT (see Section 5.4.3) where a smoother surface resulted in a lower efficiency. ${ }^{51}$

Spin coating time and spin rate was found to produce thin films when using high rates and short times (slow dried film) and thick films when using low rates and long time (fast dried film). An improved efficiency was achieved for the slowly dried film.

Concentration of polymer 8 with a fixed ratio (1:2) of PCBM and the same solvent (1,2-dichlorobenzene) showed that the efficiency increased with an increase in concentration and film thickness from $0.42 \%$ for a $35 \mathrm{~nm}$ thick film to $0.9 \%$ for a $120 \mathrm{~nm}$ thick film. However, increasing the concentration of the polymer further and hence, the film thickness, resulted in a decrease in the efficiency to $0.39 \%$ for a 270 $\mathrm{nm}$ thick film. This is ascribed to absorption mainly occurring at the glass substrate in a thick film, which results in a poorer efficiency. ${ }^{14,52}$ Details on these studies are given in Appendix A2.5.

\subsubsection{Ratio between polymer and fullerene}

The ratio between the polymer and the fullerene in bulk heterojunction devices is of great importance in terms of photovoltaic response. The optimum ratio depends on the type of polymer mixed with PCBM. For MEHPPV the ratio which gave the highest efficiency was 1:3 and 1:4. Similar results were found for MDMO-PPV. ${ }^{3}$ This was not the case for P3HT or a copolymer of benzothiadiazole, thiophene and pyrrole, where ratios of 1:1 between the polymer and PCBM have been shown to be optimum. The morphology is affected by the ratio between the polymer and PCBM. Addition of more PCBM to P3HT has been shown to increase electron mobility. ${ }^{53,54}$ The effect on the photovoltaic responses of the ratio between polymer 8 and PCBM in bulk heterojunctions has also been investigated. The results show that a maximum in efficiency of $0.6 \%$ was reached for a $1: 2$ ratio polymer/PCBM. Further details on these studies are given in Appendix A2.4.

Electron acceptors other than PCBM have been studied in devices with low band gap polymers (Table 5.1 entry 6). A better charge separation was observed in devices based on copolymers of fluorene and the electron acceptor BTPF70, a soluble derivative of $\mathrm{C}_{70}$, than devices based on the copolymer of fluorene and PCBM. This finding was explained by the better overlap between the LUMO of the polymer and the LUMO of the electron acceptor (BTPF70). ${ }^{20,55-57}$

\subsubsection{Annealing temperature}

Several groups have reported on the annealing of OPV devices based on P3HT and PCBM (see Appendix A2.3 Table 2 and 3). Both post-production annealing and pretreatment annealing (i.e. annealing before and after deposition of the aluminum electrode) have been carried out. This showed that the pretreatment resulted in a 
rougher surface which causes an increase in the efficiency of the device due to larger contact area between the polymer and the electrode. ${ }^{51}$ The post annealing also resulted in improved efficiency but the cause of this is not known. ${ }^{51}$ Annealing of a device has been shown to increase the charge carrier separation efficiency and the mobility of the charge carriers due to phase segregation. ${ }^{58,59}$ It has been shown that upon annealing of a bulk heterojunction based on P3HT and PCBM, the PCBM diffuses out of the polymer matrix and the polymer then orders in the lamella structure. The PCBM clusters improve the photocurrent due to formation of percolation paths. ${ }^{42,51,58}$

Annealing studies have been carried out by several groups, where the highest efficiency to date is $5 \%$ for a bulk heterojunction of P3HT and PCBM annealed at $155^{\circ} \mathrm{C}$ for $2-3$ min. $^{14}$ or at $150{ }^{\circ} \mathrm{C}$ for 30 min. $^{13}$

For a low band gap copolymer of fluorene, thiophene and benzothiadiazole annealing at $120^{\circ} \mathrm{C}$ showed an increase in $J_{S C}, \mathrm{FF}$ and efficiency due to the dependence of the mobility on temperature. However, a decrease in $V_{O C}$ was observed due to a thermally activated injection current from the electrodes. ${ }^{60}$

The effect of the annealing temperature on morphology and herefore, device performance has also been studied for polymer 1,8 and $\mathbf{1 4}$. For polymer 1 an increase in efficiency from 0.014 to $0.024 \%$ was observed when the device was post annealed at $70{ }^{\circ} \mathrm{C}$, and this was mainly due to the increase in $J_{S C}$. Annealing showed no effect on the photovoltaic performances of devices based on polymer 14 and PCBM. For polymer 8 a more detailed study was carried out where post-annealing was done at different temperatures under a nitrogen atmosphere. The results show an increase in $J_{S C}, V_{O C}, \mathrm{FF}, \eta$ and IPCE, when the annealing temperature was raised from no annealing to $130{ }^{\circ} \mathrm{C}$ and a decrease was observed in these parameters, when raising the temperature to $150{ }^{\circ} \mathrm{C}$. Further details on these studies are given in Appendix A2.1 and $\mathrm{A} 2.5$.

\subsubsection{Molecular weight}

The molecular weight has been shown to influence the morphology and consequently, the efficiency of OPV devices. Results obtained for polythiophene ${ }^{35,61-63}$ show that high molecular weight and low polydispersity results in higher efficiencies due to a better morphology of the narrow molecular weight distribution polymer fractions. ${ }^{61}$ However, it has been shown that the amorphous part of P3HT was required in order to obtain a better contact to PCBM nanocrystals and the crystalline part of P3HT was needed for the transport of holes. ${ }^{64}$

To study the influence of the molecular weight of a low band gap polymer, polymer $\mathbf{8}$ was fractionized into five fractions by preparative SEC (see Section 3.5.3.2) and these fractions were applied in OPV devices. The IV curves of the measurements are shown in Figure 5.10 and the photovoltaic responses of these devices are summarized in Table 5.2. 


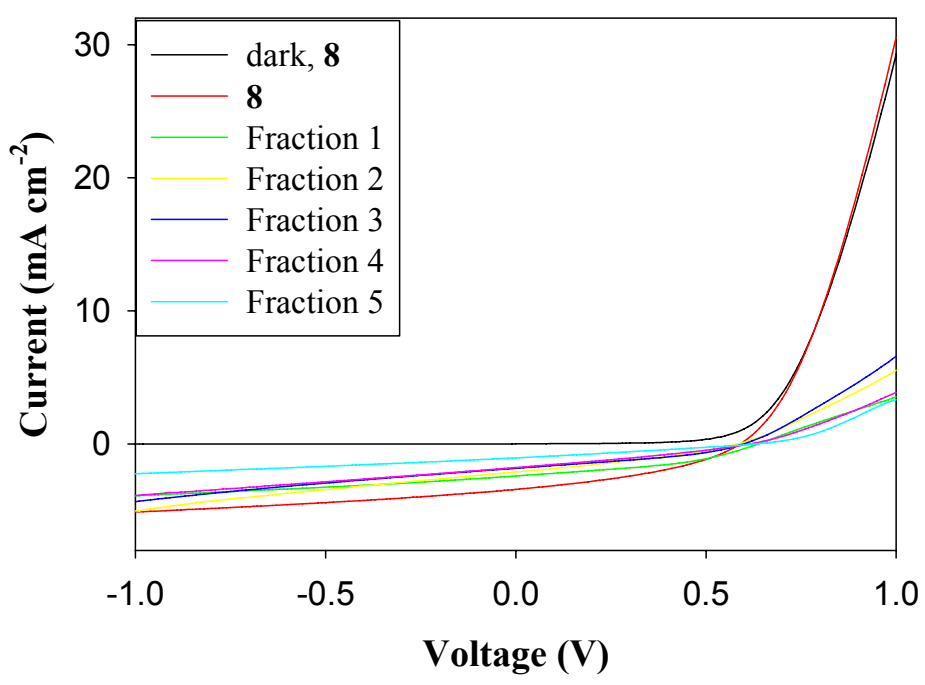

Figure 5.10. IV curves of ITO/PEDOT:PSS/polymer:PCBM(1:2)/Al.

Table 5.2. Photovoltaic response of ITO/PEDOT:PSS/1:PCBM (1:2)/Al with different $M_{w}$ of the polymer. Active area $0.1 \mathrm{~cm}^{2}$, AM1.5 and $100 \mathrm{~mW} \mathrm{~cm}$. The raw material corresponds to the nonfractionated polymer. The thickness of the active layer was measured by AFM. - indicates measurements which were not carried out.

\begin{tabular}{|c|c|c|c|c|c|c|}
\hline Fraction & $\mathbf{M}_{\mathbf{W}}$ & $\begin{array}{c}\text { Thickness } \\
\text { (nm) }\end{array}$ & $\begin{array}{c}J_{S C} \\
\left(\mathrm{~mA} \mathrm{~cm}^{-2}\right)\end{array}$ & $\begin{array}{l}V_{O C} \\
(V)\end{array}$ & $\begin{array}{c}\text { FF } \\
(\%)\end{array}$ & $\begin{array}{c}\eta \\
(\%)\end{array}$ \\
\hline Raw & - & 160 & 3.42 & 0.59 & 38 & 0.77 \\
\hline 1 & 15000 & 100 & 2.42 & 0.64 & 40 & 0.62 \\
\hline 2 & 8500 & 130 & 2.07 & 0.64 & 34 & 0.45 \\
\hline 3 & 4600 & 155 & 2.05 & 0.60 & 32 & 0.40 \\
\hline 4 & 2500 & - & 1.78 & 0.62 & 30 & 0.33 \\
\hline 5 & 1300 & - & 1.05 & 0.63 & 27 & 0.18 \\
\hline
\end{tabular}

The data show a constant $V_{O C}$ around $0.6 \mathrm{~V}$ and a decrease in $J_{S C}$ with decreasing molecular weight from $2.4 \mathrm{~mA} \mathrm{~cm}^{-2}$ for fraction 1 to $1.1 \mathrm{~mA} \mathrm{~cm}^{-2}$ for fraction 5 , and with efficiency decreasing from $0.6 \%$ for fraction 1 to $0.2 \%$ for fraction 5 . However, comparison of the raw polymer $\mathbf{8}$ with the fractions of the polymer shows a decrease in the efficiency after fractionation of the polymer. This tendency is also seen for the IPCE (see Figure 5.11). There are three possible explanations for this: thickness, doping or gluing. First, in Table 5.2 it is observed that the thicknesses of the devices are not the same and a comparison is here fore very difficult. Second, since the fractionation by preparative SEC was carried out in air it is likely that the polymer was doped during this procedure. Third, the results shown for P3HT on the amorphous and crystalline parts may very well correspond to the results shown here. In other words the low molecular weight fractions being the amorphous part give better contact to the PCBM and the higher molecular weight fractions being crystalline effectively transfer holes. ${ }^{64}$ Therefore, in order to study the effect of the molecular weight properly the fractions should be dedoped before application in OPV devices and the concentration of the fractions should be chosen so the same thickness of the active layer for all five fractions is obtained. 


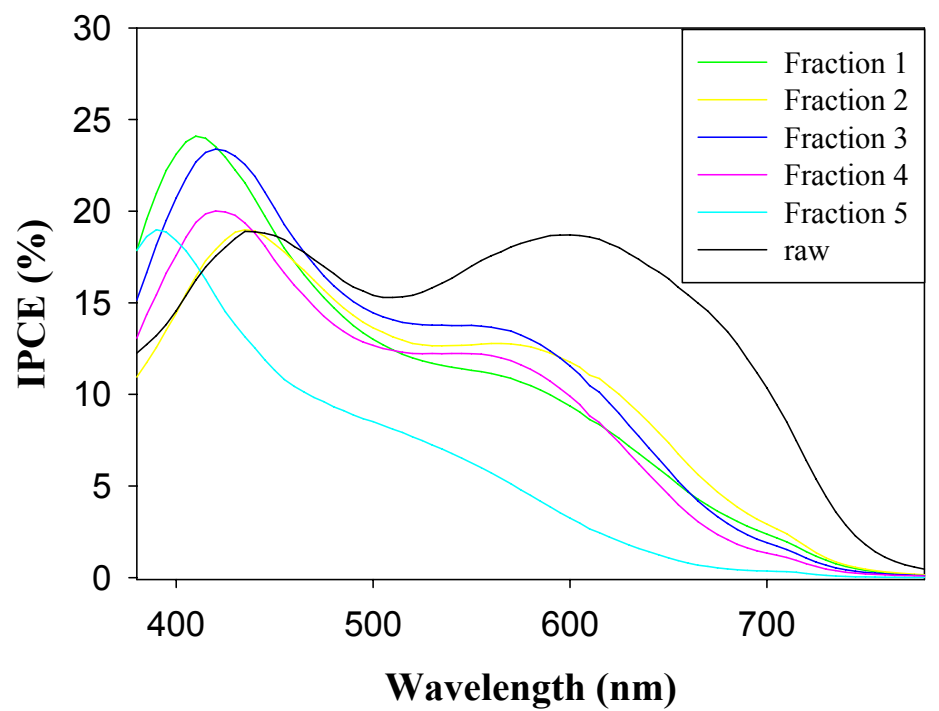

Figure 5.11. IPCE curves fractionized polymers in OPV devices.

\subsubsection{Other factors}

Besides these factors other studies have shown that the morphology of the active layer is also affected by the size of the active area. Most reported data for photovoltaics are of very small active area devices (i.e. $0.1 \mathrm{~cm}^{2}$ or less, see Appendix A2.3 Table 2-4, 6, 8 and 10). Few examples have been reported on large area devices based on PPV polymers and polythiophene. ${ }^{27-32}$ Polymer $\mathbf{8}$ was also applied in large area devices with an active area of $3 \mathrm{~cm}^{2}$ and $10 \mathrm{~cm}^{2}$ (see Figure 5.9) and the efficiencies obtained were $0.6 \%$ and $0.2 \%$ respectively. This shows that the efficiency often decreases with an increase in the active area and since the $V_{O C}=0.6 \mathrm{~V}$ was constant; the decrease in efficiency can be explained by poorer morphology in the larger active area device. This is, however, the first result reported on a low band gap polymer in a large area device and it indicates that polymer $\mathbf{8}$, or derivatives thereof, are promising polymers for OPV. For further details on these results see Appendix A2.4.

The type of compound also affects the photovoltaic response of OPV devices. ${ }^{34}$ The low band gap polymers are believed to increase the efficiency of the device compared to other types of polymers applied in OPV (e.g. PPV based polymers, see Section 2.1). Further, devices prepared with polythiophene have shown that the regioregularity of the polymer is of great importance and so, research groups are today applying highly regioregular head-to-tail coupled P3HT ${ }^{65,66}$ However, applying a head-to-head and a head-to-tail coupled copolymer of thiophene and benzothiadiazole (polymer 1 and 14, respectively) did not show any effect in the maximum photovoltaic responses that were obtained after annealing (see Appendix A2.1). The morphology has also been shown to depend on the types of side chains on the polymer back-bone and on the position of the side chains. In a copolymer of thienopyrazine and thiophene a higher efficiency was achieved for the polymer with bulky side groups on the benzene ring compared with bulky side groups on the thiophene ring. ${ }^{19}$ Studies have shown that a low band gap alone is not enough to ensure a high efficiency. The way that the molecules order in the solid phase is of great importance as for example in the case of P3HT which orders in a lamellar structure. ${ }^{67-72}$ 


\subsection{Lifetime studies}

The few results reported from lifetime studies show short lifetime. Studies on OPV degradation are therefore important and have shown very complicated mechanisms of reaction with water and oxygen in the air, and with the electrode. ${ }^{73-78}$ Recently a lifetime of more than 20,000 hours estimated from accelerated studies has been reported for a device based on a polythiophene with thermocleavable side chains. ${ }^{79,80}$ Lifetime studies have been carried out on copolymers based on thiophene and benzothiadiazole. These show very limited lifetimes of a few hours for polymer $\mathbf{1 4}$ in air. However, an increase from 2 to 80 hours was observed when a layer of $\mathrm{C}_{60}$ was added in a device based on polymer 8 (see Appendix A2.1 and A2.4).

\subsection{The $1 \%$ device}

The highest efficiency achieved for an OPV device based on polymer 8 is $1 \%$. The device ITO/PEDOT:PSS/8:PCBM (1:2)/Al with an active area of $0.1 \mathrm{~cm}^{2}$ was annealed at $110^{\circ} \mathrm{C}$. The active layer was spin coated from 1,2-dichlorobenzene using a slow drying technique. The data achieved when illuminated with $100 \mathrm{~mW} \mathrm{~cm}$ white light was $V_{O C}=0.61 \mathrm{~V}, J_{S C}=3.59 \mathrm{~mA} \mathrm{~cm}^{-2}, \mathrm{FF}=46 \%$ and $\eta=1.0 \%$. The maximum IPCE $=18 \%$ at $600 \mathrm{~nm}$ was achieved for a device with a concentration of $15 \mathrm{mg} / \mathrm{mL}$ (see Appendix A2.5).

\subsection{Hybrid PV based on ZnO}

At NREL the study of polymers in hybrid PVs based on $\mathrm{ZnO}$ was carried out and while I was visiting NREL I therefore applied polymer 8 in $\mathrm{ZnO}$ based devices and the results are summarized in this section.

\subsubsection{Introduction}

Several papers have been published on hybrid photovoltaic devices, where a metaloxide is applied in the device to increase the charge carrier mobility. ${ }^{77,81}$ The hybrid PV devices works in a similar way as an OPV device (i.e., the polymer absorbs the light and operates as the hole transporter and thus donates electrons to the metal oxide). ${ }^{77}$ Different types of metal oxides have been used in the literature, e.g. $\mathrm{SnO}_{2}$, $\mathrm{TiO}_{2}$, CdSe and $\mathrm{ZnO},{ }^{77,81-83}$ and different polymers have been applied, e.g. P3HT, MDMO-PPV and MEH-PPV. ${ }^{77,81-85}$

Hybrid PVs based on $\mathrm{ZnO}$ have shown an increase in the maximum $V_{O C}$ which can be obtained. Importantly, $\mathrm{ZnO}$ is cheap compared to the fullerene generally used in OPV and environmentally friendly when compared to $\mathrm{CdSe} .^{77,81-86} \mathrm{ZnO}$ is used in different forms in the hybrid PV devices (i.e., fibers, particles or thin films). Some results with these forms of $\mathrm{ZnO}$ in hybrid $\mathrm{PV}$ devices described in the literature are summarized in Table 5.3. 
Table 5.3. Photovoltaic performance of hybrid PV based on $\mathrm{ZnO}$ described in the literature.

\begin{tabular}{lccc}
\hline Form of ZnO & $\boldsymbol{\eta}(\mathbf{\%})$ & IPCE (\%) & Ref. \\
\hline Thin film, & 1.0 & 70 & 84 \\
$\begin{array}{l}\text { ITO/ZnO/C } 60 \\
\text { Nano-structered fibers, }\end{array}$ & 2.0 & 57 & 77,82 \\
$\begin{array}{l}\text { ITO/ZnOfibers/P3HT:PCBM/Ag } \\
\text { Nano-particles, }\end{array}$ & 1.6 & 50 & $77,85-87$ \\
$\begin{array}{l}\text { ITO/PEDOT:PSS/MDMO-PPV:ZnO/Al } \\
\text { Nano-particles, }\end{array}$ & 0.9 & 27 & 88 \\
ITO/PEDOT:PSS/P3HT:ZnO/Al & & & \\
\hline
\end{tabular}

As can be seen, use of $\mathrm{ZnO}$ results in improved efficiencies compared to the homopolymer devices. However, there are few drawbacks for the metal-oxide-based hybrid PV devices. It has been shown that the metal oxide looses oxygen, when stored in an inert atmosphere but gains oxygen when the device is stored in air. ${ }^{77,89}$ Studies showed that devices based on $\mathrm{ZnO}$ with MEH-PPV had lifetimes of only 2 hours because of polymer degradation under illumination after storage in air. ${ }^{77}$

\subsubsection{Results}

Polymer 8 was applied in $\mathrm{ZnO}$ based hybrid PV devices. In Figure 5.12 a schematic view of the hybrid $\mathrm{PV}$ with $\mathrm{ZnO}$ nanofibers is shown. The fibers are grown on top of the ITO electrode and the absorbing polymer is spin coated on top. This should result in a good contact between the electron donor (the polymer) and electron acceptor (the $\mathrm{ZnO}$ fibers).

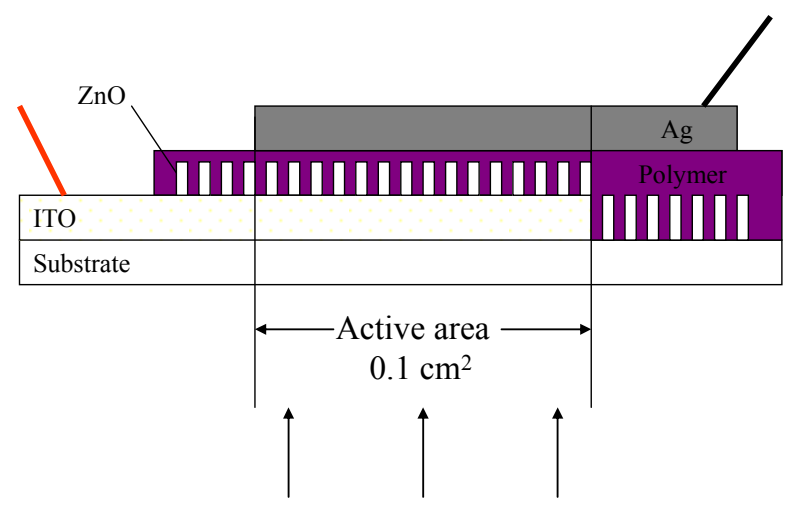

Figure 5.12. A schematic view of a hybrid PV with nanofibers.

The devices with polymer 8 were prepared according to the procedures described previously ${ }^{82,90}$ with few variations as summarized in Table 5.4.

Table 5.4. Different ITO/ZnO/8/Ag devices.

\begin{tabular}{ccccc}
\hline Type & $\begin{array}{c}\text { ZnO } \\
\text { growth time (min.) }\end{array}$ & Polymer/PCBM & Solvent & $\begin{array}{c}\text { Concentration } \\
(\mathrm{mg} / \mathrm{mL})\end{array}$ \\
\hline 1 & $10 \mathrm{~min}$ & $1: 0$ & $\mathrm{CHCl}_{3}$ & 36 \\
2 & $20 \mathrm{~min}$ & $1: 2$ & $\mathrm{CHCl}_{3} /$ chlorobenzene & 36.6 \\
& & $1: 2$ & dichlorobenzene & 22.4 \\
3 & no & $1: 2$ & dichlorobenzene & 10 \\
4 & no & & & \\
\hline
\end{tabular}


The photovoltaic responses of these devices are summarized in Table 5.5.

Table 5.5. Photovoltaic responses of the devices described in Table 5.4.

\begin{tabular}{lcccc}
\hline Type $^{\mathbf{a}}$ & $\mathbf{V}_{\mathbf{O C}}(\mathbf{V})$ & $\mathbf{I}_{\mathbf{S C}}\left(\mathbf{m A ~ \mathbf { ~ m } ^ { - 2 }}\right)$ & $\mathbf{F F} \mathbf{( \% )}$ & $\boldsymbol{\eta} \mathbf{( \% )}$ \\
\hline 1 anneal & 0.19 & 0.004 & 31 & - \\
2 & 0.22 & 0.09 & 30 & 0.01 \\
2 anneal & 0.20 & 0.09 & 29 & 0.01 \\
3 & 0.07 & 0.64 & 27 & 0.01 \\
3 anneal & 0.55 & 1.17 & 38 & 0.24 \\
4 & 0.02 & 0.78 & - & - \\
4 anneal & 0.31 & 1.82 & 36 & 0.20 \\
\hline
\end{tabular}

${ }^{\text {a }}$ The annealed samples were annealed at $120^{\circ} \mathrm{C}$ for $10 \mathrm{~min}$. in air. They were then stored in air and darkness for two days before measuring.

The results in Table 5.5 show very low $J_{S C}$ and $V_{O C}$ (except for type 3 anneal) compared to the results obtained for polymer 8 in OPV devices, i.e. $\eta=1 \%$. For type 3 anneal the $V_{O C}(0.55 \mathrm{~V})$ is in the same region as the $V_{O C}(0.6 \mathrm{~V})$ for OPV devices; however, the $J_{S C}$ for this device is very low compared to the $J_{S C}$ for the OPV devices. There are some conclusions, which can be made from the results shown in Table 5.5. Comparing the annealed device of type 3 with the non-annealed device, it can be seen that the efficiency greatly increases upon annealing as is seen for OPV. Furthermore, comparing the annealed devices of type 3 and 4 , it can be seen that the low concentration in type 4 results in a low efficiency as seen for OPV.

Comparing the growth times it can be seen that no growth results in higher efficiency. This is ascribed to two problems, as shown in the Scanning Electron Microscopy (SEM) picture (see Figure 5.13).

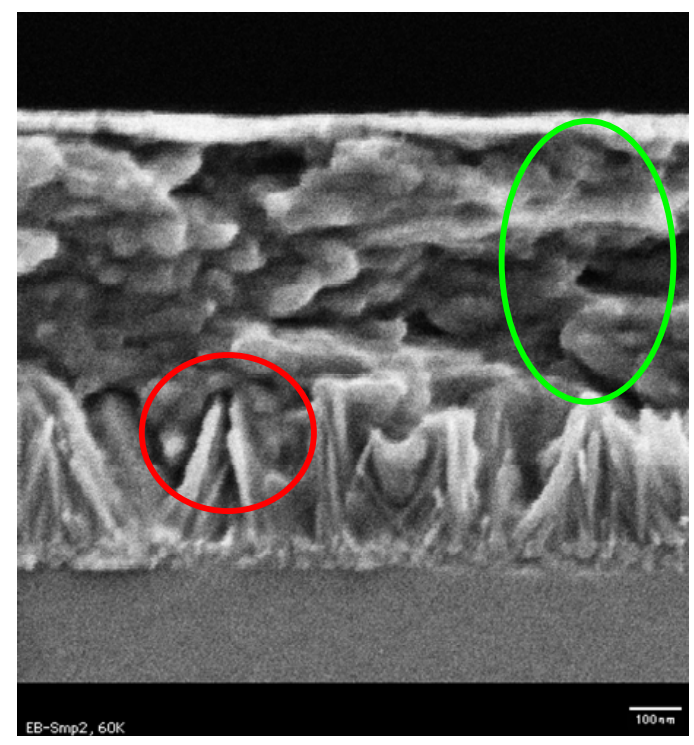

Figure 5.13. SEM pictures of type 2. Green circle: thickness of active layer, red circle: no polymer between $\mathrm{ZnO}$ fibers. The scale in bottom right corner is $100 \mathrm{~nm}$.

The SEM images suggest that the polymer concentration has been too high and this has resulted in a very thick film $(\sim 350 \mathrm{~nm})$. In addition, the SEM image shows that the polymer film is not in between the $\mathrm{ZnO}$ nanofibers and only lies on top of the 
fibers. This results in a poor charge transfer from the polymer or polymer blend to the $\mathrm{ZnO}$ and therefore, the efficiency is very low. This finding also explains the higher $\eta$ for the device with no growth (type 3 and 4).

Further work is needed to increase the efficiency of these $\mathrm{ZnO}$-based hybrid devices with polymer 8, for example by using nano-particles blended with the polymer to ensure an efficient charge transport. Addition of nano-particles has shown an increase in efficiency for hybrid PV based on MDMO-PPV. ${ }^{85-88,91}$

\subsection{Summary}

The structure and principles of single layer, bilayer and bulk heterojunction OPV devices have been described in detail. To improve the efficiency of OPVs it is important to focus on the energy level alignment when using low band gap polymers. Film morphology also has a great influence on the efficiency of the device and this is affected by the molecular weight, annealing temperature, solvent, concentration, ratio between the polymer and acceptor and the thickness of the active layer. These factors have all been studied for polymer $\mathbf{8}$ and an efficiency of $1 \%$ has been achieved for a $0.1 \mathrm{~cm}^{2}$ device annealed at $110^{\circ} \mathrm{C}$.

Studies of polymer $\mathbf{8}$ applied in hybrid photovoltaic devices with $\mathrm{ZnO}$ as the inorganic electron acceptor show poor insertion of the polymer between the $\mathrm{ZnO}$ nano-fibers. Further research is needed in order to find ways in which this polymer could function more effectively in these types of PVs.

\section{References}

$1 \quad$ M. P. Stevens, Polymer Chemistry - An Introduction, $3^{\text {rd }}$ Ed., Oxford University Press, 1999, ISBN: 0-19-512444-8.

2 H. Tsubomura, H. Kobayashi, Cri. Rev. Solid State Mater. Scien. 18 (1993) 261-326.

3 H. Hoppe, N. S. Sariciftci, J. Mater. Res. 19 (2004) 1924-1925.

4 C. J. Brabec, N. S. Sariciftci, J. C. Hummelen, Adv. Funct. Mater. 11 (2001) 15-26.

5 S.-S. Sun, N. S. Sariciftci, Organic Photovoltaic, CRS Press, 2005, ISBN: 08247-5963-X.

6 N. S. Sariciftci, L. Smilowitz, A. J. Heeger, F. Wudl, Science 258 (1992) 1474-1476.

7 C. J. Brabec, Sol. Energy Mater. Sol. Cells 83 (2004) 273-292.

8 S. E. Shaheen, C. J. Brabec, N. S. Sariciftci, F. Padinger, T. Fromherz, J. C. Hummelen, Appl. Phys. Lett. 78 (2001) 841-843.

9 L. J. A. Koster, V. D. Mihailetchi, P. W. M. Blom, Appl. Phys. Lett. 88 (2006) 093511 1-3.

10 M. C. Scharber, D. Mühlbacher, M. Koppe, P. Denk, C. Waldauf, A. J. Heeger, C. J. Brabec, Adv. Mater. 18 (2006) 789-794.

11 C. J. Brabec, A. Cravino, D. Meissner, N. S. Sariciftci, T. Fromherz, M. T. Ripens, L. Sanches, J. C. Hummelen, Adv. Funct. Mater. 11 (2001) 374-380.

12 H. Frohne, S. E. Shaheen, C. J. Brabec, D. C. Müller, N. S. Sariciftci, K. Meerholz, Chem. Phys. Chem. 9 (2002) 795-799.

13 M. Reyes-Reyes, K. Kim, J. Dewald, R. López-Sandoval, A. Avadhanula, S. Curran, D. L. Carroll, Org. Lett. 7 (2005) 5749-5752.

14 W. Ma, C. Yang, X. Gong, K. Lee, A. J. Heeger, Adv. Funct. Mater. 15 (2005) 1617-1622. 
15 A. Henckens, M. Knipper, I. Polec, J. Manca, L. Lutsen, D. Vanderzande, Thin Solid Films 451-452 (2004) 572-579.

16 D. L. Vangeneugden, D. J. M. Vanderzande, J. Salbeck, P. A. van Hal, R. A. J. Janssen, J. C. Hummelen, C. J. Brabec, S. E. Shaheen, N. S. Sariciftci, J. Phys. Chem. 105 (2001) 11106-11113.

17 C. J. Brabec, C. Winder, N. S. Sariciftci, J. C. Hummelen, A. Dhanabalan, P. A. van Hal, R. A. J. Janssen, Adv. Funct. Mater. 12 (2002) 709-712.

18 C. Winder, D. Mühlbacher, H. Neugebauer, N. S. Sariciftci, C. Brabec, R. A. J. Janssen, J. K. Hummelen, Mol. Cryst. Liq. Cryst. 385 (2002) [213]/93$[220] / 100$.

19 M. M. Wienk, M. G. R. Turbiez, M. P. Struijk, M. Fonrodona, R. A. J. Janssen, Appl. Phys. Lett. 88 (2006) 153511 1-3.

20 D. Mühlbacher, M. Scharber, M. Morana, Z. Zhu, D. Waller, R. Gaudiana, C. J. Brabec, Adv. Mater. 18 (2006) 2884-2889.

21 D. Mühlbacher, M. Scharber, M. Morana, Z. Zhu, D. Waller, R. Gaudiana, C. J. Brabec, Adv. Mater. 18 (2006) 2884-2889, correction.

22 X. Wang, E. Perzon, F. Oswald, F. Langa, S. Admassie, M. R. Andersson, O. Inganäs, Adv. Funct. Mater. 15 (2005) 1665-1670.

23 C. Winder, N. S. Sariciftci, J. Mater. Chem. 14 (2004) 1077-1086.

24 J. Roncali, Chem. Rev. 97 (1997) 173-205.

25 T. A. Skotheim, R. L. Elsenbaumer, J. R. Reynolds, Handbook of conducting polymers, $2^{\text {nd }}$ Ed., Marcel Dekker, 1998, ISBN: 0-8247-0050-3.

26 A. K. Bakhshi, G. Bhalla, J. Sci. Industri. Res. 63 (2004) 715-728.

27 S. E. Shaheen, R. Radspinner, N. Peyghambarian, G. E. Jabbour, Appl. Phys. Lett. 79 (2001) 2996-2998.

28 F. C. Krebs, J. Alstrup, H. Spangaard, K. Larsen, E. Kold, Sol. Energy Mater. Sol. Cells 83 (2004) 293-300.

29 T. Aernouts, Proceedings of the $19^{\text {th }}$ European Photovoltaics Conference, June 7-11 (2004), Paris, France.

30 F. C. Krebs, J. Alstrup, M. Biancardo, H. Spanggaard, Proc. of SPIE 5938 (2005) 593804 1-11.

31 F. C. Krebs, Refocus 6 (2005) 38-39.

32 F. C. Krebs, H. Spanggaard, T. Kjær, M. Biancardo, J. Alstrup, Mater. Sci. En. B 138 (2007) 106-111.

33 F. C. Krebs, Sol. Energy Mater. Sol. Cells 90 (2006) 3633-3643.

34 H. Hoppe, N. S. Sariciftci, J. Mater. Chem. 16 (2006) 45-61.

35 R. J. Kline, M. D. McGehee, E. N. Kadnikova, J. Liu, J. M. J. Fréchet, M. F. Toney, Macromolecules 38 (2005) 3312-3319.

36 A. Swinnen, I. Haeldersmans, M. vande Ven, J. D’Haen, G. Vanhoyland, S. Aresu, M. D’Olieslaeger, J. Manca, Adv. Funct. Mater. 16 (2006) 760-765.

37 K. M. Coakley, M. D. McGehee, Chem. Mater. 16 (2004) 4533-4542.

38 F. Padinger, R. S. Rittberger, N. S. Sariciftci, Adv. Funct. Mater. 13 (2003) 85-88.

39 G. Li, V. Shrotriya, J. Huang, Y. Yao, T. Moriarty, K. Emery, Y. Yang, Nat. Mater. 4 (2005) 864-868.

40 P. Vanlaeke, G. Vanhoyland, T. Aernouts, D. Cheyns, C. Deibel, J. Manca, P. Heremans, J. Poortmans, Thin Solid Films 511-512 (2006) 358-361.

41 V. Shotriya, G. Li, Y. Yao, C.-W. Chu, Y. Yang, Appl. Phys. Lett. 88 (2006) 073508 1-3. 
42 D. Chirvase, J. Parisi, J. C. Hummelen, V. Dyakonov, Nanotech. 15 (2004) 1317-1323.

43 I. Riedel, V. Dyakonov, Phys. Stat. Sol. 201 (2004) 1332-1341.

44 M. Drees, H. Hoppe, C. Winder, H. Neugebauer, N. S. Sariciftci, W. Schwinger, F. Schäffler, C. Topf, M. C. Scharber, Z. Zhu, R. Gaudiana, J. Mater. Chem. 15 (2005) 5158-5163.

45 K. Inoue, R. Ulbricht, P. C. Madakasira, W. M. Sampson, S. Lee, J. Gutierrez, J. Ferraris, A. A. Zakhidov, Proceeding of SPIE 5520 (2004) 256-262.

46 Y. Kim, S. A. Choulis, J. Nelson, D. D. C. Bradley, S. Cook, J. R. Durrant, J. Mater. Sci. 40 (2005) 1371-1376.

47 X. Yang, J. Loos, S. C. Veenstra, W. J. H. Verhees, M. M. Wienk, J. M. Kroon, M. A. J. Michels, R. A. J. Janssen, Nano Lett. 5 (2005) 579-583.

48 J. Hou, Z. Fan, Y. Yan, Y. He, C. Yang, Y. Li, J. Am. Chem. Soc. 128 (2006) 4911-4916.

49 R. Cugola, U. Giovanella, P. Di Gianvincenzo, F. Bertini, M. Catellani, S. Luzzati, Thin Solid Films 511-512 (2006) 489-493.

50 F. Zhang, K. G. Jespersen, C. Björström, M. Svensson, M. R. Andersson, V. Sundström, K. Magnusson, E. Moons, A. Yartsev, O. Inganäs, Adv. Funct. Mater. 16 (2006) 667-674.

51 G. Li, V. Shrotriya, Y. Yao, Y. Yang, J. Appl. Phys. 98 (2005) 043704 1-3.

52 J. Y. Kim, S. H. Kim, H.-H. Lee, K. Lee, W. Ma, X. Gong, A. J. Heeger, Adv. Mater. 18 (2006) 572-576.

53 E. van Hauff, J. Parisi, V. Dyakonov, Thin Solid Films 511-512 (2006) 506511.

54 J. Nakamura, K. Murata, K. Takahashi, Appl. Phys. Lett. 87 (2005) 132105 13.

55 L. M. Andersson, O. Inganäs, Appl. Phys. Lett. 88 (2006) 082103 1-3.

56 X. Wang, E. Perzon, J. L. Delgado, P. de la Cruz, F. Zhang, F. Langa, M. Andersson, O. Inganäs, Appl. Phys. Lett. 85 (2004) 5081-5083.

57 X. Wang, E. Perzon, W. Mammo, F. Oswald, S. Admassie, N.-K. Persson, F. Langa, M. R. Andersson, O. Inganäs, Thin Solid Films 511-512 (2006) 576580 .

58 M. Al-Ibrahim, O. Ambacher, S. Sensfuss, G. Gobsch, Appl. Phys. Lett. 86 (2005) 201120 1-3.

59 Y Kim, S. A. Cholis, J. Nelson, D. D. C. Bradley, S. Cook, J. R. Durrant, Appl. Phys. Lett. 86 (2005) 063502 1-3.

60 F. Zhang, S. Lacic, M. Svensson, M. R. Andersson, O. Inganäs, Sol. Energy Mater. Sol. Cells 90 (2006) 1607-1614.

61 P. Schilinsky, U. Asawapirom, U. Scherf, M. Biele, C. J. Brabec, Chem. Mater. 17 (2005) 2175-2180.

62 A. J. Mozer, N. S. Sariciftci, A. Pivrikas, R. Österbacka, G. Juška, L. Brassat, H. Bässler, Phys. Rev. B 71 (2005) 035214 1-9.

63 M. Trznadel, A. Pron, M. Zagorska, R. Chrzaszcz, J. Pielichowski, Macromolecules 31 (1998) 5051-5058.

64 S. Guillerez, R. de Bettignies, European Conference on Hybrid and Organic Solar Cells, ECHOS'06, June 28-30, 2006, Paris, France, paper number 28O1-3.

65 S. Glenis, G. Horowitz, G. Tourillon, F. Garnier, Thin Solid Films 111 (1984) 93-103. 
66 Y. Kim, S. Cook, S. M. Tuladhar, S. A. Choulis, J. Nelson, J. R. Durrant, D. D. C. Bradley, M. Giles, I. McCulloch, C.-S. Ha, M. Ree, Nat. Mater. 5 (2006) 197-203.

67 D. W. Breiby, E. J. Samuelsen, J. Pol. Sci. B: Pol. Phys. 41 (2003) 2375-2393.

68 K. E. Aasmundtveit, E. J. Samuelsen, W. Mammo, M. Svensson, M. R. Andersson, L. A. A. Pettersson, O. Inganäs, Macromolecules 33 (2000) 54815489.

69 D. Fichou, J. Mater. Chem. 10 (2000) 571-588.

70 H. J. Fell, E. J. Samuelsen, M. R. Andersson, J. Als-Nielsen, G. Grübel, J. Mårdalen, Synth. Met. 73 (1995) 279-283.

71 J. Mårdalen, E. J. Samuelsen, Synth. Met. 48 (1992) 363-380.

72 T. J. Prosa, M. J. Winokur, J. Moulton, P. Smith, A. J. Heeger, Macromolecules 25 (1992) 4364-4372.

73 J. Alstrup, K. Norrman, M. Jørgensen, F. C. Krebs, Sol. Energy Mater. Sol. Cells 90 (2006) 2777-2792.

74 K. Norrman, J. Alstrup, M. Jørgensen, F. C. Krebs, Surf. Interface Anal. 38 (2006) 1302-1310.

75 K. Norrman, N. B. Larsen, F. C. Krebs, Sol. Energy Mater. Sol. Cells 90 (2006) 2793-2814.

76 K. Norrman, F. C. Krebs, Sol. Energy Mater. Sol. Cells 90 (2006) 213-227.

77 M. Lira-Cantu, F. C. Krebs, Sol. Energy Mater. Sol. Cells 90 (2006) 20762086.

78 M. Lira-Cantu, K. Norrman, J. W. Andreasen, F. C. Krebs, Chem. Mater. 18 (2006) 5684-5690.

79 F. C. Krebs, H. Spanggaard, Chem. Mater. 17 (2005) 5235-5237.

80 F. C. Krebs, K. Norrman, Prog. Photovol. (2007) submitted.

81 A. J. Breeze, Z. Schlesinger, S. A. Carter, P. J. Brock, Phys. Rev. B 64 (2000) $1252051-9$.

82 D. C. Olson, J. Piris, R. T. Collins, S. E. Shaheen, D. S. Ginley, Thin Solid Films 496 (2006) 26-29.

83 P. A. van Hal, M. M. Wienk, J. M. Kroon, W. J. H. Verhees, L. H. Sloof, W. J. H. van Gennip, P. Jonkheijm, R. A. J. Janssen, Adv. Mater. 15 (2003) 118121.

84 T. Shirakawa, T. Umeda, Y. Hashimoto, A. Fujii, K. Yoshino, J. Phys. D Appl. Phys. 37 (2004) 847-850.

85 W. J. E. Beek, M. M. Wienk, M. Kemerink, X. Yang, R. A. J. Janssen, J. Phys. Chem. B 109 (2005) 9505-9516.

86 W. J. E. Beek, M. M. Wienk, R. A. J. Janssen, Adv. Mater 16 (2004) 10091013.

87 W. J. E. Beek, M. M. Wienk, R. A. J. Janssen, J. Mater. Chem. 15 (2005) 2985-2988.

88 W. J. E. Beek, M. M. Wienk, R. A. J. Janssen, Adv. Funct. Mater 16 (2006) 1112-1116.

89 H. Miyaoka, G. Mizutani, H. Sano, M. Omote, K. Nakatsuji, F. Komori, Solid State Commun. 123 (2002) 399-404.

90 M. Ohyama, H. Kozuka, T. Yoko, Thin Solid Films 306 (1997) 78-85.

91 W. J. E. Beek, L. H. Sloof, M. M. Wienk, J. M. Kroon, R. A. J. Janssen, Adv. Funct. Mater. 15 (2005) 1703-1707. 


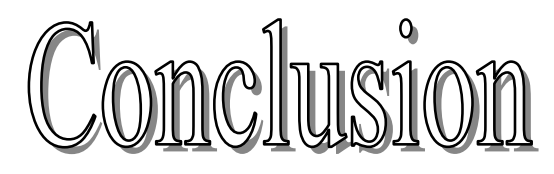

It has been shown that applying low band gap polymers will increase the maximum current of an OPV device, and hence the efficiency due to a better overlap with the solar spectrum.

The low band gap polymers described in the literature with band gaps between 2 and $1 \mathrm{eV}$ have been introduced. These low band gap polymers are based on fused ring systems often in a copolymer with a donor and acceptor moiety. In the design of polymers with a low band gap considerations such as intra-chain charge transfer and $\pi$-conjugation length should be taken into account. An example is the interactions between the donor and acceptor moieties in copolymers, which results in a charge separation in the polymer.

New low band gap polymers based on thiophene as the donor unit and benzothiadiazole or benzo-bis(thiadiazole) as the acceptor unit were designed with these considerations in mind.

The copolymers were synthesized by two strategies: one based on the oxidative ferric chloride polymerization and one based on the Stille cross coupling polymerization.

The two strategies resulted in the synthesis of 16 new copolymers with low band gaps of $2-1.65 \mathrm{eV}$ for copolymers of thiophene and benzothiadiazole and down to 0.65 $\mathrm{eV}$ for copolymers of thiophene and benzo-bis(thiadiazole).

The polymers were synthesized with different akyl side chains, i.e. hexyl, 2ethylhexyl, dodecyl and 3,7,11-trimethyldodecyl, to study the effect of the side chain on the film forming ability of the polymer. It was found that the 3,7,11trimethyldodecyl side chain gave the best film forming ability of the polymers.

The polymers where purified from transition metal particles before application in OPV devices.

UV-vis and UPS determined the band gap and the electronic structure of the polymers. It was found that the band gap of the copolymers based on thiophene and benzothiadiazole decreased with an increase in the number of thiophene $(n)$ in the repeating unit $(n=1-4)$. Further, results from UPS showed that the copolymers based on thiophene and benzo-bis(thiadiazole) may have been doped, however, chemical dedoping did not show any difference.

The polymers 1, 8 and 14 were applied in OPV devices. For polymer 1 and 14 it was shown that the head-to-head and head-to-tail coupling of the two polymers did not show any effect on the photovoltaic performances, which is in contrast to the results published for P3HT. Further, it was found that polymer 1 showed an improved efficiency upon annealing.

A detailed study of the effects the morphology has on the photovoltaic performance was carried out for devices based on polymer 8. It was found that the efficiency of the devices was greatly affected by the choice of solvent, concentration of the polymer, the ratio between the polymer and PCBM and the annealing temperature. The highest efficiency of $1 \%$ was obtained for a $0.1 \mathrm{~cm}^{2}$ device based on polymer 8 and PCBM in a 1:2 ratio, which was spin coated from 1,2-dichlorobenzene and annealed at $110{ }^{\circ} \mathrm{C}$. 


\section{Conclusion}

The future work of OPV devices should focus on low band gap polymer materials in large quantities with a high purity that are processable in large area devices and have a long lifetime. This would make the OPV a true competitor to the inorganic photovoltaics. 

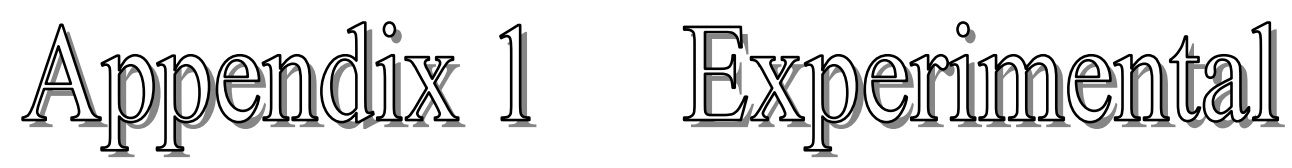

During my work at Risø National Laboratory I have spent many hours in the laboratory and I have in this time done more than 50 different types of syntheses and several of these have been carried out multiple times. Most of these syntheses have been published in papers (see Appendix A2.1 and A2.2). In this appendix the experimental details for the attempted syntheses of the compounds shown in Figure 3.18 are given followed by attempted syntheses of di-thiophene, attempted syntheses of di-stannyl derivatives of thiophene and di-thiophene and the synthesis of the $\mathrm{Pd}$ catalyst used through out this project.

\section{4,7-di-bromo-5,6-di-amino-benzo-2,1,3-thiadiazole}<smiles>O=[N+]([O-])c1c([N+](=O)[O-])c(Br)c2nsnc2c1Br</smiles><smiles>Nc1c(N)c(Br)c2nsnc2c1Br</smiles>

A mixture of 4,7-di-bromo-5,6-di-nitro-benzo-2,1,3-thiadiazole $(6.68 \mathrm{~g}, 17.40 \mathrm{mmol})$ and iron powder $(11.66 \mathrm{~g}, 208.77 \mathrm{mmol})$ in $\mathrm{AcOH}(340 \mathrm{~mL})$ was stirred at room temperature for 2 hours. After cooling the precipitate was filtered and dried (22.02 g). The powder was not attempted purified but was used directly in the next reaction.

\section{4,7-di-bromo-benzo-bis-(thiadiazole)}<smiles>Nc1c(Br)c(Br)c2nsnc2c1N</smiles><smiles>CC(C)(C)[Si](C)(C)Cl</smiles><smiles>Brc1c2c(c(Br)c3nsnc13)N=S=N2</smiles>

A mixture of 4,7-di-bromo-5,6-di-amino-benzo-2,1,3-thiadiazole (3.24 g, $10 \mathrm{mmol}$ ), $N$-thioaniline $(2.78 \mathrm{~g}, 20 \mathrm{mmol})$ and TMS-Cl $(1.95 \mathrm{~g}, 18 \mathrm{mmol})$ in pyridine $(50 \mathrm{~mL})$ was stirred at $80{ }^{\circ} \mathrm{C}$ over night. The solvent was distilled of at reduced pressure and MALDI-TOF and TLC of the green black residue showed no product and no starting material. 
<smiles>Nc1c(Br)c(Br)c2nsnc2c1N</smiles><smiles>Brc1c2c(c(Br)c3nsnc13)N=S=N2</smiles>

A mixture of 4,7-di-bromo-5,6-di-amino-benzo-2,1,3-thiadiazole (250 $\mathrm{mg}, 0.77$ mmol $)$ and $\mathrm{SOCl}_{2}(1 \mathrm{~mL}, 13.7 \mathrm{mmol})$ in toluene $(20 \mathrm{~mL})$ was refluxed for two days. MALDI-TOF of the reaction mixture showed no product and therefore it was discarded.

\section{Nitration of di-(3-hexylthiophen-yl)-benzo-2,1,3-thiadiazole}<smiles>[R]c1csc(-c2ccc(-c3cc([R])cs3)c3nsnc23)c1</smiles><smiles>[R]c1csc(-c2c([N+](=O)[O-])c([N+](=O)[O-])c(-c3cc([R])cs3)c3nsnc23)c1</smiles>

Di-(3-hexylthiophen-yl)-benzo-2,1,3-thiadiazole (100 mg, $0.2 \mathrm{mmol})$ in $\mathrm{CH}_{2} \mathrm{Cl}_{2}$ (10 $\mathrm{mL})$ and fumic nitric acid $(2 \mathrm{~mL})$ was stirred at room temperature for $30 \mathrm{~min}$. The mixture was washed with water, dried $\left(\mathrm{MgSO}_{4}\right)$, filtered and evaporated. ${ }^{1} \mathrm{H}-\mathrm{NMR}$ showed that the nitration happened at the thiophene group and not at the benzothiadiazole group, where it was attempted.

In the following syntheses 2-(tributylstannyl)-4-hexyl-thiophene is used, the synthesis of 2-(tributylstannyl)-4-hexyl-thiophene has been described in Appendix A2.1.

\section{4,7-Di-(3-hexyl-thiophene)-5,6-di-nitro-benzo-2,1,3-thiadiazole}

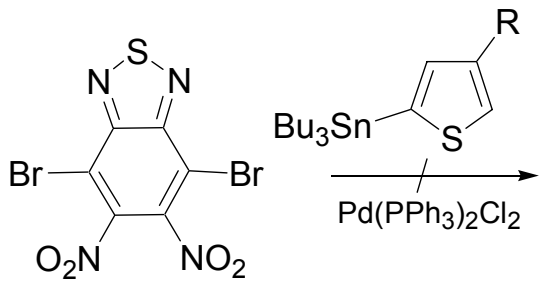<smiles>[R]c1csc(-c2c([N+](=O)[O-])c([N+](=O)[O-])c(-c3cc([R])cs3)c3nsnc23)c1</smiles>

1): 4,7-Di-bromo-5,6-di-nitro-benzo-2,1,3-thiadiazole $(3.80 \mathrm{~g}, 9.9 \mathrm{mmol}), \quad 2-$ (tributylstannyl)-4-hexyl-thiophene $(1.04 \mathrm{~g}, 22.8 \mathrm{mmol})$ and $\mathrm{Pd}\left(\mathrm{PPh}_{3}\right)_{2} \mathrm{Cl}_{2}(143 \mathrm{mg}$, $0.2 \mathrm{mmol})$ in THF $(30 \mathrm{~mL})$ was refluxed for 3 hours. TLC and MALDI-TOF showed no product, no starting material and no monosubstituted product and the dark reaction mixture was discarded.

2): 2-(tributylstannyl)-4-hexyl-thiophene $(2 \cdot 2.29 \mathrm{~g}, 10 \mathrm{mmol})$ and $\mathrm{Pd}\left(\mathrm{PPh}_{3}\right)_{2} \mathrm{Cl}_{2}(2 \cdot$ $72 \mathrm{~g}, 0.2 \mathrm{mmol}$ ) was added in two portions to a solution of 4,7-di-bromo-5,6-di-nitro- 
benzo-2,1,3-thiadiazole $(3.8 \mathrm{~g}, 9.9 \mathrm{mmol})$ in THF $(30 \mathrm{~mL})$ under reflux. After 19 hours TLC and MALDI-TOF showed no product, no starting material and no monosubstituted product. From ${ }^{1} \mathrm{H}-,{ }^{13} \mathrm{C}-\mathrm{NMR}$ and MALDI-TOF of a purified fraction it was determined that the two nitro groups fell of during the reaction.

For a faster reaction a trimethylstannyl derivate of the thiophene was used:

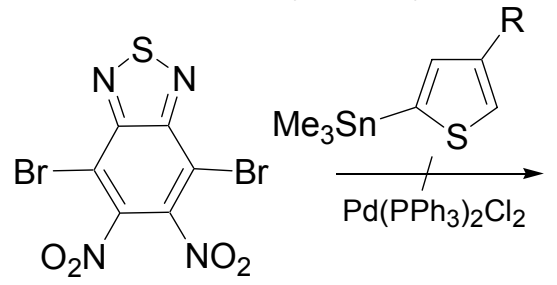<smiles>[R]c1csc(-c2c([N+](=O)[O-])c([N+](=O)[O-])c(-c3cc([R])cs3)c3nsnc23)c1</smiles>

2-(Trimethylstannyl)-4-hexyl-thiophene (16.6 mg, $50 \mathrm{mmol}), 4,7$-di-bromo-5,6-dinitro-benzo-2,1,3-thiadiazole (7.68 g, $20.0 \mathrm{mmol})$ and $\mathrm{Pd}\left(\mathrm{PPh}_{3}\right)_{2} \mathrm{Cl}_{2}(931.0 \mathrm{mg}, 1.3$ $\mathrm{mmol})$ in THF $(75 \mathrm{~mL})$ was refluxed. After 19 hours (12 hours at room temperature) the mixture was discarded since MALDI-TOF and ${ }^{1} \mathrm{H}-\mathrm{NMR}$ showed no product.

Comment: Since the reaction has previously been described with both tributylthiophene and with trimethylstannyl-3-hexyl-thiophene with and without nitrogroups, it was concluded that the nitro groups and the hexyl group of the two reagents cause the problems. This could be due to steric hindrance or a deactivation in the system with the hexyl and nitro groups and hence, a long reaction time is needed, which results in elimination of the nitro groups.

The Stille cross coupling was then attempted with the tributylstannyl-hexyl-thiophene and the amino derivate of the di-bromo-benzo-2,1,3-thiadiazole.

\section{4,7-Di-(3-hexyl-thiophene)-3,5-di-amino-benzo-2,1-3-thiadiazole}

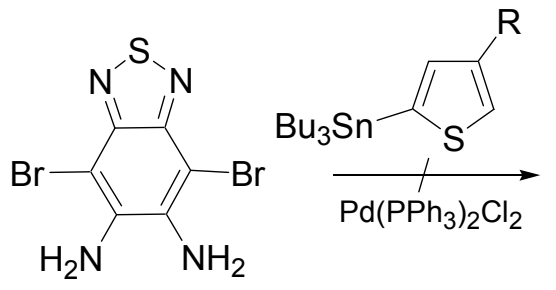<smiles>[R]c1csc(-c2c(N)c(N)c(-c3cc([R])cs3)c3nsnc23)c1</smiles>

Tributyltin-3-hexyl-thiophene (7.04 mg, $15.4 \mathrm{mmol})$, 4,7-di-bromo-5,6-di-amino2,1,3-benzothiadiazole $(2.0 \mathrm{~g}, 6.2 \mathrm{mmol})$ and $\mathrm{Pd}\left(\mathrm{PPh}_{3}\right)_{2} \mathrm{Cl}_{2}(262.5 \mathrm{mg}, 0.4 \mathrm{mmol})$ in THF $\left(22 \mathrm{~mL}\right.$ ) was refluxed for $19 \frac{1}{2}$ hours. MALDI-TOF and ${ }^{1} \mathrm{H}$ NMR showed no product or starting material. 


\section{4,7-Di-(4-(3-hexylthiophene)-thiophene)- benzo-bis(thiadiazole)}<smiles></smiles>

Tributyl-tin-3-hexyl-thiophene $(691 \mathrm{mg}, 1.51 \mathrm{mmol})$, 4,7-di-bromo-5,6-di-aminobenzo-bis(thiadiazole) (309.6 mg, $0.6 \mathrm{mmol})$ and $\mathrm{Pd}\left(\mathrm{PPh}_{3}\right)_{2} \mathrm{Cl}_{2}(262.2 \mathrm{mg}, 0.37 \mathrm{mmol})$ in THF $(20 \mathrm{~mL})$ was refluxed. TLC after 24 hours showed product and mono substituted compound. The reaction mixture was evaporated and the purification of the product was attempted by flash chromatography $\left(\mathrm{CHCl}_{3} /\right.$ cyclohexane $\left.1: 1\right)$, recrystalisation from $\mathrm{EtOH}$, heptane or chlorobenzene/ $\mathrm{MeOH}$ followed by washing with ether. ${ }^{1} \mathrm{H}-\mathrm{NMR}$ showed unclean product in $\sim 7 \%$ yield $(5.0 \mathrm{mg})$.

\section{Di-(tributylstannyl)-3-(2-ethylhexyl)-thiophene}

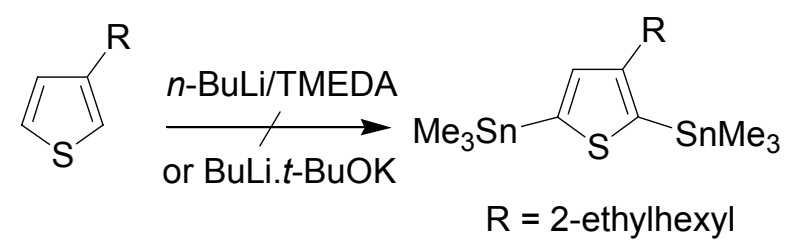

1): 3-(2-Ethylhexyl)-thiophene (5 g, $25.5 \mathrm{mmol})$ and TMEDA (11.97 $\mathrm{mL}, 88 \mathrm{mmol}, 3$ eq.) in hexane $(50 \mathrm{~mL})$ was cooled to $-78{ }^{\circ} \mathrm{C} . n$-BuLi $(50 \mathrm{~mL}, 77 \mathrm{mmol}, 3$ eq. $)$ was added drop wise over $30 \mathrm{~min}$. The cooling bath was removed and the mixture was refluxed for 1 hour. The mixture was cooled back down to $-78{ }^{\circ} \mathrm{C}$ and trimethylstannylchloride was added. After 2 days the mixture was washed with water, dried and evaporated. The yellow oil was purified by flash chromatography. ${ }^{1} \mathrm{H}$ NMR showed no product in any of the fractions.

2): $n$-BuLi (6.7 mL, $10.1 \mathrm{mmol}, 2.1$ eq.) was added to TMEDA (1.6 mL, $10.1 \mathrm{mmol}$, 2.1 eq. $)$ in hexane $(10 \mathrm{~mL})$ cooled to $-78{ }^{\circ} \mathrm{C}$. The cooling bath was removed and at room temperature 3-(2-ethylhexyl)-thiophene ( $1 \mathrm{~g}, 5.1 \mathrm{mmol})$ was added drop wise. The reaction was stirred at room temperature for 1 hour and refluxed for $30 \mathrm{~min}$. The reaction was cooled back down to $-78{ }^{\circ} \mathrm{C}$ and trimethylstannylchloride in hexane $(10.1 \mathrm{~mL}, 10.1 \mathrm{mmol}, 1 \mathrm{M})$ was added. The reaction was stirred for 1 hour at room temperature before washing with water, drying $\left(\mathrm{MgSO}_{4}\right)$ and evaporating. ${ }^{1} \mathrm{H} \mathrm{NMR}$ showed that the thiophene had only been mono substituted.

It was not clear weather the dilithitation took place and reaction with water had led to the mono-substituted product or if only one lithium was added. Therefore, it was decided to test the reaction mixture with deutrated methanol, however, ${ }^{1} \mathrm{H}-\mathrm{NMR}$ showed only mono lithation. It was concluded that the reaction conditions were not strong enough and thus, it was decided to do the reaction again with: a) longer reaction time and b) $t$-BuLi. 
a): For the longer reaction time, the same procedure was used (as described above) only changing the reaction time after addition of $n$-BuLi at $-78{ }^{\circ} \mathrm{C}$ to 2 days at room temperature. After addition of trimethylstannylchloride and work up ${ }^{1} \mathrm{H}-\mathrm{NMR}$ showed mono substituted product.

Comment: The di-stannyl product was attempted synthesized with TMEDA and $n$ BuLi with 2 different reactions times. These reactions resulted in mono-substituted product. The product was achieved by reaction with $t$-BuLi and TMEDA and this procedure is described in Appendix A2.2.

\section{Bis-trimethyldodecyl-thiophene}

Purification of di-thiophenes has been shown to be complicated ${ }^{1}$ and hence, the synthesis of a di-thiophene should result in only one of the possible three isomers and no starting material should be left in the reaction mixture. The attempts were Ullmann, ${ }^{2,3} \mathrm{Kumada}^{4}$ and Stille cross coupling ${ }^{5}$ in 4 different ways.

\section{Ullmann:}

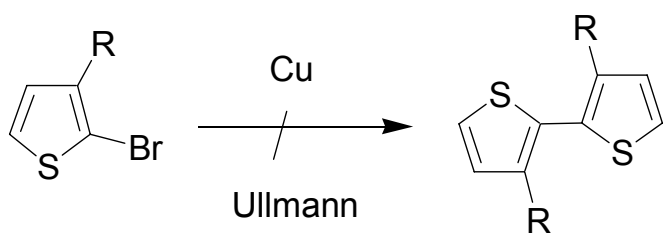

2-bromo-3-(3,7,11-trimethyldodecyl)-thiophene (11.77 g, $31.55 \mathrm{mmol})$ and $\mathrm{Cu}$ powder $(9.75 \mathrm{~g}, 0.15 \mathrm{~mol})$ in DMF $(250 \mathrm{~mL})$ was stirred under reflux over night. After 17 hours ${ }^{1} \mathrm{H}-\mathrm{NMR}$ and MALDI-TOF showed no starting material or product. The reaction mixture was evaporated, dissolved in hexane, filtered through celite, evaporated and the black oil was distilled on Kugelrohr. MALDI-TOF and ${ }^{1} \mathrm{H}-\mathrm{NMR}$ showed no product in the fractions or the residue.

\section{Kumada:}

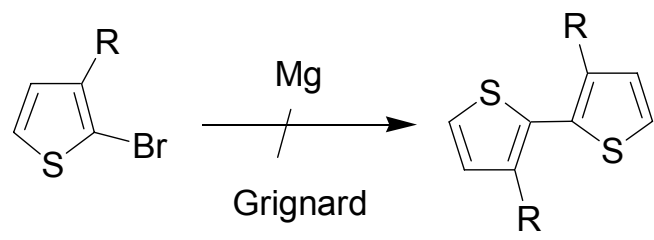

Magnesium turnings $(21.33 \mathrm{mg}, 0.88 \mathrm{mmol})$ were quenched by stirring under argon. Ether $(2 \mathrm{ml})$ and iodine was added (and a few drops of dibromoethane to start reaction). 2-Bromo-3-(3,7,11-trimethyldodecyl)-thiophene (300 $\mathrm{mg}, 1.03 \mathrm{mmol}$ ) was added drop wise keeping the reaction at gentle reflux. At the end of the addition the catalyst $\mathrm{Ni}(\mathrm{dppp}) \mathrm{Cl}_{2}(2.23 \mathrm{mg})$ was added in four portions together with 2-bromo-3(3,7,11-trimethyldodecyl)-thiophene (330 $\mathrm{mg}, 1.12 \mathrm{mmol}$ ), which was added drop wise. After 1 hour the mixture was hydrolyzed by water $(0.33 \mathrm{~mL})$ followed by $37 \%$ aq. $\mathrm{HCl}(0.13 \mathrm{~mL})$. The organic phase was separated, dried $\left(\mathrm{MgSO}_{4}\right)$, evaporated and distilled by Kugelrohr distillation $\left(200{ }^{\circ} \mathrm{C}\right.$ at $3 \cdot 10^{-3}$ mbar $)$, which resulted in 2 fractions; one containing impure starting material and one containing a mixture of product and 3-(3,7,11-trimethyldodecyl)-thiophene. 
Stille cross coupling 1:<smiles>[R]c1ccsc1Br</smiles>

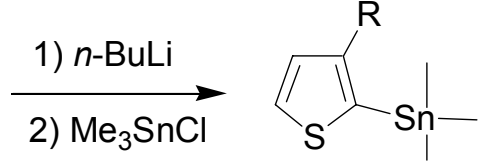<smiles>[R]c1cc[R](C)c(Br)c1Br</smiles><smiles>[R]c1ccsc1-c1sccc1[R]</smiles>

Stille

$n$-BuLi (3.35 mL, $5.4 \mathrm{mmol}, 1.6 \mathrm{M})$ in THF $(50 \mathrm{~mL})$ was cooled to $-78{ }^{\circ} \mathrm{C}$. 2-Bromo3-(3,7,11-trimethyldodecyl)-thiophene $(2.0 \mathrm{~g}, 5.4 \mathrm{mmol})$ was added. Trimethylstannylchloride $(5.36 \mathrm{~mL}, 5.4 \mathrm{mmol}, 1 \mathrm{M})$ was added after $5 \mathrm{~min}$., and the reaction mixture was allowed to reach room temperature. 2-Bromo-3-(3,7,11trimethyldodecyl)-thiophene $(2.0 \mathrm{~g}, 5.4 \mathrm{mmol})$ and $\mathrm{Pd}\left(\mathrm{PPh}_{3}\right)_{2} \mathrm{Cl}_{2}(250 \mathrm{mg}, 0.36$ mmol) was added and the reaction was refluxed over night. After 18 hours the reaction was cooled, evaporated, dissolved in $\mathrm{CHCl}_{3}$, washed with water, dried $\left(\mathrm{MgSO}_{4}\right)$, evaporated and purified by kuglerohr to give a mixture of product and 3(3,7,11-trimethyldodecyl)-thiophene.

Stille cross coupling 2:<smiles>[R]c1csc([Sn](C)(C)C)c1</smiles><smiles></smiles>

2-Trimethylstannyl-4-(3,7,11-trimethyldodecyl)-thiophene (1 g, $2.19 \mathrm{mmol})$ was added drop wise to a mixture of 2-bromo-3-(3,7,11-trimethyldodecyl)-thiophene $(899.78 \mathrm{mg}, 2.41 \mathrm{mmol})$ and $\mathrm{Pd}\left(\mathrm{PPh}_{3}\right)_{2} \mathrm{Cl}_{2}(2 \cdot 117.3 \mathrm{mg}, 0.33 \mathrm{mmol})$ in THF $(25 \mathrm{~mL})$ under reflux. After the addition, the reaction was left stirring over night at room temperature. The reaction mixture was evaporated and the residue was dissolved in hexane, washed with water, dried, evaporated and distilled on Kugelrohr to give a mixture of product, 3-(3,7,11-trimethyldodecyl)-thiophene and homo-coupled product (from 2-trimethylstannyl-4-(3,7,11-trimethyldodecyl)-thiophene).

Stille cross coupling 3 :<smiles>[R]c1csc(-c2cc([R])cs2)c1</smiles>

2-Trimethylstannyl-4-(3,7,11-trimethyldodecyl)-thiophene (1 g, $2.19 \mathrm{mmol})$ and $\mathrm{Pd}\left(\mathrm{PPh}_{3}\right)_{2} \mathrm{Cl}_{2}(96 \mathrm{mg}, 0.14 \mathrm{mmol})$ in THF $(20 \mathrm{~mL})$ was refluxed. ${ }^{1} \mathrm{H}-\mathrm{NMR}$ of the mixture showed that the stannyl groups were eliminated after 1 hour.

Comment: The 5 attempted syntheses resulted in mixture of product and 3-(3,7,11trimethyldodecyl)-thiophene or no reaction (Ullmann and Stille cross coupling 3 ). The 
product was finally achieved by reaction between iodo-thiophene and stannylthiophene, where the stannyl-thiophene was added drop wise, and since the iodoreactant reacts faster than the bromo-reactant, homo-coupling of stannyl starting materials and elimination of stannyl-groups is avoided.

\section{Dilithiation of trimethyldodecyl-thiophene}

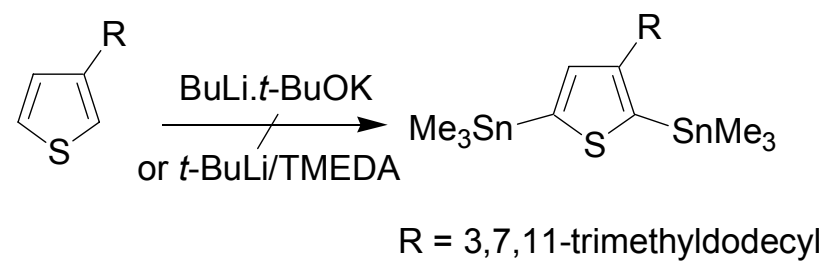

1): 3-(3,7,11-Trimethyldodecyl)-thiophene (5 g, $17 \mathrm{mmol})$ and TMEDA (6.36 mL, $42.5 \mathrm{mmol}, 2.5$ eq.) in hexane $(150 \mathrm{~mL})$ was cooled to $-78{ }^{\circ} \mathrm{C} . t$-BuLi $(25 \mathrm{~mL}, 42.5$ mmol, 2.5 eq.) was added drop wise over $30 \mathrm{~min}$. The reaction was stirred $1 / 2$ hour at $78{ }^{\circ} \mathrm{C}$ before the reaction was allowed to reach $0{ }^{\circ} \mathrm{C}$. The mixture was cooled to -78 ${ }^{\circ} \mathrm{C}$ and trimethylstannylchloride $(42.5 \mathrm{~mL}, 42.5 \mathrm{mmol})$ was added. After 2 hours at room temperature the mixture was washed with water, dried, evaporated and destilled on Kugelrohr $\left(200^{\circ} \mathrm{C}\right.$ at $4 \cdot 10^{-3}$ mbar $)$, which resulted in 2 impure fractions of product and mono-substituted compound.

2): $t$-BuOK $(1.37,12.24 \mathrm{mmol})$ in hexane $(4 \mathrm{~mL})$ was cooled to $-60{ }^{\circ} \mathrm{C} . n$-BuLi $(7.65$ $\mathrm{mL}, 12.24 \mathrm{mmol})$ in hexane $(9 \mathrm{~mL})$ was added and the reaction was stirred $10 \mathrm{~min}$. at $-40^{\circ} \mathrm{C}$. TMEDA (2.14 mL, $\left.14.28 \mathrm{mmol}\right)$ and 3-(3,7,11-trimethyldodecyl)-thiophene $(1.0 \mathrm{~g}, 5.1 \mathrm{mmol})$ was added and the reaction was stirred at $-20^{\circ} \mathrm{C}$ for 1 hour before the temperature was allowed to rise to $10^{\circ} \mathrm{C}$. The reaction was cooled to $-78{ }^{\circ} \mathrm{C}$ and trimethylstannylchloride in hexane $(10.1 \mathrm{~mL}, 10.1 \mathrm{mmol}, 1 \mathrm{M})$ was added. After 5 min. at room temperature the reaction mixture was washed with water, dried, evaporated and distilled on Kugelrohr $\left(50-100{ }^{\circ} \mathrm{C}\right.$ at $\left.8 \cdot 10^{-2} \mathrm{mbar}\right)$, which gave a mixture of product and mono-substituted product.

The reaction procedure was applied with the following conditions in attempt to prepare the di-stannyl-thiophene:

\begin{tabular}{lccc}
\hline Reaction nr. & $\mathbf{3}$ & $\mathbf{4}$ & $\mathbf{5}$ \\
\hline Eq. $t$-BuOK. $n$-BuLi & 2.5 & 4 & 5 \\
Reaction time before addition of $\mathrm{Me}_{3} \mathrm{SnCl}(\mathrm{h})$ & 1 & 2.5 & 1 \\
Temperature $\left({ }^{\circ} \mathrm{C}\right)$ & $\mathrm{rt}$ & -60 & $\mathrm{rt}$ \\
Result (product/starting material) & $2: 1$ & $3: 1$ & $-{ }^{\mathrm{a}}$ \\
\hline
\end{tabular}

${ }^{\text {a }}$ Stannyl groups was eliminated during reaction.

Finally, the product was synthesized by reaction with $t$-BuLi for 3 days, the procedure is described in Appendix A2.2. 


\section{Dilithiation of Bis-(trimethyldodecyl)-thiophene}

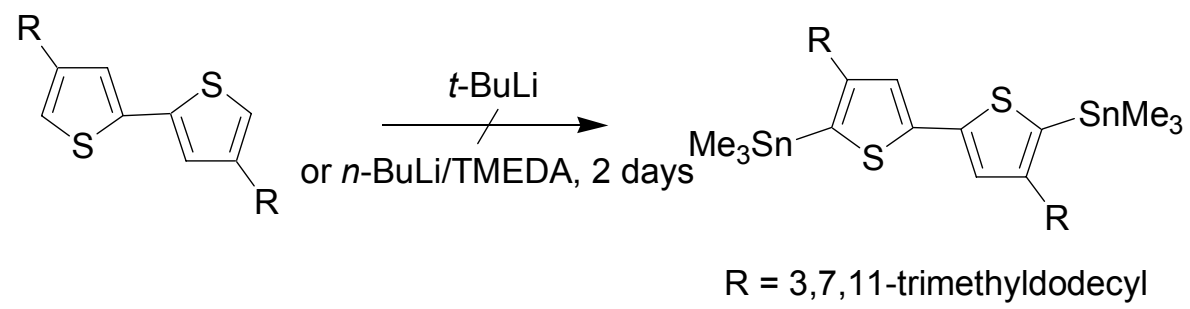

1): 4,4-Di-(3,7,11-trimethyldodecyl)-[2,2']di-thiophene (200 $\mathrm{mg}, 0.34 \mathrm{mmol})$ in hexane $(10 \mathrm{~mL})$ was cooled to $-78{ }^{\circ} \mathrm{C}$. $t$-BuLi $(0.7 \mathrm{~mL}, 1.02 \mathrm{mmol}, 3$ eq. $)$ was added drop wise over $30 \mathrm{~min}$. The reaction was stirred $1 / 2$ hour at $-78{ }^{\circ} \mathrm{C}$ before the reaction was stirred at room temperature for 2 days. ${ }^{1} \mathrm{H}-\mathrm{NMR}$ of the reaction mixture showed no reaction.

2): 4,4-Di-(3,7,11-trimethyldodecyl)-[2,2']di-thiophene $(1.0 \mathrm{~g}, 1.7 \mathrm{mmol})$ and TMEDA $(0.77 \mathrm{~mL}, 5.1 \mathrm{mmol}, 3$ eq. $)$ in hexane $(50 \mathrm{~mL})$ was cooled to $-78{ }^{\circ} \mathrm{C} . n$-BuLi ( $3.41 \mathrm{~mL}, 0.005 \mathrm{~mol}, 3$ eq.) was added drop wise over $30 \mathrm{~min}$. The cooling bath was removed, and the reaction was stirred for 2 days at $\mathrm{rt}$. The mixture was then cooled to $-78{ }^{\circ} \mathrm{C}$ and trimethylstannylchloride $(8.52 \mathrm{~mL}, 42.5 \mathrm{mmol}$, 5eq) was added. After 2 hours at room temperature the reaction mixture was washed with water, dried and evaporated. ${ }^{1} \mathrm{H}-\mathrm{NMR}$ showed unclean product.

Comment: The product was obtained by reaction with $n$-BuLi and TMEDA (3eq) for 1h, this procedure is described in Appendix A2.2.

\section{Synthesis of $\mathrm{Pd}$ catalyst, $\mathrm{Pd}\left(\mathrm{PPh}_{3}\right)_{2} \mathrm{Cl}_{2}{ }^{6}$}

Triphenylphosphine $(27.79 \mathrm{~g}, 105.9 \mathrm{mmol})$ and palladium(II)chloride (7.5 g, 24 $\mathrm{mmol})$ in DMSO $(700 \mathrm{~mL})$ was heated under stirring and argon until both compounds were dissolved. The heat and stirring was stopped and the reaction was left to reach room temperature. The orange suspension was filtered and washed with $\mathrm{Et}_{2} \mathrm{O}$ to give yellow crystals of the product in $96 \%$ yield $(28.47 \mathrm{~g})$.

\section{References}

1 F. C. Krebs, H. Spanggaard, Sol. Energy Mater. Sol. Cells 88 (2005) 363-375.

2 M. Goshaev, O. S. Otroshchenko, A. S. Sadykov, Russ. Chem. Rev. 41 (1972) 1046-1059.

3 P. E. Fanta, Synthesis 1 (1974) 9-21.

4 C. van Pharm, Synth. Commun. 16 (1986) 689-695.

5 J. K. Stille, Pure \& Appl. Chem. 57 (1985) 1771-1780.

6 R. J. Angelici, Reagents for transition metal complex and organo-metallic syntheses, Wiley Interscience, 1990, ISBN: 0-471-52619-3. 


\section{Appendine 2 Paipers, proceedings and posters}

A2.1 E. Bundgaard, F. C. Krebs, A comparison of the photovoltaic response of regioregular and regiorandom poly\{(benzo-2,1,3-thiadiazol-4,7-diyl)(dihexyl[2,2']dithiophene-5,5'-diyl', Pol. Bull. 55 (2005) 157-164.

A2.2 E. Bundgaard, F. C. Krebs, Low-band-gap conjugated polymers based on thiophene, benzothiadiazole and benzo-bis(thiadiazole), Macromolecules 39 (2006) 2823-2831.

A2.3 E. Bundgaard, F. C. Krebs, Low band gap polymers for organic photovoltaics, Sol. Energy Mater. Sol. Cells 91 (2007) 954-985.

A2.4 E. Bundgaard, F. C. Krebs, Large area photovoltaics based on low band gap copolymers of thiophene and benzothiadiazole or benzo-bis(thiadiazole), Sol. Energy Mater. Sol. Cells 91 (2007) 1019-1025.

A2.5 E. Bundgaard, S. E. Shaheen, D. Ginley, F. C. Krebs, Bulk heterojunctions based on a low band gap copolymer of thiophene and benzothiadiazole, Sol. Energy Mater. Sol. Cells (2007) accepted.

A2.6 E. Bundgaard, F. C. Krebs, Solar Cells based on copolymers of benzothiadiazole and thiophene, SPIE, San Diego, USA, $31^{\text {st }} \mathrm{July}-4^{\text {th }}$ August 2005, 5938-26 (proceeding and poster).

A2.7 E. Bundgaard, F. C. Krebs, Low band gap polymers for photovoltaic devices, SVC, Washington DC, USA, $22^{\text {nd }}-27^{\text {th }}$ April 2006 (proceeding).

A2.8 E. Bundgaard, F. C. Krebs, Low band gap polymers for organic solar cells, SPIE, San Diego, USA, $13^{\text {th }}-17^{\text {th }}$ August 2006, 6334-29 (proceeding and poster).

A2.9 E. Bundgaard, S. E. Shaheen, D. Ginley, F. C. Krebs, Photovoltaic devices with low band gap polymers, Plastic Electronics, Frankfurt, Germany, October $24^{\text {th }}-25^{\text {th }} 2006$ (poster). 


\title{
A comparison of the photovoltaic response of head-to- head and head-to-tail coupled poly\{(benzo-2,1,3- thiadiazol-4,7-diyl)-(dihexyl[2,2']dithiophene-5,5'-diyl\}
}

\author{
Eva Bundgaard and Frederik C. Krebs( $(\varangle)$
}

The Danish Polymer Center, RIS $\emptyset$ National Laboratory, P.O. Box 49, DK-4000 Roskilde, Denmark

Received: 8 November 2004 / Revised version: 13 February 2005/ Accepted: 16 February 2005 Published online: 22 July 2005 - $@$ Springer-Verlag 2005

\section{Summary}

The synthesis of two copolymers of benzothiadiazole and dihexyldithiophene were obtained by employing oxidative ferric chloride polymerisation and Stille cross coupling polymerisation. Weight average molecular weights of respectively $15200 \mathrm{~g}$ $\mathrm{mol}^{-1}$ and $3200 \mathrm{~g} \mathrm{~mol}^{-1}$ were obtained. The polymers have an optical band gap of $\sim 2 \mathrm{eV}$. Photovoltaic devices were prepared using the pure polymer materials and mixtures of the polymers and a soluble fullerene derivative. Efficiencies of $0.024 \%$ were obtained. Head-to-head and head-to-tail coupling was not found to influence the maximum photovoltaic performance that could be obtained.

\section{Introduction}

Recent developments within the field of polymer photovoltaics [1-3] have demonstrated photovoltaic conversion efficiencies of $3.8 \%$ [4] and shown the possibility of reaching the benchmark of $5 \%$ efficiency. [5] Common to most conjugated polymer systems employed for polymer photovoltaics is a poor match of the absorption spectrum of the material to the solar spectrum. A lowering of the bandgap to values found for inorganic semiconductors like silicon is of interest and is expected to open for the possibility for an increase in efficiency. [6,7]

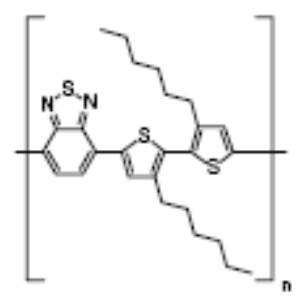

1

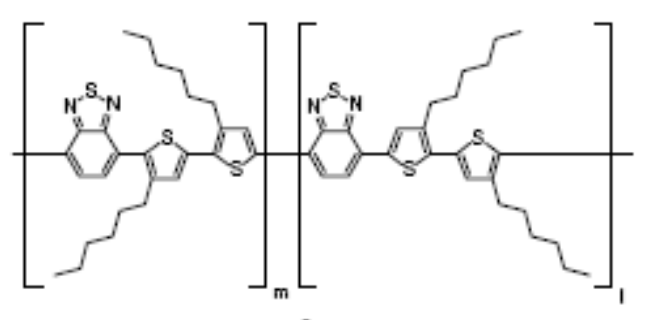

2

Scheme 1. Copolymers of benzothiadiazole and head-to-head coupled dihexyldithiophene (1) and head-to-tail coupled dihexyldithiophene (2).

In this paper we present the simple synthesis of a copolymer of benzothiadiazole and dihexyldithiophene by two different polymerisation mechanisms and demonstrate a band gap of $\sim 2 \mathrm{eV}$ for both methods of preparation. 


\section{Experimental}

Methods. Commercially available compounds were purchased from Aldrich. 3,4'Dihexyl[2,2']dithiophene was obtained as described in ref. [8], 4,7-dibromo-benzo2,1,3-thiadiazole was prepared as described in ref. [9] Two alkyl group signals are missing in the ${ }^{13} \mathrm{C}$ NMR for compound $\mathbf{5}$. This is ascribed to accidental isochrony.

Poly\{(benzo-2,1,3-thiadiazol-4,7-diyl)-(3,3'-dihexyl[2,2'] dithiophene-5,5'-diyl $\}$ (1). To a mixture of $\mathrm{FeCl}_{3}(801.2 \mathrm{mg}, 1.13 \mathrm{mmol})$ in $\mathrm{CHCl}_{3}(120 \mathrm{~mL})$ di-(3-hexylthiophene)-benzothiadiazole $\left(1.01 \mathrm{~g}, 2.15 \mathrm{mmol}\right.$ ) in $\mathrm{CHCl}_{3}$ was added drop wise. The reaction was left stirring for 25 hours. After 25 hours of reflux the reaction was cooled, washed with aq. $\mathrm{H}_{2} \mathrm{SO}_{4}$, aq. $\mathrm{Na}_{2} \mathrm{SO}_{3}$, separated, dried $\left(\mathrm{MgSO}_{4}\right)$, filtered and evaporated to a smaller fraction, which was poured into $\mathrm{MeOH}$. The suspension was filtered to give poly-(di-(3-hexyl-thiophene)-benzothiadiazole) as a red solid. Yield: $150 \mathrm{mg}(15 \%)$. ${ }^{1} \mathrm{H}$ NMR $\left(250 \mathrm{MHz}, \mathrm{CDCl}_{3}, 300 \mathrm{~K}\right.$, TMS $): \delta=0.91-0.84(\mathrm{~m}, 6 \mathrm{H}), 1.49-1.26(\mathrm{~m}, 12 \mathrm{H})$, $1.72-1.66(\mathrm{~m}, 4 \mathrm{H}), 2.74-2.68(\mathrm{~m}, 4 \mathrm{H}), 7.89(\mathrm{~s}, 2 \mathrm{H}), 8.11(\mathrm{~s}, 2 \mathrm{H}) . \mathrm{SEC}(500 \AA+10000 \AA$ $+1000000 \AA) M_{w}=15244 ; M_{p}=13605 ; M_{w} / M_{n}=2.87 ; \mathrm{DP}=11$.

Poly\{(benzo-2,1,3-thiadiazol-4,7-diyl)-(3,4'-dihexyl[2,2']dithiophene-5,5'-diyl $\}$ (2). Compound $4(4.005 \mathrm{~g}, 6.066 \mathrm{mmol})$ and 4,7-dibromo-benzo-2,1,3-thiadiazole $(1.783 \mathrm{~g}$, $6.066 \mathrm{mmol})$ were mixed in DMF $(75 \mathrm{~mL})$ and degassed with argon. $\mathrm{Pd}\left(\mathrm{PPh}_{3}\right)_{2} \mathrm{Cl}_{2}$ $\left(80.0 \mathrm{mg}, 0.11 \mathrm{mmol}\right.$ ) was added and the reaction was heated to $150^{\circ} \mathrm{C}$. After 2 hours a dark tarry mass separated (prepolymer, SEC: $M_{w}=1824 ; M_{p}=1564 ; M_{w} / M_{n}=1.19$ ). The mixture was cooled and THF $(150 \mathrm{~mL})$ was added followed by reflux overnight. The mixture was cooled and the THF evaporated. $\mathrm{MeOH}(400 \mathrm{~mL})$ was added. The mixture was filtered and the solid washed with $\mathrm{MeOH}(3 \times 100 \mathrm{~mL})$ and dried. Yield: $2.6 \mathrm{~g}(92 \%)$. The product was found to contain $583 \mathrm{ppm}$ palladium nanoparticles that were removed. ${ }^{1} \mathrm{H}$ NMR $\left(250 \mathrm{MHz}, \mathrm{CDCl}_{3}, 300 \mathrm{~K}\right.$, TMS $): \delta=0.91-0.79(\mathrm{~m}, 6 \mathrm{H}), 1.78$ $1.22(\mathrm{~m}, 16 \mathrm{H}), 2.73-2.61(\mathrm{~m}, 2 \mathrm{H}), 2.96-2.80(\mathrm{~m}, 2 \mathrm{H}), 7.17-6.94(\mathrm{~m}, 0.5 \mathrm{H}), 7.52-7.46$ $(\mathrm{m}, 0.5 \mathrm{H}), 7.74-7.67(\mathrm{~m}, 1 \mathrm{H}), 7.94-7.84(\mathrm{~m}, 1 \mathrm{H}), 8.07-7.97(\mathrm{~m}, 1 \mathrm{H}) . \mathrm{SEC}(100 \AA$ $+1000 \AA) M_{w}=3205 ; M_{p}=1971 ; M_{w} / M_{n}=1.43 ; \mathrm{DP}=5$.

5-Tributylstannyl-3-hexylthiophene (3). To a solution of 3-hexylthiophene (33.6g, $0.2 \mathrm{~mol})$ in dry THF $(300 \mathrm{~mL})$ cooled to $-78^{\circ} \mathrm{C}$ under argon, LDA in THF/ ethylbenzene/heptane $(2 \mathrm{M}, 100 \mathrm{~mL}, 0.2 \mathrm{~mol})$ was added drop wise. At the end of the addition the mixture was allowed to reach $0^{\circ} \mathrm{C}$ in $3 \mathrm{~h}$. The mixture was then cooled back down to $-78^{\circ} \mathrm{C}$ and tributylstannylchloride $(63.6 \mathrm{~g}, 0.2 \mathrm{~mol})$ was added in one portion. The mixture was then allowed to reach room temperature. Hexane $(300 \mathrm{~mL})$ was added to the reaction mixture was washed with water, dried $\left(\mathrm{MgSO}_{4}\right)$, filtered, evaporated and destilled to give 3-hexyl-5-tributylstannylthiophene. Yield: $95.36 \mathrm{~g}(52 \%)$, bp $=136$ $138^{\circ} \mathrm{C} / 5 \mathrm{mBar}$. ${ }^{1} \mathrm{H}$ NMR $\left(250 \mathrm{MHz}, \mathrm{CDCl}_{3}, 300 \mathrm{~K}\right.$, TMS $): \delta=0.94-0.89(\mathrm{~m}, 12 \mathrm{H}), 1.16-$ $1.03(\mathrm{~m}, 6 \mathrm{H}), 1.43-1.29(\mathrm{~m}, 12 \mathrm{H}), 1.68-1.53(\mathrm{~m}, 8 \mathrm{H}), 2.97(\mathrm{t}, 2 \mathrm{H}, J=7.75 \mathrm{~Hz})$, $6.98(\mathrm{~s}, 1 \mathrm{H}), 7.20(\mathrm{~s}, 1 \mathrm{H}) ;{ }^{13} \mathrm{C}$ NMR $\left(63 \mathrm{MHz}, \mathrm{CDCl}_{3}, 300 \mathrm{~K}, \mathrm{TMS}\right): \delta=11.28,14.19$, $14.60,23.25,27.83,29.69,29.75,30.58,31.35,32.37,126.12,136.25,137.18,144.59$; Anal. Calcd for $\mathrm{C}_{22} \mathrm{H}_{42} \mathrm{SSn}$ : C, 57.78; H, 9.26. Found: C, 55.70; H, 9.28.

4,7-Bis(3-hexylthiophene-5-yl)benzo-2,1,3-thiadiazole (4). To a solution of 4,7-dibromo-2,1,3-benzothiadiazole $(23.36 \mathrm{~g}, \quad 0.08 \mathrm{~mol})$ and 5-tributylstannyl-3hexylthiophene (3) $(91.45 \mathrm{~g}, 0.20 \mathrm{~mol})$ in THF $(300 \mathrm{~mL}), \mathrm{Pd}\left(\mathrm{PPh}_{3}\right)_{2} \mathrm{Cl}_{2}(3.14 \mathrm{~g}$, $4.49 \mathrm{mmol}$ ) was added. The reaction was refluxed. After 2 hours futher 5-tributylstannyl-3-hexylthiophene (3) $(91.45 \mathrm{~g}, 0.20 \mathrm{~mol})$ and $\mathrm{Pd}\left(\mathrm{PPh}_{3}\right)_{2} \mathrm{Cl}_{2}(3.14 \mathrm{~g}, 4.49 \mathrm{mmol})$ 
were added. Further $\mathrm{Pd}\left(\mathrm{PPh}_{3}\right)_{2} \mathrm{Cl}_{2}(0.5 \mathrm{~g}, 0.7 \mathrm{mmol})$ was added after 3 and 24 hours. After 2 days the reaction was cooled, evaporated and purified by flash chromatography $\left(\mathrm{CHCl}_{3}\right)$. Recrystalisation from EtOH gave the product as orange crystals. Yield: $8.2 \mathrm{~g}(22 \%), \mathrm{mp}=60.6-61.6^{\circ} \mathrm{C} .{ }^{1} \mathrm{H}$ NMR $\left(250 \mathrm{MHz}, \mathrm{CDCl}_{3}, 300 \mathrm{~K}\right.$, TMS $): \delta=0.90(6 \mathrm{H}, \mathrm{t}, J=6.75 \mathrm{~Hz}), 1.45-1.26(12 \mathrm{H}, \mathrm{m}), 1.74-1.65(4 \mathrm{H}, \mathrm{m}), 2.70(4 \mathrm{H}$, $\mathrm{t}, J=7.5 \mathrm{~Hz}), 7.04(2 \mathrm{H}, \mathrm{d}, J=0.75 \mathrm{~Hz}), 7.83(2 \mathrm{H}, \mathrm{s}), 7.98(2 \mathrm{H}, \mathrm{d}, J=1.25 \mathrm{~Hz}) ;{ }^{13} \mathrm{C} \mathrm{NMR}$ $\left(63 \mathrm{MHz}, \mathrm{CDCl}_{3}, 293 \mathrm{~K}\right.$, TMS $): \delta=14.79,23.33,29.75,31.18,31.36,32.41,122.22$, $126.23,126.75,129.71,139.72,145.07,153.36$. Anal. Calcd. for $\mathrm{C}_{26} \mathrm{H}_{32} \mathrm{~N}_{2} \mathrm{~S}_{3}: \mathrm{C}$, $66.62 ; \mathrm{H}, 6.88 ; \mathrm{N}, 5.98$. Found: C, 66.70; H, 6.70; N, 5.89.

5,5'-Bis(trimethylstannyl)-3,4'-dihexyl[2,2']dithiophene (5). Dihexylbithiophene $(3.34 \mathrm{~g}, 10 \mathrm{mmol})$ was mixed with hexane $(30 \mathrm{~mL})$ and TMEDA $(3 \mathrm{~g}, 25 \mathrm{mmol})$ and cooled to $-78^{\circ} \mathrm{C}$. $\mathrm{nBuLi}(16 \mathrm{~mL}, 1.6 \mathrm{M}, 25 \mathrm{mmol})$ was added and the cooling bath was removed and the mixture was left overnight at RT. The following day a thick paste had formed. The mixture was cooled to $-78^{\circ} \mathrm{C}$ and $\mathrm{Me}_{3} \mathrm{SnCl}(25 \mathrm{~mL}, 1 \mathrm{M}, 25 \mathrm{mmol})$ was added and the mixture was allowed to reach RT. After stirring at RT for $1 \mathrm{~h}$ hexane $(500 \mathrm{~mL})$ was added and the mixture was washed thoroughly with water and brine. Drying and evaporation gave the pure product. Yield: $6.3 \mathrm{~g}(95 \%){ }^{1} \mathrm{H}$ NMR $\left(250 \mathrm{MHz}, \mathrm{CDCl}_{3}, 300 \mathrm{~K}, \mathrm{TMS}\right): \delta=0.42(\mathrm{~m}, 9 \mathrm{H}), 0.45(\mathrm{~m}, 9 \mathrm{H}), 0.95(\mathrm{~m}, 6 \mathrm{H}), 1.34$ $(\mathrm{m}, 12 \mathrm{H}), 1.68(\mathrm{~m}, 4 \mathrm{H}), 2.65(\mathrm{t}, 2 \mathrm{H}, \mathrm{J}=7 \mathrm{~Hz}), 2.83(\mathrm{t}, 2 \mathrm{H}, \mathrm{J}=7 \mathrm{~Hz}), 7.04(\mathrm{~s}, 1 \mathrm{H}), 7.14(\mathrm{~s}$, $1 \mathrm{H}) ;{ }^{13} \mathrm{C}$ NMR $\left(63 \mathrm{MHz}, \mathrm{CDCl}_{3}, 300 \mathrm{~K}\right.$, TMS $): \delta=-8.25,-7.84,14.12,22.65,29.16$, $29.31,29.38,30.82,31.68,31.82,32.04,32.88,127.90,131.72,135.63,137.01$, 138.26, 140.14, 141.74, 151.11; Anal. Calcd for $\mathrm{C}_{26} \mathrm{H}_{46} \mathrm{~S}_{2} \mathrm{Sn}_{2}: \mathrm{C}, 47.30 ; \mathrm{H}, 7.02$. Found: C, $47.29 ; \mathrm{H}, 6.89$.

Size exclusion chromatography (SEC). SEC was performed in chloroform using either of two preparative Knauer systems employing a pre-column and two gel columns in succession with respectively pore diameters of $100 \AA$ and $1000 \AA$ or $500 \AA$, $10000 \AA$ and $1000000 \AA$. All gel columns had dimensions of $25 \mathrm{~mm} \varnothing \times 600 \mathrm{~mm}$. Polystyrene standards were used for molecular weight determination.

Photophysical and photovoltaic methods. UV-vis spectra were obtained from chloroform solution. There was no significant red-shift when comparing solution spectra and solid film spectra. Photovoltaic devices were prepared by spincoating a $2.7 \mu \mathrm{m}$ microfiltered solution of the polymer $(20 \mathrm{mg})$ and PCBM $(20 \mathrm{mg})$ in chloroform:chlorobenzene/2:1 (1.5mL). The substrates were PEDOT:PSS coated ITO on glass slides. The typical film absorbance was 0.7-0.9 absorbance units. The films were then transferred to a vacuum chamber and pumped to a pressure $<510-6 \mathrm{mBar}$. The aluminium electrode $(\sim 150 \mathrm{~nm})$ was applied by thermal evaporation. The active area of the devices were $3 \mathrm{~cm}^{2}$. Devices were subsequently mounted using epoxy glue and measurements performed in the ambient atmosphere. The wavelength dependence of the photovoltaic response was performed using a set-up described earlier with additional lenses that improve the bandwidth and reduced the intensity a little. [10] IV-curves were recorded using a Keithley 2400 sourcemeter. Simulated sunlight was obtained by using a SolarKonstant 575 from Steuernagel Lichttechnik GmBH. The luminous intensity was set to $1000 \mathrm{~W} \mathrm{~m}^{-2}$ using a precision pyranometer from Eppley Laboratories. The spectral distribution was made as close to the AM1.5 standard as possible using a Neoceram UV-stop filter. The spectrum was monitored using an AvaSpec 2048 optical spectrum analyser from Avantes. 


\section{Results and discussion}

Synthesis. The general synthetic procedures leading to conjugated polymers does not allow for directional synthesis where the two termini of the polymer chain have a different chemical nature. An excellent example is the polyalkylthiophenes that have been prepared in both regioregular and regiorandom forms. Ferric chloride oxidation generally gives regiorandom polymer materials whereas palladium catalysis has also been demonstrated to give regiorandom products. [11]

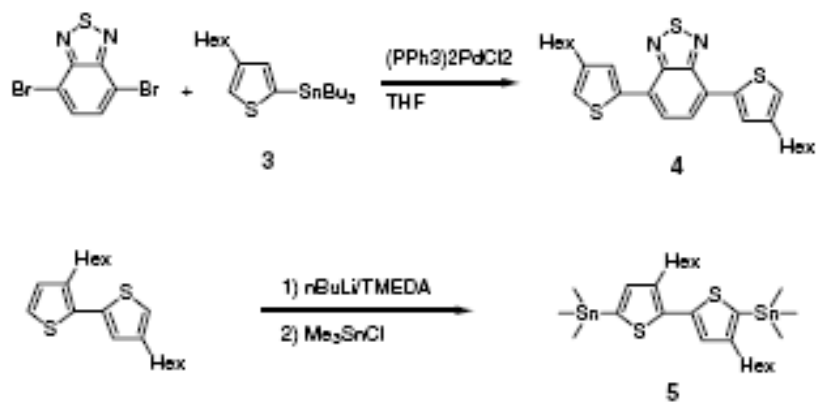

Scheme 2. Synthesis of the monomers 4 and 5.

The regioregular polymers are most often obtained by a directional approach and have been employed with success for the polythiophenes by Negishi [11], Kumada [12] or Stille [13] polycondensation reactions. It should be mentioned that the physical properties of conjugated polymer materials prepared by palladium catalysis can be hampered by even tiny amounts of residual catalyst in the form of metallic palladium nanoparticles. [14] Our interest in this paper was to compare the photovoltaic response for head-to-head and head-to-tail coupled copolymers of dihexyldithiophene and benzothiadiazole.

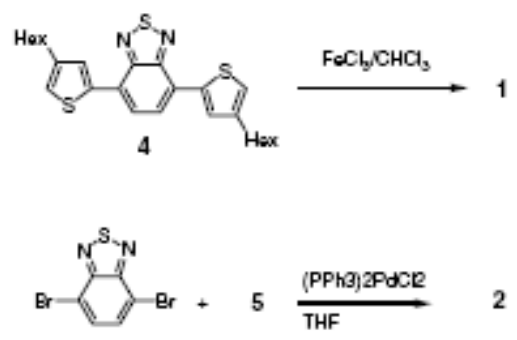

Scheme 3. Synthesis of the polymers 1 and 2 .

The synthesis of the monomers were straight forward and involved in the case of the monomer for the head-to-head coupled polymer the regioselective lithiation of 3-hexylthiophene using LDA followed by reaction with tributylstannylchloride to give 3. The subsequent reaction of $\mathbf{3}$ with 4,7-dibromo-benzo-2,1,3-thiadiazole gave $\mathbf{4}$ that was the monomer for the oxidative polymerisation using ferric chloride. The monomer for the head-to-tail coupled polymer involved dilithiation of 3,4'-dihexyl[2,2']dithiophene with $\mathrm{nBuLi}$ in THF followed by reaction with trimethylstannylchloride to give $\mathbf{5}$ as an oil that was found to be somewhat unstable. It was generally used directly but could be kept for a few weeks in the dark under argon at room temperature. The synthesis is outlined in scheme 2 . 

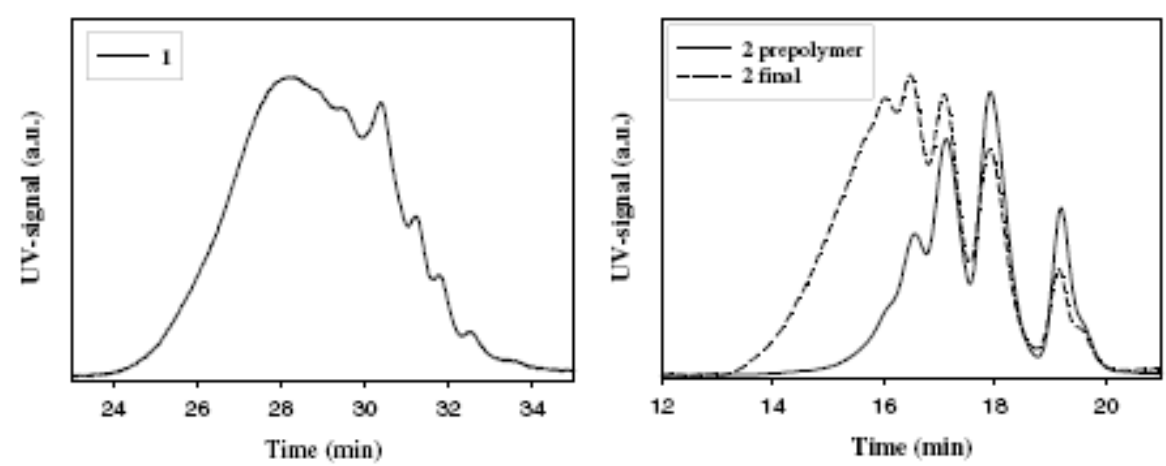

Figure 1. SEC traces of the polymers. Polymer 1 was analyzed on a gel column system column system comprising a succession of a $500 \AA, 10000 \AA$ and $1000000 \AA$ in pore diameter. Polymer 2 was analyzed column on a gel column system comprising a succession of a $100 \AA$ and $1000 \AA$ in pore diameter.

The polymerisation of $\mathbf{4}$ using ferric chloride in chloroform proceeded smoothly to give the regioregular polymer 1 with a moderate weight average molecular weight in the range of $15000 \mathrm{~g} \mathrm{~mol}^{-1}$. The polymerisation using Stille cross coupling to give the head-to-tail coupled polymer $\mathbf{2}$ was best achieved by starting the polymerisation in DMF. This gave a prepolymer that separates as a slimy solid. Addition of THF at this point dissolved the prepolymer and allowed for continuation of the polymerisation reaction (scheme 3). The results from SEC analysis of the polymer products are shown in figure 1. Spin coating of $\mathbf{1}$ and $\mathbf{2}$ gave good films and it was decided to prepare photovoltaic devices in spite of the difference in molecular weight.

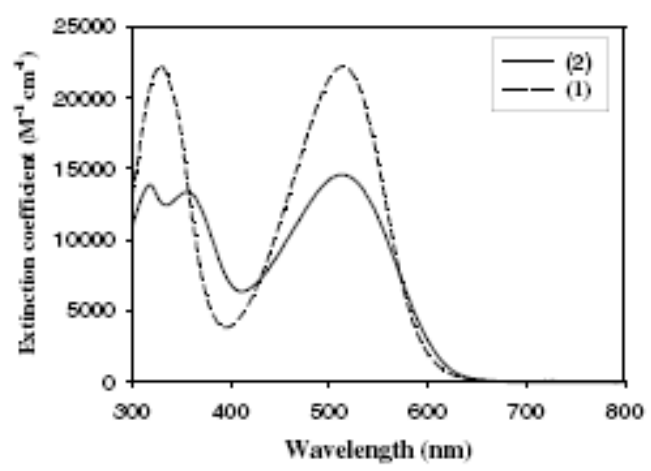

Figure 2. UV-vis spectra of the polymers 1 and 2 in chloroform solution.

Photophysical and photovoltaic measurements. The UV-vis spectra of the two polymers are similar in solution as shown in figure 2. The extinction coefficients at the maximum wavelength of absorption are $22300 \mathrm{M}^{-1} \mathrm{~cm}^{-1}$ and $22200 \mathrm{M}^{-1} \mathrm{~cm}^{-1}\left(\lambda_{\max }\right.$ $=330 \mathrm{~nm}$ and $514 \mathrm{~nm}$ ) for 1 and $14000 \mathrm{M}^{-1} \mathrm{~cm}^{-1}, 13000 \mathrm{M}^{-1} \mathrm{~cm}^{-1}$ and $15000 \mathrm{M}^{-1} \mathrm{~cm}^{-1}$ for $2\left(\lambda_{\max }=318 \mathrm{~nm}, 356 \mathrm{~nm}\right.$ and $\left.514 \mathrm{~nm}\right)$. From the UV-vis spectra the bandgap is estimated to be $2 \mathrm{eV}$. The UV-vis spectra in solution and in the solid were very similar. The similarity of the UV-vis properties for the head-to-head and head-to-tail coupled polymers is in contrast to for instance the polyalkylthiophenes where a pronounced effect of the regioregularity is seen lowering the bandgap from $2.1 \mathrm{eV}$ to 
$1.7 \mathrm{eV}$ in the solid. [11] The photovoltaic devices based on the homopolymers gave as expected very low conversion efficiencies in the ppm range and fill factors, FF, close to $25 \%$. It is noticeable that polymer 1 has an efficiency that is four times better than 2. The open circuit voltage $\left(\mathrm{V}_{\infty}\right)$ and the short circuit current $\left(\mathrm{I}_{s \infty}\right)$ are larger for 1 then for 2 (see table 1 ).
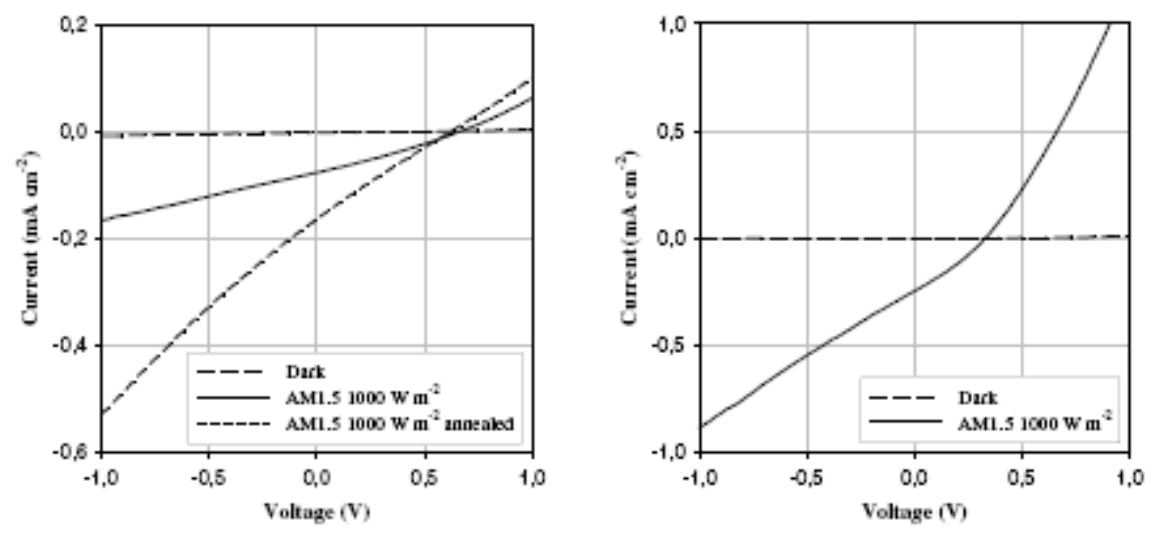

Figure 3. IV-curves for the polymers 1 (left) and 2 (right).

When a mixture of the soluble fullerene derivative PCBM [15] was mixed with the conjugated polymer material in a $1: 1 \mathrm{w} / \mathrm{w}$ ratio the efficiency was increased by more than an order of magnitude in both cases and the efficiencies became similar $(0.024 \%)$.

Table 1. Photovoltaic performance and dark resistance, $R_{d}$, of the devices (1000 $\mathrm{W} \mathrm{m}^{-2}$, AM1.5)

\begin{tabular}{|c|c|c|c|c|c|}
\hline Compound & $\mathrm{V}_{\mathrm{oc}}(\mathrm{V})$ & $I_{s c}\left(\mu \mathrm{A} \mathrm{cm}{ }^{-2}\right)$ & $\mathbf{F F}(\%)$ & $R_{d}(k \Omega)$ & $\eta(\%)$ \\
\hline 1 & 0.68 & -7.4 & 25 & 74 & 0.0013 \\
\hline 1+PCBM & 0.65 & -75 & 28 & 58 & 0.0140 \\
\hline 1+PCBM (annealed) & 0.61 & -162 & 24 & n.d. & 0.0240 \\
\hline 2 & 0.57 & -2.4 & 25 & 57 & 0.0003 \\
\hline $2+\mathrm{PCBM}$ & 0.33 & -247 & 30 & 58 & 0.0240 \\
\hline
\end{tabular}

Polymer 1 exhibited the phenomenon of annealing upon initial illumination whereas polymer 2 did not exhibit this. During illumination the sample quickly heats up to an equilibrium temperature of $\sim 70^{\circ} \mathrm{C}$. We ascribe the increase in efficiency in $\mathbf{1}$ by a factor of two to be due to annealing of the polymer material. This is supported by DSC measurements. They showed that 1 exhibits a glass transition in the $60-80^{\circ} \mathrm{C}$ range. There were no thermal transitions for polymer 2 . The IV-curves are shown in figure 3 where it is evident that annealing in the case of 1 lowers $V_{o c}$ but increases $I_{90}$. The lifetimes of the devices were generally short and the short circuit decreased to less than $10 \%$ in 24 hours. The addition of PCBM increased the lifetime but the practical applications of these devices are limited to fundamental measurements on freshly prepared or annealed samples (see figure 4). The lifetime behavior of devices based on $\mathbf{1}$ and $\mathbf{2}$ were similar. 


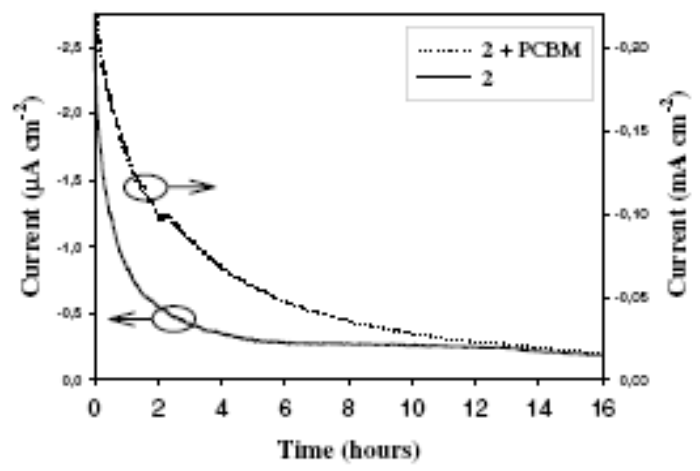

Figure 4. Lifetime curves for photovoltaic devices based on 2 monitored as $\mathrm{I}_{\mathrm{sc}}$.

The photovoltaic response as a function of the incident wavelength was finally monitored and the result is shown in figure 5 for devices based on $\mathbf{2}$ where the device absorption is shown along with $I_{s 0}$ as a function of the incident wavelength.

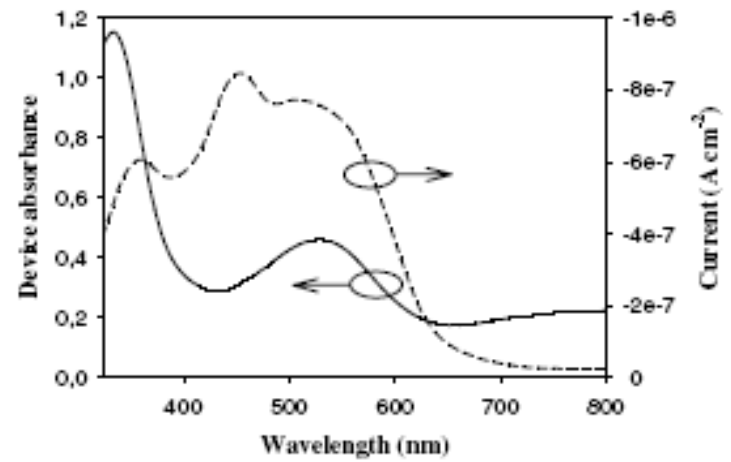

Figure 5. The device absorption (solid curve) and the photocurrent (grey curve). The broad weak band at $800 \mathrm{~nm}$ stems from the PEDOT:PSS layer. A plot of $\mathrm{I}_{\mathrm{sc}}$ is also shown.

The photovoltaic response is symbatic with the absorption spectrum as expected. The decrease in the photocurrent below $350 \mathrm{~nm}$ is ascribed to the absorbance of the glass. The maximum for conversion of incident photons to electrons in the external circuit (incident photon to current efficiency, IPCE) is $0.6 \%$ at $450 \mathrm{~nm}$. Polymer materials similar to 1 have been reported $[16,17]$ while no photovoltaic data were given. Also copolymers of dithienylbenzothiadiazole with pyrrole $[6,7]$ and dialkylfluorenes $[18,19]$ have been employed in photovoltaics where efficiencies of respectively $1 \%$ and $2.4 \%$ were documented. Common to the literature results were a smaller bandgap with values down to $1.6 \mathrm{eV}$ and the possibility for the incorporation of a much larger weight fraction of PCBM (a polymer:PCBM ratio of $1: 3$ and $1: 4 \mathrm{w} / \mathrm{w}$ respectively). A large weight fraction of PCBM has been shown to be important for the efficient conduction of electrons. [20] In our case a 1:1 ratio was employed since the formation of good homogenous films could not be obtained with a higher ratio. Provided that good films could be obtained with a 1:3 or 1:4 w/w ratio of 1 or 2 and PCBM higher efficiencies would be expected. 


\section{Conclusions}

We have presented the synthesis of two conjugated polymer materials based on copolymers of benzothiadiazole and dihexyldithiophene. The materials were characterised using NMR and SEC. The photovoltaic response of the materials were investigated and compared. We found the efficiency of homopolymer devices based on the head-to-head coupled material to be higher than for the head-to-tail material. The efficiency of devices based on mixtures of the polymer materials and the soluble fullerene derivative PCBM were however similar and too low to be of practical importance. The lifetimes of the devices were short but sufficient for physical measurements.

Acknowledgements. This work was supported by the Danish Technical Research Council (STVF).

\section{References}

1. Brabec CJ, Sariciftci NS, Hummelen JC (2001) Adv. Func. Mater. 11:15.

2. Spanggaard H, Krebs FC (2004) Sol. En. Mater. Sol. Cells 83:125.

3. Hoppe H, Sariciftci NS (2004) J. Mater. Res. 19:1924.

4. Waldauf C, Schilinsky P, Hauch J, Brabec CJ (2004) Thin Solid Films 451-452:503.

5. Brabec CJ (2004) Sol. En. Mater. Sol. Cells 83:273.

6. Dhanabalan A, van Duren JKJ, van Hal PA, van Dongen JLJ, Janssen RAJ (2001) Adv. Funct. Mater. 11:255

7. Brabec CJ, Winder C, Sariciftci NS, Hummelen JC, Dhanabalan A, van Hal PA, Janssen RAJ (2002) Adv. Funct. Mater. 12:709.

8. Kirschbaum T, Briehn CA, Băuerle P (2000) J. Chem. Soc. Perkin. I 1211; Krebs FC, Spanggaard H (2005) Sol. En. Mat. Sol. Cells, In Press.

9. Pilgram K, Zupan M, Skiles R (1970) J. Hetercycl. Chem. 7:629.

10. Krebs FC, Jørgensen M (2003) Rev. Sci. Instr. 74:3438.

11. Chen TA, Wu X, Rieke RD (1995) J. Am. Chem. Soc. 117:233.

12. McCullough RD, Lowe RD, Jayaraman M, Anderson DL (1993) J. Org. Chem. 58:904.

13. Iraqi A, Barker GW (1998) J. Mater. Chem. 8:25.

14. Krebs FC, Nyberg RB, Jørgensen M (2004) Chem. Mater. 16:1313; Nielsen KT, Bechgaard K, Krebs FC (2005) Macromolecules 38: 658-659.

15. Hummelen JC, Knight BW, LePeq F, Wudl F, Yao J, Wilkins CL (1995) J. Org. Chem. 60:532.

16. Jayakannan M, van Hal PA, Janssen RAJ (2002) J. Pol. Sci. Part A 40:251.

17. Jayakannan M, van Hal PA, Janssen RAJ (2002) J. Pol. Sci. Part A 40:2360.

18. Svensson M, Zhang F, Veenstra SC, Verhees VJH, Hummelen JC, Kroon JM, Inganäs O, Andersson MR (2003) Adv. Mater. 15:988-991.

19. Inganăs O, Svensson M, Zhang F, Gadisa A, Persson NK, Wang X, Andersson MR (2004) Appl. Phys. A 79:31-35.

20. Geens W, Martens T, Poortmans J, Aernouts T, Manca J, Lutsen L, Heremans P, Borghs S, Mertens R, Vanderzande D (2004) Thin Solid Films 451-452:498-502. 
Low-Band-Gap Conjugated Polymers Based on Thiophene, Benzothiadiazole, and Benzobis(thiadiazole)

\section{Eva Bundgaard and Frederik C. Krebs*}

The Danish Polymer Centre, RISØ National Laboratory, P.O. Box 49, DK-4000 Roskilde, Denmark

Received December 15, 2005; Revised Manuscript Received February 13, 2006

ABSTRACT: A series of low-band-gap copolymers of thiophene, benzothiadiazole, and benzobis(thiadiazole) were synthesized. The polymers were synthesized by Stille cross-coupling polymerization of distannylalkyl thiophenes and dithiophenes with dibromo derivatives of benzothiadiazoles and benzobis(thiadiazole)s. The polymers were characterized using NMR, UV-vis, and size exclusion chromatography (SEC). The molecular weight, solubility, and film-forming ability were highly dependent on the choice of side chains. $3,7,11$ Trimethyldodecyl side chains were found to give polymer products with high molecular weight, good filmforming ability, and good solubility. Band gaps were estimated from UV-vis to be $2.1-1.7 \mathrm{eV}$ for polymers based on benzothiadiazole and $\sim 0.7 \mathrm{eV}$ for polymers based on benzobis(thiadiazole). The band gap and electronic structure of the polymers were determined by a combination of UV-vis spectroscopy and ultraviolet photoelectron spectroscopy (UPS).

\section{Introduction}

Polymer photovoltaics ${ }^{1}$ bring promise as a future renewable source of energy, and while a few difficult problems need to be solved before commercialization of polymer photovoltaics for electrical energy production becomes a reality, the hopes are high. Intensive research has already led to a technology that is suitable for low-energy niche applications. The cost and environmental benefits using this technology are attractive, and the problems remain with the lifetime and the efficiency of experimental devices. While recent improvements of both efficiency ${ }^{\mathrm{li}}$ and lifetime $\mathrm{e}^{\mathrm{lh}}$ have been reported, further improvements are desirable. In terms of efficiency, many factors influence the relatively low efficiencies of around $5 \%$ that has been reported. In particular, the conjugated polymers that are typically employed as the active material exhibit a poor overlap with the solar spectrum. The band gaps are typically higher than $2.0 \mathrm{eV}$, and it is believed that lower band gaps could increase the efficiency by harvesting a larger proportion of the sunlight. There are limits to how low a band gap one can apply as the exciton binding energy becomes significant at lower energies, and while a too low band gap will result in harvesting of more photons with lower energy, excessive loss will ensue and lead yet to poorer efficiencies. Because of the unavailability of conjugated polymer materials with low band gaps, there have been few reports on the use of low-band-gap conjugated polyme materials in polymer photovoltaic devices, and therefore experimental evidence on the applicability remains scarce. For this reason low-band-gap polymers have received considerable attention recently. ${ }^{2-5}$ Spectral coverage in the range from 700 to $1200 \mathrm{~nm}$ ( 1.8 to $1 \mathrm{eV}$, respectively) is believed to enable the fabrication of photovoltaic devices with increased conversion efficiency. ${ }^{2,3}$ From a synthetic point of view low-band-gap conjugated materials are however a challenge, and only a few families of polymers exist. The most important ones have been polyisothianaphthenes, ${ }^{6,7}$ polythiophenes, $1.8,9$ and copolymers of benzothiadiazole, thiophene, and pyrrole.$^{3-5}$ Generally, lowband-gap materials have been problematic in terms of solubility, and for this reason the preparation of soluble materials was paramount in this work

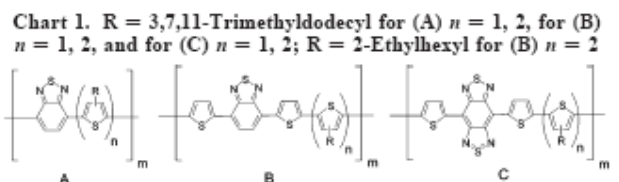

In this paper, we describe the synthesis and characterization of soluble low-band-gap copolymers of thiophenes with benzothiadiazole and benzobis(thiadiazole)s of the types shown in Chart 1 . Syntheses were carried out by oxidative ferric chloride polymerization and Stille cross-coupling polymerization.

\section{Results and Discussion}

Monomers for Stille cross-coupling polymerization were distannyl derivates of 3-(3,7,11-trimethyldodecyl)thiophene or di(3,7,11-trimethyldodecyl)dithiophene and dibromo derivative of benzothiadiazole or benzobis(thiadiazole). For the oxidative ferric chloride polymerization, di(2-ethylhexyl)dithiophenebenzothiadiazole was used.

Synthesis of Monomers. The synthesis of the long and branched alkyl chain 3,7,11-trimethyldodecyl bromide was carried out as described in the literature ${ }^{10}$ The reported hydrogenation of farnesol to give 3,7,11-trimethyldodecanol was modified using high contents of $\mathrm{Pd} / \mathrm{C} 10 \mathrm{wt} \%(0.2 \mathrm{~mol} \% \mathrm{Pd})$ instead of Adams catalyst $\left(\mathrm{PtO}_{2}\right)$ and a pressure at 45 bar. In the paper by Schouten et al. ${ }^{10}$ the temperature and pressure were not reported, and our initial attempts were carried out at 4 bar. This gave only a partially hydrogenated product, and we found that large amounts of $10 \% \mathrm{Pd} / \mathrm{C}$ at 45 bar and $60^{\circ} \mathrm{C}$ were required to complete the reaction in 1 day.

Addition of 3,7,11-trimethyldodecylmagnesium bromide to 3-bromothiophene to give 3-(3,7,11-trimethyldodecyl)thiophene (1) was carried out by a Kumada reaction (Scheme 1). ${ }^{11}$ Even Scheme 1. Synthesis of Alkylthiophene $e^{\circ}$

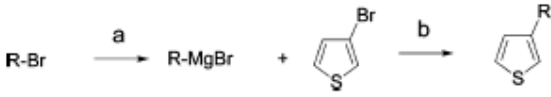

a a: $\mathrm{Mg}$, ether, b: Nidppp, $\mathrm{R}=3,7,11$-trimethyldodecyl (1) and 2-ethylhexyl (2)

$$
\text { 10.1021/ma052683e CCC: } \$ 33.50 \& 2006 \text { American Chemical Society }
$$




\section{Bundgaard and Krebs}

though the bromoalkane was added slowly and dropwise to the magnesium turnings during the Grignard reaction, a small amount of the Wurtz coupled byproduct, 2,6,10,15,19,23hexamethyltetracosane, was formed. After purification, the final product contained around $7 \%$ of $2,6,10,15,19,23$-hexamethyltetracosane. This byproduct was found difficult to remove and was alleviated in later reaction steps.

The synthesis of 3-(2-ethylhexyl)thiophene (2) was also carried out by Kumada reaction (Scheme 1). ${ }^{11}$

Lithiation of 3-Alkylthiophene. Compound 1 was lithiated with $n \mathrm{BuLi}$ and TMEDA followed by reaction with trimethylstannyl chloride to give 4-(3,7,11-trimethyldodecyl)-2-trimethylstannylthiophene (3) (Scheme 2).

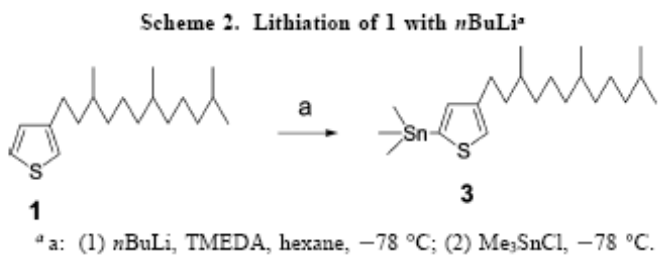

The reaction with $n \mathrm{BuLi}$ and TMEDA (1.5 equiv) resulted in modest yields of the product $(54 \%)$. Compound 2 was lithiated with $\mathrm{LDA}^{12}$ and reacted with tributylstannyl chloride to give 4-(2-ethylhexyl)-2-tributylstannylthiophene (4) (Scheme $3)$. The reaction with LDA resulted in a mixture of starting material and product, and hence the yield was lower (42\%) compared to the lithiation using $n \mathrm{BuLi}$ and TMEDA.

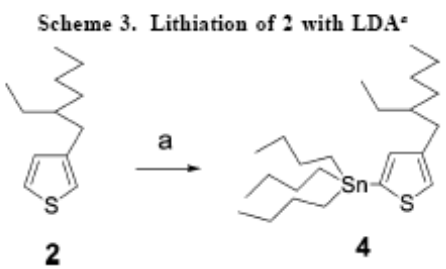

a a: (1) LDA, THF, $-78^{\circ} \mathrm{C}$; (2) $\mathrm{Bu}_{3} \mathrm{SnCl},-78^{\circ} \mathrm{C}$.

Dithiophene. The synthesis of $4,4^{\prime}$-bis(3,7,11-trimethyldodecyl)-2, $2^{\prime}$-dithiophene (6) was carried out by Stille coupling between 3 and 2-iodo-4-(3,7,11-trimethyldodecyl)thiophene (5) to give the tail-to-tail product 6 (Scheme 4). Compound 5 was made in one-pot by addition of $\mathrm{I}_{2}$ to 3 and was not isolated before performing the Stille coupling under reflux. This reaction resulted in a pure tail-to-tail product 6 . We ascribe this to a faster reaction between 3 and 5 compared to reaction between the 2-bromo-3-(3,7,11-trimethyldodecyl)thiophene (7) and 3 . In 3 and 5 there is least sterical hindrance where 7 exhibits more sterical hindrance due to the alkyl group adjacent to bromine. Hence, no homocoupling of 3 was observed, and further, decomposition of 3 to 1 was not observed.

Scheme 4. Synthesis of $6, R=3,7,11-$ Trimethyldodecyl $^{\text {s }}$

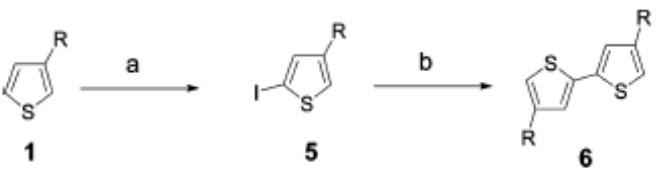

a a: (1) $n \mathrm{BuLi}, \mathrm{THF},-78^{\circ} \mathrm{C}$; (2) $\mathrm{I}_{2}$; (b) $3, \mathrm{Pd}\left(\mathrm{PPh}_{3}\right)_{2} \mathrm{Cl}_{2}$, reflux.
Macromolecules, Vol. 39, No. 8, 2006

Several other attempts was made to synthesize head-to-head and head-to-tail isomers of 6; these are described in the Supporting Information.

The large-scale synthesis of 3,4'-dihexyl-2,2'-dithiophene has been described in the literature. ${ }^{12}$ The reaction between 2-bromo3-hexylthiophene and 4-hexyl-2-trimethylstannylthiophene resulted in three isomers of the product. The purification of this mixture was complicated, ${ }^{12}$ and synthesis of only one isomer is preferred.

Dilithiation of 3-Alkylthiophenes. The dilithiation of 1 was carried out using 5 equiv of $t \mathrm{BuLi}$. This reaction resulted in dilithiation after $3^{1 / 2}$ days at room temperature. Addition of trimethylstannyl chloride gave the product 3-(3,7,11-trimethyldodecyl)-2,5-bis(trimethylstannyl)thiophene (8) (Scheme 5). Other attempts were made to dilithate 1 (see Supporting Information)

Scheme 5. Dilithation of $1, R=3,7,11$-Trimethyldodecyle

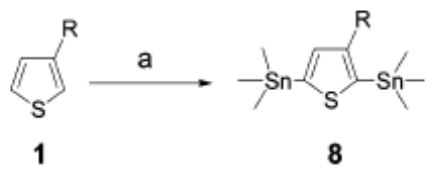

a a: (1) $t \mathrm{BuLi}$, hexane, $\mathrm{RT}$; (2) $\mathrm{Me}_{3} \mathrm{SnCl},-78^{\circ} \mathrm{C}$.

These results show that the dilithiation of 3-alkylthiophenes requires a stronger base than the monolithiation. This is ascribed to a lower acidity of the protons in alkylthiophene monoanions.

Dilithiation of Dialkylthiophene. The dilithiation of 6 was successfully carried out using $n \mathrm{BuLi}$ and TMEDA (3 equiv) which resulted in dilithiation after $1 \mathrm{~h}$, and addition of trimethylstannyl chloride gave the product $4,4^{\prime}$-bis $(3,7,11$ trimethyldodecyl)-5,5'-bis(trimethylstannyl)-2,2'-dithiophene (9) (Scheme 6). Other attempts were made to dilithate 6 (see Supporting Information).

Scheme 6. Dilithation of $6, R=3,7,11$-Trimethyldodecyl ${ }^{e}$

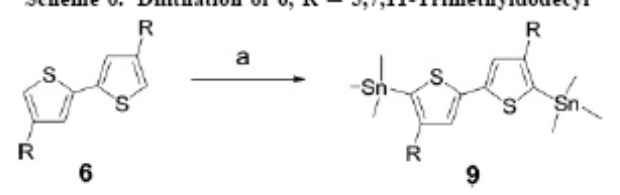

a a: (1) $n \mathrm{BuLi}$, TMEDA, hexane, $-78^{\circ} \mathrm{C}$; (2) $\mathrm{Me}_{3} \mathrm{SnCl},-78^{\circ} \mathrm{C}$.

Dibromo Derivatives of Benzothiadiazole and Benzobis(thiadiazole). The synthesis of both 4,7-dibromobenzo-[2,1,3]thiadiazole (10) and 4,7-di(5-bromothiophen-2-yl)benzo-[2,1,3]thiadiazole (11) have been described in the literature (Scheme 7)..$^{13,14}$

Scheme 7. Dibromo Derivates of Benzothiadiazole, 10 and

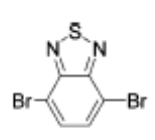

10

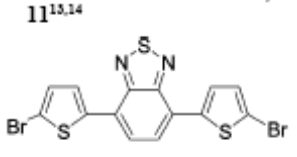

11
4,7-Bis(5-bromothiophen-2-y1)-2 $2 \lambda^{4} \delta^{2}$-benzo[ $\left[1,2-c ; 4,5-c^{\prime}\right]$ bis$[1,2,5]$ thiadiazole $(12)$ was synthesized from 4,8-dithien-2-y1$2 \lambda^{4} \delta^{2}$-benzo[ $\left[1,2-c, 4,5-c^{\prime}\right]$ bis $[1,2,5]$ thiadiazole (Scheme 8$) .{ }^{15}, 16$ The synthesis with NBS was carried out in both DMF and a 1:1 mixture of chloroform and acetic acid. Because of insolubility of the starting material in DMF, the tetra-brominated 


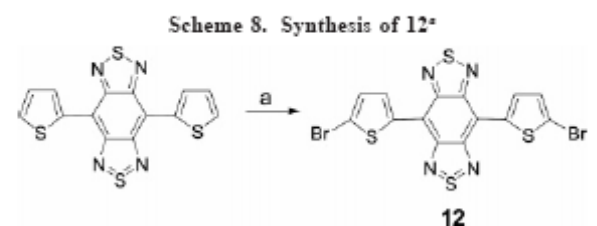

a (a): $\mathrm{NBS}, \mathrm{CHCl}_{3} / \mathrm{AcOH}$

Scheme 9. Synthesis of Monomer for Ferric Chloride Polymerization $^{*}$

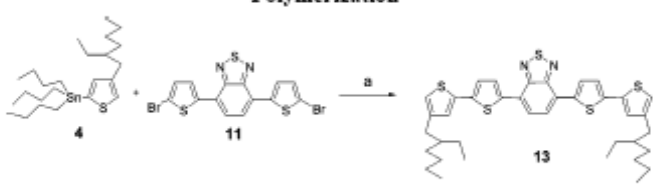

a: $\mathrm{Pd}\left(\mathrm{PPh}_{3}\right)_{2} \mathrm{Cl}_{2}, \mathrm{THF}$, reflux.

benzobis(thiadiazole), 4,7-bis(dibromothiophen-2-yl)benzo$[2,1,3]$ bis(thiadiazole), was obtained as a byproduct. Refluxing the starting material for $2 \mathrm{~h}$ in chloroform before adding acetic acid and NBS gave the pure product 12. Because of the insolubility of 12 , the ${ }^{1} \mathrm{H}$ NMR spectra could only be obtained in high boiling NMR solvent mixtures at elevated temperature. A mixture of 1,2-dichlorobenzene- $d_{4} / N, N$-dimethylforamide- $d_{7}$ $(1: 1)$ at $400 \mathrm{~K}$ was found to be suitable.

Scheme 10. Synthesis of Polymers $14-19$ by Stille Cross-Coupling Polymerization, $R=3,7,11$-Trimethyldodecyl ${ }^{*}$

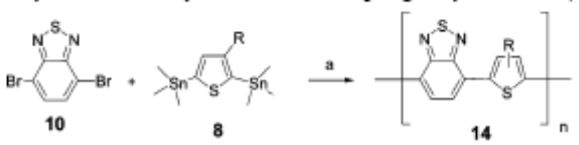

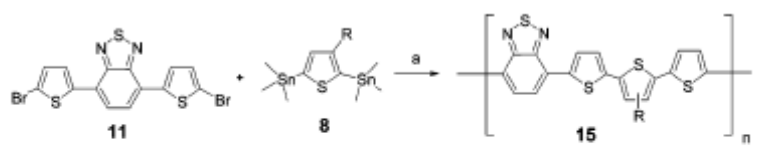

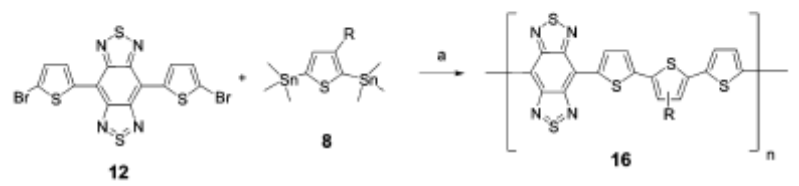

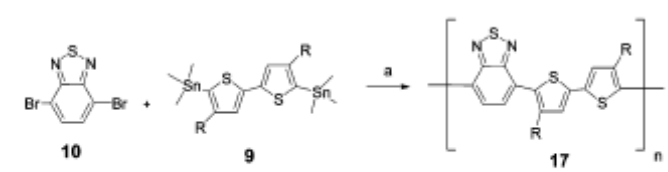
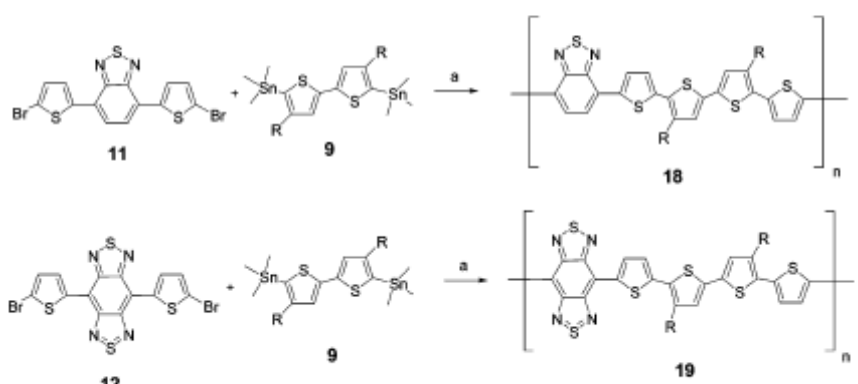

a a: $\mathrm{Pd}\left(\mathrm{PPh}_{3}\right)_{2} \mathrm{Cl}_{2}, \mathrm{DMF} / \mathrm{THF}, 150^{\circ} \mathrm{C}$
Stille Coupling. Compound $11^{13}$ was reacted with 4 in a Stille cross-coupling to give 4,7-bis(2-ethylhexyl-2,2'-thiophen-5-yl)benzo[2,1,3]thiadiazoles (13) (Scheme 9).

Synthesis of Polymer Products. Stille Cross-Coupling Stille cross-coupling polymerization between dibromo derivatives of benzothiadiazole or benzobis(thiadiazole) and distannyl derivatives of 3-(3,7,11-trimethyldodecyl)thiophene or

The monomers were heated in DMF, and the palladium catalyst was added. After a few hours a prepolymer had precipitated, and THF was added to dissolve the prepolymer ${ }^{17}$ and continue the polymerization. After 2-3 days the polymers were precipitated with methanol and water. Determination of unt of palladium in polymers synthesized from palladium catalyzed polymerization was described by Nielsen et al. ${ }^{18} \mathrm{~A}$ method for the removal of palladium from the polymer product was also reported. ${ }^{18}$ Analysis of polymer 14-19 showed a palladium content of less than $100 \mathrm{ppm}$ in the polymer. The polymers 14-19 were further purified by Soxhlet extraction with successively $\mathrm{MeOH}$, hexane, and chloroform. The chloroform fraction was recovered and concentrated before further purification by preparative SEC. The SEC data of the purified polymers are summarized in Table 1 . 
2826 Bundgaard and Krebs

Table 1. SEC Data of Purified Polymers 14-19。

\begin{tabular}{cccc}
\hline polymer & $M_{\mathrm{w}}$ & $M_{\mathrm{p}}$ & $M_{\mathrm{w}} / M_{\mathrm{S}}$ \\
\hline 14 & 5800 & 4800 & 1.4 \\
15 & 2300 & 2100 & 1.3 \\
16 & 7100 & 8600 & 1.9 \\
17 & 9400 & 9500 & 1.8 \\
18 & 14000 & 12000 & 1.9 \\
19 & 12000 & 11000 & 2.1
\end{tabular}

a The polymers were analyzed on a gel column system comprising of a succession of columns with 500,10000 , and $1000000 \AA$ p pore size with a detector wavelength of $500 \mathrm{~mm}$. The SEC traces are given in the Supporting Information

Oxidative Ferric Chloride Polymerization. The polymerization of 13 was carried out using ferric(III) chloride in chloroform to give the polymer 20 (Scheme 11) Scheme 11. Oxidative Ferric Chloride Polymerization To Give
Head-to-Head Copolymers of Dithiophene and Benzothiadiazole, Head-to-Head Copolymers of Dithiophene and Benzothiadiazole,
\[ \mathrm{R}=2 \text {-Ethylhexyl }(20)^{a} \]

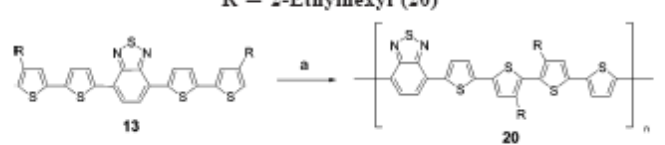

a: $\mathrm{FeCl}_{3}, \mathrm{CHCl}_{3}$.

Table 2. SEC Data of the Purified Polymer 20*

\begin{tabular}{cccc}
\hline polymer & $M_{w}$ & $M_{p}$ & $M_{w} / M_{n}$ \\
\hline 20 & 86000 & 60000 & 2.0
\end{tabular}

a The polymer was analyzed on a gel column system comprising a succession of columns with 500,10000 , and $1000000 \AA$ pore diameter with a detector wavelength of $500 \mathrm{~mm}$. The SEC trace of the polymer is given in the Supporting Information.

The monomer was dissolved in chloroform and added to the ferric(III) chloride in chloroform. The solution was refluxed for $25 \mathrm{~h}$; the resulting polymer was purified with aqueous sulfuric acid and aqueous sodium sulfite. It was not possible to establish whether complete removal of iron species was achieved. Polymer $\mathbf{2 0}$ was further purified by preparative SEC, and the SEC data are summarized in Table 2.

Film-Forming Ability and Solubility. The film-forming ability of polymers 14-20 was tested in different solvents by spin-coating the polymer solutions onto glass slides with subsequent measurement of the absorbance. Absorbencies of at least 0.3 at $\lambda_{\max }$ were required to ensure a sufficiently thick film for photovoltaic studies or other thin-film studies. The analysis showed that the film-forming ability of polymers 1420 is good in solvents like chloroform and THF.

Synthesis of polymers 14-16 with 2-ethylhexyl side chains, polymers 17-19 with hexyl side chains in a head-to-tail coupling, and polymer $\mathbf{2 0}$ with hexyl or dodecyl side chains is described in detail in the Supporting Information. Analyses of these polymers showed poor film-forming ability in $\mathrm{CHCl}_{3}$, THF, chlorobenzene, dichlorobenzene, xylene, and toluene. Hence, these polymers were not good enough to produce films with a sufficient quality for photovoltaic studies or other thinfilm studies. Further, because of the poor solubility of these polymers, SEC data did not give a correct picture of the polymer molecular weight distribution, and the data are not reported.

From these results, it can be concluded that the long and branched alkyl chain 3,7,11-trimethyldodecyl, resulted in soluble polymer products compared to polymer products bearing hexyl, 2-ethylhexyl (with the exception of polymer 20), or dodecylalkyl side chains.
Macromolecules, Vol. 39, No. 8, 2006
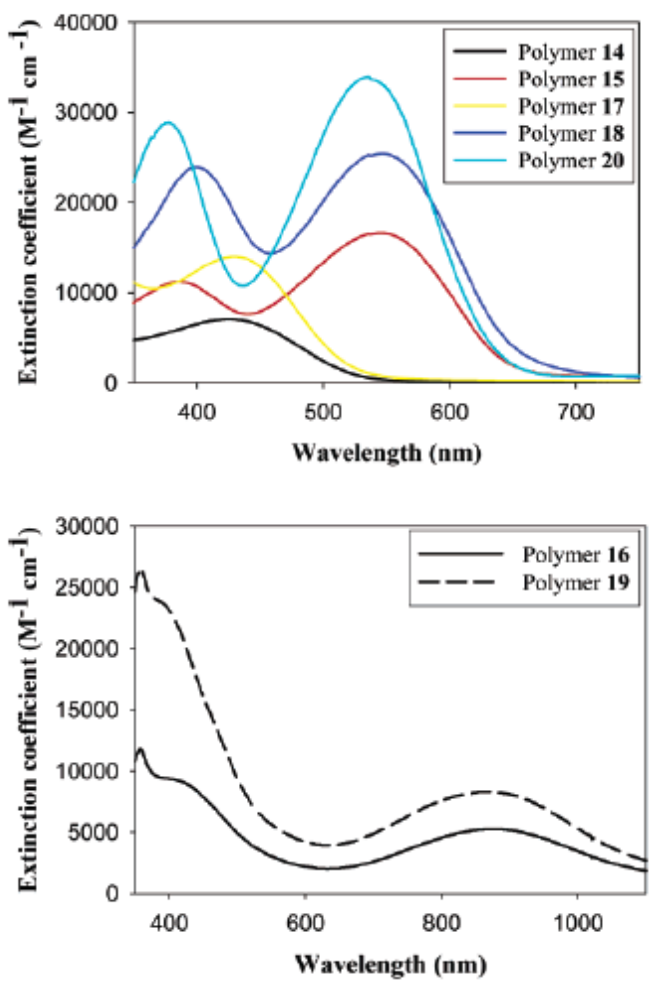

Figure 1. UV-vis spectra of polymers 14-20 in chloroform (360$1100 \mathrm{~nm}$ ). We did not observe any significant red or blue shift when comparing spectra measured in solution and on film.

Table 3. Extinction Coefficients at $\lambda_{\max }$ for the Polymers 14-20

\begin{tabular}{|c|c|c|c|c|c|c|c|}
\hline & 14 & 15 & 16 & 17 & 18 & 19 & 20 \\
\hline & 477 & $\begin{array}{l}435 \\
602\end{array}$ & 770 & 79 & & 902 & \\
\hline$\left(\mathrm{M}^{-}\right.$ & 7056 & $\begin{array}{l}11228 \\
165909\end{array}$ & 7609 & 14000 & $\begin{array}{r}23994 \\
25420\end{array}$ & 8081 & 339 \\
\hline
\end{tabular}

$\mathrm{UV}$-vis. The UV-vis spectra from $\lambda=360 \mathrm{~nm}$ to $\lambda=1100$ $\mathrm{nm}$ of polymers 14-20 are shown in Figure 1.

The extinction coefficients at $\lambda_{\max }$ for polymers $14-20$ are listed in Table 3. From Table 3 and Figure 1, it can be seen that polymer 18 has a larger extinction coefficient at $\lambda_{\max }$ than polymers $14,15,16,17$, and 19 . It can also be seen that $\lambda_{\max }$ is red-shifted for the polymers synthesized from dithiophene (polymers 17-19) compared to polymers synthesized from thiophene (polymers 14-16). Further, it can be seen that polymer 20 has a larger extinction coefficient at $\lambda_{\max }$ than polymer 18 and that $\lambda_{\max }$ for polymer 20 is red-shifted compared to polymer 18. This could be due to the different dithiophene coupling in the polymers 18 and 20 , i.e., tail-to-tail and headto-head, respectively.

Further, it can be seen that polymers 16 and 19 show absorption above $1100 \mathrm{~nm}$. In Figure 2 the UV-vis and NIR spectra of polymers 16 and 19 are shown from 800 to 2500 $\mathrm{nm}$. From these data, it can be seen that polymers 16 and 19 absorb significantly up to around $1800 \mathrm{~nm}$.

Band gaps $\left(E_{\mathrm{g}}\right)$ were estimated from UV-vis spectra by fitting a tangent to the UV curve with subsequent conversion 

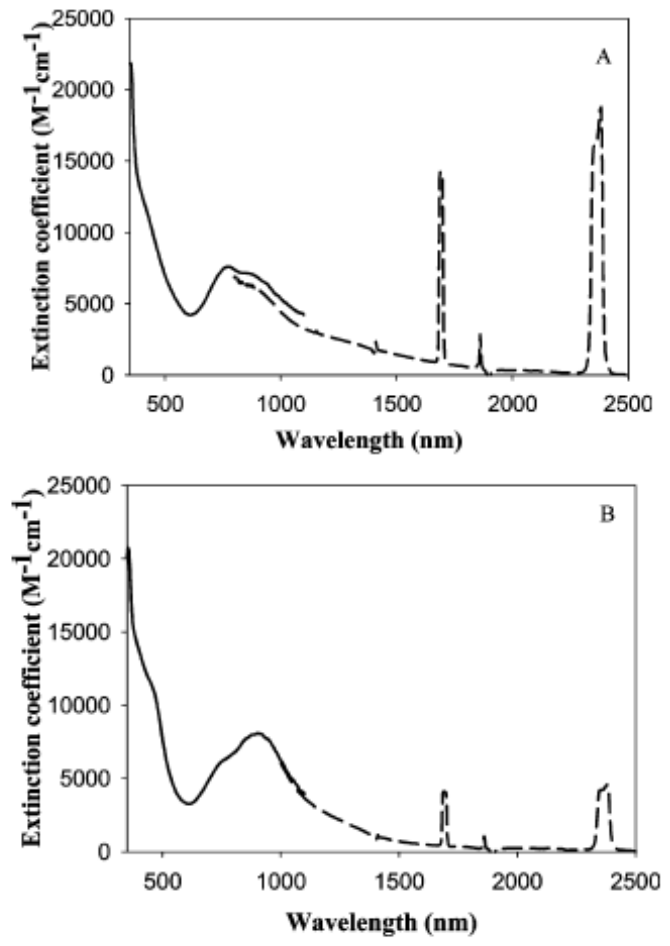
Figure 2. UV-vis (black) and NIR (dashed) for polymers 16 (A) and
19 (B). The peaks at $1400,1600,1900$, and $2400 \mathrm{~nm}$ are due to the 19 (B). The
instrument.

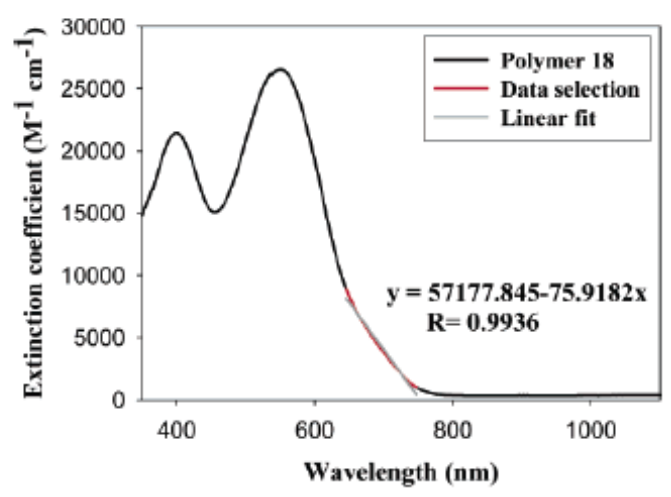

Figure 3. Band-gap estimation of polymer 18.

of the intersection with the wavelength axis $\left(x_{0}\right)$ from $\mathrm{nm}$ to $\mathrm{eV}$ (an example is given in Figure 3 with polymer 18). Because of the tailing of the absorption toward longer wavelengths (especially for polymers 16 and 19), the exact position of the optical band gap was found to be difficult to establish. We have used a conservative measure for the optical band gap, and actual values may be lower.

The band gaps are listed in Table 4 . The polymers described in the literature show band gaps of $2.0 \mathrm{eV}$ for polythiophene, ${ }^{19}$ $1.6 \mathrm{eV}$ for copolymers of thiophene, pyrrole, and benzothiadiazole, ${ }^{2,4}$ and $1.2 \mathrm{eV}$ for polyisothianaphthene. ${ }^{6}$ Comparing these polymers with polymers $14-20$ shows that polymers 14 and 17 have band gaps in the same region as polythiophene, ${ }^{19}$ polymer 15 has a band gap in the region between polythiophene and copolymers of thiophene, pyrrole, and benzothiadiazole, and polymers 18 and 20 have band gaps in the same region as copolymers of thiophene, pyrrole, and benzothiazole. ${ }^{2,4}$ Further, it can be seen that polymers 16 and 19 have lower band gaps than polyisothianaphthene. ${ }^{6}$

Ultraviolet Photoelectron Spectroscopy (UPS). The electronic structure of the materials was established by a combination of the band-gap data presented above and UPS. UPS employs the irradiation of a thin film of the sample on a metal substrate with high-energy UV photons. In the experiments performed here the incident photon energy was $50 \mathrm{eV}$. The highenergy photons result in photoelectrons that are collected and their energy measured. This gives a photoelectron spectrum that provides a map of the filled energy levels in the material and the ionization potential. One advantage of using a synchrotron source is that ESCA/XPS can be recorded for the surface region used for UPS studies. This allows for the chemical analysis, and thus one can make sure that no impurities are present and confirm the presence of the elements that are expected (in this case carbon, sulfur, and nitrogen). The method for the analysis of the UPS data has been reported earlier. ${ }^{20,21}$

The UPS spectrum and the band-gap structure of polymers 17-19 are shown in Figure 4 along with a sketch of the band structure. The UPS spectrum and band-gap structure of polymers $14-16$ and 20 are given in the Supporting Information. The results obtained by the UPS measurements on polymers 1420 are shown in Table 4 .

The values were obtained from the following equations: ${ }^{20,21}$

$$
\begin{gathered}
\Phi_{\mathrm{Au}}=h v-\mathrm{BE}_{\max } \\
E_{\mathrm{F}}{ }^{\mathrm{VB}}=\mathrm{BE}_{\min } \\
E_{\mathrm{F}}{ }^{\mathrm{VAC}}=h v-\mathrm{BE}_{\max }{ }^{20} \\
\mathrm{IP}=E_{\mathrm{F}}{ }^{\mathrm{VB}}+E_{\mathrm{F}}{ }^{\mathrm{VAC}} \\
\Delta=E_{\mathrm{F}}{ }^{\mathrm{VAC}}-\Phi_{\mathrm{Au}}
\end{gathered}
$$

where $B E_{\max }$ and $B E_{\min }$ are the cutoff at high binding energy and the onset at low binding energy, respectively. $\mathrm{BE}_{\min }$ represents the injection barrier for holes from gold into the valence band of the polymer material $\left(E_{\mathrm{f}}^{\mathrm{VB}}\right)$. The work function of the substrate $\left(\Phi_{\mathrm{Au}}\right)$ is obtained from eq 1 , where $B E_{\max }$ is obtained by measurements on a clean sample, where the Fermi level of gold is established. $E_{\mathrm{f}} \mathrm{VAC}$ is the distance from the Fermi level to the vacuum level and is obtained from eq 3 . IP, the ionization potential, is a material constant, and $\Delta$ is the vacuum level shift, i.e., the effect of the dipole layer at the interface of vacuum and the polymer layer. ${ }^{20,21}$

ESCA measurements showed no gold in the samples, indicating that the films were thick enough for the UPS measurements. Furthermore, a variation of the illuminated spot size and counting times gave the same UPS spectrum, thus eliminating the possibility of too thick films giving rise to surface charging. In the UPS experiment the Fermi level of the polymer material aligns with the Fermi level of the metal substrate. For pure semiconductors the Fermi level of the material should be in the middle of the (forbidden) optical band gap and the distance from the Fermi level to the topmost filled electronic energy level should thus be half the value for the optical band gap. In reality, this is known to vary due to impurities in the samples, and the 

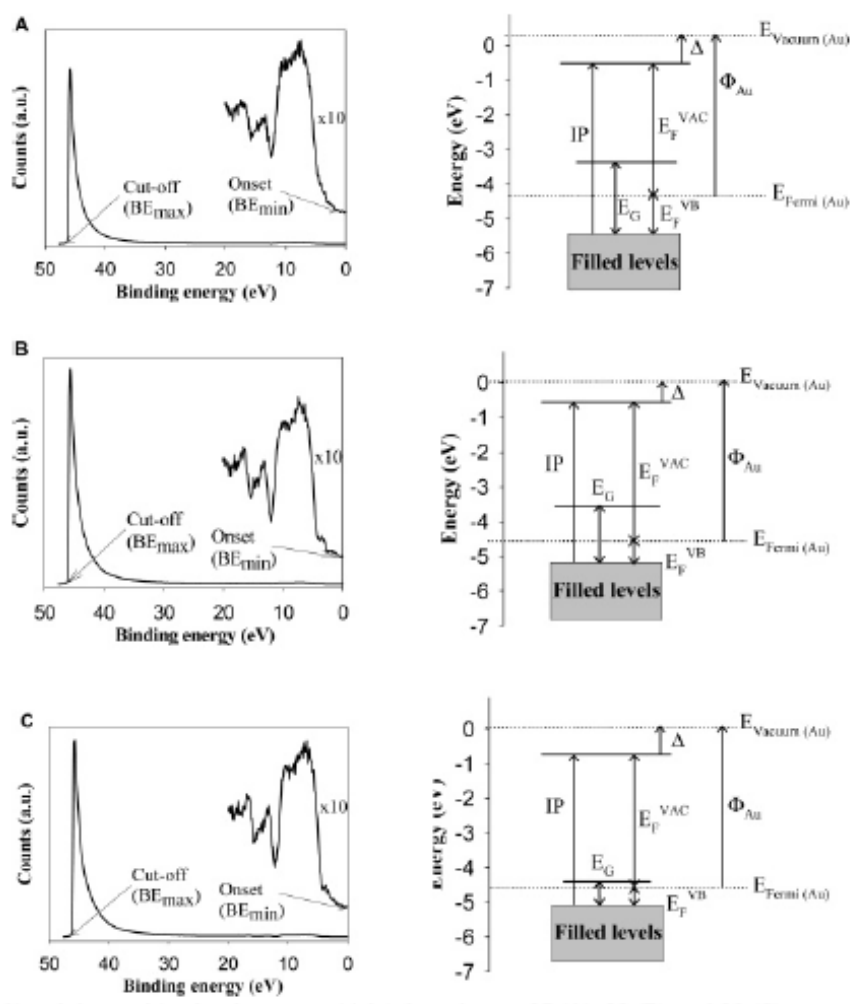

Figure 4. UPS spectra (left) and the resulting band structure (right) for polymers 17 (A), 18 (B), and 19 (C).

\begin{tabular}{|c|c|c|c|c|c|}
\hline polymer & $E_{F}^{\mathrm{VB}}(\mathrm{eV})$ & $E_{\mathrm{F}}^{\mathrm{VAC}}(\mathrm{eV})$ & $I_{\mathrm{p}}(\mathrm{eV})$ & $\Delta(\mathrm{eV})$ & $E_{0}(\mathrm{eV})$ \\
\hline $\begin{array}{l}14 \\
15 \\
16 \\
17 \\
18 \\
19 \\
20\end{array}$ & $\begin{array}{l}1.44 \\
0.80 \\
0.52 \\
1.11 \\
0.63 \\
0.48 \\
1.19\end{array}$ & $\begin{array}{l}3.96 \\
4.04 \\
3.92 \\
3.81 \\
4.04 \\
3.86 \\
3.88\end{array}$ & $\begin{array}{l}5.40 \\
5.84 \\
4.44 \\
4.92 \\
4.67 \\
4.34 \\
5.07\end{array}$ & $\begin{array}{l}-0.64 \\
-0.56 \\
-0.68 \\
-0.79 \\
-0.56 \\
-0.74 \\
-0.72\end{array}$ & $\begin{array}{l}2.10 \\
1.82 \\
0.65 \\
2.10 \\
1.65 \\
0.67 \\
1.77\end{array}$ \\
\hline
\end{tabular}

buried interface between the material and the metal substrate may shift the position of the Fermi level away from the midpoint. The ionization potential is also a direct observable from the experiment and is dependent upon the molecular orientation at the surface between the materials and vacuum. The orientation of the molecular dipoles may facilitate the escape of a photoelectron or hinder the escape. This effect is observed through the vacuum level shift, $\Delta$, that most often acquires a slightly negative value. ${ }^{22}$ The distance from the Fermi level to the topmost filled electronic energy levels, $E_{\mathrm{F}} \mathrm{VB}$, represents the barrier to the injection of holes from the metal substrate into the valence band of the conjugated polymer material.

The general observation is that the Fermi level of the materia aligns quite well with the middle of the optical band gap (Figure 4). In the case of the copolymers of thiophene and benzobis(thiadiazole), 16 and 19 , the value for $E_{\mathrm{F}} \mathrm{VB}$ is significantly larger than half the value of $E_{\mathrm{G}}$. This can be indicative of a slight amount of n-doping or an underestimation of the value for the band gap. UV-vis data for both these materials, however, show low band gap values. The low values observed for $E_{\mathrm{F}} \mathrm{VB}$ thus support our proposition of a very low band gap for these materials. Dedoping experiments with hydrazine and ammonia were attempted to establish whether the very low band gap polymers, 16 and 19 , or the polymer that exhibited a tail in the absorption spectrum, 18, were doped. This however did not change the absorption spectrum, and we conclude that the doping of the materials if present cannot be removed simply by a treatment with a chemical reducing agent (see Supporting Information). Further, we observe emission from polymer 18 and therefore assume that the impurity level is low since doping is known to efficiently quench emission (see Supporting Information). On the basis of this, we may have underestimated the band gap for the polymers 16 and 19 , and assuming that the optical band gap should be twice the value for $E_{\mathrm{F}} \mathrm{VB}$, the values for the band gaps would be 0.96 and $1.04 \mathrm{eV}$, respectively. We consider these values as upper bounds on the values for the band gap. Since the UPS experiment does not probe the empty electronic energy levels, however, the values for $E_{G}$ are still most reliably obtained from the $U V-$ vis experiment.

If the band gap $E_{\mathrm{G}}$ and the $E_{\mathrm{F}} \mathrm{VB}$ are plotted as a function of the number of thiophene units in the monomer for the polymers based on benzothiadiazole (Figure 5), it can be seen that the band gap $E_{G}$ decreases when the number of thiophene units is increased. This tendency also applies for $E_{\mathrm{F}} \mathrm{VB}$. Hence, the injection barrier for holes from the metal substrate into the polymer material is lower when the number of thiophene units is larger, $n=4$, and at the same time the band gap is lowered. 
Macromolecules, Vol. 39, No. 8, 2006

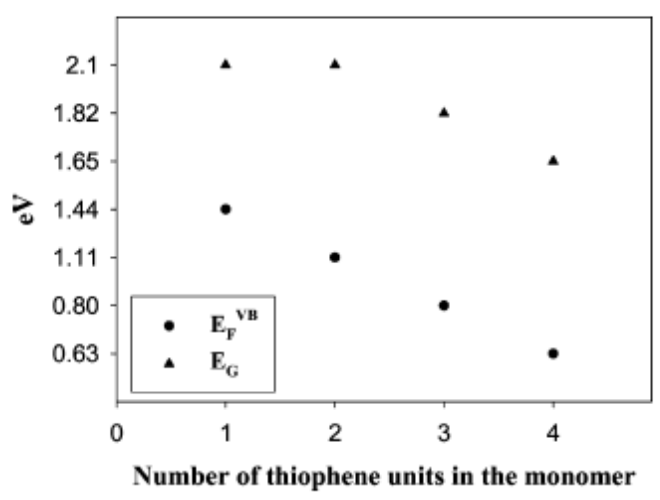

Figure 5. $E_{\mathrm{F}} \mathrm{vB}$ and $E_{\mathrm{G}}$ plotted as a function of the number of thiophene units in the monomer.

\section{Conclusion}

We have presented the synthesis of a series conjugated copolymers of thiophene and benzothiadiazole and benzobis(thiadiazole). Molecular weight, solubility, and film-forming ability were highly dependent on which side chain was used. Hexyl, 2-ethylhexyl, and dodecyl side chains gave polymer products with low molecular weight and poor solubility. We found that 3,7,11-trimethyldodecyl side chains gave polymer products with higher molecular weight, good solubility, and film-forming ability. Polymer products were characterized by SEC, UV-vis, and NMR. Band gaps were estimated by UVvis to $2.1-1.7 \mathrm{eV}$ for polymer based on benzothiadiazole and $\sim 0.7 \mathrm{eV}$ for polymers based on benzobis(thiadiazole). The electronic structures of polymers 14-20 were determined by a combination of UV-vis and UPS. This showed that both $E_{\mathrm{G}}$ and $E_{\mathrm{F}} \mathrm{VB}$ decrease with the increasing number of thiophenes in the monomer unit.

\section{Experimental Section}

General. All commercially available reagents were purchased from Aldrich 1-Bromo-3,7,11-trimethyldodecane 104 7-dibromo2,1,3-benzothiadiazole (10), 14 4,7-bis(5-bromothiophen-2-yl)-[2,1,3]benzothiadiazole (11), ${ }^{13}$ and 4,8 -dithien-2-yl- $2 \lambda^{4} \delta^{2}$-benzo[ $[1,2-c ; 4,5$ $\left.c^{\prime}\right]$ bis $[1,2,5]$ benzothiadiazole $\mathrm{e}^{15,16}$ were all synthesized according to the literature

In ${ }^{13} \mathrm{C}$ NMR for compound 8 two signals are missing. This is ascribed to accidental isocrony.

Compounds 1, 6,8, and 9 contained 2,6,10,15,19,23-hexamethyltetracosane as an impurity, and compounds 4 and 20 contained 5,8-diethyldodecane as an impurity. These alkane byproducts stem from the Würtz coupling of the alkyl halides during the Grignard reaction and are seen in the NMR spectra of the respective compounds. The products were attempted purified by chromatog. raphy and Kugelrohr distillation. It was in our hands impossible to remove these byproducts due to codistillation and very similar physical properties. Since these alkane products are neutral in terms of future chemical reactions, we chose to use these materials directly and could successfully remove the byproducts in subsequent steps.

Photophysical. The UV-vis spectra were recorded on an Schimatzu UV-1700 PharmaSpec. The NIR spectra were recorded on a Fourier transform infrared spectrometer (FTIR) Bomem/ABB model MB155. UV-vis and NIR spectra were obtained from chloroform solution. We did not observe any significant red or blue shift when comparing spectres measured on solution and film.

Size exclusion chromatography (SEC) was performed in chloroform using either of two preparative Knauer systems employing a precolumn and two gel columns in succession with respec-
Low-Band-Gap Conjugated Polymers 2829

tively pore diameters of 500,10000 , and $1000000 \AA$. All gel columns had dimensions of $25 \mathrm{~mm}$ diameter $\times 600 \mathrm{~mm}$. Poly styrene standards were used for molecular weight determination. Ultraviolet Photoelectron Spectroscopy (UPS). Gold was evaporated on the aluminum substrates in a vacuum chamber at a pressure $<5 \times 10^{-6}$ mbar. Hereafter, the $2.7 \mu \mathrm{m}$ microfiltered polymer solutions were spin-coated on the substrate from chloroform or THF. The UPS measurements were carried out with 50 $\mathrm{eV}$ photons at the ASTRID synchrotron at University of Aarhus, Denmark. The setup of the experiment was described previously. ${ }^{23-2}$

General Procedure for Addition of Alkyl Chain to Thiophene (Grignard Reaction). ${ }^{11}$ Magnesium tumings $(0.31 \mathrm{~mol})$ were crunched under argon for $30 \mathrm{~min}$. Ether $(250 \mathrm{~mL}$ ) and iodine (to color change) were added. A few drops of bromoalkane were added, and the mixture left until the reaction started (heating with a hea gun and addition of a few drops of 1,2-dibromoethane helped to start the reaction). Once started (color change from orange to gray), bromoalkane ( $0.31 \mathrm{~mol}, 10 \%$ excess) was added dropwise, keeping the reaction at gentle reflux. After end addition the mixture was left stirring for $30 \mathrm{~min}$. At this point the catalyst, Nidppp $(225 \mathrm{mg})$ was added in one portion. After the foaming had subsided 3-bromothiophene $(0.3 \mathrm{~mol})$ was added dropwise, keeping the reaction mixture at gentle reflux. After each $1 / 4$ of addition, furthe Nidppp (135 mg) was added. At the end of the addition, further Nidppp (135 mg) was added, and the mixture was left stiring overnight. The following day the mixture was hydrolyzed by carefil addition of water $(110 \mathrm{~mL})$ for $1 \mathrm{~h}$ followed by $37 \%$ aqueous $\mathrm{HCl}$ addition of water $(110 \mathrm{~mL})$ for $1 \mathrm{~h}$ followed by $37 \%$ aqueous $\mathrm{HCl}$
$(45 \mathrm{~mL})$ for $30 \mathrm{~min}$. The light brown organic phase was separated, dried $\left(\mathrm{MgSO}_{4}\right)$, evaporated, distilled, and purified by flash chromatography (cyclohexane) to give the product.

3 -(3,7,11-Trimethyldodecyl)thiophene (1): yield $61 \%$, colorless oil, bp $120-123^{\circ} \mathrm{C}$ at 5 mbar. ${ }^{1} \mathrm{H} N \mathrm{NM}\left(250 \mathrm{MHz}, \mathrm{CDCl}_{3}\right): \delta=$ $7.25-7.22(\mathrm{~m}, 1 \mathrm{H}), 6.95-6.92(\mathrm{~m}, 2 \mathrm{H}), 2.68-2.59(\mathrm{~m}, 2 \mathrm{H}), 1.70-$ $1.01(\mathrm{~m}, 17 \mathrm{H}), 0.98-0.79(\mathrm{~m}, 12 \mathrm{H}){ }^{13} \mathrm{C} \mathrm{NMR}\left(75 \mathrm{MHz}^{\circ} \mathrm{CDCl}_{3}\right)$ $\delta=143.40,128.24,125.01,119.61,39.42,37.91,37.83,37.46$ $37.42,37.34,37.30,37.26,32.83,32.52,28.01,27.89,26.97,24.84$ $24.42,22.73,22.64,19.78,19.71,19.64,19.58$. 3-(2-Ethylhexyl)thiophene (2): yield 95\%, colorless oil, bp
$150-152^{\circ} \mathrm{C}$ at 10 mbar. ${ }^{1} \mathrm{H}$ NMR $\left(250 \mathrm{MHz}, \mathrm{CDCl}_{3}\right): \delta=7.22$ (dd, $1 \mathrm{H}, J=4.75,3 \mathrm{~Hz}), 6.92-6.89(\mathrm{~m}, 2 \mathrm{H}), 2.56(\mathrm{~d}, 2 \mathrm{H}, J=$ $6.75 \mathrm{~Hz}), 1.60-1.50(\mathrm{~m}, 1 \mathrm{H}), 1.34-1.18(\mathrm{~m}, 10 \mathrm{H}), 0.92-0.80(\mathrm{~m}$ $7 \mathrm{H}) 3 \mathrm{H}$ too many. ${ }^{13} \mathrm{C}$ NMR $\left(75 \mathrm{MHz}, \mathrm{CDCl}_{3}\right): \delta=141.90$ $128.77,124.73,120.59,40.41,34.30,32.53,28.90,25.66,22.99$, 14.06, 10.81. MS (HRMS): $m / z$ calcd for $\left[\mathrm{C}_{12} \mathrm{H}_{21} \mathrm{~S}\right]+197.1364$; found 197.1238 .

General Procedure for Trialkylstannylation of Alkylthiophene with $n \mathrm{BuLi}$ and TMEDA. Alkylthiophene $(7 \mathrm{mmol})$ and TMEDA (10.5 mmol, 1.5 equiv) in hexane $(50 \mathrm{~mL})$ was cooled to $-78^{\circ} \mathrm{C} . n \mathrm{BuLi}$ (10.5 mmol, 1.5 equiv) was added dropwise over $30 \mathrm{~min}$. The cooling bath was removed, and the reaction was stirred at room temperature for $2 \mathrm{~h}$. The reaction mixture was cooled back down to $-78^{\circ} \mathrm{C}$, and trimethylstannyl chloride ( $17 \mathrm{mmol}, 2.5$ equiv) was added. After $1 \mathrm{~h}$ at room temperature, the mixture was washed with water, dried, evaporated, and purified by Kugelrohr distillation

2-(Trimethylstannyl)-4-(3,7,11-trimethyldodecyl)thiophene (3): yield $54 \%$, colorless oil, bp $175^{\circ} \mathrm{C}$ at $8 \times 10^{-3}$ mbar. ${ }^{1} \mathrm{H}$ $\operatorname{NMR}\left(250 \mathrm{MHz}, \mathrm{CDCl}_{3}\right): \delta=7.20$ (s, 1H), 7.01 (s, 1H), $2.77-$ $2.55(\mathrm{~m}, 2 \mathrm{H}), 1.72-1.01(\mathrm{~m}, 19 \mathrm{H}), 0.93-0.84(\mathrm{~m}, 13 \mathrm{H}), 0.47$ $0.24(\mathrm{~m}, 9 \mathrm{H}) .{ }^{13} \mathrm{C} \mathrm{NMR}\left(75 \mathrm{MHz}, \mathrm{CDCl}_{3}\right): \delta=144.75,137.24$ $136.58,125.49,39.38,38.06,37.97,37.43,37.38,37.30,37.26$ $37.23,32.78,32.63,27.67,27.52,24.78,24.39,22.69,22.60,19.74$, 19.68, 19.64, 19.58, -8.35 .

General Procedure for Trialkylstannylation of Alkylthio phene with LDA. ${ }^{12,26} \mathrm{LDA}$ in THF/ethylbenzene/heptane (2 M $0.2 \mathrm{~mol})$ was added dropwise to a solution of alkylthiophene $(0.2$ $\mathrm{mol})$ in dry THF $(300 \mathrm{~mL})$ cooled to $-78^{\circ} \mathrm{C}$ under argon. After the end of the addition the mixture was allowed to reach $0^{\circ} \mathrm{C}$ for $3 \mathrm{~h}$. The mixture was then cooled back down to $-78^{\circ} \mathrm{C}$, and tributylstannyl chloride $(0.2 \mathrm{~mol})$ was added in one portion. The brown color disappeared, and the temperature rose to $-40^{\circ} \mathrm{C}$. The mixture was allowed to reach room temperature. Hexane was added 
to the reaction mixture, and it was washed with water, dried $\left(\mathrm{MgSO}_{4}\right)$, filtered, evaporated, and purified by Kugelrohr distillation. 4-(2-Ethylhexyl)-2-tributylstannylthiophene (4): yield $42 \%$, yellow oil bp $140^{\circ} \mathrm{C}$ at $3 \times 10^{-3}$ mbar. ${ }^{1} \mathrm{H}$ NMR $(250 \mathrm{MHz}$, $\left.\mathrm{CDCl}_{3}\right): \delta=7.16(\mathrm{~s}, 1 \mathrm{H}), 6.93(\mathrm{~s}, 1 \mathrm{H}), 2.60(\mathrm{~d}, 2 \mathrm{H}, J=3.5 \mathrm{~Hz})$, $1.73-1.46(\mathrm{~m}, 10 \mathrm{H}), 1.43-1.89(\mathrm{~m}, 20 \mathrm{H}), 1.57-1.00(\mathrm{~m}, 8 \mathrm{H})$ $0.98-0.85(\mathrm{~m}, 20 \mathrm{H}) .{ }^{13} \mathrm{C}$ NMR $\left(75 \mathrm{MHz}, \mathrm{CDCl}_{3}\right): \delta=142.98$ $137.43,135.83,126.32,40.56,33.95,32.60,28.95,28.19,27.84$, $27.20,25.79,23.03,16.41,14.07,13.60,10.89,10.77$.

4,4'-Bis(3,7,11-trimethyldodecyl)-2,2'-dithiophene (6). 3-(3,7, 11-Trimethyldodecyl)thiophene $(4.0 \mathrm{~g}, 13.6 \mathrm{mmol})$ in THF (100 $\mathrm{mL})$ was cooled to $-78^{\circ} \mathrm{C}$. $n \mathrm{BuLi}(21.26 \mathrm{~mL}, 34.0 \mathrm{mmol}, 2.5$ equiv) was added dropwise. The temperature rose to $-40^{\circ} \mathrm{C}$. After stirring for $10 \mathrm{~min}, \mathrm{I}_{2}$ in THF was added until the color changed to weak yellow. The reaction was allowed to reach room temperature $\mathrm{Pd}\left(\mathrm{PPh}_{3}\right)_{2} \mathrm{Cl}_{2}(600 \mathrm{mg}, 0.9 \mathrm{mmol})$ was added, and the mixture was heated to reflux. 2-(Trimethylstannyl)-4-(3,7,11-trimethyldodecyl)thiophene $(5.596 \mathrm{~g}, 12.2 \mathrm{mmol})$ was added dropwise for $30 \mathrm{~min}$ The reaction was left stiming overnight under reflux. The reaction mixture was evaporated, filtered through silica (hexane), and purified by Kugelrohr distillation. Yield $55 \%$ (4.39 g), green oil bp $275^{\circ} \mathrm{C}$ at $3 \times 10^{-3}$ mbar. ${ }^{1} \mathrm{H}$ NMR $\left(250 \mathrm{MHz}, \mathrm{CDCl}_{3}\right): \delta=$ $6.94(\mathrm{~d}, 2 \mathrm{H}, J=1 \mathrm{~Hz}), 6.77(\mathrm{~d}, 2 \mathrm{H}, J=1 \mathrm{~Hz}), 2.68-2.44(\mathrm{~m}$ $4 \mathrm{H}), 1.70-1.01(\mathrm{~m}, 40 \mathrm{H}), 0.96-0.76(\mathrm{~m}, 27 \mathrm{H}) .{ }^{13} \mathrm{C} \mathrm{NMR}(75 \mathrm{MHz}$, $\left.\mathrm{CDCl}_{3}\right): \delta=144.23,137.42,124.80,118.56,39.39,37.72,37.63$ $37.43,37.39,37.30,37.25,37.21,32.78,32.47,28.10,27.97,24.79$, $24.38,22.70,22.61,19.75,19.69,19.61,19.56$. MS (HRMS): $\mathrm{m} / \mathrm{z}$ calcd for $\left[\mathrm{C}_{38} \mathrm{H}_{67} \mathrm{~S}_{2}\right]^{+} 587.4679$; found 587.4705 .

3-(3,7,11-Trimethyldodecyl)-2,5-bis(trimethylstannyl)thiophene (8). 3-(3,7,11-Trimethyldodecyl)thiophene $(1 \mathrm{~g}, 3.4 \mathrm{mmol})$ in hexane $(25 \mathrm{~mL})$ was cooled to $-78^{\circ} \mathrm{C}$. $t \mathrm{BuLi}(10.0 \mathrm{~mL}, 17$ mmol) was added dropwise over $30 \mathrm{~min}$ (yellow solution). The cooling bath was removed, and the reaction was stirred at room temperature for $3 \frac{1}{2}$ days (yellow suspension). The mixture was cooled back down to $-78^{\circ} \mathrm{C}$, and trimethylstannyl chloride in hexane $(23.8 \mathrm{~mL}, 23.8 \mathrm{mmol}$ ) was added (yellow to white suspension). After $1 \mathrm{~h}$ at room temperature, the mixture was washed with water, dried, evaporated, and purified by Kugelrohr distillation. Yield: $57 \%(1.2 \mathrm{~g})$, yellow oil, bp $200^{\circ} \mathrm{C}$ at $4 \times 10^{-3} \mathrm{mbar} .{ }^{1} \mathrm{H}$ NMR $\left(250 \mathrm{MHz}, \mathrm{CDCl}_{3}\right): \delta=7.19(\mathrm{~s}, 1 \mathrm{H}), 2.78-2.57(\mathrm{~m}, 2 \mathrm{H})$ $1.69-1.02(\mathrm{~m}, 24 \mathrm{H}), 0.96-084(\mathrm{~m}, 15 \mathrm{H}), 0.49-0.24(\mathrm{~m}, 18 \mathrm{H})$ ${ }^{13} \mathrm{C} \mathrm{NMR}\left(75 \mathrm{MHz} \mathrm{CDCl}_{3}\right): \delta=152.13,143.13,137.45,39.83$ $39.74,39.39,37.46,37.41,37.32,33.18,32.82,29.81,27.98,24.81$ $24.47,22.71,22.62,19.76,19.70,-7.96,-8.21$. MS (HRMS): $m / z$ calcd for $\left[\mathrm{C}_{25} \mathrm{H}_{50} \mathrm{SSn}_{2} \mathrm{Na}\right]^{+} 643.1597$; found 643.2317 .

4,4'-Bis(3,7,11-trimethyldodecyl)-5,5'-bis(trimethylstannyl)2,2'-dithiophenyl (9). 4,4'-Bis(3,7,11-trimethyldodecyl)-2,2'-dithiophene $(2 \mathrm{~g}, 3.4 \mathrm{mmol})$ and TMEDA $(1.53 \mathrm{~mL}, 10.2 \mathrm{mmol}, 3$ equiv) in hexane $(50 \mathrm{~mL})$ was cooled to $-78^{\circ} \mathrm{C} . n \mathrm{BuLi}(6.38 \mathrm{~mL}$ $10.2 \mathrm{mmol}, 3$ equiv) was added dropwise over $30 \mathrm{~min}$ (orange solution). The cooling bath was removed, and the reaction was stirred at room temperature for $1 \mathrm{~h}$ (light orange suspension). The mixture was cooled back down to $-78{ }^{\circ} \mathrm{C}$, and trimethylstannyl chloride ( $17 \mathrm{~mL}, 17.0 \mathrm{mmol}, 5$ equiv) was added (yellow solution). After $1 \mathrm{~h}$ at room temperature (yellow suspension), the mixture was washed with water, dried, evaporated, and purified by Kugelrohr distillation. Yield: $75 \%$ (2.34 g), yellow oil, bp $250^{\circ} \mathrm{C}$ at $3 \times 10^{-3}$ mbar. ${ }^{1} \mathrm{H} \mathrm{NMR}\left(250 \mathrm{MHz}, \mathrm{CDCl}_{3}\right): \delta=7.11(\mathrm{~s}, 2 \mathrm{H})$ $2.69-2.47(\mathrm{~m}, 4 \mathrm{H}), 1.68-1.03(\mathrm{~m}, 42 \mathrm{H}), 0.97-0.83(\mathrm{~m}, 28 \mathrm{H})$ $0.50-0.27(18 \mathrm{H}, \mathrm{m}) .{ }^{13} \mathrm{C}$ NMR $\left(75 \mathrm{MHz}, \mathrm{CDCl}_{3}\right): \delta=151.77$ $142.76,130.75,126.01,39.50,39.38,37.44,37.40,37.35,37.31$ $33.01,32.81,30.51,27.97,24.80,24.45,22.71,22.62,19.76,19.73$, $19.70,19.68,-7.89$

4,7-Bis(5-bromothiophen-2-yl)-2 $\lambda^{4} \delta^{2}$-benzo $\left[1,2-c ; 4,5-c^{\prime}\right]$ bis$[1,2,5]$ thiadiazole (12). NBS (903.1 mg, $5.1 \mathrm{mmol}, 2.5$ equiv) in $\mathrm{CHCl}_{3} / \mathrm{AcOH}(5 \mathrm{~mL})$ was added dropwise to a solution of 4,8 dithien-2-yl-2 $\lambda^{4} \delta^{2}$-benzo[1,2-c;4,5-c'] bis [1,2,5]benzothiadiazole (728.3 $\mathrm{mg}, 2 \mathrm{mmol}$ ) in $\mathrm{CHCl}_{3} / \mathrm{AcOH}(1 \mathrm{~L})$ in darkness. After $2 \frac{1}{2} \mathrm{~h}$ the mixture was filtered and recrystallized from DMF. Yield: $83 \%$ $(870.3 \mathrm{mg})$, green solid. ${ }^{1} \mathrm{H}$ NMR $(250 \mathrm{MHz}$, 1,2-dichlorobenzene$d_{4} / N, N$-dimethylforamide- $\left.d_{7} 1: 1,400 \mathrm{~K}\right): \delta=8.92(\mathrm{~d}, 1 \mathrm{H}, J=4$
$\mathrm{Hz}), 7.48(\mathrm{~d}, 1 \mathrm{H}, J=4 \mathrm{~Hz})$. UV-vis $\left(\mathrm{CHCl}_{3}\right) \lambda_{\max } 735 \mathrm{~nm}(\log \epsilon$ 4.40). Anal. Calcd for $\mathrm{C}_{14} \mathrm{H}_{4} \mathrm{Br}_{2} \mathrm{~N}_{4} \mathrm{~S}_{4}: \mathrm{C}, 32.57 ; \mathrm{H}, 0.78 ; \mathrm{N}, 10.85$. Found: C, 33.44; H, 0.64; N, 10.84.

General Procedure for Stille Coupling, ${ }^{12,15,16}$ To a solution of the dibromo compound (1.0 mmol) and 2-(tributylstannyl)thiophene $(2.5 \mathrm{mmol})$ in THF $(3.5 \mathrm{~mL}), \mathrm{Pd}\left(\mathrm{PPh}_{3}\right)_{2} \mathrm{Cl}_{2}\left(6.25 \times 10^{-2} \mathrm{mmol}\right)$ was added. The mixture was refluxed until the reaction terminated, after which it was washed, cooled, evaporated, and purified by flash chromatography and recrystallized.

4,7-Bis (4'-(2-ethylhexyl)-2,2'-dithiophenyl-5-yl)benzo [1,2,5] thiadiazole (13): yield $37 \%$, dark red oil. ${ }^{1} \mathrm{H}$ NMR $(250 \mathrm{MHz}$, $\left.\mathrm{CDCl}_{3}\right): \delta=8.03(\mathrm{~d}, 2 \mathrm{H}, J=4 \mathrm{~Hz}), 7.86(\mathrm{~s}, 2 \mathrm{H}), 7.25$ (d, $2 \mathrm{H}, J$ $=4 \mathrm{~Hz}), 7.12(\mathrm{~d}, 2 \mathrm{H}, J=1 \mathrm{~Hz}), 6.84(\mathrm{~d}, 2 \mathrm{H}, J=1 \mathrm{~Hz}), 2.55(\mathrm{~d}$ $4 \mathrm{H}, J=7 \mathrm{~Hz}), 1.69-1.58(\mathrm{~m}, 2 \mathrm{H}), 1.37-1.31(\mathrm{~m}, 16 \mathrm{H}), 0.91(\mathrm{t}$, $12 \mathrm{H}, J=7.25 \mathrm{~Hz}){ }^{13} \mathrm{C}$ NMR $\left(75 \mathrm{MHz}, \mathrm{CDCl}_{3}\right): \delta=152.50$ $143.06,139.32,137.75,136.64,128.18,125.90,125.56,125.11$, $124.19,120.42,40.30,34.63,32.53,28.90,25.66,23.02,14.09$, 10.83. Anal. Calcd for $\mathrm{C}_{38} \mathrm{H}_{44} \mathrm{~N}_{2} \mathrm{~S}_{5}$ : C, $66.23 ; \mathrm{H}, 6.44 ; \mathrm{N}, 4.07$ Found: C, 66.13; H, 6.28; N, 3.86

General Procedure for Stille Cross-Coupling Polymerization. Bis(stannyl)alkylthiophene $(0.5 \mathrm{mmol})$ and dibromo compound $(0.5$ mmol) were mixed in DMF (150 mL, fresh bottle). The mixture was degassed with argon, and $\mathrm{Pd}\left(\mathrm{PPh}_{3}\right)_{2} \mathrm{Cl}_{2}(30 \mathrm{mg})$ was added. The mixture was heated to $150^{\circ} \mathrm{C}$. After a prepolymer had precipitated, THF $(75 \mathrm{~mL})$ was added, and the reaction was stirred at $150^{\circ} \mathrm{C}$ for $3-4$ days. The suspension was evaporated, and the polymer was precipitated with $\mathrm{MeOH} / \mathrm{H}_{2} \mathrm{O}(1-1.5 \mathrm{~L})$. The suspension was filtered to give the polymer, which was purified by Soxhle extraction with $\mathrm{MeOH}$, hexane, and chloroform. The chloroform fraction was evaporated, and further purification was carried out by preparative SEC. The polymer was purified from $\mathrm{Pd}$ particles rature.

Poly\{(benzo-2,1,3-thiadiazol-4,7-diyl)-(4-(3,7,11-trimethyldodecyl)thiophen-2-yl)\} (14): yield $54 \%$. ${ }^{1} \mathrm{H}$ NMR $(250 \mathrm{MHz}$ $\left.\mathrm{CDCl}_{3}\right): \delta=8.24-7.33(\mathrm{~m}, 1.5 \mathrm{H}), 7.18-6.81(\mathrm{~m}, 0.5 \mathrm{H}), 3.10-$ $2.34(\mathrm{~m}, 2 \mathrm{H}), 1.91-1.12(\mathrm{~m}, 17 \mathrm{H}), 1.12-1.063(\mathrm{~m}, 12 \mathrm{H}) . \mathrm{UV}-$ vis: $\left(\mathrm{CHCl}_{3}, \mathrm{~nm}\right) 477(\log \in 3.85)$. SEC $(500 \AA+10000 \AA+$ $1000000 \AA) M_{\mathrm{w}}=5824 ; M_{\mathrm{p}}=4803 ; M_{\mathrm{w}} M_{\mathrm{n}}=1.436$. Contained $<100 \mathrm{ppm}$ Pd particles.

Poly $\{$ (benzo-2,1,3-thiadiazol-4,7-divl)-(4'-(3,7,11-trimethyldodecyl)-2,2'; $\mathbf{5}^{\prime}, \mathbf{2}^{\prime \prime}$-tertthiophen-5,5'-divl) $\}$ (15): yield $60 \%$. ${ }^{1} \mathrm{H}$ $\operatorname{NMR}\left(250 \mathrm{MHz}, \mathrm{CDCl}_{3}\right): \delta=8.22-767(\mathrm{~m}, 3 \mathrm{H}), 7.51-7.30$ $(\mathrm{m}, 1 \mathrm{H}), 7.24-6.82(\mathrm{~m}, 3 \mathrm{H}), 3.09-2.67(\mathrm{~m}, 2 \mathrm{H}), 1.85-1.00(\mathrm{~m}$, $34 \mathrm{H}, 17$ too many $\left.\mathrm{H}_{2} \mathrm{O}\right), 0.95-0.83(\mathrm{~m}, 12 \mathrm{H})$. UV-vis: $\left(\mathrm{CHCl}_{3}\right.$ nm) $435,602(\log \in 4.05,5.22)$. SEC $(500 \AA+10000 \AA+1000000$ A) $M_{w}=2289 ; M_{\mathrm{p}}=2099 ; M_{\mathrm{w}} / M_{\mathrm{u}}=1.280$. Contained $<100 \mathrm{ppm}$ $\mathrm{Pd}$ particles.

Poly\{(benzo-2,1,3-bis-thiadiazol-4,7-diyl)-(4'-(3,7,11-trimethyldodecyl)-2,2'; $\mathbf{5}^{\prime}, \mathbf{2}^{\prime \prime}$-tertthiophen-5,5'-diyl) $\}$ (16): yield $83 \%$. ${ }^{1} \mathrm{H}$ NMR $\left(250 \mathrm{MHz}, \mathrm{CDCl}_{3}\right): \delta=9.12-8.58(\mathrm{~m}, 0.5 \mathrm{H}), 8.13-7.61$ $(\mathrm{m}, 0.5 \mathrm{H}), 7.42-7.31(\mathrm{~m}, 1.5 \mathrm{H}), 7.16-6.62(\mathrm{~m}, 2 \mathrm{H}), 2.88-2.17$ $(\mathrm{m}, 2 \mathrm{H}), 1.88-0.98(\mathrm{~m}, 17 \mathrm{H}), 0.98-0.60(\mathrm{~m}, 12 \mathrm{H}) . \mathrm{UV}-\mathrm{vis}$ $\left(\mathrm{CHCl}_{3}, \mathrm{~nm}\right) 770(\mathrm{log} \in 3.88)$. NIR: $\left(\mathrm{CHCl}_{3}, \mathrm{~nm}\right)$ tail to 1800 . $\operatorname{SEC}(500 \AA+10000 \AA+1000000 \AA) M_{\mathrm{w}}=7095 ; M_{\mathrm{p}}=8594$; $M_{\mathrm{w}} / M_{\mathrm{n}}=1.860$. Contained $<100 \mathrm{ppm}$ Pd particles.

Poly $\{$ (benzo-2,1,3-thiadiazol-4,7-divl)-(4,4'-di(3,7,11-trimethyldodecyl)-2,2'-dithiophen-5,5'-diyl) $\}$ (17): yield $69 \%$. ${ }^{1} \mathrm{H}$ NMR $\left(250 \mathrm{MHz}, \mathrm{CDCl}_{3}\right): \delta=7.71(\mathrm{~s}, 1 \mathrm{H}), 7.18-7.13(\mathrm{~m}, 1 \mathrm{H}), 3.13-$ $2.38(\mathrm{~m}, 4 \mathrm{H}), 1.69-0.86(\mathrm{~m}, 34 \mathrm{H}), 0.86-0.61(24 \mathrm{H})$. UV-vis: $\left(\mathrm{CHCl}_{3}, \mathrm{~nm}\right) 479(\log \epsilon 4.15)$. SEC $(500 \AA+10000 \AA+1000000$ A) $M_{w}=9368 ; M_{p}=9461 ; M_{w} / M_{n}=1.807$. Contained $<100 \mathrm{ppm}$ Pd particles.

Polv\{(benzo-2,1,3-thiadiazol-4,7-divl)-(3',4"'-di(3,7,11-trimethyldodecyl)-2,2'; ;', $2^{\prime \prime} ; \mathbf{5}^{\prime \prime}, 2^{\prime \prime \prime}$-quaterthiophen-5,5'-yl)\} (18): yield $93 \%$. ${ }^{1} \mathrm{H} \mathrm{NMR}\left(250 \mathrm{MHz}^{-} \mathrm{CDCl}_{3}\right): \delta=8.22-8.01(\mathrm{~m}, 1 \mathrm{H}), 7.93-$ $7.75(\mathrm{~m}, 1 \mathrm{H}), 7.12-6.78(\mathrm{~m}, 2 \mathrm{H}), 2.96-2.48(\mathrm{~m}, 4 \mathrm{H}), 1.80-0.84$ (m, 63H). UV-vis: $\left(\mathrm{CHCl}_{3}, \mathrm{~nm}\right) 450,597(\mathrm{log} \epsilon 4.38,4.41)$. SEC $(500 \AA+10000 \AA+1000000 \AA) M_{w}=13861 ; M_{p}=12250 ;$ $M_{\mathrm{w}} / M_{\mathrm{z}}=1.880$. Contained $<100 \mathrm{ppm}$ Pd particles.

Poly $\{$ (benzo-2,1,3-bis-thiadiazol-4,7-diyl)-(3',4"'-di(3,7,11-trimethyldodecyl)-2,2'; $\mathbf{5}^{\prime}, 2^{\prime \prime} ; 5^{\prime \prime}, 2^{\prime \prime \prime}$-quaterthiophen-5,5'-yl)\} (19): 
Macromolecules, Vol. 39, No. 8, 2006

yield quant. ${ }^{1} \mathrm{H} \mathrm{NMR}\left(250 \mathrm{MHz}, \mathrm{CDCl}_{3}\right) ; \delta=9.08-8.90(\mathrm{~m}, 1 \mathrm{H})$, $7.80-7.59(\mathrm{~m}, 1 \mathrm{H}), 7.41-7.30(\mathrm{~m}, 1 \mathrm{H}), 7.21-6.78(\mathrm{~m}, 1 \mathrm{H}), 2.79-$ $2.55(\mathrm{~m}, 4 \mathrm{H}), 1.90-1.09(\mathrm{~m}, 60 \mathrm{H}, 26$ too many), 1.09-0.61 (m, $34 \mathrm{H}, 10$ too many). UV-vis: $\left(\mathrm{CHCl}_{3}, \mathrm{~nm}\right) 902(\log \in 3.91)$. NIR: $\left(\mathrm{CHCl}_{3}, \mathrm{~nm}\right)$ tail to 1800 . SEC $(500 \AA+10000 \AA+1000000$ A) $M_{w}=11705 ; M_{p}=10819 ; M_{w} / M_{n}=2.061$. Contained $<100$ ppm Pd particles.

General Procedure for Oxidative Ferric Chloride Polvmerization. ${ }^{17}$ The monomer $(0.5 \mathrm{mmol})$ in $\mathrm{CHCl}_{3}(10 \mathrm{~mL})$ was added dropwise to a mixture of $\mathrm{FeCl}_{3}(1.26 \mathrm{mmol})$ in $\mathrm{CHCl}_{3}(150 \mathrm{~mL})$, After $25 \mathrm{~h}$ of reflux the reaction was cooled, washed with aqueos $\mathrm{H}_{2} \mathrm{SO}_{4}$ and aqueous $\mathrm{Na}_{2} \mathrm{SO}_{3}$, dried $\left(\mathrm{MgSO}_{4}\right)$, filtered, and evaporated to a smaller fraction, which was poured into $\mathrm{MeOH}(1 \mathrm{~L})$. The suspension was filtered to give the polymer, which was washed with methanol and dried in a vacuum oven Polymer 35 was purified by preparative SEC.

Poly $\{4,7$-bis (4'-(2-ethylhexyl)-2,2'-dithiophene)benzo $[1,2,5]$ thiadiazole \} (20): yield $74 \%$ ' ${ }^{1} \mathrm{H}$ NMR $\left(250 \mathrm{MHz}, \mathrm{CDCl}_{3}\right) ; \delta=$ $8.22-7.77(\mathrm{~m}, 1 \mathrm{H}), 7.16-6.93(\mathrm{~m}, 2 \mathrm{H}), 6.84-6.27(\mathrm{~m}, 1 \mathrm{H}), 2.87-$ $2.21(\mathrm{~m}, 2 \mathrm{H}), 1.82-1.53(\mathrm{~m}, 2 \mathrm{H}), 1.43-1.02(\mathrm{~m}, 16 \mathrm{H}), 1.02-$ $0.84(\mathrm{~m}, 12 \mathrm{H})$. UV-vis $\left(\mathrm{CHCl}_{3}, \mathrm{~nm}\right): 428,586(\mathrm{log} \in 4.46,4.53)$. $\operatorname{SEC}(500 \AA+10000 \AA+1000000 \AA) M_{\mathrm{w}}=86362 ; M_{\mathrm{p}}=$ $60258 ; M_{w} / M_{m}=1.994$

Acknowledgment. We gratefully acknowledge Lene Hubert for assistance with the ESCA measurements and Zheshen $\mathrm{Li}$ for technical support at the ASTRID storage ring and at the beamline. This work was supported by the Danish Technical Research Council (STVF 2058-03-0016) and the Danish Strategic Research Council (DSF 2104-04-0030, DSF 2104-050052).

Supporting Information Available: Detailed synthesis attempts of compounds 6,8 , and 9 and synthesis of polymers $14-16$ with 2-ethylhexyl side chains, polymers $17-19$ with hexyl side chains in a head-to-tail coupling, and polymer 20 with hexyl or dodecyl side chains; SEC traces of polymers 14-20 and UPS schemes of polymers $14,15,16$, and 20 ; dedoping experiments of the polymers 16,18 , and 19 using hydrazine and ammonia; emission spectrum for polymer 18. This information is available free of charge via the Internet at $\mathrm{http} / /$.pubs.acs.org.

\section{References and Notes}

(1) (a) Andersson, M. R.; Thomas, O.; Mammo, W.; Svensson, M; Theander, M.; Inganäs, O J Mater. Chem. 1999, O 1933-1940. (b) Brabec, C. J.; Sariciftci, N. S.; Hummelen, J. C. Adv. Funct. Mater.
Low-Band-Gap Conjugated Polymers 2831

2001, 11, 15-26. (c) Spanggaard, H.; Krebs, F. C. Sol Energr Mater. Sol. Cells 2004, 83, 125-146. (d) Coakly, K. M.; McHehee, M D. Chem. Mater. 2004, 10, 4533-4542. (e) Hoppe, H.; Sariciftci, N. S. Chem. Mater. 2004, 10, 4533-4542. (e) Hoppe, H.; Sariciftci, N. S
J. Mater. Rer. 2004, 19, 1924-1945. (f) Special Issue: The Development of Organic and Polymer Photovoltaics. Sol. Energy Mater. Sol. Cells 2004, 83, issues 2-3. (g) Special Issue: Organic-Based Cells 2004, 83, issues 2-3. (g) Special Issue: Orgamic-Based
Photovoltaics. MRS Bull. 2005, 30, issue 1. (h) Krebs, F. C.; Shrotriya, V.; Huang, J.; Yao, Y.; Moriarty, T.; Emery, K; Yang, Y. Nat. Mater. 2005, 4, 864-868.

(2) Brabec, C. J.; Winder, C.; Sariciftci, N. S.; Hummelen, J. C. Dhanabalan, A.; van Hal, P. A.; Janssen, R. A.j. Adv. Funct. Mater. 2002, 12, 709-712

(3) Dhanabalan, A.; van Duren, J. K. J.; van Hal, P. A.; van Dogen, J. L.

J.; Janssen, R. A. J. Adv. Funct. Mater. 2001, $11,255-262$.

Synth. Met. 2001, 121, 1587-1588.

(5) Winder, C. Saricifci, S. J. Mater. Chem. 2004, 14, 1077-1086

Kiebooms, R. H. L.; Goto, H.; Akagi, K. Macromolecules 2001, 34, 989-7998.

(7) Wudl, F.; Kobayashi, M; Heeger, A. J. J. Org. Chem. 1984, 49, 3382-

(8) Roncali, J. Chem. Rev. 1997, 97, 173-205.

(9) McCullough, R. D. Adv. Mater. 1998, 10, 93-116

10) Schouten P. G.; Van Der Pol, J. F.; Zwikker, J. W.; Drenth, W. Picken, S. J. Mol. Cryst. Liq. Cryst. 1991, 195, 291-305.

(11) Van Pharm C Sinth Comunum 1986, 16, 689-695.

(12) Krebs, F. C.; Spangzaard. H. Sol Energy Mater. Sol. Cells 2005, 88, $363-375$.

(13) Hou, Q.; Xu, Y.; Yang, W.; Yuan, M.; Peng, J.; Cao, Y. J. Mater.

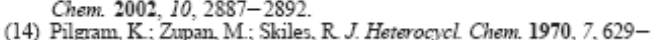
633

(15) Kankomi, M.; Kitamura, C.; Tamaka, S.; Yamashita, Y. J. Am. Chem. Soc. $1995,117,6791-6792$.

(16) Kitamura, C.; Tanaka, S.; Yamashita, Y. Chem. Mater. 1996, 8, 570-

(17) Bundgaard, E.; Krebs, F. C. Polym. Bull. 2005, 55, 157-164 Kechers, F. C. Mocromolecules 2005 , $38,658-659$.

(19) Salzner, U.; Lagowski, J. B.; Pickup, P. G.; Poiner, R A. Synth. Met. $1998,96,177-189$

(20) Krebs, F. C. Polym. Bull. 2004, 52, 49-56.

1) Salaneck, W. R.; Lögdlund, M.; Fahlman, M.; Greczynski, G.; Kugler T. Mater. Sci. Eng. 2001, R34, 121-146.

(22) Seki, K.; Furuyama, T.; Kawasumi, T.-O.; Sakurai, Y. Ishii, H. Kajlkawa, K.; Ouchi, Y.; Masuda, T. J. Phys. Chem. B 1997, 101,

(23) Krebs, F. C.; Jorgensen, M. Macromolecules 2004, 37, 3958.

(24) Krebs, F. C.; Jorgensen, M. Macromolecules 2002, 35, 7200-7206

(25) Jorgensen, M.; Krebs, F. C. Pol. Bull. 2003, 51, 23-30.

26) Lupsac, N.-O.; Catellani, M.; Luzzati, S. Mol. Cryst. Liq. Cryst. Sci. Technol. Sect. A 2002, 385, 121-128. MA052683E 


\section{Supporting information}

Low band-gap conjugated polymers based on thiophene, benzothiadiazole and benzobis-thiadiazole.

Eva Bundgaard and Frederik C. Krebs*

\section{Synthesis}

Synthesis attempts of 6

Several attempts were made to synthesize $4,4^{\prime}$-bis-(3,7,11-tri-methyl-dodecyl-[2,2']di-thiophene (6) (scheme S1).

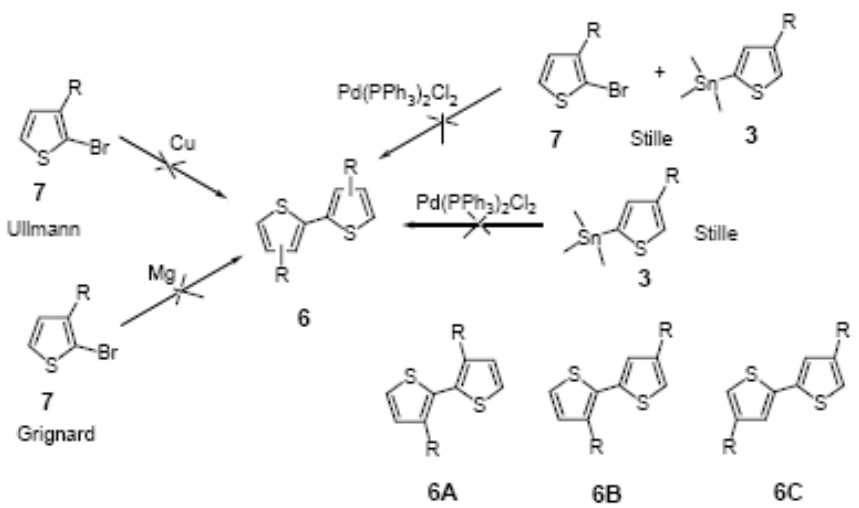

Scheme S1: Synthesis attempts of di-thiophene 6, R= 3,7,11-tri-methyl-dodecyl. The coupling of the di-thiophene is shown: $6 \mathrm{~A}=$ head-to-head, $6 \mathrm{~B}=$ head-to-tail and $6 \mathrm{C}=$ tail-to-tail $^{\text {SR. }}$

Ullmann coupling ${ }^{\mathrm{SR} 2, \mathrm{SR} 3}$ with copper as a catalyst to give $6 \mathrm{~A}$ proved unsuccessful and no product could be identified. A Grignard coupling ${ }^{\mathrm{SR} 4}$ of 2-bromo-3-(3,7,11-trimethyl-dodecyl)-thiophene $7^{\mathrm{SR} 5}$ to give head-to-head di-thiophene $6 \mathrm{~A}$ was also attempted this reaction gave some of the product, but it was in our hands difficult to reproduce the reaction. Attempts to synthesize the di-thiophene 6 by a Stille coupling ${ }^{\text {SR6-SR8 }}$ with 7 and 3 to give a head-to-tail product $6 \mathrm{~B}$ also failed in our hands. The reaction was carried out by addition of $\mathbf{3}$ in either two portions or drop wise. The 
reaction resulted in mixtures of the product $6 \mathrm{~B}$ and homo coupled product of 3 i.e. the tail-to-tail product $6 \mathrm{C}$. The mixture was according to NMR 1:1.5 and 1:0.6, respectively. It was not possible to separate the different products by chromatography or by kugelrohr distillation. We also attempted homo coupling of 3 . This reaction resulted in a mixture of 1 and the tail-to-tail product $6 \mathrm{C}$. This indicated that 3 decompose during the reaction. Purification of these two compounds was not possible in our hands.

Dilithation attempts of 1

Several attempts were made to dilithate $\mathbf{l}$ (scheme S2).

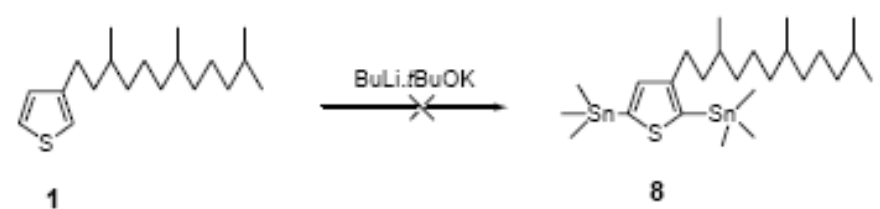

Scheme S2: Diithation attempt of 1.

Compound 1 was attempted dilithated using 2.5, 4 and 5 equivalents of BuLi.tBuOK at different temperatures $\left(-60^{\circ} \mathrm{C}, 10^{\circ} \mathrm{C}\right.$ and room temperature) in hexane. These reactions all resulted in a mixture of monolithiated and dilithiated or in the monolithiated compound alone. The products obtained upon reaction with trimethylstannylchloride could not be separated by kugelrohr distillation.

\section{Dilithation attempts of 6}

Dilithiation of 6 was attempted with $t \mathrm{BuLi}$. This however failed in our hands (scheme S3). 


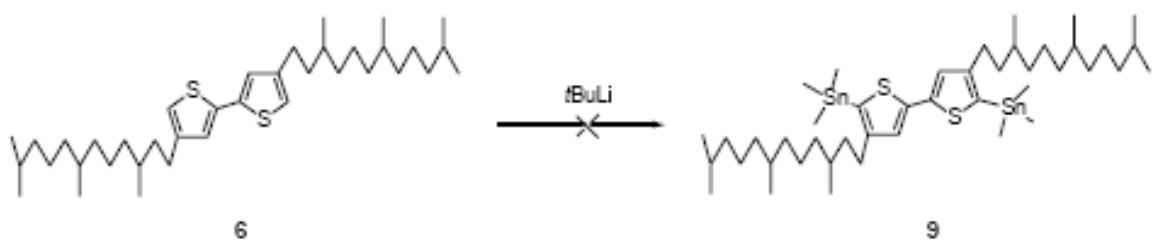

Scheme S3: Dilithiation of 6.

One possible explanation for this could be steric hindrance between the t-Butyl anion and the large and bulky alkyl side chain making dilithiation of 6 slow or impossible.

\section{Synthesis of polymers}

Stille cross coupling polymerizations of distannyl derivates of 3-(2-ethylhexyl)thiophene and 3,3'-bis-hexyl-[2,2']-di-thiophene with dibromo derivates of benzothiadiazole and benzo-bis-thiadiazole resulted in polymer 21-26 (scheme S4). 


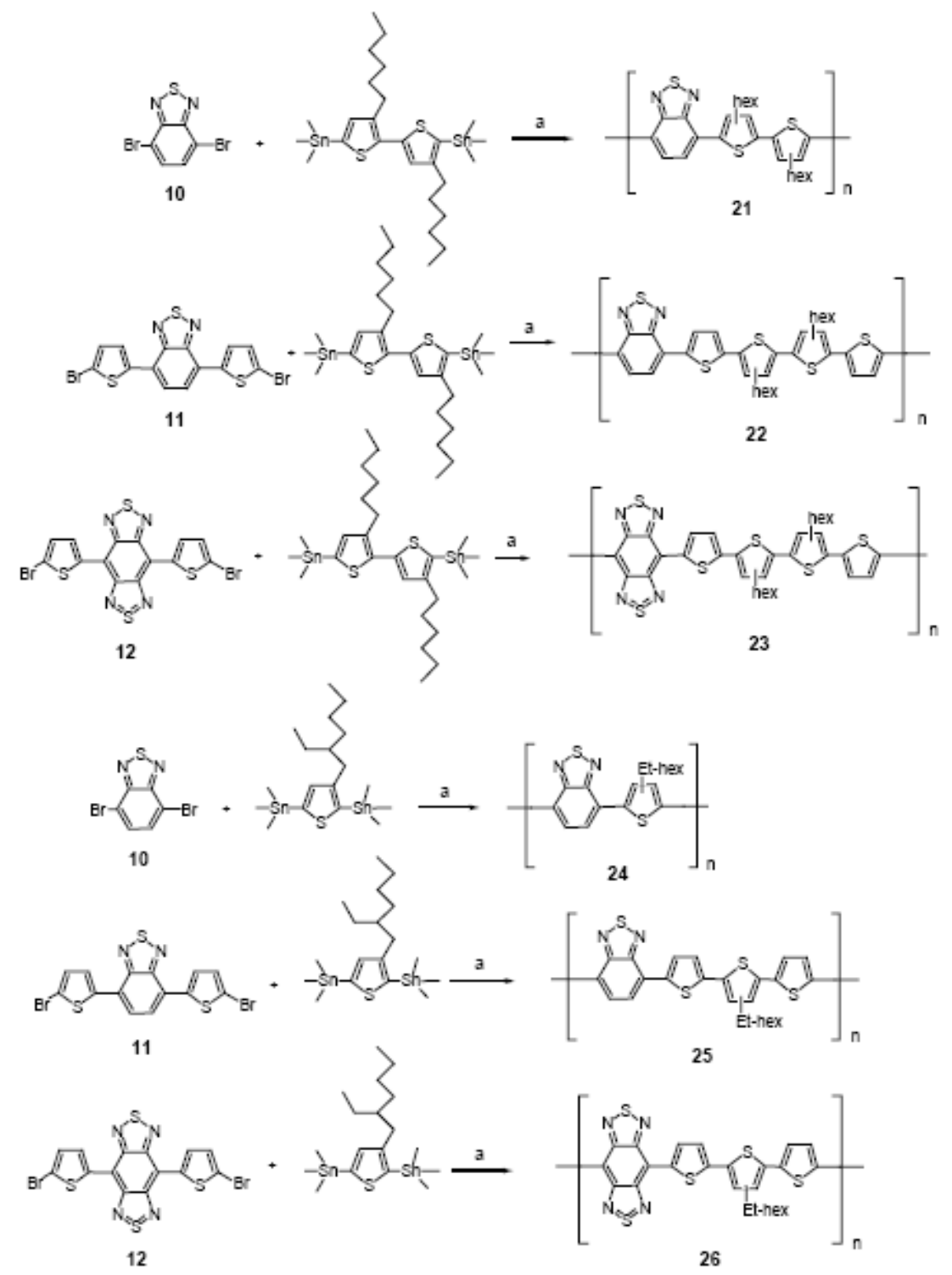

Scheme S4: Synthesis of polymer 21-26 by Stille cross coupling polymerization. a: $\mathrm{Pd}\left(\mathrm{PPh}_{3}\right)_{2} \mathrm{Cl}_{2}$, $\mathrm{DMF} / \mathrm{THF}, 150^{\circ} \mathrm{C}$.

The polymerization of 4,7-bis(alkyl-[2,2']-thiophen-5-yl)-benzo-[2,1,3]-thiadiazoles were carried out using ferric(III)chloride in chloroform to give the polymer 27 and 28 where R is hexyl and dodecyl, respectively (scheme S5). 


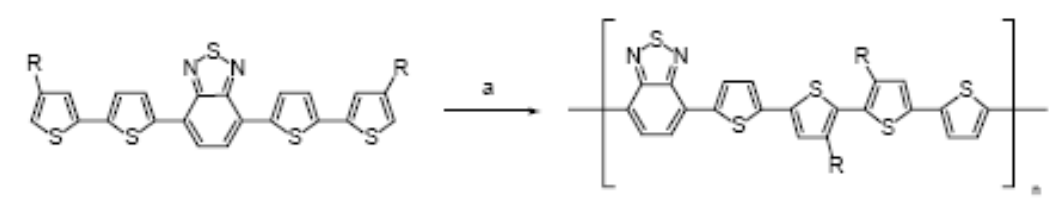

Scheme S5: Oxidative ferric chloride polymerization to give head-to-head copolymers of di-thiophene and benzothiadiazole, $\mathrm{R}=$ hexyl (27) or dodecyl (28). a: $\mathrm{FeCl}_{3}, \mathrm{CHCl}_{3}$.

Due to insolubility of the polymers shown in scheme S4 and S5, the SEC data did not give a correct picture of the polymer molecular weight distribution and the data is not given. These polymers showed poor solubility in $\mathrm{CHCl}_{3}, \mathrm{THF}$, chlorobenzene, dichlorobenzene, xylene and toluene. Polymer 22 and 24 gave uneven films with an absorbance of $\sim 0.2$ made from THF and chloroform. Micro filtration $(2.7 \mu \mathrm{m}$ pore size) of the polymer solution removed a lot of material and resulted in films with a low absorbance.

\section{Experimental details}

2-Bromo-3-(3,7,11-tri-methyl-dodecyl)-thiophene (7). ${ }^{\mathrm{SRS}}$ NBS (6.02 g, $34 \mathrm{mmol}, 1$ eq.) in DMF $(20 \mathrm{~mL})$ was added drop wise to a solution of 3(-3,7,11-tri-methyldodecyl)-thiophene (10 g, $34 \mathrm{mmol})$ in DMF $(50 \mathrm{~mL})$ in darkness. After 3 hours the mixture was evaporated and dissolved in hexane. The organic phase was washed with water, dried $\left(\mathrm{MgSO}_{4}\right)$, evaporated and purified by kugelrohr distillation. Yield: $93 \%$ (11.77 g), colourless oil, bp: $155^{\circ} \mathrm{C}$ at $6 \cdot 10^{-3}$ mbar. ${ }^{1} \mathrm{H}$ NMR $\left(250 \mathrm{MHz}, \mathrm{CDCl}_{3}\right): \delta=$ $7.18(\mathrm{~d}, 1 \mathrm{H}, J=5.75 \mathrm{~Hz}), 6.79(\mathrm{~d}, 1 \mathrm{H}, J=5.75 \mathrm{~Hz}), 2.64-2.53(\mathrm{~m}, 2 \mathrm{H}), 1.63-1.02(\mathrm{~m}$, 17H), 0.98-0.84 (m, 12H). $\left.{ }^{13} \mathrm{C} \mathrm{NMR} \mathrm{(75} \mathrm{MHz,} \mathrm{CDCl}_{3}\right): \delta=142.14,128.13,125.13$, $108.63,39.36,37.36,37.28,37.10,37.06,36.90,36.81,32.76,32.44,27.96,27.03$, $24.78,24.32,22.68,22.59,19.73,19.67,19.59,19.53$. MS (HRMS): $m / z$ calcd. for $\left[\mathrm{C}_{19} \mathrm{H}_{33} \mathrm{BrS}\right]^{+} 373.1564$ found 373.1953 . 


\section{Synthesis of monomers for polymer 21-28.}

General. 5-tributylstannyl-3-hexylthiophene ${ }^{\mathrm{SR} \theta}$ and 5,5'-bis(trimethylstannyl)-3,4'dihexyl[2,2']dithiophene ${ }^{\mathrm{SR} \theta}$ were synthesized according to literature.

3-Dodecyl-thiophene by Grignard reaction: ${ }^{\mathrm{SR} 10}$ yield $91 \%$, colourless oil, bp: 162 $164{ }^{\circ} \mathrm{C}$ at 10 mbar. ${ }^{1} \mathrm{H}$ NMR $\left(250 \mathrm{MHz}, \mathrm{CDCl}_{3}\right): \delta=7.29-7.25(\mathrm{~m}, 1 \mathrm{H}), 6.99-6.5(\mathrm{~m}$, $2 \mathrm{H}), 2.71-2.65(\mathrm{~m}, 2 \mathrm{H}), 1.71-1.65(\mathrm{~m}, 2 \mathrm{H}), 1.38-1.22(\mathrm{~m}, 18 \mathrm{H}), 0.98-0.92(\mathrm{~m}, 3 \mathrm{H})$.

4-Dodecyl-2-tributylstannyl-thiophene by trialkylstannylation with LDA: yield $33 \%$, yellow oil, bp: $185^{\circ} \mathrm{C}$ at $3 \cdot 10^{-3}$ mbar. ${ }^{1} \mathrm{H}$ NMR $\left(250 \mathrm{MHz}, \mathrm{CDCl}_{3}\right): \delta=7.18(\mathrm{~s}$, $1 \mathrm{H}), 6.96(\mathrm{~s}, 1 \mathrm{H}), 2.65 \mathrm{~d}, 2 \mathrm{H}, J=7.5 \mathrm{~Hz}), 1.67-1.49(\mathrm{~m}, 10 \mathrm{H}), 1.41-1.19(\mathrm{~m}, 30 \mathrm{H})$, 1.14-1.01 (m, 7H), 0.94-0.85 (m, 16H). ${ }^{13} \mathrm{C}$ NMR (75 MHz, $\left.\mathrm{CDCl}_{3}\right): \delta=144.41$, $136.84,136.23,125.47,31.93,30.73,29.99,29.68,29.65,29.63,29.51,29.47,29.36$, $28.96,27.23,22.69,14.08,13.62,10.78$. This compound contained tetracosane as an impurity.

3-(2-Ethyl-hexyl)-2,5-bis-trimethylstannyl-thiophene. Compound $\mathbf{2}$ (1 $\mathrm{g}, 5.1$ mmol) and TMEDA $(1.91 \mathrm{~mL}, 12.76 \mathrm{~mol}, 2.5 \mathrm{eq}$.$) in hexane (30 \mathrm{~mL})$ was cooled to $78^{\circ} \mathrm{C} . t \mathrm{BuLi}(7.5 \mathrm{~mL}, 12.76 \mathrm{~mol}, 2.5 \mathrm{eq}$ ) was added drop wise over $30 \mathrm{~min}$ (yellow suspension). The cooling bath was removed, and the reaction was allowed to reach 0 ${ }^{\circ} \mathrm{C}$. The mixture was cooled back down to $-78^{\circ} \mathrm{C}$ and trimethylstannylchloride (12.75 $\mathrm{mL}, 12.76 \mathrm{mmol}$ ) was added (yellow to white suspension). After 2 hours at room temperature the mixture was washed with water, dried, evaporated and purified by kugelrohr distillation (the fraction in the interval $50-100{ }^{\circ} \mathrm{C}$ at $8 \cdot 10^{-2}$ mbar was collected). Yield: $49 \%$ (1.30 g), yellow oil, bp: $50-100{ }^{\circ} \mathrm{C}$ at $8 \cdot 10^{-2}$ mbar. ${ }^{1} \mathrm{H}$ NMR $\left(250 \mathrm{MHz}, \mathrm{CDCl}_{3}\right): \delta=7.04(\mathrm{~s}, 1 \mathrm{H}), 2.51(\mathrm{~d}, 2 \mathrm{H}, J=7.25 \mathrm{~Hz}), 1.58-1.46(\mathrm{~m}, 1 \mathrm{H})$, $1.24-1.16(\mathrm{~m}, 8 \mathrm{H}), 0.77(\mathrm{t}, 6 \mathrm{H}, J=7.5 \mathrm{~Hz}), 0.36-0.14(\mathrm{~m}, 18 \mathrm{H}) .{ }^{13} \mathrm{C}$ NMR $(75 \mathrm{MHz}$, $\left.\mathrm{CDCl}_{3}\right): \delta=150.79,142.58,137.98,137.85,41.19,36.57,32.70,28.89,25.91,23.00$, 
$13.98,10.86,-7.82,-8.30$. This compound contained 5,8-di-ethyl-dodecane as an impurity.

4,7-Bis-(4'-hexyl-[2,2']bithiophenyl-5-yl)-benzo[1,2,5]thiadiazole by Stille coupling between 11 and 5-tributylstannyl-3-hexylthiophene ${ }^{\mathrm{SR} \theta}$ : yield $28 \%$, dark red crystals, mp $=137.5^{\circ} \mathrm{C} .{ }^{1} \mathrm{H}$ NMR $\left(250 \mathrm{MHz}, \mathrm{CDCl}_{3}\right): \delta=8.00(\mathrm{~d}, 2 \mathrm{H}, J=3.75$ $\mathrm{Hz}), 7.80(\mathrm{~s}, 2 \mathrm{H}), 7.22(\mathrm{~d}, 2 \mathrm{H}, J=4.0 \mathrm{~Hz}), 7.14(\mathrm{~d}, 2 \mathrm{H}, J=1.25 \mathrm{~Hz}), 6.85(\mathrm{~d}, 2 \mathrm{H}, J=1$ $\mathrm{Hz}), 2.61(\mathrm{t}, 4 \mathrm{H}, J=7 \mathrm{~Hz}), 1.72-1.60(\mathrm{~m}, 4 \mathrm{H}), 1.43-1.27(\mathrm{~m}, 12 \mathrm{H}), 0.91(\mathrm{t}, 6 \mathrm{H}, J=6.5$ $\mathrm{Hz}) .{ }^{13} \mathrm{C} \mathrm{NMR}\left(75 \mathrm{MHz}, \mathrm{CDCl}_{3}\right): \delta=152.46,144.29,139.25,137.77,136.82,128.17$, $125.50,125.43,125.07,124.19,119.53,31.66,30.52,30.35,28.98,22.59,14.05$ Anal. calcd. for $\mathrm{C}_{34} \mathrm{H}_{36} \mathrm{~N}_{2} \mathrm{~S}_{5}: \mathrm{C}, 64.51 ; \mathrm{H}, 5.73 ; \mathrm{N}, 4.43$. Found: $\mathrm{C}, 64.62 ; \mathrm{H}, 5.59 ; \mathrm{N}$, 4.34 .

4,7-Bis-(4'-dodecyl-[2,2']bithiophenyl-5-yl)-benzo[1,2,5]thiadiazole by Stille coupling between 11 and 5-tributylstannyl-3-dodecylthiophene ${ }^{\mathrm{SR} 10}::$ yield $27 \%$, dark red crystals, $\mathrm{mp}=130.9^{\circ} \mathrm{C} .{ }^{1} \mathrm{H}$ NMR $\left(250 \mathrm{MHz}, \mathrm{CDCl}_{3}\right): \delta=8.02(\mathrm{~d}, 2 \mathrm{H}, J=4$ $\mathrm{Hz}), 7.83(\mathrm{~s}, 2 \mathrm{H}), 7.23(\mathrm{~d}, 2 \mathrm{H}, J=4 \mathrm{~Hz}), 7.14(\mathrm{~d}, 2 \mathrm{H}, J=1.5 \mathrm{~Hz}), 6.86(\mathrm{~d}, 2 \mathrm{H}, J=1$ $\mathrm{Hz}), 2.61(\mathrm{t}, 4 \mathrm{H}, J=7.5 \mathrm{~Hz}), 1.74-1.60(\mathrm{~m}, 4 \mathrm{H}), 1.34-1.28(\mathrm{~m}, 36 \mathrm{H}), 0.87(\mathrm{t}, 6 \mathrm{H}, J=$ $7.0 \mathrm{~Hz}) .{ }^{13} \mathrm{C} \mathrm{NMR}\left(75 \mathrm{MHz}, \mathrm{CDCl}_{3}\right): \delta=152.49,144.30,139.27,137.78,136.82$, $128.19,125.55,125.45,125.11,124.20,119.54,31.91,30.53,30.40,29.67,29.64$, 29.59, 29.46, 29.34, 22.67, 14.08. Anal. calcd. for $\mathrm{C}_{46} \mathrm{H}_{60} \mathrm{~N}_{2} \mathrm{~S}_{5}: \mathrm{C}, 68.95 ; \mathrm{H}, 7.55 ; \mathrm{N}$, 3.05. Found: $\mathrm{C}, 68.97 ; \mathrm{H}, 7.46 ; \mathrm{N}, 3.44$.

Synthesis of polymer 21-26 by Stille cross coupling polymerization.

Due to the low solubility of polymer 21-26 it has not been possible to characterize these polymer products by ${ }^{1} \mathrm{H}$ NMR. Further, the SEC data given for polymer 21-26 does not give a correct picture of the polymer molecular weight distribution and 
should be interpreted as SEC data for the soluble components. Polymer 21 was described by us earlier. ${ }^{\text {SRe }}$

Poly\{(benzo-2,1,3-thiadiazol-4,7-diyl)-(3,4'-dihexyl-[2,2';5',2';,', ,2',']-quarterthiophene-5,5'-diyl)\} (22): yield 96\%. SEC (100 $\AA+1000 \AA) \mathrm{M}_{w}=1631 ; \mathrm{M}_{\mathrm{p}}=$ $1239 ; \mathrm{M}_{\mathrm{w}} / \mathrm{M}_{\mathrm{n}}=1.677$.

Poly\{(benzo-2,1,3-bis-thiadiazol-4,7-diyl)-(3,4'-dihexyl-[2,2';5',2',;', ,2',']quarter-thiophene-5,5'-diyl)\} (23): yield 93\%. SEC (100 $\AA+1000 \AA) \mathrm{M}_{\mathrm{w}}=1625$; $\mathrm{M}_{\mathrm{p}}=1974 ; \mathrm{M}_{\mathrm{w}} / \mathrm{M}_{\mathrm{n}}=1.890$.

Poly\{(benzo-2,1,3-thiadiazol-4-yl)-(3/4-(2-ethyl-hexyl)-thiophene-5-yl)\} (24): yield $80 \% . \operatorname{SEC}(100 \AA+1000 \AA) \mathrm{M}_{\mathrm{w}}=2774 ; \mathrm{M}_{\mathrm{p}}=1857 ; \mathrm{M}_{\mathrm{w}} / \mathrm{M}_{\mathrm{n}}=2.327$.

Poly\{(benzo-2,1,3-thiadiazol-4-yl)-(3'/4'-(2-ethyl-hexyl)-[2,2';5',2'’]-tert-

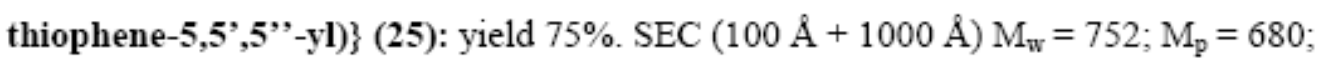
$\mathrm{M}_{\mathrm{w}} / \mathrm{M}_{\mathrm{n}}=1.777$.

Poly\{(benzo-2,1,3-bis-thiadiazol-4-yl)-(3'/4'-(2-ethyl-hexyl)-[2,2';5',2'']-tertthiophene-5,5',5',-yl)\} (26): yield 95\%. SEC (100 $\AA+1000 \AA) \mathrm{M}_{\mathrm{w}}=882 ; \mathrm{M}_{\mathrm{p}}=437$; $\mathrm{M}_{\mathrm{w}} / \mathrm{M}_{\mathrm{n}}=1.758$.

Synthesis of polymer 27 and 28 by oxidative ferric chloride polymerisation. ${ }^{\text {SRe }}$ Due to the low solubility of polymer $\mathbf{2 7}$ and 28 it has not been possible to characterize these polymer products by ${ }^{1} \mathrm{H}$ NMR. Further, the SEC data given for polymer 27 and 28 does not give a correct picture of the polymer molecular weight distribution and should be interpreted as SEC data for the soluble components.

Poly $\{4,7-$-bis-(4'-hexyl-[2,2']-di-thiophene)-benzo-[1,2,5]-thiadiazole $\}$ (27): yield $79 \% . \operatorname{SEC}(100 \AA+1000 \AA) \mathrm{M}_{\mathrm{w}}=2371 ; \mathrm{M}_{\mathrm{p}}=1917 ; \mathrm{M}_{\mathrm{w}} / \mathrm{M}_{\mathrm{u}}=1.156$.

Poly $\{4,7$-bis-(4'-dodecyl-[2,2']-di-thiophene)-benzo-[1,2,5]-thiadiazole $\}$ (28): yield $33 \% . \operatorname{SEC}(100 \AA+1000 \AA) \mathrm{M}_{\mathrm{w}}=46646 ; \mathrm{M}_{\mathrm{p}}=1740 ; \mathrm{M}_{\mathrm{w}} / \mathrm{M}_{\mathrm{n}}=18.310$. 
SEC traces
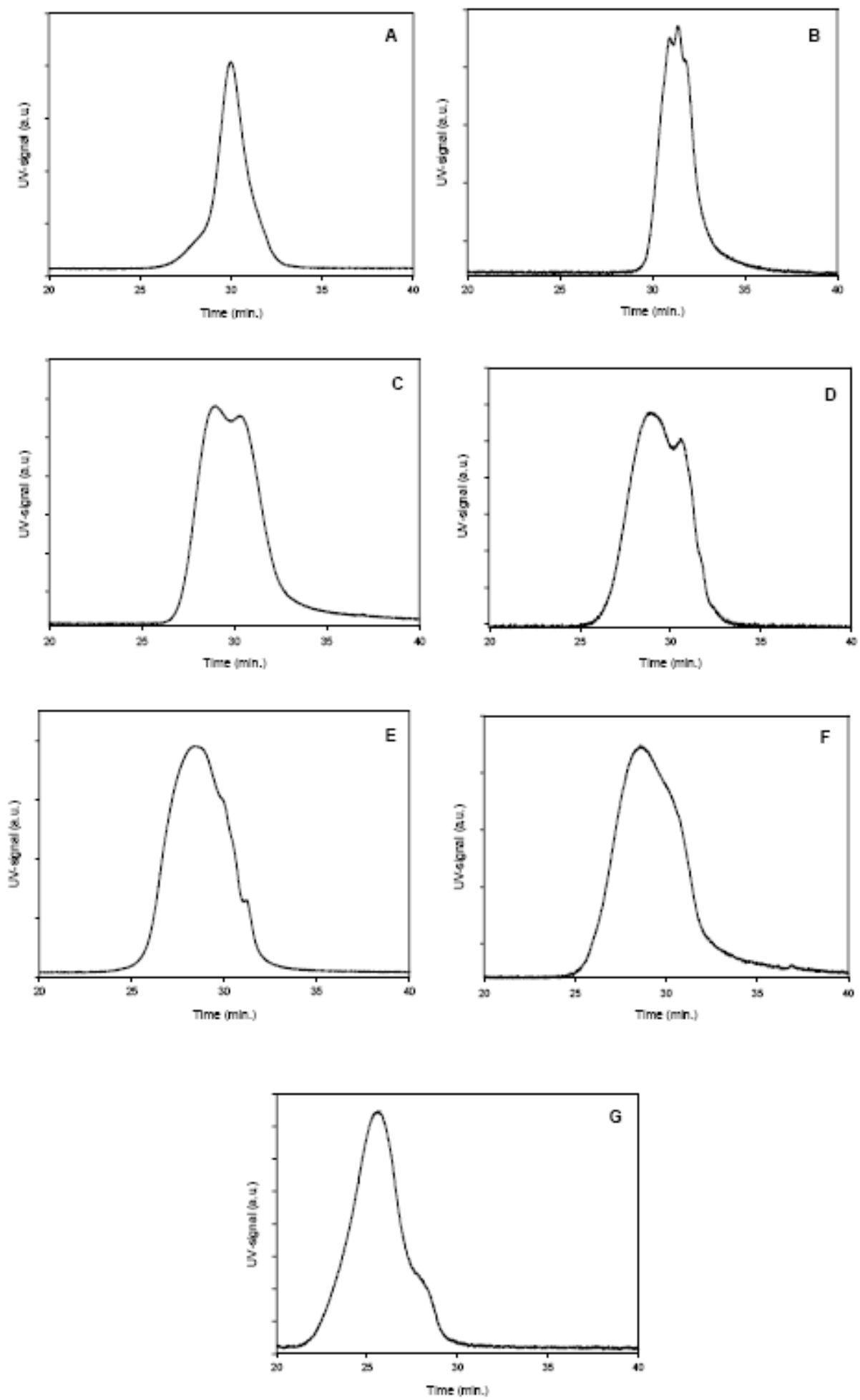
Figure S1: SEC traces of polymer 14 (A), 15 (B), 16 (C), 17 (D), 18 (E), 19 (F) and 20 (G). The polymers were analyzed on a gel column system column system comprising a succession of a $500 \AA$, $10000 \AA$ and $1000000 \AA$ in pore diameter.

\section{UPS data}
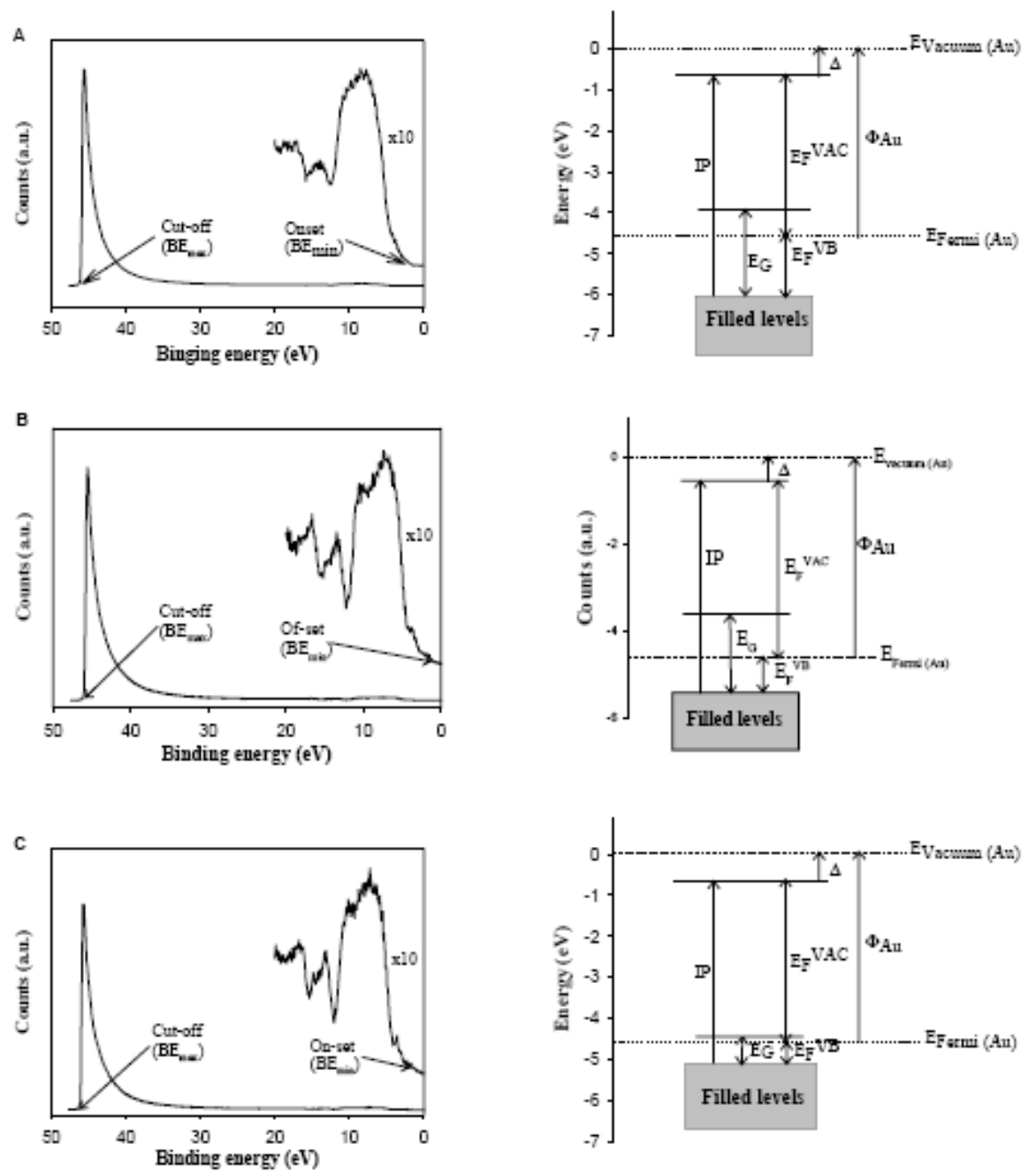

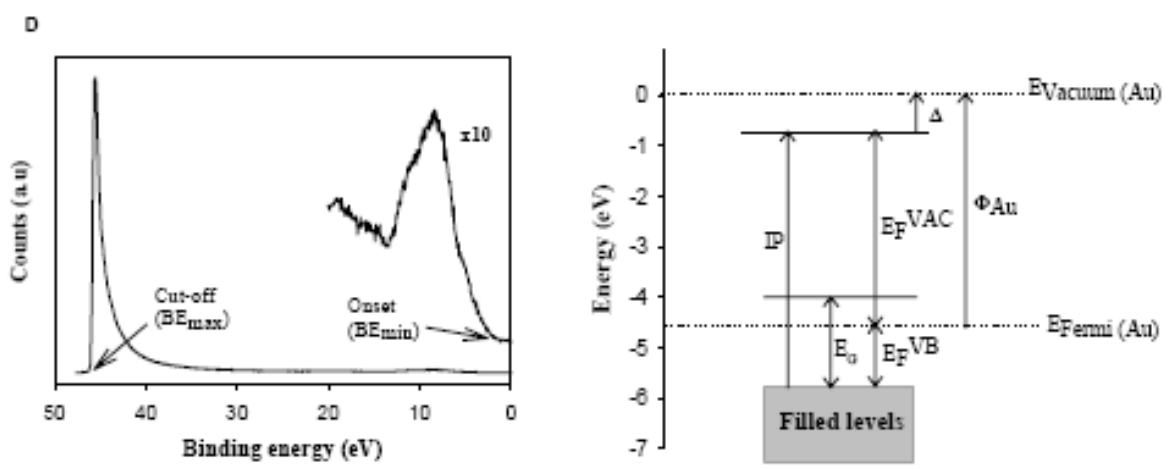

Figure S2: The UPS spectrum (right) and the resulting band structure (left) for polymer 14 (A), 15 (B), $16(\mathrm{C})$ and 20 (D).

\section{De-doping experiments with ammonia and hydrazine}

The polymers were dissolved in chloroform and the UV-vis spectra were recorded. Then hydrazine or ammonia was added to the solutions and the UV-vis spectra were recorded again. In figure S3 and S4 the spectra are shown for the experiments with hydrazine and ammonia, respectively.

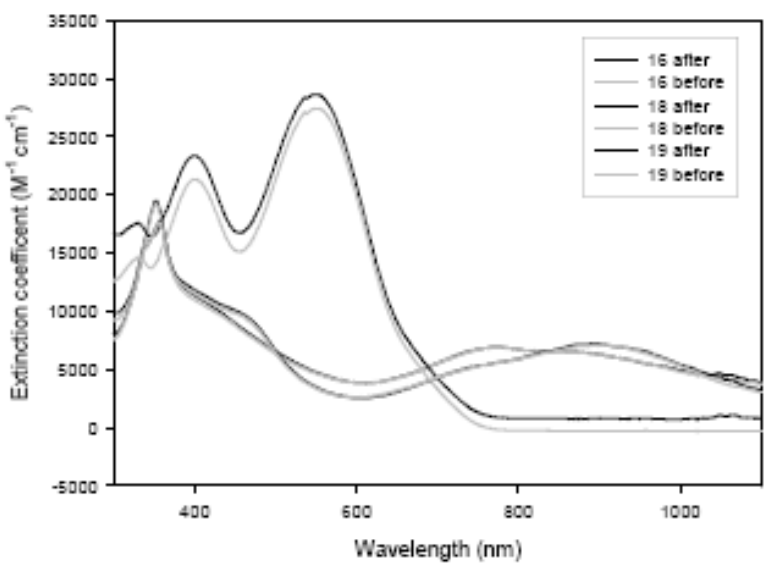

Figure S3: UV-vis spectra of polymer 16,18 and 19 before and after treatment with hydrazine. 


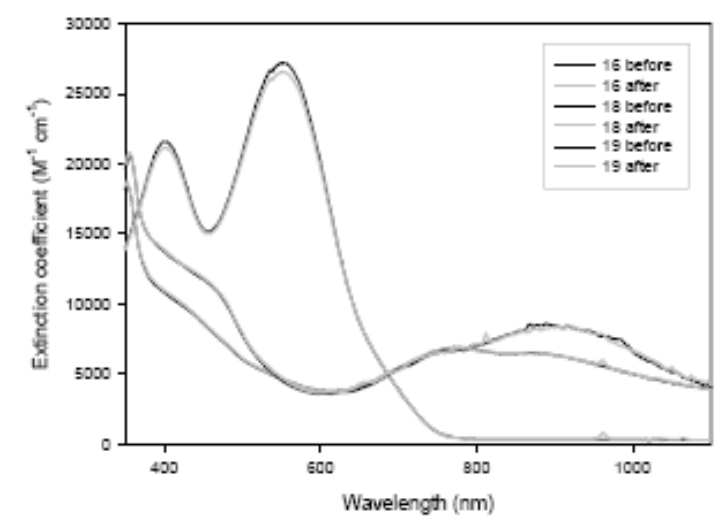

Figure S4: UV-vis spectra of polymer 16,18 and 19 before and after treatment with ammonia.

In both experiments it is seen that the $\lambda_{\max }$ does not change and hence it can be concluded that any doping can not be removed by a chemical treatment.

\section{Luminescence}

The UV-vis spectra and the emission spectra of polymer 18 are shown in figure S5. Since we observe emission we anticipate that the impurity level is low.

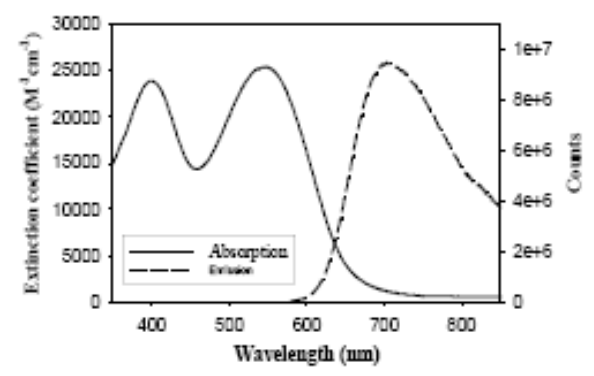

Figure S5: UV-vis spectrum and emission spectrum of polymer 18.

It was not possible to observe emission for polymer 19 due to the limits in the maximum wavelength detectable by the emission detector. 


\section{References}

(SR1) Andersson, M. R.; Thomas, O.; Mammo, W.; Svensson, M.; Theander, M.; Inganäs, O., J. Mater. Chem., 1999, 9, 1933-1940.

(SR2) Goshaev, M.; Otroshchenko, O. S.; Sadykov, A. S., Russ. Chem. Rev., $1972,41,1046-1059$

(SR3) Fanta, P. E., Synthesis, 1974, 1, 9-21.

(SR4) Van Pharm, C., Synth. Commun., 1986, 16, 689-695.

(SR5) He., M.; Leslie, T. M.; Sinicropi, J. A., Chem. Mater., 2002, 14, 46624668.

(SR6) Krebs, F. C.; Spanggaard, H., Sol. En. Mat. \& Sol. Cells 2005, 88, $363-$ 375.

(SR7) Karikomi, M.; Kitamura, C.; Tanaka, S.; Yamashita, Y., J. Amer. Chem. Soc., 1995, 117, 25, 6791-6792.

(SR8) Kitamura, C.; Tanaka, S.; Yamashita, Y., Chem. Mater., 1996, 8, 570578.

(SR9) Bundgaard, E.; Krebs, F. C., Pol. Bull., 2005, 55, 157-164.

(SR10) Amari, C.; Pelizzi, C.; Predieri, G.; Destri, S.; Porzio, W.; Einsiedel, H.; Menges, B.; Mittler-Neher, S., J. Mater. Chem., 1996, 6, 13191324. 
Available online at www.sciencedirect.com $\because$ ScienceDirect

Solar Energy Materials and Solar Cells

ELSEVIER

Solar Energy Materials \& Solar Cells 91 (2007) 954-985

www elsevier com/locate/solmat

Review

\title{
Low band gap polymers for organic photovoltaics
}

\author{
Eva Bundgaard*, Frederik C. Krebs
}

The Danish Polymer Centre, Riso National Laboratory, P.O. Box 49, Frederiksborgvej 399, Raskille, Denmark

Received 14 December 2006; received in revised form 16 January 2007; accepted 19 January 2007 Available onbine 23 March 2007

Abstract

Low band gap polymer materials and their application in organic photovoltaics (OPV) are reviewed. We detail the synthetic approaches to low band gap polymer materials starting from the early methodologies employing quinoid homopolymer structures to the current state of the art that relies on alternating copolymers of donor and acceptor groups where strategies for band gap design are possible. Current challenges for OPV such as chemical stability and energy level alignment are discussed. We finally provide a compilation of the most studied classes of low band gap materials and the results obtained in photovoltaic applications and give a tabular overview of rarely applied materials.

C) 2007 Elsevier B.V. All rights reserved.

Keywords: Low hand gap polymers; Synthesis; Organic photovoltaics (OPV)

Contents

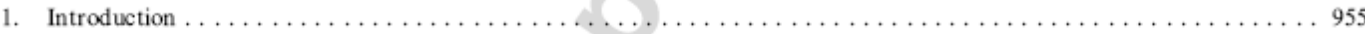

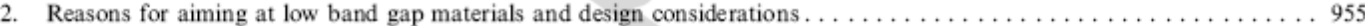

2.1. A view of the sun spectrum, the number of photons and short circuit current limits . . . . . . . . . . . . .

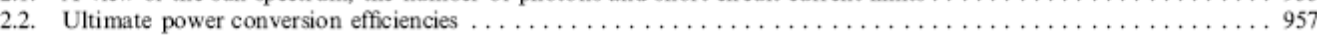

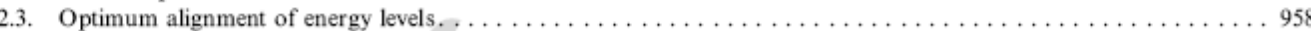

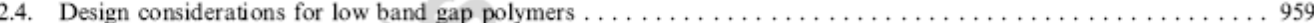

3. Types of low band gap polymers. .....

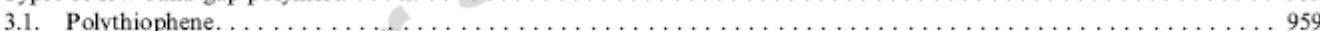

3.1.1. Optical and electrical properties of polythiophenes $\ldots \ldots \ldots \ldots \ldots \ldots \ldots \ldots \ldots \ldots \ldots \ldots \ldots \ldots \ldots$

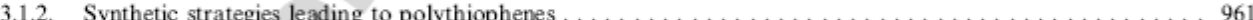

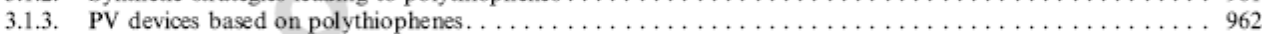

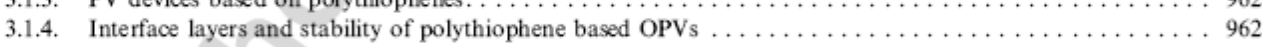

3.1.5. Morphology of the active layer in polythiophene based OPVs . . . . . . . . . . . . . . . . . . . 964

3.1.6. Hybrid solar cells and tandem cells based on polythiophenes . . . . . . . . . . . . . . . . . . . . . 964

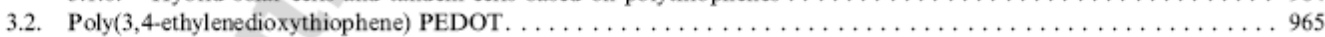

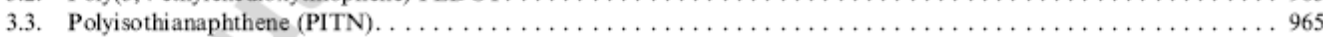

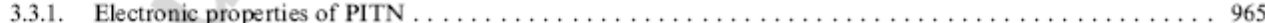

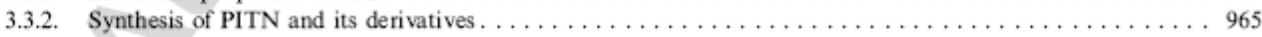

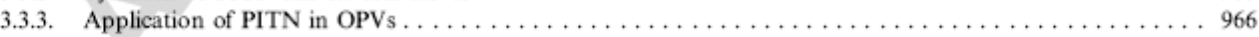

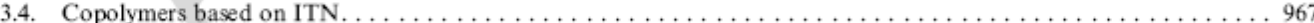

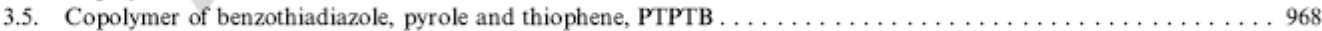

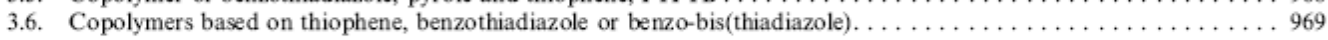

\footnotetext{
${ }^{*}$ Corresponding author.

E-mail address: eva.bundgaard@risoe.dk (E. Bundgaard).
}

0927-0248/\$ - see front matter 02007 Ekevier B.V. All rights reserved. doi:10.1016/jsolmat.2007.01.015 


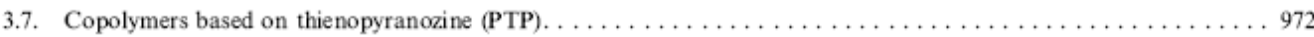

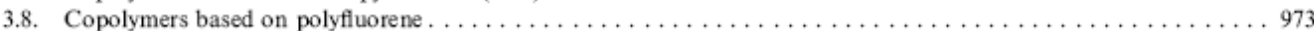

3.8.1. Copolymers based on thiophene, benzothiadiazole and fluorene . . . . . . . . . . . . . . . . . 973

3.8.2. Copolymers based on thienopyrazine or thiadiazolequinoxaline, thiophene and polyfluorene. . . . . . . 974

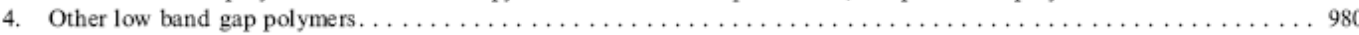

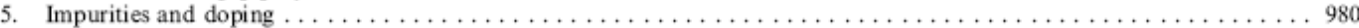

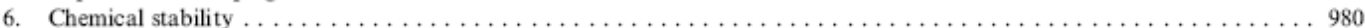

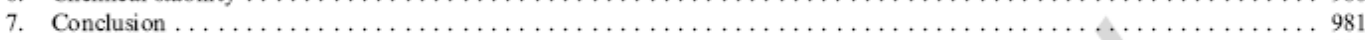

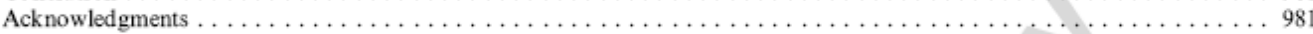

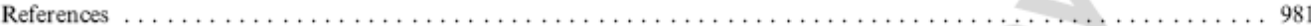

\section{Introduction}

In the past decade, focus on organic photovoltaic (OPV) devices has increased and several reviews on OPVs have been published [1-8]. There are many reasons for the interest in OPVs when comparing the technology to the silicon-based photovoltaics (PV) and interestingly the two very different technologies are complementary in many ways. The OPVs offer low cost, low thermal budget, solution processing, flexible substrates and a very high speed of processing. Until recently the silicon-based PVs had advantages in both efficiency and lifetime of the device where module efficiencies in excess of $20 \%$ and operational stabilities under outside conditions of more than 25 years have been demonstrated for monocystalline silicon devices. In the 1980 s and early 1990 s, when the OPVs were in their infancy they showed low efficiencies and short lifetimes and were thus not a real competitor [5]. In recent years, this has changed dramatically and both the efficiency and lifetime of OPVs have improved significantly with efficiencies of around $5 \%$ and estimated operational lifetimes of $20,000 \mathrm{~h}$ [9-11]. It should be emphasized that high efficiency and long lifetime has not been observed for the same device, and one of the current challenges is the combination of al the desirable properties in the same material (efficiency, stability, processability and low cost). The separate demonstration of these properties for different materials, however, does show that it should be possible and from this point of view the OPVs could become a true competitor to the silicon-based PV. In addition OPVs do have advantages of better operation at low light levels (i.e. indoor applications) [12] compared with most inorganic PVs. There are several factors that influence the efficiency of OPVs, e.g. the structure of the polymer, the morphology of the film, and the choice of electron acceptor and the ratio between this and the polymer [13].

During the last decade several research groups have reported the synthesis and use of materials which absorb light with wavelengths above $600 \mathrm{~nm}$ in OPVs. A band gap is defined as the difference between the highest occupied molecular orbital (HOMO) and the lowest unoccupied molecular orbital (LUMO) energy levels in the polymer. Low band gap polymers are loosely defined as a polymer with a band gap below $2 \mathrm{eV}$, i.e. absorbing light with wavelengths longer than $620 \mathrm{~nm}$.
In this review, an introduction to low band gap polymers is given with a detailed discussion of why we need to focus on low band gap polymers and considerations of how to design the polymer to achieve the low band gap. Further, the synthesis and PV responses of low band gap polymers from the literature are described. The polymers described have mostly been prepared by two methods: (1) electrochemical polymerization, where a potential is applied to a solution containing the monomer and an electrolyte, this results in formation of the polymer at the anode, e.g. indium tin oxide (ITO) or (2) chemical polymerization using Stille, Negishi, Kumada or Suzuki cross-coupling reactions, oxidative ferric chloride polymerizations and Yamamoto, Knoevenagel or Horner-Wadsworth-Emmons condensation polymerizations. For other reviews on low band gap polymers see [6,14-16].

2. Reasons for aiming at low band gap materials and design considerations

2.1. A view of the sun spectrum, the number of photons and short circuit cur rent limits

The sun is a stable source of renewable energy and it is estimated to last for another 5 billion years. At the core of the sun 5 million tons of energy is released every second in the form of $\gamma$-rays, which is equivalent to $3.86 \times 10^{26} \mathrm{~J}$. The $\gamma$-rays make their way to the surface of the sun by absorption and re-emission at lower and lower temperatures until it reaches the surface mainly as the visible light we observe on earth. The energy in space just outside the atmosphere of the earth is $1366 \mathrm{~W} \mathrm{~m}^{-2}$ and when the light energy passes through the atmosphere part of the visible light energy is lost by absorption in specific regions of the spectrum according to the air mass that the light passes. The air mass is abbreviated AM followed by a number that describes the air mass. In space, just outside the atmosphere the spectrum is AM0. The absorption loss amounts to $28 \%$ resulting in about $1000 \mathrm{~W} \mathrm{~m}^{-2}$ at the surface of the earth at equator under ideal conditions with a spectrum according to the air mass (AM1). At the latitudes of northern Europe and northern America the absorption loss is higher resulting in the AM1.5 spectrum, which is shown in Fig. 1 as irradiance and it is evident that most of the intensity is concentrated below $2000 \mathrm{~nm}$ but extending 
above $4000 \mathrm{~nm}$. The AM1.5 spectrum corresponds to the solar irradiance with the sun $45^{\circ}$ above the horizon [17]. It is, however, more relevant to consider the amount of photons available since PVs essentially convert 1 photon into one electron (there are particular cases where 1 photon can give rise to more than 1 electron but this is beyond the scope of this review). Thus, the representation of the solar spectrum in photon flux as a function of wavelength give a better picture of how many photons that are available for conversion into electrons under ideal conditions (Fig. 1). Fig. 1 shows a displacement of the maximum towards the infrared wavelengths when considering the number of photons rather than the energy. From this point of view it is of great interest to harvest photons at the longer wavelengths. It should be borne in mind that the energy of the charge carriers at longer wavelengths is lower and this limits the voltage difference that the device can produce. Thus, there is an optimum band gap which is currently subject to discussion for excitonic devices. The view taken in this account is experimental and the practical efficiencies that can be obtained for low band gap materials may not coincide with the theoretically predicted value for the optimum band gap. It is, however, important to extend

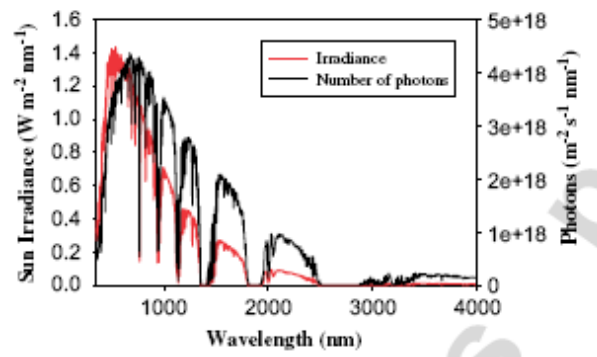

Fig. 1. Sun irradiance (red) and number of photons (black) as a function of wavelength. The sun intensity spectrum is based on data from NREL [20]. absorption beyond $600 \mathrm{~nm}$. Based on these simple considerations the low band gap polymers have the possibility to improve the efficiency of OPVs due to a better overlap with the solar spectrum $[17,18]$. Thus, for a maximum photon harvesting in the OPV devices low band gap materials are needed [19].

In Fig. 2, the photon flux from Fig. 1 is shown along with its integral, which is shown on two different scales. One axis shows the integral from $280-4000 \mathrm{~nm}$ in terms of how high a percentage of the number of the available photons that can be absorbed by having a particular band gap. The second axis shows the integral in the maximum theoretical current density that can be obtained, provided that all photons are absorbed up to the band gap and converted into one electron in an external circuit that is $1 \mathrm{e}^{-} /$photon. It should thus be considered as the maximum possible current achievable. This graph is intended as a tool so that the experimenter can check own data or literature reports. If for instance a larger current density is obtained for a particular material than the curve predicts, it could be worthwhile checking the experiment once more (incident light intensity, spectrum, sun simulator, etc.). In Table 1 , a few of the values have been highlighted for a quick overview.

In reality, most PVs can not efficiently make use of light energy below $350-400 \mathrm{~nm}$ due to absorption in the substrate and front electrodes (i.e. glass, ITO) but fortunately this part of the spectrum contains very little intensity. The range of wavelengths from 280 to $400 \mathrm{~nm}$ amounts to only $\sim 1.4 \%$ of the total possible current or $\sim 1 \mathrm{~mA} \mathrm{~cm}^{-2}$ in current density. From Table 1, it becomes evident that one will gain considerably in current when increasing the $\lambda_{\max }$ from 650 to $1000 \mathrm{~nm}$, i.e. decreasing the band gap. Poly(3-hexylthiophene) has a band gap of $650 \mathrm{~nm}(1.9 \mathrm{eV})$ and thus only has the possibility to harvest up to $22.4 \%$ of the available photons giving a maximum theoretical current density of $14.3 \mathrm{~mA} \mathrm{~cm}^{-2}$ (Note that this may increase if the polymer is applied in a bulk heterojunction device, due to the absorption of the

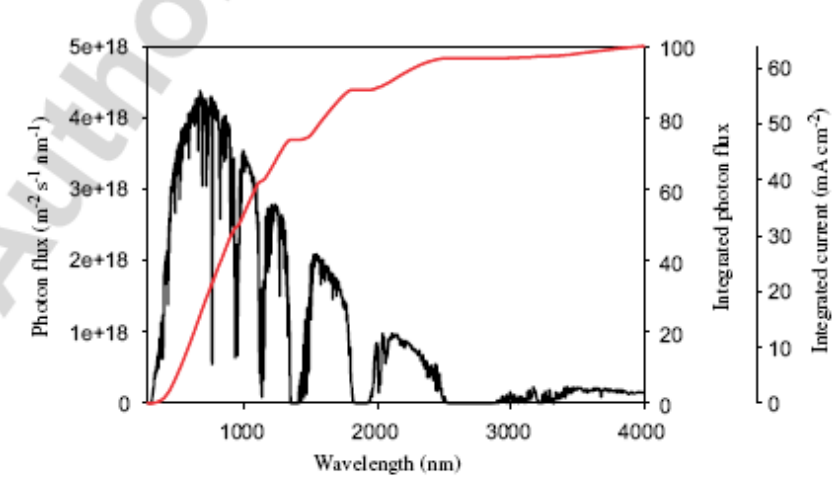

Fig. 2. Photon flux from the sun (AM1.5) as a function of wavelength. The integral of the curve is shown on the right $y$-axis as, respectively a percentage of the total number of photons and as obtainable cur rent density. 
acceptor, i.e. PCBM). Extending the band gap to $1000 \mathrm{~nm}$ will allow for absorption of $53 \%$ of the available photons giving a maximum current density of $33.9 \mathrm{~mA} \mathrm{~cm}^{-2}$. In practical terms these values can not be achieved since absorption will never be complete and incident photon to current efficiencies (IPCE) will never be unity. The values, however, are good figures to have in mind as a rule of thumb when quickly evaluating literature reports or own data.

As an example we have calculated the current which can be achieved for a low band gap polymer (Fig. 3). In Fig. 3, the fraction of photons absorbed by a single passage through a film of a low band gap polymer material is shown along with the photon flux available from the sun (we do not take double passage or reflection phenomena into account). Assuming that all the absorbed photons are converted into an electron in an external circuit the maximum current can be calculated and is shown in Fig. 3 as the integral. The maximum current density that

Table 1

The integrated photon flux and maximum current density available for a PV that harvest light from $280 \mathrm{~mm}$ up to the wavelength quoted assuming that every photon is converted into one electron in the external circuit

\begin{tabular}{lcc}
\hline Wavelength & $\begin{array}{l}\text { Max. \% harvested } \\
(280 \mathrm{~nm} \rightarrow)\end{array}$ & $\begin{array}{l}\text { Current density } \\
\left(\mathrm{mAcm}^{-2}\right)\end{array}$ \\
\hline 500 & 8.0 & 5.1 \\
600 & 17.3 & 11.1 \\
650 & 22.4 & 14.3 \\
700 & 27.6 & 17.6 \\
750 & 35.6 & 20.8 \\
800 & 37.3 & 23.8 \\
900 & 46.7 & 29.8 \\
1000 & 53.0 & 33.9 \\
1250 & 68.7 & 43.9 \\
1500 & 75.0 & 47.9 \\
\hline
\end{tabular}

The current density may increase if the polymer is applied in a bulk heterojunction device, due to the absorption of the acceptor beyond the band gap of the donor. this polymer material can produce with the absorption shown is $\sim 12 \mathrm{mAcm}^{-2}$ (Fig. 3). The current density that can be achieved, however, depends on many factors, such as morphology of the device, carrier mobility and carrier lifetime, active layer thickness, etc. The above method can give an idea of the possible current densities that can be obtained for a given material with a simple absorption spectrum of the film. However, a more useful evaluation involves performing the same calculation using an IPCE curve instead since this is a device measurement and it thus includes all the effects related to reflection, multiple passage, interference and scattering. It also includes the internal effects from morphology, carrier transport, carrier lifetime, device thickness and light absorption.

\subsection{Ultimate power conversion efficiencies}

In the examination of the solar spectrum above we have shown that lowering the band gap allows for absorption of more photons resulting in higher currents that can lead to higher power conversion efficiency. Two models proposed by Scharber et al. [21] and Koster et al. [22] predict that a higher efficiency of OPV devices can be achieved using a lower band gap polymer. The increase in power conversion efficiency is not granted by the current density alone, a high open circuit voltage $\left(V_{O C}\right)$ is also needed (a high fill factor is assumed). The $V_{O C}$ is defined in the two models as the difference between the HOMO of the donor and the LUMO of the acceptor (Fig. 4) [21,22]. For an ordinary polymer such as MEH-PVV we have $V_{\text {oc }}(1)$, now lowering the band gap, i.e. lowering the LUMO of the donor from the black line to the dotted line, does not change the $V_{\mathrm{OC}}$. However, combining the low band gap with a higher LUMO of the acceptor (the grey to the dotted grey line) results in an increase of the open circuit voltage to $V_{\mathrm{OC}}(2)$ and hence the efficiency is increased assuming that the difference between the LUMO of the donor and acceptor is large enough to insure charge separation.

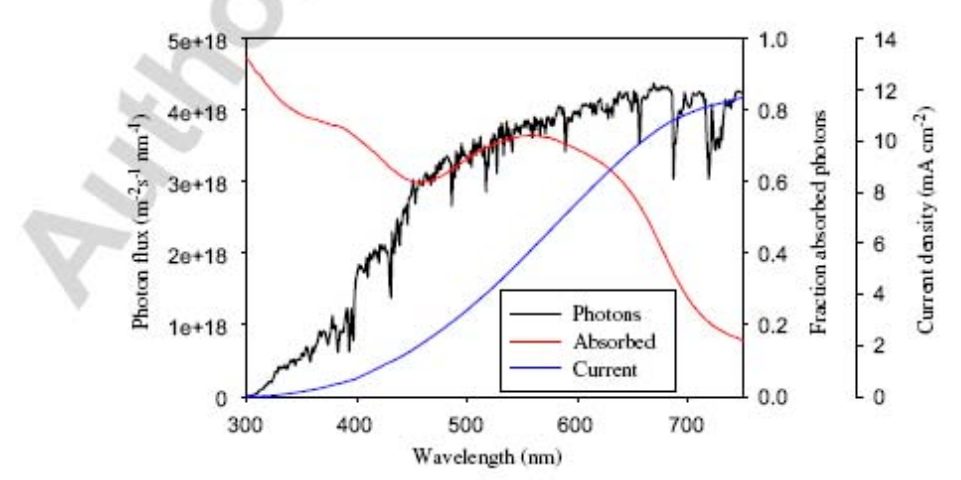

Fig. 3. Photon flux (black), photons absorbed by a copolymer of benzothiadiazole and thiophene (red) and current density (blue) as a function of wavelength. Current density is determined from the number of absorbed photons. 


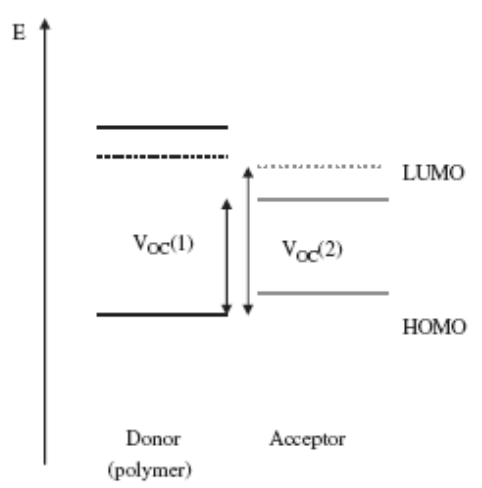

Fig. 4. Increase of $V_{O C}$ by tuning the energy levels in a bulk heterojunction OPV device.

Therefore, to increase the $V_{\mathrm{OC}}$ from $V_{\mathrm{OC}}(1)$ to $V_{\mathrm{OC}}(2)$ and thus the efficiency of the device we must prepare new low band gap polymer materials which absorb light with longer wavelengths thus absorbing more of the photons in the solar spectrum. Further, we must improve the electron transfer from the donor (polymer) to the acceptor [23]. $V_{\mathrm{OC}}$ can be increased by increasing the difference between the LUMO level of the acceptor and the HOMO level of the donor. Further, the LUMO levels of the acceptor and donor have to be far enough apart to guarantee energetically efficient electron transfer (see below) [21-23].

\subsection{Optimum alignment of energy levels}

Alignment of the energy levels in OPV is of great importance to achieve high $V_{\mathrm{OC}}$ and an efficient charge transport from the donor polymer to the acceptor fullerene. In Fig. 5, a schematic view of the energy levels in a bulk heterojunction is shown. The energy, $\alpha$, represents the difference between the LUMO of the polymer and the LUMO of PCBM. The variable $\alpha$ expresses how much lower the LUMO of the acceptor PCBM is with respect to the LUMO of the donor and it has to be large enough to ensure efficient charge separation. The energy, $\boldsymbol{\beta}$, represents the minimum acceptable value for $V_{\mathrm{OC}}$. The choice of $\alpha$ and $\beta$ is of course somewhat arbitrary as one would like efficient charge separation and as large a value for $V_{\text {OC }}$ as possible and for materials with large band gaps of $2 \mathrm{eV}$ or more this is not critical. There is thus a range of energies that the HOMO level of the donor material can take while fulfilling the criteria for $\alpha$ and $\beta$ shown as $\Delta E$ in Fig. 5 . When knowing the band gap of the polymer and the acceptable levels of $\boldsymbol{\alpha}$ and $\boldsymbol{\beta}$ it is possible to estimate the energy range that is acceptable for the HOMO level of the donor according to: $\Delta E=E_{\mathrm{g}}-\boldsymbol{\alpha}-\boldsymbol{\beta}$. When the band gap becomes low as in the case of low band gap polymer materials the values of the variables $\alpha$ and $\beta$ along with the

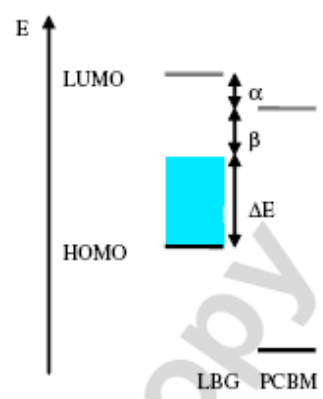

Fig. 5. Alignment of energy levels in bulk heterojunctions with a low band gap polymer (LBG) and PCBM. HOMO and LUMO are represented with thick black bines and thick gray lines, respectively. The acceptable range of energies for the HOMO level of the donor is shown as a shading.

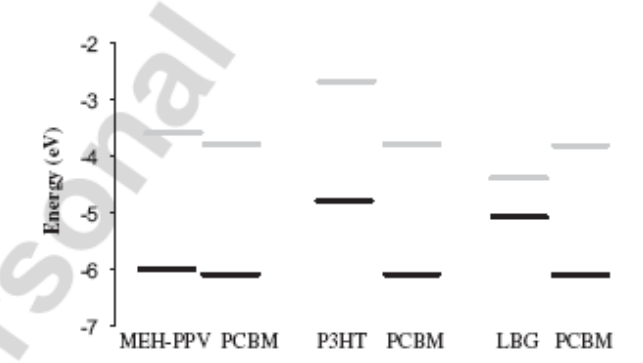

Fig. 6. Alignment of energy levels in bulk heterojunctions with PCBM using (a) MEH-PPV [24], (b) P3HT [22] and (c) low band gap polymer (LBG) $[25,26]$.

position of the donor HOMO level becomes crucial and probably impossible in many cases if the acceptor material is chosen. Most often the range of energy levels for the acceptor is fixed as the current state of the art employ fullerene materials. This aspect underlines the need for new acceptor materials with HOMO and LUMO levels that are significantly different from the fullerenes.

In Fig. 6, examples of energy level alignment in bulk heterojunctions with PCBM and commonly used polymers, i.e. MEH-PPV (poly(2-methoxy-5-ethylhexyloxy-1,4-phenylenevinylene)), P3HT (poly(3-hexylthiophene)) and an example of a low band gap polymer. Fig. 6 highlights the importance of energy level alignment when using low band gap polymers compared to polymers with larger band gaps. For MEH-PPV a high $V_{\text {OC }}$ can be achieved (see Section 2.2) and further, the alignment between the LUMO of MEH-PPV and PCBM ( $\alpha$ in Fig. 5) can result in an efficient charge transfer. A more efficient charge transfer will result if P3HT is applied since the difference $\alpha$ is higher for P3HT than for MEH-PPV. However, using P3HT also decreases the maximum $V_{\mathrm{OC}}$, which can be obtained.

For the low band gap polymer in Fig. 6 the LUMO energy level does not align with the LUMO of PCBM such 
that an efficient charge transfer can take place. For this low band gap polymer to work efficiently in an OPV device another electron acceptor with a lower energy level of the LUMO would be required.

Thus, it is not only important to synthesize polymers with a low band gap; one also needs to consider the energy level alignment to increase the efficiency of OPV devices.

\subsection{Design considerations for low band gap polymers}

There are several factors that influence the band gap of a conjugated polymer material. Among these are:

(1) intra-chain charge transfer;

(2) bond-length alternation;

(3) aromaticity;

(4) substituents effects;

(5) intermolecular interactions;

(6) $\pi$-conjugation length $[6,27]$.

Most of the low band gap polymers described in the literature are based on thiophene either as a homo polymer (polythiophene), in a copolymer or as part of a fused ring system which can be achieved by modifying the electronic properties of existing polymer units $[28,29]$. The low band gap copolymers reported are often based on thiophene but other electron rich aromatic units such as pyrrole are also found. Identical for these copolymers are the alternation between electron donor (electron rich) and electron acceptor (electron deficient) units $[27,30]$. The high energy level for the HOMO of the donor and the low energy level for the LUMO of the acceptor results in a lower band gap due to an intra-chain charge transfer from donor to acceptor $[27,30]$. By mathematical simulation it was shown that the electron affinity was higher around the acceptor units compared with the donor units in these types of copolymers [31-34].

Planarity along the aromatic backbone results in a low band gap, due to a high degree of delocalization of the $\pi$ electrons [35]. The alternation between single and double bonds along the polymer chain has a tendency to increase the band gap. A reduction of the difference in bond length alternation is achieved by the alternation of donor and acceptor units along the conjugated polymer chain thus lowering the band gap. In essence this concept suppresses the Peierls effect $[36,37]$. The alternation between donor and acceptor results in two resonance forms: D-A and $\mathrm{D}^{+}=\mathrm{A}^{-}[35]$.

As described interactions between acceptor and donor enhance double bond character between the repeating units, this stabilizes the quinoid form of e.g. benzo-bis(thiadiazole) (see Fig. 29) formed within the polymer backbone, and hence a reduction in band gap is achieved [37].

If the HOMO level of the donor and the LUMO level of the acceptor are close in energy it results in a low band gap as shown in Fig. 7. Therefore, to achieve a lower band gap the strength of the donor and the acceptor must be

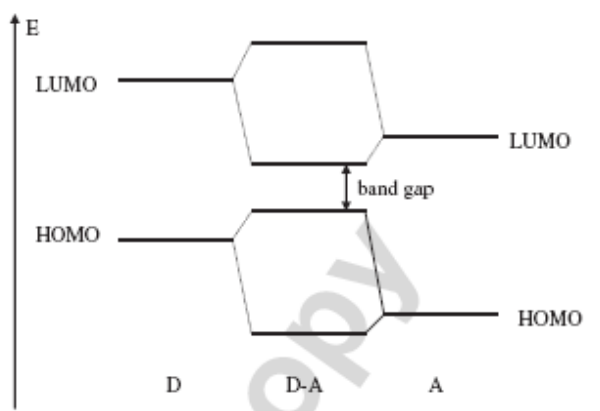

Fig. 7. Alternating donor-aceptor units lower the effective band gap by orbital mixing.

increased. This is efficiently achieved by using electron withdrawing groups (EWG) on the acceptor and electron donating groups (EDG) on the donor. EWG such as $\mathrm{CN}$, $\mathrm{NO}_{2}$, quinoxalines, pyrazines or thiadiazole lower the energy levels (and thereby LUMO) of the acceptor. EDG such as thiophene or pyrrole raise the energy levels (and thereby HOMO) of the donor [37].

It has been found that the band gap for certain polymers is lowered in the solid phase due to ordering compared to the observed disorder in solution [6,38-53]. Further, it has been found that a longer conjugation length lowers the band gap and that the band gap is increased when torsion in the polymer back bone disrupts the conjugation (see below) $[6,54]$.

\section{Types of low band gap polymers}

\subsection{Polythiophene}

The structure of polythiophene is shown in the upper part of Fig. 8. To improve the solubility of polythiophene many different $\mathrm{R}$ groups have been explored ranging from alkyl, alkoxy, acid, ester and phenyl groups etc. Since the thiophene ring is a 5 -membered ring that is polymerized through the 2 and 5 position substitution introduces directionality in the polymer and every time a monomer is incorporated in the growing polymer chain it can add with the head (2-position) or the tail (5-position) first.

This gives the possibility for a regular material where all the molecules add in a head to tail (HT) fashion or it can be random with occasional head to tail (HT), head to head $(\mathrm{HH})$ or tail to tail (TT) coupling (Fig. 8). The lower part of Fig. 8 shows the local structure resulting from the three possible couplings.

3.1.1. Optical and electrical properties of polythiophenes

The band gap of polythiophene is $2 \mathrm{eV}$ [56]. The regioregular head to tail coupled poly-3-alkylthiophene (PAT) product has a planar structure in solution and generally exhibit a lower $\pi \rightarrow \pi^{*}$ transition. This is an 


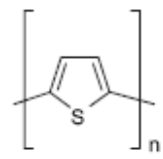

Polythiophene

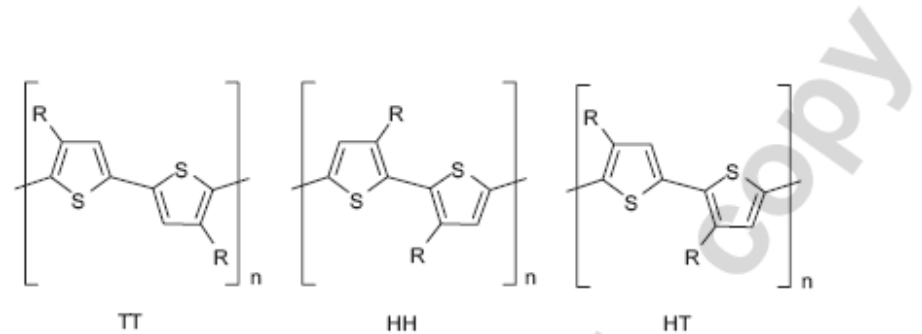

Fig. 8. Structure of polythiophene and substituted derivates of polythiophene in HH, HT and TT couplings [55].

indication of a longer conjugation length in the polymer backbone compared to regiorandom PAT (coil like structure in solution) [15]. In solution the side-chain, ordering improves with an increase in the chain length [15]. Generally, it has been established that the PAT polymer chains are straight chains with a long conjugation length both in the amorphous and crystalline phase $[45,46]$.

Poly(3-hexylthiophene), P3HT, is one of the most studied conjugated polymers. The band gap of P3HT is $1.9 \mathrm{eV}$ [22]. The $\lambda_{\max }$ of P3HT and for PAT in general varies with the percentage of head-to-tail coupling, i.e. the regularity of the side chains. Hence, the synthetic procedure leading to $\mathrm{P} 3 \mathrm{HT}$ has a large influence on the properties of the final polymer product (see below) $[38,57]$. Further, it has been shown that the absorption of P3HT depend on the molecular weight of the polymer [39]. That is, $\lambda_{\max }$ increases with an increase in molecular weight and the absorption spectrum becomes broader up to $600 \mathrm{~nm}$ [39]. The regioregularity of $\mathrm{P} 3 \mathrm{HT}$ is of great importance for the characteristics of the polymer such as conductivity and charge carrier mobility and transport. Several reports have investigated the regioregularity and its effect on packing of the polymer [38-53]. It has been shown that the regioregular P3HT with a head-to-tail coupling stack in lamella structure, which is separated by the side chains [41,43-45,47,48]. Hence, the length of the alkyl side chains affects the lamella structure only in the dimension of lamella thickness [47]. The solvent used for spin coating have been shown to be of great importance $[41,42,46]$. Films of poly(3-octylthiophene) spin coated from chloroform was found to have their side chains directed towards the substrate [46]. This was also the case for phenyl side chains [45]. It has also been shown that the drying time and drying mechanism affects the anisotropy of the polymer film $[40,41]$.

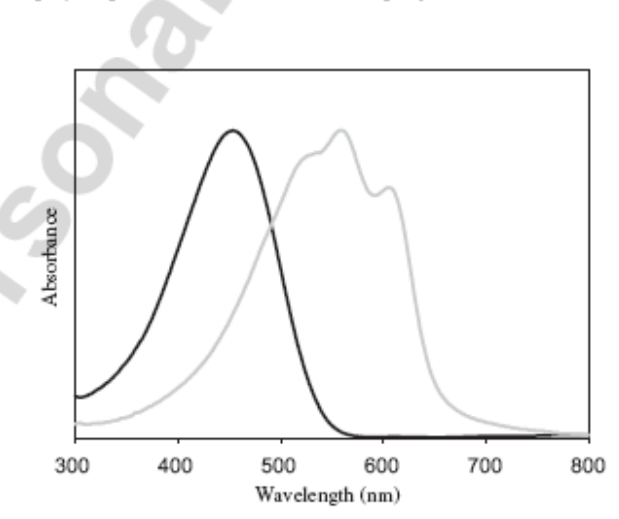

Fig. 9. Absorption spectra of regioregular P3HT in solution (black) and in a solid film obtained by spin coating from 1,2-dichlorobenzene (grey).

For P3HT or P3AT it has been found that the polymer organize in different ways in film and solution $[41,42,48,58]$. This is not the case for polythiophenes with phenyl side chains, which were found to organize similarly in both solution and in the solid film [42]. Furthermore, the absorption and hence the band gap of P3HT or P3AT is very different in the solid film and in solution, i.e. the $\lambda_{\max }$ increase when going from solution to the solid film (Fig. 9) [38]. From Fig. 9, it can also be seen that the absorption spectra for the film of P3HT is more detailed than the solution of $\mathrm{P} 3 \mathrm{HT}$, this is ascribed to the organization of the polymer in film.

Introduction of disorder was applied to investigate the effect of the regioregularity on the optical properties of the polythiophene [54]. P3HT was synthesized by Yamamoto polycondensation (see below) to give $91 \%$ regioregularity. The polymer was spin coated from chlorobenzene in a 1:1 mixture with PCBM, this resulted in PCBM segregation 
leading to a thermally stable interpenetrating network [54]. Addition of disorder alternates the driving force for crystallization leading to thermally stable bulk heterojunctions [54]. The most stable PV performance is obtained with $\mathrm{P} 3 \mathrm{HT}$ with tuned regioregularity to control the morphology of the bulk heterojunction [54]. This was also investigated for head-to-head coupled and tail-to-tail coupled polythiophene with different alkyl side chains [59]. It was found that the methyl side chain did not show any difference when the two couplings (i.e. HH and TT) was compared, however, when the length of the alkyl side chain increased a twist in the main chain was observed [59].

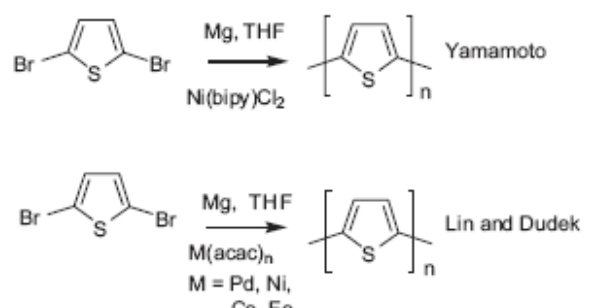

$\mathrm{Co}, \mathrm{Fe}$

Fig. 10. Synthesis of polythiophene by Yamamoto and Lin and Dudek $[57,61,62]$.
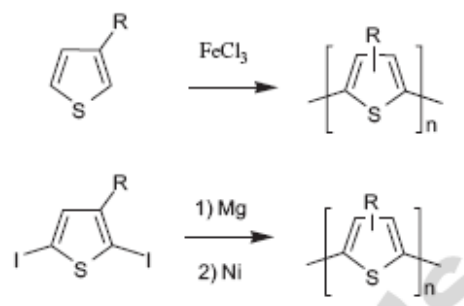

Fig. 11. Synthesis of regiorandom PAT $[55,57]$.
Cross-linking between thiophene units in polythiophene have been shown to increase the hole mobility in the polymer, and hence increase the efficiency of OPV devices [60]. However, a very high percentage of cross-linking resulted in a main chain distortion and poor solubility. This caused the hole mobility to decrease and thereby also resulted in a decrease in efficiency [60].

\subsubsection{Synthetic strategies leading to polythiophenes}

The synthesis of polythiophene has been carried out by several different strategies and the first synthesis of polythiophene was carried out by two different chemical polymerizations in 1980 by Yamamoto et al. and Lin and Dudek (Fig. 10) [61,62]. At the same time an electrochemical polymerization of thiophene was reported [14]. However, these three types of polymerizations all led to insoluble polymer products. Thus, in the late 1980 s several research groups strived to prepare soluble derivatives of polythiophene [63-65]. The PAT, first described in 1986, have three conformations; HT-HT, TT-HT, HT-HH, TT$\mathrm{HH}$ as described above, which can be achieved by the strategies shown in Fig. 11 [14,57].

As described above the regularity of P3HT is of great importance due to higher conductivity of the polymer and higher efficiency of OPV devices. However, the synthetic methods presented in Fig. 11 did not give a regioregular polymer product [46]. Highly regioregular P3HT was not reported until the early 1990 s by MoCullough [66] and Reike [67] by two related methods as shown in Fig. 12. These methods have been explored extensively [57,68-84]. The regioregularity obtained from these synthetic procedures was $99 \%$ HT and $98.5 \%$ HT, respectively $[57,66,83]$. The conductivity of the regioregular P3HT was $1000 \mathrm{~S} / \mathrm{cm}$ compared to only $1-0.1 \mathrm{~S} / \mathrm{cm}$ obtained for P3HT with a low regioregularity $(58-70 \% \mathrm{HT})$ [57].

Regioregular P3HT have also been synthesized by Stille polymerization as shown in Fig. 13, which resulted in $96 \%$ HT in 1,2-dichloroethane or toluene $[85,86]$. Controlled

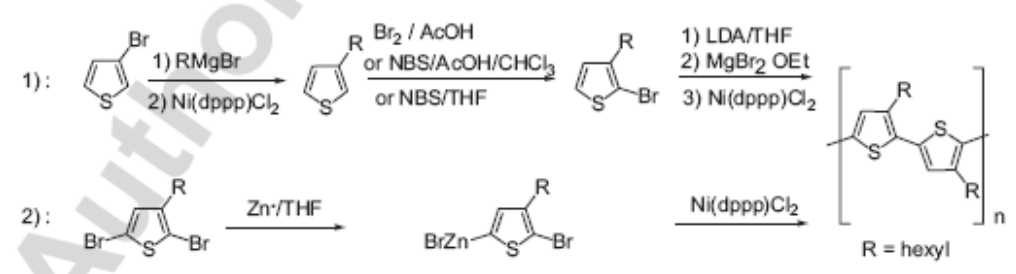

Fig. 12. Different strategies to regioregular P3HT (1) McCullough and (2) Reike.

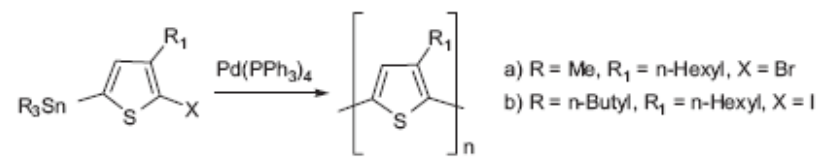

Fig. 13. Synthesis of P3HT by Stille cross-coupling polymerization $[85,86]$. 

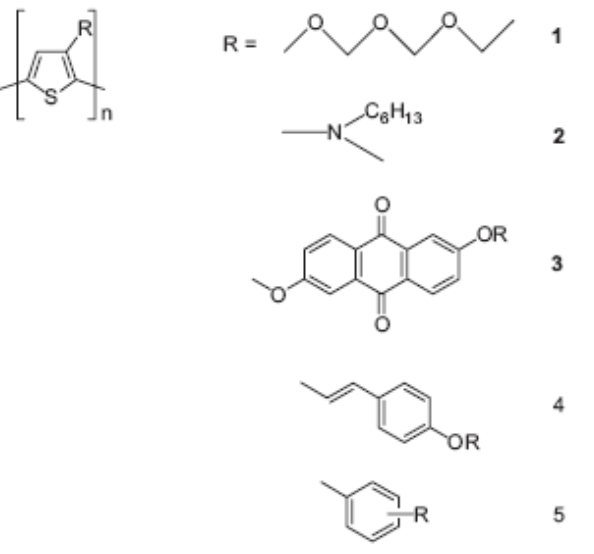

- alkyl

Fig. 14. Polythiophenes with different side chains: 1 [91], 2 [92], 3 [93-96], $4[55,90,97-100], 5[101], 6[57]$, and $\mathrm{R}=$ alkyl- $\mathrm{PO}_{3} \mathrm{H}_{2}[102]$.

length oligomers were obtained by Suzuki cross-coupling polymerization [87].

Besides the hexyl side chain, which is the most described in the literature, several other side chains have been added to achieve polythiophenes with specific solubility properties. Some examples of these are shown in Fig. 14. Copolymers of polythiophene with different side groups, i.e. resulting in donor and acceptor units, have also been reported. Examples are: $\mathrm{NH}_{2} / \mathrm{NO}_{2}$ [88], 3 and hexyl [89] and different phenyl groups [90]. In the latter example, the absorption spectra of the copolymers in solution and in film showed a red shift of $30-50 \mathrm{~nm}$ for the film [90]. A further red shift was observed when the film was annealed at $130^{\circ} \mathrm{C}$ for $10 \mathrm{~min}$., i.e. the band gap was reduced [90]. It was shown that the solubility increases with an increase in the length of the alkyl chain [65].

\subsubsection{PV devices based on polythiophenes}

The first OPV device based on poly(3-methyl-thiophene) (PMET) was reported in 1984 by Glenis et al. [103]. The polymer was synthesized by electrochemical polymerization onto an ITO electrode [103]. Thereafter, gold was evaporated on top, and the result was a simple OPV device with the configuration: Al/PMET/Au [103]. The measurements were carried out with an incident light intensity of $1 \mathrm{~mW} \mathrm{~cm}^{-2}$ and a power conversion efficiency of $0.007 \%$ was achieved [103]. Since then, several groups have reported the use of polythiophenes (especially P3HT) in OPV and the highest efficiency reported to date was reported by Reyes-Reyes et al. to be $5.2 \%$ for P3HT [10]. The most commonly employed device geometry today is the bulk heterojunction. Reported applications of polythiophenes in OPV are summarized in Table 2 for P3HT and in Table 3 for polythiophenes with side chains other than hexyl.

There are great variations in the performance of the devices shown in Table 2. However, notice the reported current densities; these have nearly reached the maximum, keeping in mind that the maximum theoretical current for P3HT with a band gap at $650 \mathrm{~nm}(1.9 \mathrm{eV})$ was found to be $14.3 \mathrm{~mA} \mathrm{~cm}^{-2}$ (AM1.5, $100 \mathrm{~mW} \mathrm{~cm}^{-2}$ ).

Nevertheless, there are too many variables in the experiments to allow for any reasonable comparison of the data. The purpose of Table 2 is thus to underline how many parameters that enter in device preparation and device characterization. From Table 2, it becomes evident that reported data is based on experiments that vary with respect to material source, molecular weight, solvent, annealing, electrodes, barrier layers and incident light. In addition to these identifiable differences there are many more variables that are not included in experimental descriptions either intentionally or unintentionally. It is, however, well established and generally agreed that regioregularity, molecular weight, processing solvent, annealing temperature and the substrate have a large influence on the device performance.

Schilinsky et al. showed that the PV performance was highly dependent on the molecular weight of the P3HT, and large efficiencies were only obtained for samples with a high molecular weight $\left(M_{n}>10,000\right)$ [39]. The molecular weight has been shown to affect absorption properties, as detailed above, showing an increase in conjugation with an increase in $M_{n}$ [124]. However, recent results suggest that in bulk heterojunction devices with PCBM a certain interplay between the highly regioregular, high molecular weight material and a low molecular weight material of low regioregularity may be important as a contact material or "glue" in the interface between the crystalline P3HT domains and the PCBM nanocrystals [122]. Besides the molecular weight the regioregularity influences the responses of the OPV [103]. Thus, it has been the aim for several research groups to use polythiophene with high degree of regioregularity in OPV devices, as described above (Table 2).

3.1.4. Interface layers and stability of polythiophene based OPVs

Several research groups have reported devices where layers between the electrodes and the active layer have been employed to improve the charge transport (Table 2). Examples are layers of lithium fluoride (LiF) between the active layer and $\mathrm{Al}[10,105,107,112,116,118]$ and transition metal oxides (i.e. $\mathrm{MoO}_{3}$ ) between the active layer and ITO [108]. These are believed to increase the efficiency of the OPV device. The focus of most research groups is currently on the PCE that can be obtained for the devices. Another problem is the stability of the devices during operation. Very few research groups have focused on the lifetime of the OPV based on polythiophenes, and in the papers summarized in Tables 2 and 3 lifetime data are only reported in two instances $[9,116$. Yang et al. documented 


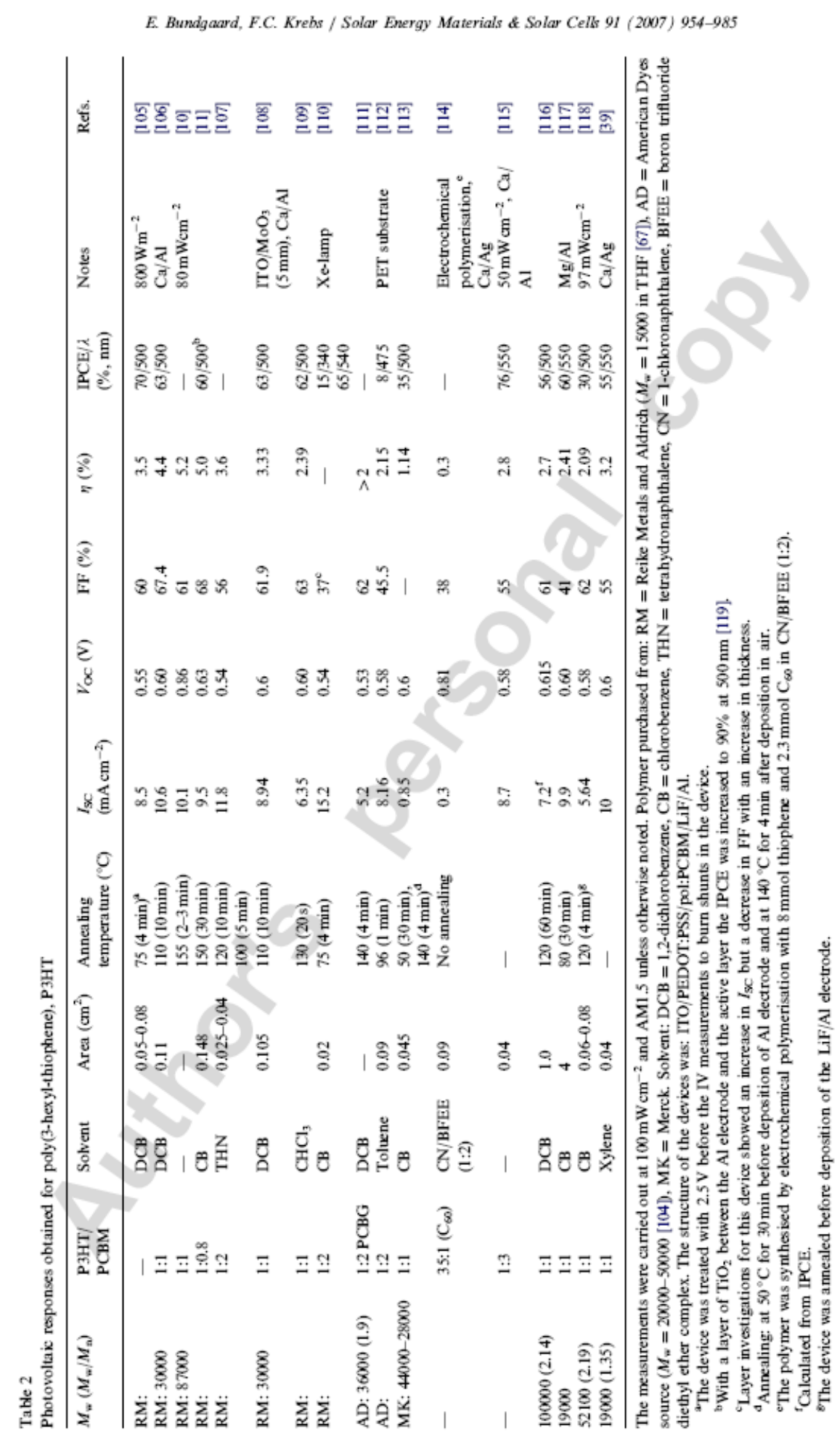


Table 3

Photovoltaic responses obtained for other polythiophenes

\begin{tabular}{|c|c|c|c|c|c|c|c|c|c|c|}
\hline $\begin{array}{l}\text { Polymer/ } \\
\text { PCBM }\end{array}$ & Solvent & $\begin{array}{l}\text { Area } \\
\left(\mathrm{cm}^{2}\right)\end{array}$ & $\begin{array}{l}\text { Annealing } \\
\text { temperature } \\
\left({ }^{\circ} \mathrm{C}\right)\end{array}$ & $\begin{array}{l}I_{\mathrm{SC}} \\
\left(\mathrm{mA} \mathrm{cm}^{-2}\right)\end{array}$ & $V_{\mathrm{OC}}(\mathrm{V})$ & FF (\%) & $\eta(\%)$ & $\begin{array}{l}\operatorname{IPCE} / \lambda(\%, \\
\mathrm{nm})\end{array}$ & Notes & Refs. \\
\hline $\mathrm{C}_{60}$ & Toluene & 10 & $200(15 \mathrm{~h})^{2}$ & 1.05 & 0.505 & 29 & 0.167 & - & $\begin{array}{l}\text { Lifetime }>20000 \\
\text { hours }\end{array}$ & [9] \\
\hline $\mathrm{C}_{60}$ & Toluene & - & - & 0.09 & 0.53 & 33 & 0.15 & - & $\begin{array}{l}\mathrm{P} 3 \mathrm{OT}, \\
10 \mathrm{~mW} \mathrm{~cm}^{-2}\end{array}$ & [120] \\
\hline- & Xylene & - & No anneal & 11 & 0.6 & - & 3.59 & - & P3HT fibers & {$[121,122]$} \\
\hline $1: 1\left(C_{60}\right)$ & Xylene & 12 & - & 1.06 & 0.6 & 30 & 1.5 & $20 / 488$ & $\begin{array}{l}\text { Flexible, P3OT } \\
10 \mathrm{~mW} \mathrm{~cm}^{-2}\end{array}$ & {$[1,123]$} \\
\hline $1: 2$ & DCB & - & - & 1.52 & 0.63 & 37 & 0.54 & - & $\begin{array}{l}\mathrm{Ca} / \mathrm{Al} \\
70 \mathrm{mWcm}^{-2}\end{array}$ & [97] \\
\hline
\end{tabular}

The measurements were carried out at $1000 \mathrm{Wm}^{-2}$ and AM1.5 unless otherwise noted. The structure of the devices was: ITO/PEDOT:PSS/pol:PCBM/Al, no PEDOT: PSS.

"Thermocleavage of ester side chains to acid side chains before deposition of $\mathrm{C}_{80}$ and $\mathrm{Al}$.

a very good morphological stability for a P3HT/PCBM bulk heterojunction device when tested under accelerated conditions by illumination with incident light intensity of $1000 \mathrm{Wm}^{-2}$ (AM1.5) at $70^{\circ} \mathrm{C}$ in a glovebox [116]. A second example of a polythiophene device with a very long lifetime was obtained by making devices via solution processing of a polythiophene with a tertiary alkyl ester side chain. The side chain could be removed by a thermal treatment giving a more stable device. A tremendous increase in the lifetime of a $3 \mathrm{~cm}^{2}$ device (ITO $/ \mathrm{P} 3 \mathrm{CT} / \mathrm{C}_{60} / \mathrm{Al}$ ) was reported [9]. The efficiency for this type of device was upto $0.17 \%$ and the lifetime was estimated to be $20,000 \mathrm{~h}$ through accelerated tests [9].

3.1.5. Morphology of the active layer in polythiophene based $O P V S$

There are several factors that influence the morphology of the active layer in OPV devices [13]. It has been shown that a good morphology, i.e. a smooth film, increases the efficiency of the device. For P3HT the dependence of the PV response on molecular weight [53], annealing temperature (Table 2) and solvent [125] have been carried out.

In Table 2, it can be seen that the various research groups employ different solvents for spin coating the active layer, and it has been shown that the evaporation time of the solvent has a large influence on the morphology of the active layer [108].

Morphology studies carried out with two different acceptors: PCBM and PCBG (see Fig. 40), showed that PCBG (phenyl- $\mathrm{C}_{61}$-butyric acid glucidol ester) stabilizes the morphology of blends with $\mathrm{P} 3 \mathrm{HT}$ upon annealing preventing phase separation $[111,126]$. In P3HT/PCBM blends used in bulk heterojunctions it has been shown that the hole and electron mobility depends on the content of PCBM $[50,127]$. An increase in the PCBM content increases the electron mobility while the hole mobility decreases only slightly $[50,127]$.

Studies of the influence of the film thickness on the PV responses shows that to achieve a high IPCE $>90 \%$ the thickness of the active layer, with P3HT and PCBM, has to be $240 \mathrm{~nm}$ [23], and further that the replacement of MEHPPV with P3HT in OPV results in a better hole transport $[23,105]$. It was found that an IPCE of $70 \%$ could be achieved at $\lambda_{\max }[23,105]$. The effect on crystallinity of annealing and the P3HT/PCBM ratio showed that the mean drift length of photogenerated charge carriers exceeds the active layer thickness under PV operation. Hence, when the thickness of the active layer is increased the $I_{\mathrm{SC}}$ increases due to improved light absorption [128]. Investigations on OPV (ITO/PEDOT:PSS/polymer:PCBM/ $\mathrm{LiF} / \mathrm{Al}$ ) shows that $V_{\mathrm{OC}}$ varies with the variations in oxidation potential of the donor polymer, i.e. polythiophene with different phenyl groups [98]. When P3HT (95.4\% HT)/PCBM with a 1:1 ratio was spin coated from chlorobenzene it was found that the highest efficiency $(4.4 \%)$ was achieved for the highest regioregularity [129].

The photoluminescence of polythiophenes [130] and the photoluminescence (PL) quenching of mixtures between P3HT and $\mathrm{C}_{60}$ [96] has been studied extensively as the PL quenching mechanisms has been linked to the processes of charge carrier of other substituted polythiophenes [130].

\subsubsection{Hybrid solar cells and tandem cells based on} polythiophenes

We have limited the results presented in Tables 2 and 3 to organic bilayer and bulk heterojunction devices. Devices based on mixtures of polythiophenes with inorganic n-type semiconductors have also been reported. These types of devices are generally termed hybrid solar cells and typical examples are based on mixtures of P3HT with $\mathrm{CdSe}, \mathrm{TiO}_{2}$, $\mathrm{GaAs}, \mathrm{ZnO}$. We have chosen not to discuss these devices here but a summery can be found in the literature $[23,131,132]$. Further, few reports on OPVs based on mixtures between carbon nanotubes and polythiophenes [133] or with P3HT [134], polythiophenes attached to fullerenes [135-137], the use of plasticizers such as propylene carbonate [138], other fullerenes [139] and tandem PV devices with MDMO-PPV [140] or $\mathrm{ZnPc}[141]$ can be found in the literature. 


\subsection{Poly(3,4-ethylenedioxythiophene) PEDOT}

PEDOT is normally used in its oxidized form with polystyrenesulfonic acid as the anion (PEDOT:PSS) as shown in Fig. 15 [8,142]. PEDOT:PSS is used as a hole conducting and transporting layer in electroactive devices and OPVs to improve the performance $[8,143-146]$ and has found widespread application. In addition the PEDOT:PSS complex also serves as a smoothing layer between the ITO electrode and the active layer in OPV devices and thus PEDOT:PSS have been applied in almost every OPV described in the literature (Table 1-8). Examples of conjugated polymers where 3,4-ethylenedioxythiophene (EDOT) has been incorporated in the backbone of a conjugated copolymer with thienopyrazine [147-148], isothionaphthene (ITN) and benzothiadiazole [149] and as cyanovinylene coupled polymers [150] have been described in the literature.

It has been shown that replacing ITO with PEDOT:PSS is sufficient to give low cost, flexible OPVs [143,151,152]. This is seen for doped states of PEDOT:PSS e.g. with sorbitol which results in higher conductivity [143,151]. Further, PEDOT:PSS have been shown to be highly anisotropic and uni-axial with the optical axis parallel to the surface [153]. PEDOT:PSS can be processed into uniform transparent films when spin coated from its dark blue aqueous dispersion/solution and it can be patterned to give different device structures $[143,154]$.

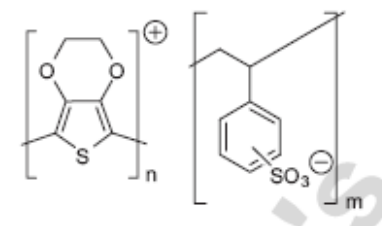

Fig. 15. Structure of poly(ethylene-dioxy-thiophene): polystyrenesulfonate complex, PEDOT:PSS.

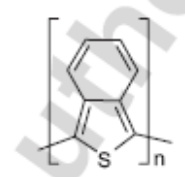

Fig. 16. Structure of polyisothianaphthene, PITN.

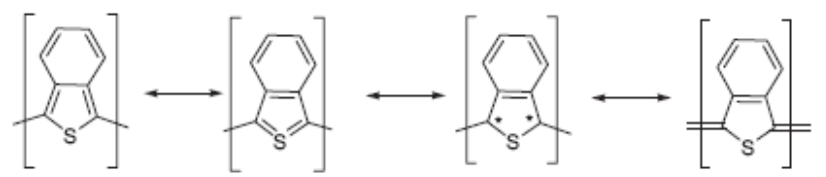

Fig. 17. Resonance structures in PITN. The stars in the third resonance structure corresponds to radicals.
Isothianaphthene (ITN) is a thiophene ring with a fused benzene ring in the 3 and 4 positions as shown in Fig. 16 $[28,155,156]$.

\subsubsection{Electronic properties of PITN}

The different resonance structures of PITN are given in Fig. 17. The last resonance structure is a quinoid form which is characteristic for these types of polymers $[6,155,156]$.

The quinoid form of PITN has different energy levels for the HOMO and LUMO compared to the aromatic form of the polymer [6]. This causes the decrease in band gap which is observed $[6,155]$. The band gap of PITN was determined by electronic spectroscopy to be $1 \mathrm{eV}$ [157]. Due to the many resonance structures of PITN and especially due to the increase in the quinoid structure in the backbone of PITN and the larger polarization causes the band gap of the polymer to decrease [157]. This is also seen for other conjugated polymers based on aromatic rings [157]. A ${ }^{13} \mathrm{C}$ NMR model simulated that PITN show a strong quinoid character [158]. Substitutions with EWG or EDG did not show any significant effect on the band gap [28].

Addition of further benzene rings as shown in Fig. 18 resulted in a larger band gap due to the increase in electron delocalization over the aromatic system and a suppression of the quinoid structure [159]. Derivatives of PITN where alkyl, alkoxy and halogen groups have been added to the backbone have been found to increase the solubility and hence the polymer is more proccessable [160].

PITN in its doped form is a highly transparent, highly conducting polymer with a conductivity of up to $50 \Omega^{-1} \mathrm{~cm}^{-1}$ for a highly doped thin film [157].

\subsubsection{Synthesis of PITN and its derivatives}

The synthesis of PITN was first described in 1984 by Wudl et al. [155] and two different methods have been reported:

(1) Electrochemical polymerization using lithiumbromide in acetonitrile by applying a potential (1.5 V) [155].

(2) Chemical cationic oxidative polymerization with sulfuric acid, aluminum chloride or TCNQ [155].

These pathways are quite possibly not suited for an industrial scale since the monomers and starting materials 
are difficult to obtain, unstable and derivatives are only obtained by circuitous synthetic strategies [161]. Therefore, the synthesis of PITN from phthalic anhydride or phathalide using $\mathrm{P}_{4} \mathrm{~S}_{10}$ was described $[161,162]$. The reaction was carried out in xylene at $140-145^{\circ} \mathrm{C}$ as shown in Fig. 19 and further the synthesis to give easy access to soluble derivatives of PITN with different alkoxy groups was described [163]. The differently substituted materials showed no significant differences in the band gap which remain $\sim 1 \mathrm{eV}[162]$.

In 2003, Polec et al. described the synthesis of soluble derivatives of PITN [163] by a non-oxidative thermal polymerization. The soluble monomer was obtained from 4,5-dichlorphtalic acid in eight synthetic steps or from 5,6dioctyloxydithiophthalide in seven synthetic steps with $p \mathrm{Ts} \mathrm{OH} \cdot \mathrm{xH}_{2} \mathrm{O}$ in xylene at $155-160^{\circ} \mathrm{C}$ as shown in Fig. 20. The polymer had a band gap of $1.2 \mathrm{eV}$ [163].

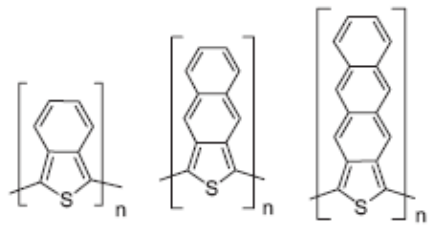

Fig. 18. Structure of PITN, poly(naphthothiophene) and poly(anthracenothiophene) [159].

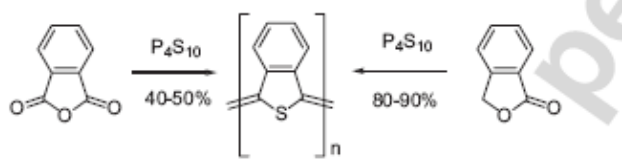

Fig. 19. Synthesis of PITN from phthalic anhydride or phathalide.

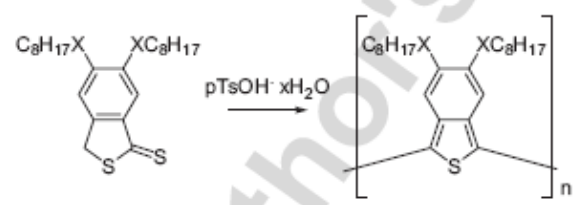

Fig. 20. Synthesis of a soluble derivative of PITN [163]. $\mathrm{X}=\mathrm{S}, \mathrm{O}$.
Chen et al. reported the dehydrogenation to achieve PITN as shown in Fig. $21[164,165]$, where the first step was carried out by a cationic polymerization of ITN followed by the dehydrogenation $[155,164,165]$.

In 2001, Meng and Wudl [160] described the synthesis of a soluble derivative of PITN with an electron withdrawing alkyl substituted imide group, poly (2-ethyl-hexyl-imideisothianaphthene), PEHI-ITN (Fig. 22). The imide was introduced to change the position of the HOMO and LUMO levels and to stabilize the n-doping of PITN [160]. The polymerization was carried out oxidatively using ferric chloride from the monomer which was synthesized in 7 steps from 3,4-dimethylbutadiene and maleic anhydride $[160]$.

\subsubsection{Application of PITN in OPVS}

The use of PITN and its derivatives in OPV devices have only been reported in a few instances. This can be ascribed mainly to the poor properties of PITN, i.e. low solubility and hence the polymer is not processable and further the polymer is infusible [163]. After the synthesis of a soluble derivative of PITN [163] was reported PV devices were prepared by Goris et al. [166] in 2003 and by Henckens et al. [167] in 2004. The results of these devices are summarized in Table 4.

The $V_{\mathrm{OC}}$ and $I_{\mathrm{SC}}$ given in Table 4 are very low and the highest efficiency is $0.008 \%$ [167]. This is mainly ascribed to properties of the polymer described above which results in rough films. This morphology results in shunts, poor diode behavior and rectification [166]. The addition of PCBM results in a higher current, due to better electron transport, however, the results are still very poor [166]. No further details on the application of PITN in OPV devices have been published.

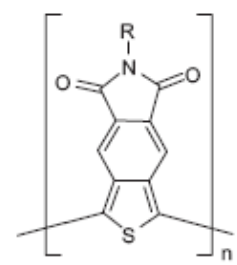

Fig. 22. Structure of poly (2-ethyl-hexyl-imide-isothianaphthene), PEHIITN.

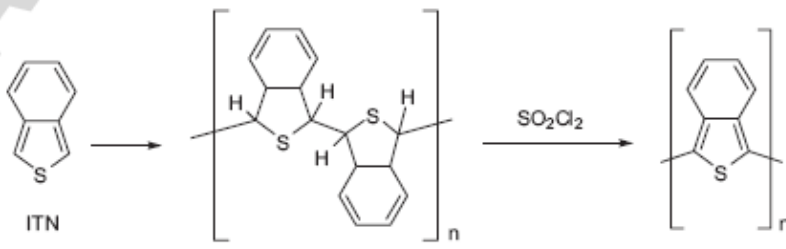

Fig. 21. Synthesis of $\mathrm{PITN}$ using $\mathrm{SO}_{2} \mathrm{Cl}_{2}[164,165]$. 
Table 4

Photovoltaic responses obtained for PITN and copolymers based on ITN

\begin{tabular}{lllllllllll}
\hline Polymer & $\begin{array}{l}\text { Polymer/ } \\
\text { PCBM }\end{array}$ & $\begin{array}{l}\text { Area } \\
\left(\mathrm{cm}^{2}\right)\end{array}$ & $\begin{array}{l}\text { Annealing } \\
\text { temperature } \\
\left({ }^{\circ} \mathrm{C}\right)\end{array}$ & $\begin{array}{l}I_{S C} \\
\left(\mathrm{~mA} \mathrm{~cm}^{-2}\right)\end{array}$ & $V_{\text {OC }}(\mathrm{V})$ & FF (\%) & $\eta(\%)$ & $\begin{array}{l}\text { IPCE @ } \lambda \\
(\%, \mathrm{~nm})\end{array}$ & Notes & Refs. \\
\hline PITN & Pristine & - & - & 0.01 & 0.35 & - & - & - & Odyl, LiF/Al & {$[166]$} \\
PITN & $1: 1$ & - & - & 0.04 & 0.20 & - & - & $0.3 / 700$ & Octyl, LiF/Al & {$[166]$} \\
PITN & - & - & - & 0.05 & 0.55 & 30 & 0.008 & - & {$[167]$} \\
P(T-ITN-T) & $1: 3$ & - & - & 1.6 & 0.26 & 37 & 0.15 & $>40 / 450$ & PMMA blend & {$[168]$} \\
P(T-ITN-T) & $1: 3$ & - & 50 during & 1.13 & 0.88 & 25 & 0.31 & $20 / 480$ & PMMA blend & {$[169]$} \\
& & & measurement & & & & & & & \\
\hline
\end{tabular}

The measurements were carried out at $80 \mathrm{~mW} \mathrm{~cm}^{-2}$ and AM1.5 unless otherwise noted. The structure of the devices was: ITO/PEDOT:PSS/pol:PCBM/Al.
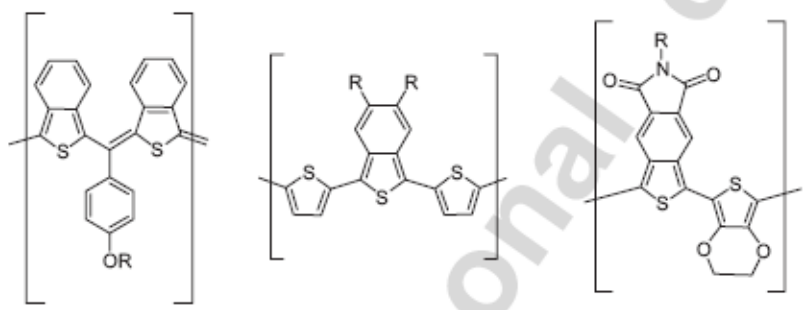

Fig. 23. Copolymers based on ITN with aromatic $[19,170,171]$, thiophene where $\mathrm{R}=$ alkyl or chlorine $[168,169,172,173]$ and EDOT $[174-176]$.

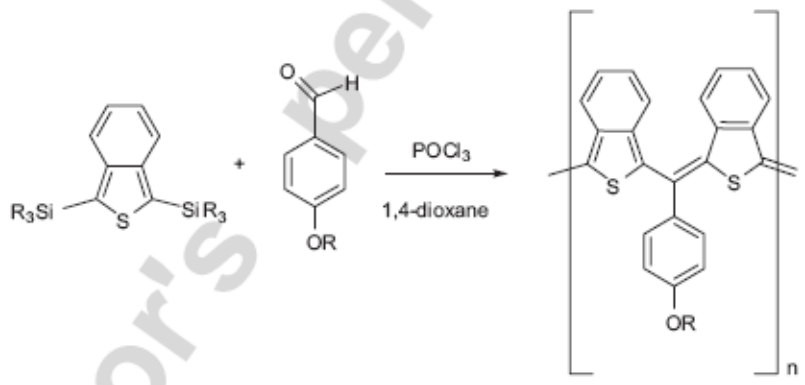

Fig. 24. Synthesis of copolymers based on ITN and aromatic units. $R=$ alkyl.

\subsection{Copolymers based on ITN}

There are a few examples of copolymers based on ITN that have been published as shown in Fig. 23 [19,168-172]. In these polymers ITN is the electron acceptor and the benzylic unit $[19,170,171]$ or the thiophene unit $[168,169,172]$ is the electron donor.

The polymer on the left-hand side of Fig. 23 was synthesized by a coupling between a bis(trialkylsilyl) derivative of ITN and a benzaldehyde derivative by reaction with $\mathrm{POCl}_{3}$ as shown in Fig. $24[170,171]$. The bis(trialkylsilyl) derivative of ITN was synthesized in 3 steps from phthalic anhydride $[170,171]$. The solubility of the copolymer was ensured by the alkoxy group on the benzene ring. The band gap of the polymer was found to be $1.2-1.3 \mathrm{eV}[170,171]$. However, the polymer product exhibited a very low conjugation length due to a nonplanar configuration. Hence, the charge carrier mobility was expected to be low [19].

The copolymer shown in the middle of Fig. 23, P(T-ITN$\mathrm{T}$ ), was first synthesized by electrochemical polymerization in 1992 [177]. Years later, in 2001, the copolymer was synthesized by oxidative ferric chloride polymerization from the monomer, which was obtained in 4 steps from 4,5dichlorophthalic acid $[169,172]$. The substituents on the benzene ring of ITN were either alkyl chains [168] or chlorine $[169,172]$. The band gap of the resulting polymers was found to be $1.5 \mathrm{eV}$ [168] and $1.76 \mathrm{eV}$ [169,172], 
respectively. The polymer was applied in OPV devices and the results are summarized in Table 4 . From Table 4 it is clear that the efficiency has increased tremendously when comparing the copolymers based on ITN with PITN. This is due to the addition of the thiophene units, i.e. the electron donating groups. Further, it is shown that the chlorine atoms on the benzene rings result in a higher efficiency. This is ascribed to the electron affinity of chlorine and hence, the ITN unit becomes a stronger electron acceptor when comparing with the copolymer having alkyl chains on the benzene ring.

The copolymer shown on the right in Fig. 23 was synthesized by a Stille cross-coupling between a dibromoderivative of ITN-imide and a bis(trialkylstannyl) derivative of EDOT [175]. The band gap was found to be $1.0 \mathrm{eV}$ with a $\lambda_{\max }$ at $807 \mathrm{~nm}$ and a tail that extended to $1240 \mathrm{~nm}$ [174-176]. The low band gap of the copolymer was achieved, due to the low lying LUMO levels in ITN-imide and the high lying HOMO level of EDOT. The polymer was found to be highly stable towards n- and p-doping [174], and bulk heterojunctions of the copolymer and PCBM showed an IPCE of $3.5 \%$ at $700 \mathrm{~nm}$ [176]. While this is a low value compared to P3HT PCBM bulk heterojunctions it shows that it is possible to achieve significant IPCE values with low band gap materials.

\subsection{Copolymer of benzothiadiazole, pyrole and thiophene,} PTPTB

Another example of an alternating copolymer based on electron donor and acceptor units are the polymer, PTPTB, shown in Fig. 25. It is based on benzothiadiazole as the electron acceptor and the block of thiophene and pyrrole as the electron donor. It has a maximum absorption around $650 \mathrm{~nm}$ and a strong red shift $(90-100 \mathrm{~nm})$ is observed when

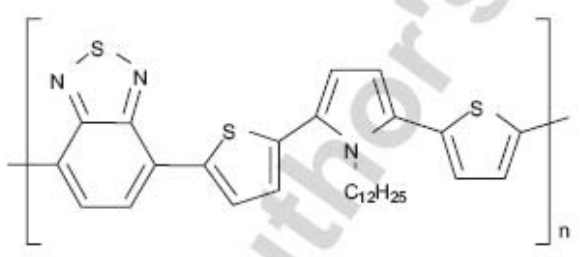

PTPTB

Fig. 25. Structure of the copolymers hased on thiophene, pyrrole and benzothiadiazole. comparing the absorption spectra of solutions and films of the polymer [17]. The band gap of the polymer varies with the length of the oligomers and for the longest oligomer synthesized the band gap was $1.6 \mathrm{eV}[17,18]$. Cyclic voltammetry in dichloromethane showed $E_{\mathrm{ox}}=0.53 \mathrm{~V}$, $E_{\mathrm{red}}=-1.24 \mathrm{~V}[18,178]$. The position of the HOMO and LUMO was determined by electrochemical voltage spectroscopy (EVS) to be -5.3 and $-3.5 \mathrm{eV}$, respectively, and the energy levels in OPVs shows good overlap between the polymer and the electrodes $[178,179]$. Copolymers of pyrrole and benzothiadiazole were found to have a band gap of $2.03 \mathrm{eV}$ [180].

The effect of the side chain on the nitrogen atom in the pyrrole ring caused an increase in the band gap from 1.2 to

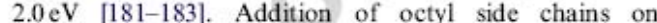
thiophene, attached to achieve solubility, resulted in a larger torsion strain due to steric hindrance and thus caused the band gap to increase [30]. PTPTB was also prepared with thermocleavable side chains on the thiophene units, which showed a significant decrease in band gap upon thermocleavage from 2.14 to $1.69 \mathrm{eV}$ [180].

The copolymer was synthesized by Stille cross-coupling polymerization between a di-bromo derivative of benzothiadiazole and a di-stannyl derivative of bis-thienylpyrrole as shown in Fig. $26[17,184]$. The Stille crosscoupling polymerization resulted in a mixture of shorter oligomers with imperfections in the polymer chain due to chain termination, destannylation, debromination, homocoupling and methylshift [17]. The polymers were purified by Soxhlet extraction. However, the ratio of the two monomers in the reaction mixture resulted in two different fractions, and it was found that an excess of the distannyl derivative of di-thiophene-pyrrole led to longer oligomers [17].

Since it was shown that the Stille coupling resulted in short chain oligomers with low molecular weight, PTPTB was synthesized by a Suzuki cross-coupling polymerization between aryl bis-boronic acid derivatives and dihaloarenes to give soluble high molecular weight polymers (Fig. 27) [30].

Several research groups have reported on the use of PTPTB in OPV devices and the results are summarized in Table 5. The low FF and low efficiency seen in Table 5 was not ascribed to a large serial resistance but was mainly ascribed to the low molecular weight of the oligomers. This resulted in thin low-quality films and hence, a poor morphology that was also observed in AFM images $[185,186]$. Further, the LUMO of the polymer and the LUMO of PCBM are very close $(3.7 \mathrm{eV}$ for the polymer
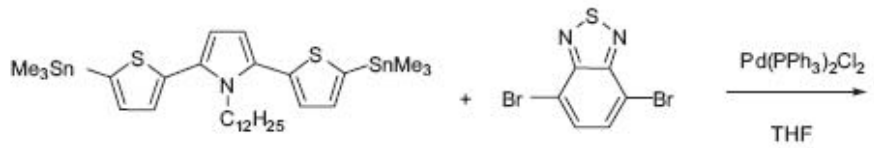

PTPTE

Fig. 26. Synthesis of PTPTB by Stille cross-coupling polymerization. 


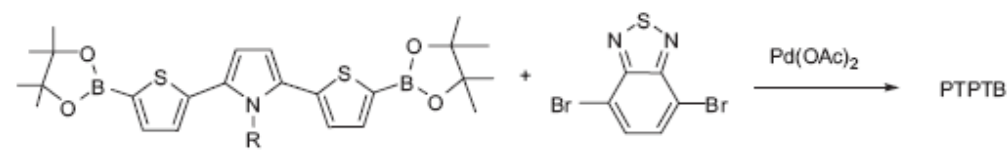

Fig. 27. Synthesis of PTPTB by Suzuki cross-coupling polymerization, $R=$ dodecyl.

Table 5

\begin{tabular}{|c|c|c|c|c|c|c|c|c|c|}
\hline $\begin{array}{l}\text { Polymer/ } \\
\text { PCBM }\end{array}$ & $\begin{array}{l}\text { Area } \\
\left(\mathrm{cm}^{2}\right)\end{array}$ & $\begin{array}{l}\text { Annealing } \\
\text { temperature } \\
\left({ }^{\circ} \mathrm{C}\right)\end{array}$ & $\begin{array}{l}I_{\mathrm{SC}} \\
\left(\mathrm{mA} \mathrm{cm}^{-2}\right)\end{array}$ & $V_{\infty C}(V)$ & FF (\%) & $\eta(\%)$ & $\begin{array}{l}\text { IPCE @ } \lambda \\
(\%, \mathrm{~nm})\end{array}$ & Notes & Refs. \\
\hline $1: 1$ & 0.1 & - & - & 0.70 & 35 & 0.34 & - & $55 \mathrm{~mW} \mathrm{~cm}^{-2}$ & {$[18]$} \\
\hline $1: 1$ & 0.1 & - & 0.8 & 0.67 & 35 & 0.34 & $7 / 600$ & $55 \mathrm{~mW} \mathrm{~cm}^{-2}$ & [17] \\
\hline 1:1 & 0.1 & $\begin{array}{l}55 \text { during } \\
\text { measurement }\end{array}$ & 3.1 & 0.72 & 37 & 1.00 & $20 / 550$ & & {$[187,188]$} \\
\hline 1:1 & 0.05 & - & 2.25 & 0.53 & 32 & 0.48 & $9 / 550$ & $\begin{array}{l}\text { Nile red } \\
(10 \%)\end{array}$ & [186] \\
\hline 1:1 & 0.05 & - & 1.0 & 0.51 & 30 & 0.20 & $9 / 500$ & $\begin{array}{l}\text { MDMO-PPV } \\
(1: 1)\end{array}$ & [186] \\
\hline
\end{tabular}

The measurements were carried out at $80 \mathrm{~mW} \mathrm{~cm}^{-2}$ and AM1.5 unless otherwise noted. The structure of the devices was: ITO/PEDOT:PSS/pol:PCBM/ LiF/Al.

and $4.0 \mathrm{eV}$ for PCBM), which caused a decrease in the selectivity of the metal electrode contacts, hence, the diode quality was low due to recombination [186,187]. It is interesting to note that the series resistance was measured to be $<10 \Omega \mathrm{cm}^{-2}$ while this does not explain the low FF [186,187].

The use of Nile red lowers the PV responses as seen in Table 5 . This was ascribed to the additional transport step for the electron [186]. The blend with MDMO-PPV increases the rectification but reduces the PV responses under illumination. Investigations of absorption and IPCE showed that PTPTB does not contribute to the photocurrent [186].

\subsection{Copolymers based on thiophene, benzothiadiazole or benzo-bis (thiadiazole)}

The copolymer based on thiophene, benzothiadiazole or benzo-bis(thiadiazole) is another example of an electron donor-acceptor alternating polymer. Again the thiophene is the electron donor unit and here benzothiadiazole or benzo-bis(thiadiazole) is the electron acceptor unit. The structures of the different copolymers are shown in Fig. 28, where $R$ represents either alkyl or alkoxy chains to achieve a soluble polymer $[25,189-191]$.

For the copolymer based on thiophene and benzothiadiazole results have shown that the number of thiophenes between the benzothiadiazole units affects the band gap of the polymer [25]. Thus, it was possible to tune the band gap of the copolymer with the number of thiophene units between the benzothiadiazole units from $2.1 \mathrm{eV}$ for one thiophene to $1.65 \mathrm{eV}$ for four thiophenes [25]. This is ascribed to an optimization of the donor properties of the oligothiophene donor segment with respect to the acceptor unit and for this reason there is an optimal length of the oligothiophene segment for a given acceptor unit such as benzothiadiazole. Increasing the number of thiophenes beyond the optimum will gradually approach the band gap of polythiophene [25]. The low band gap of these types of copolymers based on either benzothiadiazole or benzo-bis(thiadiazole) are ascribed to the strong quinoid form of the polymer as shown in Fig. 29 which contributes to the low band gap due to the more stable 1,2,5-thiazole which is formed [29]. Further, the polymer shows a planar geometry, which result in nonsteric repulsion between the two hetereocycles. The polymer has a high electron affinity due to the sulfur atoms in the thiadiazole rings and the short intermolecular contacts between $S$ and $N$ results in strong inter chain interactions [29]. It was found that the benzo-bis(thiadiazole) unit showed the highest electron-accepting ability among thienopyrazine, pyrazino-quinoxaline and benzothiadiazole and that this also resulted in the lowest band gap [27].

The use of sidechains is essential to make the polymer soluble enough for application in OPVs by for instance spin coating $[25,189]$. However, the side chains often introduce steric hindrance affecting the coplanarity of the polymer and hence, the band gap of the polymer increases [189]. Further, the side chains can affect the regularity of the structure when applied in different positions in the polymer [189]. This can be seen for the copolymers with $\mathrm{R}=\mathrm{H}$, where the band gap was found to be $1.1 \mathrm{eV}$ for the copolymer based on di-thiophene and benzothiadiazole 


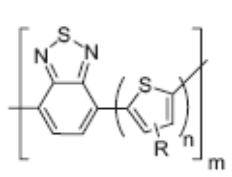

A

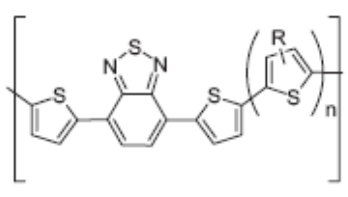

B

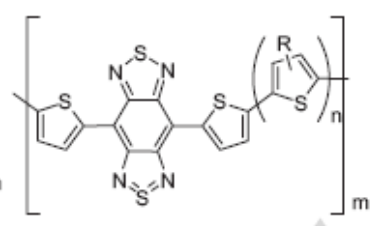

C

Fig. 28. Structure of copolymers of thiophene and benzothiadiazole or benzobisthiadiazole. $\mathrm{R}=$ alkoxy for $\mathrm{A}: n=2[191], \mathrm{R}=$ hexyl for $\mathrm{A}: n=2, \mathrm{~B}$ : $n=2$ and $\mathrm{C}: n=2, \mathrm{R}=2$-ethylhexyl for $\mathrm{A}: n=1, \mathrm{~B}: n=1,2$ and $\mathrm{C}: n=1, \mathrm{R}=$ dodecyl for $\mathrm{B}: n=2, \mathrm{R}=3,7,11$-trimethyldodecyl for $\mathrm{A}: n=1,2, \mathrm{~B}:$ $n=1,2$ and $C: n=1,2[25,190]$.

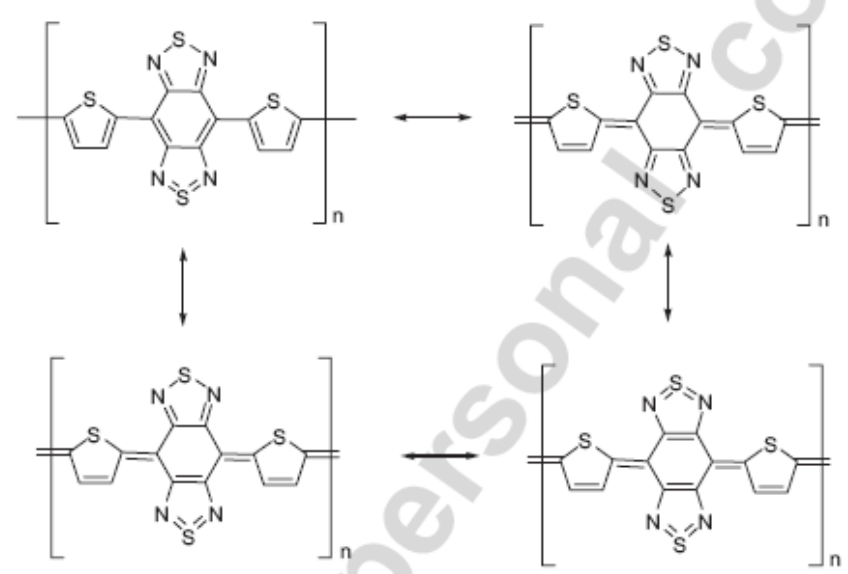

Fig. 29. Resonance structures in benzo-bis-thiadiazole.

[29] and below $0.5 \mathrm{eV}$ for the copolymer based on dithiophene and benzo-bis(thiadiazole) [29].

Mullenkom et al. have predicted that to achieve absorption maxima of less then $1 \mathrm{eV}$ for a donor-acceptor copolymer the codimer D-A must have absorption maxima at $550 \mathrm{~nm}(2.2 \mathrm{eV})$ [181]. This is not seen for the benzobis(thiadiazole) - thiophene copolymer, where the codimer have absorption maxima at $702 \mathrm{~nm}(1.7 \mathrm{eV})[27,29]$ and the polymer have absorption maxima at $902 \mathrm{~nm}(1.3 \mathrm{eV})$ [25].

The substitution in different positions also shows a large effect on the band gap [30]. It was shown for dodecyl side chains that having the side chain close to the benzothiadiazole ring in position 3 on thiophene compared to the 4 position causes the band gap to increase due to steric hindrance, which causes the planarity to break [30]. However, for the polymer with the alkyl chain in the 4 position the band gap was increased when the alkyl chain was added compared to the insoluble analog with no side chains from 1.1 to $1.96 \mathrm{eV}$ [30]. The use of alkyl side chains was of great importance to insure solubility of the polymer [25]. Several alkyl chains have been tested, i.e. hexyl, 2-ethylhexyl, dodecyl and 3,7,11-trimethyldodecyl. It was found that the latter gave the best film formability [25]. The use of four alkoxy groups on the two thiophene units (Fig. 28) resulted in a soluble polymer with a band gap of $1.72 \mathrm{eV}$ in solution and $1.55 \mathrm{eV}$ in solid state [191]

The synthesis of the copolymers has been carried out by three different methods as shown in Fig. 30.

(1) Stille cross-coupling polymerization of di-stannyl derivatives of thiophene or di-thiophenes and di-bromo derivatives of benzothiadiazole or benzo-bis(thiadiazole) with a Pd catalyst $[25,190]$.

(2) Oxidative ferric chloride polymerization of the monomer with a $\mathrm{FeCl}_{3}$ catalyst $[25,190]$.

(3) Polymerization of the di-brominated monomers with $\mathrm{Ni}(\mathrm{COD})_{2}$ as a catalyst in a Yamamoto coupling [191].

The polymer based on benzothiadiazole and two thiophenes have been synthesized with both alkyl $[25,190]$ and alkoxy groups [191] to give soluble polymers. The synthesis was carried out by oxidative ferric chloride polymerization for the alkyl $[25,190]$ and by Yamamoto coupling polymerization for the polymer with alkoxy 


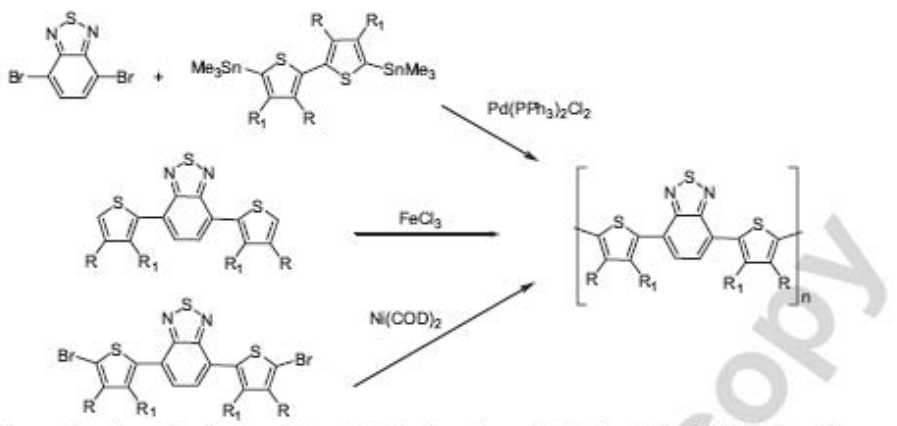

Fig. 30. Synthesis of copolymers based on thiophene and benzothiadiazole or benzobisthiadiazole by Stilk, ferric or Yamamoto [25,189-191].

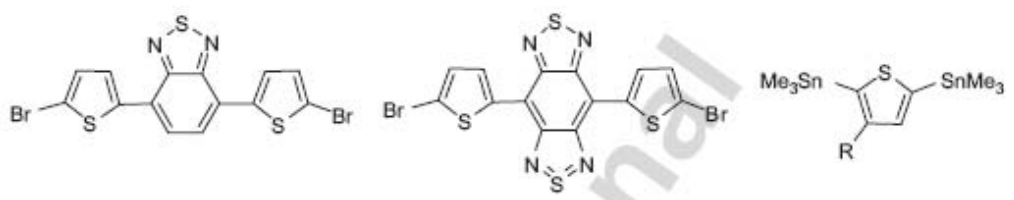

Fig. 31. Other building blocks for Stille cross-coupling polymerization which will result in the copolymers shown in Fig. 28 [25].

Table 6

Photovoltaic responses obtained for copolymers based on benzothiadiazole and thiophene

\begin{tabular}{|c|c|c|c|c|c|c|c|c|c|c|}
\hline Polymer & $\begin{array}{l}\text { Polymer/ } \\
\text { PCBM }\end{array}$ & $\begin{array}{l}\text { Area } \\
\left(\mathrm{cm}^{2}\right)\end{array}$ & $\begin{array}{l}\text { Annealing } \\
\text { temperature } \\
\left({ }^{\circ} \mathrm{C}\right)\end{array}$ & $\begin{array}{l}I_{\mathrm{SC}}(\mathrm{mA} \\
\left.\mathrm{cm}^{-2}\right)\end{array}$ & $V_{\infty C}(V)$ & FF $(\%)$ & $\eta(\%)$ & $\operatorname{IPCE} / \lambda(\%, \mathrm{~nm})$ & Notes & Refs. \\
\hline PT BT(OR) & 1:4 & $0.1-0.15$ & - & 3.4 & 0.77 & 42 & 0.9 & $13 / 650$ & $\begin{array}{l}\mathrm{LiF} / \mathrm{Al}, \\
75 \mathrm{~mW} \mathrm{~cm}^{-2}\end{array}$ & [191] \\
\hline PT ВТ(HН) & 1:1 & 3 & $70(2 \mathrm{~min})$ & 0.02 & 0.61 & 24 & 0.02 & $0.6 / 450$ & & [190] \\
\hline $\operatorname{PTBT}(\mathrm{HT})$ & $1: 1$ & 3 & No & 0.03 & 0.33 & 30 & 0.02 & - & & [190] \\
\hline PTTBTT & $1: 2$ & 3 & $70(10 \mathrm{~min})$ & 2.70 & 0.58 & 38 & 0.6 & $22 / 560$ & & [26] \\
\hline РТТВTT & $1: 2$ & 10 & $70(10 \mathrm{~min})$ & 1.29 & 0.56 & 28 & 0.2 & - & & [26] \\
\hline РТTВTT & $1: 2$ & 0.1 & $110(10 \mathrm{~min})$ & 3.59 & 0.61 & 46 & 1.0 & $18 / 600$ & $100 \mathrm{~mW} \mathrm{~cm}^{-2}$ & [192] \\
\hline
\end{tabular}

The measurements were carried out at $1000 \mathrm{Wm}^{-2}$ and AM1.5 unless otherwise noted. The structure of the devices was: ITO/PEDOT:PSS/pol:PCBM/ LiF/Al.

groups [191]. Part of the polymers shown in Fig. 28 was synthesized by Stille cross coupling between other building blocks, which are shown in Fig. 31 [25].

The copolymer based on di-thiophene and benzobis(thiadiazole) have also been synthesized from the monomer by a potential sweep electrolysis in an argon degassed $\mathrm{PhCN}$ solution with $n \mathrm{Bu}_{4} \mathrm{NBF}_{4}[27,29]$.

The CV diagrams for benzothiadiazole and benzobis(thiadiazole) showed that the $\mathrm{n}$-doping process was sharp and quasi-reversible and the p-doping was broad and irreversible [27]. Further, the benzo-bis(thiadiazole) showed a low degree of $\mathrm{n}$-doping charge before the main reduction peak [27]. This was ascribed to charge trapping in the benzo-bis(thiadiazole) unit [27].

Only a few examples of application of these polymers in OPVs have been reported and the results are summarized in Table 6 [26,190-192]. Different effects have been shown to influence the performance of the OPV devices. The morphology and hence the performance of OPV devices with the copolymer based on benzothiadiazole and four thiophenes was found to depend on solvent choice, spin rate, concentration of the spin coated solution and annealing temperature of the device where efficiencies of up to $1 \%$ was reported [192].

The regioregularity of the alkyl substituents (hexyl) was found to have a small effect on the PV responses [190]. The head-to-head coupled polymer gave a higher efficiency when applied in OPV devices (as a homopolymer) when compared to the head-to-tail coupled copolymer. However, when used in bulk heterojunctions with PCBM the polymers gave the same efficiency after the head-to-head coupled polymer was annealed [190]. 
Lifetime studies on these types of low band gap polymers are severely limited, however, an increase in lifetime have been reported when bilayer devices were prepared with $\mathrm{C}_{60}$ and a copolymer of thiophene and benzothiadiazole with four thiophenes in the repeating unit [26]. An increase from 2 to $80 \mathrm{~h}$ was observed when comparing to a device prepared with the homopolymer [26]

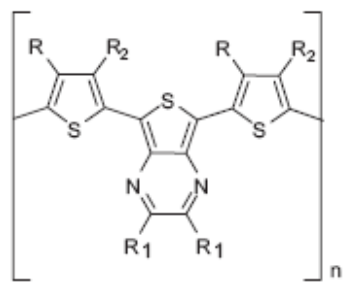

Fig. 32. Structure of thenopyrazine in a copolymer with thiophene PB3OTP, $R_{2}=\mathrm{C}_{3} \mathrm{H}_{17}$ [193], PTBEHT: $R=\mathrm{R}_{2}=\mathrm{H}, \mathbf{R}^{\prime}=$ phenyl-2. ehtylhexyloxy and PBEHTT: $R^{\prime}=H, R=$ phenyl-2-ehtylhexyloxy [194].

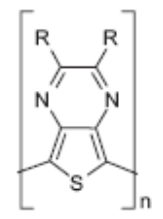

Fig. 33. Structure of poly(thienopyrazine) [195].

\subsection{Copolymers based on thienopyranozine (PTP)}

The copolymer based on thienopyranozine and thiophene is another example of the alternation between aromatic and quinoid units, which results in a low band gap polymer. Here thiophene is again used as the electron donor and thienopyranozine is used as the electron acceptor. The thienopyranozine is a thiophene with a fully fused aromatic pyrazine ring in position 3 and 4 , and is thus similar in construction to ITN as shown in Fig. 32.

The synthesis of the homopolymer of thienopyrazine (Fig. 33) was first carried out by an oxidative ferric polymerization in chloroform [195] or from 2,3-pyrazinedicarboxylic anhydride using $\mathrm{P}_{4} \mathrm{~S}_{10}$ [161]. The band gap of the polymer was found to be $0.95 \mathrm{eV}$ (solid state) and the conductivity was found to be $3.6 \times 10^{-2} \mathrm{Scm}^{-1}[195]$. The polymer was also prepared with different alkyl side chains and polymerized electrochemically [196].

A few years later the copolymer based on thienopyrazine and thiophene was synthesized by electrochemical reduction of the monomer onto an ITO electrode in $\mathrm{PhCN}$ using $\mathrm{Bu}_{4} \mathrm{NClO}_{4}$ as catalyst [36] and the band gap was determined to be $1.0 \mathrm{eV}$ [36]. The electrochemical polymerization was also carried out by a repetitive potential-sweep anodic oxidation with $n \mathrm{Bu}_{4} \mathrm{NClO}_{4}$ in $\mathrm{MeCN}$ [27]. However, the result of this polymerization was an insoluble polymer regardless of the choice of side chains on the pyrazine ring.

The chemical synthesis of PTP has been carried out by two different methods as shown in Fig. 34.

(1) Oxidative ferric chloride polymerization of TP with dodecyl side chains [193].

(2) Polymerization of the dibrominated monomers with $\mathrm{Ni}(\mathrm{COD})_{2}$ as a catalyst in a Yamamoto coupling [194].

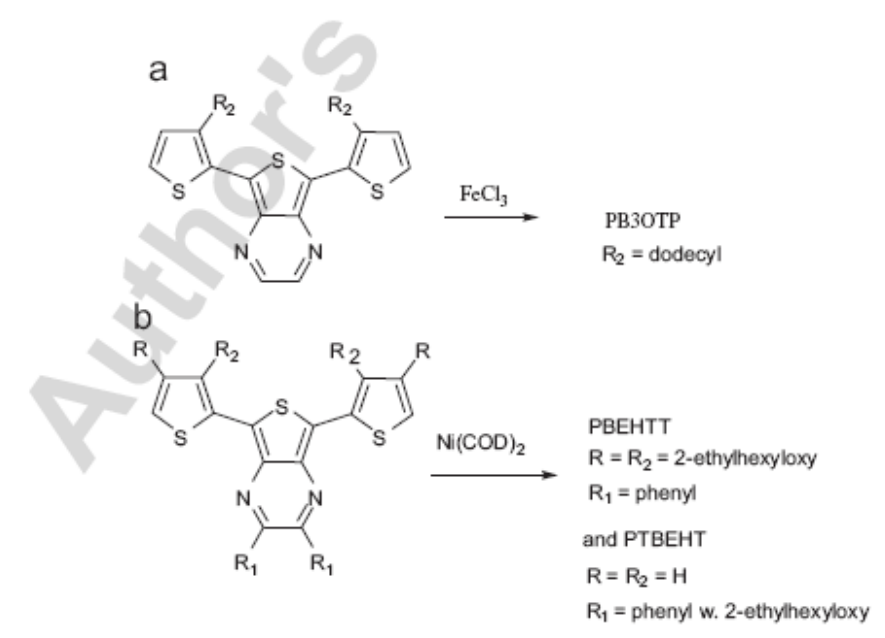

Fig. 34. Synthesis of copolymer of thienopyrazine and thiophene by (a) an oxidative ferric polymerization [193] and (b) a Yamamoto coupling polymerization [194,197]. 


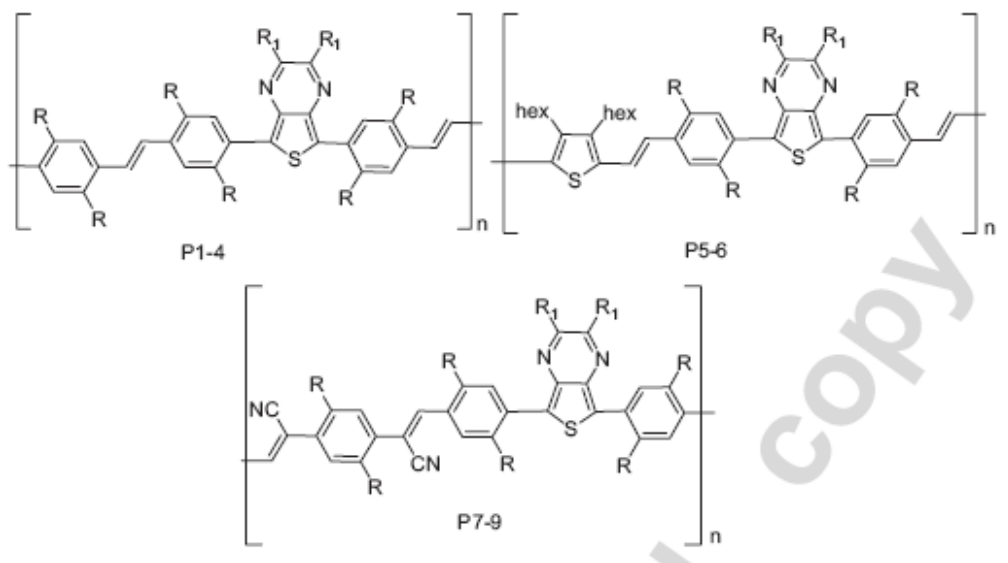

Fig. 35. Structures of copolymers of thienopyrazine and different vinyl-phenyl units.

Table 7

Photovoltaic responses obtained for copolymers based on thienopyratine and thiophene

\begin{tabular}{lllllllllll}
\hline Polymer & $\begin{array}{l}\text { Polymer/ } \\
\text { PCBM }\end{array}$ & $\begin{array}{l}\text { Area } \\
\left(\mathrm{cm}^{2}\right)\end{array}$ & $\begin{array}{l}\text { Annealing } \\
\text { temperature }(\mathrm{C})\end{array}$ & $\begin{array}{l}I_{\mathrm{SC}}(\mathrm{mA} \\
\left.\mathrm{cm}^{-2}\right)\end{array}$ & $V_{\mathrm{OC}}(\mathrm{V})$ & FF (\%) & $\eta(\%)$ & $\begin{array}{l}\text { IPCE } / \lambda \\
(\%, \mathrm{~nm})\end{array}$ & Notes & Refs. \\
\hline PB3OTP & $1: 1$ & 0.05 & - & 1.0 & 0.22 & 39 & - & $6 / 660$ & $100 \mathrm{~mW} \mathrm{~cm}^{-2}$ & {$[193]$} \\
PBEHT & $1: 4$ & 0.15 & - & 1.3 & 0.39 & 57 & 0.29 & $2 / 800$ & {$[194]$} \\
PT BEHT & $1: 4$ & 0.15 & - & 3.5 & 0.56 & 58 & 1.1 & $10 / 800$ & {$[194]$} \\
\hline
\end{tabular}

The measurements were carried out at $75 \mathrm{~mW} \mathrm{~cm}^{-2}$ and AM1.5 unless otherwise noted. The structure of the devices was: ITO/PEDOT:PSS/pol:PCBM/ LiF/Al.

The band gap of the polymers was found to be $1.3 \mathrm{eV}$ for PB3OTP [193], 1.20 eV for PTBEHT [194] and $1.28 \mathrm{eV}$ for PBEHTT [194]. The lower band gap of PTBEHT compared to PBEHTT is ascribed to the improved conjugation and more coplanar structure of PTBEHT caused by the absence of bulky substituents [194]. PB3OTP showed a broad absorption range $300-980 \mathrm{~nm}$ with a maximum at $730 \mathrm{~nm}[193]$.

The polymers shown in Fig. 35 were prepared by Horner (P1-P6) or Knoevenagel (P6-P9) polycondensation. The polymers showed band gaps of $1.56-2.08 \mathrm{eV}$ ( $1.56 \mathrm{eV}$ for P6 $R_{1}=O$-hexyl) [198]

The OPV devices prepared with PTP showed different responses depending on the side chains. The results are summarized in Table 7. The optimum ratio between the polymer and PCBM was different for the three polymers, i.e. 1:1 for PB3OTP [193] and 1:4 for PBEHTT and PTBEHT [194].

AFM images of PBEHTT showed a rough surface and phase separation, and for PTBEHT the AFM images showed a smooth surface with a more intimate mixing of the polymer and PCBM and thus a higher efficiency for PTBEHT was observed [194]. From Table 7 it can be seen that the reduction in band gap from $1.9 \mathrm{eV}$ for P3HT to
$1.2 \mathrm{eV}$ for PTBEHT causes only a small change in $V_{\mathrm{OC}}$ [194]. The poor efficiency of the OPVs with PB3OTP was ascribed to the low $V_{\mathrm{OC}}[193]$.

\subsection{Copolymers based on polyfluorene}

The homopolymer of polyfluorene have a large band gap $(3.68 \mathrm{eV})$ and have been used as a blue light emitter in lightemitting diodes [199-202]. However, the light emitted and hence the band gap of polyfluorene could be tuned with addition of different electron donating or electron accepting units in the back bone of the polymer [201]. Within the past few years the focus on fluorene units incorporated in alternating donor acceptor polymers have therefore increased tremendously.

\subsubsection{Copolymers based on thiophene, benzothiadiazole and} fuorene

The copolymer based on thiophene, benzothiadiazole and fluorene (Fig. 36) is an example of the alternation of the electron donating unit, thiophene/fluorene, and the electron accepting unit, benzothiadiazole.

The synthesis of the copolymer based on thiophene, benzothiadiazole and fluorene was carried out by Suzuki 
cross-coupling with Pd as catalyst as shown in Fig. 37.1 [201]. This polymerization was also carried out without the di-bromofluorene derivative as a comonomer as shown in Fig. 37.2 [203].

The band gap of the copolymer was estimated from UVvis to be $2.01 \mathrm{eV}$. [201,203] Hou et al. found that due to exciton trapping in the benzothiadiazole unit efficien charge transfer was achieved [201].

A derivative of the polymer shown in Fig. 36 was prepared with $O$-alkyl side chains on the thiophene rings, PF-co-DTB [204]. The polymer was synthesized by a Suzuki coupling shown in Fig. 37 [204] and the band gap was found to be $1.78 \mathrm{eV}$ [204].

A selenium derivative of the copolymer (Se instead of S in the thiadiazole ring) has also been prepared by Suzuki cross coupling and had a band gap of $1.87 \mathrm{eV}$ [205].

The derivative shown in Fig. 38 was synthesized by the routes shown in Fig. 37 and applied in OPV devices [206]

Several groups have studied OPV devices and the results are summarized in Table 8.

For the device in entry 4 of Table 8 morphological studies were carried out with different solvent systems, i.e. $\mathrm{CHCl}_{3}$ or $\mathrm{CHCl}_{3}$ mixed with xylene, toluene or chlorobenzene. It was found that $V_{\mathrm{OC}}$ was constant but $I_{\mathrm{SC}}$ varies with the solvent system [210]. The highest $I_{\mathrm{SC}}$ was achieved for the $\mathrm{CHCl}_{3}$ and chlorobenzene mixture (data given in Table 8). AFM images of the film showed a more

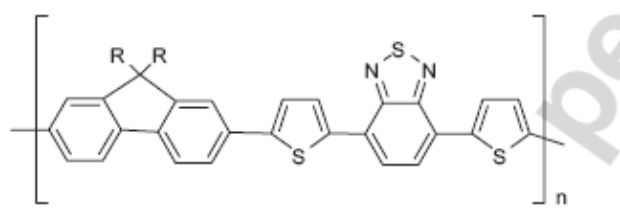

Fig. 36. Copolymer based on benzothiadiazok, thiophene and fluorene, PFO-DTBT. fine and uniform distribution of domains (RMS $=1.1-1.2)$ [210]. Investigations of the PCBM content showed a maximal efficiency for $20-50 \%$ w/w PCBM content, however, the highest $\mathrm{I}_{\mathrm{SC}}$ was obtained with $80 \%$ w/w PCBM content [218]. It was shown by time-resolved spectroscopy that the performance of the OPV is limited by charge transport and not formation of charges [219]. A detailed review of the use of the copolymers based on PFO and benzothiadiazole in PLED was published in 2000 by Bernius et al. [199].

\subsubsection{Copolymers based on thienopyrazine or} thiadiazolequinoxaline, thiophene and polyfuorene

The copolymer based on thiophene, fluorene and thienopyrazine or thiadiazolequinoxaline as shown in Fig. 39 is another example of the alternation of the electron donating unit, thiophene/fluorene, and the electron accepting unit, thienopyrazine or thiadiazolequinoxaline.

The copolymers were also synthesized by a Suzuki polymerization as shown in Fig. $37[27,203]$. The reported band gaps for APFOGreen1, 2, 3 and 4 was $1.27 \mathrm{eV}$ $[35,216,218,220], 2 \mathrm{eV}[215], 1.4$ and $1.3 \mathrm{eV}$ [217], respectively. The reported $\lambda_{\max }$ was at 400 and $780 \mathrm{~nm}$ for APFOGreenl $[35,216,220]$ and at 780 and $740 \mathrm{~nm}$ for APFOGreen 3 and 4 [217], respectively. Further, APFOGreenl was found to have a high field effect mobility of $0.03 \mathrm{~cm}^{2} \mathrm{~V}^{-1} \mathrm{~s}^{-1}[221]$.

The polymers have been applied in OPV devices and the results are summarized in Table 8 . It was found that the charge separation in the devices with these polymers was better when BTPF70 (Fig. 40) was used as electron acceptor compared to devices prepared with PCBM as electron acceptor, due to the higher LUMO level of BTPF70, and hence the better contact with the LUMO level of the polymer $[209,214]$. Studies on APFO-Green 1 in blends with PCBM and BTPF70 showed that the hole mobility has maximum at $67 \mathrm{wt} \%$ PCBM and decreases
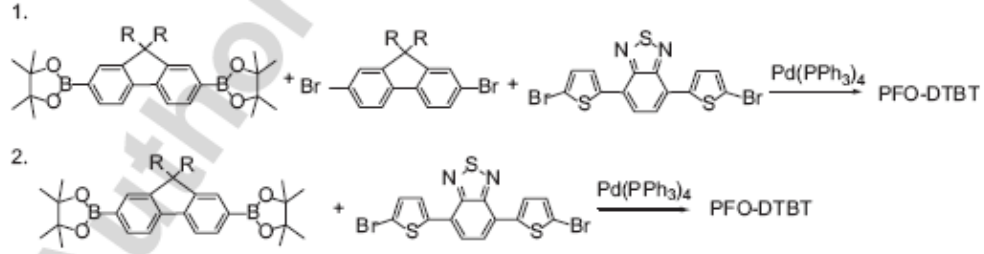

Fig. 37. Synthesis of copolymer based on benzothiadiazole, thiophene and fluorene, PFO-DTBT

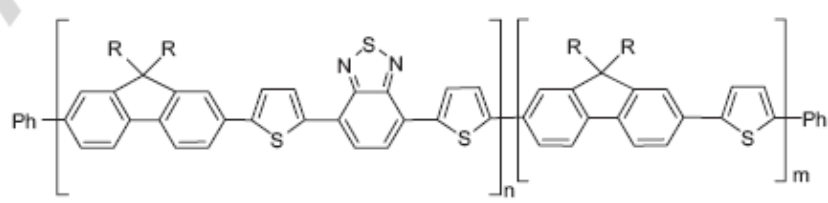

Fig. 38. APFOGreen 5 [206]. 


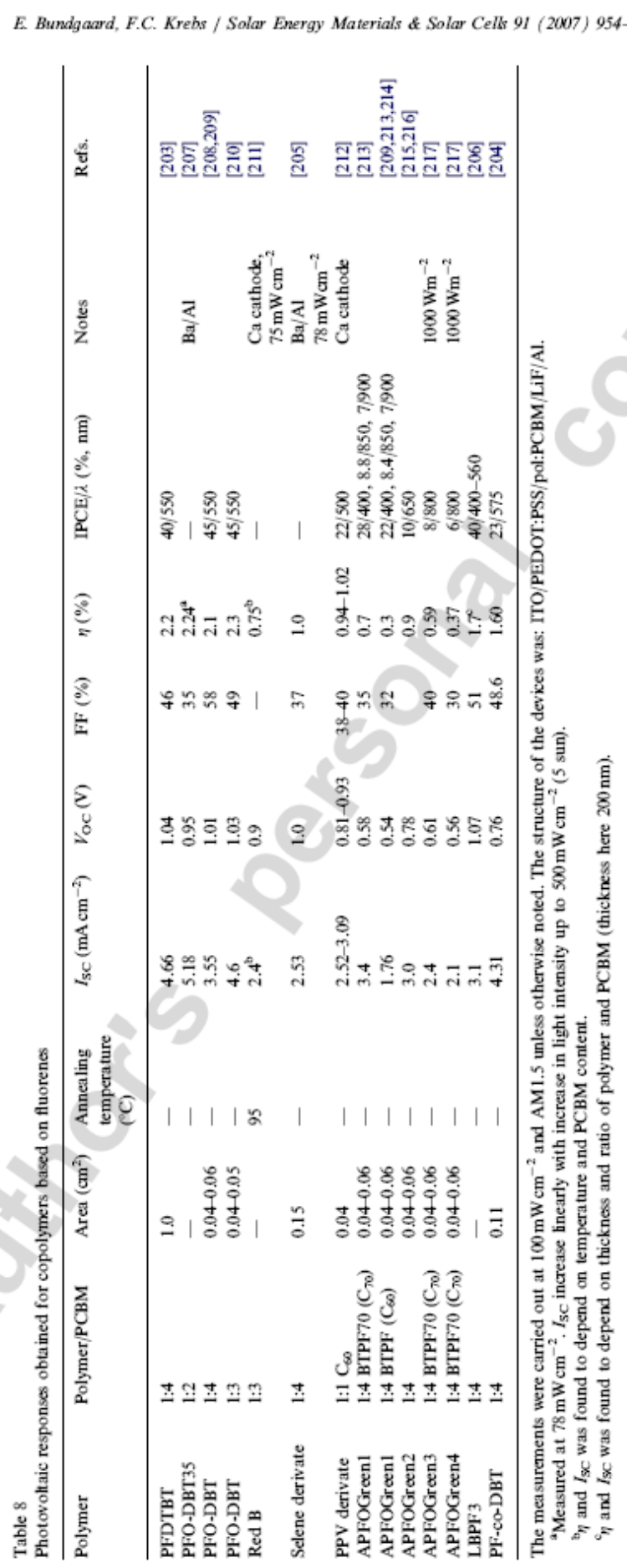




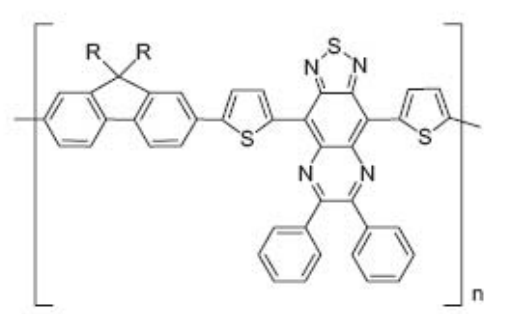

APFOGreen1

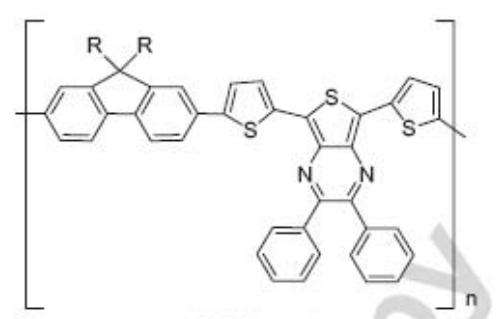

APFOGreen 2

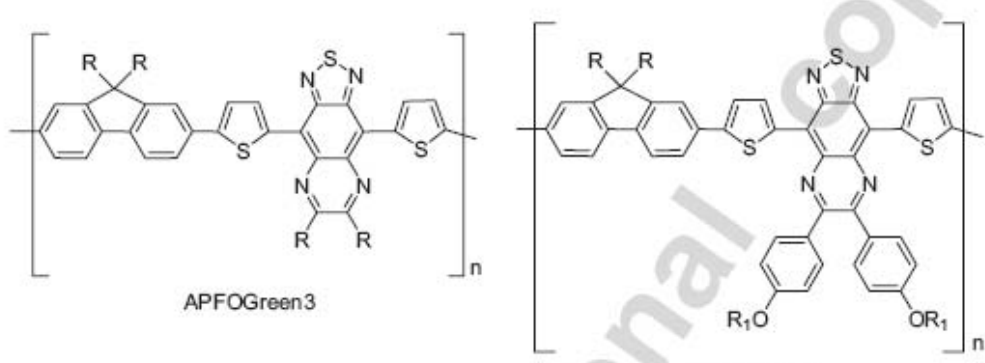

APFOGreen 4

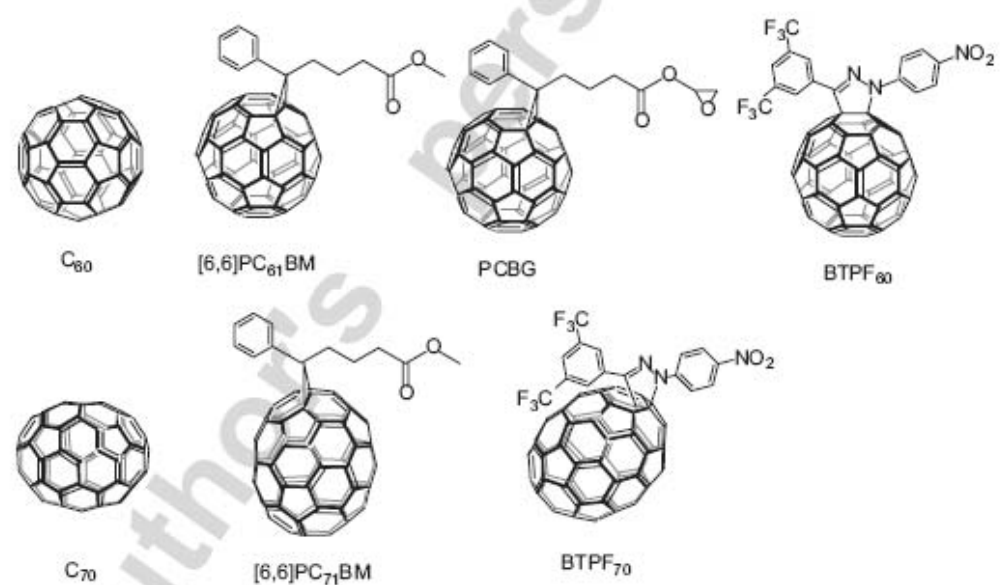

Fig. 40. Structure of electron acceptors used in OPV devices: $\left.\mathrm{C}_{60},[6,6]-\mathrm{PC}_{61} \mathrm{BM}, \mathrm{PCBG}[111], \mathrm{BTPF}_{60}, \mathrm{C}_{70},[6,6]-\mathrm{PC}_{71} \mathrm{BM} \mathrm{223}\right]$ and $\mathbf{B T P F}_{70}$.

when more BTPF70 was added. The electron mobility increases with an increases in both cases when increasing the acceptor content. However, BTPF70 gives better exciton dissociation even though the structural inhomogenity yields poor charge transport [222].

A few other examples of copolymers based on fluorene and different aromatic units have been published $[212,224,225]$. The polymer shown in Fig. 41 had a band gap of $1.95 \mathrm{eV}$ [225] and the OPV results are given in Table 8 .

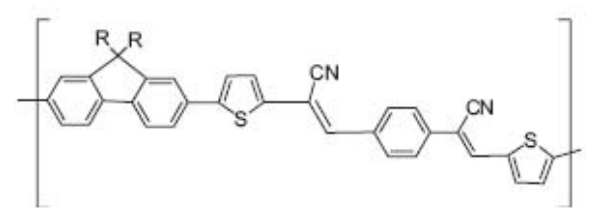

Fig. 41. Copolymer based on fluorine, thiophene and phenylvinyl (PFTPV) [225]. 
Table 9

Other low band gap polymers described in the literature

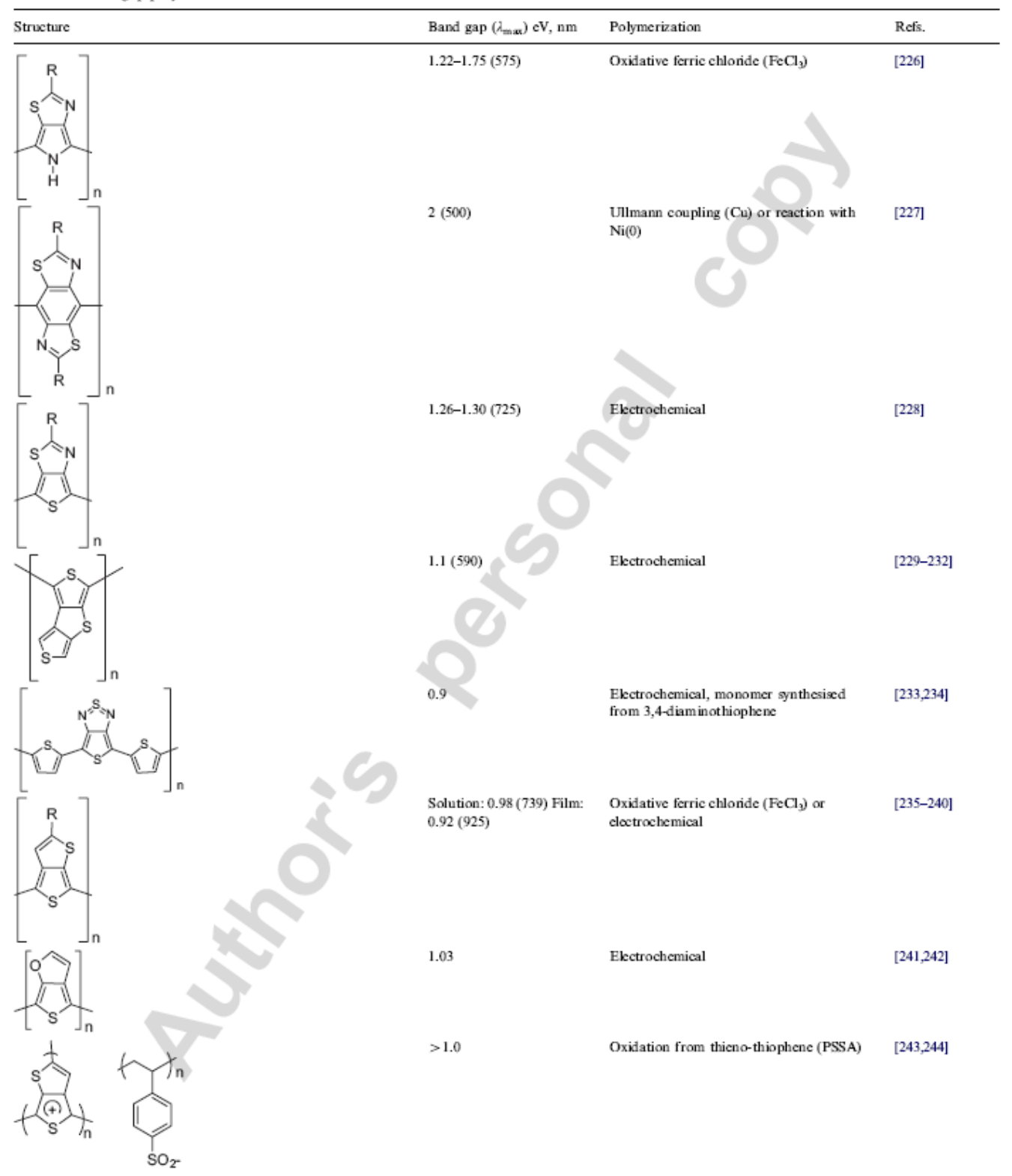


Table 9 (continued)

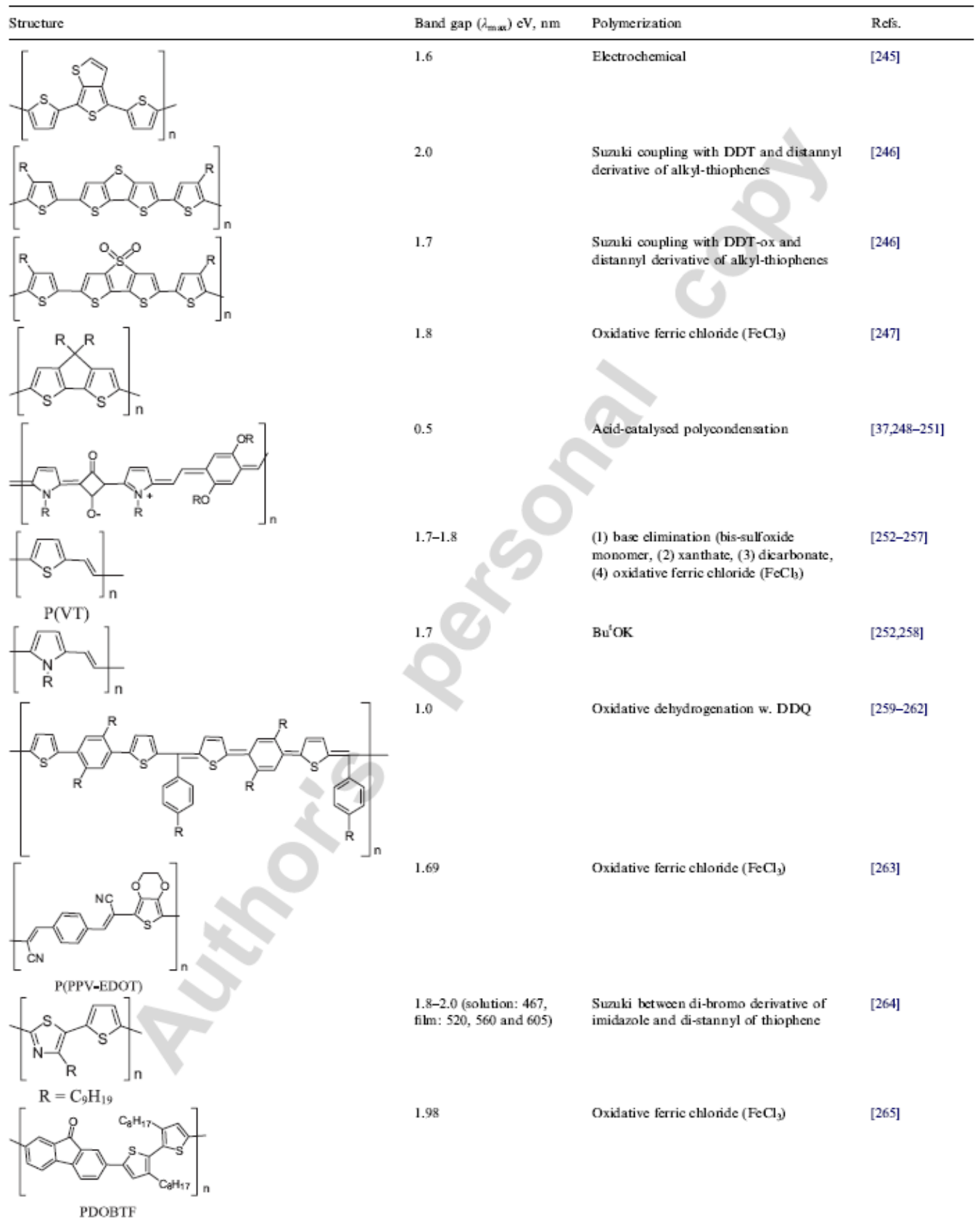




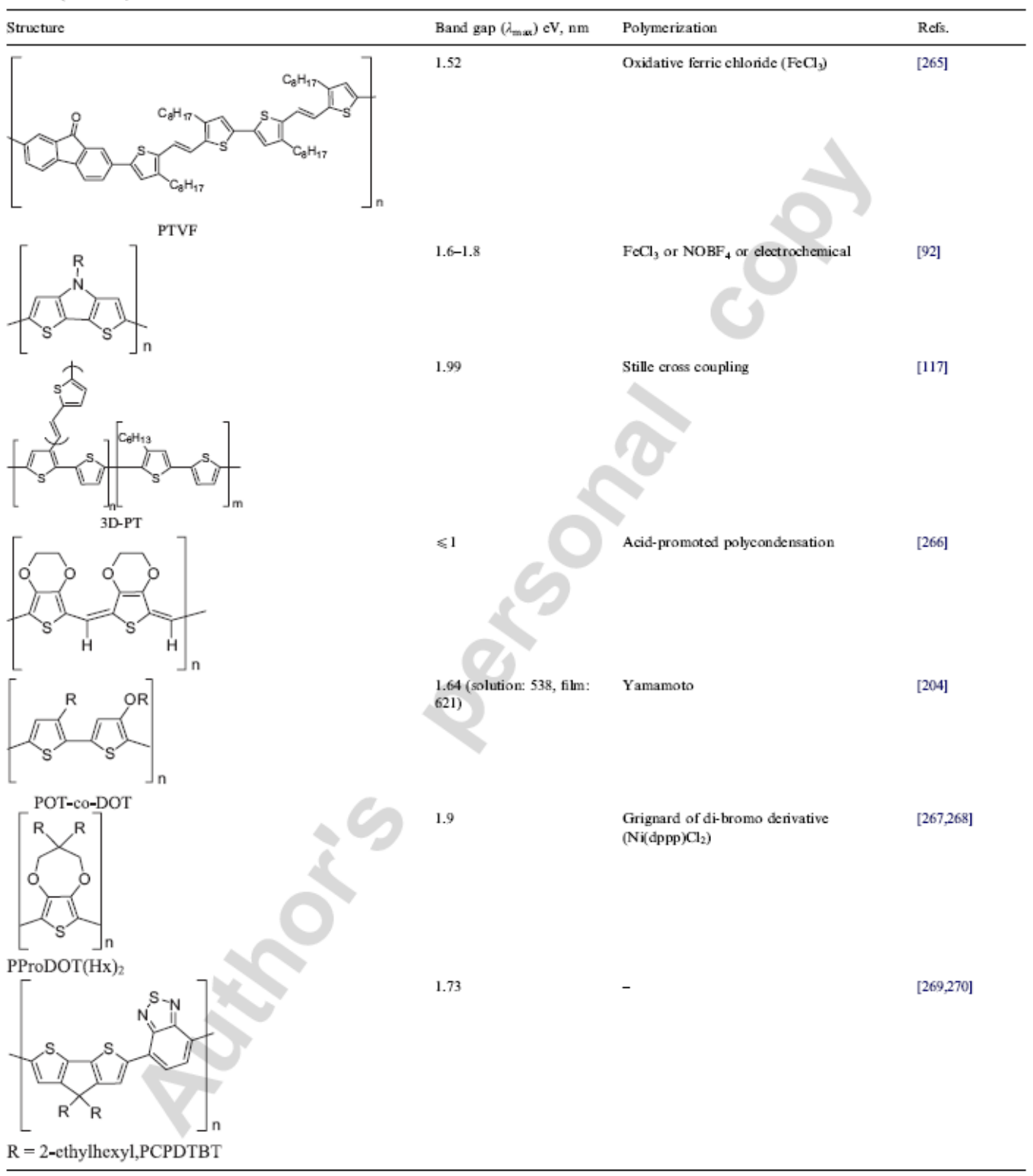




\section{Other low band gap polymers}

In addition to the low band gap polymers described above other examples have been described in the literature. These are summarized in Table 9

Only a few of these polymers have been applied in OPV devices, and the results for these are summarized in Table 10 .

In 2005 Somez et al. reported a band gap of $0.7 \mathrm{eV}$ for a copolymer of thiophene and thienopyrazine which was covalently bonded to $\mathrm{C}_{60}$ [271]. This polymer is not shown. In 2006, Cremer and Bäuerle reported on a star shaped dendrimer with an $\mathrm{N}$-triphenyl core as donor and thiophene arms as acceptor. The band gap was varied with the length of the arms from 1.72 to $1.65 \mathrm{eV}$ [272].

\section{Impurities and doping}

One currently unanswered question that remains for many of these materials is the extent of doping impurities that could affect the performance of PV devices prepared from them. Efficient methods have been reported and are commonly employed for the most studied materials today such as P3HT, MEHPPV and MDMOPPV. However, the low band gap materials that must still be considered as rather exotic materials are generally available in the few laboratories who has the experience to make them. Further, many of them are only available in small quantities and are unavailable to the public. Hopefully, many of these low band gap polymer materials will be made available in large quantities so that research groups that specialize in device preparation and testing can give their value for the efficiency that can be obtained for these materials. To this end it is very important to establish the level of impurities and if possible remove them. For instance the polymers described in Sections 3.3 and 3.4 could include impurities from $\mathrm{FeCl}_{3}, \mathrm{H}_{2} \mathrm{SO}_{4}$ and $\mathrm{PO}_{4}^{2-}$ from the polymerization reaction and there are no well documented efforts that deal with removal and estimation of the residual amount of impurities nor any correlation with the influence impurities may have on PV device operation. In Sections 3.5-3.8 polymerization is exclusively achieved with transition metal catalysts such as palladium and nickel and these are notoriously included in the polymer product as nanoparticles [273]. Very efficient methods for removal of the transition metal impurities have been developed and reported for both polymer products [274] and small molecule intermediates [275]. This has been used for purification and analysis in a few instances $[25,85,276]$. There has been only one other example that documents removal of nickel from a Yamamoto coupling using EDTA [194] and in general the level of transition metal impurities in products obtained by these reactions must be expected to be significant, especially in cases where the purification procedure is not described or mentioned. Finally the electron-rich low band gap materials with a high HOMO level can arguably be doped by molecular oxygen. This has been observed for thin film transistor devices where the influence of doping by molecular oxygen is observed in field effect mobility measurements. The removal of doping impurities that could stem from oxygen or from oxidation by molecular oxygen in the presence of a suitable anion has been investigated in the supplementary section of one literature report [25] by treatment with hydrazine and ammonia albeit with little change in the resulting properties.

\section{Chemical stability}

Chemical stability and degradation of polymers in OPV devices is of great importance, however, to our knowledge only a few reports on the issue have been published. For the low band gap polymers described above the studies are limited to a report on a P3HT/PCBM device [116], a copolymer based on thiophene and benzothiadiazole [26] and a polythiophene with thermocleavable side chains which have an estimated lifetime of $20,000 \mathrm{~h}$ under normal operating conditions [9]. Studies of the degradation mechanisms in OPVs have shown that the mechanisms include reaction with oxygen and water in the atmosphere and with the electrode materials. However, the mechanisms are complicated and hence only few reports dedicated to an

Table 10

OPV devices with other low band gap polymers

\begin{tabular}{|c|c|c|c|c|c|c|c|c|}
\hline Polymer & Polymer/PCBM & $I_{\mathrm{SC}}\left(\mathrm{mA} \mathrm{cm}^{-2}\right)$ & $V_{\mathrm{OC}}(\mathrm{V})$ & FF (\%) & $\eta(\%)$ & IPCE at $\lambda(\%, \mathrm{~nm})$ & Notes & Refs. \\
\hline 3D-PT & $1: 1$ & 10.3 & 0.72 & 43 & 3.18 & $60 / 450-550$ & $\mathrm{Mg} / \mathrm{Al}$ & {$[117]$} \\
\hline POT- $-\alpha$-DOT & $1: 1>>$ & 0.22 & 0.60 & 41.2 & 0.054 & - & & {$[204]$} \\
\hline P(PPV-EDOT) & $1: 1$ & 0.73 & 0.28 & 28 & - & - & & [263] \\
\hline $\mathrm{P}(\mathrm{VT})$ & $1: 2$ & 3.50 & 0.35 & 50 & 0.6 & $17 / 550$ & & [256] \\
\hline PDOBTF & $1.26 \mathrm{molar} \mathrm{eq}$ & 0.77 & 0.34 & 28 & 0.09 & $10 / 430$ & & {$[265]$} \\
\hline PTVF & $1.26 \mathrm{molar}$ eq & 2.97 & 0.5 & 58 & 1.1 & $21 / 420$ & & [265] \\
\hline PProDOT $(\mathrm{H} x)_{2}$ & $1: 4$ & 1.05 & 0.29 & 38 & 0.1 & $7.4 / 445$ & & {$[268]$} \\
\hline PCPDTBT & - & 9 & $0.65-0.70^{2}$ & $47^{2}$ & 2.67 & $25-35 / 400-800^{2}$ & & {$[269,270]$} \\
\hline PCPDTBT & $-\left(\mathrm{PC}_{71} \mathrm{BM}\right)$ & 11 & $0.65-070^{2}$ & $47^{2}$ & 3.16 & $38 / 700$ & & {$[269,270]$} \\
\hline
\end{tabular}

The measurements were carried out at $100 \mathrm{~mW} \mathrm{~cm}^{-2}$ and AM1.5 unkss otherwise noted. The structure of the devices was: ITO/PEDOT:PSS/pol:PCBM/ The me

LiF/Al.
${ }^{2}$ Values not unambiguously quoted in Ref. [269]. 
understanding of the mechanism have been published [277-282]. Future applications of OPVs rely heavily on the understanding of the degradation phenomena and on the development of new materials and efficient encapsulation of the OPV and alternative barrier layers which are more impervious to oxygen and water from the atmosphere.

\section{Conclusion}

The spectrum of the sun as received on earth has been presented in the context of light harvesting by low band gap polymer materials and an evaluation of the possible currents that can be obtained for a material with a given band gap has been considered. The existing literature on polymer materials with a band gap below $2 \mathrm{eV}$ have been examined and discussed in the context of polymer PV devices. The field of low band gap polymer materials for OPV is concluded to be emerging. The current problems that one is faced with when considering the application of low band gap materials are the achievement of simple large scale synthetic quantities of materials that are sufficiently pure for incorporation in devices. Further, high values for the IPCE has been reported for a few low band gap materials while the general observation is very low IPCE values that currently has been linked to carrier transport problems, perhaps impurities, poor film forming ability of the materials and a low solubility making processing difficult. Methods for purifying the materials from impurities are reported in a few instances and are deemed important for future reproducibility of results obtained for the same class of materials. The field is increasing and the success of the low band gap approach will be granted through: large-scale synthetic approaches, availability in large quantities, purification and purity, widespread physical studies and optimization.

\section{Acknowledgments}

This work was supported by the Danish Technical Research Council (STVF 2058-03-0016) and the Danish Strategic Research Council (DSF 2104-04-0030, DSF 210405-0052).

\section{References}

[1] H. Spanggaard, F.C. Krebs, Sol. Energy Mater. Sol. Cells 83 (2004) 125.

[2] Organic-based photovoltaic, MRS Bull. Special Issue 5 (2005) 1.

[3] B. Maennig, J. Drechsel, D. Gebeyehu, P. Simon, F. Kozlowski, A. Werner, F. Li, S. Grundmann, S. Sonntag, M. Koch, K. Leo, M. Pfeiffer, H. Hoppe, D. Meissner, N.S. Sariciftci, I. Riedel, V. Dyakonov, J. Parisi, Appl. Phys. A 79 (2004) 1.

[4] H. Hoppe, N.S. Sariciftci, J. Mater. Rev. 19 (2004) 1924

[5] C.J. Brabec, Sol. Energy Mater. Sol. Cells 83 (2004) 273.

[6] C. Winder, N.S. Sariciftci, J. Mater. Chem. 14 (2004) 1077.

[6] C. Winder, N.S. Sariciftci, J. Mater. Chem. 14 (2004) 1077 .
7] C.J. Brabex, S.E. Shaheen, T. Fromherz, F. Padinger, J.C Hummelen, A. Dhanabalan, R.A.J. Janssen, N.S. Sariciftc, Synth. Met. 121 (2001) 1517.
[8] S.-S. Sun, N.S. Sariciftci, Organic Photvoltaics-Mechanisms, Materials, Devices, CRC Press, Boca Raton, FL, ISBN 0-8247. 5963-X, 2005.

[9] F.C. Krebs, H. Spanggaard, Chem. Mater. 17 (2005) 5235.

[10] M. Reyes-Reyes, K. Kim, J. Dewald, R. López-Sandoval, A. Avadhanula, S. Curran, D.L. Carroll, Org. Lett. 7 (2005) 5749.

[11] W. Ma, C. Yang, X. Gong, K. Lee, A.J. Heeger, Adv. Funct. Mater. $15(2005) 1617$.

[12] R. Gaudiana, R. Eckert, J. Cardone, J. Ryan, A. Montelk, Proc. SPIE 6334 (2006) 633401.

[13] H. Hoppe, N.S. Sariciftci, J. Mater. Chem. 16 (2006) 45.

[14] J. Roncali, Chem. Rev. 97 (1997) 173.

[15] T.A. Skotheim, R.L. Elsenbaumer, J.R. Reynolds, Handbook of Conducting Polymers, second ed, Marcel Dekker, New York, 1998, pp. 225-309, ISBN0-8247-0050-3.

[16] A.K. Bakhshi, G. Bhalla, J. Sci. Ind. Res. 63 (2004) 715.

[17] A. Dhanabalan, J.K.J. van Duren, P.A. van Hal, J.L.J. van Dogen, R.A.J. Janssen, Adv. Funct. Mater. 11 (2001) 255.

[18] J.K.J. van Duren, A. Dhanabalan, P.A. van Hal, R.A.J. Janssen, Synth. Met. 121 (2001) 1587.

[19] H. Neugebauer, C.J. Brabec, N.S. Sariciftci, R. Kiebooms, F. Wudl, S. Luzzati, J. Chem. Phys. 110 (1999) 12108.

[20] National Renewable Energy Laboratory (NREL), MS Excel ${ }^{\mathrm{TM}}$ spreadsheet file downloaded from 〈http://rrede.nrel.gov/solar/ spectra/am1.5/).

[21] M.C. Scharber, D. Mahlbacher, M. Koppe, P. Denk, C. Waldauf, A.J. Heeger, C.J. Brabec, Adv. Mater. 18 (2006) 789.

[22] L.J.A. Koster, V.D. Mihaiktchi, P.W.M. Blom, Appl. Phys. Lett. 88 (2006) 093511.

[23] K.M. Coakley, M.D. McGehee, Chem. Mater. 16 (2004) 4533

[24] M. Jargensen, F.C. Krebs, Pol. Bull. 51 (2003) 23.

[25] E. Bundgaard, F.C. Krebs, Macromolecules 39 (2006) 2823

[26] E. Bundgaard, F.C. Krebs, Sol. Energy Mater. Sol. Cells 91 (2007) 1019-1025, this issue; doi:10.1016/j.solmat.2007.01.13.

[27] C. Kitamura, S. Tanaka, Y. Yamashita, Chem. Mater. 8 (1996) 570.

[28] J.L. Brédas, A J. Heeger, F. Wudl, J. Chem. Phys. 85 (1986) 4673.

[29] M. Karikomi, C. Kitamura, S. Tanaka, Y. Yamashita, J. Am. Chem. Soc. 117 (1995) 6791 .

[30] M. Jayakannan, P.A. van Hal, R.A.J. Janssen, J. Pol. Sci. A Pol. Chem 40 (2002) 251.

[31] K.G. Jespersen, W.J.D. Beenken, Y. Zaushitsyn, A. Yartsev, M. Andersson, T. Pullerits, V. Sundstrôm, J. Chem. Phys. 121 (2004) 12613.

[32] K.G. Jespersen, A. Yartsev, T. Pascher, V. Sundstrōm, Synth. Met. $155(2005) 262$

[33] N.-K. Persson, M. Sun, J. Chem. Phys. 123 (2005) 204718 1-9.

[34] L. Yang, J.-K. Feng, A.-M. Ren, Polymer 46 (2005) 10970.

[35] M. Chen, E. Perzon, M.R. Andersson, S. Marcinkevicius, S.K.M. Jônsson, M. Fahlman, M. Berggren, Appl. Phys. Lett. 84 (2004) 3570 .

[36] C. Kitamura, S. Tanaka, Y. Yamashita, J. Chem. Soc. Chem. Commun. (1994) 1585.

[37] A. Ajayaghosh, Chem. Soc. Rev. 32 (2003) 181.

[38] S.C. Rasmussen, B.D. Straw, J.E. Hutchison, Semiconducting polymers applications properties and synthesis, in: B.R. Hsieh, Y. Wei (Eds.), ACS Symposium Series 735, American Chemical Wei (Eds.), ACS Symposium Series 735, American Chemical
Society, Washington, DC, 1999, pp. 347-366, ISBN0-8412-3612-7.

[39] P. Schilinsky, U. Asawapirom, U. Scherf, M. Biele, C.J. Brabec, Chem. Mater. 17 (2005) 2175.

[40] D.W. Breiby, E.J. Samuelsen, O. Konovalov, Synth. Met. 139 (2003) 361.

[41] D.W. Breiby, EJ. Samuelsen, J. Pol. Sci. B: Pol. Phys. 41 (2003) 2375.

[42] K.E. Aasmundtveit, E.J. Samuelsen, M. Guldstein, C. Steinsland, O. Flornes, C. Fagerno, T.M. Seeberg, L.A.A. Pettersson, O. Inganas, R. Feidenhans'l, S. Ferrer, Macromolecules 33 (2000) 3120. 
[43] K.E. Aasmundtveit, E.J. Samueken, W. Mammo, M. Svensson, M.R. Andersson, L.A.A. Pettersson, O. Inganās, Macromolecules $33(2000) 5481$.

[44] D. Fichou, J. Mater. Chem. 10 (2000) 571.

[45] H.J. Fell, E.J. Samuelsen, M.R. Andersson, J. Als-Nielsen, G. Grabel, J. Mảrdalen, Synth. Met. 73 (1995) 279.

[46] H.J. Fell, EJ. Samuelsen, J. Mårdalen, M.R. Andersson, Synth. Met. 69 (1995) 283

[47] J. Mảrdalen, E.J. Samuelsen, Synth. Met. 48 (1992) 363

[48] T.J. Prosa, M.J. Winokur, J. Moulton, P. Smith, A.J. Hegger, Mactomolecules 25 (1992) 4364 .

[49] L. Sicot, C. Fiorini, A. Lorin, P. Raimond, C. Sentein, J.-M. Nunz, Sol. Energy Mater. Sol. Cells 63 (2000) 49

[50] J. Nakamura, K. Murata, K. Takahashi, Appl. Phys. Lett. 87 (2005) 1321051-3.

[51] J. Huang, G. Li, Y. Yang, Appl. Phys. Lett. 87 (2005) 112105 1-3.

[52] A.J. Mozer, N.S. Sariciftci, A. Pivrikas, R. Ósterbacka, G. Juška, L. Brassat, H. Bassler, Phys. Rev. B 71 (2005) 03521419.

[53] R.J. Kline, M.D. McGehee, E.N. Kadnikova, J. Liu, J.M.J. Fróchet, M.F. Toney, Macromolecules 38 (2005) 3312

[54] K. Sivula, C.K. Luscombe, B.C. Tompson, J.M. Fréchet, J. Am. Chem. Soc. 128 (2006) 13988.

[55] M.R. Andersson, O. Thomas, W. Mammo, M. Svensson, M. Theander, O. Inganas, J. Mater. Chem. 9 (1999) 1933.

[56] U. Satner, J.B. Lagowski, P.G. Pickup, R.A. Poirier, Synth. Met. 96 (1998) 177.

[57] R.D. MoCullough, Adv. Mater. 10 (1998) 93.

[58] K.E. Aasmundtveit, E.J. Samuelsen, J. Mårdalen, E. Bakken, P.H. Carlsen, U. Lienert, Synth. Met. 89 (1997) 203.

[59] K.E. Aasmundtveit, E.J. Samuelsen, K. Hoffmann, E. Bakken, P.H.J. Carlsen, Synth. Met. $113(2000) 7$.

[60] E. Zhou, Z. Tan, C. Yang, Y. Li, Macromol. Rapid Commun. 27 (2006) 793.

[61] T. Yamamoto, K. Sanochika, A. Yamamoto, J. Pol. Sci. Pol. Lett. Ed. $18(1980) 9$.

[62] J.W.P. Lin, L.P. Dudek, J. Pol. Sci. Pol. Lett. Ed. 18 (1980) 2869.

[63] M. Sato, S. Tanaka, K. Kaeriyama, J. Chem. Soc. Chem. Commun. $11(1986) 873$.

[64] K.-Y. Jen, G.G. Miller, R.L. Elsenbaumer, J. Chem. Soc. Chem. Commun. 17 (1986) 1346

[65] R.L. Elsenbaumer, K.Y. Jen, R. Oboodi, Synth. Met. 15 (1986) 169

[66] R.D. McCullough, R.D. Lowe, M. Jayaraman, D.L. Anderson, J. Org. Chem. 58 (1993) 904.

[67] T.-A. Chen, R.D. Reike, J. Am. Chem. Soc. 114 (1992) 10087.

[68] R.D. McCullough, R.D. Lowe, J. Chem. Soc. Chem. Commun. (1992) 70.

[69] C. van Pharm, H.B. Mark Jr., H. Zimmer, Synth. Commun. 16 (1986) 689

[70] D.D. Cunningham, L. Laguren-Davidson, H.B. Mark Jr., C. van Pharm, H. Zimmer, J. Chem. Soc. Chem. Commun. (1987) 1021.

[71] G. Consiglio, S. Gronowitz, A.-B. Hornfeldt, B. Maltesson, R. Noto, D. Spinelli, Chem. Scr. 11 (1977) 175.

[72] K. Tamao, K. Sumitani, Y. Kiso, M. Zembayashi, A. Fujoka, S. Kodama, I. Nakajima, A. Minato, M. Kumada, Bull. Chem. Soc. Japan 49 (1976) 1958.

[73] S. Kodama, I. Naajima, M. Kumada, A. Minato, K. Suzuki, Tetrahedron 38 (1982) 3347.

[74] R.D. MoCulbugh, R.D. Lowe, Polym. Prep. 33 (1992) 195.

[75] R.D. McCullough, R.D. Lowe, M. Jayaraman P.C. Ewhank, D.L. Anderson, S. Tristan-Nagle, Synth. Met. 55 (1993) 1198.

[76] R.D. McCullough, S. Tristan-Nagk, S.P. Wilbams, R.D. Lowe, M Jayaraman, J. Am. Chem. Soc. 115 (1993) 4910.

[77] R.D. McCullough, S.P. Williams, S. Tristan-Nagle, M. Jayaraman, P.C. Ewbank, L. Miller, Synth. Met. 69 (1995) 279

[78] K. Tamoa, K. Sumitani, M. Kumada, J. Am. Chem. Soc. 94 (1972) 4376

[79] R.D. McCullough, J.A. Belot, S.P. Willams, Molecular engineering of advanced materials, in: J. Becher, K. Schaumburg (Eds.), NATO
Adv. Res. Workshop Series, Series C: Math. and Phys. Sci., Kluwer, Dordrecht, vol. 456, 1995, pp. 349-363.

(80] R.D. McCullough, S.P. Willams, M. Jayaraman, J. Reddinger, L Miller, S. Tristram-Nagle, Mater. Res. Soc. Symp. Proc. 328 (1994) 215.

[81] T.-A. Chen, R.D. Reike, Synth. Met. 60 (1993) 175.

[82] X. Wu, T.-A. Chen, R.D. Reike, Macromolecules 28 (1995) 2101.

[83] T.-A. Chen, X. Wu, R.D. Reike, J. Am. Chem. Soc. 117 (1995) 233.

[84] T.-A. Chen, R.A. O'Brien, R.D. Reike, Macromolecules 26 (1993) 3462.

[85] F.C. Krebs, M. Biancardo, Sol. Energy Mater. Sol. Cells 90 (2006) 142 .

[86] A. Iraqi, G.W. Baker, J. Mater. Chem. 8 (1998) 25.

[87] J.M. Tour, Chem. Rev. 96 (1996) 537.

[88] Q.T. Zhang, J.M. Tour, J. Am. Chem. Soc. 119 (1997) 5065

[89] S. Luzzati, M. Scharber, M. Catellani, F. Giacalone, J.L. Segura, N. Martin, H. Neugebauer, N.S. Sariciftci, J. Phys. Chem. B 110 (2006) 5351.

[90] J. Hou, L. Huo, C. He, C. Yang, Y. Li, Macromolecules 39 (2006) 594

[91] E.E. Sheina, S.M. Khersonsky, E.G. Jones, R.D. McCullough, Chem. Mater. 17 (2005) 3317

[92] K. Ogawa, J.A. Stafford, S.D. Rothstein, D.E. Tallman, S.C. Rasmussen, Synth. Met. $152(2005) 137$.

[93] S. Luzzati, A. Mozer, P. Denk, M.C. Scharber, M. Catellani, N.-O Lupsac, F. Giacalone, J.L. Segura, N. Martin, H. Neugebauer, N.S. Saricifta, Proc. SPIE 5215 (2004) 41

[94] M. Catellani, S. Luzzati, N.-O. Lupsac, R. Mendichi, R. Consonni, A. Famulari, S.V. Meille, F. Giacalone, J.L. Segura, N. Martin, J. Mater. Chem. 14 (2004) 67.

[95] M. Catellani, S. Luzzati, N.-O. Lupsac, R. Mendichi, R. Consonni, F. Giacalone, J.L. Segura, N. Martín, Thin Solid Films 451-452 (2004) 2.

[96] M. Theander, A. Yartsev, D. Zigmantas, V. Sundstrồm, W. Mammo, M.R. Andersson, O. Inganas, Phys. Rev. B 61 (2000) 12957.

[97] J. Hou, C. Yang, Y. Li, Synth. Met. 153 (2006) 93.

[98] A. Gadisa, M. Svensson, M.R. Andersson, O. Inganãs, Appl. Phys. Lett. 84 (2004) 1609.

[99] E. Zhou, C. He, Z. Tan, C. Yang, Y. Li, J. Pol. Sci. A, Pol. Chem. 44 (2006) 4916

[100] Y. Greenwald, G. Cohen, J. Poplawsk, E. Ehrenfreund, S. Speiser, D. Davidor, J. Am. Chem. Soc. 118 (1996) 2980.

[101] T. Johansson, W. Mammo, M. Svensson, M.R. Andersson, O. Inganãs, J. Chem. Mater. 13 (2003) 1316

[102] K.K. Stokes, K. Heuzé, R.D. McCullough, Macromolecules 36 (2003) 7114 .

[103] S. Gknis, G. Horowitz, G. Tourillon, F. Garnier, Thin Solid Films 111 (1984) 93

[104] Homepage of America Dye Sources, Inc.: 〈http://wwwadsdyes.$\mathrm{com} /\rangle$.

[105] F. Padinger, R.S. Rittherger, N.S. Sariciftci, Adv. Funct. Mater. 13 (2003) 85 .

[106] G. Li, V. Shrotriya, J. Huang, Y. Yao, T. Moriarty, K. Emery, Y. Yang, Nat. Mater. 4 (2005) 864

[107] P. Vanlaeke, G. Vanhoyland, T. Aernouts, D. Cheyns, C. Deibel, J. Manca, P. Heremans, J. Poortmans, Thin Solid Films 511-512 (2006) 358 .

[108] V. Shotriya, G. Li, Y. Yao, C.-W. Chu, Y. Yang, Appl. Phys. Lett. 88 (2006) $0735081-3$.

[109] D. Chirvase, J. Parisi, J.C. Hummelen, V. Dyakonov, Nanotech 15 (2004) 1317

[110] I. Riedel, V. Dyakonov, Phys. Stat. Solidi (a) 201 (2004) 1332

[111] M. Drees, H. Hoppe, C. Winder, H. Neugehauer, N.S. Sariciftci, W. Schwinger, F. Schäffler, C. Topf, M.C. Scharber, Z. Zhu, R. Gaudiana, J. Mater. Chem. 15 (2005) 5158. 
[112] K. Inoue, R. Ulbricht, P.C. Madakasira, W.M. Sampson, S. Lee, J. Gutierre, J. Ferraris, A.A. Zakhidov, Proc. SPIE 5520 (2004) 256. [113] Y. Kim, S.A. Choulis, J. Nelson, D.D.C. Bradley, S. Cook, J.R. Durrant, J. Mater. Sci. 40 (2005) 1371.

[114] B. Fan, P. Wang, L. Wang, G. Shi, Sol. Energy Mater. Sol. Celk 90 (2006) 3547.

[115] P. Schilinski, C. Waldauf, CJ. Brabec, Appl. Phys. Lett. 81 (2002) 3885 .

[116] X. Yang, J. Loos, S.C. Veenstra, W.J.H. Verhees, M.M. Wienk, J.M. Kroon, M.A.J. Michels, R.A.J. Janssen, Nano Lett. 5 (2005) 579.

[117] J. Hou, Z. Fan, Y. Yan, Y. He, C. Yang, Y. Li, J. Am. Chem. Soc. $128(2006) 4911$.

[118] R. Cugola, U. Giovanella, P. Di Gianvincenzo, F. Bertini, M. Catellani, S. Luzzati, Thin Solid Films 51 1-512 (2006) 489.

[119] J.Y. Kim, S.H. Kim, H.-H. Lee, K. Lee, W. Ma, X. Gong, A.J. Heger, Adv. Mater. 18 (2006) 572.

[120] A.G. Oumnov, V.Z. Mordkovich, Y. Takeuchi, Synth. Met. 121 (2001) 1581 .

[121] S. Berson, R. De Bettignies, S. Guillerez, TNT2006, Grenoble, France, September 2006

[122] S. Guillerez, R. de Bettignies, S. Berson, European conference on hybrid and organic solar celk, in: ECHOS'06, 28-30 June 2006, Paris, France, paper number 28-O1-3.

[123] D. Gebeyehu, C.J. Brabec, F. Padinger, T. Fromherz, J.J. Hummelen, D. Badt, H. Schindkr, N.S. Sariciftci, Synth. Met. 118 (2001) 1 .

[124] M. Trznadel, A. Pron, M. Zagorska, R. Chrzaszez, J. Pielichowski, Mactomolecules 31 (1998) 5051.

[125] S.E. Shaheen, C.J. Brabec, N.S. Sariciftc, F. Padinger, T. Fromherz, J.C. Hummelen, Appl. Phys. Lett. 78 (2001) 841

[126] Z. Zhu, S. Hadjikyriacou, D. Waller, R. Gaudiana, J. Macromol. Sci. A: Pure Appl. Chem. 41 (2004) 1467.

[127] E. van Hauff, J. Parisi, V. Dyakonov, Thin Solid Fitms 511-512 (2006) 506.

[128] A. Swinnen, I. Haeldersmans, M. vande Ven, J. D'Haen, G. Vanhoyland, S. Aresu, M. D'Oliesheger, J. Manca, Adv. Funct. Mater. 16 (2006) 760 .

[129] Y. Kim, S. Cook, S.M. Tuladhar, S.A. Choulis, J. Nelson, J.R. Durrant, D.D.C. Bradley, M. Giles, I. MoCulloch, C.-S. Ha, M. Ree, Nat. Mater. 5 (2006) 197.

[130] M. Theander, M.R. Andersson, O. Inganās, Synth. Met. 101 (1999) 331

[131] W.J.E. Beek, M.M. Wienk, R.A.J. Janssen, Adv. Funct. Mater. 16 (2006) 1112

[132] G. Horowitz, F. Garnier, Sol. Energy Mater. 13 (1986) 47.

[133] J. Cao, J. Sun, G. Shi, H. Chen, Q. Zhang, D. Wang, M. Wang, Mater. Chem. Phys. 82 (2003) 44.

[134] A. Du Pasquier, H.E. Unalan, A. Kanwal, S. Miller, M. Chhowalla, Appl. Phys. Lett. 87 (2002) 2035111-3.

[135] A. Cravino, G. Zerza, M. Maggini, S. Bucella, M. Svensson, M.R. Andersson, H. Neugebauer, C.J. Brabec, N.S. Sariciftci, Monatshefte Chem. 134 (2003) 519.

[136] A. Cravino, N.S. Sariciftc, J. Mater. Chem. 12 (2002) 1931

[137] P.A. van Hal, R.A.J. Janssen, G. Lanzani, G. Cerullo, M. ZavelaniRossi, S. De Silvestri, Chem. Phys. Lett. 345 (2001) 33.

[138] P. Wentzel, A. Du Pasquier, Mater. Res. Soc. Symp. Proc. 836 (2005) 75

[139] N. Camaioni, G. Ridotti, G. Casalbore-Miceli, G. Possamai, M. Magqini, Adv. Mater. 14 (2002) 1735.

[140] L. Chen, D. Godovsky, O. Inganās, J.C. Hummelen, R.A.J. Janssen, M. Svensson. M.R. Andersson. Adv. Mater. 12 (2000) 1367.

[141] G. Dennler, H.-J. Prall, R. Koeppe, M. Egginger, R. Autengruber, N.S. Sariciftci, Appl. Phys. Lett. 89 (2006) 0735021-3.

[142] L.B. Groenendaal, F. Louwet, P. Adriaensens, R. Carleer, D. Vanderzande, J. Gelan, Abst. Papers Am. Chem. Soc. PMSE 223 (2002) 59 .
[143] F. Zhang, M. Johansson, M.R. Andersson, J.C. Hummelen, O. Inganâs, Adv. Mater. 14 (2002) 662.

144] M. Granstrồn, M. Berggren, O. Inganas, Science 267 (1995) 1479

[145] A.C. Arias, M. Granstrồm, K. Petritsch, R.H. Friend, Synth. Met $102(1999) 953$.

146] C.S. Wang, M. Kilitziraki, L.O. Palsson, M.R. Bryce, A.P. Monkman, I.D.W. Samuel, Adv. Funct. Mater. 11 (2001) 47.

[147] I.F. Perepichka, E. Levillain, J. Roncali, J. Mater. Chem. 14 (2004) 1679.

[148] A. Berlin, G. Zotti, S. Zecchin, G. Schiavon, B. Vercelli, A. Zanelli, Chem. Mater. 16 (2004) 3667.

149] J.-M. Raimundo, P. Blanchard, H. Brisset, S. Akoudad, J. Roncali, Chem. Commun. (2000) 939 .

[150] G.A. Sotzing, C.A. Thomas, J.R. Reynolds, P.J. Steel, Macromokcuks 31 (1998) 3750 .

[151] F.L. Zhang, A. Gadissa, O. Inganãs, M. Svensson, M.R. Andersson, Appl. Phys. Lett. 84 (2004) 3906

[152] B. Winther-Jensen, F.C. Krebs, Sol. Energy Mater. Sol. Celk 90 (2006) 123

153] L.A.A. Pettersson, S. Ghosh, O. Inganãs, Org. Eke. 3 (2002) 143.

[154] T. Aernouts, P. Vanlaerke, W. Geens, J. Poortmans, P. Heremans, S. Borghs, R. Mertens, R. Andriessen, L. Leenders, Thin Solid

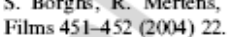

[155] F. Wudl, M. Kobayashi, A J. Heeger, J. Org. Chem. 49 (1984) 3382

[156] M.P. Cava, M.V. Lakshmikantham, Acc. Chem. Res. 8 (1975) 139

[157] M. Kobayasti, N. Colaneri, M. Boysel, F. Wudl, A.J. Heeger, J. Chem. Phys. 82 (1985) 5717.

[158] R. Kiebooms, I. Hoogmartens, P. Adriaensens, D. Vanderzande, J. Gelan, Macromolecules 28 (1995) 4961.

159] P. Otto, J. Ladik, Synth. Metal 36 (1990) 327

[160] H. Meng, F. Wudl, Macromolecules 34 (2001) 1810

[161] R. van Asselt, I. Hoogmartens, D. Vanderzande, J. Gelun, P.E. Froehbing, M. Aussems, O. Aagaard, R. Schellekens, Synth. Met. 74 (1995) 65.

[162] A.J. Hagan, S.C. Moratti, I.C. Sage, Synth. Met. 119 (2001) 147.

[163] I. Polec, A. Henckens, L. Goris, M. Nicolas, M.A. Loi, P.J. Adreaensens, L. Lutsen, J.V. Manca, D. Vanderzande, N.S Sariciftci, J. Pol. Sci. A Pol. Chem 41 (2003) 1034

[164] S.-A. Chen, C.-C. Lee, Polymer 37 (1996) 519.

[165] S.-A. Chen, C.-C. Lee, Pure \& Appl. Chem. 67 (1995) 1983.

[166] L. Goris, M.A. Loi, A. Cravino, H. Neugebauer, N.S. Sariciftci, I. Polec, L. Lutsen, E. Andries, J. Manca, L. De Schepper, D Vanderzande, Synth. Met. 138 (2003) 249.

167] A. Henckens, M. Knipper, I. Poke, J. Manca, L. Lutsen, D. Vanderzande, Thin Solid Films 451-452 (2004) 572.

[168] S.E. Shahoen, D.L. Vangeneugden, R. Kiebooms, D. Vanderzande, T. Fromherz, F. Padinger, C.J. Brabec, N.S. Sariciftci, Synth. Met. $121(2001) 1583$.

[169] D.L. Vangeneugden, D.J.M. Vanderzande, J. Salbeck, P.A. van Hal, R.A.J. Janssen, J.C. Hummelen, C.J. Brabec, S.E. Shaheen, N.S Sariciftci, J. Phys. Chem. 105 (2001) 11106.

[170] R. Kiebooms, F. Wudl, Synth. Met. 101 (1999) 40.

[171] R.H.L. Kiebooms, H. Goto, K. Akagi, Macromokeules 34 (2001) 7989.

[172] D.L. Vangeneugden, R.H.L. Kiebooms, D.J.M. Vanderzande, J.M.J.V. Gelan, Synth. Met. 101 (1999) 120.

[173] P. Bãurle, G. Gotz, U. Segelbacher, D. Huttenlocher, M. Mehring, Synth. Met. 55-57 (1993) 4768.

[174] G. Sonmez, H. Meng, F. Wudl, Chem. Mater. 15 (2003) 4923.

[175] H. Meng, D. Tucker, S. Chaffins, Y. Chen, R. Helgeson, B. Dunn, F. Wudl, Adv. Mater. 15 (2003) 146.

[176] A. Cravino, M.A. Loi, M.C. Scharber, C. Winder, H. Neupebauer, P. Denk, H. Meng, Y. Chen, F. Wudl, N.S. Saricifta, Synth. Met. 137 (2003) 1435.

[177] D. Lorcy, M.P. Cava, Adv. Mater. 4 (1992) 562

[178] D. Muhlbacher, H. Neugebauer, A. Cravino, N.S. Sariciftci, J.K.J. van Duren, A. Dhanahalan, P.A. van Hal, R.A.J. Janssen, J.C. Hummelen, Mol. Cryst. Liq. Cryst. 385 (2002) [205]/85-[212//92. 
[179] D. Mūhlbacher, H. Neugebauer, A. Cravino, N.S. Sariciftci, Synth. Met. 137 (2003) 1361.

[180] A. Dhanabalan, J.L.J. van Dogen, J.K.J. van Duren, H.M. Janssen, P.A. van Hal, R.A.J. Janssen, Macromolecules 34 (2001) 2495.

[181] H.A.M. van Mullekom, J.A.J.M. Vekemans, E.W. Meijer, Chem Eur. J. 4 (1998) 1235.

[182] H.A.M. van Mulekom, J.A.J.M. Vekemans, E.W. Mejer, Chem Commun. (1996) 2163 .

[183] C. Edder, P.B. Arnstrong, K.B. Prado, J.M.J. Fréchet, Chem. Commun. (2006) 1965

[184] A. Dhanabalan, P.A. van Hal, J.K.J. van Duren, J.L.J. van Dogen, R.A.J. Janssen, Synth. Met. 119 (2001) 169.

[185] C.J. Brabec, N.S. Sariciftci, J.C. Hummelen, Adv. Funct. Mater. 11 (2001) 15.

[186] C. Winder, G. Matt, J.C. Hummelen, R.A.J. Janssen, N.S Sariciftci, C.J. Brabec, Thin Solid Films 403-404 (2002) 373.

[187] CJ. Brabec, C. Winder, N.S. Sariciftci, J.C. Hummelen, A. Dhanabalan, P.A. van Hal, R.A.J. Janssen, Adv. Funct. Mater. 12 (2002) 709 .

[188] C. Winder, D. Mūhlbacher, H. Neugehauer, N.S. Sariciftci, C Brabec, R.A.J. Janssen, J.K. Hummelen, Mol. Cryst. Liq. Cryst. 385 (2002) [213] $93-[220] 100$

[189] M. Jayakannan, P.A. van Hal, R.A.J. Janssen, J. Pol. Sci. A Pol. Chem 40 (2002) 2360.

[190] E. Bundgaard, F.C. Krebs, Pol. Bull. 55 (2005) 157.

[191] M.M. Wienk, M.P. Struijk, R.A.J. Janssen, Chem. Phys. Lett. 422 (2006) 488 .

[192] E. Bundgaard, S.E. Shaheen, F.C. Krebs, D. Ginley, Chem. Mater (2007) (submitted).

[193] L.M. Campos, A. Tontcheva, S. Ganes, G. Sonmez, H. Neugebauer, N.S. Sariciftci, F. Wudl, Chem. Mater. 17 (2005) 4031

[194] M.M. Wienk, M.G.R. Turbiez, M.P. Struijk, M. Fonrodona, R.A.I. Janssen, Appl. Phys. Lett. 88 (2006) 153511 1-3.

[195] M. Pomerantz, B. Chaloner-Gill, L.O. Harding, J.J. Tseng, W J. Pomerantz, J. Chem. Soc. Chem. Commun. (1992) 1672.

(196] D.D. Kenning, M.R. Funfar, S.C. Rasmussen, Polym. Preprints 42 (2001) 506.

[197] T. Yamamoto, A. Morita, Y. Miyazaki, T. Marayuma, H. Wakayama, Z. Zhou, Y. Nakamura, T. Kanbara, S. Sasaki, K. Kubota, Macromolecules 25 (1992) 1214.

[198] M. Shahid, R.S. Ashraf, E. Klemm, S. Sensfass, Macromolecules 39 (2006) 7844 .

[199] M.T. Bernius, M. Inbasekaran, J. O'Brien, W. Wu, Adv. Mater. 12 (2000) 1737.

[200] G. Klaerner, R.D. Miller, Macrobecules 31 (1998) 2007.

[201] Q. Hou, Y. Xu, W. Yang, M. Yuan, J. Peng, Y. Cao, J. Mater. Chem. 12 (2002) 2887

[202] G. Groczynski, M. Fahlman, W.R. Salaneck, N. Johansson, D.A. dos Santos, A. Dkhissi, J.L. Brédas, J. Chem. Phys. $116(2002) 1700$

[203] M. Svensson, F. Zhang, S.C. Veenstra, W.J.H. Verhees, J.C. Hummekn, J.M. Kroon, O. Inganās, M.R. Andersson, Adv. Mater. 15 (2003) 988.

[204] C. Shi, Y. Yao, Y. Yang, Q. Pei, J. Am. Chem. Soc. 128 (2006) 8980

[205] R. Yang, R. Tian, J. Yan, Y. Zhang, J. Yang, Q. Hou, W. Yang, C. Zhang, Y. Cao, Macromolecules 38 (2005) 244.

[206] T. Yohannes, F. Zhang, M. Svensson, J.C. Hummekn, M.R. Andersson, O. Inganãs, Thin Sobid Fibms 449 (2004) 152

[207] Q. Zhou, Q. Hou, L. Zheng, X. Deng, G. Yu, Y. Cao, Appl. Phys. Lett. 84 (2004) 1653.

[208] O. Inganas, M. Svensson, F. Zhang, A. Gadisa, N.K. Persson, X. Wang, M.R. Andersson, Appl. Phys. A 79 (2004) 31.

[209] L.M. Andersson, O. Inganass, Appl. Phys. Lett. 88 (2006) 082103 1-3.

[210] F. Zhang, K.G. Jespersen, C. Bjōrstrồm, M. Svensson, M.R Andersson, V. Sundstrôm, K. Magnusson, E. Moons, A. Yartsev, O. Inganās, Adv. Funct. Mater. 16 (2006) 667

[211] R. Pacios, D.D.C. Bradky, J. Nelson, C.J. Brabec, Synth. Met. 137 (2003) 1469.
[212] J.-I. Lee, G. Klaerner, M.H. Davey, R.D. Miller, Synth. Met. 102 (1999) 1087.

[213] X. Wang, E. Perzon, F. Oswak, F. Langa, S. Admassie, M.R. Andersson, O. Inganās, Adv. Funct. Mater. 15 (2005) 1665.

[214] X. Wang, E. Perzon, J.L. Delgado, P. de la Cruz, F. Zhang, F. Langa, M. Andersson, O. Inganas, Appl. Phys. Lett. 85 (2004) 5081.

[215] F. Zhang, E. Perzon, X. Wang, W. Mammo, M.R. Andersson, O. Inganas, Adv. Funct. Mater. 15 (2005) 745

[216] E. Perzon, X. Wang, F. Zhang, W. Mammo, J.L. Delgado, P. de la Crw, O. Inganās, F. Langa, M.R. Andersson, Synth. Met. 154 (2005) 53.

[217] X. Wang, E. Perzon, W. Mammo, F. Oswald, S. Admassic, N.-K. Persson, F. Langa, M.R. Andersson, O. Inganās, Thin Solid Films 511-512 (2006) 576

[218] M. Chen, E. Perzon, N. Robisson, S.K.M. Jōnsson, M.R. Andersson, M. Fahlman, M. Berggren, Synth. Met. 146 (2004) 233.

[219] K.G. Jespersen, F. Zhang, A. Gadisa, V. Sundstrôm, A. Yartsev, O. Inganās, Org. Elec. 7 (2006) 235.

[220] E. Perzon, X. Wang, S. Admassie, O. Inganās, M.R. Andersson, Polymer $47(2006) 4261$.

[221] M. Chen, X. Crispin, E. Perzon, M.R. Andersson, T. Pullerits, M. Berggren, Appl. Phys. Lett. 87 (2005) 252105 1-3.

[222] A. Gadisa, X. Wang, S. Admassie, E. Perzon, F. Oswald F. Langa, M.R. Andersson, O. Inganãs, Org. Ekec. 7 (2006) 195.

[223] M.M. Wienk, J.M. Kroon, W.J.H. Verhees, J. Knol, J.C. Hummekn, P.A. van Hal, R.A.J. Janssen, Angew. Chem. Int. Ed. $42(2003) 3371$

[224] D.M. Johansson, T. Granlund, M. Theander, O. Inganãs, M.R. Ander sson, Synth. Met. 121 (2001) 1761

[225] S.K. Lee, N.S. Cho, J.H. Kwak, K.S. Lim, H.-K. Shim, D.-H. Hwang, C.J. Brabec, Thin Sobid Films 511-512 (2006) 157

226] I.T. Kim, S.W. Lee, M.H. Kwak, S.J. Kim, G.B. Park, H.W. Kim, Polym. Preprints 45 (2004) 218.

[227] I.T. Kim, S.W. Lee, H.S. Park, T.H. Kwak, C.M. Lee, S.Y. Kim, Polym. Preprints 44 (2003) 931.

[228] I.T. Kim, S.W. Lex, J.Y. Lee, Polym. Preprints 44 (2003) 1163

[229] C. Taliani, G. Ruani, R. Zamboni, A. Bolognesi, M. Catellani, S Destri, W. Porzio, P. Ostoja, Synth. Met. 28 (1989) C 507.

[230] C. Taliani, R. Zamboni, G. Ruani, in: J. Messier, F. Kajzar, P. Prasad, D. Ulrich (Eds.), Nonlinear Optical Effects in Organic Polymers, vol. 162, Kluwer Academic Publishers, Dordrecht, 1988, pp. 159-172.

[231] C. Arbizzani, M. Catellani, M. Mastragostino, M.G. Cerroni, J. Electroanl. Chem. 423 (1997) 23.

[232] A. Cravino, H. Neugebauer, S. Luzzati, M. Catellani, N.S. Sariciftci, J. Phys. Lett. B 105 (2001) 46

[233] S. Tanaka, Y. Yamashita, Synth. Met. 55-57 (1993) 1251

[234] S. Tanaka, Y. Yamashita, Synth. Met. 69 (1995) 599.

[235] M. Pomerantz, X. Gu, S.X. Zhang, Macromolecules 34 (2001) 1817.

[236] M. Pomerant, X. Gu, Synth. Met. 84 (1997) 243.

[237] B. Lee, V. Seshadri, G.A. Sotzing, Polym. Preprints 46 (2005) 1010.

[238] K. Lee, G.A. Sotzing, Macromolecules 34 (2001) 5746.

[239] G.A. Sotzing, K. Lee, Polym. Preprints 85 (2001) 604.

[240] B. Lee, M.S. Yavuz, G.A. Sotzing, Polym. Preprints 46 (2005) 860.

[241] A. Kumar, G.A. Sotzing, Polym. Preprints 46 (2005) 969.

[242] A. Kumar, Z. Buyukmumcu G.A. Sotzing, Macromolecules 39 (2006) 2723.

[243] B. Lee, V. Seshadri, G.A. Sotzing, Synth. Met. 152 (2005) 177

[244] B. Lee, V. Seshadri, G.A. Sotzing, Langmuir 21 (2005) 10797.

[245] M. Hanack, U. Schmid, U. Rōhrig, J.-M. Toussaint, C. Adant, J.-L. Brédas, Chem. Ber. 126 (1993) 1487.

[246] N.-O. Lupsac, M. Catellani, S. Luzzati, Mol. Cryst. Liq. Cryst. 385 (2002) [241] 121-[248]/128.

[247] C.-G. Wu, C.-W. Hsieh, D.-C. Chen, S.-J. Chang, K.-Y. Chen, Synth. Met. 155 (2005) 618.

[248] S. Das, A. Ajayaghosh, K.R. Gopidas, D. Ramaiah, K.G. Thomas, Metals Mater. Proces. 13 (2001) 351 
[249] J. Eldo, A. Ajayaghosh, Chem. Mater. 14 (2002) 410. [250] G. Brocks, A. Tol, J. Phys. Chem. 100 (1996) 1838.

[251] E.E. Havinga, W. ten Hoeve, H. Wynherg, Synth. Met. 55-57 (1993) 299. [252] H. Cheng,
(1995) 1451 .

[253] I.T. Kim, R.L. Elsenbaumer, Macromolecules 33 (2000) 6407.

[254] W.J. Mitchell, C. Pena, P.L. Burn, J. Mater. Chem. 12 (2001) 200. [255] A. Henckens, K. Colladet, S. Fourier, TJ. Cleij, L. Lutsen, J. Gelan, D. Vanderzande, Macromolecules 38 (2005) 19.

[256] L.H. Nguyen, S. Gūnes, H. Neugebauer, N.S. Sariciftci, F. Banishoeib, A. Henckens, T. Cleij, L. Lutsen, D. Vanderzande, Sol. Energy Mater. Sol. Cells 90 (2006) 2815.

[257] K. van de Wetering, C. Brochon, C. Ngov, G. Hadziioannou,

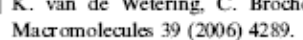

[258] I.T. Kim, R.L. Elsenbaumer, Chem. Commun. (1998) 327.

[259] Q. Zhang, Y. Li, M. Yang, J. Mater. Sci. 39 (2004) 6089.

[260] Q. Zhang, Y. Li, M. Yang, Synth. Met. 146 (2004) 69.

[261] Q. Zhang, M. Yang, P. Wu, H. Ye, X. Lui, Synth. Met. 156(2006) 135.

[262] Q. Zhang, J. Feng. K. Lui, D. Zhu, M. Yang, H. Ye, X. Lui, Synth. Met. $156(2006) 804$

[263] K. Colladet, M. Nicolas, L. Goris, L. Lutsen, D. Vanderzande, Thin Solid Films 451-452 (2004) 7 .

[264] T. Yamamoto, M. Arai, H. Kokubo, S. Sasaki, Macromolecules 36 (2003) 7986.

[265] R. Demadrille, M. Firon, J. Leroy, P. Rannou, A. Pron, Adv. Funct. Mater. 15 (2005) 1547.

[266] M.B. Zaman, D.F. Perepichka, Chem. Commun. (2005) 4187.

[267] B.D. Reeves, C.R.G. Grenier, A.A. Argun, A. Girpan, T.D. McCarley, J.R. Reynolds, Macromolecules 37 (2004) 7559.
[268] L.M. Campos, A.J. Mozer, S. Gūnes, C. Winder, H. Neựebauer, N.S. Saridiftci, B.C. Thompson, B.D. Reeves, C.R.G. Grenier, J.R. Reynolds, Sol. Energy Mater. Sol. Cells 90 (2006) 3531.

[269] D. Mühlhacher, M. Scharber, M. Morana, Z. Zhu, D. Walker, R. Gaudiana, C.J. Brabec, Adv. Mater. 18 (2006) 2284.

[270] D. Mühlhacher, M. Scharber, M. Morana, Z. Zhu, D. Walker, R. Gaudiana, C.J. Brabec, Adv. Mater. 18 (2006) 2284, correction.

[271] G. Sonmez, C.K.F. Shen, Y. Rubin, F. Wudl, Adv. Mater. 17 (2005) 897.

[272] J. Cremer, P. Bãuerle, J. Mater. Chem. 16 (2006) 874

[273] F.C. Krebs, R.B. Nyberg, M. Jørgensen, Chem. Mater. 16 (2004) 1313 .

[274] K.T. Nielsen, K. Bechgaard, F.C. Krebs, Macromolecules 38 (2005) 658.

[275] K.T. Nielsen, K. Bechgaard, F.C. Krebs, Synthesis 10 (2006) 1639.

[276] V. Duprez, M. Biancardo, H. Spanggaard, F.C. Krebs, Macromokcules 38 (2005) 10436.

[277] J. Aktrup, K. Norrman, M. Jargensen, F.C. Krebs, Sol. Energy Mater. Sol. Celk $90(2006) 2777$.

[278] K. Norrman, J. Alstrup, M. Jargensen, F.C. Krebs, Surf. Interface Anal. 38 (2006) 1302.

[279] K. Norrman, N.B. Larsen, F.C. Krebs, Sol. Energy Mater. Sol. Cells 90 (2006) 2793.

[280] K. Nornnan, F.C. Krebs, Sol. Energy Mater. Sol. Cells 90 (2006) 213.

[281] M. Lira-Cantu, F.C. Krebs, Sol. Energy Mater. Sol. Cells 90 (2006) 2076.

[282] M. Lira-Cantu, K. Norrman, J.W. Andreasen, F.C. Krebs, Chem. Mater. 18 (2006) 5684 


\title{
Large-area photovoltaics based on low band gap copolymers of thiophene and benzothiadiazole or benzo-bis(thiadiazole)
}

\author{
E. Bundgaard, F.C. Krebs* \\ The Danish Polymer Centre, RISO National Laboratory, P.O. Box 49, DK-4000 Raskilde, Denmark \\ Received 3 November 2006; received in revised form 15 January 2007; accepted 15 January 2007 \\ Availabke online 6 March 2007
}

Abstract

Large-area solar cells (active area $=3$ and $10 \mathrm{~cm}^{2}$ ) were prepared with low band gap polymers based on thiophene and benzothiadiazole (1) or thiophene and benzo-bis(thiadiazole) (2). The band gaps of the polymers were 1.65 and $0.67 \mathrm{eV}$, respectively. The best photovoltaic performance was obtained for the device ITO/PEDOT/1:PCBM (1:2)/Al with an active area of $3 \mathrm{~cm}^{2}$. The efficiency of the device was $0.62 \%$. This is a high efficiency for a low band gap polymer in a large-area organic solar cell and thus polymer $\mathbf{1}$ is a very promising material for organic solar cells. The devices based on 2 were found to give poor devices when employed in bulk heterojunctions with PCBM. This was linked to a poor alignment of the energy levels in 2 with that of the electrodes and PCBM, showing that the requirement for a control of the positions of the energy levels becomes increasingly important as the band gap decreases. (C) 2007 Elsevier B.V. All rights reserved.

Keywords: Low band gap polymers; Large-area organic photovoltaic devices

\section{Introduction}

Some of the current aims for organic photovoltaics (OPV) [1] are to achieve high-efficiency, stability, low-cost and high-speed production possibilities. The ultimate combination of all these goals in one single polymer material for OPV is a challenge and no results have yet been published. However, good results have been reported when considering these goals individually. Most notably the efficiency of optimized small-area devices has reached the $5 \%$ benchmark [2]. The operational lifetime of OPVs have traditionally been short, while operational lifetimes of $4000 \mathrm{~h}$ [3] with efficiencies below $1 \%$ for large-area devices have been documented using accelerated testing [4] and outside testing [3]. Somewhat shorter lifetimes for devices with higher efficiencies have also been documented [5]. A detailed understanding of the degradation in OPVs is dawning and is generally viewed as a complex problem where many different degradation mechanisms are in play simultaneously. A tmosphere, light and thermal effects

\footnotetext{
"Corresponding author. Tel.: +4546774799; fax: +4546774791.

E-mail address: frederik.krebs@ risoedk (F.C. Krebs).
}

have been reported and many of the mechanisms are interface phenomena [6]. Most literature reports are only concerned with relatively small active area devices, which are prepared by spin coating, solvent casting or doctor blading. There have been fewer reports on the preparation of large-area devices by true high-volume processes such as roll-to-roll coating and screen printing of devices [7] and anodes [8]. In the literature, there are few examples of the production of larger area OPVs [9]. The reported efficiency of the large-area devices are: $0.001 \%\left(1000 \mathrm{~cm}^{2}\right)$ $[7 \mathrm{~d}, 7 \mathrm{e}, 7 \mathrm{f}], 0.0046 \%\left(100 \mathrm{~cm}^{2}\right)[7 \mathrm{~b}], 1.2 \%\left(12 \mathrm{~cm}^{2}\right)$ [9a], $0.2 \%\left(4.2 \mathrm{~cm}^{2}\right)$ [8b] and $1.5 \%\left(0.25 \mathrm{~cm}^{2}\right)$ [9b]. The first four devices are based on PPV polymer materials and the latter are based on polythiophene. From the reported data, it can be seen that the efficiencies of the OPVs with a large active area are much lower than the best reported efficiencies for a small active area device with the same polymer. Therefore, the efficiency can be expected to decrease significantly when the active area of the device is increased. Careful design of the module geometry may, however, minimize the losses. Several problems can be identified that are a direct result of increasing the active area of the OPV, e.g. film quality, sheet resistive losses and 
film morphology [10]. Hence, the reported photovoltaic responses are typically measured on devices with very low active areas (below $0.1 \mathrm{~cm}^{2}$ ) [2c,11]. Several factors affect the morphology of the film, for example solvent use, chemical structure, temperature and composition between polymer and [6,6]-phenyl- $\mathrm{C}_{61}$-butyric acid methyl ester (PCBM) [10]. To summarize the requirements of the next generation of materials based on the short overview given above a lower optical band gap of the materials will be required to increase the harvesting of sunlight, the materials must also be printable such that large active areas can be prepared at high speed, they must have a stable morphology once implemented in a device and finally the materials must exhibit chemical resilience to light, electrodes and atmospheric reactants such as water and oxygen.

In this work we present results obtained for large-area devices (active area $=3$ and $10 \mathrm{~cm}^{2}$ ). The geometry of the photovoltaic devices was glass/ITO/PEDOT/active layer/Al, where the active layer was either pure polymer or a blend QJ; of polymer and PCBM (bulk hetero junctions). Devices with layers of pure polymer and $\mathrm{C}_{60}$ (bilayer heterojunction) were also prepared. The devices were prepared with low band gap polymers, 1 and 2 (Scheme 1) [12]. Low band gap polymers [13] are believed to house the possibility for increasing the efficiency of the photovoltaic device, due to a better overlap with the solar spectra. As described above only one example of low band gap polymers in large-area OPV is described in the literature $[9 \mathrm{~b}]$. The synthesis and characterization of polymers 1 and 2 were described by us earlier [12]. The band gaps of 1 and 2 are 1.65 and $0.67 \mathrm{eV}$, respectively [12].

\section{Experimental}

\subsection{Photovoltaic device preparation}

Indium-tin-oxide (ITO) coated glass substrates were etched in a $10 \mathrm{~mL} 5 \%$ nitric acid, $40 \mathrm{~mL} 20 \%$ hydrochloric acid and $50 \mathrm{~mL}$ water mixture at $50^{\circ} \mathrm{C}$ for few minutes until part of the ITO was removed (see Fig. 1). The substrates were cleaned in acetone, chloroform and isopropanol in an ultrasonic bath. The substrates were then spin coated $(1500 \mathrm{rpm}, 200 \mathrm{~s})$ with a $2.7 \mu \mathrm{m}$ filtered poly(ethylene dioxythiophene) doped with polystyrene sulfonic acid (PEDOT:PSS) $1.3 \% \quad(\mathrm{wt} / \mathrm{v})$ containing $2.5 \mathrm{mg}$ sorbitol per $\mathrm{mL}$. The substrates were baked for $2 \mathrm{~h}$ at $180^{\circ} \mathrm{C}$. The polymer ( 1 or 2$)$ and PCBM were dissolved in chlorobenzene $\left(10 \mathrm{mg} \mathrm{mL}^{-1}\right)$ and spin coated onto the substrates at $1500 \mathrm{rpm}$ for $120 \mathrm{~s}$. The aluminum electrode $(\sim 150 \mathrm{~nm})$ was thermally evaporated on top of the active layer at a pressure $<5 \times 10^{-6} \mathrm{mbar}$. After cooling of the sample and removal from the vacuum chamber, the electrical contacts were applied using silverepoxy glue. The glue was thermoset at $70^{\circ} \mathrm{C}$ for $10 \mathrm{~min}$. This also anneals the active layer. A schematic view of the devices is given in Fig. 1. Further details on device preparation have been described earlier $[14,15]$. The $10 \mathrm{~cm}^{2}$ devices were encapsulated as described in the

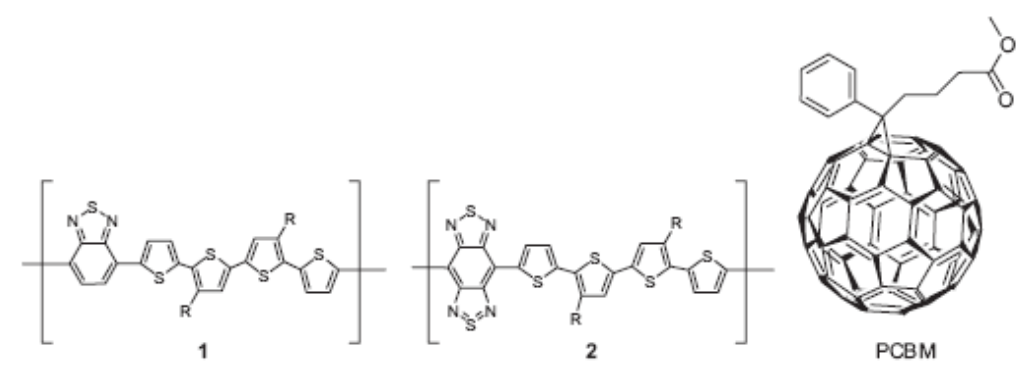

Scheme 1. Structure of polymers 1,2 [12] and PCBM.
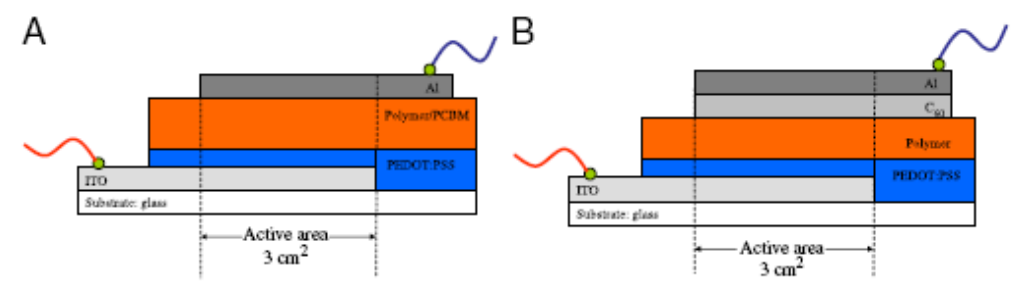

Fig. 1. Schematic side view of photovoltaic devices: (A) ITO/PEDOT/polymer:PCBM/Al and (B) ITO/PEDOT/polymer/C 6 /Al. 
literature before electrical contacts were mounted with epoxy glue [16]. A picture of this device is given in Fig. 2.

\subsection{Photovoltaic measurements}

All measurements were carried out in the ambient atmosphere. The $I-V$ curves were obtained using a Keithley 2400 source meter. The set up for the wavelength dependence of the photovoltaic response and the illuminated $I-V$ measurements were described earlier $[14,15]$. The intensity of the simulated sunlight was $\sim 1000 \mathrm{~W} \mathrm{~m}^{-2}$ and the spectral distribution was in accordance with the AM1.5 standard. The temperature of the devices during characterization was $72 \pm 2^{\circ} \mathrm{C}$

\section{Results and discussion}

Photovoltaic devices were prepared with polymers 1 and 2 and the photovoltaic responses of these devices are summarized in Table 1. $I-V$ curves of all prepared devices are given in Fig. 3.

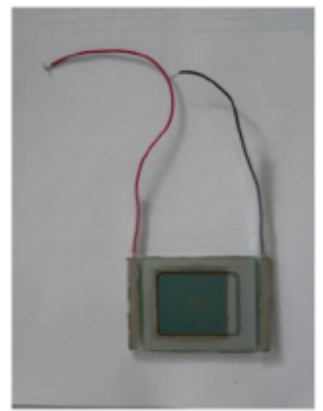

Fig. 2. Picture of the $10 \mathrm{~cm}^{-2}$ device (front view). The active are measured $3.34 \times 3.00 \mathrm{~cm}^{2}$ (outer device dimensions on the photograph are $75 \times 50 \mathrm{~mm})$.
These data show that addition of PCBM in the active layer increases the short-circuit current, $J_{\mathrm{SC}}$, and the efficiency, $\eta$, of the device as expected. In Fig. 4A it can be seen that the highest occupied molecular orbital (HOMO) and the lowest unoccupied molecular orbital (LUMO) of polymer 1 are well aligned with the electrodes (ITO and Al), PEDOT and PCBM, and hence the addition of PCBM was expected to increase $J_{\mathrm{SC}}$ and $\eta$. Larger polymer/PCBM ratio, i.e. $1: 3$ and $1: 4$, has been shown to increase the efficiency of devices prepared with MEH-PPV [10]. However, a smaller ratio has been found optimal when employing P3HT or a copolymer based on benzothiadiazole, thiophene and pyrrole in blends with PCBM $[10,13]$. In general, the optimum ratio should always be determined if the system changes [10]. Therefore, several devices were prepared with different ratios of polymer 1 and PCBM to establish the optimum amoun of PCBM in the blend. These tests showed that the ratio of polymer/PCBM $1: 1 \frac{1}{2}(\mathrm{w} / \mathrm{w})$ gave the highest $J_{\mathrm{SC}}=-2.87 \mathrm{~mA} \mathrm{~cm}^{-2}$. However, the highest $\eta=0.62 \%$ was achieved for the ratio of polymer/PCBM 1:2(w/w) (Table 1). This is a high efficiency for a low band gap polymer in a large-area OPV and thus polymer 1 is a very promising material for OPV. The open-circuit voltage, $V_{\mathrm{OC}}$, was however highest for the device with no PCBM, i.e. a ratio of 1:0 for 1:PCBM. Furthermore, the data show that the efficiency decreases when larger amounts of PCBM are added, i.e. higher ratios than $1: 2$.

From Table 1 it can be seen that for the device ITO/PEDOT/1:PCBM $(1: 2) / \mathrm{Al}$, the increase in active area from 3 to $10 \mathrm{~cm}^{2}$ results in a decrease in $J_{\mathrm{SC}}$ from -2.60 to $-1.29 \mathrm{~mA} \mathrm{~cm}^{-2}$ and a decrease in the fill factor (FF) from $39 \%$ to $28 \%$. Hence, a decrease in $\eta$ from $0.62 \%$ to $0.20 \%$ is observed with the increase in the active area. This is ascribed mainly to higher sheet resistive losses in the large-area device due to the geometry of the ITO electrode.

Comparison of the data obtained for the bulk (PCBM) and the bilayer heterojunction $\left(\mathrm{C}_{60}\right)$ with polymer 1 shows

Tabk 1

Photovoltaic response of devices with polymers 1 and 2

\begin{tabular}{|c|c|c|c|c|c|}
\hline Device & $J_{S C}\left(\mathrm{mAcm}^{-2}\right)$ & $V_{O C}(\mathrm{~V})$ & $\left|I_{\mathrm{r}} / I_{-1 \mathrm{v}}\right|$ & FF $(\%)$ & $\eta(\%)$ \\
\hline ITO/PEDOT/1/Al & $-1.22 \times 10^{-2}$ & 0.68 & 14 & 26 & 0.002 \\
\hline ITO/PEDOT/1:PCBM (1:1)/Al & -2.27 & 0.60 & 336 & 37 & 0.55 \\
\hline ITO/PEDOT/1:PCBM (1:1 $\left.\frac{1}{2}\right) / \mathrm{Al}$ & -2.87 & 0.61 & 45 & 34 & 0.61 \\
\hline ITO/PEDOT/1:PCBM (1:2)/Al & -2.60 & 0.59 & 287 & 39 & 0.62 \\
\hline ITO/PEDOT/1:PCBM (1:2-1)/Al & -2.31 & 0.58 & 229 & 32 & 0.46 \\
\hline ITO/PEDOT/1:PCBM (1:3)/Al & -1.98 & 0.58 & 336 & 38 & 0.43 \\
\hline ITO/PEDOT $/ 1 / \mathrm{C}_{60} / \mathrm{Al}$ & -0.46 & 0.29 & 57 & 23 & 0.03 \\
\hline ITO/PEDOT/1:PCBM (1:2)/Al, $10 \mathrm{~cm}^{-2}$ & -1.29 & 0.56 & 145 & 28 & 0.20 \\
\hline ITO/PEDOT/2/Al & $-8.90 \times 10^{-4}$ & 0.23 & 0.9 & - & - \\
\hline ITO/PEDOT/2:PCBM (1:1)/Al & $-7.19 \times 10^{-3}$ & 0.04 & 10 & - & - \\
\hline ITO $/ \mathrm{PEDOT} / 2 / \mathrm{C}_{60} / \mathrm{Al}$ & $-3.12 \times 10^{-4}$ & 0.13 & 0.5 & - & - \\
\hline ITO/PEDOT/1:2:PCBM/Al & -0.32 & 0.22 & 43 & - & - \\
\hline $\mathrm{ITO} / 2 / \mathrm{Au}$ & $-7.44 \times 10^{-6}$ & 0.00 & 1 & - & - \\
\hline
\end{tabular}

Measurement conditions: $\sim 1000 \mathrm{Wm}^{-2}$, AM1.5, area $\sim 3 \mathrm{~cm}^{-2}$ (unless otherwise stated). 
A

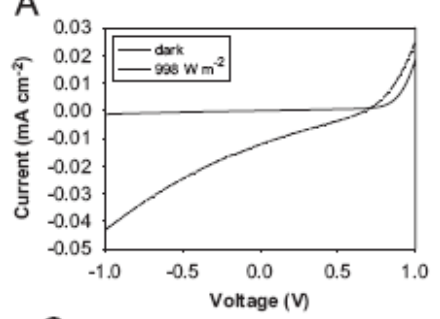

C

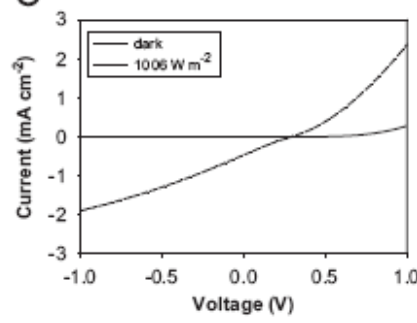

$\mathrm{E}$

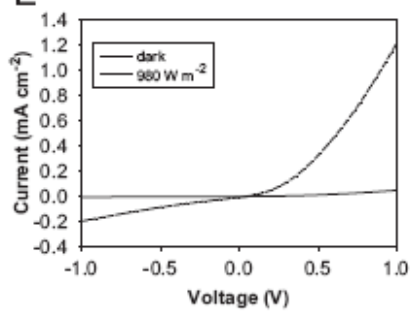

$\mathrm{G}_{30}$

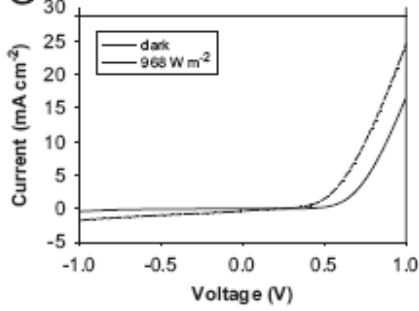

B

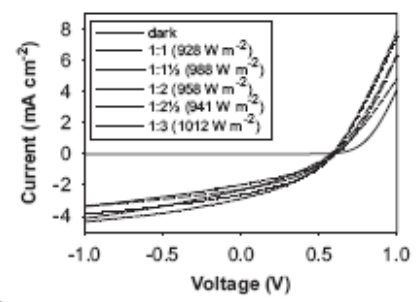

D

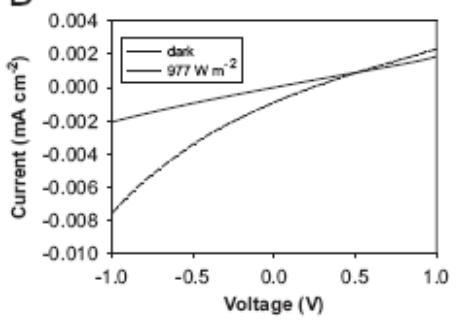

$\mathrm{F}$

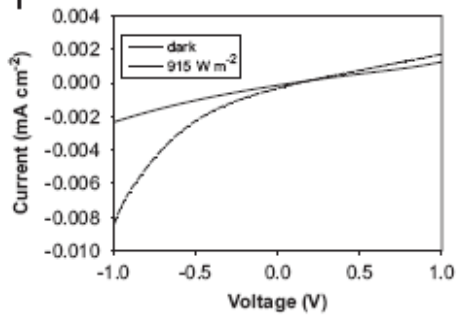

$\mathrm{H}$

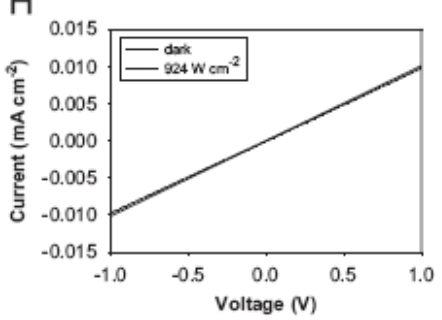

Fig. 3. $I-V$ curves for the devices: (A) ITO/PEDOT/1/Al, (B) ITO/PEDOT/1:PCBM/Al (the polymer/PCBM ratio is given in the legend), (C) ITO/ PEDOT/1/C $60 /$ Al, (D) ITO/PEDOT/2/Al, (E) ITO/PEDOT/2:PCBM (1:1)/Al, (F) ITO/PEDOT/2/C (H) $\mathrm{TTO} / 2 / \mathrm{Au}$.

that the use of PCBM increases the $J_{\mathrm{SC}}$ and the $V_{\mathrm{OC}}$ and hence the efficiency of the device. This is ascribed to the better contact between the polymer and the fullerene in a bulk heterojunction with PCBM as compared to the bilayer heterojunction with $\mathrm{C}_{60}$.

The devices produced with polymer 2 showed low $J_{\mathrm{SC}}$ and low $V_{\mathrm{OC}}$ and from the dark low rectification, it can be seen that the devices show poor diode properties. This is ascribed to the very low band gap of polymer 2, i.e. $0.67 \mathrm{eV}$, which results in a poor overlap between the LUMO of 2 and the LUMO of the PCBM and due to the low-energy level of the LUMO of 2 the reverse bias barrier for electrons is very low (Fig. 4B). In the device with gold (Fig. 4C) as the metal electrode, the electrical band structure shows a good overlap between the HOMO of 2 and the HOMO of ITO and the LUMO of 2 and the 

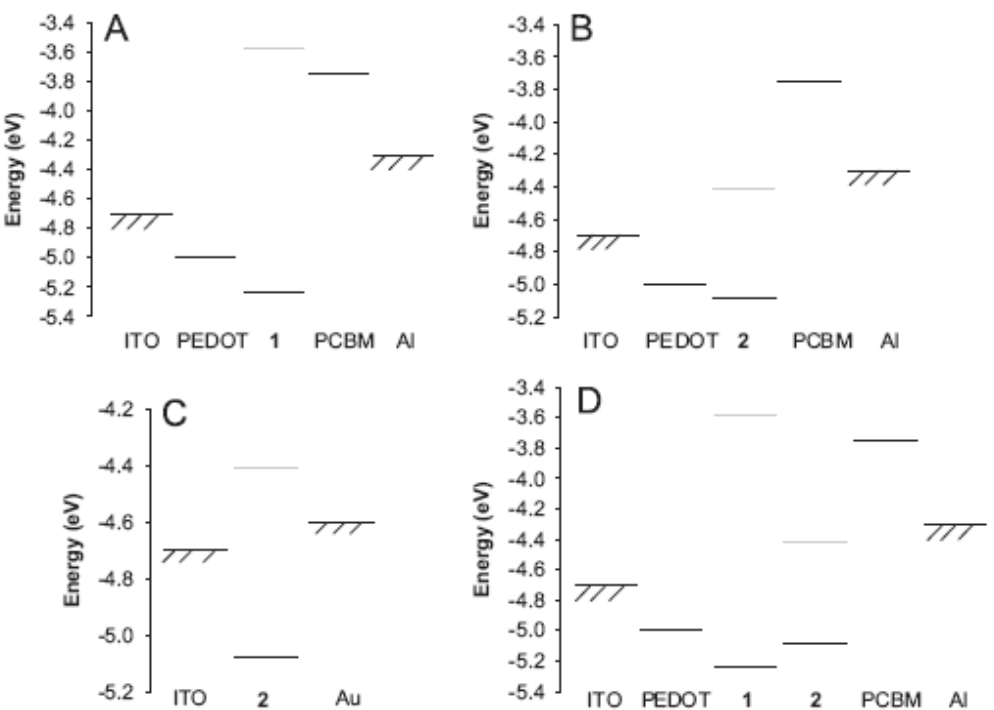

Fig. 4. Electronic structure of the devices with polymer (A) 1, (B) 2 (C) 2 with Au and (D) 1 and 2 derived from ultraviolet photoekctron spectroscopy data [12]. The HOMO and LUMO of the polymer is represented by a thick black line and a thick gray line, respectively. The LUMO of PCBM is shown as a thin black line and the HOMO of PCBM is not shown.

LUMO of Au. However, this device still shows a very poor dark rectification. This could be due to the alignment of the work function of ITO and Au and the HOMO of 2 (Fig. 4C). Thus no electrons are transferred to the LUMO of the polymer.

The device prepared based on a $1: 1(\mathrm{w} / \mathrm{w})$ mixture of polymer 1 and 2 showed low $J_{\mathrm{SC}}$ and $V_{\mathrm{OC}}$ and this device also showed poor diode properties. This is ascribed to the poor overlap of the HOMO and LUMO of polymer 1 and 2 and again the reverse bias barrier for electrons is very low (Fig. 4D). It is notable that devices based on 1 and PCBM give moderately high $V_{\mathrm{OC}}$ values. The origin of the opencircuit voltage in OPV is related to the difference between the HOMO of the donor polymer and the LUMO of the acceptor, e.g. PCBM. The alignment of the energy levels between polymer and PCBM thus becomes extremely important when aiming at optimizing the device efficiency [17]. Design rules for devices based on low band gap polymers and experience with devices prepared from low band gap polymers are relatively scarce in the literature. Recent progress with copolymers of thiophene and thienopyrazine have been reported by Campos et al [18a], and Wienk et al. [18b,18c] and Zhang et al. [19] reported copolymers of thienopyrazine, thiophene and fluorene. Campos et al. reported low values for $V_{\mathrm{OC}}$ $(0.22 \mathrm{~V})$ while both Zhang et al. and Wienk et al. consistently reported higher values (up to 0.78 and $0.77 \mathrm{~V}$, respectively). In both cases mixtures with PCBM were explored. An explanation for the discrepancy can possibly be found in the fact that Wienk et al. system- atically explored the effect of side chain substitution and used a different polymerization technique. Wienk et al. obtained values for $V_{\mathrm{OC}}$ very close to the expected values when accounting for contact losses [18c]. In our case, a moderately large $V_{\mathrm{OC}}$ of around $0.6 \mathrm{~V}$ is observed for mixtures of polymer 1 with PCBM. We, however, observe somewhat lower values for $J_{\mathrm{SC}}$, which could be ascribed to a very similar energy of the LUMO in 1 and PCBM that decreases the driving force for electron transfer. In the case of polymer $\mathbf{2}$ the LUMO level is below that of PCBM, which essentially should make polymer 2 act like an acceptor and result in poor devices when mixed with PCBM. This is indeed observed as homopolymer devices with polymer 2 on their own gives an expected low value for $V_{\mathrm{OC}}$ of $0.36 \mathrm{~V}$ and a low $J_{\mathrm{SC}}$. Devices based on mixtures with PCBM exhibit much lower $V_{\mathrm{OC}}$ and lower $J_{\mathrm{SC}}$ values than polymer 2 on its own which is probably the only example of this kind and a direct consequence of the low band gap in combination with the alignment of the electronic structure. The dark rectification is, however, better for the device based on mixtures with polymer $\mathbf{2}$ and PCBM. We ascribe this to the fact that PCBM is a good electron conductor and believe that polymer $\mathbf{2}$ is a poor electron conductor and a moderate hole conductor. By introducing PCBM the system thus exhibit marginally better rectification.

This led us to test the hypothesis by application of a sublimed layer of $\mathrm{C}_{60}$ on top of polymer 2 giving a bilayer heterojunction. The LUMO level of $\mathrm{C}_{60}$ is a little lower than PCBM but can be considered identical in this 
experiment where the $\mathrm{C}_{60}$ can be viewed as an electron transport layer. In this device the inverse rectification behavior is maintained, the current stays invariant and the $V_{\mathrm{OC}}$ is lowered by $0.1 \mathrm{~V}$ indicating that the transport properties and function is dominated by polymer 2 . Finally, we attempted a ternary mixture of polymer 1, polymer 2 and PCBM and the effect was again that results were seemingly dominated by polymer 2 but interestingly the open-circuit voltage improved to $0.22 \mathrm{~V}$. We currently have no explanation while we propose that it could be linked to the morphology of the active layer in the device where several transport channels are open and one could imagine that part of the mixture had a character of polymer 1 and PCBM that could account for the slight increase in $J_{\mathrm{SC}}$ as compared to polymer 2 on its own giving an improvement in $V_{\mathrm{OC}}$ also. Such a ternary system is too complex to conclusively account for the observed photovoltaic behavior. It does, however, underline the negative effect of polymer 2 on the photovoltaic behavior due to its poorly matching energy levels. Another important point is that as the band gap decreases for the material the correct alignment of the energy levels become increasingly important and we identify this as one of the important challenges in the field of low band gap polymer materials while techniques for energy level tuning are available [20]. This is summarized in Fig. 5 where the energy levels of a low band gap polymer along with PCBM are shown. In the ideal case, the HOMO of the polymer align with the LUMO of PCBM such that the difference, $\alpha$ (equal to $\left.V_{\mathrm{OC}}\right)$, becomes as high as possible while the difference between the LUMO of the polymer and the LUMO of PCBM, $\beta$, align for ideal charge transfer. This implies that the LUMO of the polymer always must be significantly above the LUMO of PCBM in order to have a driving force for charge separation at the expense of $V_{\mathrm{OC}}$. As the band gap becomes low this becomes increasingly important.

The wavelength dependence of the photovoltaic response showed good overlap with the absorption spectra for the device ITO/PEDOT/1:PCBM (1:2)/Al. The incident photon to current efficiency (IPCE) was found to be $18 \%$ at $560 \mathrm{~nm}$ for this device (Fig. 6), which is expected seen in the light of the moderate power conversion efficiency for

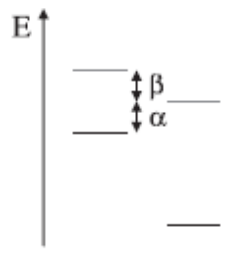

LBG PCBM

Fig. 5. An ideal alignment of the energy levels for a low band gap polymer $\left(E_{\mathrm{g}}=0.5 \mathrm{eV}\right)$ in a bulk heterojunction device with PCBM. The HOMO and LUMO of the polymer is represented by a black line and a gray line, respectively.

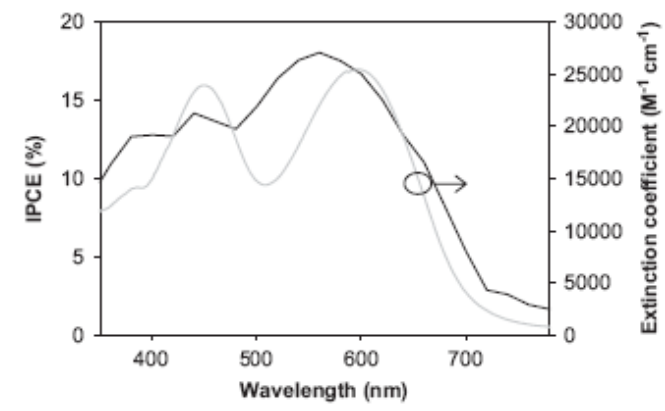

Fig. 6. IPCE curve (black) and absorption spectra (gray) for the device ITO/PEDOT/1:PCBM (1:2)/Al.

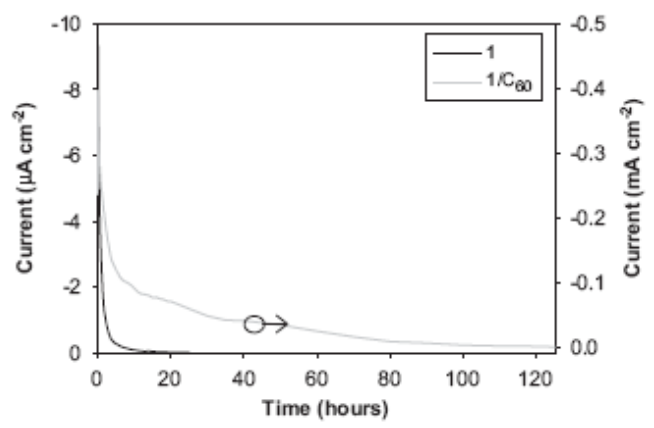

Fig. 7. Lifetime curves for the devioes ITO/PEDOT/1:PCBM (1:2)/Al and ITO/PEDOT $/ 1 / \mathrm{C}_{\text {Gol }} / \mathrm{Al}$.

the best devices. The small IPCE (1.65\%) above $700 \mathrm{~nm}$ is ascribed to a sub band gap absorption effect.

Furthermore, lifetime measurements were carried out for the devices ITO/PEDOT/1/Al and ITO/PEDOT/1/C60/Al. The lifetime curves are shown in Fig. 7. These data show a significant increase in the lifetime for the device with $\mathrm{C}_{60}$ from less than $2 \mathrm{~h}$ for ITO/PEDOT/1/Al to around $80 \mathrm{~h}$ for ITO/PEDOT $/ 1 / \mathrm{C}_{60} / \mathrm{Al}$. This is ascribed to $\mathrm{C}_{60}$ being an efficient barrier between the active layer and the aluminum electrode, which are responsible for the first decay [6a].

\section{Conclusion}

Photovoltaic devices were prepared with polymer 1 and 2 that had band gaps of 1.65 and $0.67 \mathrm{eV}$, respectively. It was found that the device ITO/PEDOT/1:PCBM (1:2)/Al gave the best photovoltaic response with a large-area $\left(3 \mathrm{~cm}^{2}\right)$ efficiency of $0.62 \%$. Devices prepared using polymer 1 were generally found to give high values for $V_{\mathrm{OC}}$ due to a good alignment of the electronic structure with respect to the electrodes and PCBM and thus 1 is a very promising material for OPV. 
Furthermore, it was found that due to the very low band gap of polymer 2, i.e. $0.67 \mathrm{eV}$, the devices prepared with this polymer (ITO/PEDOT/2/Al, ITO/PEDOT/2:PCBM/Al and $\mathrm{ITO} / \mathrm{PEDOT} / 2 / \mathrm{C}_{60} / \mathrm{Al}$ ) showed poor diode properties and low values for $J_{\mathrm{SC}}$ and $V_{\mathrm{OC}}$. In the case of polymer 2 , the much poorer performance is ascribed to a poor alignment of the electronic structure of the material with the electrodes and PCBM. The results underline the increasing need for control of the energy levels and their correct juxtaposition when the band gap decreases. Further work is in progress to improve the photovoltaic response of the prepared devices.

\section{Acknowledgments}

This work was supported by the Danish Technical Research Council (STVF 2058-03-0016) and the Danish Strategic Research Council (DSF 2104-04-0030, DSF 210405-0052).

\section{References}

[1] (a) C.J. Brabec, N.S. Sariciftci, J.C. Hummekn, Adv. Funct. Mater 11 (2001) 15;

(b) H. Spanggaard, F.C. Krebs, Sol. Energy Mater. Sol. Celk 83 (2004) 125 ;

(c) K.M. Coakley, M.D. McGehee, Chem. Mater. 16 (2004) 4533;

(d) H. Hoppe, N.S. Sariciftci, J. Mater. Res. 19 (2004) 1924;

(e) Special Issue: Sol. Energy Mater. Sol. Cells 83(2-3) (2004);

(f) Special Issue: MRS Bull. 30(1) (2005).

[2] (a) C.J. Brabec, Sol. Energy Mater. Sol. Celk 83 (2004) 273;

(b) C. Waldauf, P. Schilinsky, J. Hauch, C.J. Brabec, Thin Solid Films 451-452 (2004) 503;

(c) G. Li, V. Shr otriya, J. Huang, Y. Yao, T. Moriarty, K. Emery, Y. Yang, Nat. Mater. 4 (2005) 864;

(d) W. Ma, C. Yang, X. Gong, K. Lee, A J. Heeger, Adv. Funct. Mater. 15 (2005) 1617;

(c) M. Reyes-Reyes, K. Kim, D.L. Carroll, Appl. Phys. Lett. 87 (2005) 083506.

3] (a) F.C. Krebs, H. Spanggaard, Chem. Mater. 17 (2005) 5235;

(b) F.C. Krebs, Proc. SPIE 5938 (2005) 59380Y;

(c) E.A. Katz, S. Gevorgyan, M.S. Orynbayev, F.C. Krebs, Eur. Phys. J. Appl. Phys. 36 (2006) 307.

4] S. Schuller, P. Schilinsky, J. Hauch, C.J. Brabec, Appl. Phys. A 79 (2004) 37.

[5] (a) X. Yang, J. Loos, S.C. Veenstra, W.J.H. Verhees, M.M. Wienk, J.M. Kroon, M.A.J. Michels, R.A.J. Janssen, Nano Lett. 5 (2005) 579 ;

(b) R. de Bettignies, J. Leroy, M. Firon, C. Sentein, Synth. Metal 156 (2006) 510 .
[6] (a) F.C. Krebs, N. Cruys-Bagger, M. Andersen, M.R. Lilliedal, M.A. Hammond S. Hvidt, Sol. Energy Mater. Sol. Cells 86 (2005) 499 ;

(b) K. Norrman, F.C. Krebs, Sol. Energy Mater. Sol. Cells 90 (2006) 213.

[7] (a) S.E. Shaheen, R. Radspinner, N. Peyghambarian, G.E. Jabbour, Appl. Phys. Lett. 79 (2001) 2996;

(b) F.C. Krebs, J. Alstrup, H. Spangaard, K. Larsen, E. Kold, Sol. Energy Mater. Sol. Cells 83 (2004) 293;

(c) T. Aernouts, in: Proceedings of the1 9th European Photovoltaics Conference, June 7-11, 2004, Paris, France.;

(d) F.C. Krebs, J. Alstrup, M. Biancardo, H. Spanggard, Proc. SPIE 5938 (2005) 593804;

(e) F.C. Krebs, Refocus 6 (3) (2005) 38;

(f) F.C. Krebs, H. Spanggaard, T. Kjar, M. Biancardo, J. Aktrup, Mater. Sci. Eng. B, 2006, in press.

[8] (a) T. Aernouts, P. Vanlaeke, W. Geens, J. Poortmans, P. Heremans, S. Borghs, R. Metens, R. Andriessen, L. Leenders, Thin Solid Films 451-452 (2004) 22;

(b) B. Winther-Jensen, F.C. Krebs, Sol. Energy Mater. Sol. Cells 90 (2006) 123.

[9] (a) C.J. Brabec, F. Padinger, J.C. Hummelen, R.A.J. Janssen, N.S. Sariciftci, Synth. Metal $102(1999) 861$;

(b) M. AtIbrahim, H.K. Roht, U. Zhokhavets, G. Gobsch, S. Sensfuss, Sol. Energy Mater. Sol. Cells 85 (2005) 13.

[10] H. Hoppe, N.S. Sariciftci, J. Mater. Chem. 16 (2006) 45.

[11] S.E. Shaheen, C.J. Brabex, N.S. Sariciftci, Appl. Phys. Lett. 78 (2001) 841

[12] E. Bundgaard, F.C. Krebs, Macromolecules 39 (2006) 2823

[13] (a) C.J. Brabec, C. Winder, N.S. Sariciftci, J.C. Hummekn, A. Dhanabalan, P.A. van Hal, R.A.J. Janssen, Adv. Funct. Mater. 12 (2002) 709;

(b) A. Dhanabalan, J.K.J. van Duren, P.A. van Hal, J.L.J. van Dogen, R.A.J. Janssen, Adv. Funct. Mater. 11 (2001) 255;

(c) J.K.J. van Duren, A. Dhanabalan, P.A. van Hal, R.A.J. Janssen, Synth. Metal 121 (2001) 1587;

(d) C. Winder, N.S. Saricúftci, J. Mater. Chem. 14 (2004 1077

14] E. Bundgaard, F.C. Krebs, Pol. Bull. 55 (2005) 157

[15] F.C. Krebs, M. Jergensen, Rev. Sci. Instr. 74 (2003) 3438.

[16] F.C. Krebs, Sol. Energy Mater. Sol. Cells 90 (2006) 3633.

[17] M.C. Scharber, D. Mūhlbacher, M. Koppe, P. Denk, C. Waldauf, A.J. Heeger, C.J. Brabec, Adv. Mater. 18 (2006) 789.

[18] (a) L.M. Campos, A. Tontcheva, S. Gones, G. Sonme, H Neugebauer, N.S. Sariciftci, F. Wudl, Chem. Mater. 17 (2005) 4031

(b) M.M. Wienk, M.P. Struijk, R.A.J. Janssen, Chem. Phys. Lett. 422 (2006) 488;

(c) M.M. Wienk, M.G.R. Turbiez, M.P. Struijk, M. Fonrodona, M.M. Wienk, M.G.R. Turbiez, M.P. Struijk, M.
R.A.J. Janssen, A ppl. Phys. Lett. 88 (2006) 153511 .

[19] F. Zhang, E. Perzon, X. Wang, W. Mammo, M.R. Andersson, O. Inganâs, Adv. Funct. Mater. 15 (2005) 745.

[20] F.C. Krebs, M. Jergensen, Macromolecuks 35 (2002) 7200 


\title{
Bulk heterojunctions based on a low band gap copolymer of
}

\section{thiophene and benzothiadiazole}

\author{
Eva Bundgaard ${ }^{\mathrm{a}}$, Sean E. Shaheen ${ }^{\mathrm{b}}$, Frederik C. Krebs $^{\mathrm{a},{ }^{*}}$ and David S. Ginley ${ }^{\mathrm{b}}$ \\ ${ }^{a}$ The Danish Polymer Centre, RISØ National Laboratory, P.O. Box 49, DK-4000 Roskilde, \\ Denmark. \\ ${ }^{b}$ National Renewable Energy Laboratory, Golden, CO 80401, United States. \\ Email:fiederik.krebs@risoe.dk
}

\begin{abstract}
We report on the incorporation of a low band gap copolymer based on thiophene and benzothiadiazole with a band gap of $1.65 \mathrm{eV}$ into a bulk heterojunction device with the structure ITO/PEDOT:PSS/polymer:PCBM/Al. We have investigated the effects of process variable, including choice of solvent, polymer concentration and annealing temperature, on the photovoltaic device performance. The devices show spectral response down to the absorption edge of $1.65 \mathrm{eV}$ and exhibit an efficiency of $1 \%$ under AM1.5 illumination and a peak external quantum efficiency of $18 \%$ at $600 \mathrm{~nm}$.
\end{abstract}

Keywords: Low band gap material, polymer photovoltaic, device optimization, efficiency 


\section{Introduction}

Organic photovoltaic (OPV) devices are gaining increasing interest as efficiencies reach $5 \%$ [1] Key improvements are still needed in open circuit voltage $\left(V_{O C}\right)$, short circuit current $\left(J_{S C}\right)$ and fill factor. One of the ways to achieve higher efficiencies is to absorb more of the solar spectrum. The primary absorbers in the most efficient bulk heterojunction devices, commonly based on poly(3hexylthiophene) (P3HT), posses an optical band gap that substantially exceeds the nominally optimal $1.4 \mathrm{eV}$. Thus, there is increasing interest in developing low band gap polymers that have improved overlap between their absorption spectra and the solar spectrum in order to increase the $J_{S C}$ [2]. Models put forth by Koster et al. [3a] and Scharber et al. [3b] predict an increase in device efficiency with decreasing optical band gap. Both models predict that efficiencies exceeding $10 \%$ can be reached in OPV devices, assuming that other parameters such as band offset and charge generation and transport are optimized.

In the past decade there has been an increased emphasis on the synthesis and characterization of low band gap polymers particularly those such as polythiophene [1,4], polyisothianaphthene [5] and copolymers of thiophene, benzothiadiazole and pyrrole [2,6], for organic photovoltaic (OPV) [7] devices. In addition to the band gap, the morphology of the active layer in OPVs is critically important, strongly affecting the dissociation efficiency of excitons and the charge transport properties of the carriers $[1,2 \mathrm{a}, 8,9]$. There are different factors affecting the morphology and hence the efficiency of organic photovoltaic devices. As described by Hoppe and Sariciftci [9a] the factors which have a significant influence on the morphology are 1) the solvent used for spin coating of the polymer, 2) the nature and ratio of the polymer and fullerene, 3) the concentration of the polymer in the solution, 4) subsequent annealing of the device which induces phase separation and crystallization and 5) the structure of the polymer. However, their main focus is on the polymer MEH-PPV, and only a few examples of lower band gap polymers, e.g. polythiophene, are 
described. Efforts have been made to improve the photovoltaic responses of organic photovoltaic devices (especially using P3HT) by improving the morphology of the active layer. In 2001 Shaheen et al. [8] published bulk heterojunction devices based on MDMO-PPV with $2.5 \%$ efficiency. The choice of solvent to spin coat the polymer layer, i.e. chlorobenzene vs. toluene, proved to be important in controlling the degree of mixing of the polymer and fullerene components, as well as the domain size and charge transport properties of the blend. Lately, several groups have published results demonstrating improved efficiencies to above $5 \%$ upon thermal annealing in P3HT:PCBM blends $[1,10]$. These results show the importance of controlling the morphology in a bulk heterojunction device.

There is also an increasing effort to synthesize polymers compatible with the bulk heterojunction that have smaller band gaps and acceptable morphologies. In 2002 Brabec et al. $[2,6]$ reported an estimated $\eta=1 \%$ for device based on copolymer of thiophene, benzothiadiazole and pyrrole. However, no further improvements have been published with this polymer. Only very few details have been published on polyisothianaphthene and the use of this polymer has been limited due to its low solubility [5].

Recently, synthesis and characterization of new low band gap polymers, i.e. polythienopyrazines [11] and copolymers of dialkylfluorene and/or thiophene and benzothiadiazole or benzo-bisthiadiazole [12], have been published by this group and others. The polythienopyrazines have a band gap of about $1.20 \mathrm{eV}$ and the reported efficiency is $1.1 \%$ [11]. These new polymers are based on thiophene, i.e. a thiophene derivate such as thienopyrazine with a fused pyrazine ring on the thiophene or a copolymer with a thiophene or a fluorine in the backbone, such as copolymers of thiophene, fluorene and benzothiadiazole or benzo-bis(thiadiazole). The polymers described above are shown in Fig. 1. 


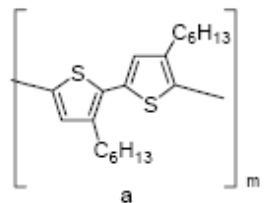

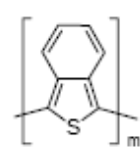

b

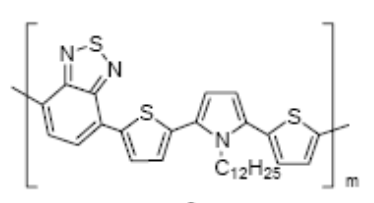

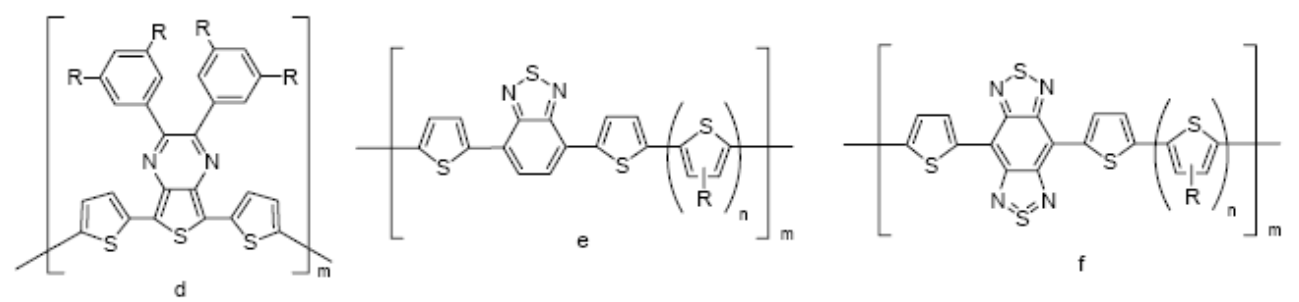

d
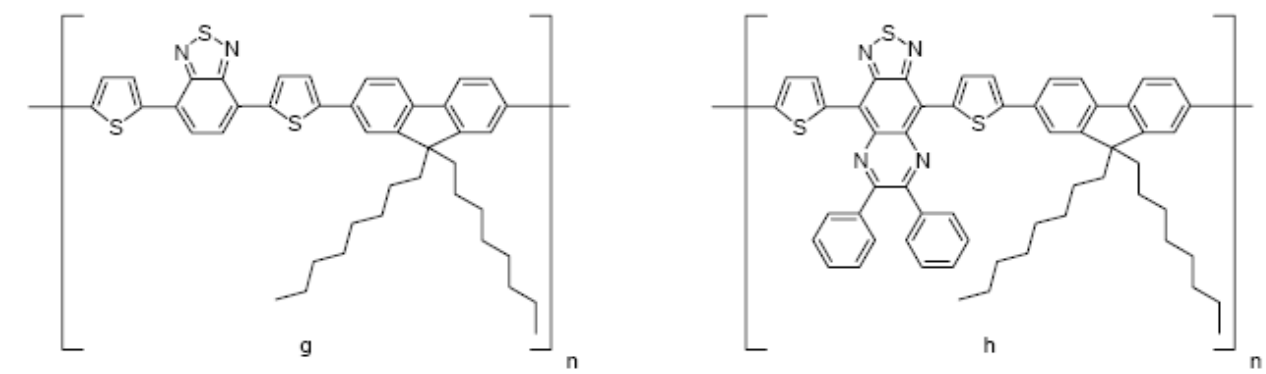

Fig. 1. Illustrates the low band gap polymers described above. a) polythiophene (here: P3HT), b) polyisothianaphthene, c) copolymers of thiophene, benzothiadiazole and pyrrole, d) polythienopyrazines (here: PTBEHT, where R $=2$ ethylhexyloxy), e) copolymers of thiophene and benzothiadiazole ( $\mathrm{R}=3,7,11$-trimethyldodecyl, $\mathrm{n}=1,2), \mathrm{f})$ copolymers of thiophene and benzo-bis-thiadiazole $(R=3,7,11$-trimethyldodecyl, $n=1,2), g)$ copolymers of thiophene, benzothiodiazole and dialkylfluorene (here: Dioctyl-PFDTBT) and h) copolymers of thiophene, dialkylfluorene and pyrazine-quinoxaline (here: APFO-7).

In this paper we describe in detail the application and dependence of efficiency on process variables for low band gap polymers based on thiophene and benzothiadiazole (Fig. 2) in a bulk heterojuncion photovoltaic cell. We discuss the relationship between morphology and efficiency for these polymers. 


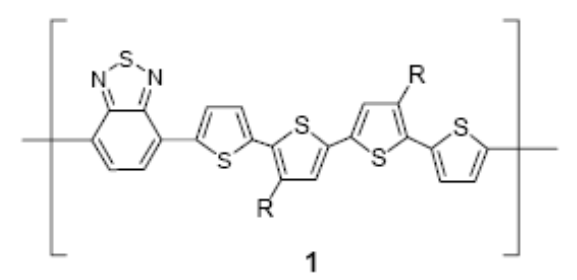

Fig. 2. Structure of polymer 1 . R=3,7,11-trimethyldodecyl.

The synthesis and characterization of polymer $\mathbf{l}$ was described previously [12c]. The band gap of polymer 1 was estimated from UV-vis to be $1.65 \mathrm{eV}$ [12c]. Details on the preparation of large area photovoltaic devices with active areas of 3 and $10 \mathrm{~cm}^{2}$ using polymer $\mathbf{l}$ have been described earlier [13]. Further, a good energy level alignment between $\mathbf{l}$ and PCBM was found and it was established that the optimal composition of $\mathbf{l}$ and PCBM is 1:2 [13]. Thus, the photovoltaic devices presented in this paper are all based on the ratio of $\mathbf{l}$ and PCBM being 1:2.

\section{Experimental}

\subsection{Device preparation.}

The polymer and PCBM was dissolved in the desired solvent to achieve the desired concentration. The solution was stirred for 12 hours at $60-70{ }^{\circ} \mathrm{C}$ and $200 \mathrm{rpm}$. Indium tin oxide (ITO) coated patterned glass slides were purified in acetone and isopropanol for $10 \mathrm{~min}$ in an ultra sound bath. The slides were purified further by oxygen plasma treatment with oxygen pressure of 0.5 Torr and $150 \mathrm{~W}$. The slides were spin coated with a $0.45 \mu \mathrm{m}$ filtered PEDOT:PSS solution at $4000 \mathrm{rpm}$ for $45 \sec (2 \times 0.25 \mathrm{~mL})$. The samples were heated to $120^{\circ} \mathrm{C}$ on a hotplate to remove excess water. The polymer solution was spin coated in a glove box $\left(<1 \mathrm{ppm} \mathrm{O}_{2}\right.$ and $\left.<1 \mathrm{ppm} \mathrm{H}_{2} \mathrm{O}\right)$ at the desired rpm. For the slow drying technique using 1,2-dichlorobenzene the sample was left to dry in a Petri dish 
for about an hour. The ITO contacts were cleaned with a razor blade. The samples were transferred to the deposition chamber and the aluminum electrode was thermally evaporated onto the substrate at a pressure of $10^{-7}$ mbar to give a $100 \mathrm{~nm}$ thick film. The samples were annealed at the desired temperature on a hot plate in the glove box.

\subsection{Photovoltaic measurements.}

The devices were tested under argon atmosphere using a Spectralab XT-10 sun simulator with AM 1.5 illumination, UV filter and intensity of $100 \mathrm{~mW} / \mathrm{cm}^{2}$. The IV curves were recorded with a Keithley 235 high current source meter. IPCE (photon to current efficiency) was measured with a calibrated Si photodiode with a spot size smaller than the device area with an incident intensity of approximately $2 \mu \mathrm{W}$. UV-vis was measured on a HP $845 \mathrm{x}$ UV-visible system. Atomic Force Microscopy (AFM) images were recorded on a Multi-Mode Scanning probe microscope with Nanoscope IV controller from Veeco. Film thicknesses were measured with AFM.

\section{Results and discussion}

The photovoltaic devices were processed such that one slide contained six smaller devices with an active area of $0.1 \mathrm{~cm}^{2}$. The six cells were tested simultaneously and the data of the best device is given in the Tables below. Further, the devices described within each Table were processed at the same time.

\subsection{Solvent and spin coating parameters}

Two different solvents (1,2-dichlorobenzene and $\mathrm{CHCl}_{3} /$ chlorobenzene (1:1)) were used for spin coating the active area of the device. The photovoltaic response was used to evaluate the effect of the solvent. The results are given in Table 1. 
Table 1. Photovoltaic response for ITO/PEDOT:PSS/1:PCBM (1:2)/A1. The active layer was spin coated from different solvents at $2000 \mathrm{rpm}$ for $10 \mathrm{sec}$. Active area $0.1 \mathrm{~cm}^{2}, \mathrm{AM} 1.5$ and $100 \mathrm{~mW} \mathrm{~cm}$.

\begin{tabular}{|c|c|c|c|c|c|}
\hline Solvent & $\begin{array}{c}\text { Thickness } \\
(\mathbf{n m})\end{array}$ & $\begin{array}{c}J_{S C} \\
\left(\mathbf{m A ~ c m}^{-2}\right)\end{array}$ & $\begin{array}{c}\text { VOC } \\
(\mathbf{V})\end{array}$ & $\begin{array}{c}\mathbf{F F} \\
(\%)\end{array}$ & $\begin{array}{c}\boldsymbol{\eta} \\
(\%)\end{array}$ \\
\hline $\mathbf{1 , 2}$-dichlorobenzene & 170 & 2.22 & 0.58 & 37 & 0.48 \\
\hline $\mathbf{C H C l}_{3} /$ chlorobenzene (1:1) & 390 & 1.49 & 0.58 & 38 & 0.33 \\
\hline
\end{tabular}

Spin coating from 1,2-dichlorobenzene resulted in a purple film when wet, which was left to dry slowly. This resulted in a dry dark-greenish film. Spin coating from $\mathrm{CHCl}_{3} /$ chlorobenzene (1:1) resulted directly in a dark-greenish dry film. The photovoltaic response shows that spin coating from 1,2-dichlorobenzene and thus the use of a slow drying method showed no difference in the $V_{O C}$. However, the slow drying method resulted in a higher $J_{S C}$ and an overall higher efficiency. To examine the different morphologies of these blends, AFM images of films of $\mathbf{1}$ on glass substrates produced from the two different solvents were taken and are shown in Fig. 3 as height, amplitude and phase, respectively.
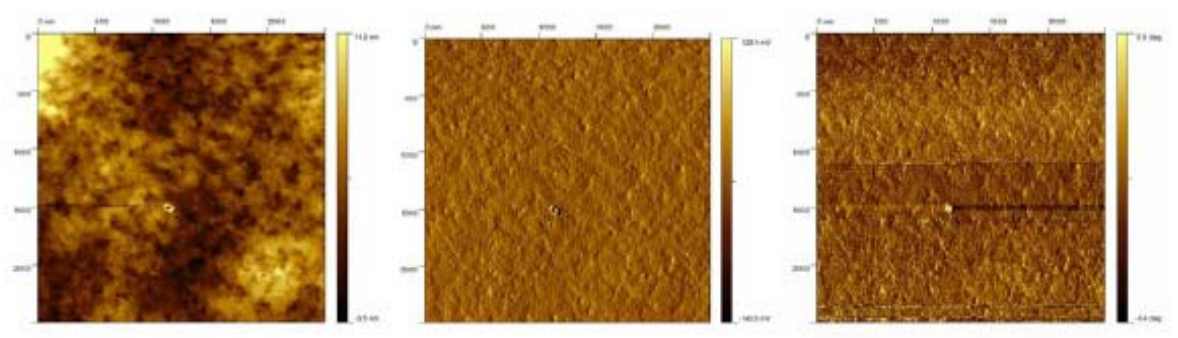

Figure 3. AFM images of 1:PCBM (1:2) in 1,2-dichlorobenzene (RMS = $2.49 \mathrm{~nm}$ ) shown as height (left), amplitude (middle) and phase (right). 
The AFM images (see also supporting information) for the pristine polymer show that the film made from 1,2-dichlorobenzene is smoother (RMS roughness $=6.32 \mathrm{~nm}$ ) than the film made from $\mathrm{CHCl}_{3}$ /chlorobenzene (1:1) (RMS roughness $=24.63 \mathrm{~nm}$ ). Further, the image for $\mathrm{CHCl}_{3} /$ chlorobenzene show a crystalline structure, which is not seen in 1,2-dichlorobenzene. Comparisons of the films processed from solutions with and without PCBM show that the films with PCBM are smoother $(\mathrm{RMS}=2.49$ and $11.76 \mathrm{~nm}$ ) (shown in figure 3 ) than the films without PCBM (RMS = 6.32 and $24.63 \mathrm{~nm}$ ). This applies for both 1,2-dichlorobenzene and $\mathrm{CHCl}_{3} /$ chlorobenzene $(1: 1)$. The film produced from 1,2 -dichlorobenzene with $\mathbf{1} / \mathrm{PCBM}$ is smoother than the film produced from $\mathrm{CHCl}_{3} /$ chlorobenzene (1:1). This may also reflect improved local order. Further, it was found that the thickness of the fast dried film (spin coated from $\mathrm{CHCl}$ /chlorobenzene (1:1)) was more then twice the thickness of the slow dried film (spin coated from 1,2-dichlorobenzene). This tendency was also found in the absorption spectra of the two films (see supporting information).

Thus, the slow drying method results in higher efficiency $(0.48 \%)$ compared to the fast drying method $(0.33 \%)$ as a consequence of improved morphology and thinner film thickness resulting in the observed increase in $J_{S C}$. Further, the crystalline structure obtained from $\mathrm{CHCl}_{3} / \mathrm{chlorobenzene}$ $(1: 1)$ is not formed when the polymer is mixed with PCBM.

Different spin coating times for the active layer from 1,2-dichlorobenzene were also investigated and the results are summarized in Table 2 . 
Table 2. Photovoltaic response of ITO/PEDOT:PSS/1:PCBM (1:2)/A1. The active layer was spin coated from 1,2dichlorobenzene at different spin time and rates. Active area $0.1 \mathrm{~cm}^{2}, \mathrm{AM} 1.5$ and $100 \mathrm{~mW} \mathrm{~cm}$.

\begin{tabular}{|c|c|c|c|c|c|}
\hline Rpm/sec & Thickness (nm) & $J_{S C}\left(\mathbf{m A ~ ~ c m ^ { - 2 } )}\right.$ & $V_{O C}(\mathbf{V})$ & FF (\%) & $\eta(\%)$ \\
\hline $\mathbf{1 0 0 0 / 3 0}$ & 300 & 2.17 & 0.53 & 36 & 0.41 \\
\hline $\mathbf{2 0 0 0 / 1 0}$ & 175 & 2.86 & 0.54 & 34 & 0.53 \\
\hline
\end{tabular}

The fast spin rate and short spin time gave a wet purple film, which was left to dry for $30 \mathrm{~min}$. to give a darker green film. The lower spin rate and longer spin time resulted directly in a greenish dry film. From the data in Table 2 it can be seen that again the slow drying method results in higher $J_{S C}$ and $V_{O C}$ and thus higher efficiency due to a thinner film.

\subsection{Concentration and film thickness}

The concentration of the polymer in the spin coating solution was investigated and the results are given in Table 3.

Table 3. Photovoltaic response of ITO/PEDOT:PSS/1:PCBM (1:2)/A1, different concentration of the polymer. Active area $0.1 \mathrm{~cm}^{2}, \mathrm{AM} 1.5$ and $100 \mathrm{~mW} \mathrm{~cm} \mathrm{c}^{-2}$

\begin{tabular}{|c|c|c|c|c|c|}
\hline $\begin{array}{c}\text { Concentration of } 1 \\
\qquad(\mathrm{mg} / \mathrm{mL})\end{array}$ & $\begin{array}{c}\text { Thickness } \\
\text { (nm) }\end{array}$ & $\begin{array}{c}J_{S C} \\
\left(\mathrm{~mA} \mathrm{~cm}{ }^{-2}\right)\end{array}$ & $\begin{array}{l}V_{O C} \\
(V)\end{array}$ & $\begin{array}{l}\text { FF } \\
(\%)\end{array}$ & $\begin{array}{c}\eta \\
(\%)\end{array}$ \\
\hline 5 & 35 & 2.08 & 0.53 & 38 & 0.42 \\
\hline 10 & 65 & 3.39 & 0.61 & 43 & 0.89 \\
\hline 15 & 120 & 3.61 & 0.62 & 40 & 0.90 \\
\hline 20 & 270 & 1.91 & 0.57 & 36 & 0.39 \\
\hline
\end{tabular}


From Table 3 it can be seen that the efficiency of the device increases from 0.42 to $0.90 \%$ when the polymer concentration is increased from 5 to $15 \mathrm{mg} / \mathrm{mL}$ and thus the thickness of the film increases from $35 \mathrm{~nm}$ to $120 \mathrm{~nm}$. However, when the polymer concentration increases even further to 20 $\mathrm{mg} / \mathrm{mL}$ and a film thickness of $270 \mathrm{~nm}$ the efficiency decreases to $0.39 \%$. This is ascribed to a significant increase in the film thickness. As described by Heeger et al. $[1 \mathrm{~b}, 16]$ the film thickness is highly important as a thick film of a polymer/PCBM blend can result in an increase of the internal resistance and hence a lower fill factor if the polymer has a low mobility. Thus, the active layer must be thin or the polymer must have a high mobility to achieve a high efficiency. Further, in a thick film (achieved for $20 \mathrm{mg} / \mathrm{mL}$ ) the light absorption may mostly be at the glass substrate whereas in a thin film (achieved for 15 and $10 \mathrm{mg} / \mathrm{mL}$ ) the light is absorbed in the whole film $[1 b, 16]$. Finally, optical interference effects could also be in play.

\subsection{Annealing temperature}

It has previously been shown by several groups in the literature that the efficiency is increased when the device is annealed thermally $[1,10,17]$. This increased the $V_{O C}$ and the $\eta$ by burning shunts and increased the $J_{S C}$ due to an enhancement of the charge carrier mobility [10]. This was ascribed to an increased crystallization of the polymer during the annealing [10]. Therefore, devices of the type ITO/PEDOT:PSS/1:PCBM (1:2)/Al were prepared and annealed at different temperatures before measuring the IV curves. The results are given in Table 4. 
Table 4. Photovoltaic response of ITO/PEDOT:PSS/1:PCBM (1:2)/Al, annealed at different temperatures for $10 \mathrm{~min}$. Active area $0.1 \mathrm{~cm}^{2}, \mathrm{AM} 1.5$ and $100 \mathrm{~mW} \mathrm{~cm}$.

\begin{tabular}{|c|c|c|c|c|}
\hline Temperature $\left({ }^{\circ} \mathbf{C}\right)$ & $J_{S C}\left(\mathbf{m A ~ \mathbf { ~ c m } ^ { - 2 } )}\right.$ & $V_{O C}(\mathrm{~V})$ & $\mathbf{F F}(\%)$ & $\boldsymbol{\eta}(\%)$ \\
\hline No annealing & 1.47 & 0.53 & 33 & 0.26 \\
\hline $\mathbf{7 5}$ & 2.86 & 0.54 & 34 & 0.53 \\
\hline $\mathbf{1 1 0}$ & 2.46 & 0.62 & 27 & 0.42 \\
\hline $\mathbf{1 3 0}$ & 2.89 & 0.64 & 42 & 0.77 \\
\hline $\mathbf{1 5 0}$ & 1.33 & 0.60 & 37 & 0.29 \\
\hline
\end{tabular}

The data in Table 4 shows that $V_{O C}$ increases slightly and that $J_{S C}$ increases significantly with annealing. The $J_{S C}$ for the device annealed at $150{ }^{\circ} \mathrm{C}$ is, however, very low $\left(J_{S C}=1.33 \mathrm{~mA} \mathrm{~cm}\right.$ ) and it is lower then the $J_{S C}$ for the device which has not been annealed $\left(J_{S C}=1.47 \mathrm{~mA} \mathrm{~cm}{ }^{-2}\right)$. The annealing temperature, which results in the highest efficiency, is between 110 and $130{ }^{\circ} \mathrm{C}$. The increase in efficiency seen here is presumably due to increased exciton dissociation, improved carrier mobilities, or both, in the device. AFM images of the polymer film on glass slides annealed at different temperatures were made (Fig. 4 and Supporting Information). The AFM image of the device with no annealing is shown in Fig. 3.
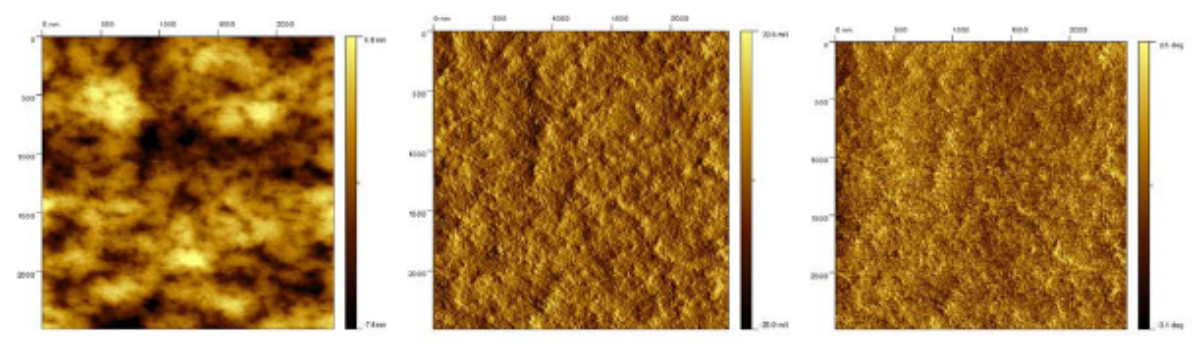

Fig. 4. AFM images of 1:PCBM 1:2 in 1,2-di-chlorobenzene annealed at $130^{\circ} \mathrm{C}(\mathrm{RMS}=4.77 \mathrm{~nm})$ shown as height (left), amplitude (middle) and phase (right) 
Fig. 3 and 4 show no significant improvement of the morphology of the film when the device is annealed at $75-130{ }^{\circ} \mathrm{C}$ (see also supporting information). However, the film annealed at $150{ }^{\circ} \mathrm{C}$ (RMS $=0.98 \mathrm{~nm}$ ) is smoother then the film which was not annealed (RMS $=2.49 \mathrm{~nm}$ ) and the films annealed at $75^{\circ} \mathrm{C}(\mathrm{RMS}=3.46 \mathrm{~nm}), 110^{\circ} \mathrm{C}(\mathrm{RMS}=1.59 \mathrm{~nm})$ and $130^{\circ} \mathrm{C}(\mathrm{RMS}=4.77 \mathrm{~nm})$. Increased phase separation is observed in the $150{ }^{\circ} \mathrm{C}$ case, which could result in improved $J_{S C}$ and efficiency as has been observed for PCBM in bulk heterojunction devices with P3HT [1c]. However, since this is not observed it may be that the phase segregation has become too extensive and thus having a negative effect on exciton dissociation.

\subsection{The best device}

The best photovoltaic response was obtained for ITO/PEDOT:PSS/1:PCBM (1:2)/Al spin coated from 1,2-dichlorobenzene at $2000 \mathrm{rpm}$ for $10 \mathrm{sec}$, dried to achieve a dark green film, evaporated with $\mathrm{Al}$ and annealed at $110{ }^{\circ} \mathrm{C}$ for $10 \mathrm{~min}$. . This device showed the following photovoltaic responses under $100 \mathrm{~mW} \mathrm{~cm}^{-2}: J_{S C}=3.59 \mathrm{~mA} \mathrm{~cm}{ }^{-2}, V_{O C}=0.61 \mathrm{~V}, \mathrm{FF}=46 \%$ and $\eta=1.0 \%$ (Fig. 5). Further, IPCE of $15 \%$ at $600 \mathrm{~nm}$ was obtained for this device (Fig. 7).

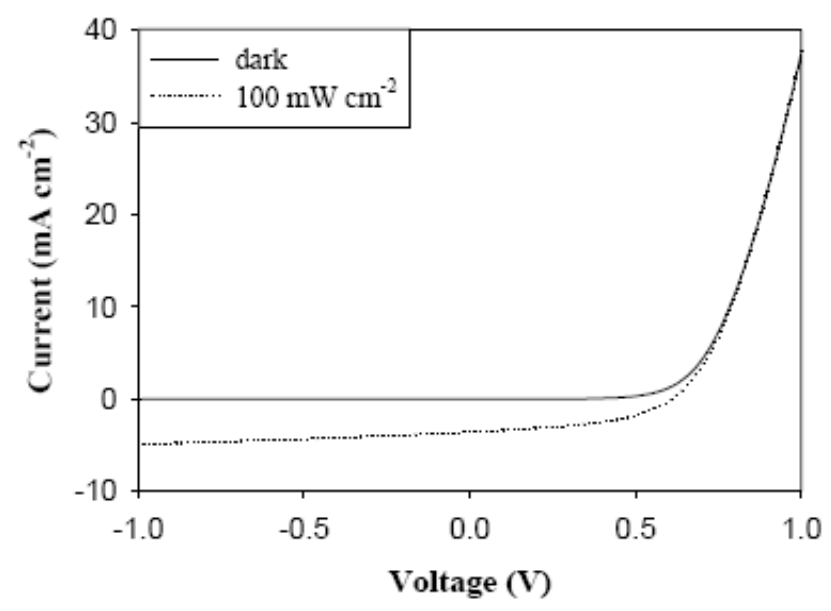

Fig. 5. IV curve for the best device. 
The efficiency of this device was measured as a function of the light intensity and the data is summarized in Fig. 6. The IV curves for these measurements are given in Supporting Information.

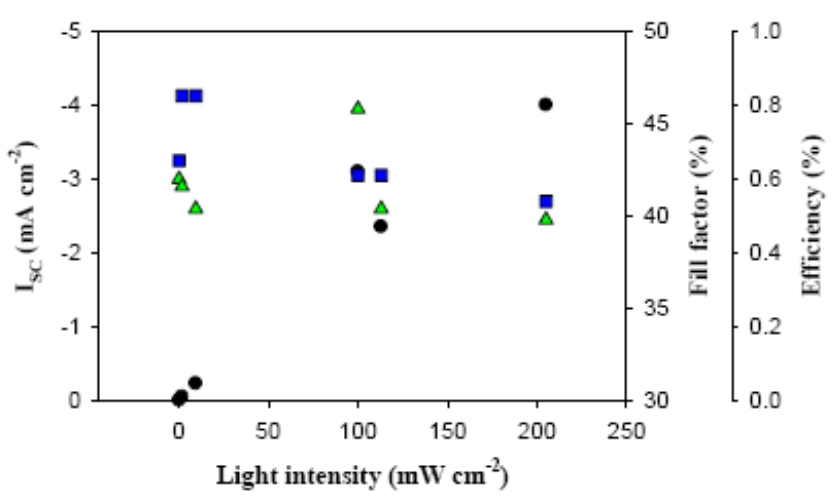

Figure 6. $J_{S C}$ (black circle)), FF (blue square) and efficiency (green triangle) as a function of light intensity for ITO/PEDOT:PSS/1:PCBM (1:2)/A1.

From Fig. 6 it can be seen that the $J_{S C}$ and efficiency are dependent on the light intensity. Further, it is seen that the $J_{S C}$ of the device increases almost linearly with the light intensity. The efficiency of the device increases almost linearly with the light intensity from 0.1 to $100 \mathrm{~mW} \mathrm{~cm}^{-2}(0.59-0.79$ $\%)$ then decreases significantly with the light intensity. The efficiency at $113 \mathrm{~mW} \mathrm{~cm}^{-2}(0.52 \%)$ is due to low $J_{S C}$.

\subsection{Incident Photon to Current Efficiency (IPCE)}

The IPCE was determined from the wavelength scan of the device ITO/PEDOT:PSS/1:PCBM (1:2)/Al prepared under different conditions. The IPCE and UV-vis for the best device is given in Fig. 7. 


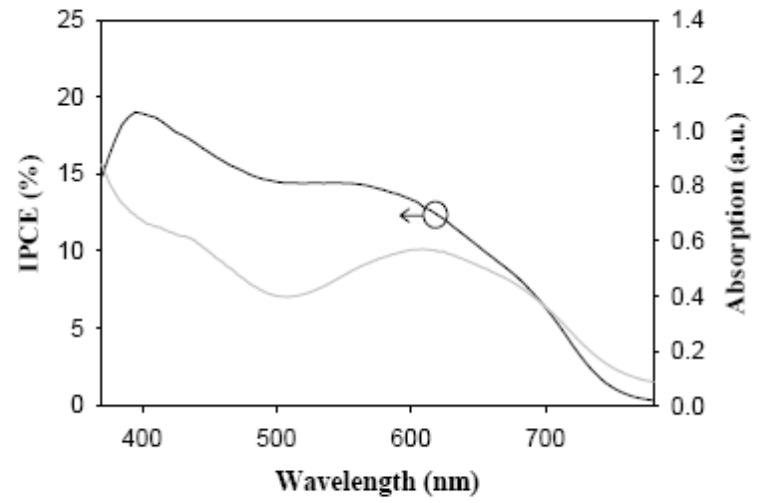

Figure 7. IPCE and UV-vis absorption spectra for the best device.

The IPCE values as a function of concentration and annealing temperature are summarized in Fig.

8. The IPCE for the different devices are given in the Supporting Information.

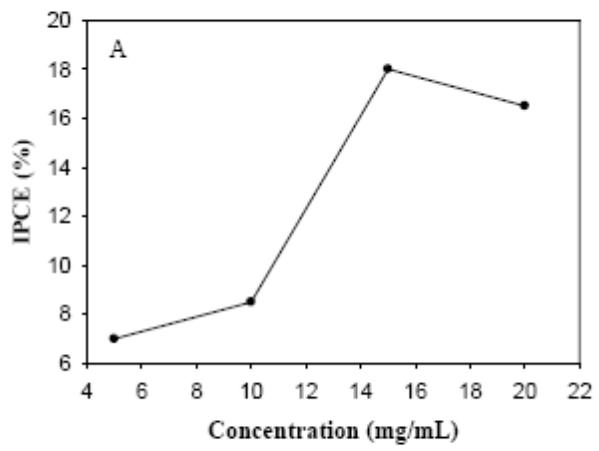




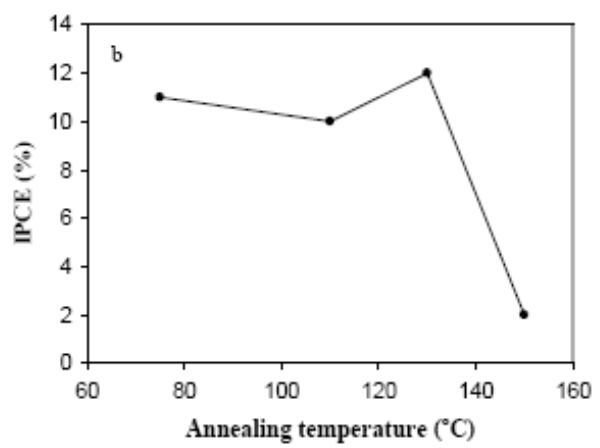

Figure 8. IPCE as a function of a) concentration and b) annealing temperature. All IPCE values are the maximum at $600 \mathrm{~nm}$.

The measurements show that the photoresponse corresponds well with the absorption spectrum of the polymer. The data also shows that the concentration and annealing temperature have a significant effect on the IPCE. The same effect on IPCE is observed for the devices prepared with different concentrations. That is; an increase in IPCE when the concentration increases from 5 to 15 $\mathrm{mg} / \mathrm{mL}$ and a decrease in IPCE when the concentration increases even further to $20 \mathrm{mg} / \mathrm{mL}$ (Fig. 8a). For the devices annealed at different temperatures (Fig. 8b), the data shows that IPCE decreases slightly with an increase in temperature from 75 to $110^{\circ} \mathrm{C}$ and then increases again to a maximum for the device annealed at $130^{\circ} \mathrm{C}$. The IPCE then decreases significantly to the lowest IPCE for the device annealed at $150^{\circ} \mathrm{C}$

However, the highest IPCE $=18 \%$ at $600 \mathrm{~nm}$ was obtained for the device with a concentration of 15 $\mathrm{mg} / \mathrm{mL}$ annealed at $110^{\circ} \mathrm{C}$.

\section{Conclusion}

Several different conditions were described for the fabrication of the device ITO/PEDOT:PSS/1:PCBM (1:2)/A1. It was found that the morphology and photovoltaic response 
was clearly affected by the choice of solvent, the concentration and the annealing temperature of the device. We found that mixtures of $\mathbf{1}$ and PCBM exhibit thermal annealing behavior with an optimum annealing temperature of $130{ }^{\circ} \mathrm{C}$. The observed thermal annealing behavior has been similarly reported for P3HT:PCBM mixtures. The best device showed the following photovoltaic responses under $100 \mathrm{~mW} \mathrm{~cm}{ }^{-2}: J_{S C}=3.59 \mathrm{~mA} \mathrm{~cm}^{-2}, V_{O C}=0.61 \mathrm{~V}, \mathrm{FF}=46 \%$ and $\eta=1.0 \%$. The highest IPCE of $18 \%$ at $600 \mathrm{~nm}$ was obtained for concentration of $15 \mathrm{mg} / \mathrm{mL}$ and an annealing temperature of $110^{\circ} \mathrm{C}$. The power conversion efficiency of $1 \%$ is comparable in magnitude to the best of the low band gap materials available and the IPCE values obtained are high over a large spectral range.

\section{Acknowledgement}

Dr. Jao van da Langemaat is gratefully acknowledged for the AFM images. This work was supported by the Danish Technical Research Council (STVF 2058-03-0016) and the Danish Strategic Research Council (DSF 2104-04-0030).

Supporting Information Available: Absorbance spectra, AFM images, IV and IPCE curves of the photovoltaic devices.

\section{References}

(1) a) G. Li, V. Sharotriya, J. Huang, Y. Yao, T. Moriarty, K. Emery, Y. Yang, Nature Mater. 4 (2005) 864-868. b) W. Ma, C. Yang, X. Gong, K. Lee, A. J. Heeger, Adv. Funct. Mater. 15 (2005) 1617-1622. c) M. Reyes-Ryes, K. Kim, J. Dewald, R. López-Sandoval, A. Avadhanula, S. Curran, D. L. Carroll, Org. Lett. 7 (2005) 5749-5752. 
(2) a) C. J. Brabec, C. Winder, N. S. Sariciftci, J. C. Hummelen, A. Dhanabalan, P. A. van Hal, R. A. J. Janssen, Adv. Funct. Mater. 12 (2002) 709-712. b) A. Dhanabalan, J. K. J. van Duren, P. A. van Hal, J.L. J. van Dogen, R. A. J. Janssen, Adv. Funct. Mater. 11 (2001) 255262.

(3) a) L. J. A. Koster, V. D. Mihailetchi, P. W. M. Blom, Appl. Phys. Lett. 88 (2006) 093511. b) M. C. Scharber, D. Mühlbacher, M. Koppe, P. Denk, C. Waldauf, A. J. Heeger, C. J. Brabec, Adv. Mater. 18 (2006) 789-794.

(4) a) J. Roncali, Chem. Rev. 97 (1997) 173-205. b) R. D. McCullough, Adv. Mater. 10 (1998) 93-116. c) M. R. Andersson, O. Thomas, W. Mammo, M. Svensson, M. Theander, O. Inganäs, J. Mater. Chem. 9 (1999) 1933-1940.

(5) a) R. H. L. Kiebooms, H. Goto, K. Akagi, Macromolecules 34 (2001) 7989-7998. b) F. Wud1, M. Kobayashi, A. J. Heeger, J. Org. Chem. 49 (1984) 3382-3384. c) A. Heckens, M. Knipper, I. Polec, J. Manca, L. Lutzen, D. Vanderzande, Thin Solid Films 451-452 (2004) 572-579. d) L. Goris, M. A. Loi, A. Cravino, H. Neugebauer, N. S. Sariciftci, I. Polec, L. Lutsen, E. Andries, J. Manca, L. De Schepper, D. Vanderzande, Synth. Met. 138 (2003) $249-253$.

(6) a) J. K. J. van Duren, A. Dhanabalan, P. A. van Hal, R. A. J. Janssen, Synth. Met. 121 (2001) 1587-1588. b) A. Dhanabalan, P. A. van Hal, J. K. J. van Duren, J. L. J. van Dogen, R. A. J. Janssen, Synth. Met. 119 (2001) 169-170. c) C. Winder, N. S. Sariciftci, J. Mater. Chem. 14 (2004) 1077-1086.

(7) a) C. J. Brabec, N. S. Sariciftci, J. C. Hummelen, Adv. Funct. Mater. 11 (2001) 15-26. b) H. Spangggard, F. C. Krebs, Sol. Energy Mater. Sol. Cells 83 (2004) 125-146. c) K. M. Coakley, M. D. McGehee, Chem. Mater. 16 (2004) 4533-4542. d) H. Hoppe, N. S. Sariciftci, J. Mater. Res. 19 (2004) 1924-1945. e) Special Issue: The development of 
Organic and Polymer Photovoltaics., Sol. Energy Mater. Sol. Cells 83 (2004) issues 2-3. f) Special Issue: Organic-Based Photovoltaics., MRS Bull. 30 (2005) issue 1. g) F. C. Krebs, H. Spanggaard, Chem. Mater. 17 (2005) 5235-5237.

(8) S. E. Shaheen, C. J. Brabec, N. S. Sariciftci, F. Padinger, T. Fromherz, J. C. Hummelen, Appl. Phys. Lett. 78 (2001) 841-843

(9) a) H. Hoppe, N. S. Sariciftci, J. Mater. Chem. 16 (2006) 45-61. b) J. Lui, Y. Shi, Y. Yang, Adv. Funct. Mater. 11 (2001) 420-424.

(10) F. Padinger, R. S. Rittberger, N. S. Sariciftci, Adv. Func. Mater. 13 (2003) 85-88.

(11) M. M. Wienk, M. G. R. Turbiez, M. P. Struijk, M. Fonrodona, R. A. J. Janssen, Appl. Phys. Lett. 88 (2006) $1535111-3$.

(12) a) M. Svensson, F. Zhang, S. C. Veenstra, V. J. H. Verhees, J. C. Hummelen, J. M. Kroon, O. Inganäs, M. R. Andersson, Adv. Mater. 15 (2003) 988-991. b) M. X. Chen, E. Perzon, N. Robinson, S. K. M. Jönsson, M. R. Anderson, M. Fahlman, M. Berggren, Synth. Met. 146 (2004) 233-236. c) E. Bundgaard, F. C. Krebs, Macromolecules 39 (2006) 2823-2831.

(13) E. Bundgaard, F. C. Krebs, Sol. Mater. Energy Sol. Cells (2007), accepted.

(14) a) P. Schilinsky, U. Asawapirom, U. Scherf, M. Biele, C. J. Brabec, Chem. Mater. 17 (2005) 2175-2180. b) R. J. Kline, M. D. McGehee, E. N. Kadnikova, J. Liu, J. M. J. Fréchet, M. F. Toney, Macromolecules 38 (2005) 3312-3319. c) A. J. Mozer, N. S. Sariciftci, A. Pivrikas, R. Österbacka, G. Juška, L. Brassat, H. Bässler, Phys. Rev. B 71 (2005) 035214 1-9. d) M. Trznadel, A. Pron, M. Zagorska, R. Chrzaszcz, J. Pielichowski, Macromolecules 31 (1998) $5051-5058$

(15) S. Guillerez, R. de Bettignies, European Conference on Hybrid and Organic Solar Cells, ECHOS'06, June 28-30, 2006, Paris, France, abstract number 28-O1-3. 
(16) J. Y. Kim, S. H. Kim, H.-H. Lee, K. Lee, W. Ma, X. Gong, A. J. Heeger, Adv. Mater. 18 (2006) $572-576$.

(17) X. Yang, J. Loos, S. C. Veenstra, W. J. H. Verhees, M. M. Wienk, J. M. Kroon, M. A. J. Michels, R. A. J. Janssen, Nano Lett. 5 (2005) 579-583. 


\section{Supporting Information}

Bulk heterojunctions based on a low band gap copolymer of thiophene and benzothiadiazole

Eva Bundgaard, Sean Shaheen, Frederik C. Krebs* and David Ginley

e-mail: frederik.krebs@risoe.dk 
Absorbance spectra
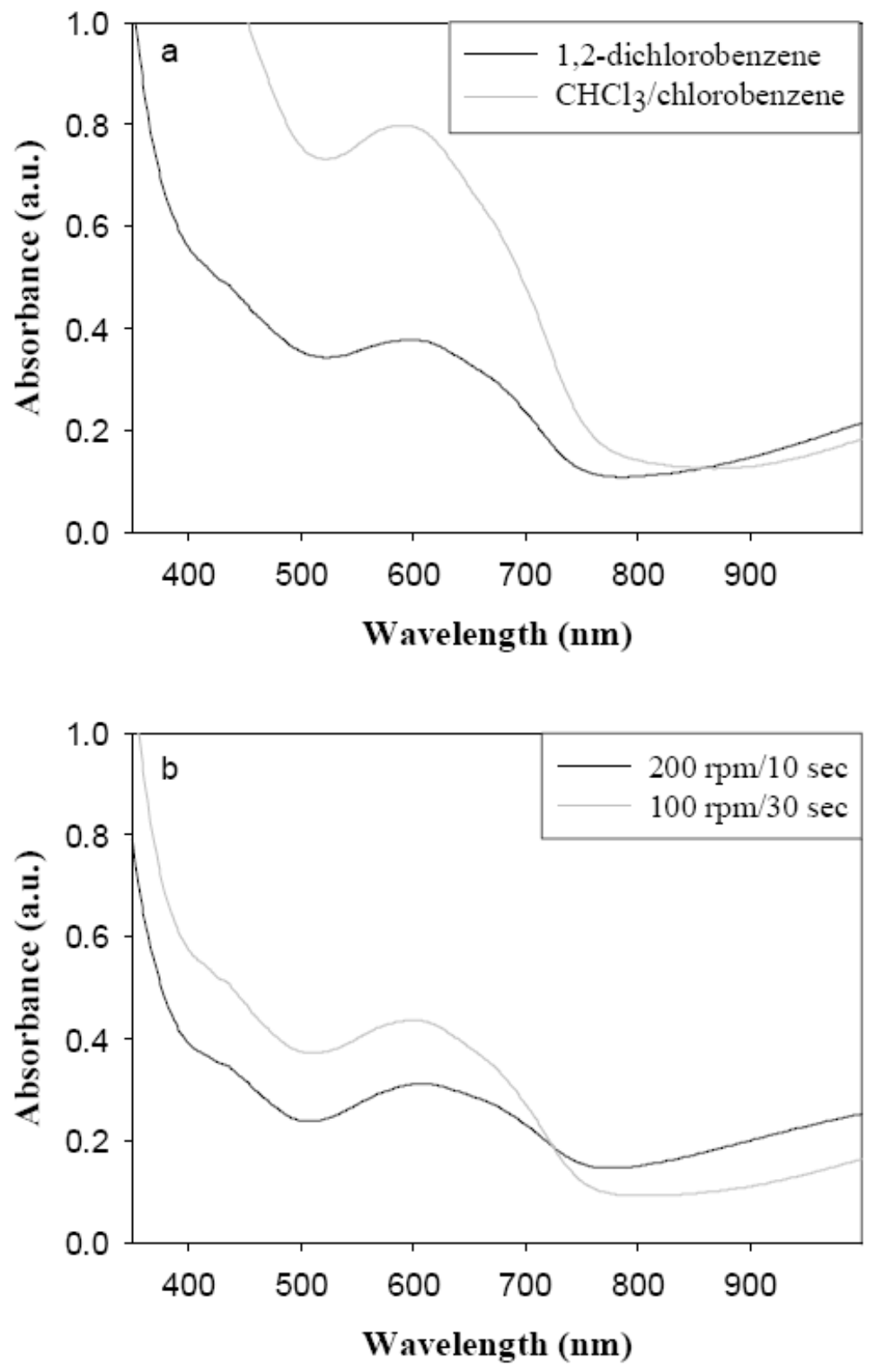

2 
A2.5

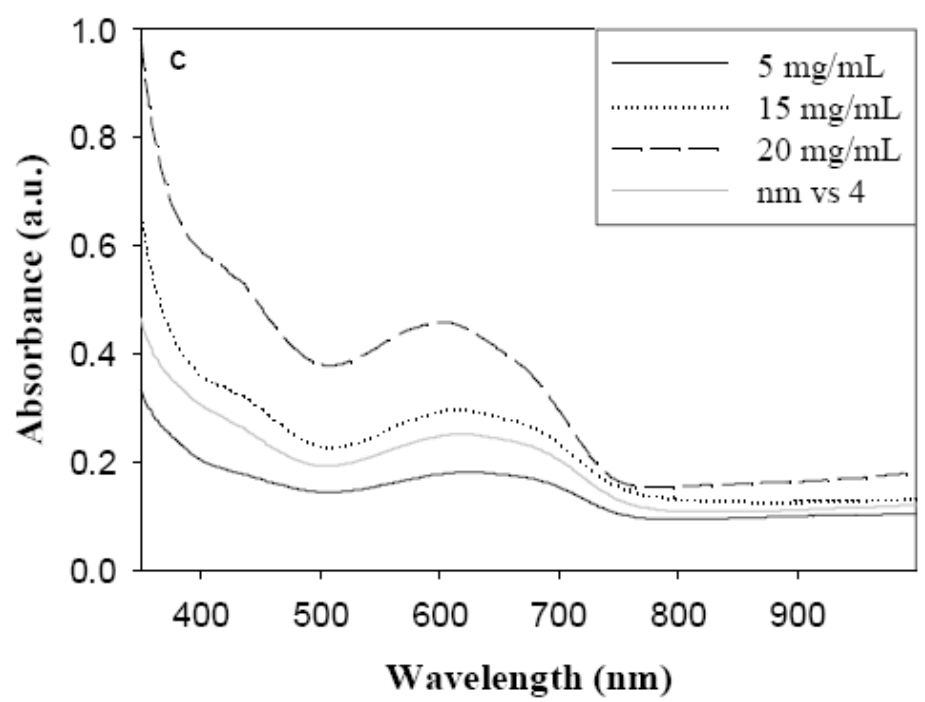

Figure S1. Absorbance spectra for ITO/PEDOT:PSS/1:PCBM (1:2)/Al obtained under the following conditions: a) solvent, b) spin time and rate and c) concentration of 1 . 


\section{AFM images}

a):
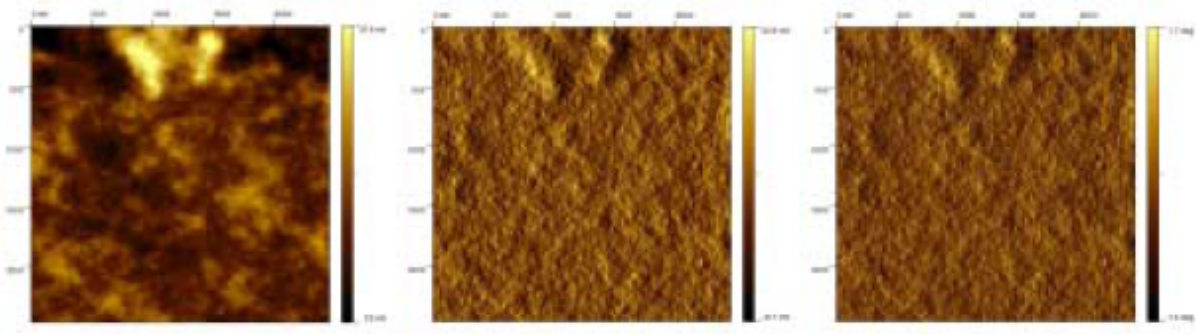

b):
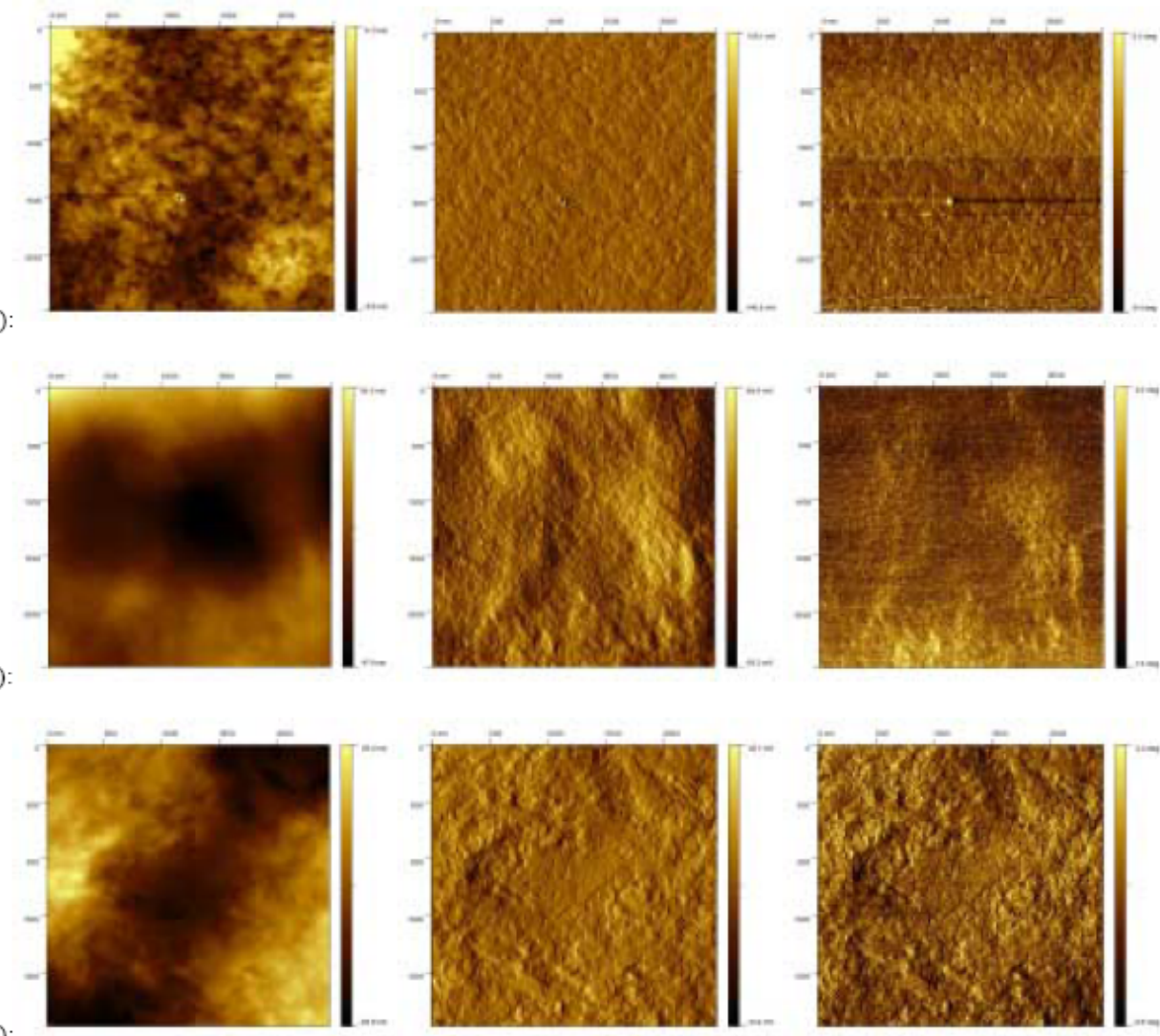

Figure S2. AFM images of a) 1 in 1,2-di-chlorobenzene (RMS = 6.32 nm), b) 1:PCBM (1:2) in 1,2-dichlorobenzene (RMS

$=2.49 \mathrm{~nm}), \mathrm{c}) 1 \mathrm{in} \mathrm{CHCl}_{3} /$ chlorobenzene $(\mathrm{RMS}=24.63 \mathrm{~nm})$ and $\left.\mathrm{d}\right) 1: \mathrm{PCBM}(1: 2)$ in $\mathrm{CHCl}_{3} / \mathrm{chlorobenzene}(\mathrm{RMS}=11.76$ nm) shown as height (left), amplitude (middle) and phase (right). 
a):
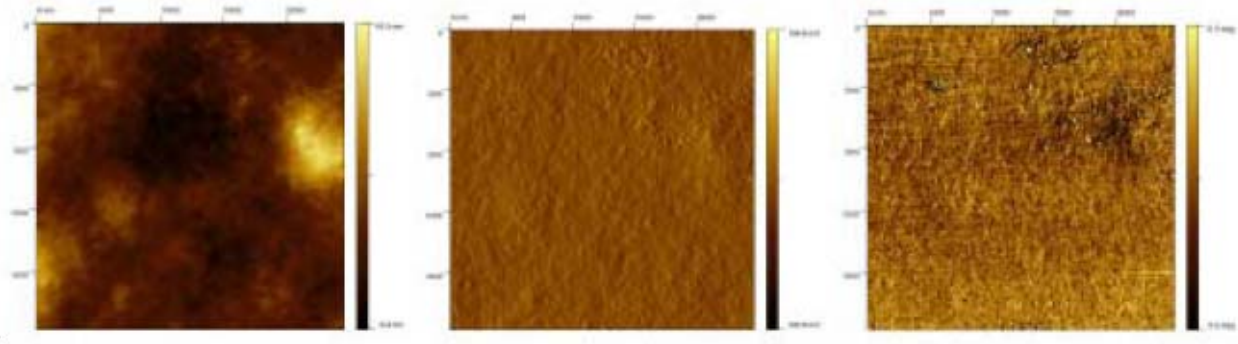

b):
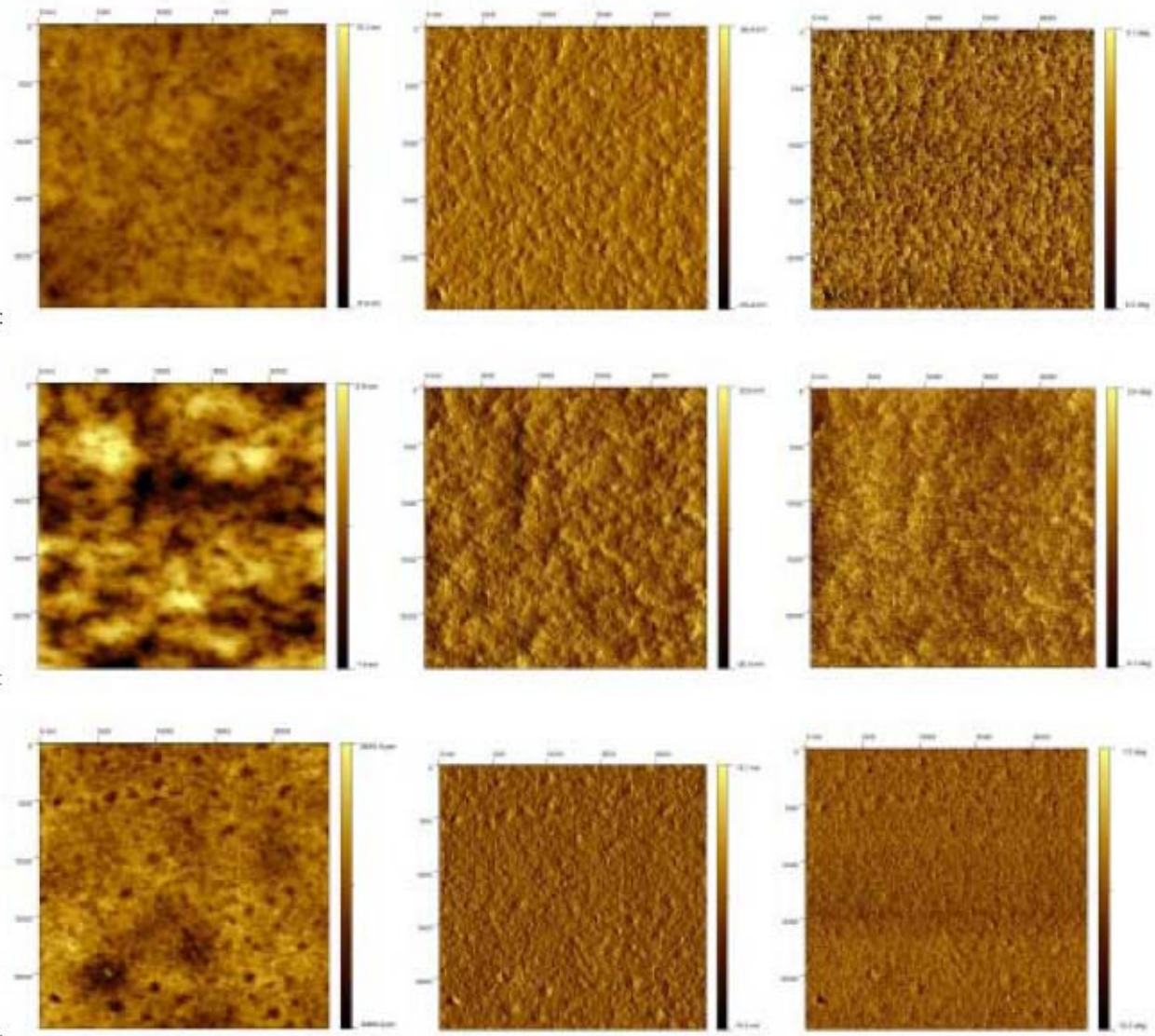

d):

Figure S3. AFM images of 1:PCBM 1:2 in 1,2-di-chlorobenzene annealed at a) $75^{\circ} \mathrm{C}(\mathrm{RMS}=3.46 \mathrm{~nm})$, b) $110^{\circ} \mathrm{C}(\mathrm{RMS}=$ $1.59 \mathrm{~nm}), \mathrm{c}) 130^{\circ} \mathrm{C}(\mathrm{RMS}=4.77 \mathrm{~nm})$ and $\left.\mathrm{d}\right) 150^{\circ} \mathrm{C}(\mathrm{RMS}=0.98 \mathrm{~nm})$ shown as height (left), amplitude (middle) and phase (right). 
Photovoltaic response measurements

IV curves
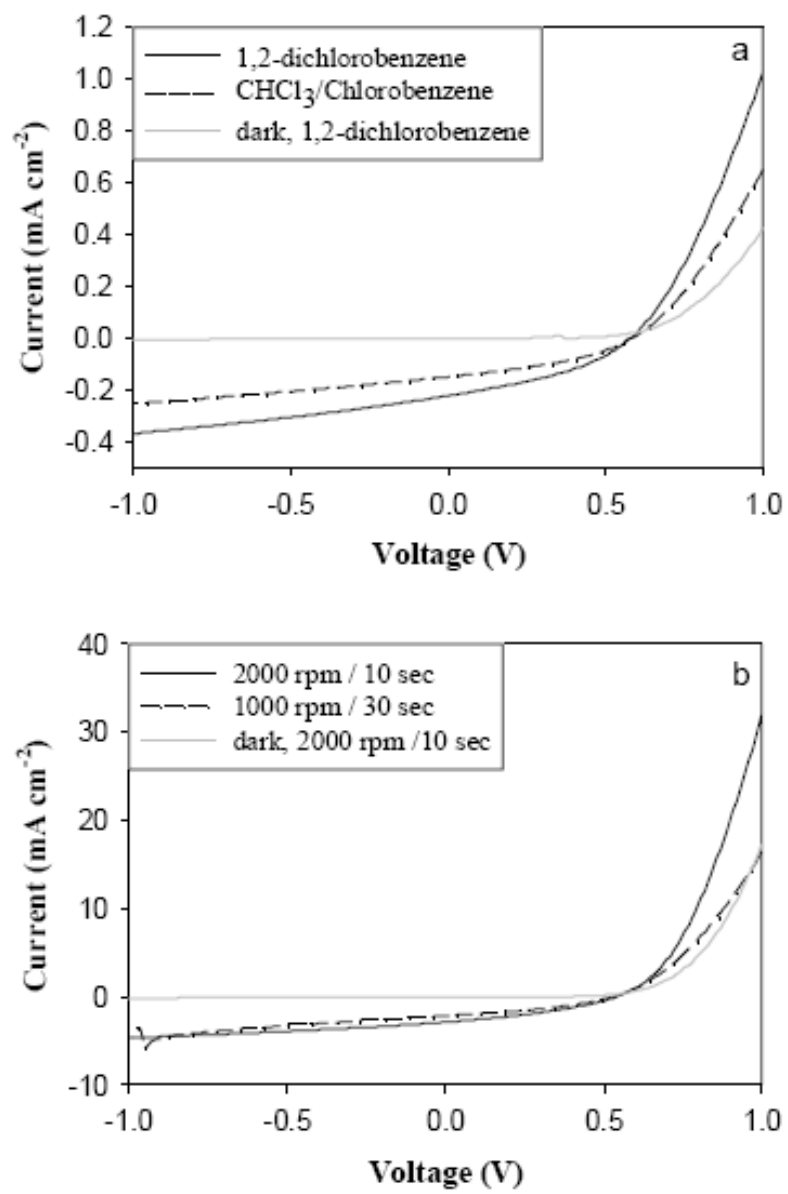

6 

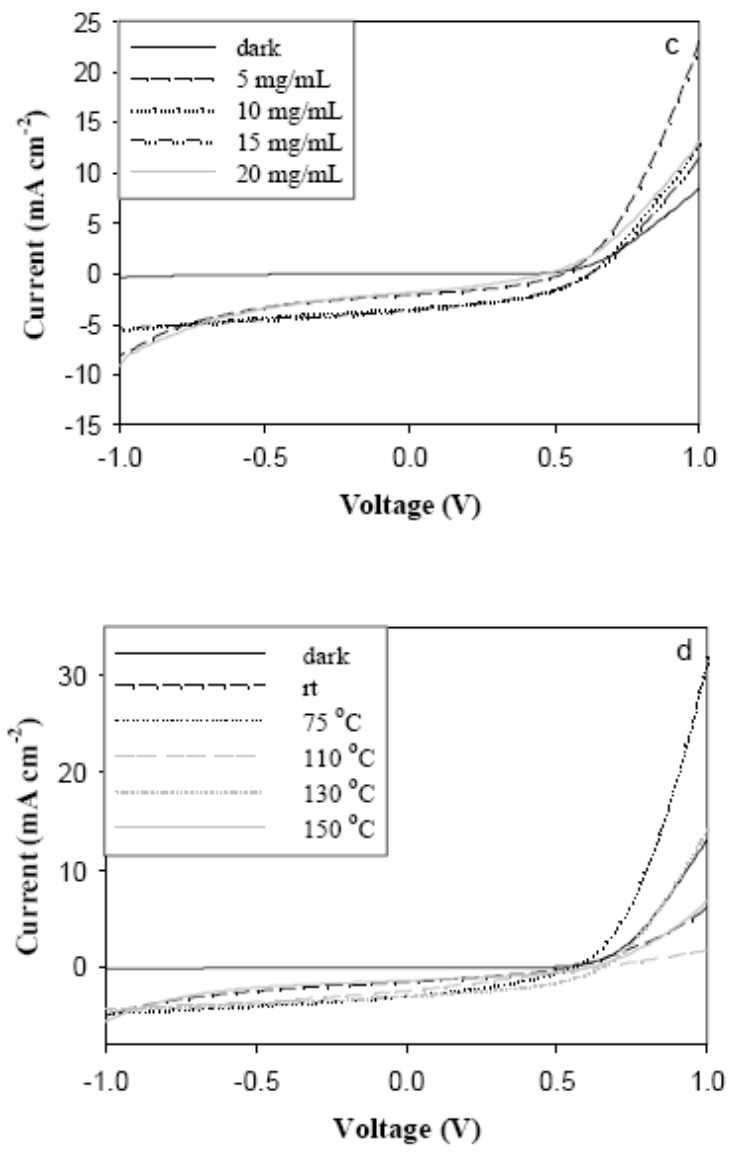

Figure S4. IV curves for ITO/PEDOT:PSS/1:PCBM (1:2)/Al obtained under the following conditions: a) solvent, b) spin time and rate, c) concentration of $\mathbf{l}$ and d) annealing temperature. 


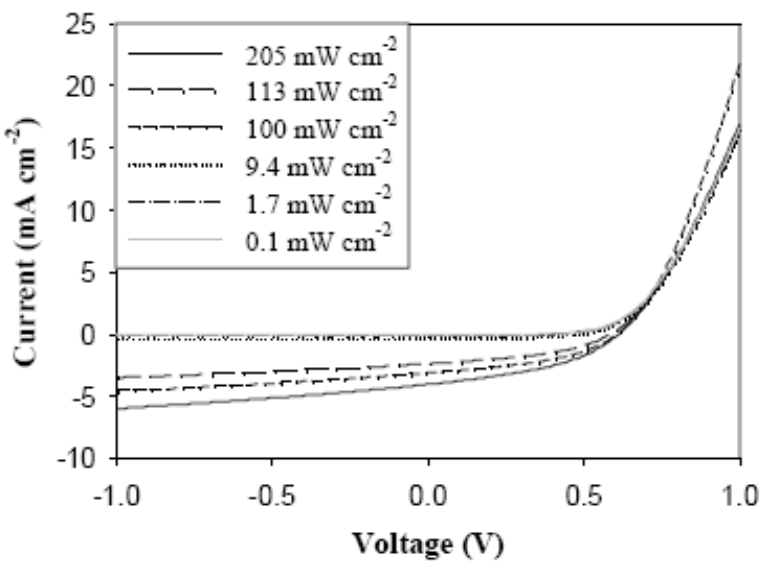

Figure S5. IV curves for ITO/PEDOT:PSS/1:PCBM (1:2)/A1 measured as a function of light intensity. 
Incident Photon to Current Efficiency (IPCE)
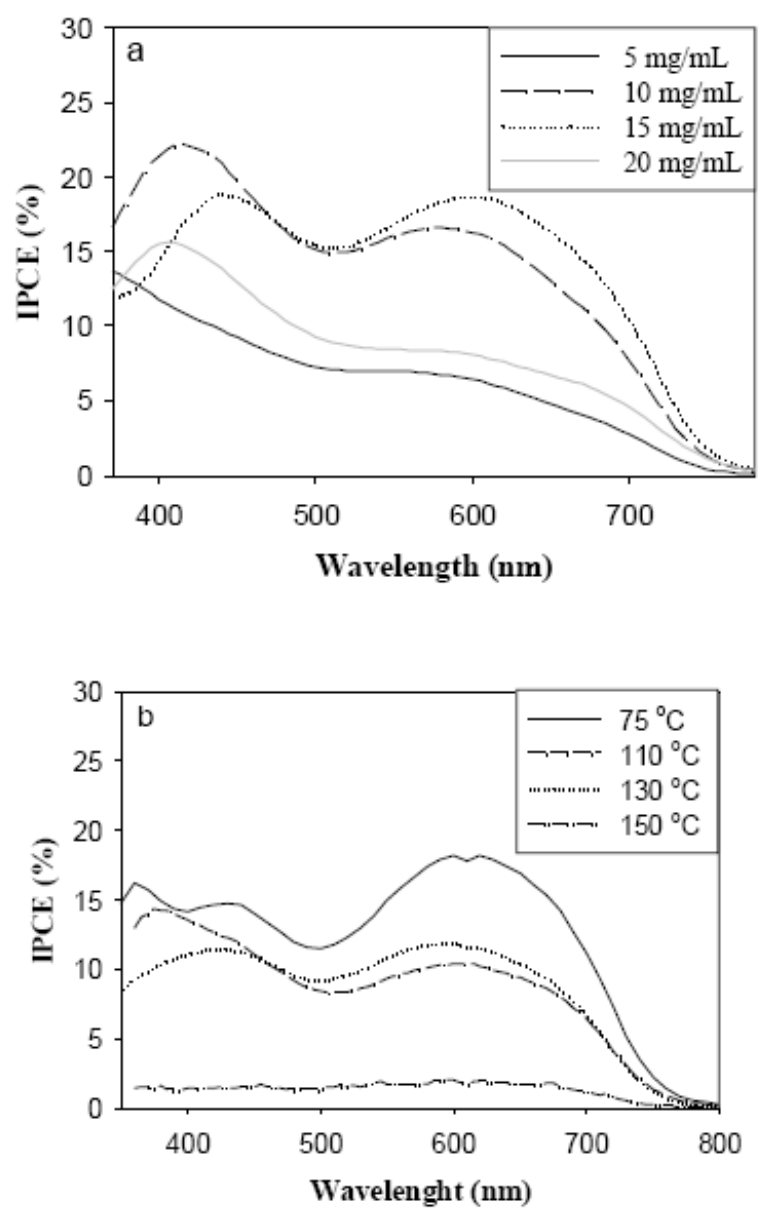

Figure S6. IPCE curves for ITO/PEDOT:PSS/1:PCBM(1:2)/A1 obtained under the following conditions: a) concentration and b) annealing temperature. 


\title{
Solar cells based on copolymers of benzothiadiazole and thiophene
}

\author{
Eva Bundgaard ${ }^{* a, b}$, Frederik C. Krebs ${ }^{\mathrm{a}}$ \\ ${ }^{a}$ Polymer Solar Cell Initiative, The Danish Polymer Centre, Risø National Laboratory, \\ PO Box 49, DK-4000 Roskilde, Denmark \\ ${ }^{b}$ Institute for Biology and Chemistry, Roskilde Universitetscenter, \\ PO Box 260, DK-4000 Roskilde, Denmark
}

\begin{abstract}
The synthesis of conjugated low band-gap copolymers based on thiophene and benzothiadiazole is described. The synthesis was carried out by oxidative ferric chloride polymerization or Stille cross coupling polymerization. The solubility of the polymer based on quarterthiophene and benzothiadiazole was tested with hexyl, 2-ethyl-hexyl and dodecyl as side chains on the thiophene. It was found that 2-ethyl-hexyl substituents gave high molecular weight polymer products with good film forming ability and good solubility. The polymers based on di-thiophene and benzothiadiazole were applied in photovoltaic devices and the coupling of the alkylthiophene showed no effect on the maximum photovoltaic performance. Band-gaps were estimated to be $2 \mathrm{eV}$ for polymers based on di-thiophene and benzothiadiazole and $1.8 \mathrm{eV}$ for polymers based on quarterthiophene and benzothiadiazole. Attempts to synthesize the polymers with a benzo-bis-thiadiazole unit are also described.
\end{abstract}

Keywords: copolymers, low band-gap, polymer photovoltaic devices

\section{INTRODUCTION}

Conjugated polymer materials with a wide absorption range are believed to enable an increase in the power conversion efficiency through a better match with the solar spectrum. ${ }^{1,2}$ So far there have been relatively few examples of low bandgap conjugated polymer materials for polymer solar cells. ${ }^{1,3-8}$ The most commonly used low band-gap polymers are polythiophene, ${ }^{3.4}$ polyisothianaphthene ${ }^{5.6}$ and copolymers of thiophene, pyrrole and benzothiadiazole. ${ }^{1.7 .8}$ Most materials employed in polymer photovoltaic research seldom absorb light at wavelengths longer than $600 \mathrm{~nm} .^{1.2}$ In this work the synthesis of copolymers of benzothiadiazole and thiophene $\mathbf{1}, \mathbf{2}$ and $\mathbf{3}$, which extend this range, is described (Chart 1).

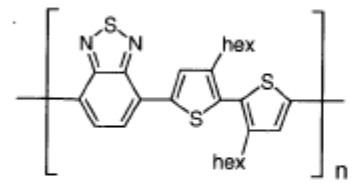

1

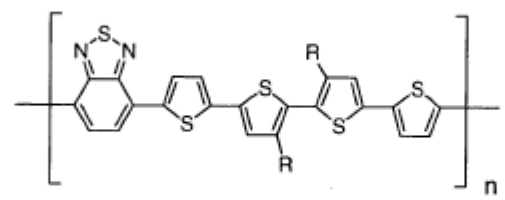

2

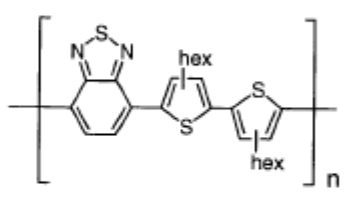

Chart 1: Copolymers of thiophene and benzothiadiazole. Polymer 1 (head-to-head coupled thiophene), polymer 2 (head-to-head coupled thiophene. $\mathrm{R}=$ hexyl, 2 -ethyl-hexyl or dodecyl) and polymer 3 (head-to-tail coupled di-thiophene).

We present results obtained using these materials for organic photovoltaics and compare our results with current work within the field of low band-gap materials (for general reviews on photovoltaics see ref. 9).

\section{EXPERIMENTAL}

Oxidative ferric chloride polymerization. The monomer was dissolved in chloroform and added dropwise to ferric(III)chloride ( 10 equivalents) in chloroform and refluxed over night. The reaction mixture was cooled, washed with

"eva_bundgaard@risoe.dk; phone +45 4677 5498; fax +45 4677 4791; www.risoe.dk/solarcells

Proc. of Organic Photovoltaics VI, edited by Zakya H. Kafafi, Paul A. Lane

Proc. of SPIE Vol. 5938, 59380Q, (2005) - 0277-786X 05/\$15 - doi: 10.1117/12.613425

Proc. of SPIE Vol. 5938 59380Q-1 
aq. sulfuric acid and aq. sodium sulfite, dried with $\mathrm{MgSO}_{4}$, filtered and concentrated. It was then poured into methanol and water $(1: 1 \mathrm{~V} / \mathrm{V})$ to precipitate the polymer. Filtration of the suspension, washing with methanol and drying resulted in the polymer. ${ }^{10}$

Stille cross coupling polymerization." The di-stannyl derivate of thiophene $(1 \mathrm{mmol})$ and the di-bromo derivate of benzothiadiazole ( $1 \mathrm{mmol}$ ) was dissolved in DMF and the solution was degassed with argon. $\mathrm{Pd}\left(\mathrm{PPh}_{3}\right)_{2} \mathrm{Cl}_{2}$ was added and the reaction was heated to $150{ }^{\circ} \mathrm{C}$. After 2 hours a pre-polymer precipitated and THF was added to dissolve the prepolymer and continue the polymerization at reflux over night. The reaction mixture was cooled and evaporated to remove the THF. The solution was poured into methanol and water (1:1) to precipitate the polymer. Filtration of the suspension, washing with methanol and drying resulted in the polymer. ${ }^{12}$ The polymer was purified from palladium as described in the literature. ${ }^{13}$

Further experimental detail have been described earlier. ${ }^{10,12}$

Photovoltaic measurements. A mixture of polymer and PCBM $(20 \mathrm{mg} / 20 \mathrm{mg})$ in chloroform and chlorobenzene $(2: 1$, $1.5 \mathrm{~mL}$ ) was filtered through a $2.7 \mu \mathrm{m}$ porous filter and spin-coated onto PEDOT:PSS coated ITO glass slides. An aluminium electrode was thermally evaporated onto the film in a vacuum chamber at a pressure of $<5 \times 10^{-6} \mathrm{mbar}$. The active area of the device was $3 \mathrm{~cm}^{2}$. Details on device preparation and set up for data measurements have been described earlier. $^{10,14}$

\section{RESULTS AND DISCUSSION}

3.1 Synthesis of monomers

The polymers 1 and $\mathbf{2}$ were synthesized by oxidative ferric chloride polymerization of monomers of thiophenebenzothiadiazole, 6 and 9. Compound 6 was synthesized by a Stille coupling between 4,7-di-bromo-2,1,3benzothiadiazole (4) ${ }^{15}$ and 2-tributylstannyl-4-hexyl-thiophene (5) ${ }^{12,16}$ (Scheme 1). Compound 5 was synthesized by lithiation of hexyl-thiophene using LDA and further reaction with tributylstannylchloride. ${ }^{1216}$

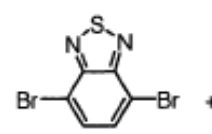

4

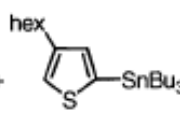

5

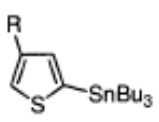

8

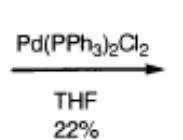

$22 \%$

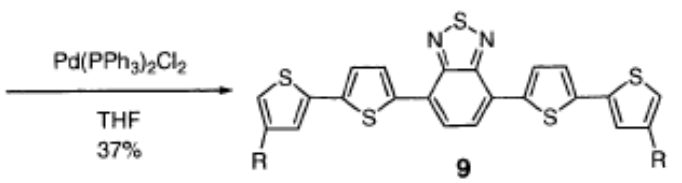

Scheme 1: Synthesis of 6 and 9. R= hexyl, 2-ethyl-hexyl or dodecyl.

Compound 9 was synthesized by a Stille coupling between 4,7-bis-(5-bromo-thiophe-2-yl)-2,1,3-benzothiadiazole (7) ${ }^{15,17}$ and 2-tributylstannyl-4-alkyl-thiophene $(\mathbf{8})^{12,16}$ (Scheme 1). Compound 8 was synthesized by lithation of alkyl-thiophene using LDA and further reaction with tributylstannylchloride. ${ }^{12,16}$ Compound $\mathbf{8}$ was synthesized with three alkyl groups to study the solubility of the resulting polymer products. The alkyl chains were hexyl, 2-ethyl-hexyl and dodecyl. ${ }^{12}$<smiles>O=C(O)c1csc(-c2cc(Nc3ccccc3)cs2)c1</smiles>

10

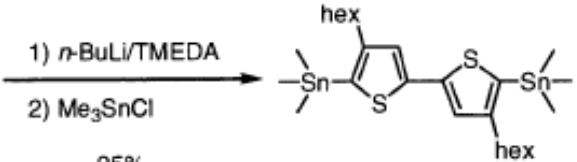

11

Scheme 2: Synthesis of 11. 
The monomers for Stille cross coupling polymerization used to synthesize polymer 3 were compound 4 and di-stannyldi-hexyl-dithiophene (11). Compound 11 was synthesized by dilithation with $n$-BuLi and TMEDA followed by reaction
with trimethylstannylchloride (Scheme 2 ). ${ }^{10}$

\subsection{Synthesis of polymers}

Compound 6 and 9 were polymerized by oxidative ferric chloride polymerization to give the copolymers of head-to-head
coupled thiophene and benzothiadiazole, i.e. polymer 1 and 2 (Scheme 3). ${ }^{10.12}$

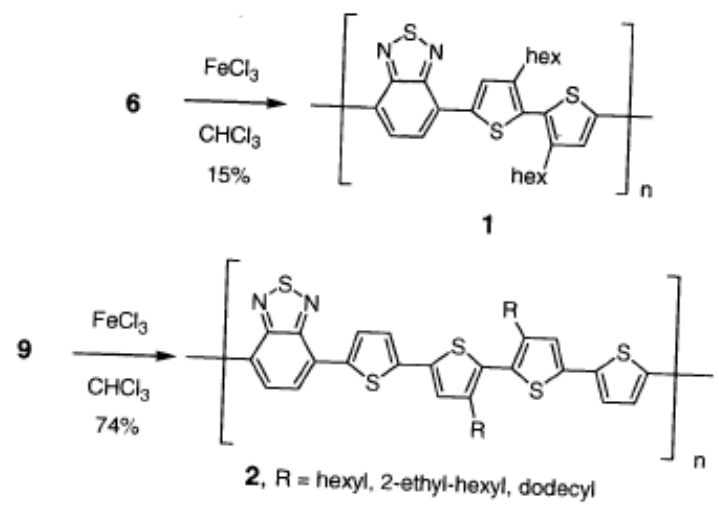

Scheme 3: Synthesis of polymer 1 and 2 by oxidative ferric chloride polymerization.

Polymer 2 was synthesized with hexyl, 2-ethyl-hexyl and dodecyl side chains to test the film forming ability and the
dependence of the solubility on the alkyl chains. ${ }^{12}$

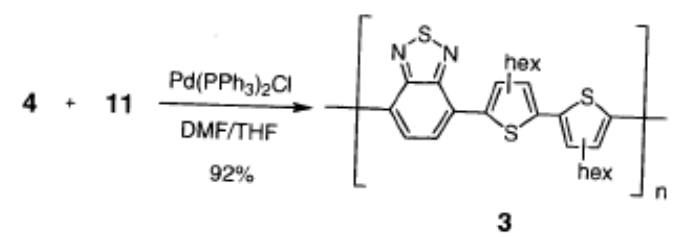

Scheme 4: Synthesis of polymer 3 by Stille cross coupling polymerization.

Compound 11 and 4 were polymerized by Stille cross coupling polymerization to give the copolymers of head-to-tail shown in Fig. I and the data is given in Table 1. Po.12 3 (Scheme 4). The SEC traces of the polymers 1, 2 and $\mathbf{3}$ are 

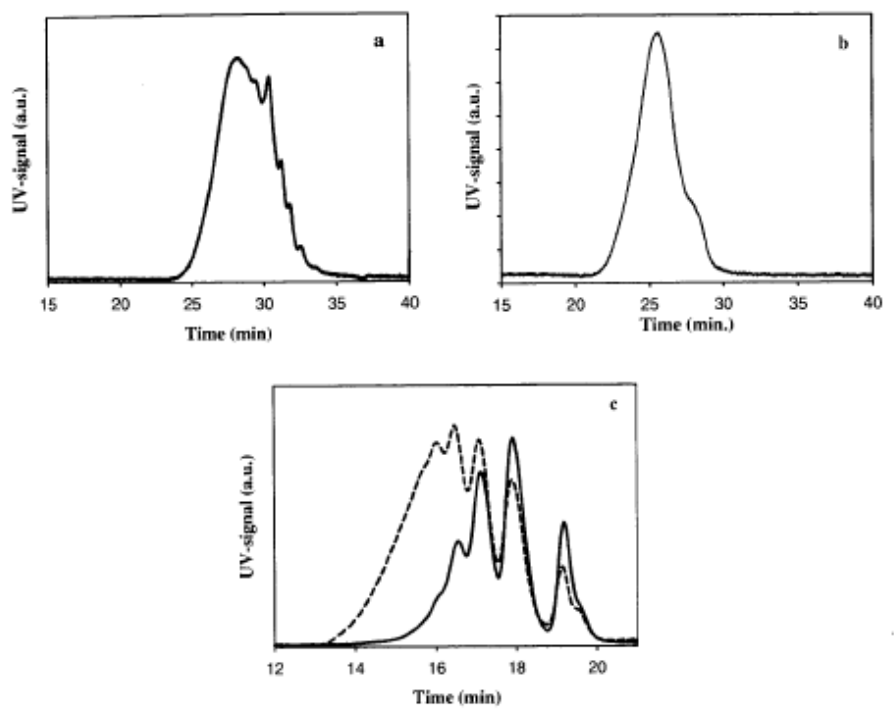

Figure 1: SEC traces of polymer $\mathbf{1}$ (a), 2 (b) and $\mathbf{3}$ (c, - prepolymer, -- final). Polymer $\mathbf{1}$ and $\mathbf{2}$ were analyzed on a gel column system comprising a succession of a $500 \AA, 10000 \AA$ and $1000000 \AA$ in pore diameter. Polymer 3 was analyzed on a gel column system comprising a succession of a $100 \AA$ and $1000 \AA$ in pore diameter. The use of the two different SEC systems changes the time scale for comprising a succession of a $100 \mathrm{~A}$ and $1000 \mathrm{~A}$ in pore diameter. The use of the two different $\mathrm{SEC}$ systems changes the time scale for

Polymer 2 was purified by preparative SEC and the data of the first fraction is given in Fig. $1 .{ }^{12}$ Fig. Ic shows that in the Stille cross coupling polymerization a pre-polymer formed during the reaction, which was dissolved by the addition of $\mathrm{THF}$ and the polymerization was continued to the final polymer 3 . $^{\text {. }}$

Table 1: SEC data of polymer $\mathbf{1 , 2}$ and $\mathbf{3}$.

\begin{tabular}{ccccc}
\hline Polymer & $\mathrm{M}_{\mathrm{w}}$ & $\mathrm{M}_{\text {pesk }}$ & $\mathrm{M}_{\mathrm{w}} / \mathrm{M}_{\mathrm{m}}$ & $\lambda$ (nm, detector) \\
\hline $\mathbf{1}$ & 15244 & 13605 & 2.87 & 500 \\
$\mathbf{2}$ & 863262 & 60258 & 1.99 & 500 \\
$\mathbf{3}$ & 3205 & 1971 & 1.43 & 520 \\
\hline
\end{tabular}

Several attempts were made to synthesize polymer 1 with a benzo-bis-thiazole function (Scheme 6). In the literature the synthetic route from $\mathbf{4}$ to the thiophene-benzo-bis-thiadiazole 12 is described (Scheme 5). ${ }^{15,18-20}$ The synthetic route

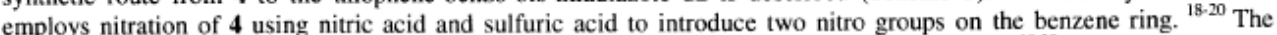
employs nitration of $\mathbf{4}$ using nitric acid and sulfuric acid to introduce two nitro groups on the benzene ring.
thiophene rings were introduced by a Stille cross coupling with 2 -tributylstannyl-thiophene. ${ }^{19,20}$ Hereafter the nitro thiophene rings were introduced by a Stille cross coupling with 2-tributylstannyl-thiophene. ${ }^{19,20}$ Hereafter the nitro sulfinylaniline to give the thiadiazole ring. ${ }^{19.2}$ 


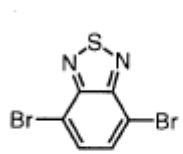

4

a) $\mathrm{HNO}_{3} / \mathrm{H}_{2} \mathrm{SO}_{4}$

b) 2-tributylstannylthiophene,

$\mathrm{Pd}\left(\mathrm{PPh}_{3}\right)_{2} \mathrm{Cl}_{2}$

c) $\mathrm{Fe}, \mathrm{AcOH}$

d) $\mathrm{N}$-sulfinylaniline, TMS-Cl

Scheme 5: Synthesis of 12 from 4 described in the literature. ${ }^{15.18-20}$

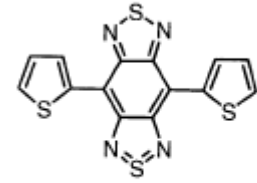

12

This reaction procedure was used in the attempts to synthesize the benzo-bis-thiadiazole analogue to polymer 1. Starting from 4,7-di-bromo-5,6-di-nitro-2,1,3-benzothiadiazole (13) the attempts included Stille coupling with $\mathbf{5}$. The reaction was carried out by either addition of $\mathbf{5}$ in one portion or in two portions. For both reactions neither product (14) nor starting material (13) could be identified. MALDI-TOF, ${ }^{1} \mathrm{H}$ and ${ }^{13} \mathrm{C}$ NMR of the reaction mixture in the latter reaction indicated that the nitro groups were eliminated from the benzene ring during the reaction.

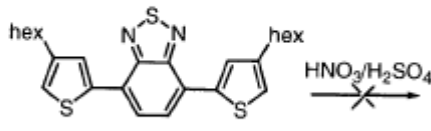

6

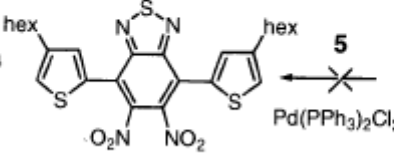

$\mathrm{O}_{2} \mathrm{~N} \mathrm{~N}$

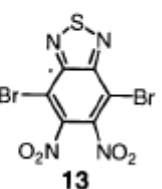

13

?

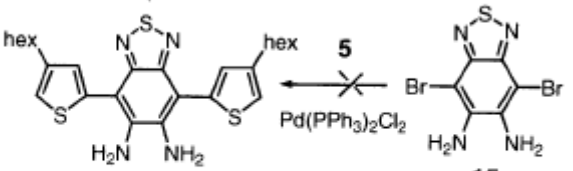

17
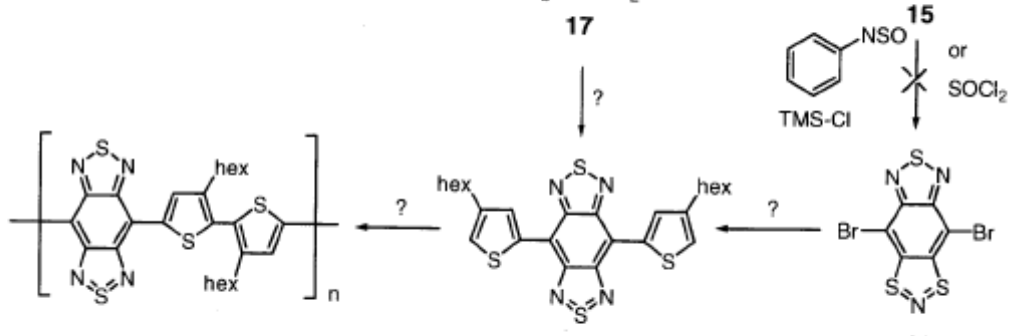

16

Scheme 6: Attempts to synthesize polymer 1 with a benzo-bis-thiadiazole function. The reactions marked with ? have not been attempted due to unsuccessful synthesis of precursors.

Attempts to reduce 13 to give 5,6-di-amino-4,7-di-bromo-2,1,3-benzothiadiazole (15) showed a change in color from yellow to orange of the reaction mixture, but due to insolubility of the resulting compound it was not possible to characterize any product by ${ }^{1} \mathrm{H}$ NMR. MALDI-TOF showed peaks at 325 and 568 . The peak at 325 could be assigned to the product with extra hydrogen and hence further reaction of compound 15 with either $N$. sulfinylaniline/chlorotrimethylsilane or with thionyldichloride to give the benzo-bis-thiadiazole ring (16) was attempted. In both reactions neither MALDI-TOF nor TLC allowed for the identification of any product (16) or starting material (15).

Compound $\mathbf{1 5}$ was mixed with $\mathbf{5}$ to perform a Stille coupling reaction. It was not possible to identify any product (17) or starting material (15) by MALDI-TOF or ${ }^{1} \mathrm{H}$ NMR.

Proc. of SPIE Vol. 5938 59380Q-5 
The final attempt was a reaction of compound 6 with fuming nitric acid and sulfuric acid to introduce the nitro groups (14) for further reduction to 17 . However, this reaction resulted in nitro groups on the thiophene ring and no further attempts were performed to synthesize polymer 1 with a benzo-bis-thiadiazole function.

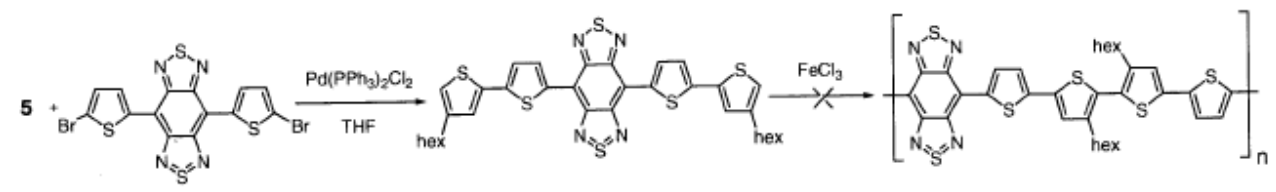

17

Scheme 7: Attempt to synthesize polymer 2 with a benzo-bis-thiadiazole function.

In addition it was attempted to synthesize polymer $\mathbf{2}$ with a benzo-bis-thiadiazole function. The reaction was carried out by a Stille cross coupling between the dibromo derivate of benzo-bis-thiadiazole $(17)^{12}$ and compound 5 . ${ }^{1} \mathrm{H}$ NMR indicated that the product had formed, though in very low yields $(\sim 7 \%)$. However, due to poor solubility of the product, purification and.polymerization in chloroform was not possible. Therefore, synthesis of the monomer in a larger scale was not attempted.

3.3 Film forming ability and solubility

The film forming ability of polymer $\mathbf{2}$ was tested with hexyl, 2-ethyl-hexyl and dodecyl as alkyl chains on the thiophene ring. The polymers were dissolved in different solvents $(10 \mathrm{mg} / \mathrm{mL})$ and spin-coated $(1500 \mathrm{rpm})$ onto glass slides, with subsequent measurements of the absorbance. The results are given in Table 2. For photovoltaic and other thin film studies an absorbance value of at least 0.3 is desirable.

Table 2: Absorbance values of thin films of polymer 2 with different alkyl group (absorbance values at $\lambda_{\max } 586 \mathrm{~nm}$ ).

\begin{tabular}{lccc}
\hline Solvent & $\mathrm{R}=$ hexyl & $\mathrm{R}=2$-ethyl-hexyl & $\mathrm{R}=$ dodecyl \\
\hline Chloroform & 0.033 & 0.560 & $<0.001$ \\
THF & 0.024 & 0.516 & $<0.001$ \\
Chlorobenzene & 0.018 & 0.263 & $<0.001$ \\
1,2-di-chlorobenzene & 0.023 & 0.136 & $<0.001$ \\
Toluene & 0.023 & 0.316 & $<0.001$ \\
\hline
\end{tabular}

From Table 2 it can be seen that polymer 2 with $\mathrm{R}=$ hexyl or dodecyl shows poor film forming ability. Since the absorbance was determined on a saturated solution of the polymers it can be concluded, that the solubility of polymer 2 with $\mathrm{R}=$ hexyl and $\mathrm{R}=$ dodecyl was poor in chloroform, THF, chlorobenzene, 1,2-di-chlorobenzene and toluene. Hence, these polymers are not suitable for photovoltaics and other thin film studies. The polymer $\mathbf{2}$ with $\mathrm{R}=2$-ethyl-hexyl showed good film forming ability and increased solubility in chloroform and THF with absorbances of 0.56 and 0.52 , respectively. ${ }^{12}$

3.4 UV-vis spectroscopy

The UV-vis spectra of polymer 1, 2 and 3 are shown in Fig. 2 and the extinction coefficients at $\lambda_{\max }$ are given in Table 3 . 


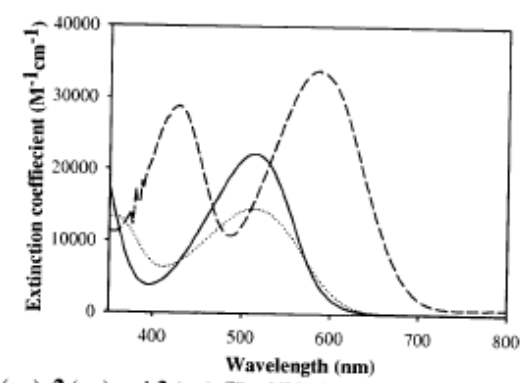

Figure 2: UV-vis spectra of polymer $1(-), 2(--)$ and $3(\cdots)$. The UV-vis spectr

not observed any red-shift when compared with the UV-vis spectra films spectra were recorded from chloroform solution. There was

Fig 2 and Table 3

and $\mathbf{3}$. Further, the $\lambda_{\max }$ for polymer $\mathbf{2}\left(586 \mathrm{~nm}\right.$ ) is canction coefficient at $\lambda_{\max }$ for polymer $\mathbf{2}$ is larger than for polymer $\mathbf{1}$ and 3 . Further, the $\lambda_{\max }$ for polymer $\mathbf{2}(586 \mathrm{~nm})$ is red-shifted compared to polymer 1 and $\mathbf{3}(514 \mathrm{~nm})$. We ascribe both these results to the number of thiophenes in the repeating unit of the polymer, i.e. four in polymer $\mathbf{2}$ and two in polymer $\mathbf{1}$ repeating unit will rofulophenes influences the conjugation length in the polymer and hence, more thiophenes in the repeating unit will result in a red shift in the UV-vis spectra. Furthermore, it can be seen that the UV-vis spectra of polymer 1 and 3 (head-to-head coupled thiophene and head-to-tail coupled dithiophene, respectively) are similar. This is regularity in the coupling of the thiophene.

Table 3: Extinction coefficients at $\lambda_{\max }$ for polymer 1,2 and 3 .

\begin{tabular}{lccc}
\hline & $\mathbf{1}$ & $\mathbf{2}$ & $\mathbf{3}$ \\
\hline$\lambda_{\max }(\mathrm{nm})$ & 514 & 428 & 514 \\
$\varepsilon\left(\mathrm{M}^{1} \mathrm{~cm}^{-1}\right)$ & & 586 & \\
& 22200 & 28900 & 15000 \\
& & 34000 & \\
\hline
\end{tabular}

The band-gaps were estimated from the UV-vis spectra by drawing a tangent to the absorption curve and converting the cut-off value to $\mathrm{eV} .^{12}$ The band-gaps were $2.0 \mathrm{eV}$ for polymer 1 and 3 and $1.8 \mathrm{eV}$ for polymer 2 . The band-gap for polymer 1 and 3 are in the same region as polythiophene $(2.0 \mathrm{eV}),{ }^{22.23}$ whereas the band-gap for polymer $\mathbf{2}$ is slightly
higher than the copolymer of thiophene, pyrrole and 3.5 Photovoltaic measurements

Polymers $\mathbf{1}$ and $\mathbf{3}$ were applied in photovoltaic devices. The I/V curves for the photovoltaic devices of polymers $\mathbf{2}$ and 3 as a mixture with PCBM are shown in Fig. 3 and the photovoltaic performance is given in Table 4. Photovoltaic studies
of polymer $\mathbf{2}$ are in progress. 

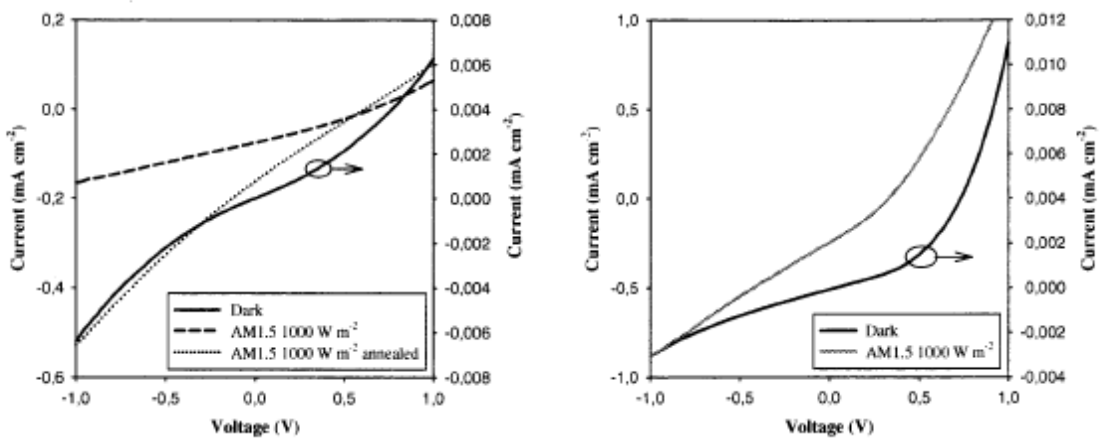

Figure 3: $/ / V$-curves for the polymers 1 (left) and 3 (right) with PCBM. The I/V-curves were recorded under ambient conditions.

From Table 4 it can be seen that the open circuit voltage $\left(\mathrm{V}_{\mathrm{OC}}\right)$ and the short circuit current $\left(\mathrm{I}_{\mathrm{SC}}\right)$ are very low for the photovoltaic devices based on the homo-polymer. Though they are higher for polymer 1 than for polymer 3 . The fill factors (FF\%) are around $25 \%$ and the efficiencies are very low for photovoltaic devices based on the homo-polymers. It is noticeable that the efficiency for the device based on homo-polymer $\mathbf{1}$ is four times higher than polymer $3{ }^{1}$

Table 4: Photovoltaic performance of the devices of polymer 1 and 3 (active area $3 \mathrm{~cm}^{2}, 1000 \mathrm{~W} \mathrm{~m}$.- AM1.5). The device with polymer 1 and PCBM was illuminated under the described conditions for $40 \mathrm{~min}$. when a second $\mathrm{I} / \mathrm{V}$-curve was recorded (annealed).

\begin{tabular}{lllll}
\hline Compound & $\mathrm{V}_{\mathrm{oc}}(\mathrm{V})$ & $\mathrm{I}_{\mathrm{sc}}\left(\mu \mathrm{A} \mathrm{cm}^{-2}\right)$ & $\mathrm{FF}(\%)$ & $\eta(\%)$ \\
\hline $\mathbf{1}$ & 0.68 & -7.4 & 25 & 0.0013 \\
$\mathbf{1}+\mathrm{PCBM}$ & 0.65 & -75 & 28 & 0.0140 \\
$\mathbf{1}+\mathrm{PCBM}$ (annealed) & 0.61 & -162 & 24 & 0.0240 \\
$\mathbf{3}$ & 0.57 & -2.4 & 25 & 0.0003 \\
3+PCBM & 0.33 & -247 & 30 & 0.0240 \\
\hline
\end{tabular}

From Table 4 and Fig. 3 it can be seen that addition of PCBM increased the efficiencies of the devices for both polymer 1 and for polymer 3 to $0.024 \%$. Furthermore, it was seen that the efficiency of polymer 1 with PCBM was increased during illumination. We ascribe the increase in efficiency of the device of 1 and PCBM to be due to the phenomenon of annealing. Upon illumination the device heats up to an equilibrium temperature of $70^{\circ} \mathrm{C}$. These results were also supported by Differential Scanning Calometry (DSC) experiments, which showed that polymer 1 has a glass transition $\left(\mathrm{T}_{g}\right.$ ) between 60 and $80^{\circ} \mathrm{C},{ }^{10}$ while polymer 3 did not have any thermal transitions. The annealing of polymer 1 increases the $\mathrm{I}_{\mathrm{SC}}$ and lowers the $\mathrm{V}_{\mathrm{OC}}$. 


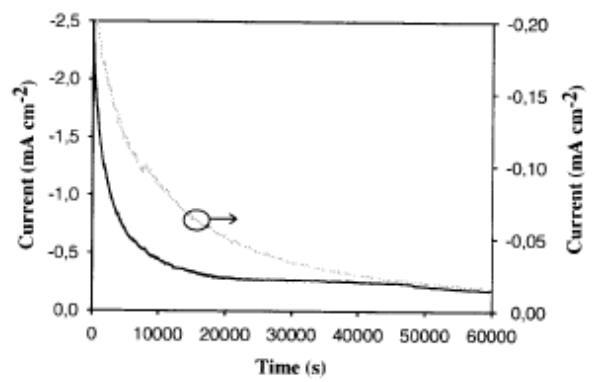

Figure 4: Lifetime curves for photovoltaic devices with polymer 3: Polymer 3 (black) and mixture of polymer 3 and PCBM (grey). The lifetime curves were recorded under ambient conditions.

The lifetime profile of the device with polymer $\mathbf{3}$ is shown in Fig. 4. The lifetime of the device with polymer $\mathbf{1}$ was similar. The lifetime curves were fitted with a four parameter exponential decay according to $\mathrm{Eq}$. (1) ${ }^{24}$ and the decay parameters are given in Table 5. The fitting with Eq. (1) indicates that the degradation of the device is affected by two mechanisms as described by Krebs et al. ${ }^{24}$ They found that decay curves of different devices with MEH-PPV could be fitted to a two-term exponential function with a fast and a slow decay. ${ }^{24}$ The first and fast degradation mechanism was found to be linked to the interface formed between the aluminum electrode and the active layer. ${ }^{24}$ The second and slow degradation mechanism was ascribed to the reaction with atmospheric oxygen. ${ }^{24}$

$$
\frac{I_{s c}(t)}{I_{s c}(0)}=A e^{-b t}+C e^{-d t}
$$

In Eq. (1) $b$ and $d$ are the time constants and $A$ and $C$ are the weighting of the individual exponential functions.

Table 5: Decay parameters according to Eq. (1).

\begin{tabular}{|c|c|c|c|c|}
\hline Device & A & $\mathrm{b}\left(\mathrm{x} 10^{-1} \mathrm{sec}^{-1}\right)$ & C & $\mathrm{d}\left(\mathrm{x} 10^{-5} \mathrm{sec}^{-1}\right)$ \\
\hline 3 & -1.725 & 3.655 & -0.416 & 1.368 \\
\hline $3+$ PCBM & -1.110 & 2.243 & -0.101 & 3.452 \\
\hline
\end{tabular}

From Fig. 4 and Table 5 it can be seen that the first degradation mechanism are weighted more than the second $(A$ and $C$ ). Further it can be seen that the first mechanism is faster than the second ( $b$ and $d$ ). The half-life is $1896 \mathrm{~s}$ and $50668 \mathrm{~s}$ for the two mechanisms in the device of polymer 3. The half-life is $3090 \mathrm{~s}$ and $20080 \mathrm{~s}$ for the two mechanisms in the device of polymer 3 and PCBM. Hence it can be concluded that the half-life of the first degradation mechanism (aluminum) was increased when PCBM was added. However, the lifetime of both devices were very short and the practical use of these devices is limited. 


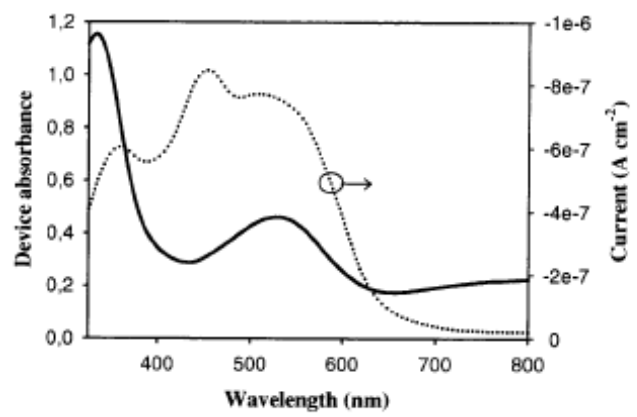

Figure 5: Photocurrent action ("-) and absorbance spectra ( - ) of photovoltaic device with a mixture of polymer 3 and PCBM. The broad peak at $800 \mathrm{~nm}$ in the absorption spectra stems from the PEDOT:PSS layer in the device. The decrease in the photocurrent below $300 \mathrm{~nm}$ stems from the absorption of the glass. The small increase in photocurrent at $450 \mathrm{~nm}$ is ascribed to an effect of the film thickness.

The wavelength scan of polymer 3 and PCBM is plotted with the absorbance spectrum of the device in Fig. 5 . Comparison of the absorption spectra with the photovoltaic response shows a good overlap in the region of 470 to 600 $\mathrm{nm}$. The incident photon to current efficiency (IPCE $\%$ ) is $0.6 \%$ at the maximum at $450 \mathrm{~nm}$. IPCE\% data has been reported on the copolymer of thiophene, pyrrole and benzothiadiazole to be $7 \%$ at $570 \mathrm{~nm}^{2}$

The data reported in the literature of the polyfluorene $\mathrm{e}^{25,26}$ and copolymer of thiophene, pyrrole and benzothiadiazole ${ }^{1}$ showed efficiencies of $2.4 \%$ and $1 \%$, respectively. ${ }^{1.25}, 26$ These polymers both showed a smaller band-gap, i.e. $1.9 \mathrm{eV}$ for polyfluorene ${ }^{25.26}$ and $1.6 \mathrm{eV}$ for the copolymer of thiophene, pyrrole and benzothiadiazole. ${ }^{1.25}$ Further the polymer/PCBM blend was larger, i.e. 1:4 and 1:3, respectively, ${ }^{1.25 .26}$ and this has been shown to be important for the efficient conduction of electrons. ${ }^{27}$ In the devices with polymer $\mathbf{1}$ and $\mathbf{3}$ it was necessary to use a $1: 1$ ratio of the polymer and PCBM to produce homogenous films. Higher efficiencies of the devices of polymer $\mathbf{1}$ and $\mathbf{3}$ with PCBM would be expected if the ratio of PCBM could be higher, i.e. 1:3 or $4 \mathrm{w} / \mathrm{w}$ ratio. ${ }^{10}$ Furthermore, a device with polymer 2 and $\mathrm{PCBM}$ is expected to show higher efficiency than polymer 1 and $\mathbf{3}$ due to the low band-gap, i.e. $1.8 \mathrm{eV}$.

\section{CONCLUSIONS}

The synthesis of copolymers of thiophene and benzothiadiazole has been described. The polymers were synthesized by oxidative ferric chloride polymerization or Stille cross coupling polymerization. The film forming ability of polymers with different alkyl chains on the thiophene, i.e. hexyl, 2-ethyl-hexyl and dodecyl, was investigated in different solvents. This showed that hexyl and dodecyl gave polymer products with poor film forming ability, whereas 2-ethyl-hexyl polymer products showed good film forming ability and solubility in solvents like chloroform and THF. The band-gaps were estimated from UV-vis to $2 \mathrm{eV}$ for polymer based on di-thiophene and benzothiadiazole 1 and 3 and $1.8 \mathrm{eV}$ for polymer based on quarterthiophene and benzothiadiazole, $\mathbf{2}$. The polymers, $\mathbf{1}$ and $\mathbf{3}$, were applied in photovoltaics. These experiments showed that the coupling of the thiophene had no effect on the maximum photovoltaic performance. Furthermore, they showed that polymer 1 annealed during the measurements, which increased the efficiencies of the device and that the lifetimes of the devices were very short. Attempts to synthesize polymer $\mathbf{1}$ and $\mathbf{2}$ with a benzo-bisthiadiazole function under the described condition were not successful.

\section{ACKNOWLEDGEMENT}

This work was supported by the Danish Technical Research Council (STVF 26-02-0174, STVF 2058-03-0016), the Danish Strategic Research Council (DSF 2104-04-0030) and Public Service Obligation (PSO 103032 FU 3301 ). 


\section{REFERENCES}

1. C. J. Brabec, C. Winder, N. S. Sariciftci, J. C. Hummelen, A. Dhanabalan, P. A. van Hal and R. A. J. Janssen, "A low-bandgap semiconducting polymer for photovoltaic devices and infrared emitting diodes", Adv. Funct. Mater.,
12, 709-712, 2002.

2. A. Dhanabalan, J. K. J. van Duren, P. A. van Hal, J. L. J. van Dogen and R. A. J. Janssen, "Synthesis and characterzation of a low bandgap conjugated polymer for bulk heterojunction photovoltaic cells", Adv. Funct.
Mater., 11, 255-262, 2001.

1997.

4. R. D. McCullough, "The chemistry of conducting polythiohenes", Adv. Mater., , 10, 93-116, 1998.

5. F. Wudl, M. Kobayashi and A. J. Heeger, "Poly(isothianaphthene)", J. Org. Chem., 49, 3382-3384, 1984.

6. R. H. L. Kiebooms, H. Goto and K. Akagi, "Synthesis of a new class of low-band-gap polymers with liquid crystalline substituents", Macromolecules, 34, 7989-7998, 2001.

7. J. K. J. van Duren, A. Dhanabalan, P. A. van Hal and R. A. J. Janssen, "Low-bandgap polymer photovoltaic cells", Synth. Metal, 121, 1587-1588, 2001.

8. C. Winder, and N. S. Sariciftci, "Low band gap polymers for photon harvesting in bulk heterojunction solar cells", J. Mater. Chem., 14, 1077-1086, 2004.

9. a) C. J. Brabec, N. S. Sariciftci, J. C. Hummelen, "Plastic solar cells", Adv. Funct. Mater., 11, 15-26, 2001, b) H. Spanggaard and F. C. Krebs, "A brief history of the development of organic and polymeric photovoltaics", Sol. Ener. Mat. \& Sol. Cells, 83, 125-146, 2004, c) H. Hoppe and N. S. Sariciftci, "Organic solar cells: an overview", J. Mater. Res., 19, 1924-1945, 2004, d) C. J. Brabec, "Organic photovoltaics: technology and market", Sol. Ener. Mat.
\& Sol. Cells, 83, 273-292, 2004.

10. E. Bundgaard and F. C. Krebs, "A comparison of the photovoltaic response of head-to-head andhead-to-tail coupled poly\{(benzo-2,1,3-thiadiazole-4,7-diyl)-(dihexyl[2,2']dithiophene-5,5'diyl\}", Pol. Bul., accepted, 2005.

11. A. Iraqi and G. W. Barker, "Synthesis and characterisation of telechelic regioregular head-to-tail poly(3alkylthiophenes)", J. Mater. Chem., 8, 25-29, 1998.

12. E. Bundgaard and F. C. Krebs, "A series of low band-gap conjugated polymers based on thiophene, benzothiadiazole and benzo-bis-thiadiazole. Part I: synthesis and characterisation", Macromolecules, submitted,
2005 .

13. K. T. Nielsen, K. Bechgaard and F. C. Krebs, "Removal of palladium nanoparticles from polymer materials", Macromolecules, 38, 658-659, 2005.

14. F. C. Krebs and M. Jørgensen, "High power spectrometer for the characterisation of photovoltaic cells in a controlled atmosphere or vacuum", Rev. Sci. Instrum., 74, 3438-3441, 2003.

15. K. Pilgram, M. Zupan, and R. Skiles, "Bromination of 2,1,3-benzothiadiazoles", J. Org. Chem., 36, 207-633, 1971

16. F. C. Krebs and H. Spanggaard, "Antibatic photovoltaic response in zinc-porphyrin-linked oligothiophenes", Sol. Ener. Mat. \& Sol. Cells, web release $18^{\text {th }}$ of January 2005.

17. Q. Hou, Y. Xu, W. Yang, M. Yuan, J. Peng and Y. Cao, "Novel red-emitting fluorine-based copolymers", J. Mater. Chem, 10, 2887-2892, 2002.

18. T. Uno, K. Takagi, and M. Tomoeda, "Synthesis of bisfurazanobenzo-2,1,3-thiadiazole and related compounds", Chem. Pharm. Bul., 28, 1909-1912, 1980.

19. M. Karikomi, C. Kitamura, S. Tanaka and Y. Yamashita, "New narrow-bandgap polymer composed of benzobis(1,2,5-thiadiazole) and thiophenes", J. Amer. Chem. Soc., 117, 6791-6792, 1995.

20. C. Kitamura, S. Tanaka and Y. Yamashita, "Design of narrow-bandgap polymers. Syntheses and properties of monomers and polymers containing aromatic-donor and o-quuinoid-acceptor units", Chem. Mater., 8, 570-578, 1996.

21. T. A. Chen, X. Wu and R. D. Rieke, "Regiocontrolled synthesis of poly(3-alkylthiophenes) mediated by Rieke zinc: their characterisation and solid-state properties", J. Am. Soc., 117, 233-244, 1995.

22. U. Salzner, J. B. Lagowski, P. G. Pickup and R. A. Poirier, "Comparison of geometries and electronic structures of polyacetylene, polyborole, polycyclopentadiene, polypyrrole, polyfuran, polysilole, polyphosphole, polythiophene, polyselenophene and poltellurophene", Synth. Metal, 96, 177-189, 1998.

23. J. L. Brédas, B. Thémans, J. G. Fripiat, J. M. André and R. R. Chance, "High conducting polyaraphenylene, polypyrrole and polythiophene chains: an $a b$ initio study of the geometry and electronic-structure modifications upon doping", Phys. Rev. B, 29, 6761-6773, 1984.

Proc. of SPIE Vol. 5938 59380Q-11 
24. F. C. Krebs, J. E. Carlé, N. Cruys-Bagger, M. Andersen, M. R. Lilliedal, M. A. Hammond and S. Hvidt, "Lifetimes of organic photovoltaics: photochemistry, atmosphere effects and barrier layers in ITO-MEHPPV:PCBM-aluminium devices", Sol. Ener. Mat. \& Sol. Cells, 86, 499-516, 2005.

25. O. Inganäs, M. Svensson, F .Zhang, A. Gadisa, N. K. Persson, X. Wang and M. R. Andersson, "Low bandgap alternating polyfluorene copolymers in plastic photodiodes and solar cells", Apl. Phys. A, 79, 31-35, 2004.

26. M. Svensson, F. Zhang, S. C. Veenstra, W. J. H. Verhees, J. C. Hummelen, J. M. Kroon, O. Inganäs, and M. R. Andersson, "High-performance polymer solar cells of an alternating polyflurene copolymer and a fullerene derivative", Adv. Mater., 15, 988-991, 2003.

27. W. Geens, T. Martens, J. Poortmans, T. Aernouts, J. Manca, L. Lutsen, P. Heremans, S. Borghs, R. Mertens and D. Vanderzande, "Modelling the short-circuit current of polymer bulk heterojunction solar cells", Thin Solid Films, 451-452, 498-502, 2004. 


\title{
Solar cells based on copolymers of benzothiadiazole and thiophene
}

\author{
Eva Bundgaard $^{a, b}$ and Frederik C. Krebs ${ }^{a}$ \\ a Polymer Solar Cell Initiative, The Danish Polymer Centre, Ris $\phi$ National Laboratory, \\ PO Box 49, DK-4000 Roskilde, Denmark. \\ ${ }^{b}$ Institute for Biology and Chemistry, Roskilde Universitycenter, Universitetsvej 1 , \\ PO Box 260, DK-4000 Roskilde, Denmark.
}

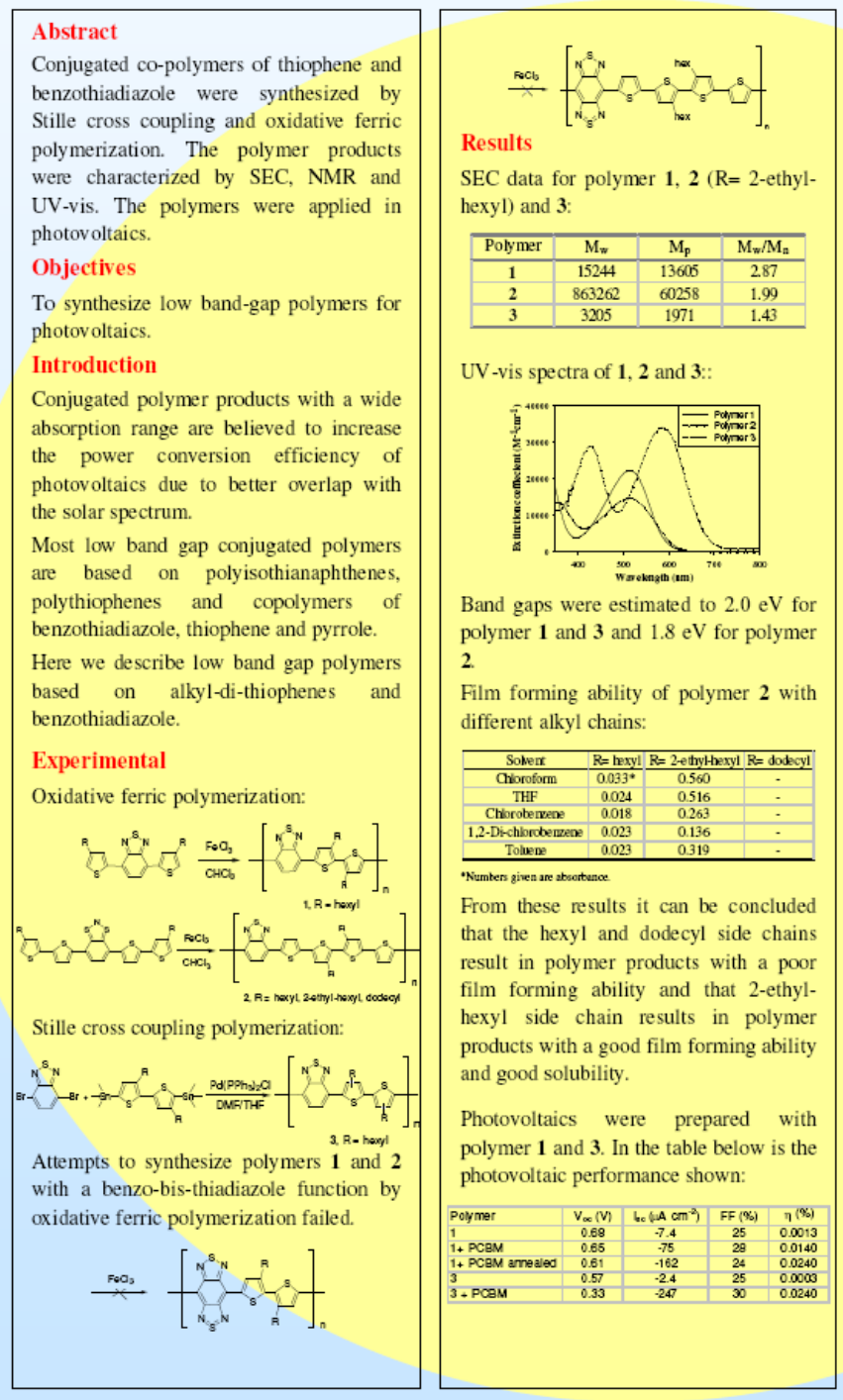

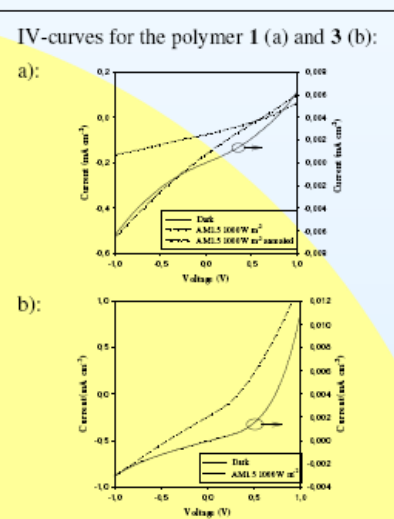

The IV curves and the photovoltaic data shows that:

- $\mathrm{V}_{\mathrm{OC}}$ and $\mathrm{I}_{\mathrm{SC}}$ are higher for $\mathbf{1}$ (homopolymer)

- Addition of PCBM increases the efficiency of $\mathbf{1}$ and $\mathbf{3}$

- Polymer 1 shows annealing upon illumination.

Lifetime measurements showed that the degradation of the device was affected by two mechanisms (aluminium and oxygen).

Conclusion

Polymers of benzothiadiazole and thiophene were synthesized. Band gaps were estimated to be $2.0 \mathrm{eV}$ for $\mathbf{1}$ and 3 and $1.8 \mathrm{eV}$ for 2 . Molecular weight, solubility and film forming ability was found to depend on the side chain. 2Ethyl-hexyl side chains gave higher molecular weight and better solubility than hexyl and dodecyl side chains. Photovoltaic performance was higher for homopolymer 1 than 3 . PCBM addition increased the photovoltaic performance of both 1 and 3. Polymer 1 showed annealing upon illumination.

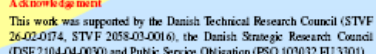

www.risoe.dk/solarcells, Tel (+45) 4677 5498, Fax(+45) 46774791, eva.bundgaard@risoe.dk 


\title{
Low Band Gap Polymers for Photovoltaic Devices
}

\author{
E. Bundgaard and F.C. Krebs, Risø National Laboratory, Roskilde, Denmark
}

\section{ABSTRACT}

The application of low band gap polymers in organic photovoltaics (OPV) is described. The synthesis of low band gap polymers based on thiophene and bezothiadiazole or benzobis-thiadiazole is described. The polymers were obtained by Stille cross-coupling polymerization. The band gaps of the polymers were estimated by UV-vis spectroscopy. This showed the polymers based on thiophene and benzothiadiazole have band gaps of 2.1-1.7 eV and the polymers based on thiophene and benzo-bis-thiadiazole have band gaps of $\sim 0.7 \mathrm{eV}$ for Photovoltaic devices were prepared using the pure polymer material and mixtures of the polymer and a soluble fullerene derivative.

\section{INTRODUCTION}

Organic photovoltaic (OPV) are one of the most promising devices in the search of sustainable renewable energy [1-3] Recently new interest has been focused on OPV since the ef ficiency has been reported to reach $5 \%$ [1] and the lifetime has been reported to be more than ten thousands hours [4]. The use of low band gap polymers in OPV is expected to increase the efficiency due to better overlap between the polymer absorption and the solar spectrum $[5,6]$. In the literature only a few families of low band gap polymers have been reported and the most important ones are polythiophenes [7-9], polyisothianaphtenes $[10,11]$ and copolymers of benzothiadiazole, thiophene and pyrrole $[6,12,13]$. These polymers have a band gap of 2.0 [14], 1.2 [10] and $1.6 \mathrm{eV}[5,12]$, respectively. These polymers have been applied in OPVs and the results have showed an efficiency of $4.4 \%$ for polythiohene [15], $1 \%$ for the copolymers of benzothiadiazole, thiophene and pyrrole [5] and $0.008 \%$ for polyisothianaphtenes [16]. The synthesis and characterization of low band gap polymers based on thiophene and bezothiadiazole or benzo-bis-thiadiazole of the types shown in Figure 1 was described by us earlier [17]. In this paper we will give a short summery of the results obtained.

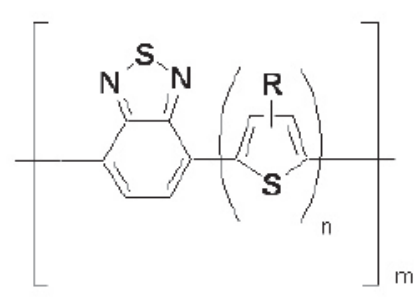

A

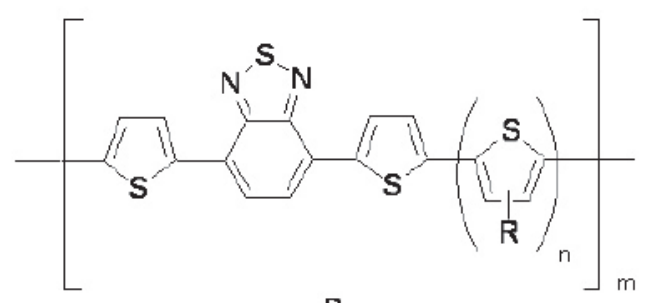

B

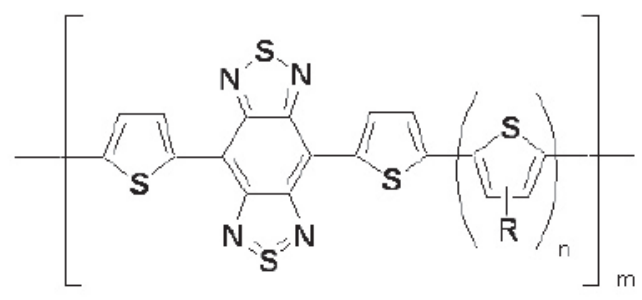

c

Figure 1: Types of polymers synthesized, $R=3,7,11$-trimethyldodecyl [17]. 


\section{SYNTHESIS}

\section{Monomers}

The thiophene monomers were synthesized as shown in Figure 2. First the alkyl group was added to 3-bromo-thiophene by a Kumada reaction [17]. Then the di-thiophene was synthesized by lithitation followed by addition of Iodine and trimethylstannyl-trimethyldodecyl-thiohene. Both the thiophene and the di-thiophene were dilithated to give monomers 1 and 2 [17].<smiles>[R]c1cc([Sn](C)(C)C)sc1[Sn](C)(C)C</smiles>

1

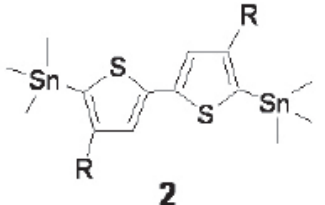

2
Figure 2: Thiophene monomers, $\mathrm{R}=3,7,11$-trimethyldodecyl.

The benzothiadiazole monomers 3 and 4 (Figure 3) were synthesized according to the literature [17]. The di-bromobenzo-bis-thiadiazole 5 was synthesized by a bromination of benzo-bis-thiadiazole using N-bromosuccinimid [17].

\section{Polymers}

The polymers were synthesized by Stille cross coupling polymerization of di-stannylderivates of thiophene or di-thiophene and di-bromo-derivates of benzothiadiazole or benzo-bisthiadiazole [17] as shown in Figure 4.

The polymers were synthesized with different alkyl side chains i.e. hexyl, 2-ethyl-hexyl and dodecyl to ensure solubility and good film formability of the polymer products. 3,7,11-Trimethyldodecyl as an alkyl side chain was found to give soluble polymer products with good film formability $[17,18]$.

\section{RESULTS AND DISCUSSION}

\section{Photophysical studies}

The polymers were analyzed by UV-vis and the spectra are given in Figure 5. It can be seen from Figure $5 b$ that polymers based on thiophene and benzo-bis-thiadiazole absorbs light even further out than $1100 \mathrm{~nm}$. NIR spectra of the two polymers based on thiophene and benzo-bis-thiadiazole, 8 and 11 , showed that the absorption goes out to around $1800 \mathrm{~nm}$ [17].<smiles>Brc1ccc(Br)c2nsnc12</smiles>

3<smiles>Brc1ccc(-c2ccc(-c3ccc(Br)s3)c3nsnc23)s1</smiles>

4<smiles>Brc1ccc(-c2c3c(c(-c4ccc(Br)s4)c4nsnc24)N=S=N3)s1</smiles>

\section{5}

Figure 3: Benzothiadiazole and benzo-bis-thiadazole monomers. 


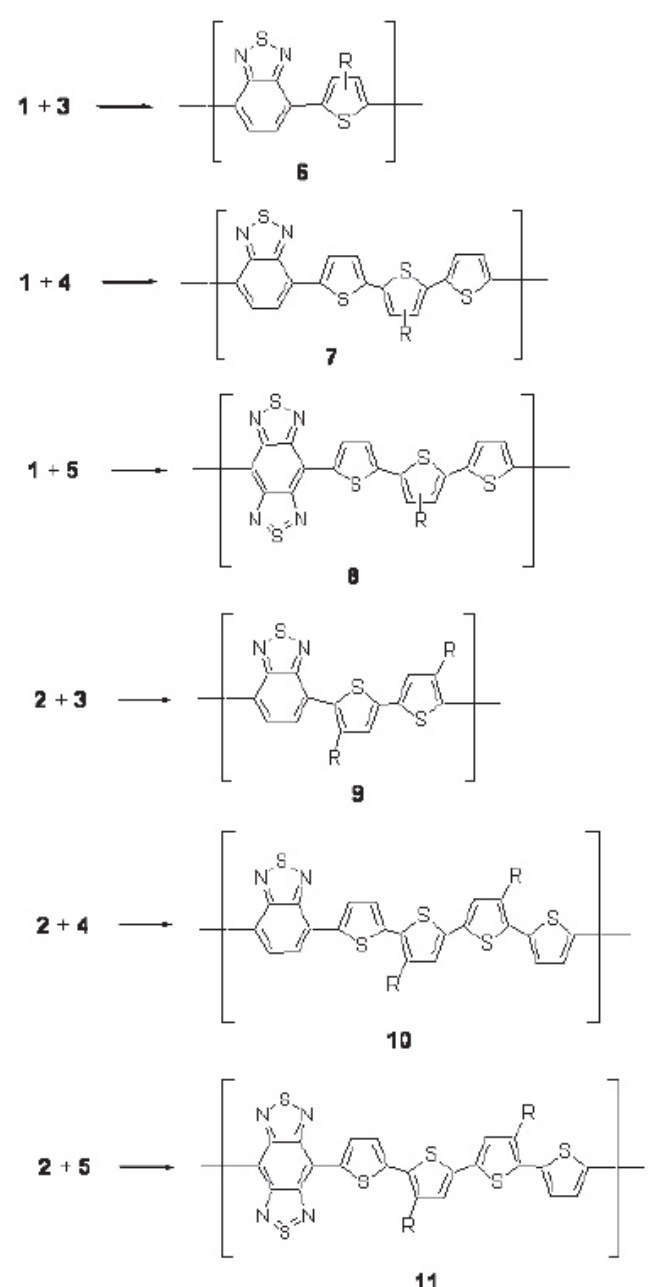

Figure 4: Synthesis of polymer 6 - 11 by Stille cross coupling polymerisation.

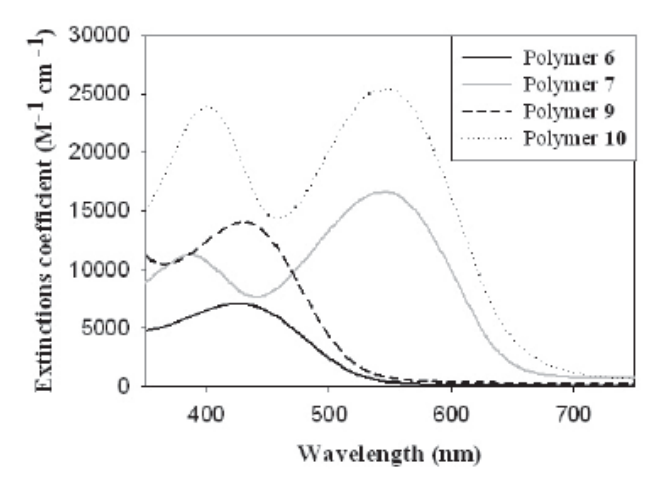

a.

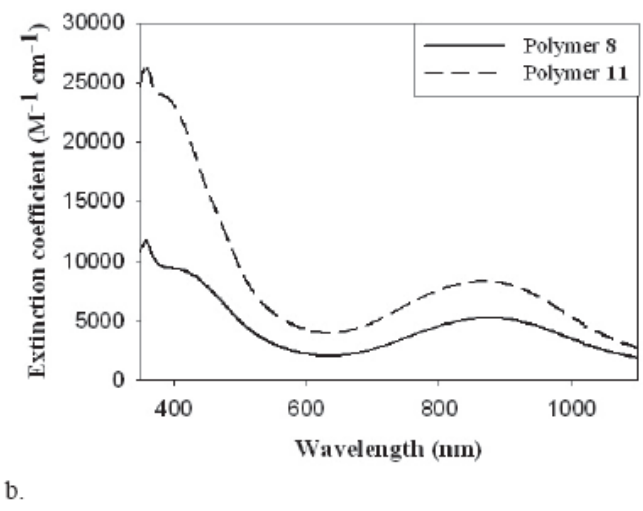

Figure 5: UV-vis spectra of low band gap polymers based on a) thiophene and benzothiadiazole and b) thiophene and benzo-bis-thiadiazole.

The band gaps of the polymers were estimated from UV-vis and these are summarized in Table 1.

Table 1: Band gap estimated from UV-vis.

\begin{tabular}{|c|c|}
\hline Polymer & Band gap (eV) \\
\hline 6 & 2.1 \\
\hline 7 & 1.82 \\
\hline 8 & 0.65 \\
\hline 9 & 2.10 \\
\hline 10 & 1.65 \\
\hline 11 & 0.67 \\
\hline
\end{tabular}


Comparing the polymers with the polymers described in the literature shows that polymer 6 and 9 have a band gap in the same region as polythiophene, polymer 7 has a band gap in the region between polythiophene and the copolymer of thiophene, pyrrole and benzothiadiazole, and polymer $\mathbf{1 0}$ has a band gap in the same region as the copolymer of thiophene, pyrrole and benzothiadiazole. Further it can be seen that the polymers 8 and 11 have a band gap even lower than polyisothianapthene [17]. From Table 1 it can also be seen that the polymers based on thiophene and benzothiadiazole, i.e. polymer 6, 7,9 and 10 show a decrease in band gap when the number of thiophenes in the polymer repeating unit increases [17].

\section{Photovoltaic studies}

Polymer 10 was applied in large area photovoltaic devices (3 $\mathrm{cm}^{-2}$. The compositions of the devices were: ITO-PEDOT-10 Al (1) and ITO-PEDOT-10/PCBM (1:1)-Al (2). The results obtained are given in Table 2.

Table 2: Photovoltaic response of device 1) ITO-PEDOT-10$\mathrm{Al}$ and 2) ITO-PEDOT-10/PCBM-A1.

\begin{tabular}{|c|c|c|c|c|}
\hline Device & $\begin{array}{c}\mathrm{I}_{\mathrm{vc}}\left(\mathrm{mA} / \mathrm{cm}^{-}\right. \\
\left.{ }^{2}\right)\end{array}$ & $\begin{array}{c}\mathrm{V}_{\text {oc }} \\
(\mathrm{V})\end{array}$ & $\mathrm{FF}\left(\sigma_{0}\right)$ & $\begin{array}{c}\eta \\
(\%)\end{array}$ \\
\hline 1 & -0.012 & 0.69 & 25 & 0.002 \\
\hline 2 & -2.3 & 0.60 & 37 & 0.51 \\
\hline
\end{tabular}

In Table 2 it can be seen that the efficiency is increased significantly when PCBM is added as expected. This is due to PCBM working as electron acceptor and thereby helps separating the electron and hole [19]. Though the efficiency has been increased it is still low and further work is in progress to optimize the photovoltaic response for large area devices.

\section{CONCLUSION}

The important use of low band gap polymers in OPVs were described and the synthesis and characterization of six new low band gap copolymers of thiophene and benzothiadiazole or benzo-bis-thiadiazole has been described.

\section{ACKNOWLEDGEMENT}

This work was supported by the Danish Technical Research Council (STVF 2058-03-0016), the Danish Strategic Research Council (DSF 2104-04-0030, 2104-05-0052).

\section{REFERENCES}

1. C. J. Brabec, "Organic photovoltaics: technology and market", Sol. Ener. Mater. Sol. Cells, 83, 273, 2004.
2. C. J. Brabec, N. S. Sariciftci, J. C. Hummelen, "Plastic solar cells", Adv. Func. Mater., 11, 15, 2001.

3. H. Hoppe, N. S. Saricftci, "Organic solar cells: An overview", J. Mater. Res., 19, 1924, 2004.

4. F. C. Krebs, H. Spanggaard, "Significant improvement of polymer solar cell stability", Chem. Mater., 17, 5235, 2005 .

5. C. J. Brabec, C. Winder, N. S. Sariciftci, J. C. Hummelen, "Alow-bandgap semiconducting polymer for photovoltaic devices and infrared emitting diodes", Adv. Func. Mater., $12,709,2002$.

6. A. Dhanabalan, J. K. J. van Duren, P. A. van Hal, J. L. J. van Dogen, R. A. J. Janssen, "Synthesis and characterization of a low bandgap conjugated polymer for bulk heterojunction photovoltaic cells", Adv. Func. Mater., 11, $255,2001$.

7. M. R. Anderson, O. Thomas, W. Mammo, M. Svensson, M. Theander, O. Iganäs, "Substituted polythiophenes designed for optoelectronic devices and conductors", $J$. Mater: Chem., 9, 1933, 1999.

8. J. Roncali, "Synthetic principles for bandgap control in linear $\pi$-conjugated systems", Chem. Rev., 97, 173, 1997.

9. R. D. McCullough, "The chemistry of conducting polythiophene", Adv. Mater:, 10, 93, 1998.

10. R. H. L. Kiebooms, H. Goto, K. Akagi, "Synthesis of a new class of low-band-gap polymers with liquid crystalline substituents", Macromolecules, 34, 7989, 2001.

11. F. Wudl, M. Kobayashi, A. J. Heeger, "Poly(isothianaph thene)", J. Org. Chem., 49, 3382, 1984.

12. J. K. J. van Duren, A. Dhanabalan, P. A. van Hal, R. A. J. Janssen, "Low-bandgap polymer photovoltaic cells", Synth. Metals, 121, 1587, 2001.

13. C. Winder, N. S. Sariciftci, "Low bandgap polymers for photon harvesting in bulk heterojunction solar cells", $J$. Mater: Chem., 14, 1077, 2004.

14. U. Slazner, J. B. Lagowski, P. G. Pickup, R. A. Poirier, "Comparison of geometries and electronic structures of polyacetylene, polyborole, polycyclopentadiene, polypyrrole, polyfuran, polysilole, polyphosphole, polythiophene, polyselenophene and polytellurophene", Synth. Metal, 96, $177,1998$. 
15. G. Li, V. Shrotriya, J. Huang, Y. Yao, T. Moriarty, K. Emery, Y. Yang, "High-efficiency solution processable polymer photovoltaic cells by self-organization of polymer blends", Nature Mater, , 4, 864, 2005.

16. A. Henckens, M. Knipper, I. Polec, J. Manca, L. Lutsen, D. Vanderzande, "Poly(thienylene vinylene) derivatives as low band gap polymers for photovoltaic applications", Thin Solid Films, 451-452, 572, 2004.

17. E. Bundgaard, F. C. Krebs, "Low band gap polymers based on thiophene, benzothiadiazole and benzo-bisthiadiazole", Macromolecules, accepted, 2006.
18. E. Bundgaard, F. C. Krebs, "A comparison of the photovoltaic response of head-to-head and head-to-tail coupled poly $\{$ (benzo-2,1,3-thiadiazol-4,7-diyl)-(dihexyl[2,2']dithi ophene-5,5'-diyl\}.", Pol. Bull., 55, 157, 2005.

19. E. Bundgaard, F. C. Krebs, "Large area photovoltaics based on copolymers of thiophene and benzothiadiazole", Macromolecules, submitted for publication, 2006. 


\title{
Low band gap polymers for organic solar cells
}

\author{
Eva Bundgaard ${ }^{1 \mathrm{a}, \mathrm{b}}$, Frederik C. Krebs ${ }^{\mathrm{a}}$ \\ ${ }^{2}$ Polymer Solar Cell Initiative, The Danish Polymer Centre, Risø National Laboratory, \\ PO Box 49, DK-4000 Roskilde, Denmark \\ ${ }^{\mathrm{b}}$ Institute for Biology and Chemistry, Roskilde Universitetscenter, \\ PO Box 260, DK-4000 Roskilde, Denmark
}

\begin{abstract}
The synthesis of copolymers based on thiophene. benzothiadiazole and benzo-bis-thiadiazole are described. The polymers were obtained by employing Stille cross coupling polymerization. The polymers were characterized by NMR, size exclusion chromatography, UV-vis and ultraviolet photoelectron spectroscopy. The results obtained from UV-vis and ultraviolet photoelectron spectroscopy showed band gaps of $2.1-1.7 \mathrm{eV}$ for polymers based on benzothiadiazole and $0.7 \mathrm{eV}$ for polymers based on benzo-his-thiadiazole. Furthermore the results showed that the hand gap decreases with an increase in the number, $n$, of thiophenes in the polymer repeating unit $(n=1-4)$. Large area photovoltaic devices were prepared and the results of these devices are described
\end{abstract}

Keywords: Low band gap polymers, ultraviolet photoelectron spectroscopy (UPS), organic solar cells

\section{INTRODUCTION}

The past decade low band gap polymers have received more attention since it is believed that due to a better overlap with the solar spectrum these polymers will lead to an increase in the power conversion efficiency. ${ }^{1-4}$

However, low band gap polymers for organic solar cells are a challenge to synthesize. So far there have been relatively few exampies of low band gap conjugated polymer materials for polymer solar cells. The most important ones are: polyisothianaphthenes, ${ }^{5,6}$ polythiophene ${ }^{7,8}$ and copolymers of thiophene, pyrrole and benzothiadiazole. ${ }^{2.4}$ The band gaps of these polymers are $1.2^{9}, 2.0^{1.3}$ and $1.6^{5} \mathrm{eV}$, respectively. In this work the successful synthesis and characterization by Size Exclusion Chromatography (SEC), UV-vis and Ultraviolet Photoelectron Spectroscopy (UPS) of copolymers based on thiophene, benzothiadiazole and benzo-bis-thiadiazole is described (Chart 1$).^{10}$

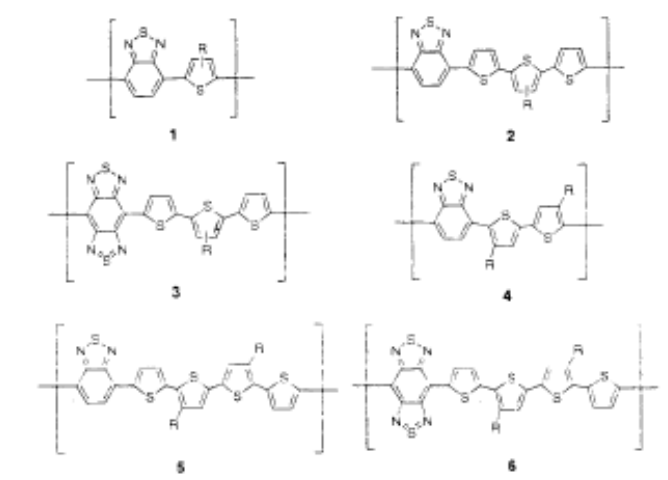

Chart 1: Copolymers of thiophene, benzothiadiazole and benzo-bis-thiadiazole. $R=3,7,11$-trimethyl-dodecyl. ${ }^{\text {iv }}$

eva bundgaard@ risoe.dk; phone +4546775498 ; fax +4546774791 ; ww risoe.dk/solarcells

Organic Photovoltaics VII. edited by Zakya H. Kafaf, Paul A. Lane.
Proc. of SPIE Vol. $6334,63340 \mathrm{~T},(2006) \cdot 0277-786$ X/O6/\$15 doi: $10.1117 / 12.679012$

Proc. of SPIE Vol. $633463340 \mathrm{~T}-1$ 
Results obtained from large area organic photovoltaic devices are presented (for general reviews on organic photovoltaics see ref. 11)

\section{EXPERIMENTAL}

Monomers. Lithiation of alkyl-thiophene. To a mixture of alkyl-thiophene ( $7 \mathrm{mmol})$ and TMEDA (10.5 mmol) in hexane $(50 \mathrm{~mL})$ at $-78^{\circ} \mathrm{C}, n \mathrm{BuLi}(10.5 \mathrm{mmol})$ was added drop wise. The mixture was allowed to reach room temperature and was left to stir for 2 hours. The reaction mixture was then cooled back down to $-78^{\circ} \mathrm{C}$ and $\mathrm{Me}_{3} \mathrm{SnCl}(17 \mathrm{mmol})$ was added drop wise. The reaction was stirred at room temperature for 1 hour and then washed with water. The organic phase was dried with $\mathrm{MgSO}_{4}$, filtered. concentrated by evaporation and purified by kugelrohr distillation. ${ }^{10}$

Di-thiophene. To a mixture of alkyl-thiophene $(13.6 \mathrm{mmol})$ in THF $(100 \mathrm{~mL})$ at $-78^{\circ} \mathrm{C}, n \mathrm{BuLi}(34 \mathrm{mmol})$ was added drop wise. After 10 minutes a solution of $\mathrm{I}_{2}$ in THF was added drop wise until a color change was observed. The reaction was allowed to reach room temperature before $\mathrm{Pd}\left(\mathrm{PPh}_{3}\right)_{2} \mathrm{Cl}_{2}(0.9 \mathrm{mmol})$ was added and the mixture was heated to reflux. Then trimethyltin-alkyl-thiophene (12.2 mmol) was added drop wise, and the reaction was left stirring overnight under reflux. The reaction was cooled, evaporated and filtered through silica using hexane before purification by kugelrohr destillation. ${ }^{10}$

Dilithation of alkvl-thiophene. To a mixture of alkyl-thiophene $(3.4 \mathrm{mmol})$ in hexane $(25 \mathrm{~mL}), t \mathrm{BuLi}(17 \mathrm{mmol})$ was added drop wise at $-78^{\circ} \mathrm{C}$. The reaction mixture was left stirring at room temperature for 3 days. The reaction mixture was then cooled back down to $-78^{\circ} \mathrm{C}$ and $\mathrm{Me}_{3} \mathrm{SnCl}(23.8 \mathrm{mmol})$ was added drop wise. The reaction was stirred at room temperature for 1 hour and then washed with water. The organic phase was dried with $\mathrm{MgSO}_{4}$, filtered, concentrated by evaporation and purified by kugelrohr distillation.

Dilithiation of di-thiophene. To a mixture of alkyl-di-thiophene $(3.4 \mathrm{mmol})$ and TMEDA (10.2 mmol) in hexane (50 $\mathrm{mL}), n \mathrm{BuLi}(10.2 \mathrm{mmol})$ was added drop wise at $-78^{\circ} \mathrm{C}$. The reaction mixture was left stirring at room temperature for 1 hour. The reaction mixture was then cooled back down to $-78^{\circ} \mathrm{C}$ and $\mathrm{Me}_{3} \mathrm{SnCl}(17 \mathrm{mmol})$ was added drop wise. The reaction was stirred at room temperature for 1 hour and then washed with water. The organic phase was dried with $\mathrm{MgSO}_{4}$, filtered, concentrated by evaporation and purified by kugelrohr distillation.

Di-bromo derivate of benzo-bis-thiadiazole. Di-thiophene-benzo-bis-thiadiazole ( $2 \mathrm{mmol})$ was dissolved in chloroform $(500 \mathrm{~mL})$ by refluxing for 2 hours. Acetic acid $(500 \mathrm{~mL})$ was added and NBS $(5.1 \mathrm{mmol})$ in chloroform/acetic acid $(5$ $\mathrm{mL}, 1: 1)$ was added drop wise in darkness. The reaction was stirred at room temperature for $2 \frac{1}{2} 2$ hour, then filtered and the resulting solid was recrystallized from DMF. ${ }^{10}$

Stille cross coupling polymerization. ${ }^{12}$ The di-stannyl derivate of thiophene or di-thiophene $(0.5 \mathrm{mmol})$ and the dibromo derivate of benzothiadiazole or benzo-bis-thiadiazole $(0.5 \mathrm{mmol})$ was dissolved in $\mathrm{DMF}(150 \mathrm{~mL})$ and the solution was degassed with argon. $\mathrm{Pd}\left(\mathrm{PPh}_{3}\right)_{2} \mathrm{Cl}_{2}\left(6 \times 10^{-2} \mathrm{mmol}\right)$ was added and the reaction was heated to $150{ }^{\circ} \mathrm{C}$. After 2 hours a pre-polymer precipitated and THF $(75 \mathrm{~mL})$ was added to dissolve the pre-polymer and continue the polymerization at reflux over night. The reaction mixture was cooled and THF was removed by evaporation. The solution was poured into methanol to precipitate the polymer. Filtration of the suspension resulted in the polymer product, which was purified by Soxhlett extraction with successively use of methanol, hexane and chloroform. The chloroform fraction was concentrated and further purification was carried out on preparative SEC. ${ }^{10}$ The polymer was purified from palladium as described in the literature. ${ }^{13}$

Further experimental detail have been described earlier. ${ }^{10}$

UV-vis. The UV-vis and Near Infrared (NIR) spectra were obtained from chloroform solutions. No significant red or blue shift was observed when comparing spectra obtained from solution and film. ${ }^{10}$

Ultraviolet Spectroscopy (UPS). A gold film was thermally evaporated on to an aluminum substrate with subsequent spin coating of a $2.7 \mu \mathrm{m}$ filtered polymer solution onto the gold substrate. The UPS measurements were carried out at the ASTRID synchrotron at Aarhus University and further details on the measurements have been described eise where. ${ }^{10.14}$ Photovoltaic measurements. A mixture of polymer and PCBM (1:2) in chlorobenzene (10 mg polymer/mL) was filtered through a $2.7 \mu \mathrm{m}$ porous filter and spin-coated onto PEDOT:PSS coated ITO glass slides. An aluminum electrode was thermally evaporated onto the film in a vacuum chamber at a pressure of $<5 \times 10^{-6} \mathrm{mbar}$. The active area of the device was $3 \mathrm{~cm}^{2}$ or $10 \mathrm{~cm}^{2}$. The $10 \mathrm{~cm}^{2}$ device was encapsulated as described in the literature. Details on device preparation and setup for data measurements have been described earlier. ${ }^{16.13}$ 


\section{RESULTS AND DISCUSSION}

3.1 Synthesis of monomers

The polymers 1-6 were synthesized by Stille cross coupling polymerication between di-stannyi derivates of thiophene and di-thiophene and di-bromo derivates of benzothadiazole and benzo-bis-thadiadiazole. ${ }^{10}$

The di-thiophene, 7, was synthesized from 3-alkyl-thiophene by lithation with $n$ BuLi, addition of $\mathrm{I}_{2}$ and finally reaction with trimethylstannyl-alkyl-thiophene (Scheme 1). ${ }^{10}$
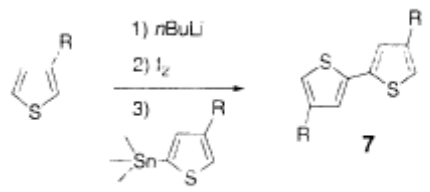

$\mathrm{Pd}(\mathrm{PPh})_{2} \mathrm{Cl}_{2}$

Scheme 1: Synthesis of di-thiophene. 7. $R=3,7,11$-trimethyl-dodecyl.

The di-stannyl derivate of thiophene, 8 , was synthesized by dilithation of 3-alkyl-thiophene with $t$ BuLi followed by reaction with $\mathrm{Me}_{3} \mathrm{SnCl}$ (Scheme 2). ${ }^{10}$ And the di-stannyl derivate of di-thiophene, 9, was synthesized by dilithation of 7 with $n \mathrm{BuLi}$ and TMEDA followed by reaction with $\mathrm{Me}_{3} \mathrm{SnCl}$ (Scheme 2 ). ${ }^{10}$

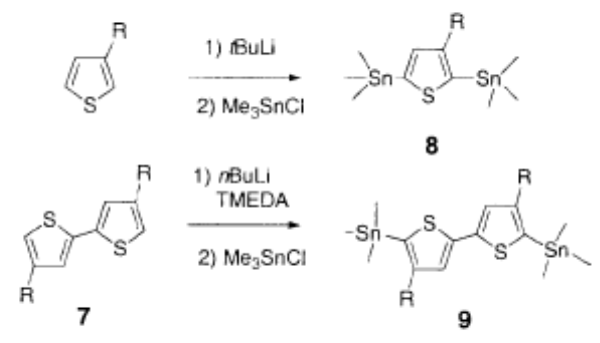

Scheme 2: Synthesis of di-stannyl derivates of thiophene, 8 and di-thiophene, 9.

The synthesis of di-bromo derivates of benzothiadiazole, $\mathbf{1 0}$ and $\mathbf{1 1}$, is described in the literature (Scheme 3 ). ${ }^{18}$ The dibromo derivate of benzo-bis-thiadiazole, 12, was synthesized by reaction of di-thiophene-benzo-bis-thiadiazole with NBS in chloroform and acetic acid (Scheme 3 ). ${ }^{10}$

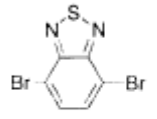

10

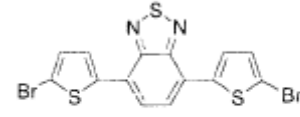

11

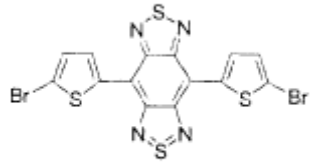

12

Scheme 3: Di-bromo derivates of benzothiadiazole, 10 and 11, and benzo-bis-thiadiazole, 12 
3.2 Synthesis of polymers The polymers 1-6 were synthesized by Stille cross coupling polymerization using $\mathrm{Pd}\left(\mathrm{PPh}_{3}\right)_{2} \mathrm{Cl}_{2}$ as a catalyst (Scheme

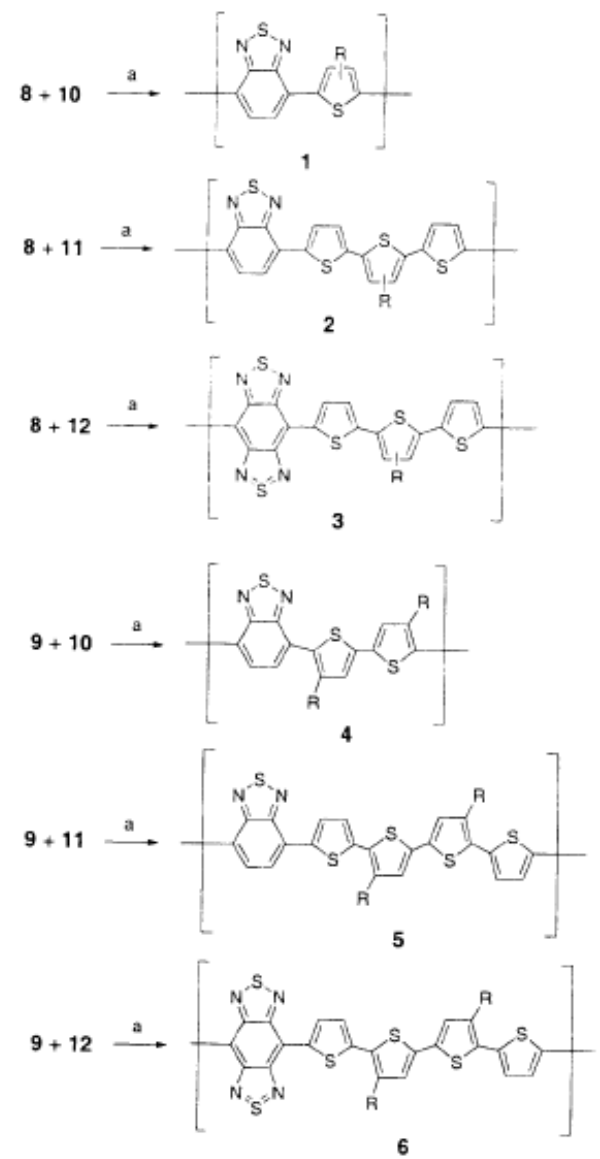

Scheme 4: Synthesis of polymer 1-6 by Stille cross coupling polymerization. a) $\mathrm{Pd}\left(\mathrm{PPi}_{13}\right) \mathrm{Cl}_{2}, \mathrm{R}=3,7,11$-trimethyl-dodecyl.

The SEC data of the purified polymers is given in Table $1 .^{10}$

Proc. of SPIE Vol. $633463340 T-4$ 
Table 1: SEC data of polymer 1-6. The polymers were analyzed on a gel column system comprising a succession of a $500 \AA$. $10000 \AA$ and $1000000 \AA$ in pore diameter. Polymer standards were used for molecular weight distribution. The wavelength of the detector was $500 \mathrm{~nm}$.

\begin{tabular}{cccc}
\hline Polymer & $\mathrm{M}_{\mathrm{w}}$ & $\mathrm{M}_{\text {neak }}$ & $\mathrm{M}_{\mathrm{w}} / \mathrm{M}_{n}$ \\
\hline $\mathbf{1}$ & 5800 & 4800 & 14 \\
$\mathbf{2}$ & 2300 & 2100 & 1.3 \\
$\mathbf{3}$ & 7100 & 8600 & 1.9 \\
$\mathbf{4}$ & 9400 & 9500 & 1.8 \\
$\mathbf{5}$ & 14000 & 12000 & 1.9 \\
$\mathbf{6}$ & 12000 & 11000 & 2.1 \\
\hline
\end{tabular}

3.3 UV-vis spectroscopy

The UV-vis spectra of polymer 1-6 are shown in Fig. 1 and the extinction coefficients at $\lambda_{\max }$ are given in Table 2. ${ }^{10}$

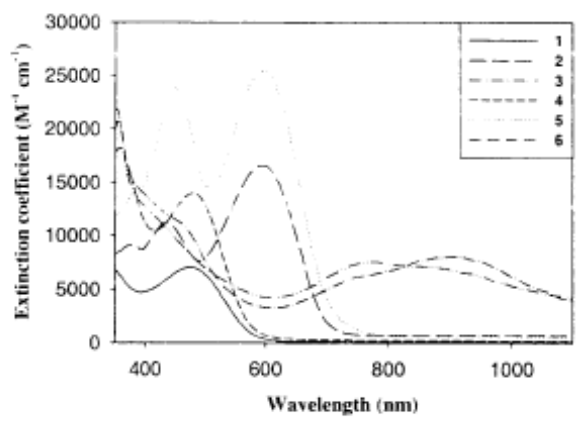

Figure 1: UV-vis spectra of polymer 1-6

From Fig. 1 and Table 2 it is evident that the extinction coefficient at $\lambda_{\max }$ for polymer $\mathbf{5}$ is larger compared to polymer $\mathbf{1}$, 2, 3, 4 and 6. Furthermore, there is a small red-shift in $\lambda_{\max }$ for polymer 4,5 and 6 synthesized from di-thiophene compared to polymer $\mathbf{1 , 2}$ and $\mathbf{3}$ synthesized from thiophene. This is ascribed to the number of thiophenes (n) in the repeating unit which influences the conjugation length in the polymer and hence, the larger number of thiophenes in the repeating unit results in a red shift in the UV-vis spectra. It can be seen from Fig. 1 that the polymer based on benzo-bisthiadiazole, $\mathbf{3}$ and 6, absorbs light above $1100 \mathrm{~nm}$. The NIR spectra (Fig. 3) show that polymer $\mathbf{3}$ and $\mathbf{6}$ absorbs light up until around $1800 \mathrm{~nm}$.

Table 2: Extinction coefficients at $\lambda_{\max }$ for polymer 1-6.

\begin{tabular}{ccc}
\hline Polymer & $\lambda_{\max }(\mathrm{nm})$ & $\varepsilon\left(\mathrm{M}^{-1} \mathrm{~cm}^{-1}\right)$ \\
\hline $\mathbf{1}$ & 477 & 7056 \\
$\mathbf{2}$ & 435 & 11228 \\
& 602 & 165909 \\
$\mathbf{3}$ & 770 & 7609 \\
$\mathbf{4}$ & 479 & 14000 \\
$\mathbf{5}$ & 450 & 23994 \\
& 597 & 25420 \\
$\mathbf{6}$ & 902 & 8081 \\
\hline
\end{tabular}

The band gaps were estimated from the UV-vis spectra by drawing a tangent to the absorption curve and converting the cut-off value to $\mathrm{eV} .2$ The band gaps are presented in Table 3 . The band gap for polymer 1 and 4 ( $\mathrm{n}=1$ and 2 , 
respectively) are in the same region as polythiophene $(2.0 \mathrm{eV})$, whereas the band gap for polymer 2 ( $\mathrm{n}=3$ ) is in the region between polythiophene and the copolymer of benzothiadiazole, thiophene and pyrrole $(1.6 \mathrm{eV})$, polymer $5(\mathrm{n}=4)$ is in the same region as the copolymer of thiophene, pyrrole and benzothiadiazole. Polymer 3 and 6 ( $n=3$ and 4 . respectively) has lower band gaps than polyisothianaphthene $(1.2 \mathrm{eV})$. The data also shows that the band gap is decreasing with an increase in the number of thiophenes $(n)$ in the repeating unit of the polymer. Furthermore, it can be seen that the benzobisthiadiazole ring lowers the band gap of the polymer significantly (from 1.7 to $0.7 \mathrm{eV}$ ).
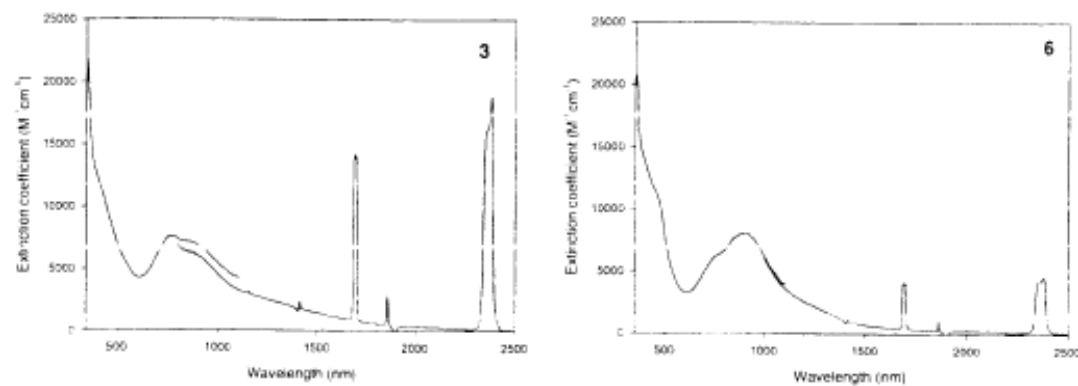

Figure 2: NIR spectra of polymer 3 and 6 . The peaks at 1400, 1600, 1900 and $2400 \mathrm{~nm}$ are ascribed to the instrument.

\subsection{UItraviolet Photoelectron Spectroscopy}

The UPS spectra and the band structure of polymer 5 and 6 are shown in Fig. $3^{10}$ (for UPS spectra and electronic band structure of polymer 1-4 see ref. 10).
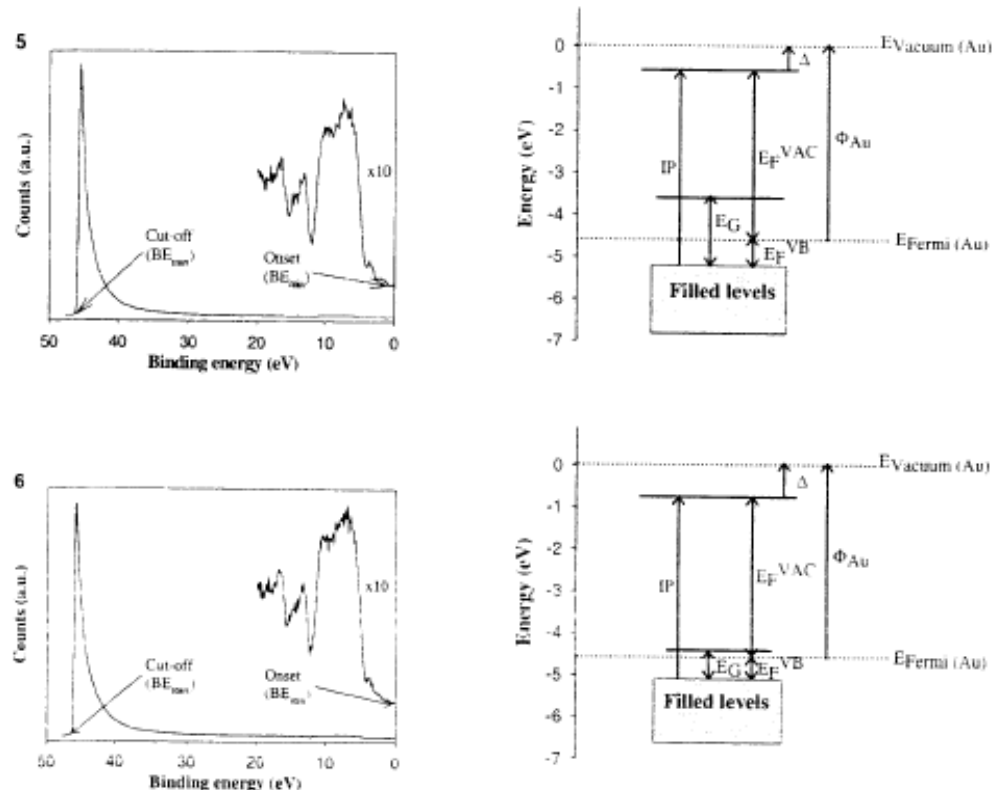

Figure 3: LPS spectra and electronic band structure of polymer 5 and 6 
From the cut-off $\left(\mathrm{BE}_{\max }\right)$ and the on-set $\left(\mathrm{BE}_{\min }\right)$ in the UPS spectra the data reported in Table 3 can be obtained by the following equations: ${ }^{14}$

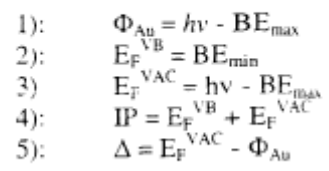

where $\Phi_{\mathrm{Au}}$ is the work function of gold (i.e. the Fermi level of gold), $\mathrm{E}_{\mathrm{F}}{ }^{\mathrm{B}}{ }^{\mathrm{B}}$ is the injection barrier for holes from gold into the valance band (or the Highest Occupied Molecular Orbital, HOMO) of the polymer material. E ${ }_{\mathrm{F}}^{\mathrm{vaC}}$ is the distance from the Fermi level to the vacuum level, IP is the ionization energy and $\Delta$ is the vacuum level shift. ${ }^{14}$ These parameters together with the band gap $\left(E_{G_{1}}\right)$ estimated from the UV-vis spectra gives the electronic band structure shown in Fig. 3 for polymer 5 and 6.

Tahle 3: UPS data from the photoelectron spectra of polymer 1-6. The hand gaps ( $F_{G}$ ) were estimated from the IIV-vis and NIR spectra in Fig. 2 and 3.

\begin{tabular}{cccccc}
\hline Polymer & $\mathrm{E}_{\mathrm{F}}{ }^{\mathrm{VB}}(\mathrm{eV})$ & $\mathrm{E}_{\mathrm{F}}{ }^{\mathrm{AC}}(\mathrm{eV})$ & $\mathrm{IP}(\mathrm{cV})$ & $\Delta(\mathrm{eV})$ & $\mathrm{E}_{\mathrm{g}}(\mathrm{eV})$ \\
\hline $\mathbf{1}$ & 1.44 & 3.96 & 5.40 & -0.64 & 2.10 \\
$\mathbf{2}$ & 0.80 & 4.04 & 5.84 & -0.56 & 1.82 \\
$\mathbf{3}$ & 0.52 & 3.92 & 4.44 & -0.68 & 0.65 \\
$\mathbf{4}$ & 1.11 & 3.81 & 4.92 & -0.79 & 2.10 \\
$\mathbf{5}$ & 0.63 & 4.04 & 4.67 & -0.56 & 1.65 \\
$\mathbf{6}$ & 0.48 & 3.86 & 4.34 & -0.74 & 0.67 \\
\hline
\end{tabular}

From Table 3 and Fig. 3 it can be seen that the Fermi level of gold, which should lie in the middle of the optical band gap, lies very close to the Lowest Unoccupied Molecular Orbital (LUMO) for polymer 6 (this is also seen for polymer 3 ). This could be due to doping of the polymer and hence the band gap would be underestimated. Treatment with chemical reducing agents such as hydrazine and ammonia showed neither $n$ nor $p$ doping. The low values of the $E_{F}{ }^{\mathrm{VB}}$ also support the estimation from UV-vis and NIR of a very low band gap for polymer $\mathbf{3}$ and $\mathbf{6}$.

From the UPS measurements the HOMO is determined and the LUMO can be estimated using the band gap. These results are then used to compare the polymer energy levels with the energy levels of the electrodes in a photovoltaic device (Fig. 4).

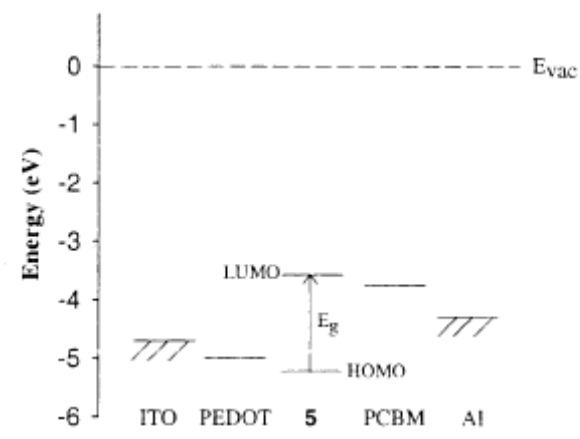

Figure 4: Energy level diagram in a photovoltaic device with polymer $\mathbf{5}$ derived from the UPS data.

Proc. of SPIE Vol. 6334 63340T-7 
This shows that the HOMO level and the LUMO level of polymer $\mathbf{5}$ is in good alignment with the PEDOT and PCBM. respectively, and hence an efficient charge separation should be observed.

3.5 Photovoltaic measurements

Polymer $\mathbf{5}$ was applied in photovoltaic devices. The VV curve for the photovoltaic device of polymer $\mathbf{5}$ and of polymer $\mathbf{5}$ in a mixture with PCBM are shown in Fig. 5 and the photovoltaic performance is given in Table $4 .{ }^{17}$ Photovoltaic studies of polymer $\mathbf{1 . 4}$ and 6 are in progress.
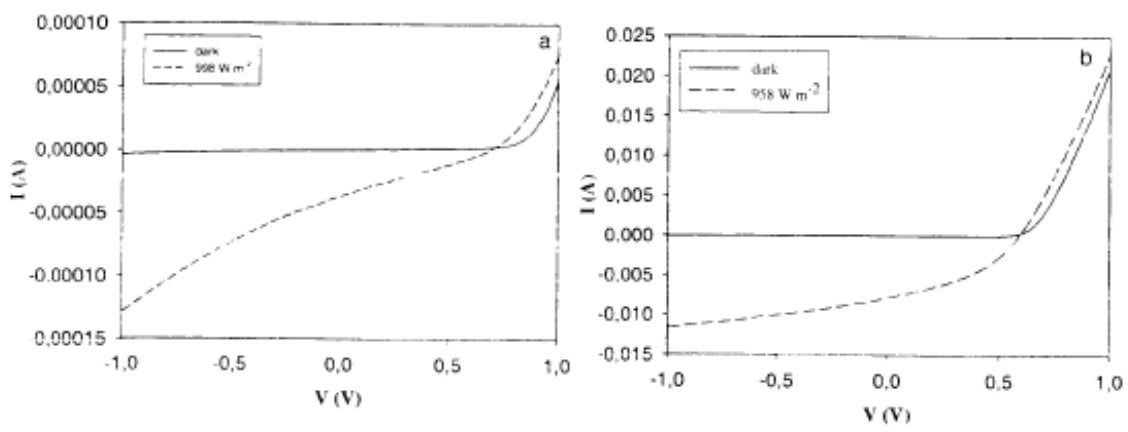

Figure 5: $\mathrm{l} / \mathrm{V}$-curves for the devices a): ITO/PEDOT/5/Al and b): ITO/PEDOT/5:PCBM (1:2)/Al. The L/V-curves were recorded under ambient conditions.

From Table 4 and Fig. 5 it can be seen that the addition of PCBM to the active layer increases the short circuit current, $\mathrm{I}_{\mathrm{SC}}$, from -0.012 to $-2.7 \mathrm{~mA} \mathrm{~cm}{ }^{-2}$ and hence increases the efficiency from 0.002 to $0.6 \%$ even though the open circuit voltage. $\mathrm{V}_{\mathrm{OC}}$, decreases from 0.69 to $0.58 \mathrm{~V}$. Furthermore, it can be seen that the $\mathrm{I}_{\mathrm{SC}}$ decreases from -2.7 to $-1.29 \mathrm{~mA} \mathrm{~cm}$ ${ }^{2}$ and the efficiency decreases from 0.6 to $0.2 \%$ when the active area of the device is increased from 3 to $10 \mathrm{~cm}^{2}$. This is ascribed to a poorer morphology for the large area device. ${ }^{17}$

Table 4: Photovoltaic performance of the devices of polymer 5 and polymer 5 mixed with PCBM (active area 3 on less otherwise noted, $1000 \mathrm{~W} \mathrm{~m}^{-2}, \mathrm{AM} 1.5$ )

\begin{tabular}{lllll}
\hline Device & $\mathrm{V}_{\propto c}(\mathrm{~V})$ & $\mathrm{I}_{\mathrm{sc}}\left(\mathrm{mA} \mathrm{cm} \mathrm{cm}^{-2}\right)$ & $\mathrm{FF}(\%)$ & $\eta(\%)$ \\
\hline $\mathbf{5}$ & 0.69 & -0.012 & 25 & 0.002 \\
$\mathbf{5} / \mathrm{PCBM}(1: 2)$ & 0.58 & -2.7 & 38 & 0.6 \\
$\mathbf{5} / \mathrm{PCBM}(1: 2), 10 \mathrm{~cm}^{2}$ & 0.56 & -1.29 & 28 & 0.2 \\
\hline
\end{tabular}

The absorption spectra and the photocurrent spectra showed good overlap of the absorption spectra of the device and the wavelength scan. ${ }^{17}$ From the wavelength scan the incident photon to current efficiency (IPCE) was found to be $22 \%$ at $560 \mathrm{~nm}$ for the $3 \mathrm{~cm}^{-2} 5 /$ PCBM device. ${ }^{17}$ The lifetime of the device with pure polymer 5 was recorded as the time for the efficiency to reach half of the maximum value. ${ }^{19}$ This showed a lifetime of less than 2 hours. ${ }^{17}$ The $10 \mathrm{~cm}^{2}$ device was encapsulated as described in the literature, ${ }^{15}$ and this device still showed photovoltaic response after several weeks stored in darkness under air. ${ }^{17}$

\section{CONCLUSIONS}

The synthesis of copolymers of thiophene, benzothiadiazole and benzo-bis-thiadiazole has been described. The polymers were synthesized by Stille cross coupling polymerization. The polymers were characterized by NMR, SEC and UV-vis. The band gaps were estimated from UV-vis to be 2.1-1.7 eV for polymers based on thiophene and benzothiadiazole and $0.7 \mathrm{eV}$ for polymers based on thiophene and benzo-bis-thiadiazole. The electronic structure of the polymers was 
determined by UPS. From UV-vis and UPS it can be seen that the band gap of the polymer decreases with an increase in the number of thiophene $(n)$ in the repeating unit of the polymer $(n=1-4)$. Polymer 5 was applied in large area photovoltaic devices. This showed an efficiency of $0.6 \%$ for a $3 \mathrm{~cm}^{-2}$ device with the composition ITO/PEDOT/5:PCBM (1:2)/Al.

\section{ACKNOWLEDGEMENT}

We gratefully acknowledge Zheshen Li for technical support at the ASTRID storage ring and the beam line and Lene Hubert for assistance with the ESCA measurements. This work was supported by the Danish Technical Research Council (STVF 2058-03-0016) and the Danish Strategic Research Council (DSF 2104-04-0030).

\section{REFERENCES}

1. C. J. Brabec, C. Winder, N. S. Sariciftci, J. C. Hummelen, A. Dhanabalan, P. A. van Hal and R. A. J. Janssen, "A low-bandgap semiconducting polymer for photovoltaic devices and infrared emitting diodes", Adv. Funct. Mater.. 12. 709-712, 2002.

2. A. Dhanabalan. J. K. J. van Duren. P. A. van Hal. J. L. J. van Dogen and R. A. J. Janssen. "Synthesis and characterzation of a low bandgap conjugated polymer for bulk heterojunction photovoltaic cells", Adv. Funct. Mater., 11, 255-262, 2001.

3. J. K. J. van Duren, A. Dhanabalan, P. A. van Hal and R. A. J. Janssen, "Low-bandgap polymer photovoltaic cells". Synth. Metal, 121, 1587-1588, 2001.

4. C. Winder, and N. S. Sariciftci, "Low band gap polymers for photon harvesting in bulk heterojunction solar cells", J. Mater. Chem., 14, 1077-1086, 2004.

5. R. H. L. Kiebooms, H. Goto and K. Akagi, "Synthesis of a new class of low-band-gap polymers with liquid crystalline substituents", Macromolecules, 34, 7989-7998, 2001

6. F. Wudl, M. Kobayashi and A. J. Heeger, "Poly(isothianaphthene)", J. Org. Chem., 49, 3382-3384, 1984.

7. J. Roncali, "Synthetic principels for bandgap control in linear $\pi$-conjugated systems", Chem. Rev., 97, 173-205, 1997.

8. R. D. McCullough, "The chemistry of conducting polythiohenes", Adv. Mater., , 10, 93-116, 1998.

9. U. Salzner, J. B. Lagowski, P. G. Pickup and R. A. Poirier, "Comparison of geometries and electronic structures of polyacetylene, polyborole, polycyclopentadiene, polypyrrole, polyfuran, polysilole, polyphosphole, polythiophene, polyselenophene and poltellurophene". Synth. Metal, 96, 177-189, 1998.

10. E. Bundgaard and F. C. Krebs, "Low band gap polymers based on thiophene, benzothiadiazole and benzobis(thiadiazole)", Macromolecules, 39, 2823-2831, 2006.

11. a) C. J. Brabec, N. S. Sariciftci, J. C. Hummelen, "Plastic solar cells", Adv. Funct. Mater., 11, 15-26, 2001, b) H. Spanggaard and F. C. Krebs, "A brief history of the development of organic and polymeric photovoltaics", Sol. Ener. Mat. \& Sol. Cells, 83, 125-146, 2004, c) H. Hoppe and N. S. Sariciftci, "Organic solar cells; an overview", J. Mater. Res., 19, 1924-1945, 2004, d) C. J. Brabec, "Organic photovoltaics: technology and market", Sol. Ener. Mat. \& Sol. Cells, 83, 273-292, 2004.

12. A. Iragi and G. W. Barker. "Synthesis and characterisation of telechelic regioregular head-to-tail poly(3alkylthiophenes)", J. Mater. Chem., 8, 25-29, 1998.

13. K. T. Nielsen, K. Bechgaard and F. C. Krebs, "Removal of palladium nanoparticles from polymer materials", Macromolecules, 38, 658-659, 2005 .

14. a) F, C. Krebs. "Directional polymerization and electronic properties of a cyanosubstituted dialkylphenylenevinylene", Polym. Bull., 52, 49-56, 2004, b) W. R. Salaneck, M. Lögdlund, M. Fahlman, G. Greczynski and Th. Kugler, "The electronic structure of polymer-metal interfaces studied by ultraviolet photoelectron spectroscopy", Mater. Sci. Eng., R34, 121, 2001.

15. F. C. Krebs, "Encapsulation of polymer photovoltaic prototypes"., Sol. Ener. Mat, \& Sol. Cells, 2006, in press.

16. F. C. Krebs and M. Jørgensen, "High power spectrometer for the characterisation of photovoltaic cells in a controlled atmosphere or vacuum", Rev. Sci. Instrum., 74, 3438-3441, 2003 ,

17. E. Bundgaard and F. C. Krebs, "Large area photovoltaics based on low band gap copolymers of thiophene and benzothiadiazoles", Macromolecules, submitted, 2006. 
18. a) Q. Hou, Y. Xu, W. Yang, M. Yuan, J. Peng, Y. Cao, J. Mater. Chem, 12, 2887-2892, 2002, b) K. Pilgram, M. Zupan, R. J. Skiles. J. Heterocycl. Chem., 7, 629-633, 1970.

19. F. C. Krebs and H. Spanggaard, "Significant improvement of polymer solar cell stability", Chem. Mater., 17, 2005, $5235-5237$

Proc, of SPIE Vol. $633463340 \mathrm{~T}-10$ 


\section{Low band gap polymers for organic solar cells}

Eva Bundgaard $^{a, b}$ and Frederik C. Krebs ${ }^{a}$

a Polymer Solar Cell Initiative, The Danish Polymer Centre, Ris $\phi$ National Laboratory, PO Box 49, DK-4000 Roskilde, Denmark.

${ }^{b}$ Institute for Biology and Chemistry, Roskilde Universitycenter, Universitetsvej 1 , PO Box 260, DK-4000 Roskilde, Denmark.

\section{Abstract}

The synthesis of copolymers based on thiophene, benzothiadiazole and benzobis(thiadiazole) is presented. The band gaps were estimated from UV-vis and the electron structure of the polymers were determined by Ultraviolet photoelectron spectroscopy (UPS). Results for some photovoltaic devices are given.

Introduction

The use of low band gap polymers for organic photovoltaic are believed to increase the efficiency of the device by a better overlap with the solar spectrum. The synthesis of low band gap polymers are however a challenge and only a few examples have been reported. The most important ones are polythiophene, polyisothianaphthene and copolymers of benzothiadiazole, thiophene and pyrrole with band gaps of 2.0, 1.2 and $1.6 \mathrm{eV}$, respectively. Here we present the synthesis and characterization of copolymers based on thiophene, benzothiadiazole and benzobisthiadiazole.

Synthesis

Monomers:

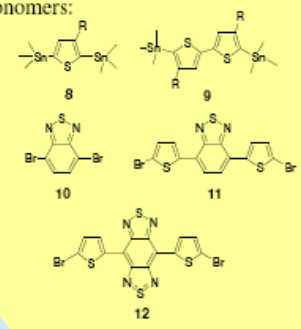

Stille cross coupling polymerization:

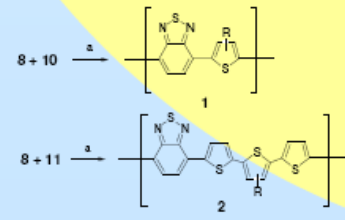

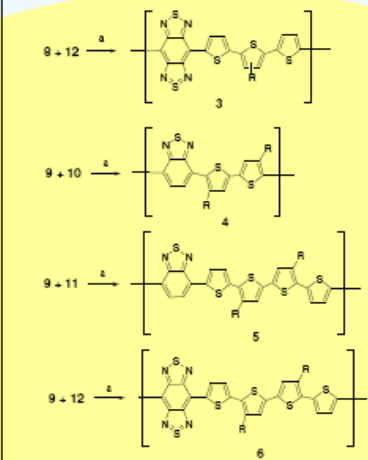

Results

SEC data for polymer 1-6:

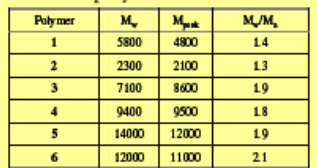

UV-vis spectra for polymer 1-6:

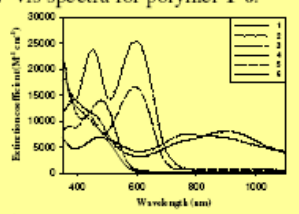

UPS data for polymer 1-6 ( $\mathrm{E}_{\mathrm{g}}$ estimated from UV-vis):

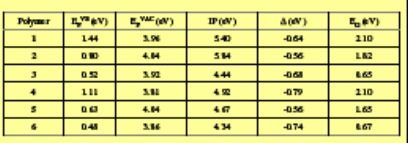

Energy levels in a photovoltaic device with $\mathbf{5}$ and PCBM:

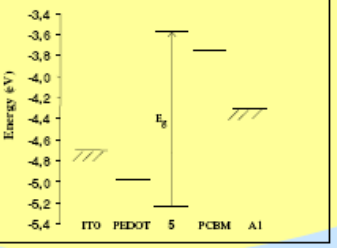

Photovoltaic devices were prepared with polymer $\mathbf{5}$ and with a blend of polymer $\mathbf{5}$ and PCBM. The photovoltaic performance for these devices is summarized in the table below.

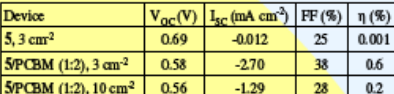
\begin{tabular}{|l|l|l|l|l|}
\hline SPCBM $(1: 2), 3 \mathrm{~cm}^{-2}$ & 0.58 & -270 & 38 & 0.6 \\
\hline 5 PPCBM $(1: 2), 10 \mathrm{~cm}^{2}$ & 0.56 & -1.29 & 28 & 0.2 \\
\hline
\end{tabular}

IV-curve for the polymer 5 and PCBM:

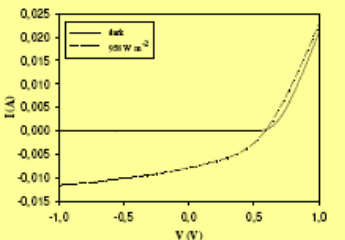

The photovoltaic studies showed:

- $\mathrm{I}_{\text {SC }}$ increased when PCBM was added. - Highest $\eta$ for 5/PCBM 1:2 ratio.

- $\mathrm{I}_{\mathrm{SC}}$ and $\eta$ decreases with increase in area ( 3 and $10 \mathrm{~cm}^{2}$ devices).

- Lifetime of less than 2 hours for non encapsulated devices.

- IPCE of $22 \%$ at $560 \mathrm{~nm}$ for ITO-PDOT5/PCBM (1:2)-Al.

Conclusion

Low band gap copolymers based on thiophene, benzothiadiazole and benzobis-thiadiazole were synthesized by Stille cross coupling polymerization and the band gaps were estimated to $2-1.7 \mathrm{eV}$ for polymers based on benzothiadiazole and $0.7 \mathrm{eV}$ for polymers based on benzobis(thiadiazole).

Polymer 5 was applied in large area photovoltaic devices $\left(3\right.$ and $\left.10 \mathrm{~cm}^{2}\right)$ with the configuration ITO-PEDOT-5/PCBM (1:2)-Al which gave a efficiency up to $0.6 \%$. Further work is in progress to apply all polymers in OPV and to improve the efficiency of the devices with polymer $\mathbf{5}$.

www.risoe.dk/solarcells, Tel (+45) 4677 5498, Fax(+45) 46774791, eva.bundgaard@risoe.dk 


\title{
Riso
}

\section{Photovoltaic devices with low band gap polymers}

\author{
Eva Bundgaard, Sean Shaheen ${ }^{b}$, David S. Ginley, Frederik C. Krebs ${ }^{a}$
}

aRISØ National Laboratory, Raskilde Denmank

${ }^{b}$ National Reneable Energy Laboratory, Colorado, USA

Abstract Progress in organic photovoltaic devices has recently resulted in reported efficiencies of up to $5 \%$ under solar illumination. Within the past decade low band gap polymers with band gaps $<1.8 \mathrm{eV}$ have received more attention since it is believed that due to a better overlap with the solar spectrum these polymers can increase the efficiency of the PV. Earlier we described the synthesis and characterization by NMR, SEC, UV-vis and UPS of copolymer based on thiophene and benzothiadiazole. In this presentation the dependence on different factors e.g. choice of solvent, spin coating speed and time, annealing temperature, active area of the device and molecular weight of the polymer, on the photovoltaic response of photovoltaic devices made with the copolymer.

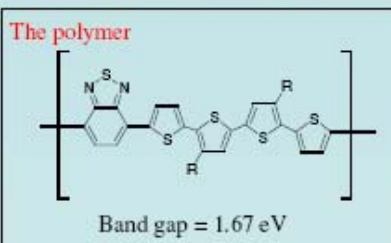

The device

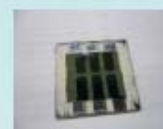

ITO/PEDOT:PSS/polymer:PCBM (1:2)/A1

- spin coated from 1,2-dichlorobenzene

- annealed for $10 \mathrm{~min}$. at different temperatures

Results and discussion

Concentration

\begin{tabular}{|c|c|c|c|c|}
\hline $\begin{array}{c}\text { Conoentration } \\
(\mathrm{mg} / \mathrm{mL})\end{array}$ & $\begin{array}{c}J_{S C} \\
(\mathrm{~mA} C \mathrm{~m}-2)\end{array}$ & $\begin{array}{c}V_{O C} \\
(\mathrm{~N})\end{array}$ & $\begin{array}{c}\mathrm{FF} \\
(\%)\end{array}$ & $\begin{array}{c}\eta \\
(\%)\end{array}$ \\
\hline 5 & 2.08 & 0.53 & 38 & 0.42 \\
\hline 10 & 3.39 & 0.61 & 43 & 0.89 \\
\hline 15 & 3.61 & 0.62 & 40 & 0.90 \\
\hline 20 & 1.91 & 0.57 & 36 & 0.39 \\
\hline
\end{tabular}

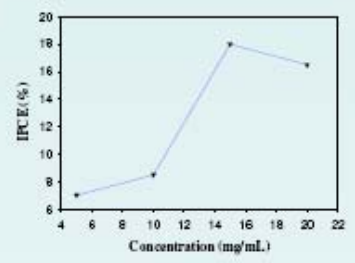

The increase in concentration or thicknes affects the $\eta$ and IPCE due to

- increase in $\mathrm{R}_{\mathrm{S}}$ and hence a low FF if the mobility of the polymer is low

- light absorption at the glass slide in the thick film.
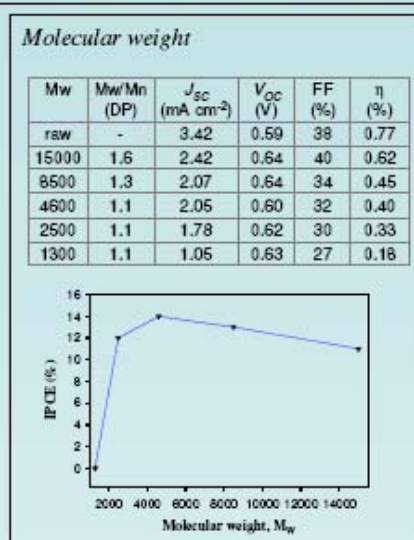

The non-purified polymer fraction (raw) shows a higher $\eta$ then the high $\mathrm{M}_{\mathrm{w}}$ fraction due to

- the smaller molecular weight fractions of the polymer make a better contact to the PCBM and therefore is needed to obtain high $\eta$.

Annealing temperature

\begin{tabular}{|c|c|c|c|c|}
\hline $\begin{array}{c}\text { Temperature } \\
\left({ }^{2} \mathrm{C}\right)\end{array}$ & $\begin{array}{c}J_{S C} \\
\left(\mathrm{~mA} \mathrm{~cm}^{-2}\right)\end{array}$ & $\begin{array}{c}V_{G c} \\
(\mathrm{~N})\end{array}$ & $\begin{array}{c}\mathrm{FF} \\
(\%)\end{array}$ & $\begin{array}{c}\eta \\
(\%)\end{array}$ \\
\hline No annealing & 1.47 & 0.53 & 33 & 0.26 \\
\hline 75 & 2.86 & 0.54 & 34 & 0.53 \\
\hline 110 & 2.46 & 0.62 & 27 & 0.42 \\
\hline 130 & 2.89 & 0.64 & 42 & 0.77 \\
\hline 150 & 1.33 & 0.60 & 37 & 0.29 \\
\hline
\end{tabular}

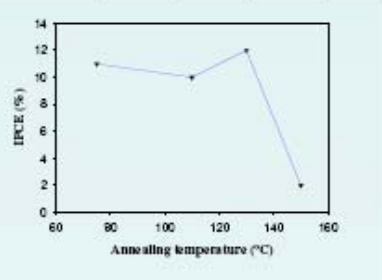

Annealing of the devices results in an increase in $\eta$. Due to

- improved charge carrier mobility

- increase in exciton dissociation.

Best device

- Spin coated from 1,2-dichlorobenzene

- annealed at $110^{\circ} \mathrm{C}$

- $J_{S C}=3.6 \mathrm{~mA} \mathrm{~cm}{ }^{-2}, V_{o C}=0.6 \mathrm{~V}, \mathrm{FF}$ $\sim 46 \%, \eta=1 \%$ and IPCE $=18 \%$ at 600 $\mathrm{nm}$.
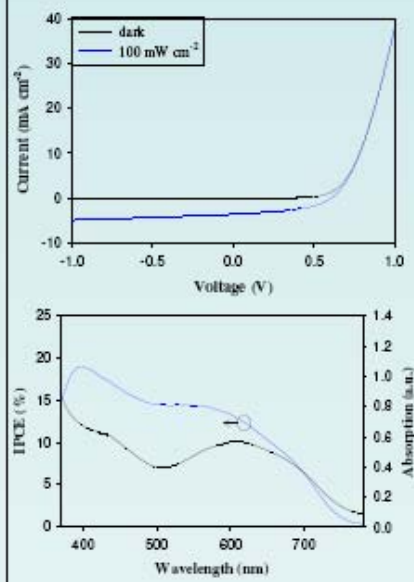

Conclusion: It was found that the photovoltaic responce was highly dependent on choice of solvent, spin coating condetions, concentration, molecular weight of the polymer and the annealing temperature of the device. Best device gave $\eta=1 \%$ and $\mathrm{IPCE}=18 \%$.

www.risoe.dk/solarcells, Tel (+45) 4677 5498, Fax (+45) 46774791 , eva.bundgaard@risoe.dk 
Risø's research is aimed at solving concrete problems in the society.

Research targets are set through continuous dialogue with business, the political system and researchers.

The effects of our research are sustainable energy supply and new technology for the health sector. 